\title{
WEST VALLEY DEMONSTRATION PROJECT ANNUAL SITE ENVIRONMENTAL REPORT CALENDAR YEAR 2003
}

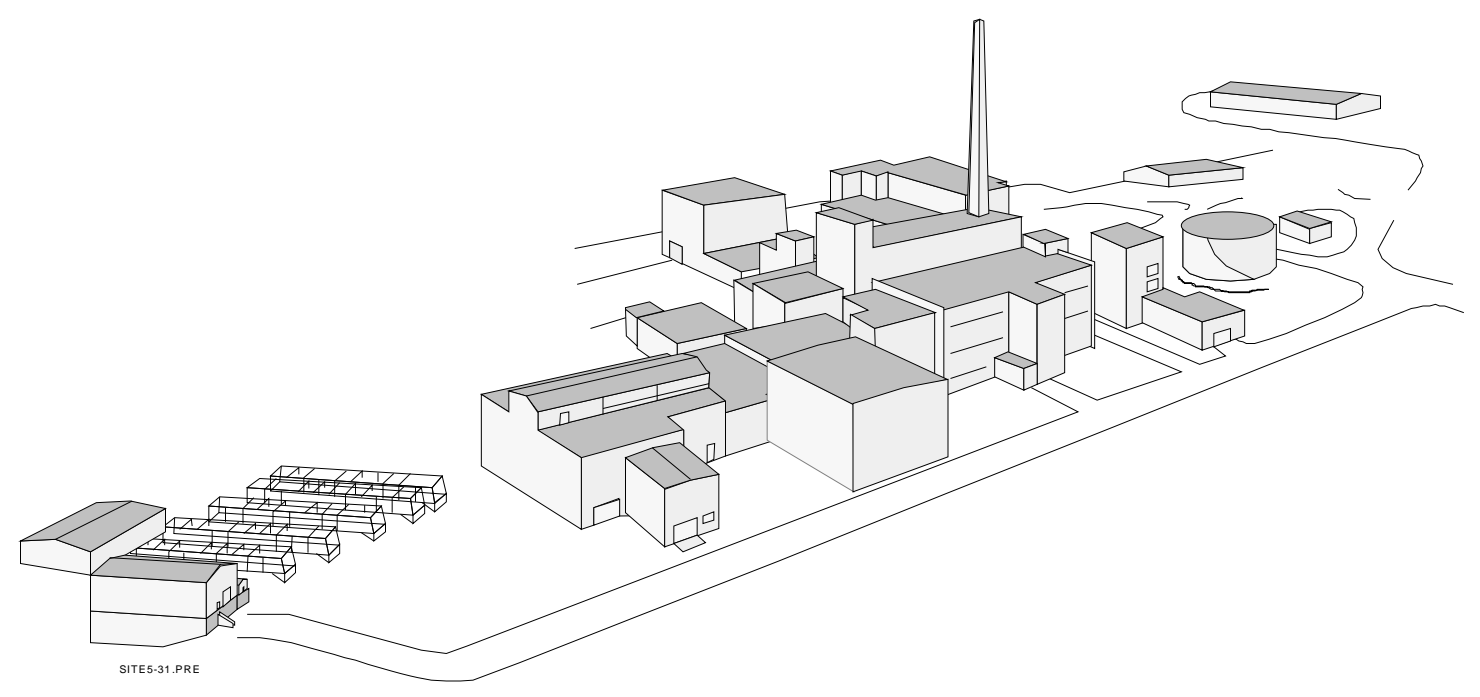

\section{WEST VALLEY NUCLEAR SERVICES COMPANY \\ AND \\ URS GROUP, INC.}
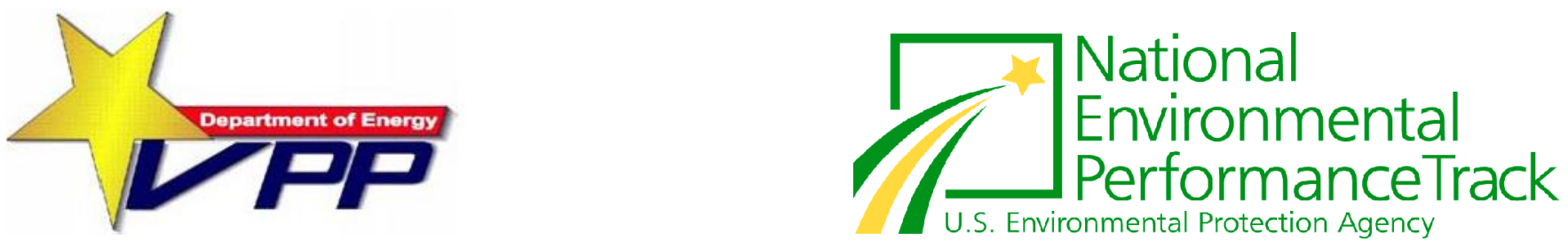

Prepared by: West Valley Nuclear Services Co. and URS Group, Inc.

Prepared for: U.S. Department of Energy

Ohio Field Office OH/WVDP

August 2004

Under: Contract DE-AC24-81NE44139

10282 Rock Springs Road

West Valley, New York 14171-9799 



\section{Department of Energy}

Ohio Field Office

West Valley Demonstration Project

10282 Rock Springs Road

West Valley, NY 14171-9799

To the Reader:

This report, prepared by the U.S. Department of Energy (DOE) Ohio Field Office West Valley Demonstration Project (OH/WVDP), summarizes the environmental protection program at the West Valley Demonstration Project (WVDP) for calendar year 2003. As has been the practice in prior years, this report is being made available to the public as soon as possible in advance of DOE's required release date of October 1, 2004.

Monitoring and surveillance of the WVDP facilities are conducted in order to verify that public health and safety and the environment are protected. The quality assurance protocols applied to the environmental monitoring program by the DOE ensure the validity and accuracy of the monitoring data. Also included in this report are groundwater and ambient air data from the New York State Energy Research and Development Authority's (NYSERDA) New York State-licensed Disposal Area (SDA).

Air, surface water, groundwater, soil, sediment, and biological samples collected and analyzed for radiological and nonradiological constituents are evaluated for indication of potential effects of activities at the WVDP. Monitoring of treated water effluents and facility ventilation system emissions verified that the dose received by off-site residents continues to be minimal.

Calculated doses to the hypothetical maximally exposed off-site individual from airborne and waterborne radiological releases in 2003 were less than one percent of the DOE limit. Radionuclide concentrations in biological samples were at levels near or statistically identical to background concentrations.

Nonradiological liquid effluent discharges are controlled and permitted through the New York State Pollutant Discharge Elimination System (SPDES). Discharges in 2003 were within effluent limits without exception.

The Project's continuing commitment to safety was reaffirmed in 2003 when it was again awarded the DOE Voluntary Protection Program Star of Excellence Award. The WVDP is one of the few DOE sites to be awarded both the VPP Star and National Environmental Performance Track membership.

If you have any questions or comments about the information in this report, please contact the West Valley Nuclear Services Company (WVNSCO) Community Relations Department at (716) 942-2152 or complete and return the enclosed survey.

Sincerely,

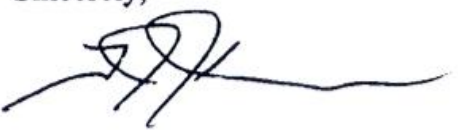

T. J. Jackson, Acting Director

West Valley Demonstration Project 



\section{SUMMARY OF CHANGES TO THE 2003 WVDP ANNUAL SITE ENVIRONMENTAL REPORT}

FROM THE 2002 ANNUAL SITE ENVIRONMENTAL REPORT

This report, prepared by the U.S. Department of Energy (DOE) West Valley Demonstration Project (WVDP) office, summarizes the environmental protection program at the WVDP for calendar year (CY) 2003. Monitoring and surveillance of the facilities used by the DOE for the WVDP are conducted in order to protect public health and safety and the environment. The quality assurance protocols applied to the environmental monitoring program by the DOE ensure the validity and accuracy of the monitoring data. Also included in this report are groundwater and ambient air data from the New York State Energy Research and Development Authority's New York State-licensed Disposal Area.

Changes in content for the 2003 Annual Site Environmental Report (ASER) are summarized below.

\section{REVISIONS AND ADDITIONS}

- In an effort to streamline the ASER, sections were condensed throughout and Appendices B through $\mathrm{L}$ were moved from the text to a compact disk to be included inside the back cover of the final report.

- The Environmental Compliance Summary was updated to describe implementation of the WVDP environmental management system (EMS), compliance with new DOE Order 450.1 (Environmental Protection Program), status of regulatory compliance in CY 2003, and permits effective during the year. A new table summarizing the WVDP EMS was added.

- Discussions of the vitrification process in the 2002 ASER were greatly condensed or deleted altogether because CY 2003 was the first full year since vitrification was completed.

- $\quad$ Data and text were updated throughout to reflect results from the CY 2003 environmental monitoring program. Modifications to the list of sampling locations and analytical constituents were summarized. Tables, graphs, maps, supplemental information sections, and references were updated. Most graphs representing time-series data were standardized to include 10-year data sets.

- The "Dose to Biota" section in Chapter 2 was updated to include dose estimates derived using the new RESRAD-BIOTA Code, issued in 2003, in accordance with Guidance for the Preparation of DOE ASERs for CY 2003.

- $\quad$ Appendix $\mathrm{C}$ tables summarizing water monitoring data were updated to include changes to chemical constituents in the monitoring program in 2003 to refine the Project's ability to evaluate surface water quality. Newly-required site drinking water monitoring test data are also included in Appendix C. Air data tables in Appendix D were reformatted for consistency with the content and format of Appendix C.

- $\quad$ New Appendix K-3, "West Valley Demonstration Project Act," containing the complete text of the Act, was added. 


\section{SPECIAL ISSUES IN CY 2003}

- $\quad$ Spent nuclear fuel rods that were packaged in 2001 and awaited shipment through 2002 were successfully shipped to the Idaho National Engineering and Environmental Laboratory.

- $\quad$ High-level waste tanks 8D-1 and 8D-2 were placed in lay-up mode by isolating the tanks from the main plant, deactivating components, replacing and relocating pumps, and placing grout around pipe penetrations to reduce groundwater infiltration.

- $\quad$ The fuel receiving and storage pools (the fuel storage pool and the cask unloading pool) were drained and cleaned.

- Decontamination of the main plant south product purification cell was completed.

- Decontamination of the head end cells and extraction cell \#2, also in the main plant, began early in 2003 and continued throughout the year.

- A decontamination plan for dismantlement of the vitrification facility was drafted in 2003 for implementation in 2004.

- $\quad$ Construction of the remote-handled waste facility continued through 2003, with start-up to occur in 2004.

- $\quad$ Low-level radioactive waste shipments continued.

- $\quad$ The WVDP Waste Management Final Environmental Impact Statement was transmitted to DOE-HQ for release to the public in January 2004. 


\section{ERRATA and CORRIGENDA \\ West Valley Demonstration Project \\ Annual Site Environmental Report (ASER) \\ Calendar Year (CY) 2002}

Petroleum spill: An eight (8) gallon spill of petroleum was recorded and reported to the New York State Department of Environmental Conservation (NYSDEC) in December 2002. This spill was not mentioned in the Environmental Compliance Summary (ECS), on page ECS-13, for CY 2002, nor was it included in Chapter 1, page 1-19 in Figure 1-6, Number of Immediately Reportable Spills or Releases. The 2002 spill has been noted in the ECS and included in Figure 1-6 of the 2003 ASER.

Figure units: The y-axis of Figure 2-12, Collective Effective Dose Equivalent From Liquid and Airborne Effluents to the Population Residing Within 50 Miles $(80 \mathrm{~km}$ ) of the WVDP, was labeled in units of mrem instead of person-rem in the 2002 ASER. Values in Figure 2-12 have been correctly labeled as person-rem in the 2003 ASER.

If you have any questions about the above information, please contact the West Valley Nuclear Services Company Community Relations Department at (716) 942-2152. 



\title{
West Valley Demonstration Project
}

\section{Annual Site Environmental Report}

\author{
for \\ Calendar Year 2003
}

Prepared for the U.S. Department of Energy

Ohio Field Office

West Valley Demonstration Project Office

under contract DE-AC24-81NE44139

\author{
August 2004 \\ West Valley Nuclear Services Company and URS Group, Inc. \\ 10282 Rock Springs Road \\ West Valley, New York 14171-9799
}


This page intentionally left blank 


\section{Preface}

Environmental monitoring at the West Valley Demonstration Project (WVDP) is conducted by the West Valley Nuclear Services Company (WVNSCO), under contract to the U.S. Department of Energy (DOE). The data collected provide an historical record of radionuclide and radiation levels and chemical data from natural and man-made sources in the survey area. The data also document the chemical and radiological quality of the groundwater on and around the WVDP and of the air and water released by the WVDP. Meteorological data are also presented.

It is the policy of the WVDP to conduct all activities, including design, construction, testing, start-up, commissioning, operation, maintenance, and decontamination and decommissioning, in a manner that is appropriate to the nature, scale, and environmental effects of these activities. The WVDP is committed to full compliance with applicable federal and New York State laws and regulations for the protection of the environment, to continual improvement, to the prevention and/or minimization of pollution, and to public outreach, including stakeholder involvement.

This report represents a single, comprehensive source of off-site and on-site environmental monitoring data collected during 2003 by environmental monitoring personnel. The environmental monitoring program and results are discussed in the body of this report. Additional monitoring information is presented in the appendices. Appendix A contains maps of on-site and off-site sampling locations. Appendices $B$ through $L$ can be found in electronic format on the compact disk (as indicated by the $C$ icon) located inside the back cover. Appendix $B$ is a summary of the site environmental monitoring schedule. Appendices $C$ through J contain summaries of data obtained during 2003 and are intended for those readers interested in more detail than is provided in the main body of the report. Appendix $K$ lists laws and regulations pertaining to the WVDP. Appendix L provides groundwater monitoring data from the New York State-licensed Disposal Area.

Requests for additional copies of the 2003 Annual Site Environmental Report and questions regarding the report should be referred to the WVDP Community Relations Department, 10282 Rock Springs Road, West Valley, New York 14171 (telephone: 716-942-4555). Additional Project information is available on the internet at http://www.wv.doe.gov. 
This page intentionally left blank

$i v$ 


\section{Table of Contents}

PREFACE

iii

EXECUTIVE SUMMARY

EXE-1

Purpose of This Report

EXE-1

Project Description

EXE-1

Compliance

EXE-2

Environmental Monitoring Program

EXE-2

Surface Water Monitoring

EXE-3

Soil and Stream Sediments

EXE-4

Groundwater Monitoring

EXE-4

Air Monitoring

EXE-4

Vegetation, Beef, Milk, Fish, and Game Animals

EXE-5

Environmental Monitoring

EXE-5

Safety and Environmental Management Systems

EXE-6

Conclusion

EXE-6

INTRODUCTION

INT-1

Information in This Report

INT-1

History of Fuel Reprocessing at the Western New York Nuclear Service Center

INT-2

Description of the West Valley Demonstration Project

INT-2

General Environmental Setting

INT-5

Location of the West Valley Demonstration Project

INT-5

Socioeconomics

INT-5

Climate

INT-6

Biology

INT-6

Geology and Hydrology

INT-6

Environmental Monitoring Program

INT-7

Monitoring and Sampling

INT-7

Permits and Regulations

INT-7

Exposure Pathway Monitoring

INT-8

Surface Water and Sediment Pathways

INT-8

Groundwater Pathways

INT-8

Air Pathways

INT-9

Atmospheric Fallout

INT-9

Food Pathways

Direct Radiation Measurement

INT-10 


\section{Table of Contents}

\section{Introduction (concluded)}

Meteorological Monitoring

INT-10

Quality Assurance and Control

INT-10

Environmental and Safety Performance Recognition

INT-10

ENVIRONMENTAL COMPLIANCE SUMMARY ECS-1

Compliance Program ECS-1

Compliance Status ECS-2

Environmental Protection Program (DOE Order 450.1) ECS-2

Radiation Protection of the Public and the Environment (DOE Order 5400.5) ECS-2

Radioactive Waste Management (DOE Order 435.1) ECS-2

Resource Conservation and Recovery Act ECS-2

Clean Air Act ECS-7

Emergency Planning and Community Right-to-Know Act ECS-8

Clean Water Act ECS-9

Safe Drinking Water Act ECS-13

Toxic Substances Control Act ECS-14

National Environmental Policy Act ECS-15

Decommissioning and/or Long-Term Stewardship at the WVDP and WNYNSC ECS-15 Migratory Bird Treaty Act ECS-15 Endangered Species Act

Current Achievements and Program Highlights ECS-16

Spent Nuclear Fuel Shipment Completed ECS-16

Integrated Safety Management System ECS-16

STAR Status ECS-16

EPA National Environmental Performance Track ECS-16

Environmental Management System ECS-17 Environmental Issues and Actions ECS-17

Closed Landfill Maintenance

Release of Materials Containing Residual Radioactivity ECS-17

Decommissioning and/or Long-Term Stewardship at the WVDP and WNYNSC ECS-17 Project Assessment Activities in 2003 ECS-17 


\section{Table of Contents}

CHAPTER 1. ENVIRONMENTAL PROGRAM INFORMATION

Introduction $1-1$

Radiation and Radioactivity

Measurement of Radioactivity $1-3$

Measurement of Dose 1-3

Environmental Monitoring Program Overview $1-4$

Data Reporting $1-4$

Changes in the 2003 Environmental Monitoring Program $1-6$ Completion of Vitrification $1-7$

2003 Activities at the WVDP $1-7$

Decontamination $1-7$

Spent Nuclear Fuel Shipment Completed $1-8$

Remote-Handled Waste Facility Construction ___ 1-8

Environmental Management of Aqueous Radioactive Waste ___ 1-8

Environmental Management of Airborne Radioactive Emissions ___ 1-9

Environmental Management of Radiological Exposure ___ 1-9

Unplanned Radiological Releases_____ 1-11

NRC-Licensed Disposal Area Interceptor Trench and Pretreatment System ___ 1-11

Waste Minimization Program ___ _ 1-11

Pollution Prevention Awareness Program ___ 1-11

Waste Management ___ 1-11

Low-Level Radioactive Waste Shipping Program ___ 1-12

National Environmental Policy Act Activities ___ 1-12

Self-Assessments ____ 1-14

Occupational Safety and Environmental Training ___ 1-14

Voluntary Protection Program STAR Status __ 1-15

Environmental Management System Implementation ___ 1-15

Integrated Safety Management System Implementation ___ 1-15

Performance Measures ___ 1-16

Radiation Doses to the Maximally-Exposed Off-Site Individual ___ 1-16

State Pollutant Discharge Elimination System Permit Limit Exceptions ___ 1-16

Waste Minimization and Pollution Prevention____ 1-17

Spills and Releases ___ 1-18 


\section{Table of Contents}

CHAPTER 2. ENVIRONMENTAL RADIOLOGICAL PROGRAM INFORMATION

RADIATION IN THE ENVIRONMENT

Sources of Radiation

Exposure Pathways

Land Use Survey

Dose to the Public

ROUTINE MONITORING PROGRAM ___ $2-5$

Radiological Sampling Program Overview _____ 2-5

Overview of Water Effluent and Ambient Surface Water Monitoring __ 2-5

Low-Level Waste Treatment Facility Effluent

Northeast Swamp and North Swamp Drainage

Other North Plateau Surface Waters and Water Effluent

South Plateau Surface Water and NDA Interceptor Trench

Ponded (Standing) Waters

Off-Site Surface Water

2-11

Overview of Drinking Water Monitoring

2-12

On-Site Tap Water

Off-Site Drinking Water Wells

2-12

Overview of Sediment Monitoring

2-13

On-Site Sediments

2-13

Off-Site Sediments

$2-13$

Overview of Air Emission and Ambient Air Monitoring

$2-14$

Ventilation and Emission Systems

2-15

Perimeter and Remote Ambient Air Monitoring

Atmospheric Deposition and Soil Monitoring

2-18

Fallout Pots

2-18

Off-Site Surface Soil

2-18

Overview of Food Chain Monitoring

$2-20$

Fish

$2-20$

Venison

2-20

Beef

2-21

Milk

Vegetables and Fruit

2-21

Direct Environmental Radiation Monitoring

2-21

On-Site Radiation Monitoring

Perimeter and Off-Site Radiation Monitoring

Confirmation of Results 


\section{Table of Contents}

Chapter 2 (concluded)

Meteorological Monitoring ____ 2-23

Special Monitoring ______ 2-24

RADIOLOGICAL EFFLUENTS AND DOSE__ 2-25

Dose Assessment Methodology ____ 2-25

Measurement of Radionuclide Concentrations in Liquid and Air Releases ___ 2-25

Measurement of Radionuclide Concentrations in Food ___ 2-25

Predicted Dose From Airborne Emissions ___ 2-27

Maximum Dose to an Off-Site Individual____ 2-27

Collective Population Dose___ 2-27

Iodine Emissions From the Main Stack ___ 2-27

Predicted Dose From Waterborne Releases ___ 2-29

Maximum Dose to an Off-Site Individual___ 2-30

Collective Dose to the Population___ 2-30

Calculated Dose From Local Foodstuff Tests ___ 2-30

Predicted Dose From All Pathways ___ 2-31

Risk Assessment ___ 2-32

Dose to Biota: Aquatic and Terrestrial Wildlife____ 2-32

Summary ___ 2-35

CHAPTER 3. ENVIRONMENTAL NONRADIOLOGICAL PROGRAM INFORMATION ___ 3-1

Overview of New York State Water Classifications, Water Quality Standards, and Water Effluent Limits ___ 3-1

Surface Water, Subsurface Drainage Water, and Water Effluent Monitoring ___ 3-2

SPDES Permit-Required Monitoring ___ 3-2

Mercury Analytical Method Study ___ 3-2

South Plateau Surface and Subsurface Water ___ 3-3

Other On-Site and Off-Site Surface Water Monitoring ___ 3-4

Drinking Water Monitoring ___ 3-5

Soil and Sediment Monitoring ___ 3-5

Air Emission Monitoring ___ _ _ _ _ _ _ _ _ _ _ _ _ _ _ _ _ _ _ _

$i x$ 


\section{Table of Contents}

CHAPTER 4. SITE HYDROLOGY AND GROUNDWATER MONITORING 4-1

Groundwater Monitoring Program Overview 4-1

Geologic History of the West Valley Site 4-1

Surface Water Hydrology of the West Valley Site 4-2

Hydrogeology of the West Valley Site 4-2

Kent Recessional Sequence 4-2

Lavery Till 4-2

Sand and Gravel and Till-Sand Units 4-4

Routine Groundwater Monitoring Program 4-4

Monitoring Well Network 4-4

Groundwater Monitoring Program Highlights 1982 Through 2003 4-6

Annual Analytical Trigger Level Review 4-7

Results of Routine Groundwater Monitoring 4-7

Long-Term Trends of Gross Beta and Tritium at Selected Groundwater Monitoring Locations 4-8

North Plateau Seeps 4-10

North Plateau Well Points $4-10$

Results of Radioisotopic Sampling 4-10

Results of Monitoring at the NDA 4-11

Off-Site Groundwater Monitoring 4-11

Results for Volatile and Semivolatile Organic Compounds

Gross Beta Plume on the North Plateau 4-12

Permeable Treatment Wall 4-13

Northeast Swamp Drainage Monitoring 4-13

North Plateau Groundwater Quality Early Warning Monitoring 4-14

Investigation of Chromium and Nickel in the Sand and Gravel Unit and Evaluation of Corrosion in Groundwater Monitoring Wells 4-14

Ten-Year Sampling Pump Inspections 4-15 


\section{Table of Contents}

CHAPTER 5. QUALITY ASSURANCE

Organizational Responsibilities ___ 5-1

Program Design __ 5-1

Responsibility ___ _ _ 5-1

Planning ___ 5-2

Control of Design, Procedures, Items, and Documents ___ 5-2

Documentation ___ 5-2

Corrective Action ___ _ 5-2

Audits ___ 5-2

Procedures ___ 5-2

Quality Control in the Field ___ 5-2

Field Duplicates ___ 5-3

Field Blanks ___ 5-3

Trip Blanks __ 5-3

Environmental Background Samples ___ 5-3

Quality Control in the Laboratory ___ 5-3

Standards ___ 5-4

Spikes ___ 5-4

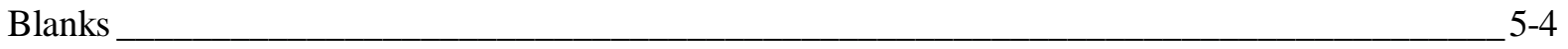

Duplicates___ 5-4

Crosschecks _ـ 5-5

Personnel Training ___ 5-6

Recordkeeping ___ 5-6

Chain-of-Custody Procedures___ 5-6

Audits and Appraisals ___ 5-6

Self-Assessments ___ 5-6

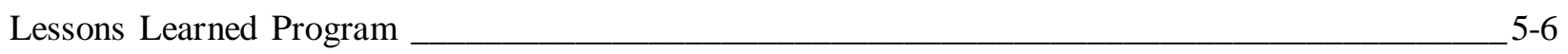

Data Management ___ 5-7

Data Verification and Validation ___ 5-7

Data Assessment and Reporting ___ 5-7

Summary ___ 5-8

$x i$ 


\section{Table of Contents}

REFERENCES and BIBLIOGRAPHY

$\mathrm{R} \& \mathrm{~B}-1$

GLOSSARY

GLO-1

ACRONYMS and ABBREVIATIONS

A\&A-1

UNITS OF MEASURE and UNIT PREFIXES UOM-1

SCIENTIFIC NOTATION and CONVERSION CHART

UOM-2

DISTRIBUTION DST-1

APPENDIX A. ENVIRONMENTAL MONITORING PROGRAM MAPS

A-i

xii 


\section{Table of Contents}

\section{List of Figures}

INT-1. Location of the Western New York Nuclear Service Center INT-4

ECS-1. WVDP SPDES Effluent Limit Exceptions ECS-12

1-1. Annual Average Exposure at the CPC-WSA (DNTLD24) $1-10$

1-2. Annual Average Exposure at the Drum Cell (DNTLD36)

1-3. Annual Effective Dose Equivalent to the Maximally-Exposed Off-Site Individual $1-17$

1-4. Yearly SPDES Effluent Limit Exceptions 1-18

1-5. Percentage of Waste-Reduction-Exceeding Goals $1-19$

1-6. Number of Immediately Reportable Spills or Releases $1-19$

2-1. Comparison of Doses From Natural and Man-Made Sources to the Dose From 2003 WVDP Effluents

2-2. Ten-Year Trends of Gross Alpha, Gross Beta, and Tritium Concentrations at Sampling Location WNSP006

2-3. Ten-Year Trends of Gross Alpha, Gross Beta, and Tritium Concentrations at Sampling Location WNNDADR

2-4. Ten-Year Trends of Gross Alpha, Gross Beta, and Tritium Concentrations at Sampling Location WFFELBR

2-5. Ten-Year Trends of Cesium-137 in Stream Sediments at Two Locations Upstream and Three Locations Downstream of the WVDP

2-6. Comparison of Cesium-137 With Naturally-Occurring Potassium-40 Concentrations in 2003 at Downstream Sampling Location SFTCSED

2-7. Ten-Year Trends of Gross Alpha and Gross Beta Activity at the Main Stack (ANSTACK) $2-16$

2-8. Ten-Year Trends of Gross Alpha and Gross Beta Concentrations at Rock Springs Road (AFRSPRD) $2-18$

2-9. Ten-Year Trends of Environmental Radiation Levels at Perimeter TLDs

2-10. Estimated Iodine-129 Releases From the WVDP Main Plant Stack 2-29

2-11. Effective Dose Equivalent From Liquid and Airborne Effluents to a Maximally-Exposed Individual Residing Near the WVDP

2-12. Collective Effective Dose Equivalent From Liquid and Airborne Effluents to the Population Residing Within 50 Miles $(80 \mathrm{~km})$ of the WVDP 


\section{Table of Contents}

List of Figures (concluded)

4-1. Geologic Cross Section Through the North Plateau 4-3

4-2. Geologic Cross Section Through the South Plateau 4-3

4-3. North Plateau Gross Beta Plume Area: Fourth-Quarter 2003 Results 4-9

4-4. Annualized Average Strontium-90 Concentrations at WNSWAMP 4-14

4-5. Average Yearly Gross Beta Concentrations at Selected Locations in the Sand and Gravel Unit 4-16

4-6. Average Yearly Gross Beta Concentrations at Selected Locations in the Sand and Gravel Unit 4-16

4-7. Average Yearly Gross Beta Concentrations at Selected Locations in the Sand and Gravel Unit $4-17$

4-8. Average Yearly Tritium Concentrations at Selected Locations in the Sand and Gravel Unit

4-9. Concentrations of 1,2-DCE-t, 1,1,1-TCA, and 1,1-DCA at Well 8612 in the Sand and Gravel Unit 4-18

4-10. Concentrations of Tributyl Phosphate at Selected Locations in the Sand and Gravel Unit 4-18

A-1. West Valley Demonstration Project Base Map A-1

A-2. On-Site Surface Water and Soil/Sediment Sampling Locations A-2

A-3. Off-Site Surface Water and Soil/Sediment Sampling Locations A-3

A-4. On-Site Air Monitoring and Sampling Locations A-4

A-5. Off-Site Air and Fallout Sampling Locations A-5

A-6. Active WVDP Groundwater Monitoring Locations A-6

A-7. North Plateau On-Site Groundwater Monitoring Network A-7

A-8. South Plateau On-Site Groundwater Monitoring Network A-8

A-9. Near-Site Drinking Water and Biological Sampling Locations A-9 A-10. Location of On-Site Thermoluminescent Dosimeters (TLDs) A-10 A-11. Location of Off-Site Thermoluminescent Dosimeters (TLDs) Within 5 Kilometers of the WVDP A-11

A-12. Environmental Sampling Locations Between 5 and 10 Kilometers From the WVDP A-12

A-13. Environmental Sampling Locations More Than 10 Kilometers From the WVDP A-13

A-14. Estimated 2002 Population by Sector Within 80 Kilometers of the WVDP A-14 


\section{Table of Contents}

\section{List of Tables}

Compliance Tables:

ECS-1. Elements of the Environmental Management System Implementation at the WVDP ECS-19

ECS-2. West Valley Demonstration Project 2003 Air Quality Noncompliance Episodes ECS-23

ECS-3. West Valley Demonstration Project 2003 NPDES/SPDES Permit Noncompliance Episodes ECS-24

ECS-4. Release of Property Containing Residual Radioactive Material ECS-24

ECS-5. West Valley Demonstration Project Migratory Bird Nest Depredation Episodes in 2003 ECS-25

ECS-6. Status of EPCRA Reporting in 2003 ECS-25

ECS-7. Reportable Chemicals Above Threshold Planning Quantities Stored at the WVDP in 2003 ECS-25

ECS-8. West Valley Demonstration Project Environmental Permits ECS-26

2-1. Potential Local Off-Site Exposure Pathways Under Existing WVDP Conditions $2-4$

2-2. 2003 Gross Alpha Concentrations at Surface Water Sampling Locations $2-8$

2-3. 2003 Gross Beta Concentrations at Surface Water Sampling Locations $2-8$

2-4. 2003 Gross Alpha Concentrations at Off-Site, Perimeter, and On-Site Ambient Air Sampling Locations 2-19

2-5. 2003 Gross Beta Concentrations at Off-Site, Perimeter, and On-Site Ambient Air Sampling Locations 2-19

2-6. Summary of Annual Effective Dose Equivalents to an Individual and Population From WVDP Releases in 2003 $2-28$

2-7. Evaluation of Dose to Aquatic and Terrestrial Biota $2-36$

2-8. WVDP Radiological Dose and Release Summary $2-37$

4-1. Summary of Groundwater Monitoring Program by Geographic Area; Monitoring Year 2003 4-5

4-2. Summary of Groundwater Monitoring Program by Monitoring Purpose; Monitoring Year 2003 4-5 


\section{Table of Contents}

\section{List of Figures \\ (Available only on CD, as indicated by the $\mathrm{C}$ icon.)}

H-1. 2003 Average Yearly Gamma Exposure Rates Around the WVDP ___ H-6

H-2. 2003 Average Yearly Gamma Exposure Rates on the WVDP ___ H-6

I-1. Regional Monitoring Station Wind Frequency Rose: 10-Meter I-3

I-2. Primary Monitoring Station Wind Frequency Rose: 10-Meter I-4

I-3. Primary Monitoring Station Wind Frequency Rose: 60-Meter I-5

I-4. Calendar Year 2003 Weekly Precipitation I-6

I-5. Calendar Year 2003 Cumulative Precipitation I-6

$x v i$ 


\section{Table of Contents}

\section{List of Tables \\ (Available only on $\mathrm{CD}$, as indicated by the $\mathrm{C}$ icon.)}

APPENDIX B. 2003 ENVIRONMENTAL MONITORING PROGRAM B-i

APPENDIX C-1. SUMMARY OF WATER LIMITS, GUIDELINES, AND STANDARDS C-1

C-1A. West Valley Demonstration Project State Pollutant Discharge Elimination System Sampling Program C-3

C-1B. New York Water Quality Standards and Guidelines C-5

C-1C. New York State Department of Health/U.S. Environmental Protection Agency MCLs, MCLGs, and Raw Water Standards C-7

C-1D. U.S. Department of Energy Derived Concentration Guides C-8

APPENDIX C-2. PROCESS EFFLUENT DATA C-9

C-2A. Total Radioactivity of Liquid Effluents Released From Lagoon 3 (WNSP001) in 2003 C-11

C-2B. Comparison of 2003 Lagoon 3 (WNSP001) Liquid Effluent Radioactivity Concentrations With U.S. Department of Energy Guidelines C-12

C-2C. 2003 SPDES Results for Outfall 001 (WNSP001): Water Quality C-13

C-2D. 2003 SPDES Results for Outfall 001 (WNSP001): Metals C-15

C-2E. 2003 SPDES Results for Outfall 001 (WNSP001): Organics $\mathrm{C}-17$

C-2F. 2003 SPDES Results for Outfall 007 (WNSP007): Water Quality and Iron $\mathrm{C}-18$

C-2G. 2003 SPDES Results for Outfall 008 (WNSP008): Water Quality C-19

C-2H. 2003 SPDES Results for Sums of Outfalls 001, 007, 008, and 116: Water Quality C-20

C-2I. 2003 Quarterly/Semiannual/Annual SPDES Results for Outfall 001 (WNSP001): Water

Quality, Metals, and Organics C-21

C-2J. 2003 Annual SPDES Results for Outfall 007 (WNSP007): Water Quality $\mathrm{C}-22$

C-2K. 2003 Annual SPDES Results for Outfall 008 (WNSP008): Water Quality $\mathrm{C}-22$ C-2L. 2003 SPDES Results for Outfall 01B (WNSP01B): Water Quality $\mathrm{C}-23$ C-2M. 2003 Results for Sewage Treatment Outfall (WNSP007) C-23

APPENDIX C-3. SITE SURFACE DRAINAGE, SUBSURFACE DRAINAGE, AND CONTAINED WATER C-25

C-3A. 2003 Results in Surface Water at Facility Yard Drainage (WNSP005) C-27

C-3B. 2003 Results in Surface Water at French Drain (WNSP008)

C-3C. 2003 Results in Surface Water at the North Swamp (WNSW74A) C-28 


\section{Table of Contents}

List of Tables (continued)

C-3D. 2003 Results in Surface Water at the Northeast Swamp (WNSWAMP)

C-31

C-3E. 2003 Results at Storage and Disposal Area Drainage (WNNDADR) ___ C-34

C-3F. 2003 Results in Subsurface Water at the NDA Interceptor Trench (WNNDATR) ___ C-34

C-3G. 2003 Results at SDA Drainage (WNSDADR) ___ C-35

C-3H. 2003 Results in Surface Water at Cooling Tower Basin (WNCOOLW) ___ C-35

APPENDIX C-4. AMBIENT SURFACE WATER DATA____ C-37

C-4A. 2003 Results in Surface Water Downstream of the WVDP in Cattaraugus Creek at

Felton Bridge (WFFELBR) ___ C-39

C-4B. 2003 Results in Surface Water Downstream of the WVDP in Buttermilk Creek at

Thomas Corners Bridge (WFBCTCB) ___ C-39

C-4C. 2003 Results in Surface Water Downstream of the WVDP at Frank's Creek (WNSP006) _ C-42

C-4D. 2003 Results From Outfall WNSP116____ C-45

C-4E. 2003 Results in Surface Water at Erdman Brook (WNERB53)___ C-45

C-4F. 2003 Results in Surface Water at Frank's Creek East of the SDA (WNFRC67)____ C-46

C-4G. 2003 Results in Surface Water at Drum Cell Drainage (WNDCELD) ___ C-46

C-4H. 2003 Results in Surface Water at the Standing Water (WNSTAW-Series) Locations ___ C-47

APPENDIX C-5. POTABLE WATER (DRINKING WATER) DATA __ C-49

C-5A. 2003 Results in Potable Well Water Around the WVDP __ C-51

C-5B. 2003 Results in Main Plant Potable Water (WNDNKMP); 2003 Results in Environmental

Laboratory Potable Water (WNDNKEL); and 2003 Results in Maintenance Shop Potable

Water (WNDNKMS) __ C-52

C-5C. 2003 Results in Utility Room Potable Water (WNDNKUR) ___ C-53

C-5D. 2003 Results in Utility Room Raw (Untreated) Water (WNURRAW) ___ C-54

C-5E. Various Site Tap Water Locations ___ C-54

C-5F. Tap Water Sample Results From WVDP Restroom Sink ___ C-54

xviii 


\section{Table of Contents}

List of Tables (continued)

APPENDIX D. SUMMARY OF AIR MONITORING DATA

D-1

D-1. 2003 Airborne Radioactivity at Main Stack (ANSTACK) ___ D-3

D-2. 2003 Airborne Radioactivity at Vitrification System (HVAC) (ANVITSK) ___ D-4

D-3. 2003 Airborne Radioactivity at Seismic Sampler (ANSEISK) ___ D-4

D-4. 2003 Airborne Radioactivity at 01-14 Building (ANCSSTK) ___ D-5

D-5. 2003 Airborne Radioactivity at Contact Size-Reduction Facility (ANCSRFK) ___ _ D-5

D-6. 2003 Airborne Radioactivity at Supernatant Treatment System (ANSTSTK) ___ D-6

D-7. 2003 Airborne Radioactivity at Container Sorting and Packaging Facility (ANCSPFK) ___ D-7

D-8. 2003 Airborne Radioactivity at Low-Level Waste Treatment Facility (ANLLW2V) ___ _ D-7

D-9. 2003 Airborne Radioactivity at Outdoor Ventilation Enclosures/Portable Ventilation Units (OVEs/PVUs) ___ _ D

D-10. 2003 Airborne Radioactivity at Lag Storage (ANLAGAM) ___ D-9

D-11. 2003 Airborne Radioactivity at the NDA (ANNDAAM) ___ D-10

D-12. 2003 Airborne Radioactivity at SDA Trench 9 (ANSDAT9) ___ D-10

D-13. 2003 Airborne Radioactivity at Rock Springs Road (AFRSPRD)___ D-11

D-14. 2003 Airborne Radioactivity at Dutch Hill Road (AFBOEHN) ___ D-12

D-15. 2003 Airborne Radioactivity at Fox Valley Road (AFFXVRD) __ D-12

D-16. 2003 Airborne Radioactivity at the Bulk Storage Warehouse (AFBLKST) ___ D-13

D-17. 2003 Airborne Radioactivity at Route 240 (AFRT240)___ D-13

D-18. 2003 Airborne Radioactivity at Thomas Corners Road (AFTCORD) ___ D-14

D-19. 2003 Airborne Radioactivity at West Valley (AFWEVAL) ___ D-14

D-20. 2003 Airborne Radioactivity at Springville (AFSPRVL) __ D-15

D-21. 2003 Airborne Radioactivity at the Nashville Background (AFNASHV)___ D-15

D-22. 2003 Results in Fallout: Dutch Hill (AFDHFOP) ___ D-16

D-23. 2003 Results in Fallout: Rain Gauge (ANRGFOP)___ D-16

D-24. 2003 Results in Fallout: Route 240 (AF24FOP) ___ D-17

D-25. 2003 Results in Fallout: Thomas Corners (AFTCFOP)___ D-17

D-26. 2003 Results in Fallout: Fox Valley Road (AFFXFOP)___ D-18 


\section{Table of Contents}

List of Tables (continued)

APPENDIX E. SUMMARY OF GROUNDWATER MONITORING DATA E-1

Groundwater Sampling Methodology E-2

2003 Groundwater Sampling and Analysis Agenda E-3

E-1. Groundwater Monitoring Network: Super Solid Waste Management Units ___ E-4

E-2. 2003 Indicator Results From the Sand and Gravel Unit ___ E-9

E-3. 2003 Indicator Results From the Lavery Till-Sand Unit ___ E-13

E-4. 2003 Indicator Results From the Weathered Lavery Till Unit____ E-14

E-5. 2003 Indicator Results From the Unweathered Lavery Till Unit___ E-15

E-6. 2003 Indicator Results From the Kent Recessional Sequence ___ E-16

E-7. 2003 Indicator Results From the North Plateau Seep Monitoring Locations ___ E-17

E-8. 2003 Indicator Results From the North Plateau Well Points ___ E-17

E-9. 2003 Volatile Organic Compound Results at Selected Groundwater Monitoring Locations __ E-18

E-10. 2003 Tributyl Phosphate Results at Selected Groundwater Monitoring Locations ___ E-18

E-11. 2003 Sampling Results for Metals ____ E-19

E-12. 2003 Sampling Results for Early Warning Monitoring Wells ___ E-21

E-13. 2003 Radioisotopic Results From Selected Groundwater Monitoring Locations ___ E-22

E-14. Practical Quantitation Limits ____ E-26

APPENDIX F. SUMMARY OF BIOLOGICAL DATA____ F-1

F-1. 2003 Radioactivity Concentrations in Milk ___ F-3

F-2. 2003 Radioactivity Concentrations in Meat ___ F-4

F-3. 2003 Radioactivity Concentrations in Food Crops ___ F-5

F-4. 2003 Radioactivity Concentrations in Fish Flesh From Cattaraugus Creek___ F-6

APPENDIX G-1. SUMMARY OF SOIL AND AQUATIC SEDIMENT GUIDELINES AND

STANDARDS ___ __ G-1

G-1A. Eastern U.S.A. Background Concentrations for Soils ___ G-3

G-1B. Screening Concentrations for Contaminated Sediments ___ G-4

G-1C. Screening Thresholds for In-Water and Riparian Management of Sediment and Dredge Materials G-4 


\section{Table of Contents}

List of Tables (continued)

APPENDIX G-2. SOIL AND SEDIMENT DATA G-5

G-2A. 2003 Results in On-Site Soils Downstream of the WVDP at Frank's Creek (SNSP006) G-7

G-2B. 2003 Results in On-Site Soils From North Swamp (SNSW74A) G-8

G-2C. 2003 Results in On-Site Soils From Northeast Swamp (SNSWAMP) G-9

G-2D. 2003 Results in Surface Soils Collected at Air Stations Around the WVDP G-10

G-2E. 2003 Results in Stream Sediments Around the WVDP G-12

APPENDIX H. SUMMARY OF DIRECT RADIATION MONITORING DATA H-1

H-1. Summary of 2003 Quarterly Averages of Off-Site TLD Measurements $\mathrm{H}-3$

H-2. Summary of 2003 Quarterly Averages of On-Site TLD Measurements H-4

H-3. Third-Quarter 2003 TLD Results and Instantaneous Exposure Rate Readings With a HighPressure Ion Chamber (HPIC) at Each Monitoring Location H-5

APPENDIX I. SUMMARY OF METEOROLOGICAL DATA I-1

I-1. 2003 Site Precipitation Collection Data I-7

I-2. 2003 Annual Temperature Summary at the 10-Meter Primary Meteorological Tower I-8

I-3. 2003 Annual Barometric Pressure Summary I-8

APPENDIX J. SUMMARY OF QUALITY ASSURANCE CROSSCHECK ANALYSES $\mathrm{J}-1$

J-1. Comparison of Radiological Results With Known Results of Crosscheck Samples From the DOE Environmental Measurements Laboratory Quality Assessment Program 58; EML-621 QAP 0303; June 2003

J-2. Comparison of Radiological Results With Known Results of Crosscheck Samples From the DOE Environmental Measurements Laboratory Quality Assessment Program 59;

QAP 0309; December 2003

J-3. Comparison of Results From Crosscheck Samples Analyzed for Water Quality Parameters as Part of the EPA's 2003 Discharge Monitoring Report - Quality Assurance Study 23 for the National Pollutant Discharge Elimination System

$x x i$ 


\section{Table of Contents}

List of Tables (concluded)

APPENDIX K. ENVIRONMENTAL LAWS, REGULATIONS, STANDARDS, AND

ORDERS $\mathrm{K}-1$

K-1. U.S. Department of Energy Radiation Protection Standards and Derived Concentration Guides $\mathrm{K}-3$

K-2. Environmental Laws, Regulations, Standards, and Orders $\mathrm{K}-4$

K-3. West Valley Demonstration Project Act $\mathrm{K}-7$

APPENDIX L. SUMMARY OF NEW YORK STATE ENERGY RESEARCH AND DEVELOPMENT AUTHORITY GROUNDWATER MONITORING DATA FOR THE NEW YORK STATE-LICENSED DISPOSAL AREA L-1

L-1. 2003 Contamination Indicator Results From SDA Monitoring Wells L-3

L-2. 2003 Radiological Indicator Results From SDA Monitoring Wells L-5

L-3. 2003 Radioisotopic Results From SDA Monitoring Wells $\mathrm{L}-7$

xxii 


\section{EXECUTIVE SUMMARY}

\section{Purpose of This Report}

This Annual Site Environmental Report for the West Valley Demonstration Project (WVDP or Project) is published to inform those with interest about environmental conditions at the WVDP. In accordance with U.S. Department of Energy (DOE) Order 231.1A, Environment, Safety, and Health Reporting, the report summarizes calendar year (CY) 2003 environmental monitoring data so as to describe the performance of the WVDP's environmental management system (EMS), confirm compliance with standards and regulations, and highlight important programs.

\section{Project Description}

During 2003, cleanup of radioactive waste from the former nuclear fuels reprocessing plant that shut down operations in the 1970s was continued at the WVDP. The Project is located in western New York State, about 30 miles south of Buffalo, within the New York State-owned Western New York Nuclear Service Center (WNYNSC). The WVDP is being conducted in cooperation with the New York State Energy Research and Development Authority.
Work activities at the WVDP during 2003 included:

- maintaining canisters of vitrified high-level waste in a shielded facility

- shipping low-level radioactive waste off-site for disposal

- shipping packaged spent nuclear fuel assemblies to Idaho National Engineering and Environmental Laboratory

- constructing a facility where large high-activity components can be safely size-reduced and packaged for disposal

- decontaminating the fuel storage pool and the cask unloading pool

- decontaminating the general purpose cell and the process mechanical cell (also referred to as the head end cells)

$A$ reader opinion survey has been inserted in this report. If it is missing, please contact the Community Relations Department at (716) 9422152. Additional Project information is available on the internet at http://www.wv.doe.gov.

EXE - 1 
- cleanup of waste in the plutonium purification cell (south) and extraction cell number 2 in the main plant

- planning for decontamination and dismantlement of the vitrification facility

- continuing preparation of the Decommissioning and/or Long-Term Stewardship Environmental Impact Statement

- monitoring the environment and managing contaminated areas within the Project facility premises.

\section{Compliance}

Management at the WVDP continued to provide strong support for environmental compliance in 2003. DOE Orders and applicable state and federal statutes and regulations are integrated into the Project's compliance program. Highlights of the 2003 compliance program were:

- No notices of violation or inspection findings from any environmental regulatory agencies were received by the WVDP in 2003.

- Inspections by the New York State Department of Environmental Conservation (NYSDEC) and the local department of health verified Project compliance with the applicable environmental and health regulations.

- The WVDP continued to successfully monitor specific waste management areas at the site in order to comply with the Resource Conservation and Recovery Act \$3008(h) Administrative Order on Consent.

- The Project met the requirements of the Emergency Planning and Community Right-to-Know Act by collecting information about hazardous materials used at the Project and making this information available to the local community.
- The New York State Pollutant Discharge Elimination System (SPDES) Permit currently identifies five permitted liquid outfalls (for example, a pipe outlet where treated process water or storm water flows into a stream) at the Project. In August 2003, the WVDP filed an application with NYSDEC for renewal of the SPDES Permit. In September 2003 NYSDEC renewed the permit, which will expire in 2009.

- In fulfilling the requirements of the Site Treatment Plan developed under the Federal Facility Compliance Act, all important events in calendar year 2003 for the characterization, treatment, and disposition of mixed waste at the WVDP were completed.

- Among other pollution-prevention accomplishments, waste minimization goals for 2003 were met or exceeded in three of five specified waste categories. Although low-level radioactive waste generation did not decline by the targeted $70 \%$ reduction set in the one-year goals statement, generation was reduced by $65 \%$. Sanitary waste generation was reduced by $50 \%$, whereas the goal was $70 \%$.

\section{Environmental Monitoring Program}

In 2003, Project environmental scientists continued to sample and monitor effluent air and water, groundwater, surface streams, soil, sediment, vegetation, meat, milk, and game animals, and to measure environmental radiation. More than 13,500 samples were collected in 2003 to assess the effect of site activities on public health, safety, and the environment.

The Project's environmental monitoring network is evaluated and updated to ensure that all the locations and sample types that would be sensitive to process-related changes are monitored. 
Samples are tested for radioactivity and/or nonradioactive substances using approved laboratory procedures. Both the laboratory test results and direct measurement data are reviewed at several stages for quality and are compared with historical data from the same locations, with background data, and with data from similar locations.

The environmental data are entered into a controlled database and are automatically matched against high and low values within an expected range. Data points above or below these values are brought to the attention of WVDP scientists for further investigation. WVDP scientists periodically assess the data and evaluate the importance of trends at each location.

Radiation doses to the public are calculated using approved computer modeling codes. Dose calculations predict the impacts of air and water releases and the potential effects from consumption of game animals and locally-grown food.

Surface Water Monitoring. Surface water is routinely sampled on the Project premises by automatic samplers: timed composite samples are collected at Frank's Creek where water exits the Project, at two other on-site points where water flows off-site, and at a surface drainage point near the former radioactive waste disposal areas. Samples are also collected at other points of drainage from facility areas. The data from these samples are used to determine the type, amount, and probable origin of both radiological and nonradiological contaminants.

Radiological Releases. The largest single, treated effluent source of radioactivity released to surface waters from the WVDP is the discharge from the low-level waste treatment facility (LLWTF) through the lagoon 3 outfall. The treated effluent water flows into Erdman Brook, which joins Frank's Creek just before exiting the Project's fenced area. Seven treated batches totaling approximately 15.0 million gallons (56.7 million liters) were released periodically over the course of about 60 days in 2003.

The combined average concentration of all radionuclides in liquid releases from lagoon 3 in 2003 was approximately $29.3 \%$ of the DOE derived concentration guide (DCG), which is used to evaluate liquid process discharges. The average radioactivity concentrations from 1999 through 2002 were $32 \%, 34 \%, 33 \%$, and $34 \%$ of the DCGs, respectively. The major dose contributors in the total combined liquid effluent in 2003 were strontium-90, cesium-137, and uranium-232.

Seepage of contaminated groundwater in an elongated plume across the north plateau was another source of strontium-90 radioactivity in surface water. Some of this contaminated groundwater enters a ditch upstream of surface drainage sampling location WNSWAMP and eventually flows into Frank's Creek. This location has been carefully monitored since gross beta contamination, originating from pre-Project operations, was identified in 1993. A groundwater recovery and treatment system is currently being used to reduce the migration of strontium-90 on the north plateau. Total strontium-90 curies released from WNSWAMP and average concentration of strontium-90 were both lower in 2003 than in 2002. The calculated hypothetical dose to a member of the public from strontium-90 at WNSWAMP in 2003 was far below $1 \%$ of the applicable DOE limit.

Dose Assessment. The dose to the maximallyexposed off-site individual (MEOSI) from the liquid pathway in 2003 was estimated to be 0.032 millirem (mrem) (0.00032 millisieverts [mSv]). Of this dose, 0.018 mrem $(0.00018 \mathrm{mSv})$ was attributable to Project effluents, primarily from lagoon 3 , and 0.014 mrem $(0.00014 \mathrm{mSv})$ was contributed by the north plateau drainage.

EXE - 3 
Nonradiological Releases. Nonradiological contaminants, measured at three outfalls and calculated at one monitoring point, were below the WVDP SPDES Permit limits.

Soil and Stream Sediments. Surface soil is collected annually near each of the ten air sampler locations to track long-term deposition. Sediments from off-site creeks are collected annually from three downstream and two upstream locations. Soil and sediment from three on-site drainage channels are also sampled annually to track waterborne movement of contaminants.

Surface soil samples in 2003 showed little change from previous years. Except for one area that historically has shown average cesium-137 concentrations higher than background values, the concentrations of radionuclides normally present in soil from both worldwide fallout and from Project air emissions at near-site locations are indistinguishable from background concentrations found in the region away from the WVDP.

Because of pre-Project releases from nuclear fuel reprocessing activities, the concentrations of cesium-137 in downstream creek sediments have been historically higher than concentrations in the upstream sediments. Results from 2003 were consistent with historical results. Monitoring results for cesium-137 in sediments over the last ten years show no upward trends at either upstream or downstream points.

Groundwater Monitoring. Groundwater samples were collected as scheduled from 69 onsite locations in 2003. In addition to thorough data evaluation, computerized screening of the groundwater data facilitates early identification of potentially-changing conditions. Four monitoring wells were installed in 2003 to provide groundwater information in the area of the newly-constructed remote-handled waste facility. The 2003 ground- water program continued to indicate that strontium-90 is still the major contributor to elevated gross beta values in the north plateau plume. The concentrations of other isotopes were below the DCG levels usually applied to surface water.

In addition to collecting samples from wells, groundwater was routinely collected from seeps on the bank above Frank's Creek along the northeastern edge of the north plateau. Results of radiological analyses indicate that gross beta activity from the north plateau plume has not migrated to these seepage areas.

Site groundwater also is tested for a number of nonradiological constituents. In 2003 there were no statistically remarkable changes in the concentrations measured.

Calendar year 2003 sample results from near-site residential water-supply wells were indistinguishable from results at background wells.

Air Monitoring. The WVDP airborne radiological monitoring program in 2003 included emissions from six routinely-operated permitted exhaust points and four exhausts excluded from permitting because of their low emission potential.

Six air samplers on the perimeter of the WNYNSC and four in more-distant locations continuously collect samples of air at the average human breathing height. These samples are tested for radioactivity carried by airborne particles. Samples are also collected for measurement of tritium and iodine-129 at two of the ten locations - the Rock Springs Road sampler near the site and the Great Valley background sampler.

Radiological Releases. As anticipated, radioactive releases from the Project in 2003 were far below the applicable Environmental Protection Agency (EPA) and DOE limits that ensure public 
health and safety. Radiological air releases in 2003 were less than those in 2002, coinciding with completion of the vitrification process.

Although several fission products contribute to airborne radiological releases, the most significant continues to be iodine-129, a long-lived radionuclide that exists in gaseous form. Iodine-129 is not fully removed during treatment of the air effluent. The CY 2003 levels of gaseous iodine-129 emissions were lower than 2002 levels.

Gross radioactivity in air samples (airborne particulate) from around the site's perimeter was within the historical range of radioactivity measured at remote background locations or nearby communities. Concentrations in samples from three on-site outdoor air samplers and two portable samplers located near waste storage facilities in operation during 2003 also were far below any applicable limits.

Dose Assessment. The dose from air emissions in calendar year 2003 was about $0.02 \%$ of the EPA and DOE radionuclide emissions standard of 10 mrem per year effective dose equivalent to the MEOSI. (In 2001 the dose from these emissions was about $0.05 \%$ and in 2002 the dose was about $0.04 \%$.) More than $90 \%$ of the total 2003 calculated airborne dose to the MEOSI from main plant stack emissions was from iodine-129 emissions.

Nonradiological Releases. The WVDP has monitored nitrogen oxides and sulfur dioxide emissions as a condition of the New York State Facility Air Permit to demonstrate that emissions were well below the 99-ton limit for each. When melter operations came to an end, the vitrification process source of nitrogen oxides and sulfur dioxides, the primary source at the WVDP, was permanently shut down. With this shutdown, the WVDP is no longer required to submit reports of nitrogen and sulfur oxide emissions to NYSDEC.
Vegetation, Beef, Milk, Fish, and Game Animals. Calculated dose estimates based on the consumption of near-site foodstuffs are used as an independent confirmation of (not added to) computer-modeled estimates. Test results from near-site samples of beans, apples, corn, beef, milk, fish, and deer in 2003 were consistent with results noted in previous years. When near-site samples were compared with background samples, minimal or no site-related effects were noted. If near-site foods had been consumed in normal quantities by the same person in one year, that individual would have received less than 0.10 mrem $(0.0010 \mathrm{mSv})$, the equivalent of about three hours of background radiation. No upward trends were observed.

\section{Environmental Monitoring}

The WVDP environmental monitoring program is designed to produce high-quality, reliable results. To maintain this standard, each scientist must give continuous attention to the details of sample handling, collection and analysis, data review, and evaluation procedures. Formal self-assessments were performed, and the WVDP Environmental Laboratory continued the practice of analyzing radiological crosscheck samples sent from a national laboratory. All (100\%) of the on-site laboratory crosscheck results and $96 \%$ of the off-site commercial laboratory crosscheck results were within statistical acceptance limits for the year.

Test results from the crosscheck program and self-assessments indicate that high quality standards are being met.

The West Valley Nuclear Services Co. Environmental Affairs and Quality Assurance Departments also periodically conducted and documented reviews of program activities in 2003. Off-site laboratories are required to meet standards as outlined in the WVDP contracts. Any data defi-

EXE - 5 
ciencies were addressed under approved quality assurance programs.

\section{Safety and Environmental Management Systems}

In 2003 the WVDP continued to demonstrate its commitment to an all-inclusive approach to safety through implementation of its integrated safety management system (ISMS). As a key component of the ISMS, the sitewide work review group reviewed work plans, identified environmental safety and health concerns, and specified practices to ensure that work was performed safely. The environmental management system, an integral part of the WVDP ISMS, was coordinated with other safety management and work planning processes through the integrated environmental, health, and safety management program.

In recognition of excellence in safety and health, the WVDP has received the DOE STAR award each year from 2000 through 2003. The WVDP is also recognized as a top environmental leader as part of the EPA's National Environmental Performance Track.

\section{Conclusion}

The West Valley Demonstration Project conducts extensive monitoring of on-site facilities and the surrounding environment. This program fulfills federal and state requirements to assess the effect of WVDP activities on public health and safety and the environment. In 2003 the maximum predicted dose to a member of the public from the Project via all pathways was 0.03 mrem (0.0003 $\mathrm{mSv}$ ), or $0.03 \%$ of the 100 -mrem DOE limit. In comparison, the typical dose to a member of the public from natural background sources is 295 mrem per year.
The dose to the population within a 50-mile (80kilometer) radius of the WVDP from DOE activities was 0.10 person-rem. This same population would have received approximately 453,000 person-rem from natural background radiation in 2003.

In addition to demonstrating compliance with environmental regulations and directives, evaluation of data collected in 2003 continued to indicate that WVDP activities pose no threat to public health or safety, or to the environment. 


\section{INTRODUCTION}

\section{Information in This Report}

Individual chapters in this report provide information on compliance with regulations, general information about the monitoring program and significant activities in calendar year (CY) 2003, summaries of the results of radiological and nonradiological monitoring, calculations of radiation doses to the population within 50 miles ( 80 kilometers $[\mathrm{km}]$ ) of the site, and information about practices that ensure the quality of environmental monitoring data. Graphs and tables illustrate important trends and concepts. The bulk of the supporting information and data is found in Appendices B through $\mathrm{L}^{\mathrm{C}}$, included on the attached compact disk (CD), as referenced in the text ${ }^{C}$.

Appendix A, included with the text, contains maps showing on-site and off-site sampling locations. Sample locations are designated by a coded abbreviation indicating sample type and location. (A complete listing of the codes is found in the index to Appendix A [pp. A-iv through A-vii].)

Appendix $B^{C}$ summarizes the CY 2003 environmental monitoring program and lists the kinds of samples taken, the frequency of collection, the parameters analyzed, the location of the sampling points, the monitoring and reporting requirements, and a brief rationale for the monitoring activities conducted at each location.

Appendices $\mathrm{C}$ through $\mathrm{I}^{\mathrm{C}}$ summarize radiometric, chemical analytical, and physical data from air, surface water, groundwater, fallout in precipitation, sediment, soils, biological samples (meat, milk, food crops, and fish), and direct radiation measurements and meteorological monitoring.

Appendix $\mathrm{J}^{\mathrm{C}}$ provides data from the comparison of results of analyses of identically-prepared samples (crosscheck samples) by both the West Valley Demonstration Project (WVDP or Project) and independent laboratories. The data include radiological concentrations and chemical parameters in crosscheck samples of air, water, soil, and vegetation.

Appendix $\mathrm{K}^{\mathrm{C}}$ provides a list of radiation protection standards set by the U.S. Department of Energy (DOE) that are most relevant to the operation of the WVDP. It also lists federal and state laws and regulations that affect the WVDP. Complete text of the WVDP Act has been added this year.

Appendix $\mathrm{L}^{\mathrm{C}}$ contains groundwater monitoring data for the New York State-Licensed Disposal Area, provided by the New York State Energy Research and Development Authority (NYSERDA).

INT -1 
Acronyms and abbreviations are used to shorten the text and make this document more readable. Each acronym is defined the first time it appears in a section of this report (e.g., the Annual Site Environmental Report [ASER]), after which the acronym alone may be used in the remainder of the section. For a complete listing of acronyms from the ASER, see the Acronyms and Abbreviations section at the end of this report. Other information that may be helpful is found in the References and Bibliography, Glossary, Units of Measure and Unit Prefixes, Scientific Notations, and Conversion Chart sections at the back of this report.

\section{History of Fuel Reprocessing at the Western New York Nuclear Service Center}

In the early 1950s, interest in promoting peaceful uses of atomic energy led to the passage of an amendment to the Atomic Energy Act that allowed the Atomic Energy Commission to encourage commercialization of nuclear fuel reprocessing as a way of developing a civilian nuclear industry. The Atomic Energy Commission made its technology available to private companies and invited proposals for the design, construction, and operation of reprocessing plants.

In 1961 the New York State Office of Atomic Development acquired 3,345 acres (1,354 hectares [ha]) near West Valley, New York and established the WNYNSC. Davison Chemical Co., together with the New York State Atomic Research and Development Authority (which later became NYSERDA), constructed and began operating a nuclear fuel reprocessing plant under a co-license issued by the Atomic Energy Commission (which later became the U.S. Nuclear Regulatory Commission [NRC] and the DOE). Nuclear Fuel Services, Inc. (NFS) was formed by Davison Chemical Co. to operate the plant as a commer- cial facility. NFS leased the property at the WNYNSC and in 1966 began operations to recycle fuel from both commercial and federallyowned reactors.

In 1972, while the plant was closed for modifications and expansion, new and more-rigorous safety regulations were imposed. Most of the changes concerned the disposal of liquid high-level radioactive waste (HLW) and the prevention of earthquake damage to the facilities. NFS decided that compliance with the new regulations was not economically feasible and in 1976 notified NYSERDA that it would not continue in the fuel-reprocessing business.

Following this decision, the reprocessing plant was shut down. Under the original agreement between the NFS and New York State, the state was ultimately responsible for both the radioactive wastes and the facility.

\section{Description of the West Valley Demonstration Project}

Numerous studies followed the decision by NFS to discontinue operations, which lead to the passage of Public Law 96-368, the West Valley Demonstration Project Act, in 1980. This Act authorized the DOE to demonstrate a method for solidifying the 600,000 gallons (2.3 million liters) of liquid HLW that remained at the West Valley site. Congress anticipated that the technologies developed at West Valley would be used at other facilities in the United States. (See Appendix K-3 ${ }^{C}$ for complete text of the WVDP Act.)

The purposes of the WVDP were to carry out the following activities: solidify the high-level radioactive waste that was left at the site from the original nuclear fuel reprocessing activities, develop suitable containers for holding and transporting the solidified waste, arrange transportation of the so-

INT - 2 
lidified waste to a federal repository, dispose of any low-level and transuranic radioactive waste resulting from the solidification of HLW, and decontaminate and decommission Project facilities used for solidification of radioactive waste.

DOE and NYSERDA entered into a Cooperative Agreement on October 1, 1980 (amended September 18, 1981). The Cooperative Agreement between the DOE and NYSERDA established the cooperative framework for implementation of the Project.

The WVDP Act specifically provides that the facilities and the high-level radioactive waste onsite shall be made available (by the state of New York) to the DOE without the transfer of title for as long as required to complete the Project. The facility's NRC license was amended in 1981 to allow the DOE to proceed at the Project under a Memorandum of Understanding. Although the lead agency for the WVDP is the DOE, under the Memorandum of Understanding the DOE and the NRC each have specific responsibilities related to the WVDP.

The former West Valley Nuclear Services Company, Inc., a subsidiary of Westinghouse Electric Corporation, was chosen by the DOE to be the management and operating contractor for the West Valley Demonstration Project. Site operations began at the WVDP in March 1982. The West Valley Nuclear Services Company, a unit of the Westinghouse Environmental Services Company (in 2003, the Energy and Environmental Division of Washington Group International), is the contractor for the WVDP.

The high-level waste, contained in underground storage tanks, had separated into two layers - a liquid supernatant and a settled sludge layer. Various subsystems were constructed that permitted the successful startup in May 1988 of the inte- grated radwaste treatment system (IRTS). The system removed most of the radioactivity from the liquid supernatant by ion exchange. The ionexchange zeolite material then was stored in a spare underground tank for later processing. This allowed the major portion of the liquid to be treated as low-level radioactive waste. Treatment of the supernatant liquid from the high-level waste tanks through the IRTS was completed in 1990.

The next step in the process, washing the sludge with water to remove soluble constituents, began in late 1991 and was completed in 1994. In 1995, the contents of the HLW tanks were combined and the subsequent mixture was washed a final time. Vitrification of the high-level waste residues began in July 1996. In June 1998, the WVDP successfully completed the first phase of the vitrification campaign. By late 2002, the WVDP was conducting the final phase of the campaign by removing most of the waste in tanks 8D-1 and 8D2. Vitrification was completed and the melter was shut down in September 2002. Activities for decontaminating the vitrification and support facilities were then initiated. These activities continued through 2003.

The following projects were initiated, continued, or completed in 2003:

Spent Fuel Shipping. After the original operator at the site, NFS, discontinued fuel reprocessing in 1972,750 spent fuel assemblies remained in storage. These spent fuel assemblies were stored in the on-site fuel pool. During an early 1980s shipping campaign, 625 of the spent fuel assemblies were returned to the utilities that owned them. During 2001, the remaining 125 assemblies were prepared for transport to the Idaho National Engineering and Environmental Laboratory (INEEL) for interim storage. In July 2003, the assemblies were shipped to INEEL, completing this task.

INT - 3 


\section{Introduction}

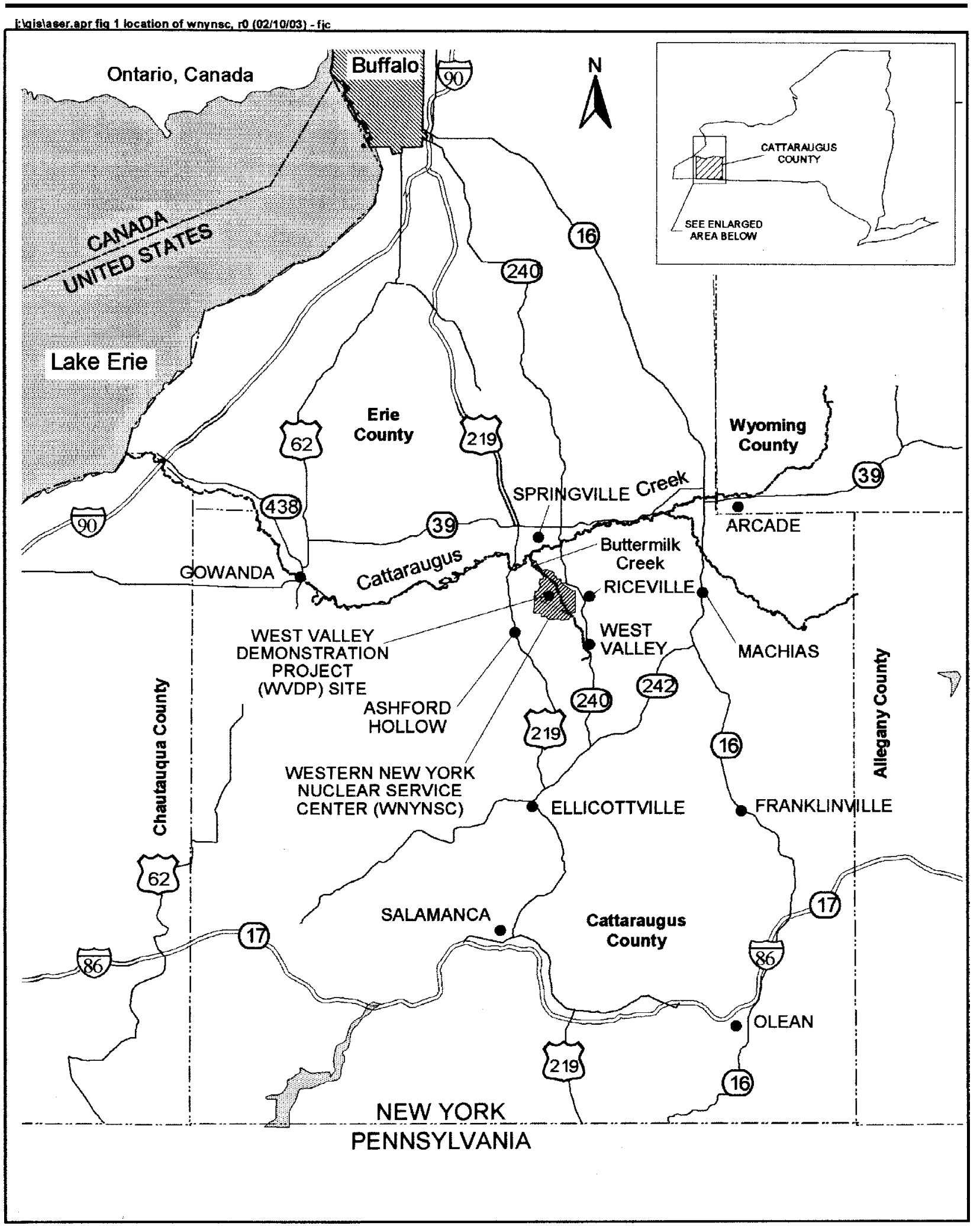

Figure INT-1. Location of the Western New York Nuclear Service Center

$$
\text { INT - } 4
$$


Decontamination of the Fuel Receiving and Storage Pools. After spent fuel, equipment, and debris were removed from the pools, they were drained, scrubbed and rinsed, the floors were grouted, surfaces were sealed, and a contamination fixative was applied. This project was completed in May 2003.

Decontamination of Cells in the Main Plant. Decontamination of cells and facilities in the main plant continued in 2003. The south product purification cell was decontaminated and work in the head end cells (the process mechanical cell and the general purpose cell) and extraction cell 2 continued throughout the year. Also in 2003, a plan for decontamination and dismantlement of the vitrification facility was prepared for implementation in 2004.

Waste Management. Part of the DOE's cleanup mission at the West Valley site is the disposal of low-level radioactive waste (LLW) that is generated through WVDP operations. In 2003, waste continued to be shipped off-site to storage facilities. (See Low-Level Radioactive Waste Shipping Program [p. 1-12].)

High-Level Waste Tank Lay-Up. Lay-up of HLW tanks 8D-1 and 8D-2 was completed in July 2003. Lay-up included isolating the tanks from the main plant, deactivating components, replacing and relocating pumps, and placing grout around pipe penetrations to reduce groundwater infiltration.

Remote-Handled Waste Facility. An on-site remote-handled waste facility was under construction in 2003. It will be used to prepare higher-activity wastes for shipment and disposal, with start-up projected for 2004.

Environmental Monitoring. Sitewide environmental monitoring and management of contaminated areas continued to ensure the safety of the public and the environment.

\section{General Environmental Setting}

The geography, socioeconomics, climate, ecology, physiography, and geology of the region are principal factors in assessing possible effects of site activities on the surrounding population and environment, and are an integral consideration in the design and structure of the environmental monitoring program.

Location of the West Valley Demonstration Project. The WVDP is located in northern Cattaraugus County, about 30 miles $(50 \mathrm{~km})$ south of Buffalo, New York (Fig. INT-1 [facing page]). The WVDP facilities occupy a security-fenced area of about 164 acres (66 ha) within the WNYNSC. This fenced area is referred to as the Project premises.

The WVDP is situated on New York State's Allegheny Plateau at an approximate average elevation of 1,300 feet $(400 \mathrm{~m})$. The communities of West Valley, Riceville, Ashford Hollow, and the village of Springville are located within approximately 5 miles $(8 \mathrm{~km}$ ) of the Project. Several roads and a railway approach or pass through the WNYNSC, but the public does not have access to the WNYNSC. Hunting, fishing, and human habitation on the WNYNSC generally are prohibited. ANYSERDA-sponsored program to control the deer population, initiated in 1994, continued through 2003. Limited access to the WNYNSC was given to local hunters, and community response has been favorable.

Socioeconomics. The WNYNSC lies primarily within the town of Ashford in Cattaraugus County. The nearby population, approximately 9,200 residents within 6.2 miles $(10 \mathrm{~km})$ of the Project, relies largely on an agricultural economy. No major industries are located within this area. The WVDP is one of the largest employers in Cattaraugus County.

INT - 5 
The land immediately adjacent to the WNYNSC is used principally for agriculture and arboriculture. Cattaraugus Creek is used locally for swimming, canoeing, and fishing. Although some water to irrigate nearby golf course greens and tree farms is taken from Cattaraugus Creek, no public potable water supply is drawn from the creek downstream of the WNYNSC before the creek flows into Lake Erie south of Buffalo, New York. Water from Lake Erie is used as a public drinkingwater supply.

Climate. Although there are recorded extremes of $98.6^{\circ} \mathrm{F}\left(37^{\circ} \mathrm{C}\right)$ and $-43.6^{\circ} \mathrm{F}\left(-42^{\circ} \mathrm{C}\right)$ in western New York, the climate is moderate, with an average annual temperature (1971-2000) of $48^{\circ} \mathrm{F}$ $\left(8.9^{\circ} \mathrm{C}\right)$. Rainfall is relatively high, averaging about 41 inches $(104 \mathrm{~cm})$ per year. Precipitation in 2003 totaled 41 inches $(104 \mathrm{~cm})$, equal to the long-term average. Precipitation is evenly distributed throughout the year and is markedly influenced by Lake Erie to the west and, to a lesser extent, by Lake Ontario to the north. Regional winds are generally from the west and south at about $9 \mathrm{mph}$ (4 m/sec).

Biology. The WNYNSC lies within the northern deciduous forest biome, and the diversity of its vegetation is typical of the region. Equally divided between forest and open land, the site provides a habitat especially attractive to white-tailed deer and various indigenous migratory birds, reptiles, and small mammals. No species on the federal endangered-species list are known to be present on the WNYNSC.

Geology and Hydrology. The geologic sediments beneath the WVDP site include a sequence of glacial sediments above shale bedrock. The site is divided by a stream valley into two areas: the north plateau and the south plateau.
The uppermost layer on the south plateau is a silty clay till, the Lavery till. Weathering has fractured the near-surface sediments. Groundwater flows through this weathered till horizontally to the northeast and vertically downward. Groundwater flow in the unweathered till, beneath the weathered till, is predominantly downward at a negligible rate.

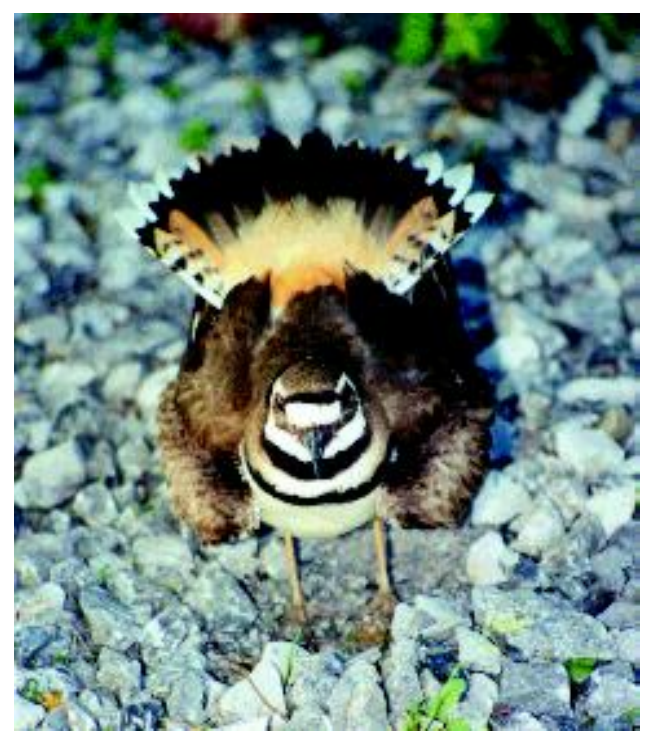

A Killdeer (Charadrius vociferus) Protects Her Nest

On the north plateau, a permeable alluvial sand and gravel layer overlies less-permeable glacial sediments (i.e., the Lavery till, the Kent recessional sequence, and the Kent till). Groundwater flow is predominantly horizontal, toward the northeast, discharging along the plateau's edge. Within the Lavery till on the north plateau is a silty, sandy layer of limited extent, the Lavery till-sand.

The Kent recessional sequence underlies the Lavery till beneath both the north and south plateaus and is composed of silt and silty sand with localized pockets of gravel. Groundwater in this unit flows to the northeast with discharge to Buttermilk Creek.

INT - 6 


\section{Environmental Monitoring Program}

The WVDP's environmental monitoring program began in February 1982. The primary program goal is to detect and evaluate changes in the environment resulting from Project or pre-Project activities and to assess the effect of any such changes on the human population.

The monitoring network and sample collection schedule have been structured to accommodate specific biological and physical characteristics of the area. Among the several factors considered in designing the environmental monitoring program were the kinds of wastes and other by-products resulting from the processing of HLW; possible routes that radiological and nonradiological contaminants could follow into the environment; geologic, hydrologic, and meteorologic site conditions; quality assurance standards for monitoring and sampling procedures and analyses; and the limits and standards set by federal and state governments and agencies. When new processes and systems become part of the Project, appropriate additional monitoring is provided. As processes are completed, unnecessary monitoring is eliminated from the program.

Monitoring and Sampling. The environmental monitoring program consists of on-site effluent monitoring and on- and off-site environmental surveillance to measure both radiological and nonradiological constituents. (See the Glossary for more detailed definitions of effluent monitoring [p. GLO-3] and environmental surveillance [p. GLO-4].) Monitoring and surveillance include both the continuous recording of data and the collecting of soil, sediment, water, air, and other samples at specific times.

Monitoring and sampling of environmental media provide two ways of assessing the effects of
Project or pre-Project activities. Monitoring generally is a continuous (or periodic) process of measurement that allows rapid detection of any changes in the levels of constituents that could affect the environment. Sampling is the collection of media at specific times; sampling is slower than direct monitoring to indicate changes in constituent levels because the samples must be analyzed in a laboratory. However, sample analysis allows much smaller quantities of radioactivity or chemical concentrations to be detected.

Permits and Regulations. Data gathering, analysis, and reporting to meet stringent federal and state requirements and standards are an integral part of the monitoring program. The 2003 program met the requirements of DOE Orders 450.1 (Environmental Protection Program), 5400.1 (General Environmental Protection Program, canceled early in 2003), 5400.5 (Radiation Protection of the Public and Environment), and 231.1A (Environment, Safety, and Health Reporting), and DOE Regulatory Guide DOE/EH-0173T (Environmental Regulatory Guide for Radiological Effluent Monitoring and Environmental Surveillance). The environmental monitoring program also supports requirements of the Resource Conservation and Recovery Act $§ 3008(\mathrm{~h})$ Administrative Order on Consent.

The WVDP holds a New York State Pollutant Discharge Elimination System (SPDES) Permit as required by the New York State Department of Environmental Conservation, which regulates liquid effluent discharges containing nonradiological pollutants. The SPDES Permit identifies the outfalls where liquid effluents are released to surface water drainage systems and specifies the sampling and analytical requirements for each outfall.

For more information about air and SPDES Permits see the Environmental Compliance Summary (pp. ECS-7 through ECS-12). Environmental permits are listed at the back of the Environmental

INT - 7 
Compliance Summary (Table ECS-8 [pp. ECS26 and ECS-27]).

Radiological air emissions must comply with the National Emission Standards for Hazardous Air Pollutants regulations. Depending upon the potential to emit radionuclides, some radiological emission points must be permitted by the U.S. Environmental Protection Agency (EPA).

In addition, the site operates under a New York State-issued facility air-emission permit for nonradiological contaminants.

\section{Exposure Pathway Monitoring}

The major pathways for potential near-term movement of contaminants away from the site are surface water drainage and airborne transport. For this reason, the environmental monitoring program emphasizes the collection of air and surface water samples.

Samples are collected on-site from locations such as plant ventilation stacks, various water effluent points, and surface water drainage locations. Analyses of samples of air, water, soils, and biota from the environment surrounding the site would detect radioactivity that might reach the public from site releases. Extensive groundwater monitoring addresses the relatively slower subsurface pathways and provides surveillance of potential releases from solid waste management units.

Surface Water and Sediment Pathways. Process waters are treated by filtration and ion-exchange in a liquid-treatment facility, the LLW2. The treated water is sent to a series of on-site holding lagoons for testing before being discharged through a single outfall. (The locations of the lagoons are noted on Fig. A-2 [p. A-2].) Samples of this process water and the effluent at two other discharge points are collected in accordance with SPDES Permit and DOE requirements.

The samples are analyzed for radiological parameters, including gross alpha and gross beta, tritium, strontium-90, and gamma-emitting radionuclides, and for nonradiological parameters, including $\mathrm{pH}$. Additional analyses of composite samples determine metals content, solids, biochemical oxygen demand, nitrates, nitrites, ammonia, sulfate, organic chemicals, and specific radionuclides.

In general, surface water samples are collected regularly and analyzed, at a minimum, for gross alpha and gross beta radioactivity, tritium, and $\mathrm{pH}$. A smaller number of samples are analyzed for conductivity, chlorides, metals, volatile organic compounds, and other parameters. Potable water on the site is analyzed monthly for radioactivity and annually for chemical constituents.

Off-site surface waters, primarily from Cattaraugus Creek and Buttermilk Creek, are sampled upstream of the Project for background radioactivity and downstream to measure possible Project contributions. Sediments deposited downstream of the facility and at upstream background locations are collected annually and analyzed for gross alpha, gross beta, and specific radionuclides. (See Appendix $\mathrm{C}^{\mathrm{C}}$ and Appendix $\mathrm{G}^{\mathrm{C}}$ for water and sediment data summaries.)

Groundwater Pathways. Groundwater discharge at the WVDP site occurs as springs or seeps along stream channels, direct discharge to streams, evapotranspiration, vertical groundwater migration to underlying strata, and discharge to artificial draining systems and lagoons. All of these discharges vary with the seasons. Discharge from springs and seeps is highest during the spring. Evapotranspiration is at a maximum during the summer. Groundwater discharge is, in general,

INT - 8 
lowest during the winter because the ground surface is frozen, which minimizes recharge.

Routine monitoring of groundwater includes sampling for contamination and radiological indicator parameters ( $\mathrm{pH}$ and conductivity, and gross alpha, gross beta, and tritium) and for specific analytes of interest such as volatile organic compounds, semivolatile organic compounds, metals, and radionuclides at selected monitoring locations. (See Table E-1 in Appendix $\mathrm{E}^{\mathrm{C}}$.)

Residential drinking water wells located near the site are sampled annually and analyzed for gross alpha and gross beta radioactivity, tritium, strontium-90, gamma-emitting radionuclides, $\mathrm{pH}$, and conductivity.

Air Pathways. Permitted effluent air emissions are continuously monitored for alpha and beta activity. Alarms indicate any unusual rise in radioactivity. Air particulate sampling filters, which are retrieved and analyzed weekly for gross radioactivity, are also composited quarterly and analyzed for strontium-90 and specific gamma- and alpha-emitting radionuclides.

Tritium and iodine-129 also are measured in effluent ventilation air at some locations. Silica gel-filled columns are used at two of the effluent locations to collect water vapor that is then distilled from the drying agent and analyzed for tritium. These distillates are analyzed weekly. Six permanent samplers at effluent locations contain activated charcoal adsorbent that is analyzed for iodine-129; the charcoal is collected weekly and composited for quarterly analysis.

Off-site sampling locations include those considered most representative of background conditions and those most likely to be downwind of airborne releases. Among the criteria used to position off- site air samplers are prevailing wind direction, land usage, and the location of population centers.

Off-site air is continuously sampled at ten locations. Background samplers are located far from the site in Great Valley and Nashville, New York. (The Nashville sampling location was discontinued at the end of March 2003.) Nearby-community samplers are in Springville and West Valley, New York. (See Figs. A-12 and A-13 [pp. A-12 and A-13] for these four off-site air sampling locations.) Six samplers are located on the perimeter of the WNYNSC. (See Fig. A-5 [p. A-5].) Samples from these locations are analyzed for parameters similar to the effluent air samples. (See Appendix $\mathrm{D}^{\mathrm{C}}$ for air monitoring data summaries.)

Atmospheric Fallout. An important contributor to environmental radioactivity is atmospheric fallout. Sources of fallout include earlier atmospheric testing of nuclear weapons and residual radioactivity from accidents such as that which occurred at Chernobyl in the Ukraine.

Four site perimeter locations and one on-site location currently are monitored for fallout using pottype collectors that are sampled every month. Long-term fallout is assessed by analyzing soil collected annually at each of the six perimeter and four off-site air samplers. Three additional on-site soil samples are taken annually. (See Appendix $\mathrm{D}^{\mathrm{C}}$ for fallout data summaries and Appendix $\mathrm{G}^{\mathrm{C}}$ for soil data summaries.)

Food Pathways. A potentially significant pathway for radioactivity to reach humans is through consuming produce, meat, and milk from domesticated farm animals raised near the WVDP and game animals and fish that live in the vicinity of the WVDP. Animal and fish samples from potentiallyaffected areas are gathered and analyzed for radionuclide content in order to reveal any long-term

INT - 9 
trends. Fish are collected along Cattaraugus Creek at locations downstream of the WVDP. Venison is sampled from deer whose range includes the WNYNSC. Control samples of both fish and venison are collected from background areas outside WVDP influence. Beef, milk, and produce samples also are collected at nearby farms and at selected locations well away from WVDP influence. (See Appendix $\mathrm{F}^{\mathrm{C}}$ for biological data summaries.)

Direct Radiation Measurement. Direct penetrating radiation is measured using thermoluminescent dosimeters (TLDs) located on- and off-site. Measurement points within the site are placed near selected waste management units and around the inner security fence. Other locations are around the site perimeter and access road and at background locations remote from the WVDP. Forty-three measurement points were used in 2003. The TLDs are retrieved quarterly and are processed by an off-site service to obtain the integrated gamma exposure. (See Appendix $\mathrm{H}^{\mathrm{C}}$ for a summary of the direct radiation data.)

\section{Meteorological Monitoring}

Meteorological data are continuously gathered and recorded at meteorological towers on-site and a nearby regional location south of the WNYNSC. Wind speed and direction, barometric pressure, temperature, dewpoint, and rainfall are measured on-site. Wind speed and direction are measured at the regional tower. These data are valuable for modeling both airborne dispersion and long-term hydrologic trends. In the event of an emergency, immediate access to the most recent meteorological data is indispensable for predicting the path and concentration of any materials that become airborne. (See Appendix $\mathrm{I}^{\mathrm{C}}$ for meteorological data summaries.)

\section{Quality Assurance and Control}

The work performed by and through the on-site WVDP Environmental Laboratory is regularly reviewed by several agencies for accuracy and compliance with applicable regulations. Assessments of the laboratory routinely focus on proper recordkeeping and reporting, timely calibration of equipment, training of personnel, adherence to accepted procedures, and general laboratory safety.

The Project's Environmental Laboratory also participates in quality assurance crosscheck programs administered by federal agencies. (See Appendix $\mathrm{J}^{\mathrm{C}}$ for a summary of crosscheck performance.) The performance of outside laboratories contracted to analyze WVDP samples also is regularly assessed.

Environmental monitoring management continues to strengthen the formal self-assessment program by developing and implementing new strategies and procedures for ensuring high-quality data. Experienced senior scientists and specialists in relevant disciplines follow an annual schedule of self-assessments, produce formal reports with recommended corrective actions, and track the actions as they are completed.

\section{Environmental and Safety Performance Recognition}

In August 2003, a self-assessment was conducted to confirm that the WVDP's integrated environmental, safety, and health management system continued to be effectively implemented at the WVDP. Results from the self-assessment were verified in the DOE's annual review, conducted in December 2003. In 2003 the WVDP continued the achievement level and practices worthy of a National Environmental Performance Track and

INT - 10 
STAR-designated site. For a more-detailed discussion of the integrated safety management system, the environmental management system, and associated performance awards at the WVDP, see Integrated Safety Management System, STAR Status, EPA National Environmental Performance Track, and Environmental Management System on pp. ECS-16 and ECS-17.

INT - 11 
This page intentionally left blank

INT - 12 


\section{ENVIRONMENTAL COMPLIANCE SUMMARY Calendar Year 2003}

\section{Compliance Program}

The West Valley Demonstration Project (WVDP) is currently focusing on several goals that will lead to completion of the WVDPAct. (See Appendix K-3C [p. K-7].) Construction of the remote-handled waste facility, which will be used to process and package radioactive Project waste into shipping containers, was completed in early 2004. The WVDP completed dismantling of process equipment and removal of waste from the fuel receiving and storage pool facility. Preparations for dismantlement of process equipment in the vitrification facility were initiated. Decontamination of former fuel reprocessing cells within the main process building and management of contaminated groundwater continued.

In January 2003 the U.S. Department of Energy (DOE), the federal agency that oversees the WVDP, issued a directive (DOE Order 450.1) requiring implementation of an environmental management system (EMS) for conducting work at DOE sites, including the WVDP. In response to this directive, the existing WVDP EMS was reviewed and further enhanced. (See pp. ECS-2 and ECS-17 and Table ECS-1 [p. ECS-19].)

Activities in progress at the WVDP are regulated by various federal and state laws that protect the public, workers, and the environment.
Major federal environmental laws and regulations applicable to the WVDP are: the Resource Conservation and Recovery Act; the Clean Air Act; the Emergency Planning and Community Rightto-Know Act (enacted as Title III of the Superfund Amendments and Reauthorization Act); the Clean Water Act; the Safe Drinking Water Act; the Toxic Substances Control Act; the Migratory Bird Treaty Act; and the National Environmental Policy Act. These laws are administered primarily by the U.S. Environmental Protection Agency (EPA), the U.S. Fish and Wildlife Service, the U.S. Army Corps of Engineers (ACOE), the New York State Department of Environmental Conservation (NYSDEC), and the New York State Department of Health (NYSDOH) through programs and regulatory requirements for permitting, reporting, inspecting, self-monitoring, and audits.

Because release of radiological and nonradiological materials from an active facility cannot be completely prevented, the EPA, NYSDEC, and the DOE have established standards for such emissions and discharges that are intended to protect human health and the environment. The WVDP applies to NYSDEC and the EPA for permits to release limited amounts of radiological and nonradiological constituents through controlled and monitored effluent releases into water and air in concentrations determined to be safe for humans 
and the environment. In general, the permits describe release points, specify management and reporting requirements, list limits on those pollutants likely to be present, and define the sampling and analysis regimen. A summary of permits may be found in Table ECS-8 (pp. ECS-26 and ECS-27).

\section{Compliance Status}

The following summary describes WVDP compliance with DOE Orders 450.1, 5400.5, and 435.1 and federal and state laws and regulations applicable to the Project.

Environmental Protection Program (DOE Order 450.1). DOE Order 450.1, issued in January 2003, requires DOE sites to implement an EMS by December 31, 2005. An EMS is a continuing cycle of systematic planning, implementing, evaluating, and improving processes and actions undertaken to achieve environmental goals. Since 1999, the WVDP has implemented an EMS via policies and procedures that provide for accomplishing work through proactive management, environmental stewardship, and integration of appropriate technologies across all Project functions. The West Valley Nuclear Services Co. (WVNSCO) EMS satisfies the requirements of both the Code of Environmental Management Principles for federal agencies and the International Organization for Standardization 14001, Environmental Management Systems: Specifications for Guidance and Use. Elements of the WVDP EMS are summarized in Table ECS-1 (p. ECS-19).

\section{Radiation Protection of the Public and the En- vironment (DOE Order 5400.5). DOE Order} 5400.5, issued in February of 1990, established standards and requirements for protection of the public and the environment against undue risk from radiation resulting from activities of the $\mathrm{DOE}$ and DOE contractors. The objectives of the Order were to ensure that (1) operations are conducted so that radiation exposures to members of the public are maintained within the limits established in the Order, (2) potential exposures to members of the public are as far below the limits as is reasonably achievable, (3) routine and non-routine releases are monitored and dose to the public is assessed, and (4) the environment is protected from radioactive contamination to the extent practical.

This report summarizes radiological releases from the WVDP in 2003, presents estimates of dose to the public and the environment in 2003, and compares these values with release and dose standards established by DOE Order 5400.5. (See Appendix $\mathrm{K}^{\mathrm{C}}$.) In 2003, both releases and estimates of dose to the public were well within applicable limits.

Radioactive Waste Management (DOE Order 435.1). DOE Order 435.1 was issued in July of 1999 to ensure that all DOE radioactive waste - including high-level waste (HLW), transuranic waste, low-level radioactive waste (LLW), and the radioactive component of mixed waste - is managed to (1) protect the public from exposure to radiation from radioactive materials, (2) protect the environment, (3) protect workers, and (4) comply with applicable federal, state, and local laws and regulations, as well as applicable Executive Orders and other DOE directives. The WVDP Radioactive Waste Acceptance Program, a formal document describing how radioactive waste is managed at the WVDP, was updated in 2003.

\section{Resource Conservation and Recovery Act} (RCRA). RCRA was enacted to ensure that hazardous wastes are managed in a manner that protects human health and the environment. RCRA and its implementing regulations govern the life cycle of hazardous waste and mandate that generators take responsibility for ensuring the proper treatment, storage, and disposal of their wastes. The EPA is the federal agency responsible for is- 
suing guidelines and regulations for the proper management of solid and hazardous waste (including mixed [radioactive and hazardous] waste).

In New York, the EPA has delegated the authority to issue permits and enforce these regulations to NYSDEC. In addition, the U.S. Department of Transportation is responsible for issuing guidelines and regulations for labeling, packaging, and spillreporting for hazardous and mixed wastes while in transit.

A hazardous waste permit is required for facilities that treat or store large quantities of hazardous waste for more than 90 days or dispose of hazardous waste at the facility. Facilities in existence on the date that hazardous waste regulations impacting their operations take effect must apply for interim status. These facilities must therefore apply for interim status from the NYSDEC by submitting a RCRA Part A Permit Application. Facility operations during interim status must limit operations to those described in the Part A Permit Application and must comply with the Interim Status Standards regulations.

For existing hazardous waste management facilities in New York, the NYSDEC sets a date for submitting the Part B Application (also known as Part 373 Permits in New York). Facilities with interim status are treated as having been issued a permit until a final determination on the RCRA Permit Application is made. The Part 373 Application must be submitted in narrative form and contain all of the information specified in Title 40, Protection of Environment, Code of Federal Regulations (CFR) Parts 270.14 through 270.29 and Title 6 of the Official Compilation of Codes, Rules, and Regulations of the State of New York (6 NYCRR) Part 373-1.5. Hazardous waste management facilities must have a permit throughout the active life of hazardous waste management activities.
In 1984 the DOE notified the EPA of hazardous waste activities at the WVDP and identified the WVDP as a generator of hazardous waste. In June 1990, the effective date of the New York State regulations governing treatment, storage, and disposal of mixed (i.e., RCRA hazardous and Atomic Energy Commission radioactive) waste, the WVDP filed a Part A Hazardous Waste Permit Application with NYSDEC for storage and treatment of hazardous and mixed wastes and has been operating under interim status since then.

The WVDP updates its Part A Permit Application as changes to the site's interim-status waste-management operations occur. An updated Part A Permit Application was submitted to NYSDEC on March 6, 2001. On November 13, 2001, NYSDEC responded that the RCRA Part A Permit modifications met the requirements for changes to interim status treatment and storage operations at the WVDP.

In a July 16, 2003 letter to DOE, NYSDEC made an official request for the submittal of a Part 373 Permit Application for the WVDP. The complete Part 373 Permit Application is planned for transmittal to NYSDEC for review and processing during 2004.

Hazardous Waste Management Program. Hazardous wastes at the WVDP are managed in accordance with 6 NYCRR Parts 370-374 and 376. To dispose of hazardous wastes generated from on-site activities, the WVDP uses New York Statepermitted transporters (pursuant to 6 NYCRR Part 364) to ship RCRA-regulated wastes to permitted or authorized treatment, storage, or disposal facilities (TSDFs). The WVDP shipped approximately 1.20 tons (1.09 metric tons) of nonradioactive hazardous waste to off-site TSDFs in 2003.

Off-site hazardous waste shipments and their receipt at designated TSDFs are documented by

ECS - 3 
signed manifests that accompany the shipment. If the signed manifest is not returned by the TSDF to the WVDP within the regulatory limit of 45 days from shipment, an exception report must be filed with NYSDEC and it must be confirmed that the waste was received by the TSDF. No exception reports were required during 2003.

Hazardous and mixed waste activities must be reported to NYSDEC each year through the submittal of the facility's annual Hazardous Waste Report. This report summarizes the hazardous waste activities for the previous year, specifies the quantities of waste generated, treated, and/or disposed, and identifies the TSDFs used. The annual Hazardous Waste Report for calendar year (CY) 2003 was submitted to NYSDEC in February 2004. In addition, a hazardous waste reduction plan must be filed every two years and updated annually. This plan documents efforts to minimize the generation of hazardous waste and was first submitted to NYSDEC in 1990. The most recent Annual Status Report for the Hazardous Waste Reduction Program was submitted to NYSDEC in June 2002. The hazardous waste reduction plan was also updated in 2003, as required.

An annual inspection to assess compliance with hazardous waste regulations was conducted by NYSDEC on March 20, 2003. No deficiencies were noted.

Mixed Waste Management Program. Mixed waste contains both a radioactive component, regulated under the Atomic Energy Act, and a hazardous component, regulated under RCRA. Both the EPA and NYSDEC oversee mixed waste management at the WVDP.

The Federal Facility Compliance Act of 1992, an amendment to RCRA, requires DOE facilities to prepare plans (i.e., the Site Treatment Plan) for treating their mixed waste inventories and to up- date these plans annually to account for development of treatment technologies, capacities, and changes in mixed waste inventories. Each plan is approved by the respective state agency or the EPA after consultation with other affected states and after consideration of public comments.

The WVDP's Site Treatment Plan comprises two volumes: the Background Volume provides information on each mixed waste stream and information on the preferred treatment method for the waste, and the Plan Volume contains proposed schedules for treating the mixed waste to meet the land disposal restriction requirements of RCRA.

The DOE and NYSDEC entered into a Consent Order in August 1996 that requires the completion of the milestones identified in the Plan Volume. The WVDP began implementing its Site Treatment Plan immediately and updates it annually to bring waste stream, inventory, and treatment information current through September 30, the end of the DOE fiscal year. A draft update of the fiscal year 2003 activities was forwarded to NYSDEC before the due date of February 15, 2004.

Just as for hazardous waste, shipments of mixed waste to off-site TSDFs for treatment are documented via uniform hazardous waste manifests. In 2003 the WVDP made one mixed waste shipment, which consisted of elemental lead and solid metal debris. A total of 1.83 tons (1.66 metric tons) were shipped to Envirocare of Utah for treatment and disposal.

RCRA $\$ 3008(h)$ Administrative Order on Consent. The DOE and the New York State Energy Research and Development Authority (NYSERDA) entered into a RCRA §3008(h) Administrative Order on Consent with NYSDEC and the EPA in March 1992. The Consent Order re- 
quired NYSERDA and the DOE's West Valley Demonstration Project Office to conduct RCRAfacility investigations (RFIs) at on-site solid waste management units (SWMUs) to determine if there had been a release or if there is a potential for release of RCRA-regulated hazardous constituents from SWMUs. The final RFI reports were submitted in 1997, completing the investigative activities associated with the Consent Order. No corrective actions were required as a result of the RFIs. Groundwater monitoring, as specified in the RFI reports, continued during 2003. The WVDP also continued to monitor SWMUs and to comply with the requirements of the RCRA $\$ 3008(\mathrm{~h})$ Administrative Order on Consent. Groundwater monitoring results are detailed in Chapter 4.

Two new SWMUs were identified in 2003 and an additional SWMU was identified in early 2004: a breach in the laundry wastewater line, the concrete vault staging area, and the remote-handled waste facility. Notifications were submitted to the EPA and to NYSDEC, as required.

Nonhazardous, Regulated Waste Management Program. The WVDP shipped approximately 19 tons (17 metric tons) of nonradioactive, nonhazardous material off-site to solid waste management facilities in 2003. Of this amount, 3.4 tons (3.1 metric tons) were recycled or reclaimed. Some of the recycled materials were lead-acid batteries and spent lamps, which were recycled at off-site authorized reclamation and recycling facilities. Lead-acid batteries and spent lamps are managed as universal wastes. (See universal wastes [p. GLO-12].) The WVDP also shipped approximately 415 tons (376 metric tons) of digested sludge and treated wastewater from the site sanitary and industrial wastewater treatment facility to the Buffalo Sewer Authority for disposal.

Waste Minimization and Pollution Prevention. The WVDP continued a long-term program to minimize the generation of low-level radioactive waste, mixed waste, hazardous waste, industrial waste, and sanitary waste, and to promote affirmative procurement as directed by Executive Order 13101 (Greening the Government Through Waste Prevention, Recycling, and Federal Acquisition) and Executive Order 13148 (Greening the Government Through Leadership in Environmental Management), which promote the Affirmative Procurement Program and RCRA $\$ 6002$, Federal Procurement. These Executive Orders are also supported by DOE Order 450.1, Environmental Protection Program. The Affirmative Procurement Program specifies responsibilities and direction for federal agencies in acquiring recycled and environmentally-preferable products and services designated by the EPA in 40 CFR Part 247, Comprehensive Procurement Guideline for Products Containing Recovered Material. WVNSCO reports its challenges and successes associated with the purchase and use of these materials and services to the DOE each year.

For purposes of waste-reduction tracking, on-site waste streams are separated into either waste from sources directly associated with the vitrification process or from nonvitrification sources. See Chapter 1 (p. 1-17) for further discussion of waste minimization activities from all sources in 2003.

Underground Storage Tanks Program. RCRA regulations also cover the use and management of underground storage tanks and establish minimum design requirements to protect groundwater resources from releases. The regulations, specified in 40 CFR Part 280, require underground storage tanks to be equipped with overfill protection, spill prevention, corrosion protection, and leak detection systems. New tanks must comply with regulations at the time of installation.

New York State also regulates underground storage tanks through two programs - petroleum bulk

ECS - 5 
storage (6 NYCRR Parts 612-614) and chemical bulk storage (6 NYCRR Parts 595-599). State registration and minimum design requirements are similar to those of the federal program except that petroleum tank fill ports must be color-coded, using American Petroleum Institute standards, to indicate the product being stored.

A 550-gallon, double-walled, steel underground storage tank, upgraded in 1998 to bring it into compliance with the most recent EPA requirements (40 CFR Part 280.21), is used to store diesel fuel for the supernatant treatment system/permanent ventilation system standby power unit. This tank is equipped with aboveground piping, an upgraded interstitial leak-detection system, and a high-level warning device, and meets the state requirements of 6 NYCRR Parts 612-614. This is the only underground petroleum-storage tank currently in use at the WVDP.

A former underground petroleum-storage tank, closed in place before the New York State underground storage tank program closure requirements were implemented in 1985, was removed in 1997. Testing of soils from the tank excavation had shown evidence of earlier petroleum leakage, and on March 19, 1999, the DOE and NYSDEC executed a Stipulation Agreement Pursuant to Section 17-0303 of the Environmental Conservation Law and Section 176 of the Navigation Law for mitigation of the petroleum contamination.

A soil bioventing system was installed in August 1999 to remediate localized petroleum-contaminated soils in the vicinity of the former underground petroleum storage tank. The system stimulated natural in-situ biodegradation of petroleum hydrocarbons in the soil by providing an abundant oxygen supply to existing soil microorganisms within the contaminated soil zone. Soil and groundwater samples were collected in 2002 to evaluate whether an adequate level of remediation has been achieved. Sample results reviewed by NYSDEC determined that no further remediation is required at this time.

There are no underground chemical bulk storage tanks at the WVDP.

New York State-Regulated Aboveground Storage Tanks. New York State regulates aboveground petroleum bulk storage under 6 NYCRR Parts 612-614, and aboveground hazardous bulk chemical storage under 6 NYCRR Parts 595-599. These regulations require secondary containment, external gauges to indicate the content levels, monthly visual inspections of petroleum tanks, and documented daily, annual, and five-year inspections of chemical tanks. Documentation relating to these periodic inspections is maintained by the WVDP and is available for regulatory agencies to review. Petroleum tank fill ports also must be color-coded, and chemical tanks must be labeled to indicate the product stored.

WVDP registration at the end of 2003 included nine aboveground petroleum tanks and ten aboveground chemical storage tanks. Three of the petroleum tanks contain No. 2 fuel oil, one contains unleaded gasoline, and the others contain diesel fuel. WVNSCO Quality Assurance Department personnel inspect the aboveground petroleum tanks every month.

Nine of the chemical storage tanks were used as needed to contain nitric acid or nitric acid mixtures. Sodium hydroxide was stored in the other tank. A tank formerly used to store anhydrous ammonia was closed in 2002. All 11 tanks were emptied in the fall of 2002 after vitrification operations were completed. The sodium hydroxide tank and one nitric acid tank were permanently closed in 2003. Plans are under development for future use or closure of the remaining eight tanks.

ECS - 6 
All the tanks are equipped with gauges and secondary containment systems. The WVDP is in compliance with the most recent requirements to upgrade chemical bulk storage tanks that went into effect in December 1999. An inspection by NYSDEC was performed in December of 2002 and it was determined that all chemical bulk storage tanks were in compliance with New York State regulations.

Medical Waste Tracking. Medical waste can potentially expose humans to infectious diseases and pathogens from contact with bodily fluids. Medical evaluations, inoculations, and laboratory work at the on-site Health Services office regularly generate potentially infectious medical wastes that must be tracked in accordance with NYSDEC requirements (6 NYCRR Part 364.9).

The WVDP has retained the services of a permitted waste hauler and disposal firm to manage these medical wastes. Medical wastes are sterilized with an autoclave by the disposal firm to remove the associated hazard and are then disposed. Thirty pounds ( $14 \mathrm{~kg}$ ) of medical waste consisting of dressings, protective clothing, such as rubber gloves, and needles, syringes, and other sharps were generated and disposed in 2003.

CleanAirAct (CAA). The CAA, including Titles I through VI, establishes a framework for the EPA to regulate air emissions from both stationary and mobile sources. These amendments mandate that each state establish a program to permit operation of sources of air pollution. In 1996 NYSDEC amended 6 NYCRR Parts 200, 201, 231, and 621 to implement the requirements of the new EPA CAATitle $\mathrm{V}$ permitting processes.

In New York State, NYSDEC issues permits for stationary sources that emit regulated pollutants, including hazardous air pollutants. Sources requiring permits are those that emit regulated pollutants from a particular source (e.g., a stack, duct, vent, or other similar opening), if the pollutants are in quantities above a predetermined threshold. WVDP radiological emissions are regulated by the EPA.

Radiological Emissions. Air emissions of radionuclides at the WVDP are regulated by the EPA under the National Emission Standards for Hazardous Air Pollutants (NESHAP) regulations, 40 CFR Part 61, Subpart H, National Emission Standards for Emission of Radionuclides other than Radon from Department of Energy Facilities. The WVDP currently has permits for six radionuclide sources, including the slurry-fed ceramic melter and the vitrification heating, ventilation, and airconditioning (HVAC) system.

In 2003, in compliance with updated stack inspection requirements of 40 CFR 61, Appendix B, Method 114, sampling systems in use for major emission points were inspected and the results were documented. Cleaning was carried out, as appropriate. Sampling systems for the main stack (ANSTACK), the supernatant treatment system/ permanent ventilation system (ANSTSTK), and the vitrification HVAC system (ANVITSK) were inspected.

Other less-significant sources of radionuclide emissions, such as those from the on-site laundry, do not require permits. Non-point radiological sources of air emissions, such as open-air lagoons, also do not require permits. The WVDP reports the radionuclide emissions from its non-permitted and permitted sources to the EPA annually, in accordance with NESHAP regulations. The annual NESHAP Report is submitted to EPA by June 30th of the following calendar year. Calculations to demonstrate compliance with NESHAP radioactive dose limits showed calendar year 2003 doses to be approximately $0.02 \%$ of the 10 millirem standard. (See Table 2-6 [p. 2-28].)

ECS - 7 
Nonradiological Emissions. Nonradiological point sources of air emissions are regulated by NYSDEC. Major-source facilities are required by 6 NYCRR Part 201 to file a Title V Permit Application unless emissions are capped below operating limits. The WVDP submitted - and has received NYSDEC approval of - a capping plan for oxides of nitrogen $\left(\mathrm{NO}_{\mathrm{x}}\right)$ and sulfur dioxide $\left(\mathrm{SO}_{2}\right)$.

The WVDP opted to file a State Facility Permit Application for the site. A State Facility Permit modification to incorporate sitewide air emission sources was submitted in December 1997 and approved June 1, 2000. Annual $\mathrm{NO}_{\mathrm{x}}$ and $\mathrm{SO}_{2}$ emissions under the updated permit were capped at 99 tons each.

The main contributing source of $\mathrm{NO}_{\mathrm{x}}$ and $\mathrm{SO}_{2}$ at the WVDP was the melter, which was shut down in September of 2002. This left site boilers and standby diesel generators as the only contributors of $\mathrm{NO}_{\mathrm{x}}$ and $\mathrm{SO}_{2}$ (at greatly-reduced levels as compared to the melter). Accordingly, a request was submitted to NYSDEC to discontinue submission of annual $\mathrm{NO}_{\mathrm{x}}$ and $\mathrm{SO}_{2}$ emissions. The request was granted on November 1, 2002.

Air permits that were in effect at the WVDP in 2003 are included in Table ECS-8, West Valley Demonstration Project Environmental Permits (pp. ECS28 and ECS-29). There were no air permit or regulatory exceedances in 2003. (See also Table ECS-2, West Valley Demonstration Project 2003 Air Quality Noncompliance Episodes [p. ECS-23].)

\section{Emergency Planning and Community Right-} to-Know Act (EPCRA). EPCRA was designed to create a working partnership between industry, business, state and local governments, public health and emergency response representatives, and interested citizens. This Act is intended to address concerns about the effects of chemicals used, stored, and released in local communities.
Executive Order 13148, Greening the Government Through Leadership in Environmental Management, requires all federal agencies to comply with the following EPCRA provisions: planning notification (Sections 302-303), extremely hazardous substance (EHS) release notification (Section 304), material safety data sheet (MSDS)/chemical inventory (Sections 311-312), and toxic release inventory (TRI) reporting (Section 313). The WVDP continued to comply with these provisions in 2003. (See also Table ECS-6, Status of EPCRAReporting in 2003 [p. ECS-25].)

- WVDP representatives participated in semiannual meetings of the Cattaraugus County Local Emergency Planning Committee (EPCRA Sections 302-303). WVDP representatives also attended meetings held by the Cattaraugus and Erie County Emergency Management Services concerning WVDP and other local emergency planning activities. Area hospitals and the West Valley Volunteer Hose Company continued to participate in on-site briefings, emergency response exercises, and information exchanges concerning hazardoussubstance management at the WVDP. The WVDP continues to interface with off-site organizations with which Memoranda of Understanding or Letters of Agreement exist. These organizations are annually provided an opportunity to participate in a site tour and update to better understand on-site hazards for emergency response.

- Compliance with all EPCRA reporting requirements was maintained and all required reports were submitted within the required timeframe. There were no releases of EHS at the WVDP that triggered the release notification requirements of EPCRA Section 304.

- Under EPCRA Section 311 requirements, the WVDP reviews information about reportable chemicals every quarter. If a hazardous chemical

ECS - 8 
not previously reported is present on-site in an amount exceeding the threshold planning quantity, an MSDS and an updated hazardous chemical list are submitted to the state and local emergency response groups. This supplemental reporting ensures that the public and emergency responders have current information about hazardous chemicals at the WVDP. No new chemicals were added to the hazardous chemicals list in 2003 and no additional EPCRASection 311 notifications were required.

- Under EPCRA Section 312 regulations, the WVDP submits annual reports to state and local emergency response organizations and fire departments specifying the quantity, location, and hazards associated with chemicals stored on-site. Nine reportable chemicals above threshold planning quantities were stored at the WVDP in 2003. (A list of reportable chemicals is provided in Table ECS-7 [p. ECS-25].)

- Under EPCRA Section 313, the WVDP provides information about releases to all environmental media of EPA-listed TRI chemicals used at or above specified regulatory thresholds at the WVDP. In 2003 no chemical exceeded the reporting threshold for the EPCRA Section 313 report.

Clean Water Act (CWA). Section 404 of the CWA regulates the development of areas in and adjacent to waters of the United States. Supreme Court interpretations of Section 404 have resulted in the inclusion of certain non-isolated wetlands in the regulatory definition of waters of the United States. Section 404 regulates the disposal of solids, in the form of dredged or fill material, into these areas by granting the U.S. Army Corps of Engineers the authority to designate disposal areas and issue permits for these activities. Executive Order 11990, Protection of Wetlands, directs federal agencies to "avoid to the extent possible the long- and short-term adverse impacts associated with the destruction or modification of wetlands and to avoid direct or indirect support of new construction in wetlands wherever there is a practical alternative." Article 24 of the New York State Environmental Conservation Law also contains requirements for the protection of freshwater wetlands.

Also, Section 401 of the CWA requires applicants for a federal license or permit pursuant to Section 404 to obtain certification from the state that the proposed discharge complies with effluent- and water-quality-related limitations, guidelines, and national standards of performance, identified under Sections 301-303, 306-307, and 511(c) of the CWA. The EPA delegated administration of this program to New York State.

Wetlands. Jurisdictional wetlands are defined in Section 404 of the CWA as those satisfying specific technical criteria related to vegetation, soils, and hydrologic conditions. The WVDP notifies the ACOE and NYSDEC of proposed actions that could affect wetland units not specifically exempted from regulation or notification.

A wetlands assessment, conducted in August 1998, identified and delineated jurisdictional wetlands regulated under the CWA, Section 404, and/ or those wetlands that may be regulated by the state of New York under Article 24 of the Environmental Conservation Law. The 375-acre (152ha) assessment area covered a portion of the Western New York Nuclear Service Center (WNYNSC), including the entire 164-acre (66ha) WVDP and adjacent parcels north, south, and east of the WVDP premises. The assessment also supported the requirements of Executive Order 11990 and updated a 1993 investigation. In 1998, 1999, and 2000, 83 jurisdictional wetlands ranging in size from 0.01 to 8.6 acres, a total of approximately 53 acres (22 ha) of wetland, were identi-

ECS - 9 
fied. This wetland delineation was submitted to the ACOE for verification of the wetland boundaries.

The ACOE verification of site wetlands delineations will expire starting in 2004. In anticipation of these expirations, assessment of site lands for wetland features was completed in 2003 to support re-verification by the ACOE.

State Pollutant Discharge Elimination System (SPDES) Permit Renewal. In August 2003, the WVDP filed an application with the NYSDEC for renewal of the SPDES Permit. In September 2003, the NYSDEC issued a renewed permit, which will expire in 2009.

Storm Water Discharge Permit. Section 402 of the CWA generally regulates disposal of liquids and, as amended, authorizes the EPA to regulate discharges of pollutants to surface water through a National Pollutant Discharge Elimination System (NPDES) Permit program. The EPA has delegated this authority to the state of New York, which issues SPDES Permits for discharges to surface water.

Surface water runoff from precipitation can become contaminated with pollutants from industrial process facilities, material storage and handling areas, access roads, or vehicle parking areas. To protect the environment, aquatic resources, and public health, Section 402(p) of the CWA requires that a storm water discharge permit application containing facility-specific information be submitted to the permitting authority. NYSDEC, the permitting authority in New York State, uses this information to ascertain the potential for pollution from storm water collection and discharge systems and to determine appropriate permitting requirements.

In January 2003, a supplement to an earlier permit application was filed with NYSDEC to request separate permits for storm water discharges from the WVDP and discharges from the State-Licensed Disposal Area, maintained by NYSERDA In March 2003, NYSDEC issued a notice with questions and comments on this application. A permit application with response to the NYSDEC questions and comments was filed in July 2003. This application also addressed new requests, including reduction in monitoring for chemical constituents no longer detected in site discharges and authorizations for storm water discharges associated with future dismantlement and demolition-related activities.

NYSDEC SPDES Inspection. In March 2003, NYSDEC completed its annual facility inspection of the WVDP with observations of the SPDES outfalls, the site sanitary and industrial wastewater treatment facility (WWTF), low-level waste treatment facility (LLWTF), and discharge monitoring records. No deficiencies were identified.

Process Sewer Integrity Evaluation. In 2002, NYSDEC requested that the site process sewer system integrity be assessed. This assessment was requested after an unplanned release occurred in 2001, when boiler wastewater was released through a suspected leaking underground sanitary sewer. Later in 2002, the WVDP issued a report evaluating the condition of the process sewer system, with a plan for an inspection of accessible process sewer lines between the main process building and the LLWTF, using video camera technology.

Video inspection of the process sewer lines was initiated in 2003. During this inspection, a hole was discovered in a tributary sewer line where laundry wastewater was released. The breached line was removed from service and laundry wastewater flow was diverted to another line with known integrity. Reports on this discovery were filed with the NYSDEC in November and December 2003.

ECS - 10 
Video inspection of process sewer lines is scheduled to resume in 2004, followed by submission of the final report to NYSDEC by the end of the year.

SPDES-Permitted Outfalls. Point-source liquid effluent discharges to surface waters of New York State are permitted through the New York SPDES program. The WVDP has five SPDES-permitted compliance points for discharges to Erdman Brook and Frank's Creek.

- Outfall 001 (WNSP001) discharges treated wastewater from the LLWTF and the north plateau groundwater recovery system. (See North Plateau Groundwater Recovery System [p. ECS12] and Chapter 4, Special Groundwater Monitoring [p. 4-12].) The treated wastewater is held in lagoon 3, sampled and analyzed, then periodically released after notifying NYSDEC. In 2003, the treated wastewater from the LLWTF was discharged at WNSP001 in seven batches totaling 15.0 million gallons (56.7 million liters) for the year. The annual average concentration of radioactivity at the point of release was approximately $29.3 \%$ of DOE-derived concentration guides (DCGs). None of the individual releases exceeded the DCGs. (See derived concentration guide in the Glossary [p. GLO-3] and in Chapter 1 [p. 1-5].)

- Outfall 01B (WNSP01B) is an internal process compliance point established by the final SPDES Permit modification issued on July 15, 2002. This internal outfall receives effluent from the liquid waste treatment system (LWTS) evaporator process after passing through a mercury pretreatment system. The LWTS is used to pretreat residual radioactive wastes from the main process building and the HLW storage tanks before final polishing treatment at the LLWTF. Effluent is sampled and tested at this location to determine compliance with Federal Great Lakes Initiative and SPDES Permit requirements for total mercury. As required by the SPDES Permit, samples from this location and outfall 001 are analyzed using the proven EPA Test Method 245.1, with a duplicate sample analyzed using the relatively new "ultraclean" Method 1631. Testing with Method 1631, which was issued by the EPA in 1999, is conducted as part of a required study to verify effectiveness of this method on radioactively-contaminated effluent. During 2003, a total flow of over 156,000 gallons (592,000 liters) was measured at outfall $01 \mathrm{~B}$.

- Outfall 007 (WNSP007) discharges the effluent from the WWTF, which treats sewage and various nonradioactive wastewaters from physical plant systems (e.g., water plant production residuals and boiler blowdown). The average daily flow at WNSP007 in 2003 was approximately 26,000 gallons (98,000 liters).

- Outfall 008 (WNSP008) formerly discharged groundwater and surface water runoff directed from the northeast side of the site's LLWTF lagoon system through a French drain to Erdman Brook. This outfall was capped off in May 2001 after elevated concentrations of total recoverable lead were observed. The elevated lead concentration was believed to be caused by silt accumulation in the pipe and reduced flow typical of an aging groundwater drain system.

- Monitoring point 116, located in Frank's Creek, represents the confluence of discharge from outfalls 001, 007, and 008; base stream flow; wet weather flows (e.g., surface water runoff); groundwater seepage; and augmentation water (untreated water from the site reservoirs). This is not a physical outfall but a location where the combination of source-flow inputs is used to calculate values for determining compliance with SPDES Permit limits for total dissolved solids (TDS) during discharge of lagoon 3. Before discharge of lagoon 3, sample data for TDS and flow measurements from up-

ECS -11 


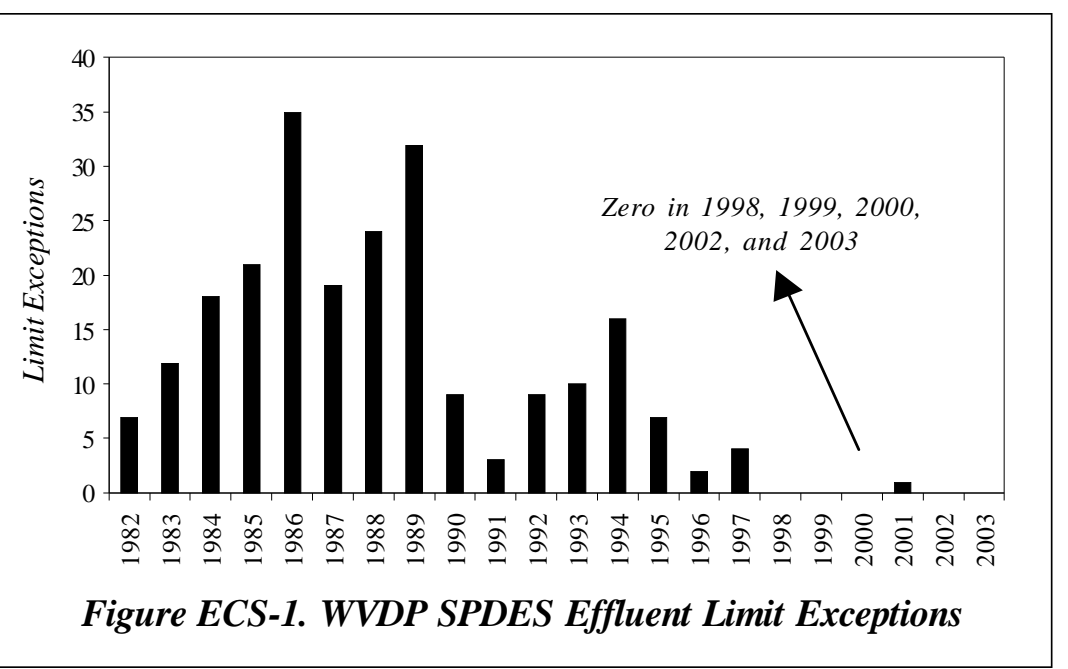

are summarized in Table ECS-3 (p. ECS-24).

North Plateau Groundwater Recovery System. In November 1995 the WVDP installed a groundwater recovery system to mitigate the movement of strontium-90 contamination in groundwater and reduce groundwater seepage northeast of the process building. Three recovery wells, installed near the leading edge of the groundwater plume, collect contaminated groundwater

stream sources are used to calculate the amount of augmentation water and flow needed to maintain compliance with SPDES-permitted TDS limits.

As shown in Figure ECS-1 (above), the annual number of effluent exceptions specified in the site's SPDES Permit have been substantially reduced, especially when compared to the peak of 35 exceptions noted in 1986. As indicated in this figure, there were no permit effluent exceptions recorded during 2003.

In June 2003, however, analyses by a vendor laboratory of samples obtained at outfall 007 for fiveday biochemical oxygen demand $\left(\mathrm{BOD}_{5}\right)$ and total suspended solids (TSS) and samples obtained at outfall 001 for surfactant (as linear alkylate sulfonate [LAS]) were performed outside the maximum allowable sample holding time. As a result, the minimum number of sample analyses specified by the SPDES Permit for these parameters was not met. These incidents of analyses performed outside the allowable holding time were attributable to vendor laboratory personnel changes and associated communication breakdowns. To prevent recurrence, WVDP sample analytical requirements were reviewed with contract laboratory personnel. All permit non-compliance episodes from the underlying sand and gravel unit. The collected groundwater is then treated at the low-level waste treatment building (LLW2) using ion-exchange to remove strontium-90. After the groundwater is processed, it is discharged to lagoon 4 or 5 of the LLWTF. Approximately 34 million gallons (128 million liters) of groundwater have been processed through the system since its inception, including about 4.5 million gallons (17 million liters) in 2003.

In 1999 the Project installed a pilot-scale permeable treatment wall (PTW) to test this in-situ passive technology for treating contaminated groundwater. Analytical data collected from within and around the wall indicate that only a portion of the contaminated groundwater in this area is entering and being treated by the PTW. The hydrogeologic evaluation of the pilot test was completed in 2002. The evaluation concluded that complex hydrogeologic conditions and disturbances from the installation are influencing groundwater flow into and around the pilot PTW.

Petroleum- and Chemical-Product Spill Reporting. The WVDP has a Spill Notification and Reporting Policy to ensure all spills are properly managed, documented, and remediated in accordance with applicable regulations. This policy iden-

ECS - 12 
tifies departmental responsibilities for spill management and proper spill-control procedures. The policy stresses the responsibility of each employee to notify the plant systems operations shift supervisor upon discovery of a spill. This first-line reporting requirement helps to ensure spills are properly evaluated and managed.

Under a 1996 agreement with NYSDEC, the WVDP is not required to report a spill of petroleum products onto an impervious surface if the spill is less than 5 gallons (19 liters) and is cleaned up within two hours of discovery. Any spill of 5 gallons or less onto the ground is entered into a petroleum spill log that is submitted monthly to NYSDEC on the fifteenth day following the subject month. A spill of more than 5 gallons on any surface must also be logged and reported within two hours to the NYSDEC hotline. A spill of any amount that enters state waters must be reported to the NYSDEC hotline within two hours of discovery and, if it has reached navigable state waters, also reported to the National Response Center. The last reportable petroleum spill at the WVDP, a contained spill of 8 gallons that did not reach state waters, occurred in 2002 . No reportable spills of over 5 gallons of petroleum products to an impervious surface, or to the ground or waters of the state, occurred at the WVDP in 2003.

The WVDP also reports spills or releases of hazardous substances in accordance with reporting requirements of RCRA, the Comprehensive Environmental Response, Compensation, and Liability Act if a reportable quantity has been exceeded, and the CAA, EPCRA, CWA, and Toxic Substances Control Act (TSCA). No chemical spills or releases exceeded reportable quantities and, thus, no reporting during calendar year 2003 was required.

In the event of a spill or release, all spills are cleaned up in a timely manner in accordance with the WVDP Spill Notification and Reporting Policy, thereby minimizing any effects on the environment. Debris generated during cleanup is characterized and dispositioned appropriately.

Safe Drinking Water Act (SDWA). The SDWA requires that each federal agency operating or maintaining a public water system must comply with all federal, state, and local requirements regarding safe drinking water. Compliance with regulations promulgated under the SDWA in the state of New York is overseen by NYSDOH through county health departments.

The WVDP obtains its drinking water from surface water reservoirs on the WNYNSC and is considered a non-transient, non-community public water supplier. The WVDP's drinking water treatment facility purifies the water by clarification, filtration, and chlorination before it is distributed on-site.

Monitoring. As an operator of a drinking water supply system, the WVDP routinely collects and analyzes drinking water samples to monitor water quality. Results of these analyses are reported to the Cattaraugus County Health Department, which also independently analyzes a monthly sample of WVDP tap water to determine bacterial and residual chlorine content, and an annual WVDP tap water sample for nitrate (as nitrogen).

Results for microbiological analysis of monthly tap water samples collected in 2003 indicated that total coliform and E. coli were not present in the potable water distribution system. Monthly tap water sample results for residual chlorine were positive on all occasions, indicating proper disinfection. The annual result for nitrate was also within the drinking water limit.

As a result of the EPA Disinfection By-Products Rule and Long-Term 1 Enhanced Surface Water

ECS - 13 
Treatment Rule, analysis of water samples from the WVDP potable water system for disinfection by-products and disinfection by-product precursors for compliance with maximum contaminant levels (MCLs) and treatment standards was performed at the WVDP in 2003 on a required routine basis. Quarterly sample results for disinfection by-products, which include total trihalomethanes and five haloacetic acids, were within MCLs for these parameters. Monthly sample results for disinfection by-product precursors, which include total organic carbon and alkalinity, were also within treatment system performance standards.

Cross-Connection Control. The SDWArequires that public water suppliers implement practices to protect the water supply from sanitary hazards. One specific requirement is to prevent cross-connections between the potable water supply and systems containing hazardous or infectious substances. Cross-connection control devices, which include double check valves and reduced-pressure zone valves, must be installed, inspected, and maintained at strategic locations at facilities where hazardous materials are used in a manner that could result in their introduction into the potable water distribution system under low-pressure conditions. In addition, secondary cross-connection controls, such as air gaps, at the point of use are also recommended to protect users within a specific facility from hazards posed by intrafacility operations. The WVDP has a total of 12 backflow prevention devices, all of which were tested by NYSDOH in 2003. If problems are encountered, these devices are repaired and retested or replaced.

Toxic Substances Control Act. The TSCA regulates the manufacture, processing, distribution, and use of chemicals, including asbestos-containing material (ACM) and polychlorinated biphenyls (PCBs).
Asbestos-Containing Material. In 2003, the WVDP continued to maintain compliance with all TSCA requirements pertaining to asbestos by managing asbestos-containing material at the site in accordance with the Asbestos Management Plan (WVNSCO, revised December 6, 2002). The plan was prepared to ensure compliance with TSCA requirements and includes requirements for limiting worker exposure to ACM and for asbestosabatement projects, maintenance activities, and periodic surveillance inspections (at least once every three years). The plan also identifies the inventory and status of on-site ACM.

Activities in 2003 included the repair or abatement of damaged/friable ACM, removal of approximately 68 linear feet of ACM insulation from abandoned lines, and maintenance of signs and labels to warn workers of asbestos-containing material. All activities associated with ACM are completed by personnel who are certified by the New York State Department of Labor (NYSDOL). WVNSCO maintains an asbestos-handling license issued by NYSDOL.

Polychlorinated Biphenyls. Because PCBs are regulated as a hazardous waste in New York State, the WVDP continued in 2003 to manage radioactively-contaminated PCB waste as mixed waste and nonradioactive PCB waste as hazardous waste. Details concerning PCB-contaminated radioactive waste management, including a description of the waste, proposed treatment technologies, and schedules, can be found in Section 3.1.5 of the Site Treatment Plan, Fiscal Year 2003 Update (WVNSCO, February 5, 2004).

To comply with TSCA and PCB regulations, all operations associated with PCBs comply with the PCB and PCB-Contaminated Material Management Plan. The WVDP also maintains an annual document log that details PCB use, appropriate storage on-site, and any changes in storage or dis-

ECS -14 
posal status. The WVDP complies with regulations for disposal of PCBs, which conditionally allow radioactive and nonradioactive $\mathrm{PCBs}$ to be stored for more than one year (40 CFR Parts 750 and 761).

\section{National Environmental Policy Act (NEPA).} NEPA, as amended, establishes a national policy to ensure protection of the environment is included in federal planning and decision-making (Title I). Its goals are to prevent or eliminate potential damage to the environment that could arise from federal legislative actions or proposed federal projects.

Nationwide Management of Waste. In May 1997, DOE Headquarters issued the Final Waste Management Programmatic Environmental Impact Statement (EIS) to evaluate nationwide management and siting alternatives for treatment, storage, and disposal of five types of radioactive and hazardous waste. The alternatives address waste generated, stored, or buried over the next 20 years at 54 sites in the DOE complex.

The Final Waste Management Programmatic EIS was issued with the intent of developing and issuing separate records of decision for each type of waste analyzed. In 1998 the DOE issued records of decision for transuranic and non-wastewater hazardous waste. In 1999 the DOE issued the record of decision for high-level radioactive waste. This decision specifies that WVDP high-level vitrified waste will remain in storage on-site until it is accepted for disposal at a geologic repository.

On February 25, 2000, the DOE issued its record of decision for the management of low-level radioactive waste and mixed low-level waste, including West Valley's wastes. Hanford and the Nevada Test Site (NTS) were identified as designated national DOE disposal sites for these waste types (Volume 65, Federal Register [FR], p. 10061 [65 FR 10061]). In 2001, West Valley success- fully completed the program approval process for access to the NTS, and on July 17, 2001 received approval to ship. Six LLW shipments were sent in 2001 and 2002, and 13 shipments were sent to NTS in 2003.

\section{Decommissioning and/or Long-Term Stew-} ardship at the WVDP and WNYNSC. DOE published a Federal Register Notice of Intent (NOI) on March 26, 2001 (66 FR 16447) formally announcing its rescoping plan and preparation of the waste management EIS. DOE published an NOI on March 13, 2003 (68 FR 12044), announcing its intent to prepare, in cooperation with NYSERDA, a Decommissioning and/or Long-Term Stewardship EIS. DOE and NYSERDA are joint lead agencies on this EIS, while the EPA, U.S. Nuclear Regulatory Commission, and NYSDEC are cooperating agencies. Work on preparation of the Decommissioning and/or Long-Term Stewardship EIS continued in 2003.

In May 2003, DOE issued a draft of the Waste Management EIS (68 FR 26587) for public comment. DOE considered public comments and issued the final EIS in January 2004.

Migratory Bird Treaty Act. The WVDP monitors wildlife activity near WVDP work areas and, where possible, implements controls to prevent and minimize nesting of migratory birds within radiologically-contaminated areas of the site.

In 2003, the WVDP filed for renewal and modification of its bird depredation permit to allow for removal of nests of Canada Geese, which in recent years were observed within radiologicallycontrolled areas of the site. In June 2003, the U.S. Fish and Wildlife Service renewed and modified this permit to allow for removal of Canada Geese nests. Similarly, the NYSDEC renewed and modified the bird depredation license to allow for removal of migratory bird and Canada Geese nests.

ECS - 15 
(See Table ECS-5 [p. ECS-25] for a summary of the bird depredation action taken at the WVDP during 2003.)

Endangered Species Act. The WVDP periodically updates its information about the potential for federally-listed or proposed endangered or threatened species in the vicinity of Project activities. This was last done via correspondence with the U.S. Fish and Wildlife Service in October 2003. Their reply on October 23, 2003 reconfirmed that, "except for occasional transient individuals," no plant or animal species protected under the Endangered Species Act were known to exist at the WVDP.

In December 2003, the WVDP submitted an inquiry to NYSDEC's Natural Heritage Program seeking information in the state database of the potential for rare or endangered species or threatened ecological communities within the site premises. Corollary information was received from NYSDEC on January 26, 2004 confirming the absence of known New York State protected or endangered species at the WVDP.

\section{Current Achievements and Program Highlights}

The WVDP's successful high-level radioactive waste vitrification program was the first program to reach completion in the nation. The vitrification facility was closed in September 2002 after a total of 275 containers of HLW had been processed. During July 2003, the WVDP developed and implemented plans for equipment removal and cleanup of the vitrification cell.

Spent Nuclear Fuel Shipment Completed. In 2003 , two casks containing spent nuclear fuel were safely transported from the WVDP to the Idaho National Engineering and Environmental Laboratory.
Integrated Safety Management System (ISMS). In August 2003 a self-assessment was conducted to confirm that the WVDP's integrated environmental, safety, and health management system continues to be effectively implemented at the WVDP. Results from the self-assessment were verified in the DOE's annual review, conducted in December 2003.

The WVDP continues to demonstrate its commitment to an all-inclusive approach to safety through its safety programs and through ongoing efforts to strengthen its integrated safety management program by worker involvement in the safety program.

STAR Status. The WVDP has reaffirmed its commitment to DOE's Voluntary Protection Program (VPP). During the reporting period, the VPP was reviewed as part of the annual ISMS review. The DOE completed an on-site review of the VPP and the WVDP has been recertified as a DOE-VPP STAR site. At the annual VPP Participants National Conference, the WVDP was awarded the DOE's Star of Excellence Award, which is given to sites with outstanding safety programs. The WVDP is the only site to receive this award three years in a row.

\section{EPA National Environmental Performance} Track. The WVDP was recognized as a top environmental leader in 2000 and was accepted into the EPA's National Environmental Performance Track. The WVDP was awarded Charter Member status as part of the first group of applicants.

To qualify for the award, the WVDP had to demonstrate that it voluntarily has adopted and implemented an environmental management system, has attained previous specific environmental achievements, has made a commitment to achieve four future goals, has a public outreach program, and has a sustained record of environmental compliance.

ECS - 16 
The WVDP's four commitments are listed in Table ECS-1 (p. ECS-19), together with performance toward each in CY 2001, CY 2002, and CY 2003.

Environmental Management System. The WVDP EMS is integrated with other safety management and work planning processes at the WVDP. In August 2003, the DOE completed an audit of the WVDP environmental compliance program and concluded that required elements of the program are being implemented. Elements of the EMS are outlined in Table ECS-1 (pp. ECS19 through ECS-23).

\section{Environmental Issues and Actions}

Closed Landfill Maintenance. Closure of the on-site nonradioactive construction and demolition debris landfill (CDDL) was completed in August 1986. The landfill area was closed in accordance with NYSDEC requirements for this type of landfill, following a closure plan (Standish, 1985) approved by NYSDEC. To meet routine post-closure requirements, the CDDL cover was inspected twice in 2003 and found to be in generally good condition. The grass cover on the clay and soil cap is routinely maintained and cut, and drainage is maintained to ensure that no obvious ponding or soil erosion occurs.

\section{Release of Materials Containing Residual Ra-} dioactivity. The release of property containing residual radioactivity from DOE facilities is carefully controlled by DOE guidelines and procedures. In two special memoranda issued in January and July of 2000, the Secretary of Energy placed a moratorium on release of contaminated materials and on unrestricted release, for recycling, of metal from radiological areas within DOE facilities. The moratorium will remain in effect until directives clarifying the release criteria have been developed and implemented. Any transfer that places property (real property, structures, equipment, or scrap metal) containing radioactivity into public use is classified as a type of environmental release.

In keeping with DOE initiatives to expand environmental information provided to the public, certain details of transfers of property containing residual radioactivity are to be included in Annual Site Environmental Reports. The information provided should include, among other things, the type of material and amount of residual radioactivity, the basis for releasing the property for public use (including release limits and when the property was released), the end use and cost savings associated with release of the property, and potential doses to individuals and potential collective dose to the public associated with each release. As indicated in Table ECS-4 [p. ECS-24], the WVDP did not release any property classified per DOE Order 5400.5 as material containing residual radioactivity in 2003.

Decommissioning and/or Long-Term Stewardship at the WVDP and WNYNSC. Although negotiations conducted between the DOE and NYSERDA to date have not resulted in agreement on long-term cleanup responsibilities, both parties remain committed to accomplishing important goals. These include completing environmental impact statement analyses to support decisions on site decommissioning and/or long-term stewardship. (See also p. ECS-15.) Other important Project goals include safely managing low-level radioactive waste, operating the remote-handled waste facility, and managing contaminated groundwater on the north plateau.

\section{Project Assessment Activities in 2003}

As the primary contractor for the DOE at the WVDP, WVNSCO maintains a comprehensive review program for proposed and ongoing opera-

ECS - 17 
tions. Assessments are conducted through formal surveillances and informal programs. Formal surveillances monitor compliance with regulations, directives, and DOE Orders. The informal program is used to identify issues or potential problems that can be corrected immediately.

The local DOE Project office and other agencies with responsibilities for the WVDP also independently review various aspects of the environmental and waste management programs, as discussed in preceding sections. In 2003, overall results reflected continuing, well-managed environmental programs at the WVDP. 


\section{Compliance Tables}

DOE Headquarters uses environmental compliance summary information from sites across the DOE complex to compile national environmental summary reports. The tables on the following pages were prepared to assist in this compilation.

\section{Table ECS-1 \\ Elements of the Environmental Management System Implementation at the WVDP}

\section{Environmental Policy}

\section{Environmental Aspects and Impacts}

The WVDP environmental policy is to conduct all activities, including design, construction, testing, start-up, commissioning, operation, maintenance, and decontamination and decommissioning in a manner appropriate to the nature, scale, and environmental impacts of these activities. The WVDP is committed to full compliance with applicable federal and New York State laws and regulations for the protection of the environment, continual improvement, the prevention and/or minimization of pollution, and public outreach, including stakeholder involvement.

When operations have an environmental aspect, WVDP implements the Environmental Management System (EMS) to minimize or eliminate any adverse potential impact. The EMS is a prerequisite for the EPA National Environmental Performance Track awarded by the EPA to the WVDP. Using the EMS, the WVDP evaluates its operations, identifies the aspects of operations that can impact the environment, and determines which of those impacts are significant. The WVDP has determined that the following operational aspects have the potential to affect the environment:

- Waste generation

- Atmospheric emissions

- Liquid effluents

- Storage or use of chemicals and radioactive materials

- Natural resource usage - power and water consumption

- Noise

- Soil disturbance

- Disturbances to endangered species/protected habitats

- Contamination areas from historical operations

- Other facility-specific compliance aspects. 


\section{Table ECS-1 (continued) \\ Elements of the Environmental Management System Implementation at the WVDP}

\section{Legal and Other \\ Requirements}

Objectives and Targets
The WVDP has implemented an environmental regulatory review and assessment process to deliver WVDP-level requirements and guidance to all staff. New or revised requirements (e.g., new regulations) are analyzed to determine their applicability to the WVDP and to identify whether actions are required to achieve compliance. This may involve developing or revising WVDP documents or operating procedures, implementing administrative controls, providing training, installing engineered controls, or increasing monitoring.

The performance-based management system is designed to develop, align, balance, and implement the WVDP's strategic objectives, including environmental objectives. Objectives and targets are developed by calendar year (CY). For the three-year period of $\mathrm{CY}$ 2001-2003, the following objectives were also commitments made under the EPA National Environmental Performance Track:

- Commitment 1 - Reduction in routinely-generated hazardous waste - achieve a $62 \%$ reduction over the three-year period from the CY 2000 baseline.

Results: CY 2001 - 69\%, CY 2002 - 90\%, CY 2003 - 90\%. This goal was exceeded.

- Commitment 2 - Reduction in routine generation of condensate oil wastewater - achieve a $94 \%$ reduction over the three-year period from the CY 2000 baseline.

Results: CY 2001 - 14\%, CY 2002 - 51\%, CY 2003 - 96\%.

This goal was exceeded.

- Commitment 3 - Reduction in total energy use - achieve an $11 \%$ reduction over the three-year period from the CY 2000 baseline in combined electric and natural gas usage.

Results: CY 2001 - 22\% over baseline, CY 2002 - 0.4\%, CY $2003-5.4 \%$.

This goal was not achieved. However, there were no "normalizing" factors considered. Had they been incorporated, it is likely this goal would also have been achieved.

$$
\text { ECS - } 20
$$




\section{Table ECS-1 (continued) \\ Elements of the Environmental Management System Implementation at the WVDP}

\section{Objectives and Targets (concluded)}

\section{Environmental Management Program}

\section{Structure and}

Responsibility

Training, Awareness and Competence

\section{Communication and} Community Involvement

EMS Documentation
- Commitment 4 - Removal of 22\% (2,000 feet) of the asbestos in the CY 2000 baseline.

Results: CY 2001 - 48\% (4,354 feet) removed, CY 2002 - 25\% (2,213 feet) removed, CY $2003-1 \%$ (68 feet) removed. This goal was exceeded.

Commitments for CY 2004-2006 will be submitted to the EPA for approval in early 2004 as part of the National Environmental Performance Track renewal application.

The WVDP has a pollution prevention program to conserve resources and minimize waste generation. The WVDP has a budgeting system designed to ensure that priorities are balanced and that resources essential to the implementation and control of the EMS are provided.

All employees at the WVDP have specific roles and responsibilities in key areas, including environmental protection. Environmental and waste management technical support personnel assist the line organization with their environmental responsibilities.

Training on EMS requirements has been provided to staff whose responsibilities include environmental protection. The training program includes general environmental awareness for all employees, regulatory compliance training for select staff, and specific courses for managers, internal assessors, EMS implementation teams, and operations personnel whose work can impact the environment.

The WVDP continues to improve processes for internal and external communications on environmental issues. Communications with the local community include monthly meetings with the local Citizen Task Force and meetings with the general public on a quarterly basis. Notable community involvement activities by the WVDP in 2003 included the Annual Food Drive and participation in the United Way Day of Caring.

WVDP has comprehensive, up-to-date written environmental policies describing the EMS. Written procedures and manuals tell staff how to control processes and perform work at the WVDP in a manner that protects the environment. 


\section{Table ECS-1 (continued) \\ Elements of the Environmental Management System Implementation at the WVDP}

\section{Document Control}

Operational Control

\author{
Emergency Preparedness \\ and Response
}

Monitoring and Measurement

Nonconformance and Corrective and Preventive Actions

Records

EMSAudit
The WVDP maintains a comprehensive electronic document control system to ensure the effective management of procedural documents. When facilities require additional procedures to control their work, document-control protocols are implemented to ensure that workers have access to the current version of procedures.

Operations at the WVDP are evaluated for the adequacy of current controls to prevent impacts to the environment. As needed, additional administrative or engineered controls are identified and plans for upgrades and improvements are developed and implemented.

The WVDP has an emergency preparedness and response program and specialized staff to provide timely response to hazardous material releases or other environmental emergencies. This program includes procedures for preventing, as well as responding to, emergencies.

Liquid effluent and air-emission monitoring helps ensure the effectiveness of controls, adherence to regulatory requirements, and timely identification and implementation of corrective measures. The WVDP has a comprehensive, sitewide environmental monitoring program. Results are reported to regulatory agencies and summarized in this Annual Site Environmental Report. In addition, the WVDP assesses monitoring data for adverse trends to determine site performance, impacts from site conditions, and the need for proactive or corrective measures.

The WVDP continues to implement processes that identify and correct problems. This includes a lessons learned program to prevent recurrences, robust self-assessment and environmental assessment programs, and an electronic action tracking system.

EMS-related records, including audit and training records, are maintained to ensure integrity, facilitate retrieval, and protect them from loss.

To periodically verify that the EMS is operating as intended, assessments are conducted by DOE and its contractors. These assessments are designed to ensure that nonconformances are identified and addressed. In addition, compliance with regulatory requirements is verified through routine inspections, operational evaluations, and periodic assessments and self-assessments.

\section{$E C S-22$}




\section{Table ECS-1 (concluded) \\ Elements of the Environmental Management System \\ Implementation at the WVDP}

Management Review

In addition to audits, a management review process has been established to involve top management in the overall assessment of environmental performance, the EMS, and progress toward achieving environmental goals. This review also identifies, as necessary, the need for changes to and continual improvement of the EMS.

Table ECS-2

West Valley Demonstration Project 2003 Air Quality

Noncompliance Episodes

\begin{tabular}{|lcccc|}
\hline Permit Type & Facility & Parameter & Date(s) Exceeded & Description/Solutions \\
EPANESHAP & All & All & None & None \\
NYSDEC Air & All & All & None & None \\
& \multicolumn{2}{c}{ There were no episodes of noncompliance in 2003. } \\
\hline
\end{tabular}

ECS - 23 
Table ECS-3

\section{West Valley Demonstration Project 2003 NPDES/SPDES* Permit Noncompliance Episodes}

\begin{tabular}{|c|c|c|c|c|c|c|c|}
\hline $\begin{array}{c}\text { Permit } \\
\text { Type }\end{array}$ & Outfall(s) & Parameter & $\begin{array}{c}\text { No. of } \\
\text { Permit } \\
\text { Exceptions }\end{array}$ & $\begin{array}{c}\text { No. of } \\
\text { Samples } \\
\text { Taken }\end{array}$ & $\begin{array}{c}\text { No. of } \\
\text { Compliant } \\
\text { Samples** }\end{array}$ & $\begin{array}{c}\text { Percent } \\
\text { Compliance } \\
\text { Samples }\end{array}$ & $\begin{array}{l}\text { Description/ } \\
\text { Solutions }\end{array}$ \\
\hline SPDES & All & All & 3 & 1,243 & 1,240 & $99.8 \%$ & $\begin{array}{l}\text { Samples analyzed outside } \\
\text { allowable holding time./ } \\
\text { Sample holding time } \\
\text { requirements were reviewed } \\
\text { with laboratory personnel. }\end{array}$ \\
\hline SPDES & 001 & $\begin{array}{l}\text { Surfactant } \\
\text { (as LAS) }\end{array}$ & 1 & 14 & 13 & $92.9 \%$ & See above. \\
\hline SPDES & 007 & $\mathrm{BOD}_{5}$ & 1 & 36 & 35 & $97.2 \%$ & See above. \\
\hline SPDES & 007 & $T S S$ & 1 & 36 & 35 & $97.2 \%$ & See above. \\
\hline SPDES & $\begin{array}{l}\text { Sum of } 001 \\
\text { 007, } 008\end{array}$ & $\mathrm{BOD}_{5}$ & 1 & 12 & 11 & $91.7 \%$ & See above. \\
\hline $\begin{array}{l}\text { Radiont } \\
\text { concent }\end{array}$ & $\begin{array}{l}\text { ides are not } r \\
\text { ion of radion }\end{array}$ & $\begin{array}{l}\text { egulated under } \\
\text { uclides in the a }\end{array}$ & $\begin{array}{l}\text { the site's } S P D \\
\text { lischarge is sul }\end{array}$ & $\begin{array}{l}\text { ES Permit. } \\
\text { bject to requi }\end{array}$ & $\begin{array}{l}\text { owever, special } \\
\text { ements of DOI }\end{array}$ & $\begin{array}{l}\text { requirements in } \\
\text { Order } 5400.5 \text {. }\end{array}$ & e permit specify that the \\
\hline
\end{tabular}

Table ECS-4

\section{Release of Property Containing Residual Radioactive Material}

\begin{tabular}{|ccccccccc|}
\hline $\begin{array}{c}\text { Approved } \\
\text { Limit }\end{array}$ & Rationale & $\begin{array}{c}\text { Date } \\
\text { of } \\
\text { Approval }\end{array}$ & $\begin{array}{c}\text { Type } \\
\text { of } \\
\text { Material }\end{array}$ & $\begin{array}{c}\text { Basis } \\
\text { for } \\
\text { Release }\end{array}$ & $\begin{array}{c}\text { End } \\
\text { Use }\end{array}$ & $\begin{array}{c}\text { Volume } \\
\text { of } \\
\text { Material }\end{array}$ & $\begin{array}{c}\text { Total } \\
\text { Activity }\end{array}$ & $\begin{array}{c}\text { Maximum } \\
\text { Individual } \\
\text { Dose }\end{array}$ \\
NA & $N A$ & $N A$ & None & $N A$ & $N A$ & 0 & 0 & 0 \\
Dose
\end{tabular}

ECS - 24

WVDP Annual Site Environmental Report

Calendar Year 2003 


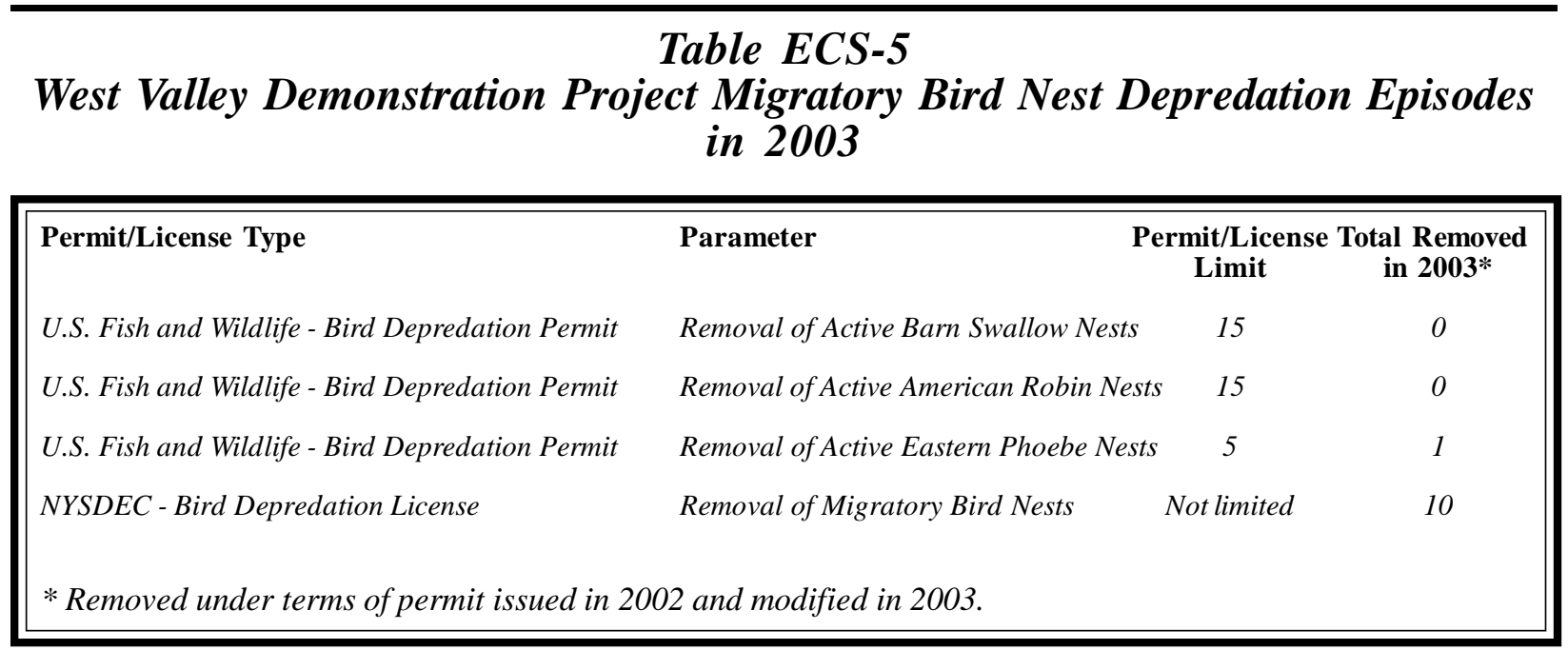

\section{Table ECS-6}

Status of EPCRA Reporting in 2003

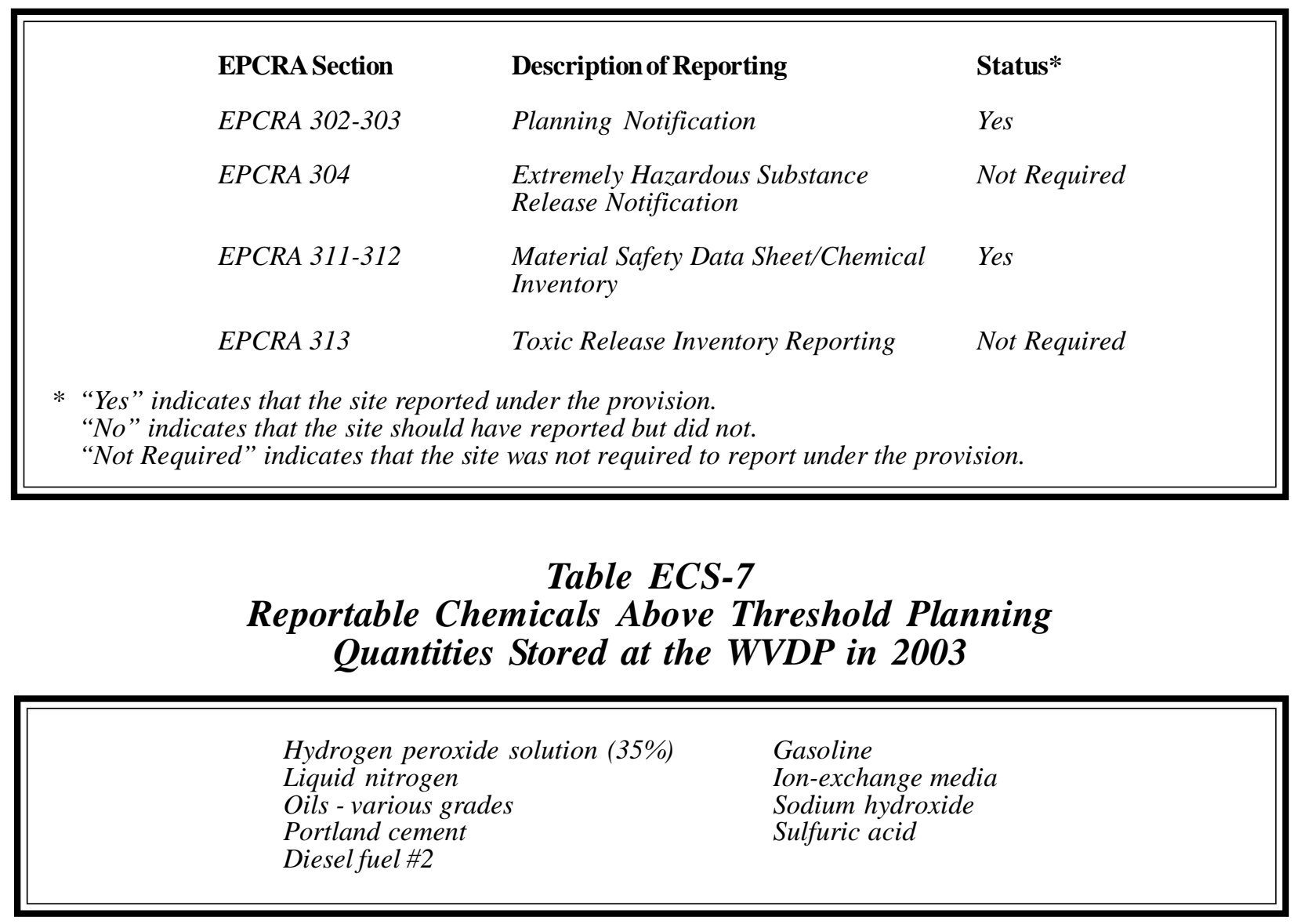

ECS - 25 


\section{Table ECS-8 \\ West Valley Demonstration Project Environmental Permits}

\begin{tabular}{|c|c|c|c|c|}
\hline $\begin{array}{c}\text { Permit Name and } \\
\text { Number }\end{array}$ & $\begin{array}{c}\text { Agency/Permit } \\
\text { Type }\end{array}$ & Description & 2003 Changes & Status \\
\hline $\begin{array}{l}\text { West Valley } \\
\text { Demonstration Project } \\
\text { RCRA Part A Permit } \\
\text { Application }\end{array}$ & $\begin{array}{l}\text { NYSDEC/Hazardous } \\
\text { Waste }\end{array}$ & $\begin{array}{l}\text { Provides interim status } \\
\text { under RCRA for treatment } \\
\text { and storage of hazardous } \\
\text { waste }\end{array}$ & $\begin{array}{l}\text { No changes to Part A. A } \\
\text { request for a Part B Permit } \\
\text { Application was received in } \\
\text { July 2003. The application is } \\
\text { currently under } \\
\text { development. }\end{array}$ & No expiration date. \\
\hline $\begin{array}{l}\text { Article } 19 \text { State Facility } \\
\text { Air Permit } \\
(9-0422-00005 / 00091)\end{array}$ & NYSDEC/Air Emissions & $\begin{array}{l}\text { Sitewide permit includes: } \\
\text { - } 1 \text { boiler } \\
\text { - } \quad \text { cold chemical solids } \\
\text { transfer system } \\
\text { - } \quad \text { cold chemical vessel } \\
\text { vent system } \\
\text { - cold chemical vessel } \\
\text { dust-collection hood }\end{array}$ & None & $\begin{array}{l}\text { Effective } 6 / 1 / 00 . \text { No } \\
\text { expiration date. }\end{array}$ \\
\hline $\begin{array}{l}\text { Slurry-fed ceramic melter } \\
\text { (modification to WVDP- } \\
\text { 687-01) process building } \\
\text { ventilation }\end{array}$ & EPA/NESHAP & $\begin{array}{l}\text { Slurry-fed ceramic melter } \\
\text { radionuclide emissions - } \\
\text { main plant stack modified } \\
\text { 2/18/97 }\end{array}$ & None & $\begin{array}{l}\text { Permit approved 2/18/97. } \\
\text { No expiration date. Request } \\
\text { to modify submitted to the } \\
\text { EPA } 8 / 99 \text {. }\end{array}$ \\
\hline $\begin{array}{l}\text { Vitrification Facility } \\
\text { HVAC System }\end{array}$ & EPA/NESHAP & $\begin{array}{l}\text { Vitrification facility HVAC } \\
\text { system for radionuclide } \\
\text { emissions }\end{array}$ & None & $\begin{array}{l}\text { Permit approved 2/18/97. } \\
\text { No expiration date. }\end{array}$ \\
\hline $\begin{array}{l}\text { 01-14 Building } \\
\text { Ventilation System } \\
\text { (WVDP-187-01) }\end{array}$ & EPA/NESHAP & $\begin{array}{l}\text { Liquid waste treatment } \\
\text { system ventilation of } \\
\text { radionuclide emissions in } \\
\text { the } 01-14 \text { building }\end{array}$ & None & $\begin{array}{l}\text { Issued 10/5/87. Modified } \\
5 / 25 / 89 . \text { No expiration } \\
\text { date. }\end{array}$ \\
\hline \begin{tabular}{|l|} 
Contact Size-Reduction \\
Facility (WVDP-287-01)
\end{tabular} & EPA/NESHAP & $\begin{array}{l}\text { Contact size-reduction and } \\
\text { decontamination facility } \\
\text { radionuclide emissions }\end{array}$ & None & $\begin{array}{l}\text { Issued } 10 / 5 / 87 . \text { No } \\
\text { expiration date. }\end{array}$ \\
\hline $\begin{array}{l}\text { Supernatant Treatment } \\
\text { System/Permanent } \\
\text { Ventilation System } \\
(\text { WVDP-387-01) } \\
\end{array}$ & EPA/NESHAP & $\begin{array}{l}\text { Supernatant treatment } \\
\text { system ventilation for } \\
\text { radionuclide emissions }\end{array}$ & None & $\begin{array}{l}\text { Revised 1/1/97. No } \\
\text { expiration date. }\end{array}$ \\
\hline $\begin{array}{l}\text { Outdoor Ventilated } \\
\text { Enclosures } \\
\text { (WVDP-587-01) } \\
\end{array}$ & EPA/NESHAP & $\begin{array}{l}\text { Ten portable ventilation } \\
\text { units for removal of } \\
\text { radionuclides }\end{array}$ & None & $\begin{array}{l}\text { Issued 12/22/87. No } \\
\text { expiration date. }\end{array}$ \\
\hline \begin{tabular}{|l|} 
State Pollutant Discharge \\
Elimination System \\
$(\mathrm{NY} 0000973)$
\end{tabular} & NYSDEC/Water & $\begin{array}{l}\text { Covers discharges to surface } \\
\text { waters from various on-site } \\
\text { sources }\end{array}$ & $\begin{array}{l}\text { Renewed on } 9 / 10 / 03 \text { with no } \\
\text { changes. }\end{array}$ & $\begin{array}{l}\text { A draft permit modification } \\
\text { addressing storm water } \\
\text { discharges, monitoring } \\
\text { modifications, and other } \\
\text { items is expected in } 2004 .\end{array}$ \\
\hline
\end{tabular}

ECS - 26 


\section{Table ECS-8 (concluded) West Valley Demonstration Project Environmental Permits}

\begin{tabular}{|c|c|c|c|c|}
\hline $\begin{array}{c}\text { Permit Name and } \\
\text { Number }\end{array}$ & $\begin{array}{c}\text { Agency/Permit } \\
\text { Type }\end{array}$ & Description & 2003 Changes & Status \\
\hline $\begin{array}{l}\text { Buffalo Pollutant } \\
\text { Discharge Elimination } \\
\text { System (03-05-TR096) }\end{array}$ & $\begin{array}{l}\text { Buffalo Sewer } \\
\text { Authority/sanitary sewage } \\
\text { and sewage sludge disposal }\end{array}$ & $\begin{array}{l}\text { Permit issued to hauler of } \\
\text { waste from the wastewater } \\
\text { treatment facility }\end{array}$ & Renewed 6/30/03. & $\begin{array}{l}\text { Hauler must renew permit } \\
\text { by } 6 / 30 / 04 \text {. }\end{array}$ \\
\hline $\begin{array}{l}\text { Fill Discharge Permit } \\
(94-973-29[4])\end{array}$ & $\begin{array}{l}\text { U.S. Army Corps of } \\
\text { Engineers/water }\end{array}$ & $\begin{array}{l}\text { Buttermilk Creek culvert } \\
\text { repairs and railroad spur } \\
\text { improvements }\end{array}$ & None & $\begin{array}{l}\text { Issued 4/27/00. Expires } \\
\text { 4/27/05. }\end{array}$ \\
\hline $\begin{array}{l}\text { Freshwater Wetlands } \\
\text { Permit and Water Quality } \\
\text { Certification } \\
(9-0422-00005 / 00093) \\
\end{array}$ & NYSDEC/Water & $\begin{array}{l}\text { Buttermilk Creek culvert } \\
\text { repairs and railroad spur } \\
\text { improvements }\end{array}$ & None & $\begin{array}{l}\text { Issued 3/31/00. Expires } \\
\text { 4/1/05. }\end{array}$ \\
\hline $\begin{array}{l}\text { Chemical Bulk Storage } \\
(9-000158)\end{array}$ & $\begin{array}{l}\text { NYSDEC/chemical bulk } \\
\text { storage tank }\end{array}$ & $\begin{array}{l}\text { Registration of bulk storage } \\
\text { tanks used for listed } \\
\text { hazardous chemicals }\end{array}$ & $\begin{array}{l}\text { New registration issued } \\
6 / 19 / 03 \text {. Ammonia tank } \\
\text { permanently closed and } \\
\text { deleted from registration } \\
\text { effective } 6 / 19 / 03 \text {. }\end{array}$ & Registration expires $7 / 5 / 05$ \\
\hline $\begin{array}{l}\text { Petroleum Bulk Storage } \\
(9-008885)\end{array}$ & $\begin{array}{l}\text { NYSDEC/petroleum bulk } \\
\text { storage tank registration }\end{array}$ & $\begin{array}{l}\text { Registration of bulk storage } \\
\text { tanks used for petroleum }\end{array}$ & None & $\begin{array}{l}\text { Registration expires 9/2/06 } \\
\text { Will be renewed before } \\
\text { expiration. }\end{array}$ \\
\hline $\begin{array}{l}\text { Bird Depredation License } \\
\text { (DWP03-002) }\end{array}$ & $\begin{array}{l}\text { New York State Division } \\
\text { of Fish and Wildlife }\end{array}$ & $\begin{array}{l}\text { State license for the removal } \\
\text { of all nests of migratory } \\
\text { birds }\end{array}$ & $\begin{array}{l}\text { License amended and } \\
\text { renewed on 7/8/03. }\end{array}$ & $\begin{array}{l}\text { NYS license expires } \\
5 / 31 / 04 . \text { Renewal request } \\
\text { has been submitted. }\end{array}$ \\
\hline $\begin{array}{l}\text { Bird Depredation Permit } \\
\text { (MB747595-0) }\end{array}$ & $\begin{array}{l}\text { U.S. Fish and Wildlife } \\
\text { Service }\end{array}$ & $\begin{array}{l}\text { Federal permit for the } \\
\text { limited taking of migratory } \\
\text { birds and active bird nests }\end{array}$ & $\begin{array}{l}\text { Permit renewed and } \\
\text { modified on } 6 / 23 / 03 \text {. }\end{array}$ & $\begin{array}{l}\text { Permit expires 5/31/04. } \\
\text { Renewal request has been } \\
\text { submitted. }\end{array}$ \\
\hline
\end{tabular}


This page intentionally left blank

ECS - 28 


\section{ENVIRONMENTAL PROGRAM INFORMATION}

\section{Introduction}

The vitrified high-level radioactive waste (HLW) presently stored at the Western New York Nuclear Service Center (WNYNSC) on the West Valley Demonstration Project (WVDP or Project) premises is the by-product of the reprocessing of spent nuclear fuel during the late 1960s and early 1970s. At that time, the WNYNSC was leased by Nuclear Fuel Services, Inc. (NFS) for a commercial nuclear fuel reprocessing facility.

As the WNYNSC is no longer an active nuclear fuel reprocessing facility, the environmental monitoring program focuses on measuring radioactivity and chemicals associated with the residual by-products of the former NFS operations, the Project's former HLW treatment operations, and the Project's operations for management of HLW, transuranic waste, and low-level radioactive waste (LLW). The following information about the operations at the WVDP and about radiation and radioactivity will be useful in understanding the activities of the Project and the terms used in reporting the results of environmental test measurements.

Radiation and Radioactivity. Radioactivity is a characteristic of some elements that have unstable atomic nuclei which spontaneously disintegrate or "decay" into atomic nuclei of another isotope or element. (See isotope [p. GLO-6] in the Glossary.) The nuclei decay until only a stable, nonradioactive isotope remains. Depending on the isotope, this process can take anywhere from less than a second to billions of years.

As atomic nuclei decay, radiation is released in three main forms: alpha particles, beta particles, and gamma rays. By emitting energy or particles, the nucleus moves toward a less energetic, more stable state.

Alpha Particles. An alpha particle, released by decay, is a fragment of a much larger nucleus. It consists of two protons and two neutrons (similar to the nucleus of a helium atom) and is positively charged. Compared to beta particles, alpha particles are relatively large and heavy and do not travel very far when ejected by a decaying nucleus. Alpha radiation, therefore, is easily stopped by a thin layer of material such as paper or skin. However, if radioactive material is ingested or inhaled, the alpha particles released inside the body can damage soft internal tissues because all of their energy is absorbed by tissue cells in the immediate vicinity of the decay. An example of an alphaemitting radionuclide is the uranium isotope with an atomic weight of 232 (uranium-232). Uranium232 was in the HLW mixture at the WVDP as a 


\section{Radioactivity}

Atoms that emit radiation are called radionuclides. Radionuclides are unstable isotopes of an element that have the same number of protons but different numbers of neutrons, resulting in different atomic masses. For example, the element hydrogen has two stable isotopes, hydrogen-1 $\left(\mathrm{H}^{1}\right)$ and hydrogen-2 $\left(\mathrm{H}^{2}\right)$ (deuterium), and one radioactive isotope, hydrogen-3 $\left(\mathrm{H}^{3}\right)$ (tritium). The numbers following the element's symbol identify the atomic mass, which is the number of protons plus neutrons in the nucleus. Thus, $H^{l}$ has one proton and no neutrons, $H^{2}$ has one proton and one neutron, and $H^{3}$ has one proton and two neutrons.

When radioactive atoms decay by emitting radiation, the daughter products that result may be either radioactive or stable. Generally, radionuclides with high atomic numbers, such as uranium-238 and plutonium-239, have many generations of radioactive progeny. For example, the radioactive decay of plutonium-239 creates uranium-235, thorium-231, protactinium-231, and so on, through 11 progeny until only the stable isotope lead-207 remains.

Radionuclides with lower atomic numbers often have no more than one daughter. For example, strontium-90 has one radioactive daughter, yttrium-90, which finally decays into stable zirconium; cobalt-60 decays directly to stable nickel with no intermediate nuclide.

The time required for half of the radioactivity of a radionuclide to decay is referred to as the radionuclide's half-life. Each radionuclide has a unique half-life; both strontium-90 and cesium-137 have half-lives of approximately 30 years while plutonium-239 has a half-life of 24,110 years. Knowledge of radionuclide half-lives is often used to estimate past and future inventories of radioactive material. For example, a 1.0-millicurie source of cesium-137 in 2000 would have measured 2.0 millicuries in 1970 and will be 0.5 millicuries in 2030.

Radiation emitted by radionuclides may consist of electromagnetic rays, such as $x$-rays and gamma rays, or charged particles, such as alpha and beta particles. A radionuclide may emit one or more of these radiations at characteristic energies that can be used to identify them.

\section{Background Radiation}

Background radiation is always present, and everyone is constantly exposed to low levels of such radiation from both naturally-occurring and man-made sources. In the United States the average total annual exposure to low-level background radiation is estimated to be about 360 millirem (mrem) or 3.6 millisieverts $(\mathrm{mSv})$. Most of this radiation, approximately 295 mrem $(2.95 \mathrm{mSv})$, comes from natural sources. The rest comes from medical procedures, consumer products, and other man-made sources (NCRP Report 93, 1987). (See Figure 2-1 [p. 2-3] in Chapter 2, Environmental Radiological Program Information.)

Background radiation includes cosmic rays; the decay of natural elements, such as potassium, uranium, thorium, and radon; and radiation from sources such as chemical fertilizers, smoke detectors, and televisions. Actual doses vary depending on such factors as geographic location, building ventilation, and personal health and habits.

\section{$1-2$}


result of a thorium-based nuclear fuel reprocessing campaign conducted by NFS. Uranium-232 has been detected in liquid waste streams.

Beta Particles. A beta particle is an electron that results from the breakdown of a neutron in a radioactive nucleus. Beta particles are small compared with alpha particles, travel at a higher speed (close to the speed of light), and can be stopped by a material such as wood or aluminum less than an inch thick. If beta particles are released inside the body, they do much less damage than an equal number of alpha particles. This is because beta particles are smaller, faster, and have less of a charge; beta particles deposit energy in tissue cells over a larger volume than alpha particles. Strontium-90, a fission product, is an example of a betaemitting radionuclide. (See fission [p. GLO-5] in the Glossary.) Strontium-90 is found in the stabilized supernatant.

Gamma Rays. Gamma rays are high-energy "packets" of electromagnetic radiation, called photons, that are emitted from the nucleus. They are similar to X-rays but generally have a shorter wavelength, and therefore are more energetic than $\mathrm{x}$-rays. If the alpha or beta particle released by the decaying nucleus does not carry off all the energy generated by the nuclear disintegration, the excess energy may be emitted as gamma rays. If the released energy is high, a very penetrating gamma ray is produced that can be effectively reduced only by shielding consisting of several inches of a dense material, such as lead, or of water or concrete several feet thick. Although large amounts of gamma radiation are dangerous, gamma rays are also used in many lifesaving medical procedures. An example of a gamma-emitting radionuclide is barium-137m, a short-lived daughter product of cesium-137. Both barium-137m and its precursor, cesium-137, are major constituents of the WVDP high-level radioactive waste.
Measurement of Radioactivity. The rate at which radiation is emitted from a disintegrating nucleus can be described by the number of decay events or nuclear transformations that occur in a radioactive material over a fixed period of time. This process of emitting energy, or radioactivity, is measured in curies $(\mathrm{Ci})$ or becquerels $(\mathrm{Bq})$.

The curie is based on the decay rate of the radionuclide radium-226. One gram of radium-226 decays at the rate of 37 billion nuclear disintegrations per second $(3.7 \mathrm{E}+10 \mathrm{~d} / \mathrm{s})$, so one curie equals 37 billion nuclear disintegrations per second. One becquerel equals one decay, or disintegration, per second. (See the Scientific Notation section at the back of this report [UOM-2] or pp. 1-5 and 1-6 of this chapter for information on exponentiation [i.e., the use of "E" to mean the power of 10].)

Very small amounts of radioactivity are sometimes measured in picocuries. A picocurie is one-trillionth (1E-12) of a curie, equal to 3.7E-02 disintegrations per second (3.7E-02 Bq), or 2.22 disintegrations per minute.

Measurement of Dose. The amount of energy absorbed by the receiving material is measured in rads (radiation absorbed dose). A rad is $100 \mathrm{ergs}$ of radiation energy absorbed per gram of material. (An erg is the approximate amount of energy necessary to lift a mosquito one-sixteenth of an inch.) "Dose" is a means of expressing the amount of energy absorbed, taking into account the effects of different kinds of radiation.

Alpha, beta, and gamma radiation affect the body to different degrees. Each type of radiation is given a quality factor that indicates the extent of human cell damage it can cause compared with equal amounts of other ionizing radiation energy. Alpha particles cause 20 times as much damage to internal tissues as x-rays, so alpha radiation has a quality factor of 20, compared to gamma rays, 
X-rays, or beta particles, all of which have a quality factor of 1 .

The unit of dose measurement to humans is the rem (roentgen-equivalent-man). (See rem and roentgen [pp. GLO-10 and GLO-11] in the Glossary.) The number of rem are equal to the number of rad multiplied by the quality factor for each type of radiation. Dose can also be expressed in sieverts. One sievert equals 100 rem.

\section{Environmental Monitoring Program Overview}

Exposure of human beings to radioactivity from site activities would be primarily through air, water, and food. At the WVDP all three pathways are monitored, but air and surface water pathways are the two primary near-term means by which radioactive material can move off site.

The geology of the site (types of soil and bedrock), the hydrology (location and flow of surface water and groundwater), and meteorological characteristics of the site (wind speed, patterns, and direction) are all considered in evaluating potential exposure through the major pathways.

The on-site and off-site monitoring program at the WVDP includes measuring the concentration of alpha and beta radioactivity, conventionally referred to as "gross alpha" and "gross beta," in air and water effluents. Measuring the total alpha and beta radioactivity from key locations, which can be done within a matter of hours, produces a comprehensive picture of on-site and off-site levels of radioactivity from all sources. For a U.S. Department of Energy (DOE) site such as the WVDP, frequent updating and tracking of the overall levels of radioactivity in effluents is an important tool in maintaining acceptable operations.
More-detailed measurements are also made for specific radionuclides. Strontium-90 and cesium137 are measured because they have been previously detected in WVDP waste materials. Radiation from other important radionuclides, such as tritium or iodine-129, is not sufficiently energetic to be detected by gross measurement techniques, so these must be analyzed separately using methods with greater sensitivity. Heavy elements, such as uranium, plutonium, and americium, require special analysis to be measured because they exist in such small concentrations in the WVDP environs.

The radionuclides monitored at the Project are those that might produce relatively higher doses or that are most abundant in air and water effluents. Because man-made sources of radiation at the Project have been decaying for more than thirty years, the monitoring program does not routinely include short-lived radionuclides, that is, isotopes with a half-life of less than two years, which would have less than $1 / 1,000$ of the original radioactivity remaining. (See Appendix $\mathrm{B}^{\mathrm{C}}$ for the schedule of samples and radionuclides measured and Appendix $\mathrm{K}^{\mathrm{C}}$, Table $\mathrm{K}-1$ for a listing of the half-lives of radionuclides measured in WVDP samples and related DOE protection standards, such as the derived concentration guides [DCGs]. See also the discussion of DCGs [facing page].)

Data Reporting. Because the decay of radioactive atoms is a random process, there is an inherent uncertainty associated with all measurements of environmental radioactivity. This can be demonstrated by repeatedly measuring the number of atoms that decay in a radioactive sample over some fixed period of time. The result of such an experiment would be a range of values for which the average value would provide the best indication of how many radioactive atoms were present in the sample. 


\section{Derived Concentration Guides}

A derived concentration guide (DCG) is defined by the DOE in DOE Order 5400.5 as the concentration of a radionuclide in air or water that, under conditions of continuous exposure by one exposure mode (i.e., ingestion of water, immersion in air, or inhalation) for one year, would result in an effective dose equivalent of 100 mrem $(1 \mathrm{mSv})$ to a "reference man." (See "reference man" in the Glossary [p.GLO-10].) These concentrations - DCGs - are used as reference screening levels to enable WVDP personnel reviewing effluent and environmental data to decide if further investigation is needed. (See Table $K-1^{\mathrm{C}}$, Appendix $K$ for a list of DCGs.)

For liquid effluent screening purposes, the percentages of the DCGs for all radionuclides present are summed. If the total is less than 100\%, then the effluent complies with the DOE guideline. DCGs are also compared with radionuclide concentrations from these sources to verify that Best Available Technology standards for treatment of water are being met.

The DOE provides DCGs for airborne radionuclides in locations where members of the public could, over an extended period of time, breathe air containing contaminants. DCGs are only applicable to radionuclides in air breathed by members of the public. DCGs may be used as a comparative basis for screening concentrations from air emission points.

DOE Orders and federal regulations require that the hypothetical dose to the public from facility effluents be estimated using specific computer codes. (See Dose Assessment Methodology [p. 2-25] in Chapter 2, Environmental Radiological Program Information.) Doses estimated for WVDP activities are calculated using actual site data and are not related directly to summed $D C G$ values. Dose estimates for liquid effluents are based on the product of radionuclide quantities released and the site-specific dose equivalent effects for that radionuclide. Although airborne DCGs are used for comparison purposes, the more stringent U.S. Environmental Protection Agency (EPA) National Emission Standards for Hazardous Air Pollutants regulate Project airborne effluents at the point of release. For a consistent guide to relative concentrations, both air and water sampling results are compared with DCGs throughout this report.

In actual practice an environmental sample usually is measured for radioactivity only once. The inherent uncertainty of the measurement, then, stems from the fact that it cannot be known whether the result that was obtained from one measurement is higher or lower than the "true" value.

The term confidence interval is used to describe the range of measurement values above and below the test result within which the "true" value is expected to lie. (See confidence interval in the
Glossary [p. GLO-2].) This interval is derived statistically. The width of the interval is based primarily on a predetermined confidence level, that is, the probability that the confidence interval actually encompasses the "true" value. The WVDP environmental monitoring program uses a $95 \%$ confidence level for all radioactivity measurements and calculates confidence intervals accordingly.

The confidence interval around a measured value is indicated by the plus-or-minus $( \pm$ ) value following the result (e.g., $5.30 \pm 3.6 \mathrm{E}-09 \mu \mathrm{Ci} / \mathrm{mL}$ ), with 
the exponent of $10^{-9}$ expressed as "E-09." Expressed in decimal form, the result $5.30 \pm 3.6 \mathrm{E}-09$ would be $0.00000000530 \pm 0.0000000036 \mu \mathrm{Ci} / \mathrm{mL}$. A sample measurement expressed this way is correctly interpreted to mean "there is a 95\% probability that the concentration of radioactivity in this sample is between 1.7E-09 $\mu \mathrm{Ci} / \mathrm{mL}$ and $8.9 \mathrm{E}-09$ $\mu \mathrm{Ci} / \mathrm{mL} . "$ (See also Scientific Notation [p. UOM2] at the end of this report.) If the confidence interval for the measured value includes zero (e.g., $5.30 \pm 6.5 \mathrm{E}-09 \mu \mathrm{Ci} / \mathrm{mL}$ ), the value is considered to be below the detection limit. The values listed in tables of radioactivity measurements in the appendices include the confidence interval regardless of the detection limit value.

In general, the detection limit is the minimum amount of constituent or material of interest detected by an instrument or method that can be distinguished from background and instrument noise. Thus, the detection limit is the lowest value at which a sample result shows a statistically positive difference from a sample in which no constituent is present.

Nonradiological data conventionally are presented without an associated uncertainty and are expressed by the detection limit prefaced by a "lessthan" symbol $(<)$ if that analyte was not measurable. (See also Data Assessment and Reporting [p. 5-7] in Chapter 5, Quality Assurance.)

Units of measure, as used in this document, are listed on p. UOM-1. In the text, traditional radiological units (e.g., rem, rad, curie, roentgen) are presented first, followed by Systeme Internationale (S.I.) units. Nonradiological measurements are presented in English units, with the metric equivalent noted in parentheses. A conversion chart for comparing traditional and S.I. radiological units and English and metric nonradiological units is presented on p. UOM-2.
Changes in the 2003 Environmental Monitoring Program. Several modifications to the environmental sampling and surveillance network were made in 2003 to better reflect current facility status.

- Air monitoring at ANSEISK, backup for the vitrification facility heating, ventilation, and airconditioning system, was discontinued at the end of March 2003. It was restarted in October 2003 for operational reasons and became the primary ventilation sampling point (ANVITSK) when the original location for ANVITSK was shut down.

- Air monitoring at the low-level waste treatment facility ventilation (ANLLW2V) was discontinued at the end of March 2003 because continued monitoring has confirmed that releases are at very low levels.

- The nonradiological parameter list for surface water monitoring locations WNSP006, WNSWAMP, WNSW74A, WFBCBKG, and WFBCTCB was modified to assess compliance with New York State Water Quality Standards.

- Strontium-90 analysis of sanitary waste discharge samples (location WNSP007) was added on a quarterly basis.

- Quarterly strontium-90 and gamma-isotopic analyses were added for surface water monitoring locations WNSP005, WNERB53, and WNFCR67.

- Monitoring of cooling water from plant systems (location WNCOOLW) was changed from monthly to quarterly and strontium- 90 analysis was added.

- Annual strontium-90 and gamma-isotopic analyses were added for the standing water (WNSTAW-series) monitoring locations. 
- Monitoring frequency for potable water sampling locations WNDNKEL, WNDNKMS, and WNDNKMP was changed from monthly to a rotating, quarterly basis. No contamination has been noted in these samples in over a decade of sampling.

- Quarterly technetium-99 analysis was added for surface water monitoring locations WFBCTCB and WFFELBR to monitor for the radionuclide after effluents leave the site.

- Annual strontium-90 analysis was added for offsite well locations WFWEL01 through WFWEL10.

- Air and soil sampling was discontinued at the secondary background location in Nashville, New York (locations AFNASHV and SFNASHV). Historical sampling has provided a substantial quantity of data for use in background comparisons. Sampling will continue at the primary background location.

- Milk sampling was discontinued at the northern background location BFMCTLN after the first quarter of 2003. Sampling will continue at the southern background location.

- Sampling of hay was deleted from the program because these data are not directly used in dose assessments and because no radionuclides have been detected in hay since monitoring began in the 1980s.

- Redundant background thermoluminescent dosimeter locations DFTLD17, DFTLD37, and DFTLD41 used for monitoring exposure levels were deleted from the program.

See Appendix $\mathrm{B}^{\mathrm{C}}$ for a detailed summary of the program changes and the sample points and parameters measured in 2003.

\section{Completion of Vitrification}

High-level radioactive waste from NFS operations was originally stored in two of four underground tanks (tanks 8D-2 and 8D-4). Contents in the tanks were pretreated to remove sodium salts and sulfates and most of the radioactive cesium, and resulting wastes were fixed into about 20,000 drums of cemented LLW. Vitrification of the HLW began in 1996 and continued through most of 2002. (See the 2002 WVDP Annual Site Environmental Report [WVNSCO and URS, 2003] for a complete description of the vitrification process.)

Over the course of vitrification, more than 12.2 million cesium/strontium curies were transferred to the vitrification facility and 275 canisters were filled. Two additional waste canisters were generated when the melter was evacuated. The melter was shut down in September 2002. Canisters are being stored in a shielded cell in the main plant, the former chemical processing cell, and are being maintained until a disposal facility becomes available.

\section{Activities at the WVDP}

The WVDP's environmental management system (EMS) is an important factor in the environmental monitoring program and the accomplishment of its mission. Significant components, initiatives, and accomplishments at the WVDP in 2003 are summarized below.

Decontamination. Initial decontamination efforts in the main plant focused on the process mechanical cell (PMC) and the general purpose cell (GPC) to place the cells in a safer configuration for future facility decommissioning. Following a series of infrastructure upgrades, decontamination work began in the PMC in 2001 and in the GPC in 2002. Initial debris removal in both cells was completed in 2003. Efforts have now shifted to the removal of excess equipment. 
Preparations for the decontamination of the south side of the product purification cell was initiated in 2002 and the work was completed in September 2003. Decontamination of extraction cell 2 is in progress.

Fuel storage racks, canisters, and debris were removed from the fuel receiving and storage (FRS) pool. The water was drained from the fuel storage pool and the cask unloading pool, the walls were decontaminated and a fixative was applied, and the floors were grouted. This work was completed in 2003.

A plan for decontamination and dismantlement of the vitrification facility was prepared in 2003. Dismantlement is scheduled to begin in 2004.

Spent Nuclear Fuel Shipment Completed. In 2003, two dual-purpose shipping and storage casks containing spent nuclear fuel were safely transported from the WVDP to the Idaho National Engineering and Environmental Laboratory (INEEL). The casks were specifically designed to ship this fuel to the INEEL and store it until a federal repository is available for disposal.

A dedicated train was used to ship the containers over 2,300 miles through 11 states, one tribal territory, and five Federal Railroad Administration regions without incident. More than 22 state agencies worked directly with DOE and other federal agencies, as well as the four involved railroads, in planning and preparing for this shipment.

Preparations had been completed in 2001 when the shipment was postponed due to the need to complete other work that was in progress at the INEEL. DOE notified the corridor states and tribes in December 2002 of its intent to conduct the shipment in 2003, based on the planning and preparation completed in 2001 with changes that were limited to only those that were essential to safety and/or task completion.

Shipment planning and conduct were consistent with DOE M 460.2-1, Radioactive Material Transportation Practices Manual, issued in 2002. DOE worked with the corridor states and tribe on route evaluation and selection, emergency response preparedness, security planning, shipment timing, and general coordination issues.

Remote-Handled Waste Facility Construction. As part of project operations, various contaminated materials/components have been removed from the former process building and are in storage awaiting disposal. In addition, as efforts increase toward eventual decommissioning, additional materials and components will be removed from the waste tank farm and the former process building. Before these waste materials can be shipped for disposal, they have to be characterized, sorted, processed as necessary, and packaged to meet regulatory requirements for transportation. Construction of the remote-handled waste facility (RHWF) started in September 2000 and continued throughout 2003. The RHWF will be used to process and package these highly-contaminated, high-activity, solid radioactive wastes. The facility is scheduled to begin operations during calendar year 2004.

\section{Environmental Management of Aqueous Ra-} dioactive Waste. Water containing radioactive material from site process operations is collected and treated in the low-level waste treatment facility (LLWTF). (Water from the sanitary system, which does not contain added radioactive material, is managed in a separate system.)

The treated process water is held, sampled, and analyzed before it is released through a New York State Pollutant Discharge Elimination System (SPDES)-permitted outfall. In 2003, about 15.0 
million gallons (56.7 million liters) of water were treated in the LLWTF system, which includes the low-level waste treatment building (LLW2) and associated holding lagoons, and discharged through outfall 001, the lagoon 3 weir. The total 2003 discharge waters contained an estimated 14.6 millicuries of gross alpha plus gross beta radioactivity. Comparable releases during the previous 18 years averaged about 33 millicuries per year. The 2003 release was about $44 \%$ of this average. (See Overview of Water Effluent and Ambient Surface Water Monitoring [p. 2-5] in Chapter 2.)

Approximately 0.23 curies of tritium were released in WVDP-controlled liquid effluents in 2003 about $20 \%$ of the 18 -year average of 1.17 curies.

Environmental Management of Airborne Radioactive Emissions. Ventilated air from the various WVDP facilities is sampled continuously during operation for both particulate matter and for gaseous radioactivity. In addition to monitors that alarm if particulate matter radioactivity increases above pre-set levels, the sample media are analyzed in the laboratory for the specific radionuclides that are present in the radioactive materials being handled.

Air used to ventilate the facilities where radioactive material cleanup processes are being conducted is passed through filtration devices before being emitted to the atmosphere. These filtration devices are generally more effective for particulate matter than for gaseous radioactivity. For this reason, facility air emissions tend to contain a greater amount of gaseous radioactivity (e.g., tritium and iodine-129) than radioactivity associated with particulate matter (e.g., strontium-90 and cesium-137). However, gaseous radionuclide emissions still remain so far below the most restrictive regulatory limit for public safety that additional treatment technologies beyond those already provided are not necessary.
Gaseous radioactivity emissions from the main plant in 2003, the first full year since vitrification was completed, included approximately 2.41 millicuries of tritium (as hydrogen tritium oxide) and 0.065 millicuries of iodine-129. (See Chapter 2 [p. 2-27] for a discussion of iodine-129 emissions from the main plant stack.) As expected, these 2003 values are quite low in comparison to values from 1997, a year in which the vitrification system was in operation for the entire year at a relatively high rate of production. In 1997, tritium and iodine-129 emissions were 140 millicuries and 7.43 millicuries, respectively.

Particulate matter radioactive emissions from the main plant in 2003 included approximately 0.05 millicuries of gross beta-emitting radioactivity and 0.002 millicuries of gross alpha-emitting radioactivity. In 1997, beta-emitting and alpha-emitting radioactivity emissions were 0.4 millicuries and 0.001 millicuries, respectively.

\section{Environmental Management of Radiological} Exposure. Radiological exposures measured at on-site monitoring locations DNTLD24, located near the chemical process cell waste storage area (CPC-WSA), and DNTLD36, located near the drum cell, have generally shown decreases for several years. (See Fig. A-10 [p. A-10] for the locations of these two monitoring points.) Exposure data are shown in Figures 1-1 and 1-2 (p. 1-10).

Although exposure values have generally been declining at DNTLD36, the graph shows an increase in 2003. Wastes from decontamination of the FRS were stored near the drum cell in the first and second quarters of 2003 and produced exposure rates as much as three times higher than those normally measured at DNTLD36. Once the FRS waste was removed, measured results returned to normal and the average exposure noted in the third and fourth quarters of 2003 was about $33 \mathrm{mR} /$ quarter. 

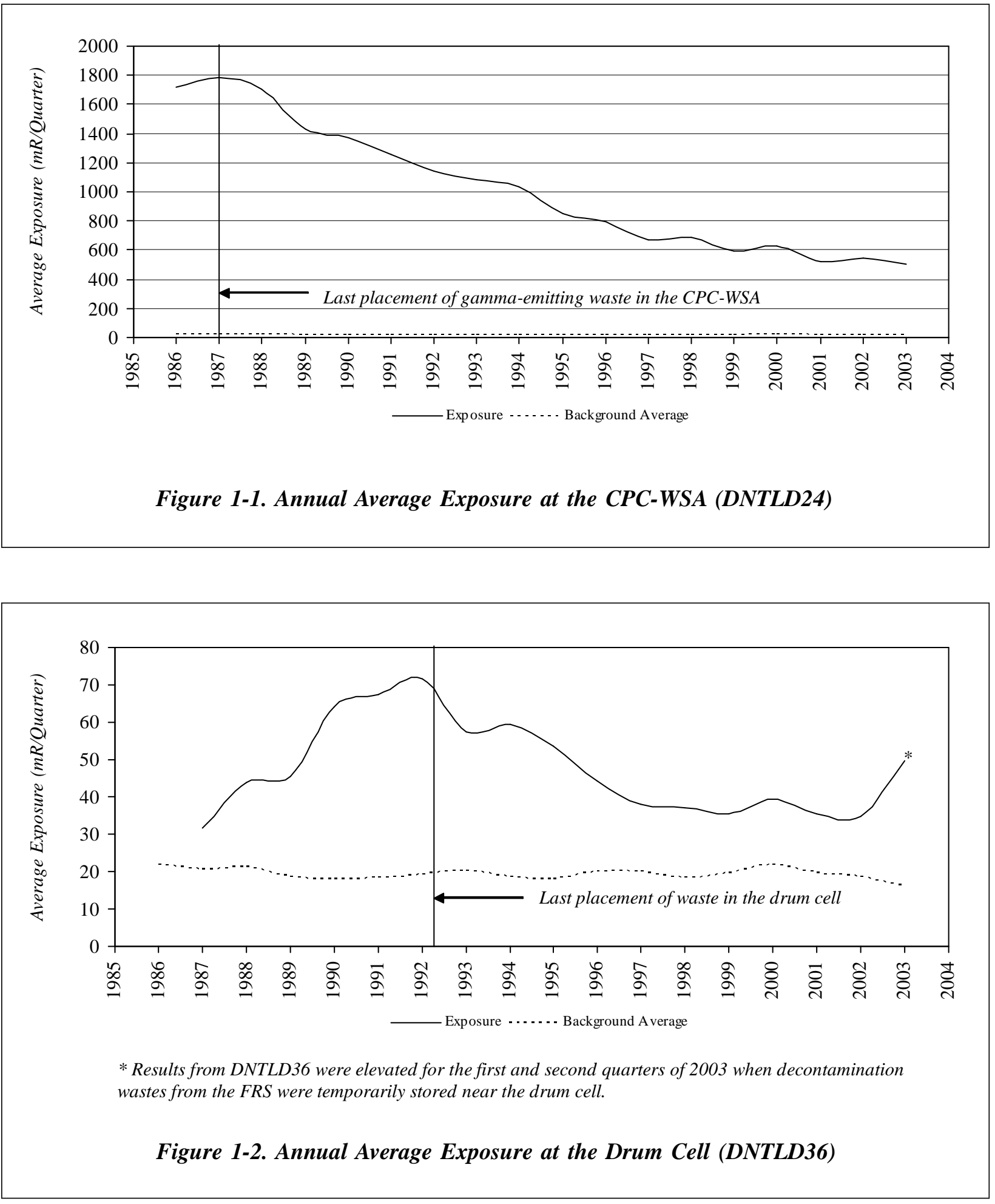

$$
1-10
$$


The beginning of the long-term steady decrease in exposure atDNTLD24 correlates well with the cessation of placement of waste containers in the CPCWSA in 1987 and with the decay of the mix of isotopes in the stored waste. The decreases noted at DNTLD36 can be attributed to the cessation of the placement of waste drums in the drum cell, as well as the decay of the mix of isotopes in the stored waste over time, and to the revised stacking plan initiated in 1990, which changed the arrangement of waste and shield drums in the drum cell.

Unplanned Radiological Releases. There were no unplanned airborne or liquid radiological releases on-site or to the off-site environment from the Project in 2003.

\section{NRC-Licensed Disposal Area (NDA) Inter- ceptor Trench and Pretreatment System.} Radioactively-contaminated n-dodecane, in combination with tributyl phosphate (TBP), was discovered at the northern boundary of the NDA in 1983, shortly after the DOE assumed control of the WVDP site. Extensive sampling and monitoring through 1989 revealed the possibility that the n-dodecane/TBP could migrate. To contain migration of this subsurface radioactive organic contaminant, an interceptor trench and liquid pretreatment system (LPS) were built.

As in previous years, in 2003 no water containing TBP was encountered in the trench and no water was treated by the LPS. Approximately 370,000 gallons $(1,400,000$ liters) of radiologically contaminated water were collected from the interceptor trench and transferred to the LLWTF for treatment during the year. Results of surface and groundwater monitoring in the vicinity of the trench are discussed in Chapter 2 under South Plateau Surface Water and NDA Interceptor Trench (p. 2-9) and in Chapter 4 under Results of Monitoring at the NDA (p. 4-11).
Waste Minimization Program. The WVDP formalized a waste minimization program in 1991 to reduce the generation of LLW, mixed waste, and hazardous waste. This program is a comprehensive and continual effort to prevent or minimize pollution, with the overall goals of reducing health and safety risks, protecting the environment, and complying with all federal and state regulations. (See also the Environmental Compliance Summary, Waste Minimization and Pollution Prevention [p. ECS-5] and p. 1-17 of this chapter.)

\section{Pollution Prevention Awareness Program.} The WVDP's Pollution Prevention (P2) Awareness Program is a significant part of the Project's waste minimization program. The goal of the program is to make all employees aware of the importance of pollution prevention both at work and at home.

A crucial component of the P2 Awareness Program at the WVDP is the Pollution Prevention Coordinators group. This group communicates, shares, and publicizes prevention, reduction, reuse, and recycling information to all departments at the WVDP. The P2 Coordinators identify and facilitate the implementation of effective sourcereduction, reuse, recycling, and procurement of recycled products. The WVDP employs an incentive-based program (the Bright Ideas Program) to encourage waste stream reduction/elimination, energy savings, and affirmative procurement. This program continues to foster cost savings and avoidances resulting from waste minimization and P2 activities.

Waste Management. The WVDP continued accomplishments in reducing and eliminating waste generated by site activities. Reductions in the generation of low-level radioactive waste, mixed waste, hazardous waste, industrial wastes, and sanitary waste, such as paper, plastic, wood, and scrap metal were targeted. 
Waste minimization and recycling activities during 2003 resulted in reduced waste generation and cost savings. To accomplish this, the following items were recycled:

- paper and paper products - 108 tons (97.9 metric tons)

- scrap metals - 62.1 tons (56.3 metric tons)

- other materials - 412 tons (374 metric tons).

Low-Level Radioactive Waste Shipping Program. The WVDP initiated the LLW shipping program in 1997 to reduce the inventory of legacy and newly-generated waste stored on-site. To date, more than 189,000 cubic feet (5,350 cubic meters) of LLW have been safely shipped for off-site disposal. In the past, most waste was sent to commercial disposal facilities. However, in July 2001, the WVDP was approved to ship LLW to the Nevada Test Site (NTS), a DOE facility. To date, more than 18,000 cubic feet of waste have been safely shipped to NTS.

In calendar year (CY) 2003, a total of about 46,500 cubic feet $(1,320$ cubic meters) of LLW was shipped. Thirteen shipments were made to NTS, for a total volume of about 13,800 cubic feet (390 cubic meters) of waste disposed. Commercial shipments included 12 truckloads, for a volume of about 32,800 cubic feet ( 929 cubic meters). The larger volume of waste in less truckloads was due to the significant volume reduction obtained from waste-compacting operations.

\section{National Environmental Policy Act (NEPA)} Activities. Under NEPA, the DOE is required to consider the overall environmental effects of its proposed actions or federal projects. The President's Council on Environmental Quality established a screening system of analyses and documentation that requires each proposed action to be categorized according to the extent of its potential environmental effect. The levels of documentation include categorical exclusions (CXs), environmental assessments (EAs), and environmental impact statements (EISs).

Categorical exclusions evaluate and document actions that will not have a significant effect on the environment. Environmental assessments evaluate the extent to which the proposed action will affect the environment. If a proposed action has the potential for significant effects, an EIS is prepared that describes proposed alternatives to an action and explains the effects.

Facility maintenance, decontamination activities, and minor projects that support HLW vitrification are documented and submitted for approval as CXs, although EAs occasionally are necessary for larger-scale activities.

In December 1988, the DOE published a joint Notice of Intent (NOI) with the New York State Energy Research and Development Authority (NYSERDA) to prepare an EIS for the completion of the WVDP and closure of the facilities at the WNYNSC.

The draft EIS, which describes the potential environmental effects associated with Project completion and various site closure alternatives, was completed in 1996 and released without a preferred alternative for a six-month public review and comment period. Having met throughout 1997 and 1998 to review alternatives presented in the draft EIS, the Task Force (see inset [facing page]) issued the West Valley Citizen Task Force Final Report (July 29, 1998). This report provided recommendations and advice on the development of a preferred alternative. The Task Force continues to meet and discuss issues related to Project completion and site closure decision-making. 
Because the Nuclear Regulatory Commission (NRC) is authorized by the West Valley Demonstration Project Act to prescribe decommissioning criteria for the WVDP, from 1998 until early 2002 the NRC worked to develop those decommissioning criteria through a series of draft policy papers and public meetings.

The DOE and NYSERDA continue efforts to reach agreement on a preferred alternative and agency responsibilities for decommissioning and/ or long-term stewardship at the WVDP and the WNYNSC. In 2001, DOE formally initiated its plan to revise the scope of the 1996 draft EIS by splitting that scope into two separate documents. The decision-making process has been separated into two phases by revising the scope of the 1996 draft EIS. Re-scoping will allow two separate environmental impact statements - one for near-term waste management decision-making and one for final decommissioning and/or long-term stewardship decision-making.

DOE published a Federal Register (FR) NOI on March 26, 2001 (66 FR 16447) formally announcing its rescoping plan and preparation of the waste management EIS.

DOE also published an Advance NOI on November 6, 2001 (66 FR 56090) announcing its commitment to begin work, in cooperation with NYSERDA, on the Decommissioning and/or Long-Term Stewardship EIS.

In January 2002, the NRC announced that it was issuing its final policy statement establishing the criteria of its existing license termination rule as the decommissioning criteria for the WVDP.

On February 1, 2002, the NRC issued its Decommissioning Criteria for the West Valley Demonstration Project (M-32) at the West Valley Site; Final Policy Statement in the Federal Reg-

\section{West Valley Citizen Task Force}

In addition to the public comment process required by the National Environmental Policy Act, the New York State Energy Research and Development Authority, with participation from the DOE, formed the West Valley Citizen Task Force in January 1997. The mission of the Task Force is to provide advice on the completion of the West Valley Demonstration Project and cleanup, closure, and/or long-term management of the facilities at the site. The Task Force process has helped illuminate the various interests and concerns of the community, increased the two-way flow of information between the site managers and the community, and provided an effective way for the Task Force members to establish mutually-agreed-upon recommendations for the site managers to consider in their decision-making process.

ister (67 FR 5003). The Final Policy Statement applies the NRC's License Termination Rule (10 CFR Part 20, Subpart E) as the decommissioning criteria for the WVDP and as the decommissioning goal for the entire WNYNSC.

DOE published an NOI on March 13, 2003 (68 FR 12044) announcing its intent to prepare, in cooperation with NYSERDA, The Decommissioning and/or Long-Term Stewardship EIS. DOE and NYSERDA are joint lead agencies on this EIS. The EPA, the NRC, and the New York State Department of Environmental Conservation (NYSDEC) are cooperating agencies on The Decommissioning and/or Long-Term Stewardship EIS.

Work on preparation of The Decommissioning and/or Long-Term Stewardship EIS continued in 2003. On May 16, 2003, DOE issued the draft of the Waste Management EIS (68 FR 26587) for 
public comment. DOE is considering public comments received, and revisiting the draft EIS accordingly, for anticipated completion of the waste management EIS in 2004.

Self-Assessments. Self-assessments continued to be conducted in 2003 to review the management and effectiveness of the WVDP environmental protection and monitoring programs. Results of these self-assessments are evaluated and corrective actions are tracked through to completion. Overall results of these self-assessments found that the WVDP continued to implement quality requirements and in some cases improve the quality of the environmental protection and monitoring program. (See the Environmental Compliance Summary [p. ECS-17] and Chapter 5, Quality Assurance [p. 5-6].)

\section{Occupational Safety and Environmental} Training. The safety of personnel who are involved in industrial operations under DOE cognizance is protected by standards mandated by DOE Order 440.1A, Worker Protection Management for DOE Federal and Contractor Employees, which directs compliance with specific Occupational Safety and Health Act (OSHA) requirements. This act governs diverse occupational hazards ranging from electrical safety and protection from fire to the handling of hazardous materials. The purpose of OSHA is to maintain a safe and healthy working environment for employees. Hazardous waste operations and emergency response regulations require that employees at treatment, storage, and disposal facilities, particularly those who may be exposed to health and safety hazards during hazardous waste operations, receive training appropriate to their job function and responsibilities. The WVDP environmental, health, and safety training matrix identifies the specific training requirements for such employees.
The WVDP provides basic 24-hour hazardous waste operations and emergency response training. (Emergency response training includes spill response measures and controlling contamination of groundwater.) The WVDP trains decontamination workers and their supervisors according to the 40-hour program for hazardous waste operations and emergency response to meet the additional OSHA training requirements of a cleanup site. The additional training provides workers with information and techniques for decontamination operations.

Training programs also contain information on waste minimization, pollution prevention, and the WVDP environmental management program. Besides this standard training, employees working in radiological areas receive additional training on subjects such as understanding radiation and radiation warning signs, dosimetry, and respiratory protection. In addition, qualification standards for specific job functions at the site are required and maintained. These programs have evolved into a comprehensive curriculum of knowledge and skills necessary to maintain the health and safety of employees and ensure the continued compliance of the WVDP.

Medical emergencies on-site are handled by the WVDP Emergency Medical Response Team. This team consists of on-site professional medical staff and volunteer New York State-certified emergency medical technicians.

Any person working at the WVDP who has a personal photo badge receives general employee training that covers health and safety, emergency response, and environmental compliance issues. All visitors to the WVDP receive a site-specific briefing on safety and emergency procedures before being admitted to the site. 
Voluntary Protection Program STAR Status. On May 5, 2000 the WVDP received Voluntary Protection Program (VPP) STAR status, the highest safety award given within OSHA or the DOE. This prestigious award was granted in recognition of the WVDP's excellent worker safety and health programs. (See also the Environmental Compliance Summary [p. ECS-16].)

The WVDP has reaffirmed its commitment to DOE's VPP. During the 2003 reporting period, the VPP was reviewed as part of the annual integrated safety management system (ISMS) review. The DOE completed an on-site review of the VPP program and has been recertified as a DOE-VPP STAR site. At the annual VPP Participants National Conference, the WVDP was awarded the DOE's Star of Excellence Award. The WVDP is the only site to receive this award for three consecutive years. This award is given to sites with outstanding safety programs.

Employees of the WVDP reached one million consecutive safe work hours on September 1, 2003 and one year without a lost-time work accident on November 20, 2003. They were awarded the Washington Group International President's Award for Safety on December 18, 2003.

\section{Environmental Management System Imple-} mentation. The Project's environmental management system provides the basic policy and direction for work at the WVDP through procedures that support proactive management, environmental stewardship, and the integration of appropriate technologies throughout all aspects of work at the WVDP. EMS implementation is summarized in Table ECS-1 (pp.ECS-19 to ECS-23).

The WVDP EMS satisfies requirements of the new DOE Order 450.1, Environmental Protection Program. (See the discussion of new DOE Order 450.1 in the Environmental Compliance Summary [pp. ECS-1 and ECS-2].) The EMS is also in compliance with the Code of Environmental Management Principles (CEMP) for federal agencies and International Organization for Standardization 14001, Environmental Management Systems: Specification for Guidance and Use, which is being implemented worldwide. The CEMP was developed by the EPA in response to Executive Order (EO) 12856, Federal Compliance with Right-toKnow Laws and Pollution Prevention Requirements, in order to serve as the basis for responsible environmental management. (EO 12856 was revoked in April 2000 by EO 13148, Greening the Government Through Leadership in Environmental Management.)

Following the principles and performance objectives of the CEMP helps to ensure that a federal facility's environmental performance is proactive, flexible, cost-effective, and sustainable. The WVDP has maintained its charter membership in the EPA's National Environmental Performance Track program for implementation of this EMS. (See inset [p. 1-16].) The most recent self-assessment by West Valley Nuclear Services Co. (WVNSCO), performed in August 2003, verified that the EMS continues to be effectively implemented at the WVDP.

\section{Integrated Safety Management System} Implementation. A plan to integrate environmental, safety, and health (ES\&H) management programs at the WVDP was developed and initiated at the WVDP during 1998. During development of the ISMS, the EMS was identified as an integral part of the ISMS. Environmental subject matter experts participate on a sitewide work review group to review work plans, identify ES\&H concerns, and specify practices that ensure work is performed safely.

Implementation of an ISMS at the WVDP, including the EMS, was verified by the DOE Ohio Field 


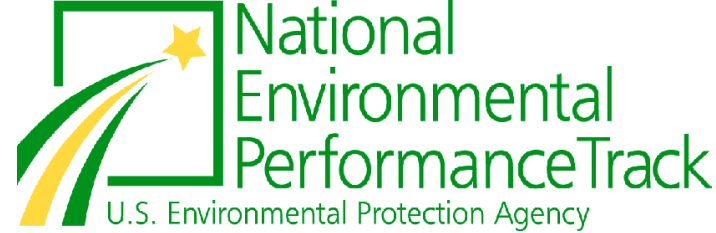

The National Environmental Performance Track is designed to recognize and encourage top environmental performers - those who go beyond compliance with regulatory requirements to attain levels of environmental performance and management that benefit people, communities, and the environment.

The logo identifies those facilities that qualify for Achievement Track membership. Achievement Track facilities can participate in a peer exchange network to share experience, benchmark each other's performance, share information on successful practices and strategies, and receive recognition for their work at state and local levels. The WVDP was awarded charter membership in this program.

Office in November 1998. The most recent selfassessment by WVNSCO, performed in August 2003, verified that the ISMS continues to be effectively implemented at the WVDP. An annual ISMS review by the DOE occurred in December 2003. DOE specifically looked at the integration of EMS into the ISMS and confirmed results of the WVNSCO self-assessment.

\section{Performance Measures}

Performance measures can be used to evaluate effectiveness, efficiency, quality, timeliness, productivity, safety, or other areas that reflect achievements related to organization or process goals, and can be used as a tool to identify the need to institute changes.
The performance measures applicable to operations conducted at the WVDP, discussed here, reflect process performance related to wastewater treatment in the LLW treatment facility, the identification of spills and releases, the reduction in the generation of wastes, the potential radiological dose received by the maximally exposed off-site individual (MEOSI), and the transfer of HLW to the vitrification system.

\section{Radiation Doses to the Maximally-Exposed} Off-Site Individual. One of the most important pieces of information derived from environmental monitoring program data is the potential radiological dose to an off-site individual from on-site activities. As an overall assessment of Project activities and the effectiveness of the as-low-asreasonably-achievable concept, the effective radiological dose to the MEOSI is an indicator of well-managed radiological operations. The effective dose equivalents for air effluent emissions, liquid effluent discharges, and other liquid releases (such as swamp drainage) from 1994 through 2003 are graphed in Figure 1-3 (facing page). Note that the sum of these values is well below the DOE standard of 100 mrem per year. These consistentlylow results indicate that radiological activities at the site are well-controlled. (See also Table 2-6 [p. 2-28] in Chapter 2, Environmental Radiological Program Information.)

\section{State Pollutant Discharge Elimination System Permit Limit Exceptions. Effective operation} of the site wastewater treatment facilities is indicated by compliance with the applicable discharge permit limitations. Approximately 60 parameters are monitored regularly as part of the SPDES Permit requirements. The analytical results are reported to NYSDEC via Discharge Monitoring Reports, required under the SPDES program.

Although the goal of the low-level waste treatment facility and wastewater treatment facility operations 
is to maintain effluent water quality consistently within the permit requirements, occasionally SPDES Permit limit exceptions do occur. All SPDES Permit limit exceptions are evaluated to determine their cause and to identify corrective measures.

A Water Task Team, composed of WVDP personnel with expertise in wastewater engineering, treatment plant operations and process monitoring, and National Pollutant Discharge Elimination System/SPDES permitting and compliance, was formed in 1995 to address the causes of these exceptions. The Water Task Team's efforts produced three consecutive years (1998, 1999, and 2000) with no permit limit exceptions. In 2001, one permit limit exception for total recoverable lead occurred at outfall 008 - the french drain for the LLWTF lagoon system. There were no SPDESeffluent limit exceptions during 2002 or 2003. (See Fig. 1-4 [p. 1-18].)

Although exceptions are not always related to operating deficiencies, corrective actions may include improved operation or treatment techniques. In 1997 the WVDP notified NYSDEC of the presence of mercury in the influent wastewater to the LLWTF and of its likely presence at outfall 001 at concentrations below the detectable level of $0.2 \mu \mathrm{g} / \mathrm{L}$. In 2002, a modification to the SPDES Permit required that samples being collected for measurement of mercury be analyzed in duplicate by Method 245.1 (with a method detection level of $0.2 \mu \mathrm{g} / \mathrm{L}$ ) and by newer, more-sensitive, Method 1631. Results of the comparison are reported to NYSDEC on a quarterly basis. Results from Method 1631 in 2003 were consistent with those from Method 245.1. (See Chapter 3, Mercury Analytical Method Study [p. 3-2], for a discussion of this study.)

\section{Waste Minimization and Pollution Preven-} tion. In 2003 the WVDP continued its program of reducing and eliminating the amount of waste generated from site activities. Emphasis on good business practices, source-reduction, and recycling continued to reduce the generation of low-level radioactive waste, mixed waste, hazardous waste, industrial wastes, and sanitary wastes, such as paper, glass, plastic, wood, and scrap metal.

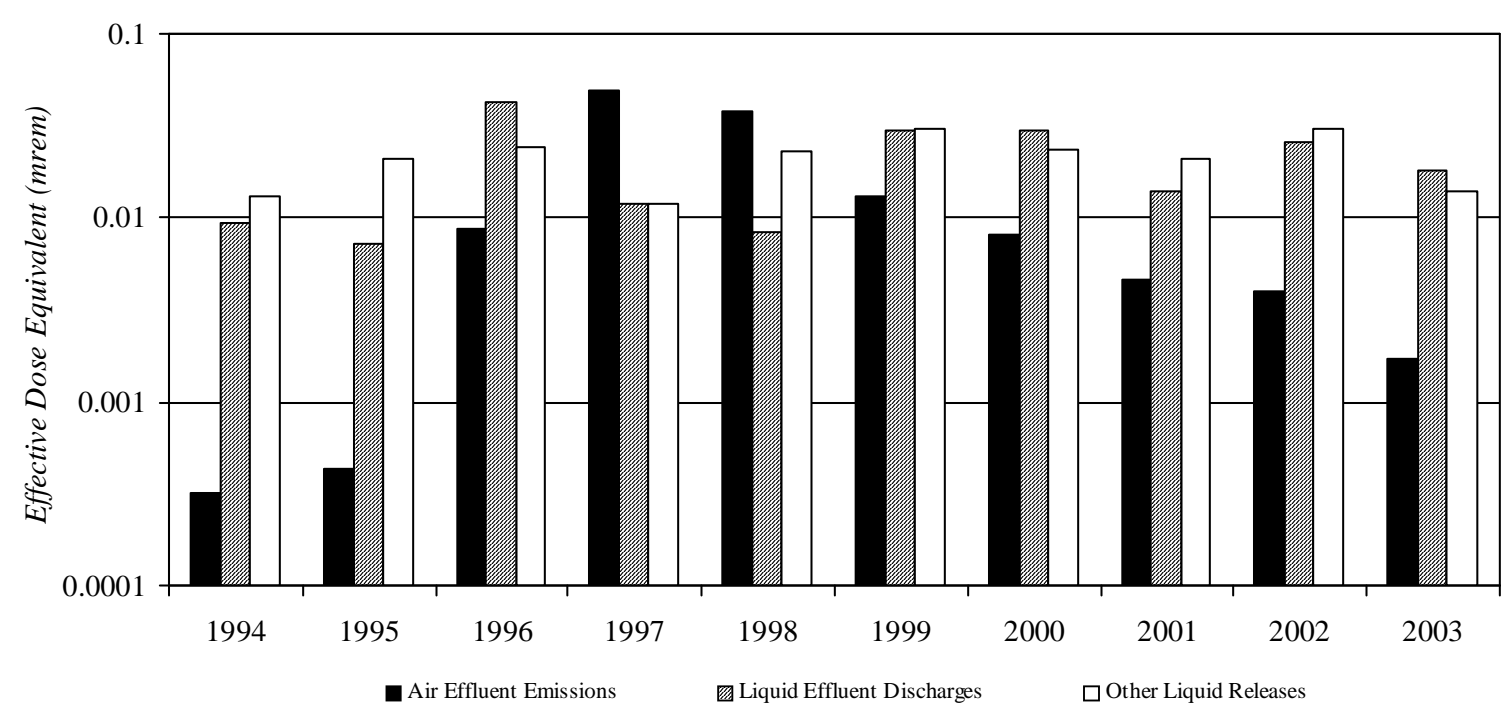

Figure 1-3. Annual Effective Dose Equivalent to the Maximally-Exposed Off-Site Individual 


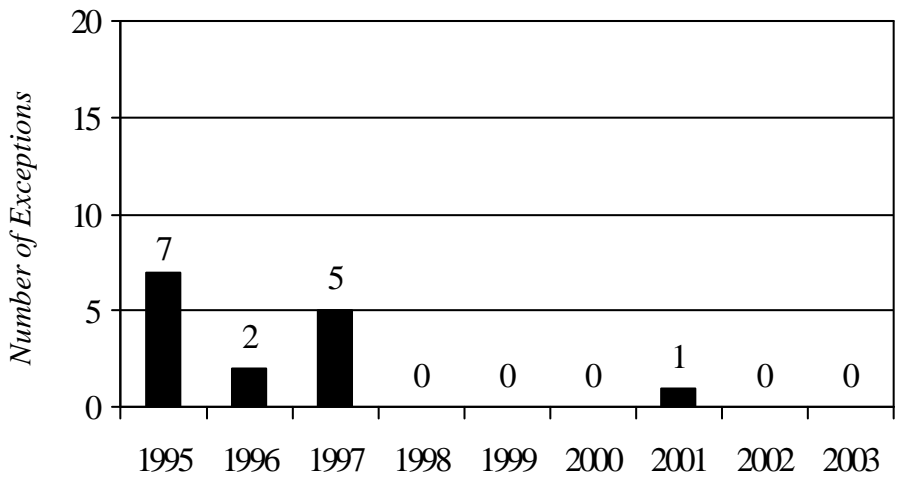

Figure 1-4. Yearly SPDES Effluent Limit Exceptions
A number of waste streams have been tracked over this period. Hazardous waste and industrial waste volumes have been tracked separately for vitrification-related and nonvitrification-related waste streams since vitrification began in 1996. To maintain historical comparability, the percentages in Figure 1-5 include only the nonvitrification portions of these two waste streams.

Spills and Releases. Chemical spills greater than the applicable reportable quantity must be reported immediately

To demonstrate the effectiveness of the waste minimization program, a graph of the percentage of waste reduction achieved above the annual goal for each category is presented in Figure 1-5 (facing page) for CYs 1996 through 2003.

The WVDP set the following cumulative nonvitrification waste-reduction goals for fiscal year 2003: a $70 \%$ reduction in the generation of LLW, a 75\% reduction in the generation of mixed waste, a $65 \%$ reduction in the generation of hazardous waste, a $55 \%$ reduction in the generation of industrial waste, and a $70 \%$ reduction in the generation of sanitary waste. These goals were based on quantities of routine waste generated in 1993. (As of fiscal year 2002, all WVDP pollution prevention goals are in alignment with the DOE's pollution prevention goals, which are based on a federal fiscal year.) All but two of these goals were exceeded during fiscal year 2003. LLW generation was reduced by $65 \%$, missing the established goal of $70 \%$ by just $5 \%$. Mixed waste generation was reduced by $85 \%$, hazardous waste by $88 \%$, industrial waste by $86 \%$, and sanitary waste generation was reduced by $50 \%$, below the goal of $70 \%$. (Sanitary waste generation during fiscal year 2003 exceeded expectations due to construction of the RHWF, personnel staffing changes, and site initiatives to improve housekeeping.) to NYSDEC, the National Response Center, and other agencies as required. There were no reportable chemical spills during 2003.

Petroleum spills greater than five gallons - or of any amount that travel to waters of the state must be reported immediately to the NYSDEC spill hotline and entered in the WVDP's monthly $\log$. There were no reportable petroleum spills in 2003. Figure 1-6 (facing page) is a bar graph of immediately-reportable spills from 1996 to 2003. Prevention is the best means of protection against oil, chemical, and hazardous substance spills or releases. WVDP employees are trained in applicable standard operating procedures for equipment that they use, and best management practices have been developed that identify potential spill sources and preventive measures that will reduce the likelihood of releases. Spill training, notification, and reporting policies have also been developed to emphasize the responsibility of each employee to report spills immediately upon discovery. This first-line reporting helps to ensure that spills will be properly documented and mitigated in accordance with applicable regulations. 

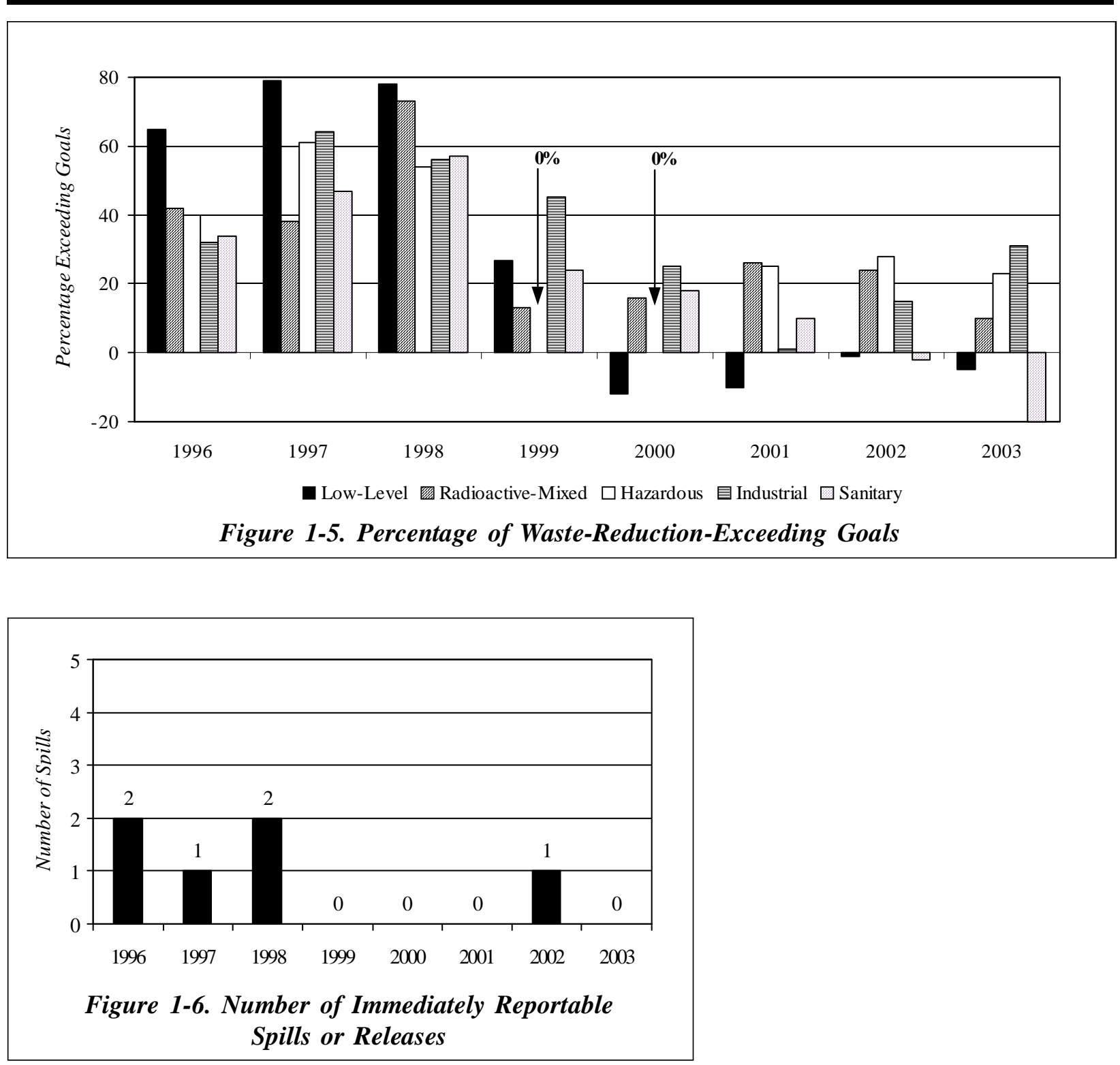
This page intentionally left blank

$$
1-20
$$




\section{ENVIRONMENTAL \\ RADIOLOGICAL \\ PROGRAM INFORMATION}

\section{Radiation in the Environment}

\section{Sources of Radiation}

Members of the public are routinely exposed to ionizing radiation from both natural and man-made sources. The National Council on Radiation Protection and Measurements (NCRP) Report 93 (1987b) estimates that an individual living in the United States (U.S.) receives an average annual effective dose equivalent of about 360 millirem (mrem) (3.6 millisieverts [mSv]). (Ionizing radiation and radiation effects are described on p. 2-2.)

While most of the radiation dose received by the general public is from natural background sources, man-made sources of radiation also contribute to the average dose. Such sources include diagnostic and therapeutic $x$-rays, nuclear medicine, fallout residues from atmospheric nuclear weapons tests, effluents from nuclear fuel-cycle facilities, and consumer products such as smoke detectors and cigarettes. (See Figure 2-1 on p. 2-3.)

Routine activities at the West Valley Demonstration Project (WVDP or Project) have the potential to release radioactive or hazardous substances that could affect the environment.

\section{Exposure Pathways}

The radionuclides present at the WVDP site are residues from the reprocessing of commercial nuclear fuel during the 1960s and early 1970s. A very small fraction of these radionuclides is released off-site during the year through ventilation systems and liquid discharges. These releases make a negligible contribution to the radiation dose to the surrounding population through several exposure pathways.

An exposure pathway consists of a way for a source of contamination or radiation to be transported by environmental media to a receptor where exposure to contaminants may occur. For example, a member of the public could be exposed to low concentrations of radioactive particulates carried by prevailing winds.

The potential pathways of exposure from Project emissions are inhalation of gases and particulates, ingestion of locally-grown food products, consumption of fish, beef, and venison, and exposure to external penetrating radiation emitted from contaminated materials. Table 2-1 (p. 2-4) summarizes the potential exposure pathways for the local

$2-1$ 


\section{Ionizing Radiation}

Radiation can be damaging if, in colliding with other matter, the alpha or beta particles or gamma rays knock electrons loose from the absorber atoms. This process is called ionization, and the radiation that produces it is referred to as ionizing radiation. Ionization changes an electrically neutral atom, in which the positively charged protons and the negatively charged electrons balance each other, into a charged atom called an ion. An ion can be either positively or negatively charged. Various kinds of ionizing radiation produce different degrees of damage.

\section{Potential Effects of Radiation}

Biological effects of radiation can be either somatic or genetic. Somatic effects are effects to radiation exposure that are limited to the exposed individual. For example, sufficiently high exposure to radiation can cause clouding of the lens of the eye or a decrease in white blood cells.

Radiation can also cause chromosomes to break or rearrange themselves or to join incorrectly with other chromosomes. These changes may produce genetic effects and may show up in future generations. Radiation-produced genetic defects and mutations in the offspring of an exposed parent, while not positively identified in humans, have been observed in some animal studies.

The effect of radiation depends on the amount absorbed within a given exposure time. The only observable effect of an instantaneous whole-body dose of $50 \mathrm{rem}(0.5 \mathrm{~Sv})$ might be a temporary reduction in white blood cell count. An instantaneous dose of 100-200 rem (1-2 Sv) might cause additional temporary effects, such as vomiting, but usually would have no long-lasting side effects. Assessing biological damage from low-level radiation is difficult because other factors can cause the same symptoms as radiation exposure. Moreover, the body is able to repair damage caused by low-level radiation. There have been no documented effects from exposures of less than 10 rem.

The effect most often associated with exposure to relatively high levels of radiation appears to be an increased risk of cancer. However, scientists have not been able to demonstrate with certainty that exposure to low-level radiation causes an increase in injurious biological effects, nor have they been able to determine if there is a level of radiation exposure below which there are no biological effects.

\section{Health Effects of Low-Level Radiation}

Radionuclides entering the body through air, water, or food are distributed in different organs of the body. For example, isotopes of iodine concentrate in the thyroid. Strontium, plutonium, and americium isotopes concentrate in the skeleton. When inhaled, particulate uranium and plutonium isotopes may remain in the lungs for a long period of time. Some radionuclides such as tritium, carbon-14, or cesium-137 are distributed uniformly throughout the body. Thus, depending on the radionuclide, some organs may receive quite different doses. Moreover, at the same dose levels, certain organs (such as the breast) are more prone to developing a fatal cancer than other organs (such as the thyroid).

Because of the uncertainty and difficulty in measuring the incidence of increased cancer resulting from exposure to ionizing radiation, to be conservative, a linear model is used to predict health risks from low levels of radiation. This model assumes that there is a risk associated with all dose levels even though the body may effectively repair damage incurred from low levels of alpha, beta, and gamma radiations.

$2-2$ 
off-site population and describes the rationale for including or excluding each pathway when calculating dose from the WVDP. For instance, drinking water is not considered as a pathway for exposure from the WVDP because surveys revealed that local residents do not use Cattaraugus Creek as a source of drinking water.

\section{Land Use Survey}

Periodic surveys of local residents provide information about local family sizes, sources of food, and gardening practices. In early 2003 , census information from calendar year (CY) 2000 was used to update population files used for dose assessment. Information from the most recent land use survey, conducted in early 2002 , was used to confirm the locations of the nearest residences. These parameters are required for computer models that are used for the annual dose assessments. (See the discussion of Dose Assessment Methodology [p. 2-25] for more information on calculation of dose to the public.)

\section{Dose to the Public}

Each year the potential radiological dose to the public that is attributable to operations and effluents from the WVDP is assessed to verify that no individual could credibly have received a dose exceeding the limits established by the regulatory agencies.

Estimated doses are compared directly with current radiation standards established by the U.S. Department of Energy (DOE) and the U.S. Environmental Protection Agency (EPA) for protection of the public. These values are also compared with the annual dose an average resident of the U.S. receives from natural background radiation and to doses reported in previous years for the Project. Figure 2-1 (below) shows the relative contribution to the annual dose in mrem from natural and man-made sources in comparison with the estimated calendar year 2003 maximum individual dose from the WVDP. (Units of dose measurement are explained in detail on p. 2-26.)

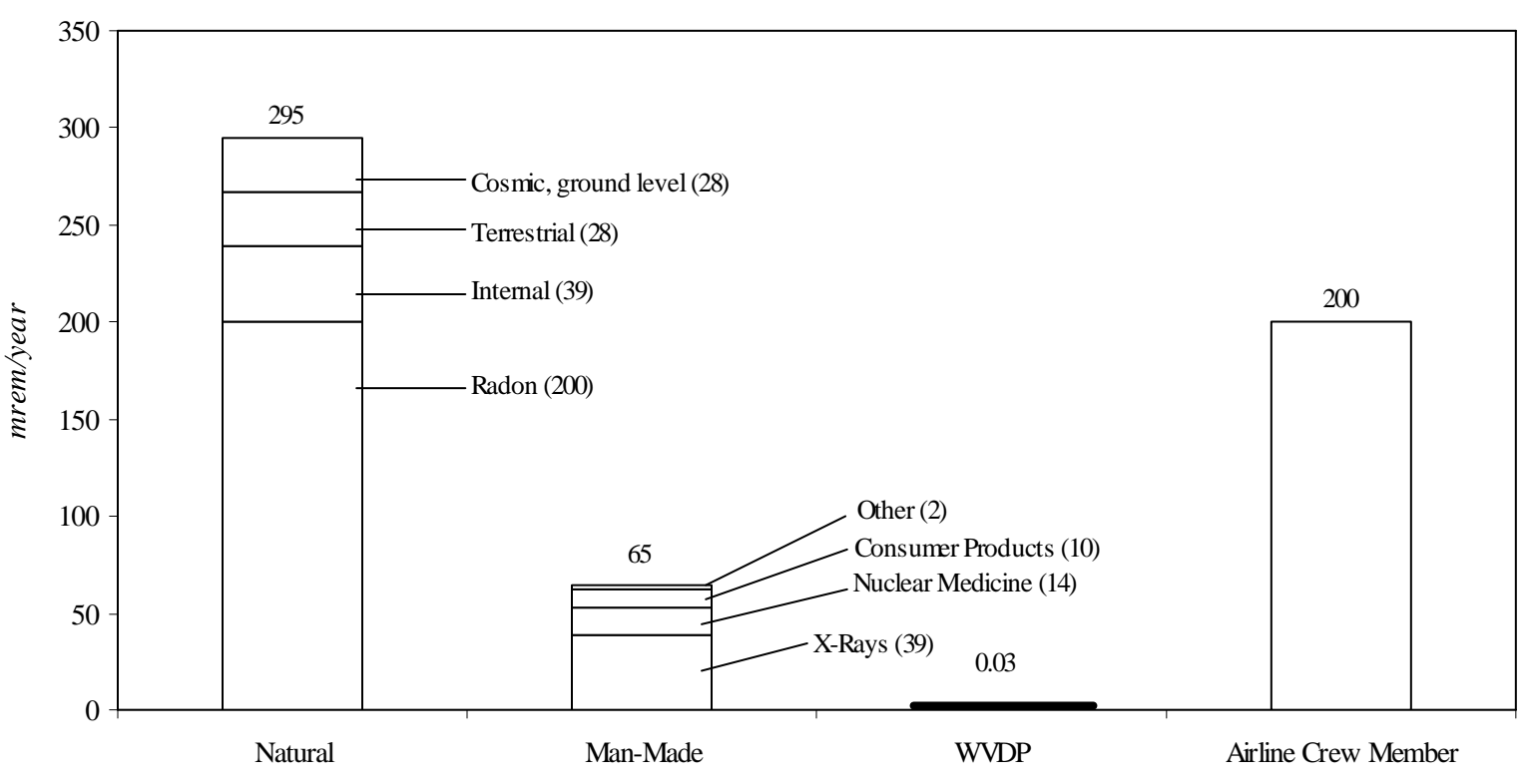

Figure 2-1. Comparison of Doses From Natural and Man-Made Sources to the Dose From 2003 WVDP Effluents

$2-3$ 
As can be seen in Figure 2-1, natural sources of radiation contribute $295 \mathrm{mrem}(2.95 \mathrm{mSv})$ and man-made sources contribute $65 \mathrm{mrem}(0.65 \mathrm{mSv})$ of the total annual U.S. average dose of $360 \mathrm{mrem}$ ( $3.60 \mathrm{mSv})$. In 2003, the WVDP contributed a very small amount $(0.034 \mathrm{mrem}[0.00034 \mathrm{mSv}])$ of the total annual man-made radiation dose to the maximally exposed off-site individual (MEOSI) residing near the WVDP. This is much less than the average dose received from using consumer products and is insignificant compared to the federal standard of 100 mrem allowed from any DOE site operations in a calendar year or the $295 \mathrm{mrem}$ received annually from natural sources. The dose from WVDP operations also is small compared to the estimated average additional dose an airline crew member typically receives from cosmic radiation (200-900 mrem/year).

The results of these conservative dose calculations demonstrate that the potential maximum dose to an off-site resident is well below permissible standards and is consistent with the as-low-asreasonably-achievable (ALARA) philosophy of radiation protection.

The following sections describe the monitoring program used to measure radiation in the environment near the WVDP and the methods used and results of dose assessments using these measurements. (See Routine Monitoring Program [p. 2-5] and Radiological Effluents and Dose [p. 2-25].)

\section{Table 2-1 \\ Potential Local Off-Site Exposure Pathways Under Existing WVDP Conditions}

\section{Exposure Pathway and Transporting Medium}

Inhalation: gases and particulates in air (included)

Ingestion: cultivated crops (included)

Ingestion: surface and groundwater (excluded)

Ingestion: fish, beef, venison, and milk (included)

External exposure: radiation emanating from particulates and gases directly from air or surface water or indirectly from surface deposition (included)

\section{Reason for Inclusion/Exclusion}

Off-site transport of contaminants from WVDP stacks or resuspended particulates from soils or water

Local agricultural products irrigated with potentially-contaminated surface or groundwater; foliar deposition and uptake of deposited airborne contaminants

No documented use of local surface water or downgradient groundwater wells as drinking water by local residents

Fish exposed to contaminants in water or sediments may be consumed; beef, venison, and milk consumption following deposition of transported airborne and surface water contaminants

Transport of air particulates and gases to offsite receptors; transport of contaminants in surface water and direct exposure during stream use and swimming

\section{$2-4$}




\section{Routine Monitoring Program}

\section{Radiological Sampling Program Overview}

Samples from environmental media listed in Table 2-1(p. 2-4) are collected each year and measured for radioactivity. Environmental sampling locations are shown on maps in Appendix A and the complete environmental monitoring schedule is summarized in Appendix $\mathrm{B}^{\mathrm{C}}$. This schedule provides information on monitoring and reporting requirements and the types and extent of sampling and monitoring at each location. An explanation of the codes that identify the sample medium and the specific sampling or monitoring location is also found in Appendix $B^{C}$. For example, a sample location code such as AFGRVAL indicates an air sample (A), collected off-site (F), at the Great Valley (GRVAL) sampling station. These codes are used throughout this report for ease of reference and to be consistent with the data reported in the appendices.

The food pathway is monitored by collecting samples of beef, milk, and produce at near-site and remote locations, samples of fish upstream and downstream of the site, and venison samples from near-site deer and deer taken from background locations. Stream sediments are sampled upstream and downstream of the WVDP, and both on-site groundwater and off-site drinking water are routinely sampled. Direct radiation is monitored on-site, at the perimeter of the site, in communities near the site, and at background locations.

The primary focus of the monitoring program, however, is on surface water and air pathways, as these are the principal means of transport of radionuclides from the WVDP.
Liquid and air effluents are monitored on-site by collecting samples at locations where radioactivity or other regulated substances are released or might be released. Release points include water effluent outfalls and plant ventilation stacks.

Surface water samples are collected within the Project area from ponds, swamps, seeps, and drainage channels that flow through the Western New York Nuclear Service Center (WNYNSC) and then off-site into Cattaraugus Creek.

Both surface water and air samples are collected at site perimeter locations where the highest offsite concentrations of transported radionuclides might be expected. Samples are also collected at remote locations to provide background concentration data for comparison with data from on-site and near-site samples.

\section{Overview of Water Effluent and Ambient Surface Water Monitoring}

The WVDP site is drained by several small streams. (See Surface Water Hydrology of the West Valley Site in Chapter 4 [p. 4-2] and Figs. A-2 [p. A-2] and A-3 [p. A-3].) Frank's Creek flows along and receives drainage from the south plateau. As Frank's Creek flows northward, it is joined by a tributary, Erdman Brook, which receives effluent from the low-level waste treatment facility (LLWTF). On the north plateau, beyond the Project fence line, the north and northeast swamp areas and Quarry Creek drain into Frank's Creek.

Frank's Creek continues across the WNYNSC and flows into Buttermilk Creek, which leaves the WNYNSC and enters Cattaraugus Creek. 
Liquid effluents from three locations (the LLWTF and the two natural drainages from the northeast and north swamps) are primary contributors to site dose estimates. (See Predicted Dose From Waterborne Releases [p. 2-29] for an estimate of the dose attributable to these waterborne effluents.)

\section{Low-Level Waste Treatment Facility Efflu-} ent. The discharge from the LLWTF through the lagoon 3 weir (WNSP001 on Fig. A-2 [p. A-2]) into Erdman Brook is the largest single source of radioactivity released to surface waters from the Project. There were seven batch releases totaling about 15.0 million gallons (56.7 million liters) in 2003 .

The total amounts of radioactivity from specific radionuclides in the lagoon 3 effluent are listed in Appendix $\mathrm{C}^{\mathrm{C}}$, Table $\mathrm{C}-2 \mathrm{~A}$. The annual average concentration of each radionuclide is divided by

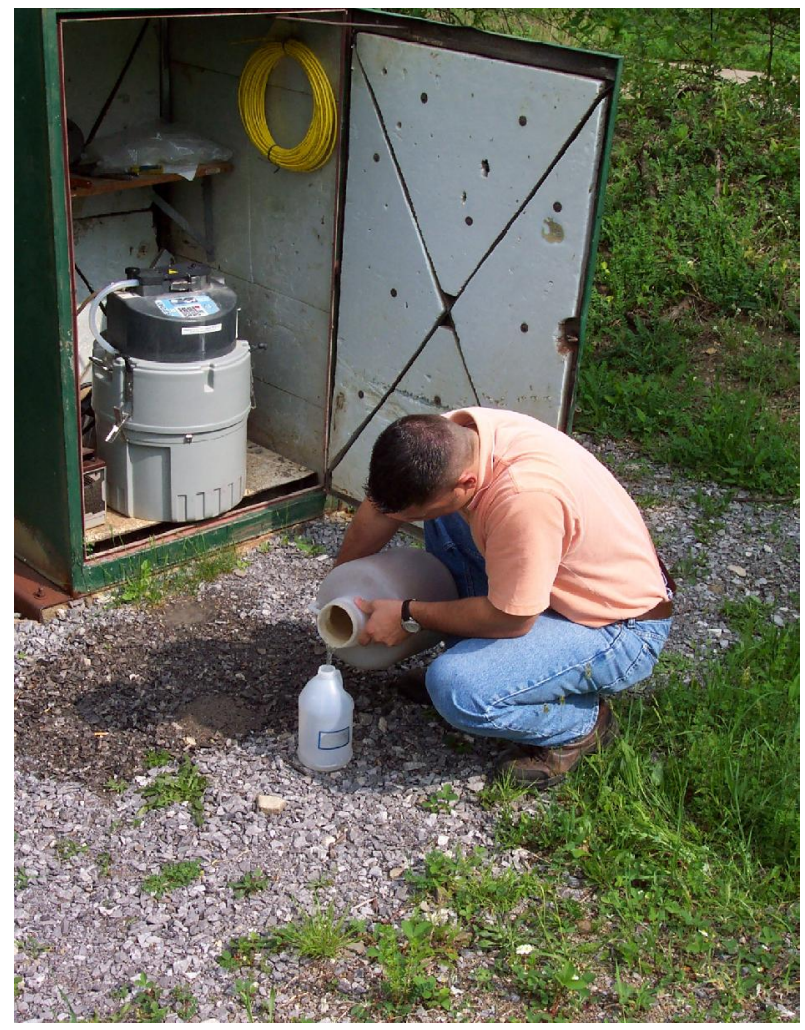

Collecting a Sample at a Stream Sampling Location its corresponding DOE derived concentration guide (DCG) to determine what percentage of the DCG was released. (DCGs are discussed on p. 1-5. DOE DCGs for radionuclides of interest at the WVDP are found in Appendix $\mathrm{K}^{\mathrm{C}}$, Table K-1.) As a DOE policy, the sum of the percentages calculated for all radionuclides released should not exceed $100 \%$.

The combined annual average of radionuclide concentrations from lagoon 3 effluent in 2003 was approximately $29.3 \%$ of the DCGs. (See Table $\mathrm{C}-2 \mathrm{~B}^{\mathrm{C}}$.) This is within the range of average concentrations over the last ten years (about 22\% to $47 \%$, averaging approximately $35 \%$ ).

The low-level waste treatment facility was designed to efficiently remove strontium- 90 and cesium-137, the more prevalent of the long-lived fission products in WVDP wastewaters. Other radionuclides, such as uranium isotopes, are also removed to a lesser extent. Uranium isotopes are found in WVDP liquid waste because they were present in the nuclear fuel that was once reprocessed at the site. Uranium-232, a major contributor to the combined DCG in lagoon 3 effluent, averaged about $11 \%$ of its DCG in 2003 . Variations in liquid effluent radionuclide ratios continue to reflect the dynamic nature of the waste streams being processed through the LLWTF.

Outfall WNSP001 and other selected discharge points are also monitored for nonradiological parameters under the New York State Pollutant Discharge Elimination System program. See Chapter 3, Environmental Nonradiological Program Information.

Northeast Swamp and North Swamp Drainage. The northeast swamp sampling location (WNSWAMP) is used to monitor surface water drainage from the northeastern portion of the site's north plateau. The north swamp sampling point (WNSW74A) is used to monitor drainage to

$2-6$ 
Quarry Creek from the northern portion of the plateau. (See Fig. A-2 [p. A-2].) These two drainages conduct surface water and emergent groundwater off-site.

Gross alpha and gross beta indicator results from WNSW74A and WNSWAMP are compared with those from other surface water locations in Tables 2-2 and 2-3 (p. 2-8). Data summaries from these two locations are found in Tables $\mathrm{C}-3 \mathrm{C}$ and $\mathrm{C}-3 \mathrm{D}^{\mathrm{C}}$. Elevated gross beta concentrations at WNSWAMP, first noted in 1993, continued to be elevated through 2003. Gross beta activity at this location is largely attributable to strontium-90. (See Special Groundwater Monitoring [p. 4-12].) Concentrations of all radioisotopic parameters detected at the two locations, other than strontium-90 at WNSWAMP, were less than $1 \%$ of the respective DCGs for these parameters.

Strontium-90 concentrations at WNSWAMP in 2003 averaged $7.08 \mathrm{E}-07 \mu \mathrm{Ci} / \mathrm{mL}(26.2 \mathrm{~Bq} / \mathrm{L})$, less than one-half of the average result in 2002. (See Chapter 4, Fig. 4-4 [p. 4-14] for a graph of annualized average strontium-90 concentrations at WNSWAMP in 2003.) Even though waters with elevated strontium-90 concentrations drain from WNSWAMP into Frank's Creek, concentrations in waters collected from Cattaraugus Creek downstream at the first point of access by the general public (WFFELBR) were not significantly different from those at background location WFBIGBR, upstream of the location where site drainage enters Cattaraugus Creek. (See Off-Site Surface Water [p. 2-11].)

\section{Other North Plateau Surface Waters and Water Effluent. Discharges from WNSP001 and WNSP007 leave the site through point WNSP006. Radiological results of analyses from WNSP006 and WNSP007 are summarized in Table C-4C and Table C-2M ${ }^{\mathrm{C}}$, respectively.}

WNSP006. WNSP006 is located more than 2.5 miles $(4.0 \mathrm{~km})$ upstream from Thomas Corners Road, the last monitoring point before Buttermilk Creek leaves the WNYNSC and before the public has access to the creek waters.

Gross alpha and gross beta data from location WNSP006 are noted in Tables 2-2 and 2-3 (p. 2-8) for comparison with sampling results from other surface water locations. As shown in Table 2-3, gross beta results for WNSP006 are generally higher than those at off-site locations. Figure 2-2 (p. 2-9) shows the ten-year trends of gross alpha, gross beta, and tritium concentrations at WNSP006. Fluctuations over this period reflect variable concentrations in treated WVDP liquid effluent being released from the site.

Many of the constituents detected in effluent from WNSP001 were not detectable a short distance downstream at location WNSP006. Except for strontium-90, all radionuclides detected were found at concentrations lower than $1 \%$ of the respective DCG. The highest strontium-90 concentration at WNSP006 in 2003 was $2.93 \mathrm{E}-08 \mu \mathrm{Ci} / \mathrm{mL}(1.08$ $\mathrm{Bq} / \mathrm{L})$, which is less than $3 \%$ of its DCG (1E-06 $\mu \mathrm{Ci} / \mathrm{mL})$.

Average concentrations for the radiological parameters detected at WNSP007 in 2003 were also at small percentages of their respective DCGs.

WNSP005 and WNCOOLW. Sampling point WNSP005 monitors overland drainage and groundwater seepage on the east side of the main plant and WNCOOLW monitors coolant water from a contained basin within the facility. Summaries of radiological data for WNSP005 and WNCOOLW are found in Tables C-3A and $\mathrm{C}-3 \mathrm{H}^{\mathrm{C}}$.

Average gross alpha, tritium, and cesium-137 concentrations for both locations were below detection levels in 2003. Although gross beta and 
Table 2-2

\section{Gross Alpha Concentrations at Surface Water Sampling Locations}

\author{
Location \\ Number of \\ Samples
}

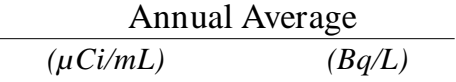

Off-Site

$\begin{array}{llll}\text { WFBCBKG } & 12 & <5.80 \mathrm{E}-10 \text { to } 1.08 \mathrm{E}-09 & <2.15 \mathrm{E}-02 \text { to } 3.98 \mathrm{E}-02 \\ \text { WFBCTCB } & 12 & <4.90 \mathrm{E}-10 \text { to } 1.44 \mathrm{E}-09 & <1.81 \mathrm{E}-02 \text { to } 5.34 \mathrm{E}-02 \\ \text { WFBIGBR } & 12 & <7.06 \mathrm{E}-10 \text { to } 1.29 \mathrm{E}-09 & <2.61 \mathrm{E}-02 \text { to } 4.77 \mathrm{E}-02 \\ \text { WFFELBR } & 12 & <7.67 \mathrm{E}-10 \text { to } 2.55 \mathrm{E}-09 & <2.84 \mathrm{E}-02 \text { to } 9.44 \mathrm{E}-02\end{array}$

On-Site

$\begin{array}{llll}\text { WNNDADR } & 12 & <9.16 \mathrm{E}-10 \text { to } 1.24 \mathrm{E}-09 & <3.39 \mathrm{E}-02 \text { to } 4.59 \mathrm{E}-02 \\ \text { WNSP006 } & 52 & <8.59 \mathrm{E}-10 \text { to } 8.05 \mathrm{E}-09 & <3.18 \mathrm{E}-02 \text { to } 2.98 \mathrm{E}-01 \\ \text { WNSW74A } & 52 & <1.08 \mathrm{E}-09 \text { to } 3.26 \mathrm{E}-09 & <3.98 \mathrm{E}-02 \text { to } 1.21 \mathrm{E}-01 \\ \text { WNSWAMP } & 52 & <1.26 \mathrm{E}-09 \text { to } 2.67 \mathrm{E}-09 & <4.66 \mathrm{E}-02 \text { to } 9.87 \mathrm{E}-02\end{array}$

$4.87 \pm 6.81 \mathrm{E}-10$

$5.75 \pm 7.62 \mathrm{E}-10$

$0.24 \pm 1.03 \mathrm{E}-09$

$0.92 \pm 1.17 \mathrm{E}-09$

$1.80 \pm 2.52 \mathrm{E}-02$

$2.13+2.82 \mathrm{E}-02$

$0.88 \pm 3.82 \mathrm{E}-02$

$3.40 \pm 4.32 \mathrm{E}-02$ $\begin{array}{rr}0.86 \pm 1.34 \mathrm{E}-09 & 3.20 \pm 4.97 \mathrm{E}-02 \\ 0.94 \pm 1.44 \mathrm{E}-09 & 3.49 \pm 5.32 \mathrm{E}-02 \\ -0.17 \pm 3.19 \mathrm{E}-09 & -0.06 \pm 1.18 \mathrm{E}-01 \\ 0.20 \pm 2.11 \mathrm{E}-09 & 0.74 \pm 7.79 \mathrm{E}-02\end{array}$

Table 2-3

\section{Gross Beta Concentrations at Surface Water Sampling Locations}

Location $\quad \begin{gathered}\text { Number of } \\ \text { Samples }\end{gathered}$

Off-Site

$\begin{array}{lrrr}\text { WFBCBKG } & 12 & <1.23 \mathrm{E}-09 \text { to } 4.76 \mathrm{E}-09 & <4.54 \mathrm{E}-02 \text { to } 1.76 \mathrm{E}-01 \\ \text { WFBCTCB } & 12 & 6.10 \mathrm{E}-09 \text { to } 9.98 \mathrm{E}-09 & 2.26 \mathrm{E}-01 \text { to } 3.69 \mathrm{E}-01 \\ \text { WFBIGBR } & 12 & <1.24 \mathrm{E}-09 \text { to } 6.00 \mathrm{E}-09 & <4.57 \mathrm{E}-02 \text { to } 2.22 \mathrm{E}-01 \\ \text { WFFELBR } & 12 & <1.88 \mathrm{E}-09 \text { to } 7.10 \mathrm{E}-09 & <6.96 \mathrm{E}-02 \text { to } 2.63 \mathrm{E}-01 \\ & & & \\ \text { On-Site } & & & \\ & & & \\ \text { WNNDADR } & 12 & 1.50 \mathrm{E}-07 \text { to } 2.26 \mathrm{E}-07 & 5.53 \mathrm{E}+00 \text { to } 8.37 \mathrm{E}+00 \\ \text { WNSP006 } & 52 & 1.48 \mathrm{E}-08 \text { to } 1.08 \mathrm{E}-07 & 5.48 \mathrm{E}-01 \text { to } 3.98 \mathrm{E}+00 \\ \text { WNSW74A } & 52 & 7.43 \mathrm{E}-09 \text { to } 2.87 \mathrm{E}-08 & 2.75 \mathrm{E}-01 \text { to } 1.06 \mathrm{E}+00 \\ \text { WNSWAMP } & 52 & 5.85 \mathrm{E}-08 \text { to } 3.83 \mathrm{E}-06 & 2.16 \mathrm{E}+00 \text { to } 1.42 \mathrm{E}+02\end{array}$

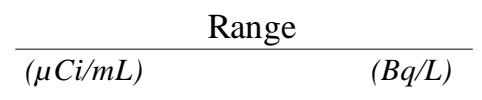

$2.16 \mathrm{E}+00$ to $1.42 \mathrm{E}+02$

\author{
Annual Average \\ $(\mu \mathrm{Ci} / m L) \quad(B q / L)$
}

$\begin{array}{ll}2.36 \pm 1.21 \mathrm{E}-09 & 8.73 \pm 4.49 \mathrm{E}-02 \\ 7.84 \pm 1.53 \mathrm{E}-09 & 2.90 \pm 0.57 \mathrm{E}-01 \\ 2.49+2.00 \mathrm{E}-09 & 9.21 \pm 7.39 \mathrm{E}-02 \\ 3.77 \pm 1.78 \mathrm{E}-09 & 1.40 \pm 0.66 \mathrm{E}-01\end{array}$

$1.83 \pm 0.06 \mathrm{E}-07 \quad 6.78 \pm 0.23 \mathrm{E}+00$

$3.82 \pm 0.38 \mathrm{E}-08 \quad 1.41 \pm 0.14 \mathrm{E}+00$

$1.38 \pm 0.50 \mathrm{E}-08 \quad 5.11 \pm 1.84 \mathrm{E}-01$

$1.44 \pm 0.02 \mathrm{E}-06 \quad 5.34 \pm 0.07 \mathrm{E}+01$ 


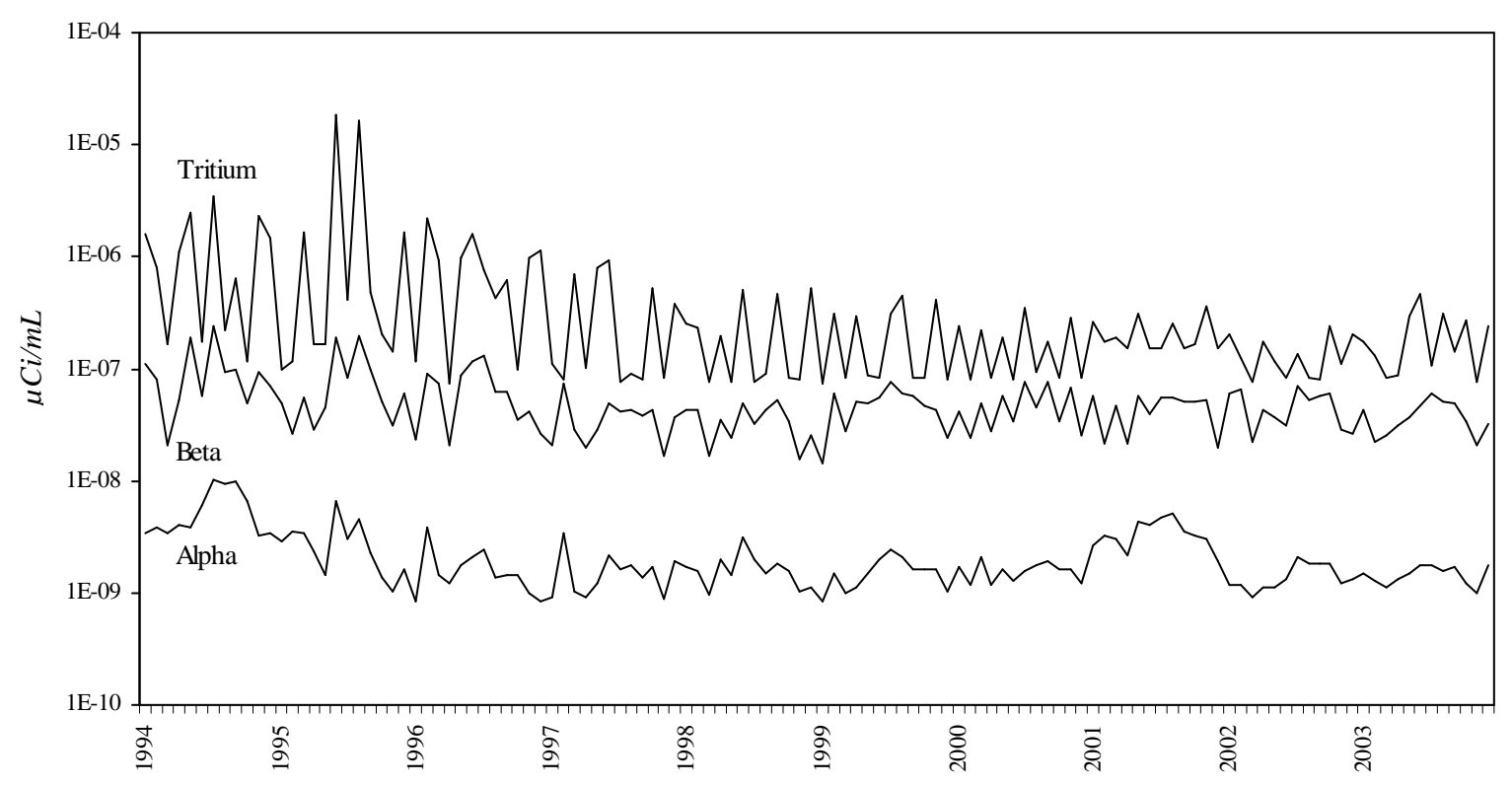

Figure 2-2. Ten-Year Trends of Gross Alpha, Gross Beta, and Tritium Concentrations at Sampling Location WNSP006

strontium-90 were detected at both locations, results were far below the strontium-90 DCG.

\section{South Plateau Surface Water and NDA Inter-} ceptor Trench. Two inactive underground radioactive waste disposal areas, the Nuclear Regulatory Commission (NRC)-Licensed Disposal Area (NDA) and the State-Licensed Disposal Area (SDA), lie on the south plateau of the site. (The SDA is managed by the New York State Energy Research and Development Authority [NYSERDA].) The drum cell, an aboveground structure used to store approximately 20,000 drums of processed low-level radioactive waste, is located nearby. Surface waters, which flow from the south to the north, are routinely monitored at several points around these areas. (See Fig. A-2 [p. A-2].) In addition to the routine samples collected by the WVDP, samples are collected and analyzed by the New York State Department of Health (NYSDOH) at the two stream sampling points that receive drainage from the south plateau, WNFRC67 and WNERB53.
NRC-Licensed Disposal Area. Sampling point WNNDATR is a sump at the lowest point in the collection trench system that intercepts groundwater from the northeastern and northwestern sides of the NDA. Water collected underground at this location is pumped to the LLWTF for treatment prior to discharge at outfall WNSP001. (See p. 1-11 for an explanation of the NDA Interceptor Trench and Pretreatment System.) If contamination were to migrate through the NDA, it would most likely be first detected in samples from WNNDATR.

Surface water drainage downstream of the NDA is monitored at WNNDADR. Further downstream, water from sampling point WNERB53 in Erdman Brook, which represents surface waters from the NDA before they join with drainage from the main plant and lagoon areas, is also monitored. Some drainage from western and northwestern portions of the SDA also passes through sampling points WNNDADR and WNERB53. 
Annual concentrations from WNNDATR are listed in Table $\mathrm{C}-3 \mathrm{~F}^{\mathrm{C}}$ and quarterly results are listed under "NDATR" in Tables E-4, E-11, and E-13 in Appendix $E^{C}$. Results from WNNDADR, surface water drainage downstream of the NDA, are in Table C-3E $\mathrm{E}^{\mathrm{C}}$, and results from WNERB53, the sampling location even further downstream of the NDA, are in Table C-4E ${ }^{C}$.

Gross alpha and gross beta results from WNNDADR are included in Tables 2-2 and 2-3 (p. 2-8) for comparison with results from other surface water locations. In addition, ten-year trends of gross alpha, gross beta, and tritium concentrations at WNNDADR are plotted in Figure 2-3 (below). Allowing for seasonal variations, gross alpha and gross beta concentrations have been relatively stable over this time-period, whereas tritium concentrations have been decreasing.

No gross alpha or cesium-137 activity was detected at WNNDATR, WNNDADR, and WNERB53 in 2003. No iodine-129 was detected at WNNDATR and WNNDADR in 2003. (Samples from WNERB53 are not analyzed for iodine-129.) Strontium-90 and associated gross beta results at all three locations were elevated with respect to background (WFBCBKG), but all were far below the strontium-90 DCG. Residual soil contamination from past waste burial activities is thought to be the source of the strontium-90 activity. The NDA is thought to be the predominant source of gross beta activity observed at WNNDATR.

Although tritium concentrations at WNNDATR and WNNDADR were also elevated with respect to background values (those from WNERB53 were not), the maximum concentrations from both WNNDATR and WNNDADR were less than $1 \%$ of the DCG for tritium in water $(2 \mathrm{E}-03 \mu \mathrm{Ci} / \mathrm{mL})$. Allowing for seasonal variations, tritium concentrations seem to be generally decreasing at both WNNDATR and WNNDADR. Since the halflife of tritium is slightly longer than 12 years, decreasing tritium concentrations may be partially attributable to radioactive decay.

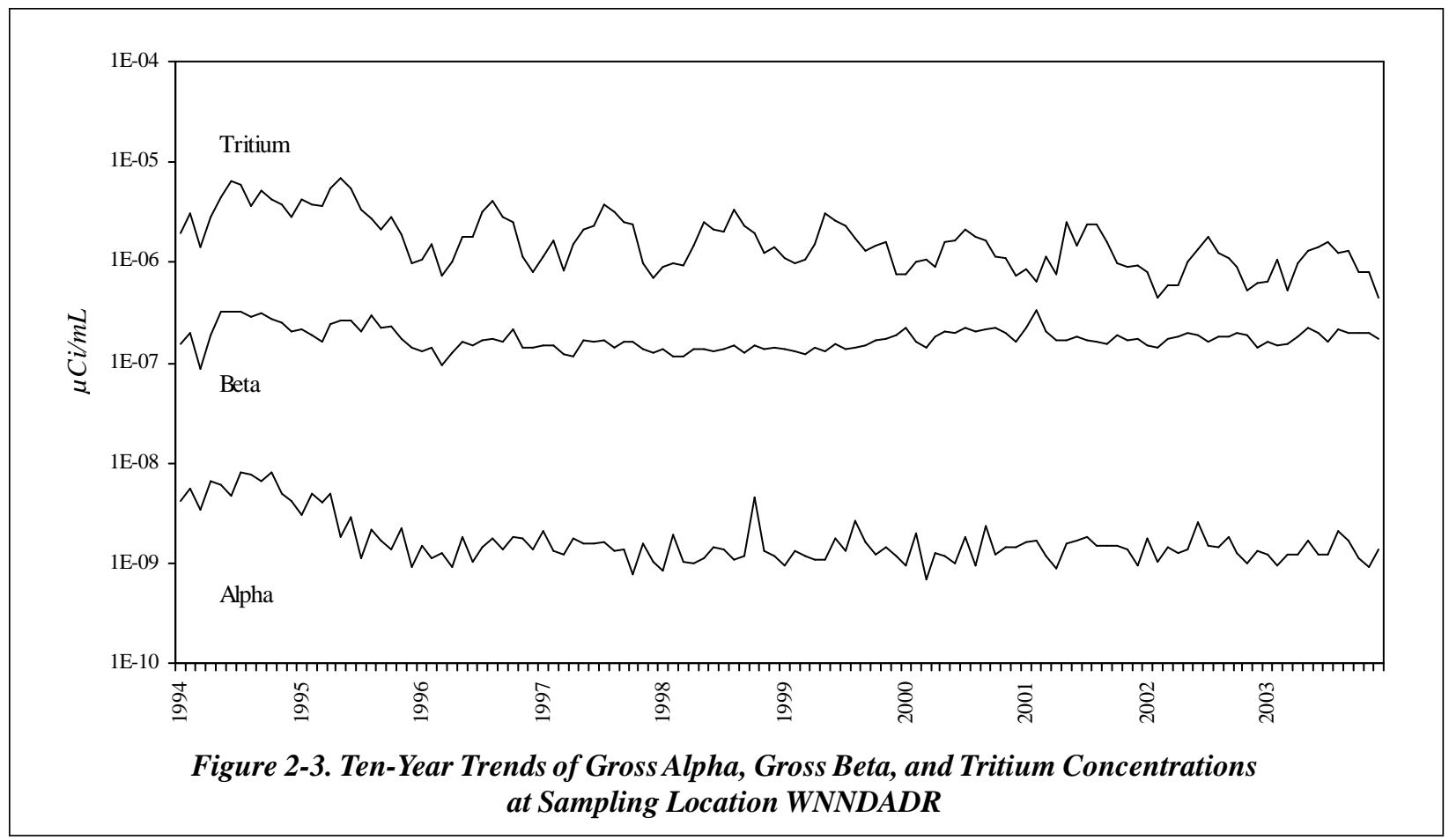


New York State-Licensed Disposal Area. Point WNSDADR is used to monitor drainage from trench covers on the southwestern area of the SDA. Immediately south of the SDA, and upstream of WNSDADR, sampling point WNDCELD is used to monitor surface drainage from the area around the drum cell. (See Fig. A-2 [p. A-2].) To the northeast, sampling point WNFRC67, in Frank's Creek, is used to monitor drainage downstream of the drum cell and the eastern and southern borders of the SDA. A summary of results from WNSDADR, WNDCELD, and WNFRC67 are in Tables C-3G, C-4G, and C$4 \mathrm{~F}^{\mathrm{C}}$, respectively.

Tritium results at WNSDADR were elevated with respect to background measurements at WFBCBKG. Even so, the maximum result was less than $1 \%$ of the tritium DCG $(2 \mathrm{E}-03 \mu \mathrm{Ci} / \mathrm{mL})$. All other radiological results in calendar year 2003 at sampling points WNSDADR, WNDCELD, and WNFRC67 were statistically indistinguishable from background.

Ponded (Standing) Waters. Four ponds near the site were tested in 2003. For comparison, a background pond 8.8 miles $(14.1 \mathrm{~km})$ north of the Project was also tested. (See Figs. A-2, A-3, and A-13 [pp. A-2, A-3, and A-13] for the locations of the five ponds and Table $\mathrm{C}-4 \mathrm{H}^{\mathrm{C}}$ for a summary of sampling results.) All radiological results were statistically the same as concentrations in the background pond.

Off-Site Surface Water. Samples of surface water are collected at four off-site locations, two on Buttermilk Creek and two on Cattaraugus Creek. Offsite sampling locations are shown on Fig. A-3 (p. A-3). Tables 2-2 and 2-3 (p. 2-8) list the ranges and annual averages for gross alpha and gross beta activity at off-site surface water locations, which may be compared with data from on-site locations.
Fox Valley Road and Thomas Corners Bridge Sampling Locations. Buttermilk Creek is the major surface drainage from the WNYNSC. One monitoring station is located upstream of the WVDP at Fox Valley Road (WFBCBKG) and one is located downstream at Thomas Corners Bridge (WFBCTCB). The Thomas Corners Bridge sampling location is upstream of Buttermilk Creek's confluence with Cattaraugus Creek. This sampling location represents an important intercept point in the pathway to humans because dairy cattle have access to the water here. Table $\mathrm{C}-4 \mathrm{~B}^{\mathrm{C}}$ lists radionuclide concentrations at background location WFBCBKG compared with those downstream at WFBCTCB.

Gross alpha, tritium, technetium-99, and cesium137 concentrations at Thomas Corners Bridge were statistically indistinguishable from background concentrations in 2003. Gross beta and strontium-90 concentrations at Thomas Corners Bridge, although detected at less than $1 \%$ of the strontium90 DCG, were elevated in comparison to background. These elevated concentrations may be attributed to small amounts of radioactivity moving from the site, principally during periods of lagoon discharge, via Frank's Creek.

Cattaraugus Creek at Felton Bridge and Bigelow Bridge Sampling Locations. Radiological data from samples taken at Felton Bridge (WFFELBR), downstream of the point where Buttermilk Creek enters Cattaraugus Creek, and from Bigelow Bridge (WFBIGBR), upstream of this point, are summarized in Table $\mathrm{C}-4 \mathrm{~A}^{\mathrm{C}}$.

No statistically-significant differences were noted between upstream and downstream concentrations of gross alpha, tritium, strontium-90, technetium-99, and cesium-137. Gross beta concentrations at Felton Bridge (WFFELBR), however, were higher than background concentrations, although detected at less than $1 \%$ of the 
DOE DCG for strontium-90. Figure 2-4 (below) shows gross alpha, gross beta, and tritium results over the past ten years at Felton Bridge. For the most part, tritium concentrations represent detection limits and not detected radioactivity. (See detection limit [p. GLO-3].) Taking into account seasonal fluctuations, gross beta activity appears to have remained relatively constant at this location over the last decade.

\section{Overview of Drinking Water Monitoring}

Drinking water (potable water) is sampled both off-site (near the WVDP) and on-site. Off-site drinking water samples are taken from wells that represent the nearest unrestricted use of groundwater near the Project; none of these wells draw from groundwater units underlying the site. Drinking water and utility water for the Project are drawn from two on-site surface water reservoirs.
On-Site Tap Water. On-site drinking water sources were monitored for radionuclides at four locations: the entry point at the utility room (WNDNKUR), the Environmental Laboratory (WNDNKEL), the maintenance shop (WNDNKMS), and the main plant (WNDNKMP). No differences were noted between control values at the utility room and those from other site locations. (See Tables C-5B through C-5F ${ }^{C}$.)

Off-Site Drinking Water Wells. Nine off-site private, residential groundwater wells between 0.9 miles $(1.5 \mathrm{~km})$ and 4.3 miles $(7 \mathrm{~km})$ from the facility (WFWEL01 through WFWEL05 and WFWEL07 through WFWEL10) were sampled for radiological parameters in 2003. A tenth private well (WFWEL06), 18 miles (29 km) south of the site, provides a background sample. Sampling locations are shown in Figures A-9, A-12, and A-13 (pp. A-9, A-12, and A-13). Results are presented in Table C$5 \mathrm{~A}^{\mathrm{C}}$. Radiological results in 2003 were statistically indistinguishable from background.

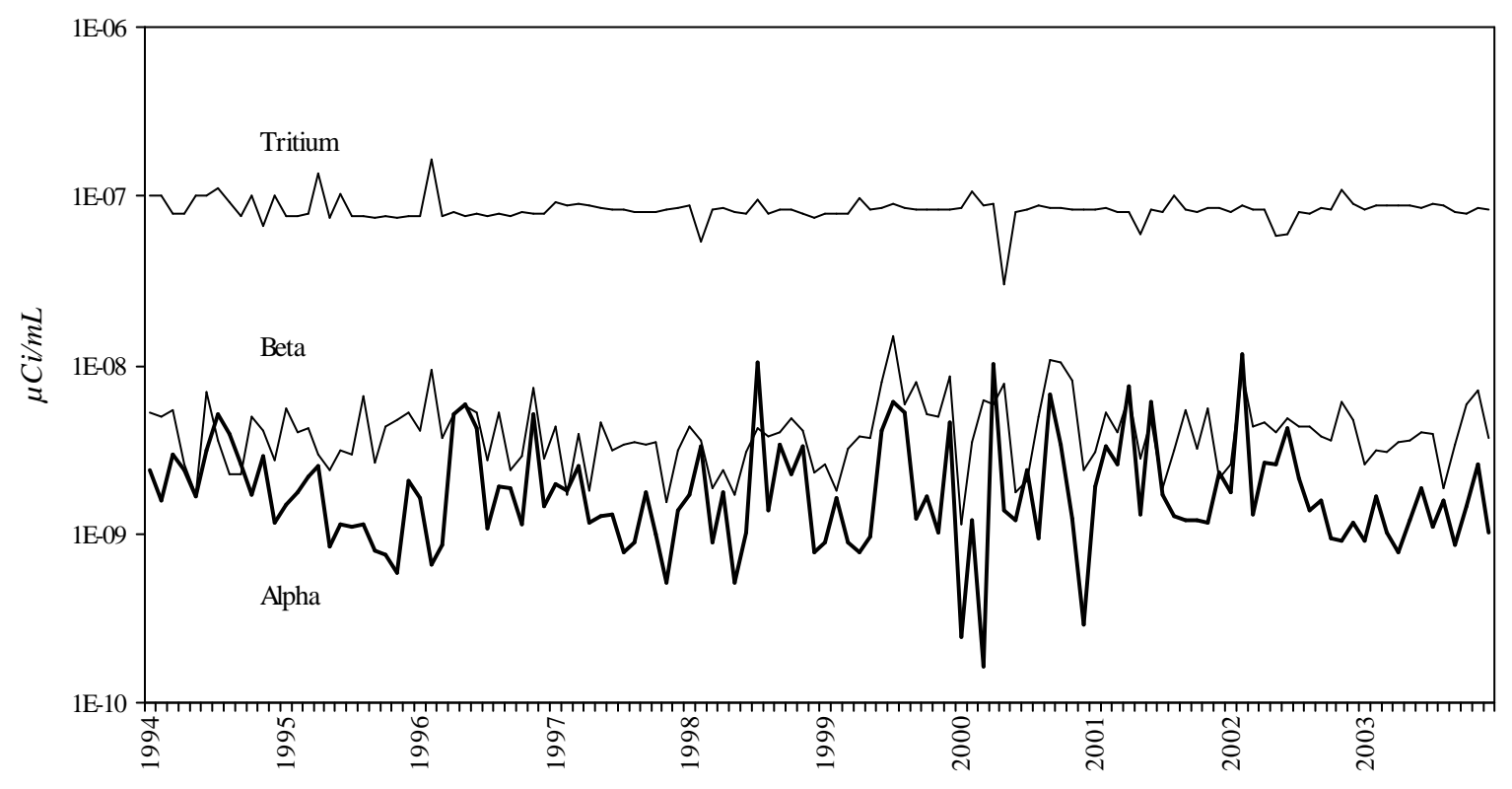

Figure 2-4. Ten-Year Trends of Gross Alpha, Gross Beta, and Tritium Concentrations at Sampling Location WFFELBR 


\section{Overview of Sediment Monitoring}

Particulate matter in streams can adsorb radiological constituents in liquid effluents, settle on the bottom of the stream as sediment, and subsequently be eroded or resuspended, especially during periods of high stream flow. These resuspended sediments may provide a pathway for radiological constituents to reach humans either directly via exposure or indirectly through the food pathway.

On-Site Sediments. Sediments are collected at three on-site surface water sampling points where liquid effluents leaving the site are most likely to be radiologically contaminated: Frank's Creek where it leaves the security fence (SNSP006), the north swamp drainage swale (SNSW74A), and the northeast swamp drainage swale (SNSWAMP). Figure A-2 (p. A-2) shows the onsite sediment sampling locations. (Note that swamp sediment samples may be partially composed of soils.) Results from radiological analyses of these samples are listed in Appendix $\mathrm{G}^{\mathrm{C}}$, Tables G-2A through G-2C. As in previous years, gross beta, strontium-90, cesium-137, and certain alpha isotopic results higher than background were noted.

Off-Site Sediments. Sediments are collected offsite at three locations downstream of the WVDP: Buttermilk Creek at Thomas Corners Road (SFTCSED), Cattaraugus Creek at Felton Bridge (SFCCSED), and Cattaraugus Creek at the Springville dam (SFSDSED). The first two points are at water sampling locations. The other is behind the Springville dam where significant sediments accumulate, including sediments that may have adsorbed radionuclides from the site. Locations upstream of waters receiving effluents from the WVDP are Buttermilk Creek at Fox Valley Road (SFBCSED) and Cattaraugus Creek at Bigelow Bridge (SFBISED). The two upstream locations provide background data for comparison with downstream points. Figure A-3 (p. A-3) shows the off-site sediment sampling locations.

Most radiological results from downstream sediment sampling sites were statistically the same as

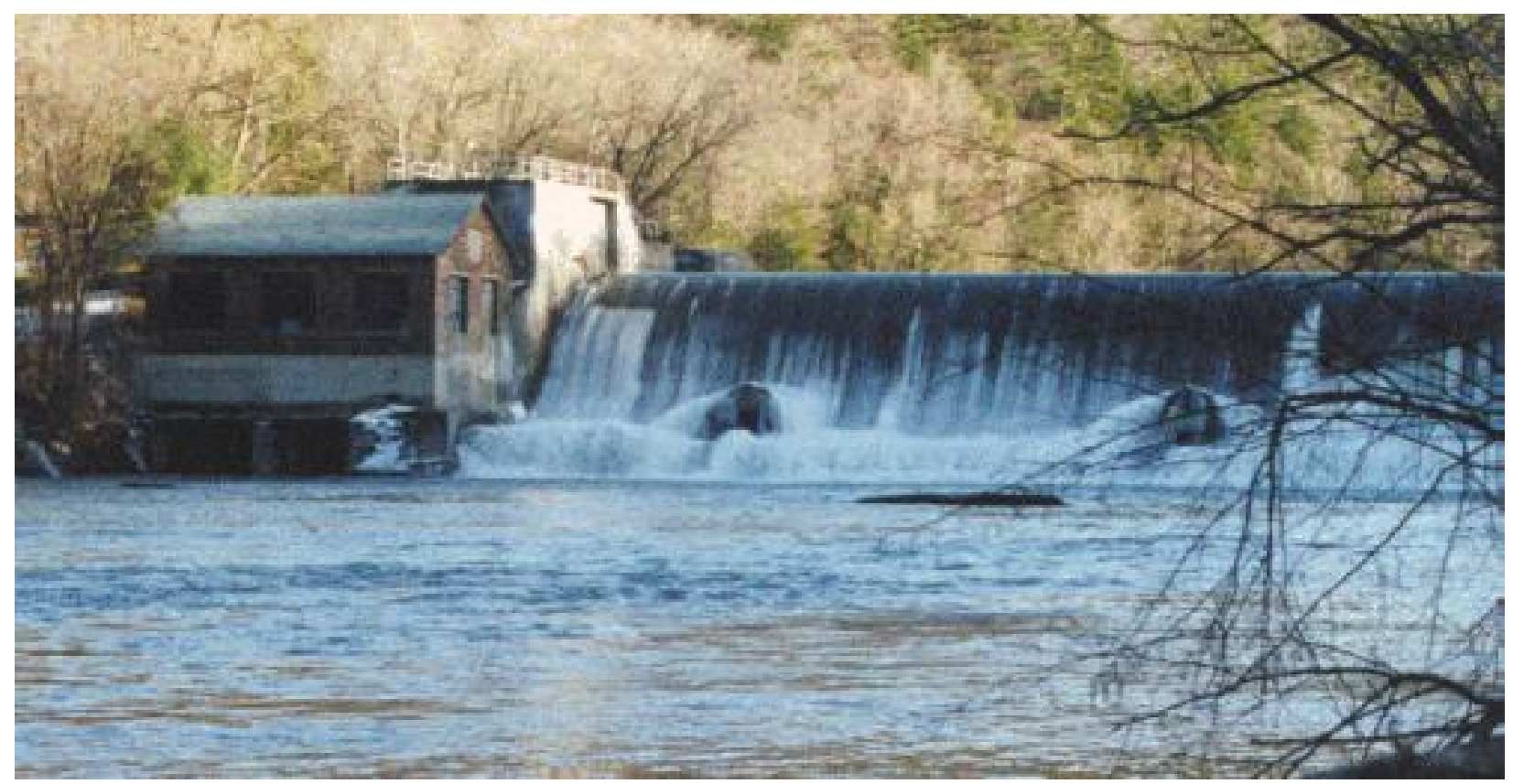

Springville Dam on Cattaraugus Creek

$2-13$ 
those from background locations. However, sediments from the sampling locations downstream of the site contained cesium-137 concentrations statistically higher than background. A comparison of annual averaged cesium- 137 concentrations from 1994 through 2003 for the five off-site sampling locations is illustrated in Figure 2-5 (below). As the figure indicates, cesium-137 concentrations are relatively stable at the two background locations (SFBCSED and SFBISED) and are generally higher at the three locations downstream of the WVDP (SFTCSED, SFCCSED, and SFSDSED). As first noted in the 1999 Annual Site Environmental Report, the level of cesium-137 behind the Springville dam (SFSDSED) were noticeably lower in 1998 and 1999. This may have been due to scouring of sediments during the flood of June 28, 1998. In 2000, the cesium-137 concentrations returned to pre-flood levels.

Although cesium-137 activity historically is elevated in downstream Cattaraugus Creek sediments relative to upstream sediments (Table G- $2 \mathrm{E}^{\mathrm{C}}$ ), the lev- els are far lower than those of naturally-occurring gamma emitters, such as potassium-40. (See Fig. 2-6 [facing page], which is a graphic comparison of cesium-137 to potassium-40 at the downstream location nearest the WVDP, Buttermilk Creek at Thomas Corners Road - SFTCSED.)

\section{Overview of Air Emission and Ambient Air Monitoring}

Permits obtained from the EPA allow air containing small amounts of radioactivity to be released from plant ventilation stacks during normal operations. The air released must meet criteria specified in the National Emission Standards for Hazardous Air Pollutants (NESHAP) regulations to ensure that the environment and the public's health and safety are protected. Dose-based comparisons of WVDP emissions against NESHAP criteria are presented later in this chapter. (See Predicted Dose From Airborne Emissions [p. 2-27].)

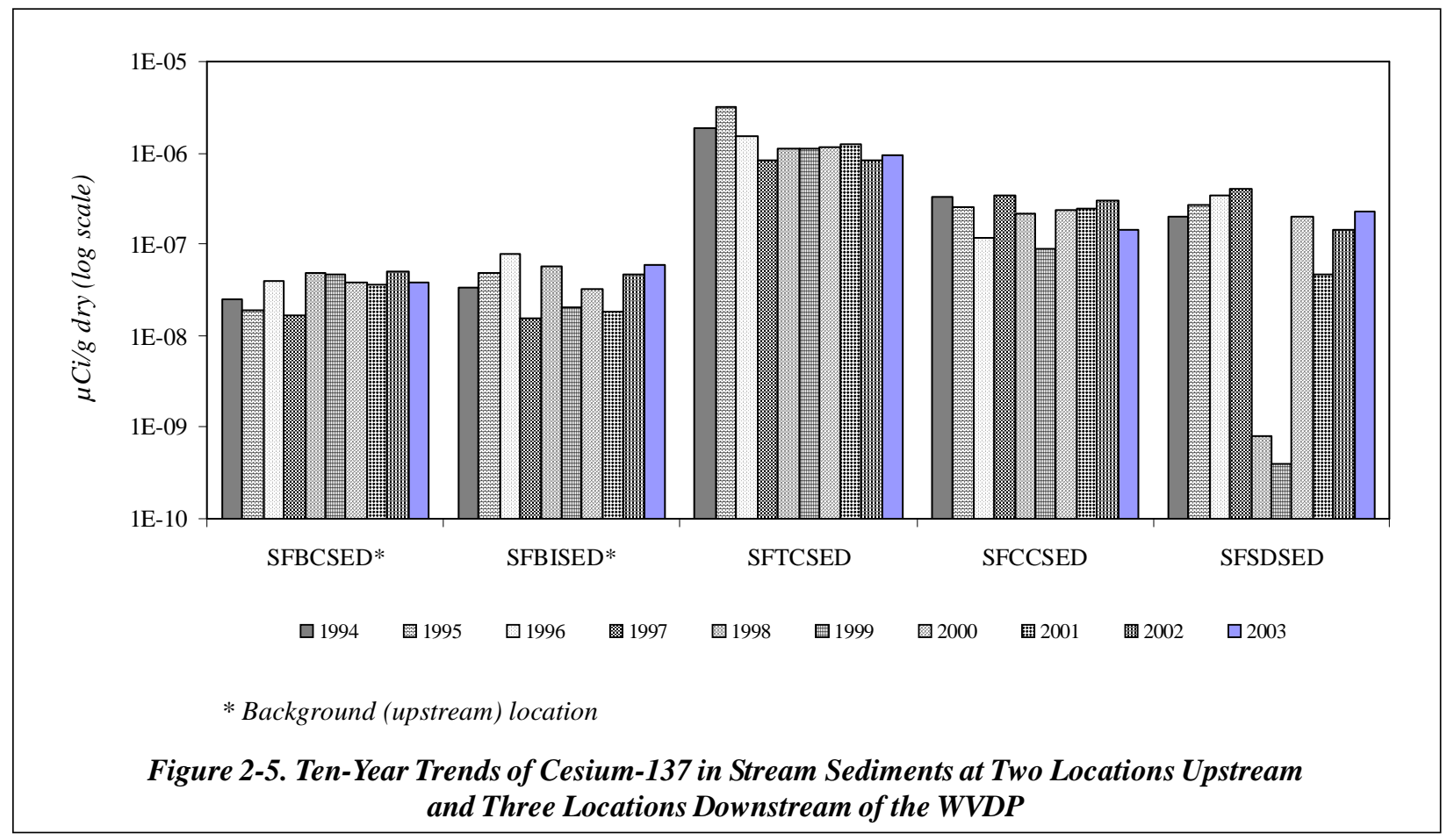




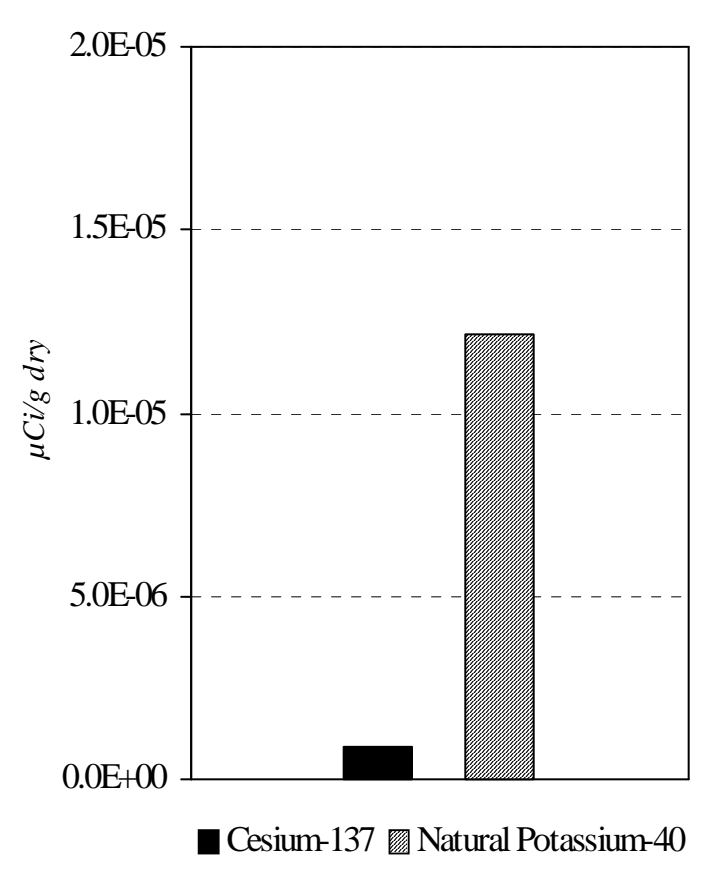

Figure 2-6. Comparison of Cesium-137

With Naturally-Occurring Potassium-40 Concentrations in 2003 at Downstream Sampling Location SFTCSED

Unlike NESHAP dose criteria, the DOE DCGs are expressed in units of $\mu \mathrm{Ci} / \mathrm{mL}$ and therefore can be directly compared with concentrations of radionuclides in WVDP air emissions. DOE standards and DCGs for radionuclides of interest at the WVDP are found in Table $\mathrm{K}-1^{\mathrm{C}}$. When isotopic data are not available, gross alpha and beta measurements are assumed to come from americium-241 and strontium-90, respectively, because the DCGs for these radionuclides are the most limiting for major particulate emissions at the WVDP.

Ventilation and Emission Systems. The exhaust from each EPA-permitted ventilation system onsite is continuously filtered and the permanent systems are monitored as air is released to the atmosphere. Because concentrations of radionu- clides in air emissions are quite low, a large volume of air must be sampled at each point in order to measure the quantity of specific radionuclides released from the facility. Emissions are sampled for both particulate and gaseous forms of radioactivity (i.e., tritium and iodine-129).

The Main Plant Ventilation Stack. The main ventilation stack (ANSTACK) is the primary source of airborne releases at the WVDP. This stack, which vents to the atmosphere at a height of approximately $200 \mathrm{ft}$ (more than 60 meters), releases ventilation exhaust from several facilities, including the liquid waste treatment system, the analytical laboratories, and off-gas from the former vitrification system.

Total curies released from the main stack in 2003 are listed in Appendix D, Table D- ${ }^{\mathrm{C}}$, together with annual averages, maxima, and a comparison of average isotopic concentrations with the applicable DCGs. As in previous years, in 2003 average radioactivity levels at the point of discharge from the stack were already below concentration guidelines for airborne radioactivity in an unrestricted environment. At the site boundary, emissions are further reduced via dispersion by a factor of more than 200,000. Results from air samples taken just outside the site boundary confirm that WVDP operations had no discernible effect on off-site air quality. (See Perimeter and Remote Ambient Air Monitoring [p. 2-17].)

Figure 2-7 (p. 2-16) shows the gross alpha and gross beta curies released per month from the main stack during the past ten years. Airborne releases increased when pre-vitrification transfers of cesium-loaded zeolite from waste tank 8D-1 to 8D-2 began in late 1995.

During vitrification operations, begun in mid-1996 and completed in September 2002 when the melter was shut down, the radionuclide concentrations in 
air emissions fluctuated while generally remaining higher than concentrations before vitrification began. Gross beta concentrations are trending back to pre-vitrification levels, however, alpha concentrations remain elevated, possibly due to decontamination activity in the main plant.

Other On-Site Air Sampling Systems. Sampling systems similar to those of the main stack monitor airborne effluents from the former vitrification heating, ventilation, and air-conditioning sampling system (ANVITSK), the 01-14 building ventilation stack (ANCSSTK), the contact size-reduction facility ventilation stack (ANCSRFK), the supernatant treatment system ventilation stack (ANSTSTK), and the container sorting and packaging facility ventilation stack (ANCSPFK). (See Fig. A-4 [p. A-4].)

Tables D-2 through D-7 ${ }^{\mathrm{C}}$ show total radioactivity released for specific radionuclides (as available) at each of these sampling locations. Samples from locations ANVITSK, ANSEISK, ANCSSTK, ANSTSTK, and ANCSPFK may occasionally show detectable concentrations of gross radioactivity as well as specific beta- and alpha-emitting radionuclides, but none approached any DOE effluent limitations. (ANCSRFK did not operate in 2003, therefore no samples were taken.)

One other operation, the LLWTF ventilation system (ANLLW2V), was routinely monitored for airborne radioactive releases in 2003. This emission point is not required to be permitted because the potential magnitude of the emissions is low. Data for this facility are presented in Table D-8 ${ }^{C}$. Average results were below detection levels. Sampling at this location was discontinued after the first quarter of 2003.

Permitted portable outdoor ventilation enclosures (OVEs) are used occasionally to provide the ventilation necessary for the safety of personnel working with radioactive materials in areas outside permanently-ventilated facilities or in areas where permanent ventilation needs to be augmented. In 2003, decontamination of extraction cell 2 in the

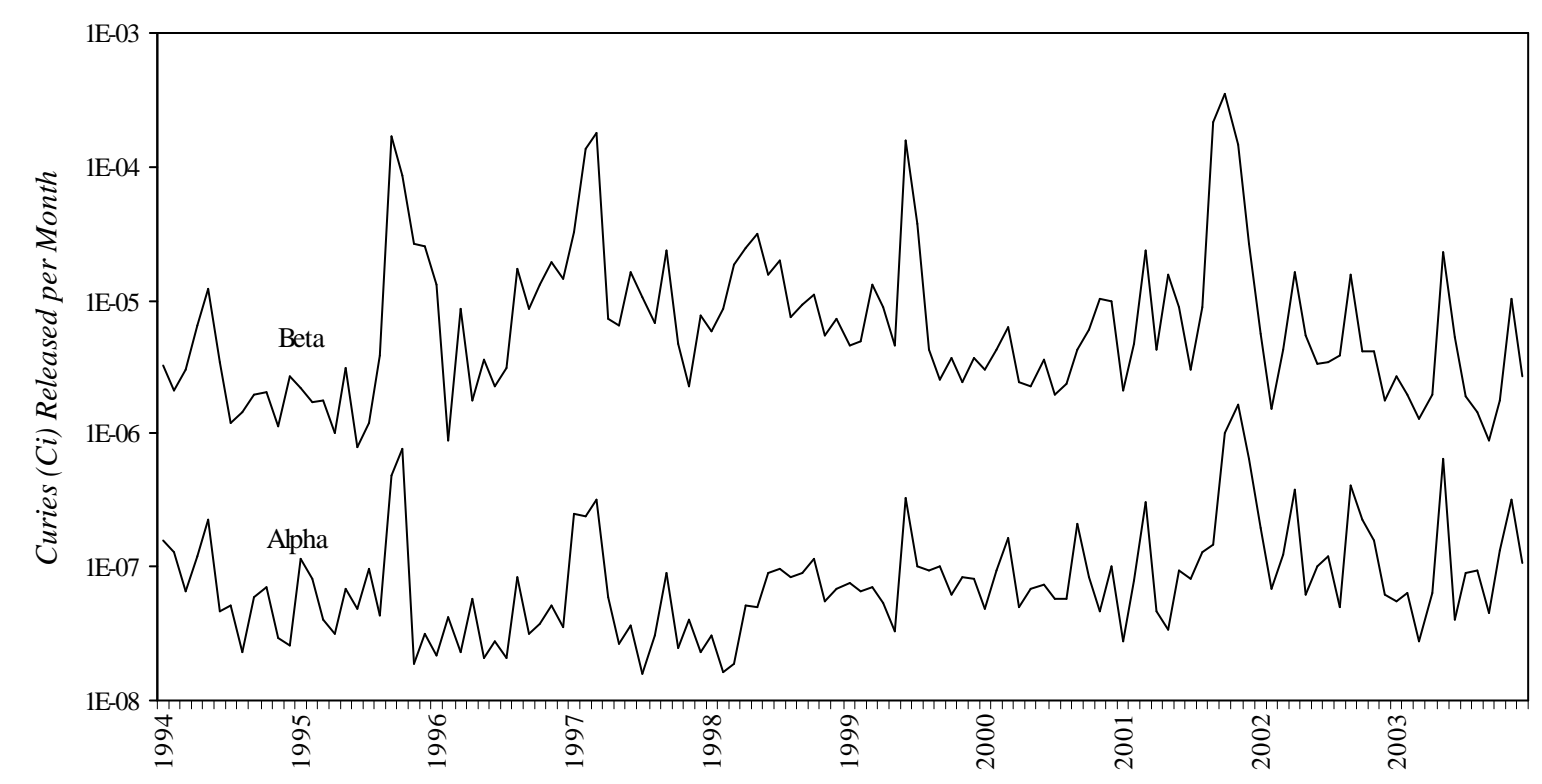

Figure 2-7. Ten-Year Trends of Gross Alpha and Gross Beta Activity at the Main Stack (ANSTACK) 
main plant was monitored by OVEs. Air samples from OVEs are collected continuously while those emission points are discharging, and data from these portable ventilation units are included in annual airborne emission evaluations. (See Table D-9C.) Average discharges from OVEs were well below DOE guidelines.

Three air samplers monitor ambient air near three on-site waste storage units - the lag storage area (ANLAGAM), the NDA (ANNDAAM), and the SDA (ANSDAT9). (See Fig. A-4 [p. A-4].) These samplers were put in place to monitor potential diffuse releases of radioactivity. Monitoring data from these locations are presented in Tables D-10 through D-12 .

With the exception of tritium results at ANSDAT9, radiological data sets for the three locations were statistically indistinguishable from results for back-

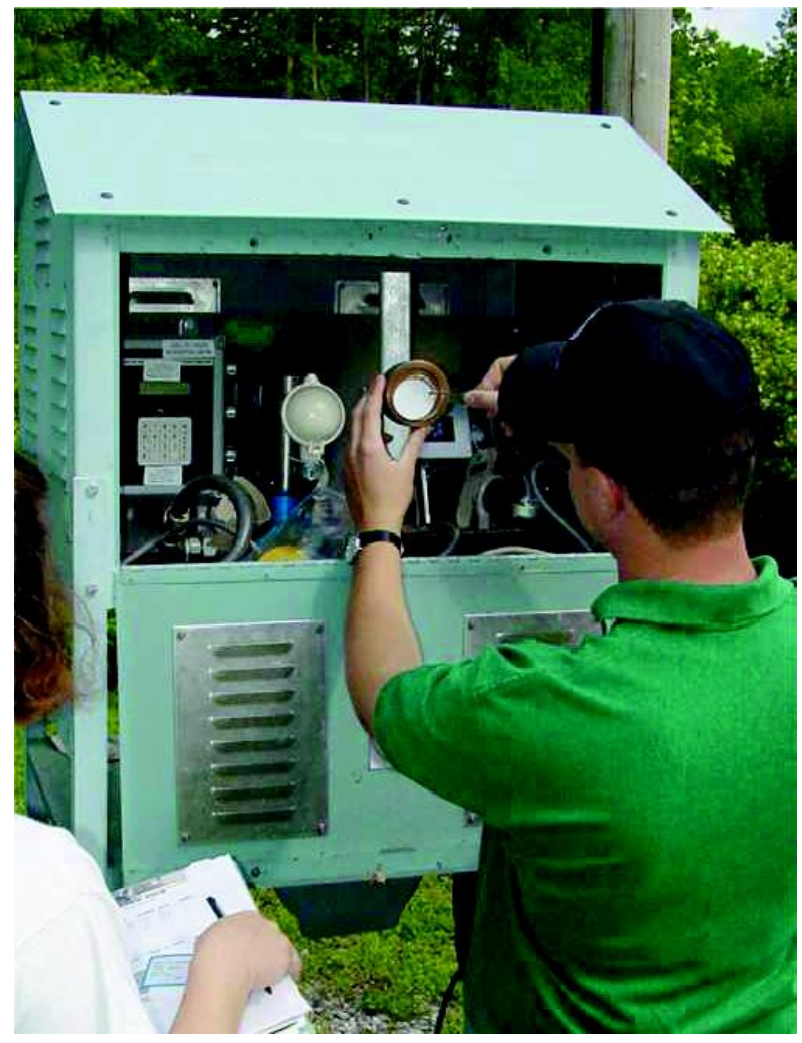

Changing an Air Filter at an Air Sampling Station ground air monitoring locations at Great Valley (AFGRVAL) and Nashville (AFNASHV). Although tritium results at ANSDAT9 were elevated with respect to background, even the highest re$\operatorname{sult}(2.14 \mathrm{E}-12 \mu \mathrm{Ci} / \mathrm{mL}$ [7.92E-05 Bq/L]) was less than $0.01 \%$ of the DOE DCG for tritium in air (1E-07 $\mu \mathrm{Ci} / \mathrm{mL})$.

Perimeter and Remote Ambient Air Monitoring. In 2003, samples for radionuclides in air were collected at six locations around the perimeter of the site and at four remote locations. Maps of the sampling locations are found on Figures A-5, A-12, and A-13 (pp. A-5, A-12, and A-13).

The perimeter locations on Fox Valley Road (AFFXVRD), Rock Springs Road (AFRSPRD), Route 240 (AFRT240), Thomas Corners Road (AFTCORD), Dutch Hill Road (AFBOEHN), and at the site's bulk storage warehouse (AFBLKST) were chosen because they provide historical continuity (as former Nuclear Fuel Services, Inc. sampling locations) or because they represent the most likely locations for detecting off-site airborne concentrations of radioactivity.

The remote locations provide data from nearby communities - West Valley (AFWEVAL) and Springville (AFSPRVL) - and from more distant background areas. Concentrations measured at Great Valley (AFGRVAL, 19 miles [30.9 km] south of the site) and Nashville (AFNASHV, 25 miles $[39.8 \mathrm{~km}]$ west of the site in the town of Hanover) are considered representative of regional background air. Data from these locations are presented in Tables D-13 through D-21 ${ }^{C}$. (Sampling at secondary background location AFNASHV was discontinued after the first quarter of 2003.)

Ten-year gross alpha and gross beta concentrations at the Rock Springs Road location are shown in Figure 2-8 (p. 2-18). Within a range of seasonal and weekly fluctuations, the concentrations have 
been relatively constant over the past ten years. The gross alpha and gross beta ranges and annual averages for each of the off-site sampling points are noted on Tables 2-4 and 2-5 (facing page).

Radioisotopic results from samples taken at two near-site communities and from the site perimeter were statistically indistinguishable from results from the background samples, suggesting that there is no adverse site influence on the air quality at these near-site locations.

\section{Atmospheric Deposition and Soil Monitoring}

Fallout Pots. Fallout samples are analyzed to monitor short-term deposition of radionuclides at four of the perimeter air sampler locations and at one on-site location near the rain gauge outside the Environmental Laboratory. (See Figs. A-4 and A-5 [pp. A-4 and A-5].) The data from these analyses and the $\mathrm{pH}$ in precipitation are summa- rized in Tables D-22 through D-26C ${ }^{\mathrm{C}}$. The low levels of tritium and cesium-137 released in main stack emissions did not measurably affect on-site or perimeter fallout pot samples in 2003.

Off-Site Surface Soil. Surface soil near the offsite air samplers is collected to assess long-term deposition of radionuclides. Maps of the off-site surface soil sampling locations are on Figures A-3, A-12, and A-13 (pp. A-3, A-12, and A-13).

The measured concentrations of most site-related radionuclides in soils from the perimeter and community locations (Table G-2D ${ }^{C}$ ) were statistically indistinguishable from regional background concentrations. Elevated gross beta concentrations were noted at Thomas Corners, consistent with historical data from this soil sampling location. In 2003 , as in the past, cesium-137 concentrations in surface soil from the Rock Springs Road location - northwest of the site - remained higher than background concentrations.

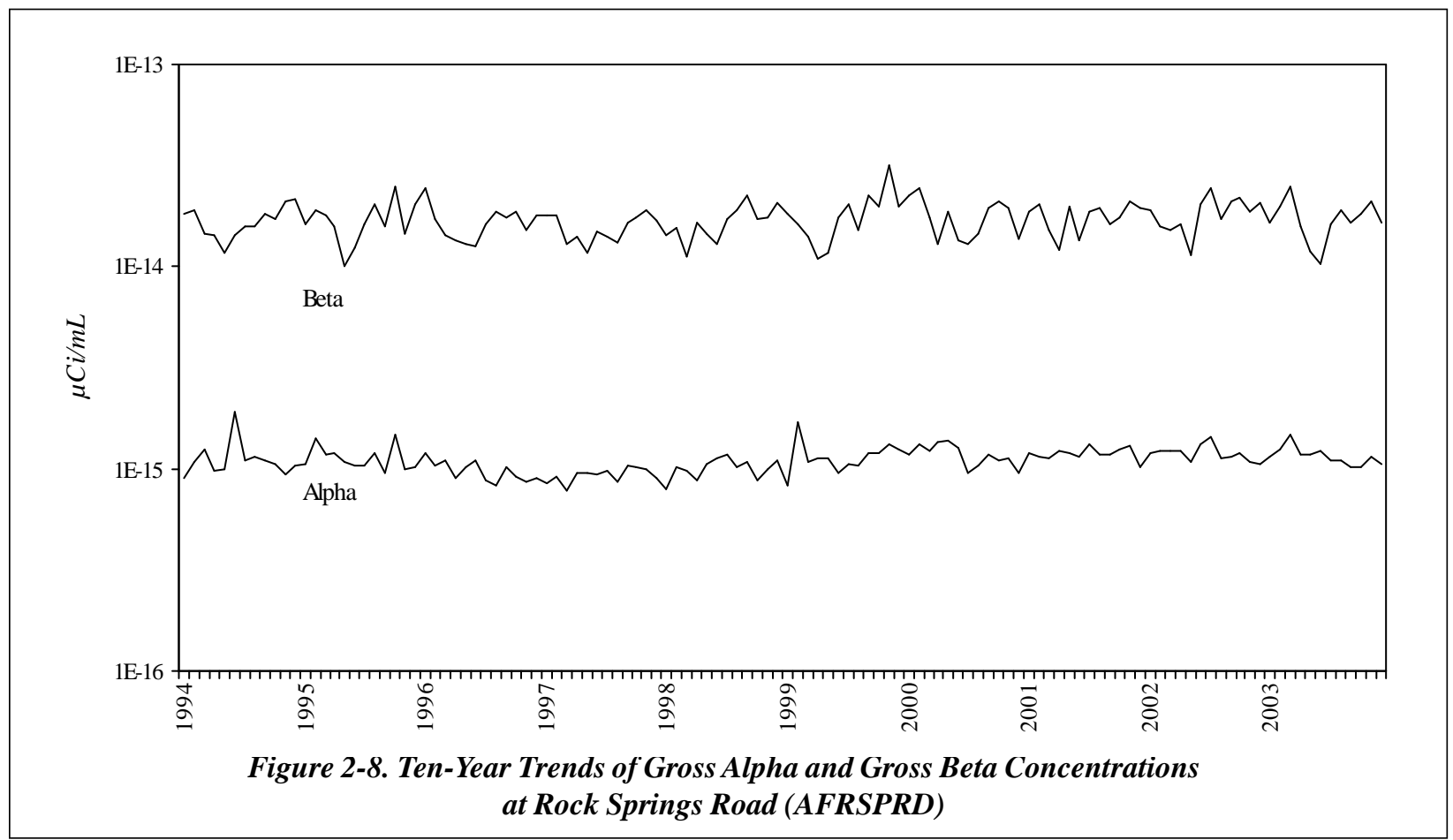


Atmospheric Deposition and Soil Monitoring

\section{Table 2-4}

\section{Gross Alpha Concentrations at Off-Site, Perimeter, and On-Site Ambient Air Sampling Locations}

\begin{tabular}{|c|c|c|c|c|c|}
\hline \multirow[t]{2}{*}{ Location } & \multirow{2}{*}{$\begin{array}{c}\text { Number of } \\
\text { Samples }\end{array}$} & \multicolumn{2}{|c|}{ Range } & \multicolumn{2}{|c|}{ Annual Average } \\
\hline & & $(\mu \mathrm{Ci} / m L)$ & $\left(B q / m^{3}\right)$ & $(\mu \mathrm{Ci} / \mathrm{mL})$ & $\left(B q / m^{3}\right)$ \\
\hline AFBLKST & 52 & $<8.00 \mathrm{E}-16$ to $2.50 \mathrm{E}-15$ & $<2.96 \mathrm{E}-05$ to $9.25 \mathrm{E}-05$ & $0.49 \pm 1.13 \mathrm{E}-15$ & $1.81 \pm 4.18 \mathrm{E}-05$ \\
\hline AFBOEHN & 52 & $<8.12 \mathrm{E}-16$ to $2.00 \mathrm{E}-15$ & $<3.00 \mathrm{E}-05$ to $7.40 \mathrm{E}-05$ & $0.43 \pm 1.12 \mathrm{E}-15$ & $1.59 \pm 4.16 \mathrm{E}-05$ \\
\hline AFFXVRD & 52 & $<6.36 \mathrm{E}-16$ to $2.14 \mathrm{E}-15$ & $<2.35 \mathrm{E}-05$ to $7.92 \mathrm{E}-05$ & $0.50 \pm 1.25 \mathrm{E}-15$ & $1.86 \pm 4.64 \mathrm{E}-05$ \\
\hline AFGRVAL & 52 & $<7.71 \mathrm{E}-16$ to $6.15 \mathrm{E}-15$ & $<2.85 \mathrm{E}-05$ to $2.28 \mathrm{E}-04$ & $0.72 \pm 1.32 \mathrm{E}-15$ & $2.68 \pm 4.88 \mathrm{E}-05$ \\
\hline AFNASHV & 13 & $<9.63 \mathrm{E}-16$ to $2.07 \mathrm{E}-15$ & $<3.56 \mathrm{E}-05$ to $7.67 \mathrm{E}-05$ & $0.74 \pm 1.33 \mathrm{E}-15$ & $2.73 \pm 4.93 \mathrm{E}-05$ \\
\hline AFRSPRD & 52 & $<6.42 \mathrm{E}-16$ to $1.73 \mathrm{E}-15$ & $<2.38 \mathrm{E}-05$ to $6.42 \mathrm{E}-05$ & $0.51 \pm 1.16 \mathrm{E}-15$ & $1.87 \pm 4.28 \mathrm{E}-05$ \\
\hline AFRT240 & 52 & $<7.58 \mathrm{E}-16$ to $2.39 \mathrm{E}-15$ & $<2.80 \mathrm{E}-05$ to $8.85 \mathrm{E}-05$ & $0.52 \pm 1.14 \mathrm{E}-15$ & $1.94 \pm 4.23 \mathrm{E}-05$ \\
\hline AFSPRVL & 52 & $<6.96 \mathrm{E}-16$ to $1.83 \mathrm{E}-15$ & $<2.58 \mathrm{E}-05$ to $6.77 \mathrm{E}-05$ & $0.44 \pm 1.21 \mathrm{E}-15$ & $1.62 \pm 4.48 \mathrm{E}-05$ \\
\hline AFTCORD & 52 & $<7.54 \mathrm{E}-16$ to $2.28 \mathrm{E}-15$ & $<2.79 \mathrm{E}-05$ to $8.42 \mathrm{E}-05$ & $0.52 \pm 1.14 \mathrm{E}-15$ & $1.93 \pm 4.23 \mathrm{E}-05$ \\
\hline AFWEVAL & 52 & $<6.85 \mathrm{E}-16$ to $1.96 \mathrm{E}-15$ & $<2.53 \mathrm{E}-05$ to $7.26 \mathrm{E}-05$ & $0.52 \pm 1.13 \mathrm{E}-15$ & $1.91 \pm 4.19 \mathrm{E}-05$ \\
\hline ANLAGAM & 52 & $<5.83 \mathrm{E}-16$ to $1.69 \mathrm{E}-15$ & $<2.16 \mathrm{E}-05$ to $6.25 \mathrm{E}-05$ & $6.54 \pm 8.76 \mathrm{E}-16$ & $2.42 \pm 3.24 \mathrm{E}-05$ \\
\hline ANNDAAM & 52 & $<6.23 \mathrm{E}-16$ to $2.75 \mathrm{E}-15$ & $<2.31 \mathrm{E}-05$ to $1.02 \mathrm{E}-04$ & $7.13 \pm 8.84 \mathrm{E}-16$ & $2.64 \pm 3.27 \mathrm{E}-05$ \\
\hline ANSDAT9 & 52 & $<8.06 \mathrm{E}-16$ to $1.85 \mathrm{E}-15$ & $<2.98 \mathrm{E}-05$ to $6.83 \mathrm{E}-05$ & $0.24 \pm 1.75 \mathrm{E}-15$ & $0.87 \pm 6.47 \mathrm{E}-05$ \\
\hline
\end{tabular}

Table 2-5

\section{Gross Beta Concentrations at Off-Site, Perimeter, and On-Site Ambient Air Sampling Locations}

\begin{tabular}{lccc} 
Location & $\begin{array}{c}\text { Number of } \\
\text { Samples }\end{array}$ & \multicolumn{2}{c}{ Range } \\
\cline { 3 - 4 } & & & \multicolumn{2}{c}{$\left(\mathrm{B} q / \mathrm{m}^{3}\right)$} \\
AFBLKST & 52 & $8.36 \mathrm{E}-15$ to $3.33 \mathrm{E}-14$ & $3.09 \mathrm{E}-04$ to $1.23 \mathrm{E}-03$ \\
AFBOEHN & 52 & $8.52 \mathrm{E}-15$ to $3.39 \mathrm{E}-14$ & $3.15 \mathrm{E}-04$ to $1.26 \mathrm{E}-03$ \\
AFFXVRD & 52 & $7.36 \mathrm{E}-15$ to $3.06 \mathrm{E}-14$ & $2.72 \mathrm{E}-04$ to $1.13 \mathrm{E}-03$ \\
AFGRVAL & 52 & $8.97 \mathrm{E}-15$ to $3.38 \mathrm{E}-14$ & $3.32 \mathrm{E}-04$ to $1.25 \mathrm{E}-03$ \\
AFNASHV & 13 & $1.34 \mathrm{E}-14$ to $3.11 \mathrm{E}-14$ & $4.97 \mathrm{E}-04$ to $1.15 \mathrm{E}-03$ \\
AFRSPRD & 52 & $6.99 \mathrm{E}-15$ to $3.22 \mathrm{E}-14$ & $2.59 \mathrm{E}-04$ to $1.19 \mathrm{E}-03$ \\
AFRT240 & 52 & $7.32 \mathrm{E}-15$ to $3.39 \mathrm{E}-14$ & $2.71 \mathrm{E}-04$ to $1.25 \mathrm{E}-03$ \\
AFSPRVL & 52 & $8.54 \mathrm{E}-15$ to $3.76 \mathrm{E}-14$ & $3.16 \mathrm{E}-04$ to $1.39 \mathrm{E}-03$ \\
AFTCORD & 52 & $8.61 \mathrm{E}-15$ to 3.30E-14 & $3.19 \mathrm{E}-04$ to $1.22 \mathrm{E}-03$ \\
AFWEVAL & 52 & $8.22 \mathrm{E}-15$ to 3.09E-14 & $3.04 \mathrm{E}-04$ to $1.14 \mathrm{E}-03$ \\
ANLAGAM & 52 & $9.46 \mathrm{E}-15$ to 3.64E-14 & $3.50 \mathrm{E}-04$ to $1.35 \mathrm{E}-03$ \\
ANNDAAM & 52 & $9.30 \mathrm{E}-15$ to $3.23 \mathrm{E}-14$ & $3.44 \mathrm{E}-04$ to $1.20 \mathrm{E}-03$ \\
ANSDAT9 & 52 & $6.92 \mathrm{E}-15$ to $3.04 \mathrm{E}-14$ & $2.56 \mathrm{E}-04$ to $1.12 \mathrm{E}-03$
\end{tabular}

\begin{tabular}{cc}
\multicolumn{2}{c}{ Annual Average } \\
\hline$(\mu \mathrm{Ci} / \mathrm{mL})$ & $\left(B q / \mathrm{m}^{3}\right)$ \\
& \\
$1.74 \pm 0.31 \mathrm{E}-14$ & $6.46 \pm 1.16 \mathrm{E}-04$ \\
$1.82 \pm 0.32 \mathrm{E}-14$ & $6.75 \pm 1.19 \mathrm{E}-04$ \\
$1.69 \pm 0.34 \mathrm{E}-14$ & $6.27 \pm 1.24 \mathrm{E}-04$ \\
$1.77 \pm 0.35 \mathrm{E}-14$ & $6.56 \pm 1.28 \mathrm{E}-04$ \\
$2.06 \pm 0.34 \mathrm{E}-14$ & $7.64 \pm 1.27 \mathrm{E}-04$ \\
$1.71 \pm 0.32 \mathrm{E}-14$ & $6.33 \pm 1.17 \mathrm{E}-04$ \\
$1.66 \pm 0.31 \mathrm{E}-14$ & $6.12 \pm 1.15 \mathrm{E}-04$ \\
$1.71 \pm 0.32 \mathrm{E}-14$ & $6.32 \pm 1.19 \mathrm{E}-04$ \\
$1.66 \pm 0.31 \mathrm{E}-14$ & $6.13 \pm 1.15 \mathrm{E}-04$ \\
$1.72 \pm 0.31 \mathrm{E}-14$ & $6.36 \pm 1.15 \mathrm{E}-04$ \\
$1.89 \pm 0.26 \mathrm{E}-14$ & $7.01 \pm 0.96 \mathrm{E}-04$ \\
$1.73 \pm 0.25 \mathrm{E}-14$ & $6.42 \pm 0.92 \mathrm{E}-04$ \\
$1.54 \pm 0.39 \mathrm{E}-14$ & $5.69 \pm 1.44 \mathrm{E}-04$
\end{tabular}




\section{Overview of Food Chain Monitoring}

Each year food samples are collected from locations near the site (Fig. A-9 [p. A-9]) and from remote locations (Figs. A-12 and A-13 [pp. A-12 and A-13]). Fish and deer are collected during periods when they would normally be taken by sportsmen for consumption. Corn, apples, and beans are collected annually at the time of harvest. (See Measurement of Radionuclide Concentrations in Food [p. 2-25] for a discussion of estimating doses from foodstuffs.) Monitoring results are listed in Appendix $\mathrm{F}^{\mathrm{C}}$.

Fish. Fish are obtained under a collector's permit by electrofishing, a method that temporarily stuns the fish, allowing them to be netted for collection. Electrofishing allows more efficient species-selective control than sport fishing, with unwanted fish being returned to the creek essentially unharmed.
Fish were collected from three locations in Cattaraugus Creek in 2003: ten fish were collected at each of two locations downstream of WNYNSC drainage - one above the Springville dam (BFFCATC) and one below the Springville dam (BFFCATD). Ten more fish were collected upstream of the site (BFFCTRL). The fish taken below the dam (BFFCATD) included species that migrate about 40 miles (more than $60 \mathrm{~km}$ ) upstream from Lake Erie. See Table F- ${ }^{C}$ for a summary of results.

Strontium-90 results from fish downstream of the site (BFFCATC) were elevated in comparison with the background results (BFFCTRL). No other results were statistically higher than background. All results were within the range of historical values.

Venison. Radionuclide data for venison samples from vehicle-deer accidents around the WNYNSC and from deer collected far from the site (in the towns of Friendship, Olean, and Randolph, New York ) are shown in Table F-2 C.

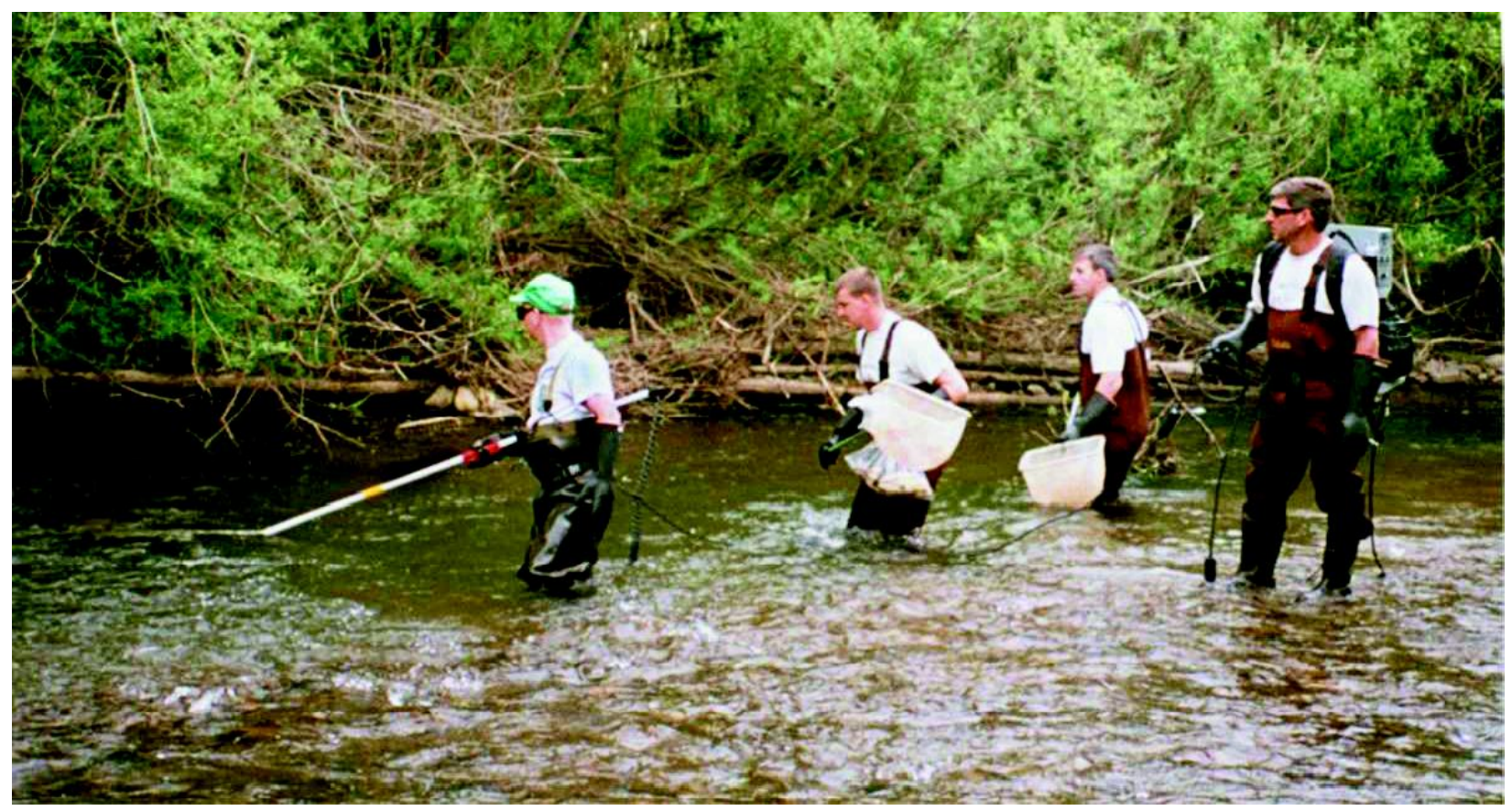

Fish Collection in Cattaraugus Creek

$2-20$ 
Data from 2003 (as well as for the last ten years) show no statistical differences between concentrations of these radionuclides in near-site and control samples.

From 1994 through 2003 (except 2001), during the big-game hunting season, hunters were allowed access to designated areas within the WNYNSC, excluding the WVDP premises, in a controlled hunting program established by NYSERDA. (The hunt was canceled in 2001 because of heightened security concerns.) Data from previous hunts have shown that concentrations of radioactivity in deer flesh have been very low, indicating that Project activities have little or no effect on the local herd.

Beef. Results from beef samples are presented in Table $\mathrm{F}-2^{\mathrm{C}}$. As with the deer samples, no significant differences were found between results from near-site and background samples.

Milk. Results from milk samples are presented in Table F-1 ${ }^{C}$. Near-site sample results were indistinguishable from background control sample results.

Vegetables and Fruit. Results from sweet corn, beans, and apples collected at harvest time are presented in Table F-3 ${ }^{C}$. As observed in previous years, low levels of strontium-90 were noted in both background and near-site samples for all sample types. In 2003, strontium-90 concentrations in near-site beans and apples were slightly elevated with respect to background, but results were consistent with historical results. Although cesium-137 was also slightly elevated in near-site apples, other radionuclide results were statistically the same as measurements from background samples.

\section{Direct Environmental Radiation Monitoring}

The year 2003 marked the twentieth full year that environmental direct penetrating radiation was continuously monitored by the WVDP.

Monitoring points are located on-site at the waste management units, at the site security fence, around the WNYNSC perimeter and the access road, and at background locations remote from the WVDP (Figs. A-10 through A-13 [pp. A-10 through A-13]). The identification numbers associated with each location were assigned in chronological order of original installation. (See TLD Locations and Identification Numbers [p. 2-23].)

Quarterly and annual averages of thermoluminescent dosimeter (TLD) measurements at off-site and on-site locations are noted in Appendix $\mathrm{H}$, Tables $\mathrm{H}-1$ and $\mathrm{H}-2^{\mathrm{C}}$. The results of measurements in 2003 show typical seasonal variations and are similar to results from previous years.

On-Site Radiation Monitoring. Table $\mathrm{H}-2^{\mathrm{C}}$ shows the average quarterly exposure rate at each on-site TLD. The on-site monitoring point with the highest dose readings was location \#24. Sealed containers of radioactive components and debris from the plant decontamination work are stored nearby. This storage area is well within the WNYNSC boundary, just inside the WVDP fenced area, and is not accessible by the public.

The average exposure rate at location \#24 was about 508 milliroentgens $(\mathrm{mR})$ per quarter $(0.23$ $\mathrm{mR} / \mathrm{hr}$ ) during 2003, slightly lower than the exposure rate noted at this location in $2002(0.25 \mathrm{mR} /$ hr). Although 2002 and 2003 values are basically the same, exposure rates at this location have been generally decreasing over time because the radioactivity in the materials stored nearby is decaying. (See Fig. 1-1 [p. 1-10] in Chapter 1.) 
The average penetrating radiation exposure rate in 2003 at locations 100 to 400 feet ( 30 to $120 \mathrm{~m}$ ) distant from the integrated radwaste treatment storage building - the drum cell - including TLDs \#18,\#32,\#34,\#35, \#36, and \#43, was $0.02 \mathrm{mR} /$ $\mathrm{hr}$, about the same as in 2002. Exposure rates around the drum cell are above background levels (by approximately $0.01 \mathrm{mR} / \mathrm{hr}$ ) because the building contains drums filled with decontaminated supernatant mixed with cement. (See also Fig. 1-2 [p. 1-10] in Chapter 1.) The drum cell and the surrounding TLD locations are well within the WNYNSC boundary and are not accessible by the public.

\section{Perimeter and Off-Site Radiation Monitoring.}

Table $\mathrm{H}-1^{\mathrm{C}}$ lists the average quarterly exposure rate at each off-site TLD location. The perimeter TLDs (TLDs \#1-16 and \#20) are distributed in the 16 compass sectors around the facility near the WNYNSC boundary. Results from the perimeter and community TLDs were statistically the same as results from background TLDs. The perimeter
TLD quarterly averages (expressed in microroentgen per hour $[\mu \mathrm{R} / \mathrm{hr}]$ ) shown on Figure 2-9 (below) indicate seasonal fluctuations but no long-term trends. The quarterly average of the seventeen WNYNSC-perimeter TLDs was 17.1 $\mathrm{mR}$ per quarter $(7.8 \mu \mathrm{R} / \mathrm{hr})$ in 2003 , slightly lower than in 2002.

Confirmation of Results. Performance of the environmental TLDs is confirmed periodically using a portable high-pressure ion chamber (HPIC) detection system. Results for 2003 are listed in Table H-3 ${ }^{C}$. The TLD results include the entire third quarter of 2003; the HPIC results were collected over a period of less than 30 minutes.

Since these measurements are made with different systems and over differing periods of time, they are not directly comparable. Even so, the average relative percent difference between the two sets of measurements was less than $8 \%$, indicating good agreement between these two different measurement methods. (Guidance in American

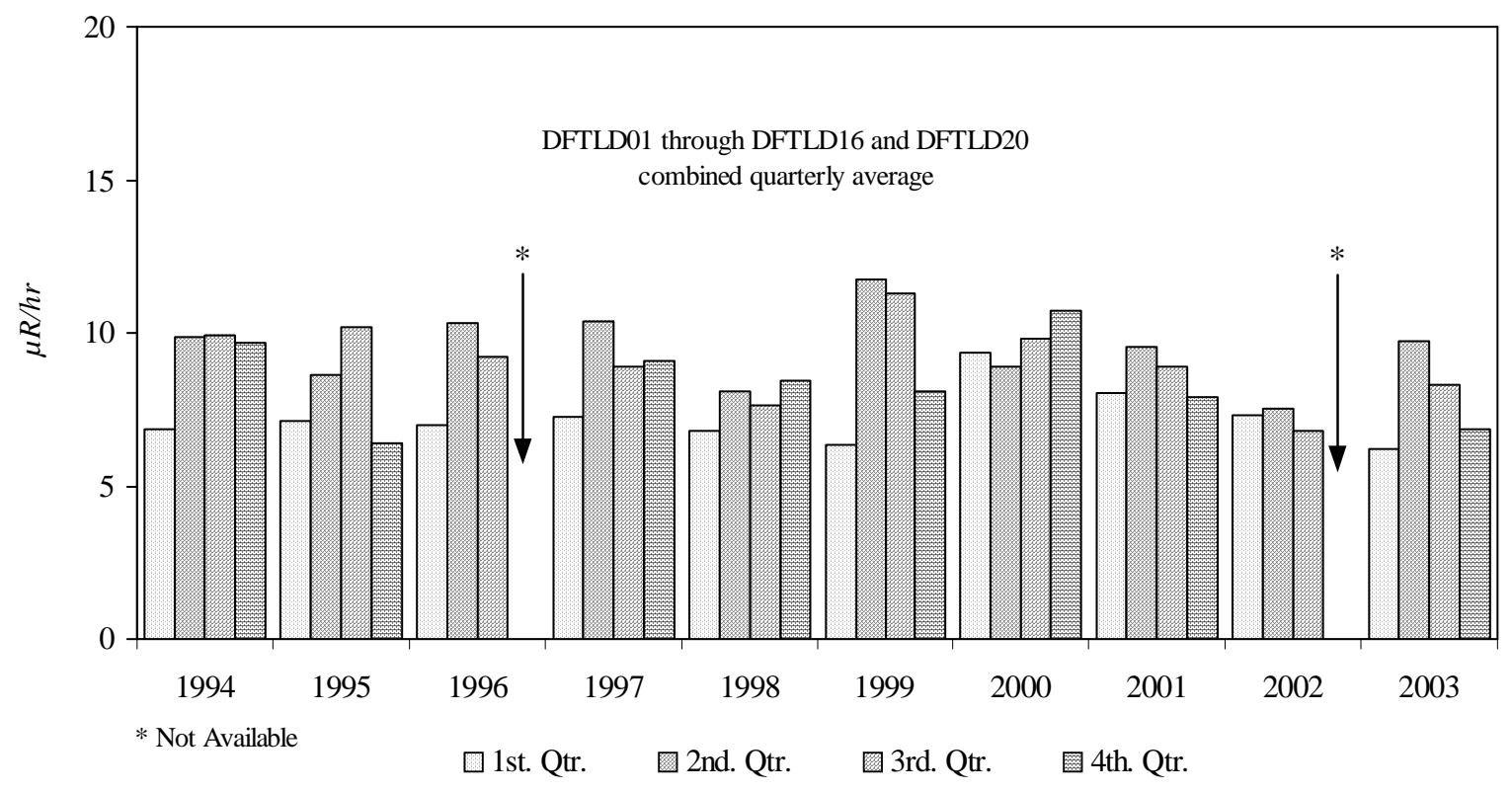

Figure 2-9. Ten-Year Trends of Environmental Radiation Levels at Perimeter TLDs 
National Standards Institute N545-1975, the standard for environmental dosimetry, uses measurement agreement within $30 \%$ total uncertainty as a performance specification for TLD measurements.)

\section{Meteorological Monitoring}

Meteorological monitoring at the WVDP provides representative and verifiable data that characterize the local and regional climatology of the site. These data are used primarily to assess potential effects of routine and nonroutine releases of airborne radioactive materials and to develop dispersion models used to calculate the effective dose equivalent to off-site residents. Since dispersive capabilities of the atmosphere are dependent upon wind speed, wind direction, and atmospheric sta- bility (which includes a function of the difference in temperature between two elevations), these parameters are closely monitored and are available to the emergency response organization at the WVDP.

The on-site 197-foot (60-m) meteorological tower (Fig. A-1 [p. A-1]) continuously monitors wind speed, wind direction, and temperature at both the 197-foot (60-m) and 33-foot (10-m) elevations. In addition, an independent, remote 33-foot (10-m) meteorological station, located approximately 5 miles $(8 \mathrm{~km})$ south of the site on a hillcrest on Dutch Hill Road, continuously monitors wind speed and wind direction. (See Fig. A-12 [p. A-12].) Dewpoint, precipitation, and barometric pressure are also monitored on-site.

\section{TLD Locations and Identification Numbers}

\begin{abstract}
Perimeter of the WNYNSC
Perimeter of the WVDP security fence

On-site sources or waste management units

(Note: Some TLDs monitor more than one waste management unit.)
\end{abstract}

Near-site communities

Background
$1-16,20$

$24,26-34$

18, 32-36, 43 (drum cell)

$18,19,33,42,43$ (SDA)

24 (component storage, near WVDP security fence)

25 (maximum measured exposure rate at the closest point of public access)

38 (main plant and, in previous years, the cement solidification system)

39 (parking lot security fence closest to the vitrification facility)

40 (high-level waste tank farm)

21 (Springville)

22 (West Valley)

17 (Five Points Landfill in Mansfield)

23 (Great Valley)

37 (Nashville)

41 (Sardinia) 
The two meteorological locations supply data to the primary digital and analog data acquisition systems located within the Environmental Laboratory. On-site systems are provided with either uninterruptible or standby power backup in case of site power failures. In 2003 the on-site system data recovery rate (the time valid data were logged versus the total elapsed time) was approximately 93.3\%. Regional data at the 33-foot (10-m) elevation are shown in Appendix I in Figure I- ${ }^{C}$. Figures I-2 and I-3 ${ }^{C}$ illustrate the mean wind speed and wind direction at the 33- and 197-foot (10-m and $60-\mathrm{m}$ ) elevations on the on-site tower during 2003.

Weekly and cumulative total precipitation data are illustrated in Figures I-4 and I-5 ${ }^{\mathrm{C}}$. Precipitation in 2003 was approximately 41.0 inches $(104 \mathrm{~cm})$, equal to the long-term annual average.
Documentation, such as meteorological system calibration records, site log books, and analog strip charts, is stored in protected archives. Meteorological towers and instruments are examined three times per week for proper function and are calibrated semiannually and/or whenever instrument maintenance might affect calibration.

\section{Special Monitoring}

Special monitoring comprises sampling and analyses not covered by the routine environmental monitoring program but that address items of environmental interest. Special monitoring programs are used to verify and/or track these items. No special monitoring for radiological parameters was conducted in 2003.

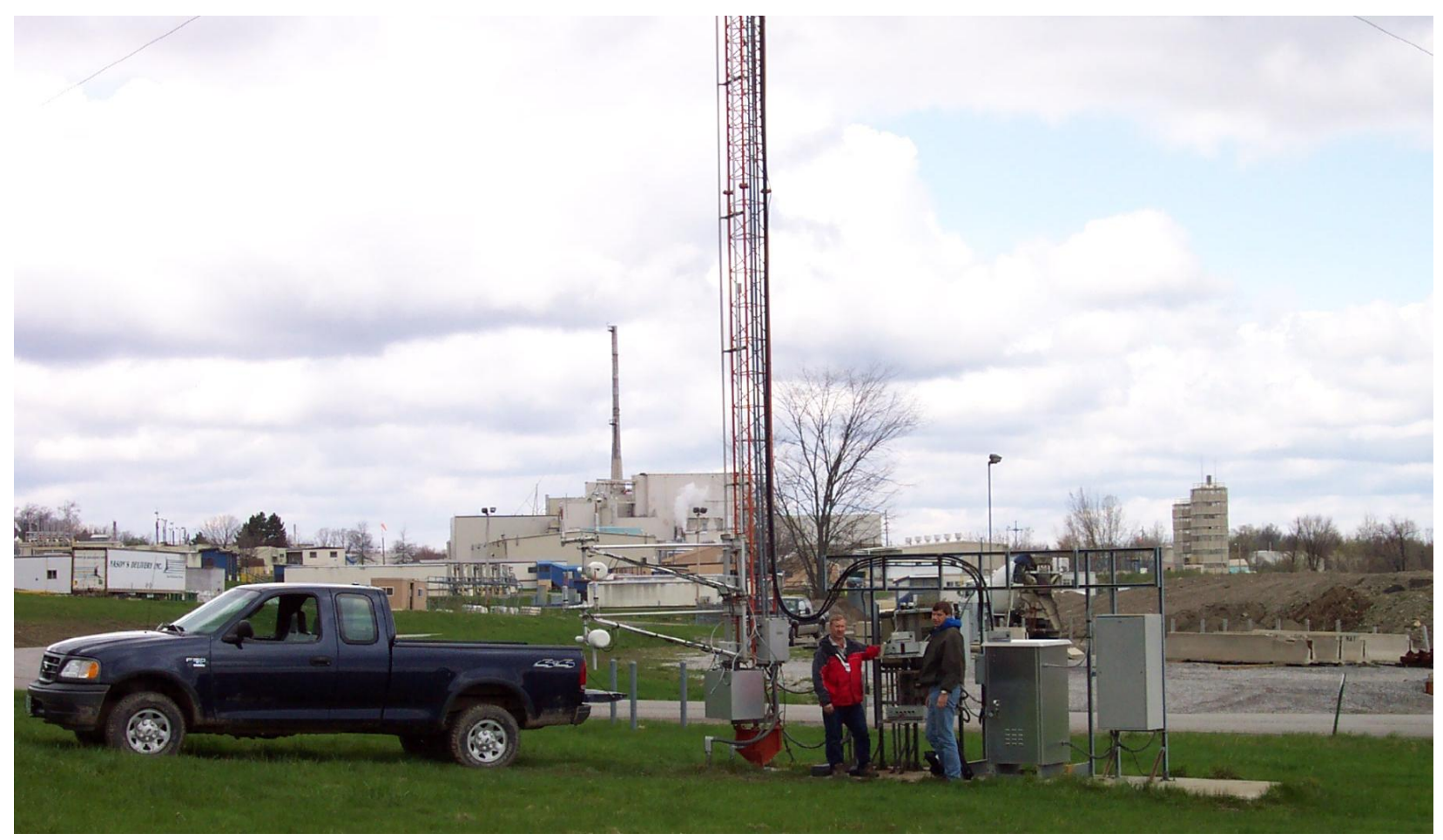

On-Site Meteorological Tower

$2-24$ 


\section{Radiological Effluents and Dose}

\section{Dose Assessment Methodology}

The potential radiation dose to the general public from activities at the WVDP is evaluated by using a two-part methodology applied in a manner consistent with the requirements of DOE Order 5400.5. The first part uses the measurements of radionuclide concentrations in liquid and air released from the Project to determine annual total effect. The second part uses measurements of radioactivity in food from locations near the Project boundaries to confirm the low impact of the totals.

Radiological dose is evaluated for all major exposure pathways, including external irradiation, inhalation, and ingestion of local food products. The dose contributions from each radionuclide and pathway combination are then combined to obtain the total dose estimates reported in Table 2-6 (p. 2-28).

\section{Measurement of Radionuclide Concentra-} tions in Liquid and Air Releases. Because it is difficult to distinguish the health effects of the small amount of radioactivity originating from the Project and naturally-occurring radiation in the environment, computer codes are used to model the environmental dispersion of radionuclides that originate from on-site monitored ventilation stacks and liquid discharge points.

Actual data from release-monitoring samples are collected, together with annual weather measurements and the most recent demographic information. (See Appendices C, D, and $\mathrm{I}^{\mathrm{C}}$.) The effective dose equivalent (EDE) to the maximally-exposed off-site individual (MEOSI) and the collective EDE to the population within a 50 -mile $(80-\mathrm{km})$ radius are then calculated using conservative models that have been approved by the DOE and the EPA to demonstrate compliance with radiation standards. (See inset Radiation Dose and Units of Dose Measurement [p. 2-26].)

Measurement of Radionuclide Concentrations in Food. The second part of the dose assessment is based on actual measurements of radioactivity in samples of foodstuffs grown in the vicinity of the WVDP and the comparison of these values with measurements of samples collected from locations well beyond the potential influence of site effluents. These measurements show that the concentrations of radioactivity, whether from sites near the WVDP or from distant locations, are small - usually near the analytical detection limits - thereby providing additional assurance that operations at the WVDP are not adversely affecting the public.

If any of the near-site food samples contain radionuclide concentrations that are statistically higher than the concentrations in control samples, separate dose calculations are performed to verify that the calculated foodstuff dose is within the dose range estimated by computer modeling. (See Calculated Dose From Local Foodstuff Tests [p. 2-30].)

These calculated doses are used as an independent confirmation of (not added to) the computermodeled estimates (Table 2-6 [p. 2-28]) because the models already include contributions from all environmental pathways. 


\section{Radiation Dose}

The energy released from a radionuclide is eventually deposited in matter encountered along the path of the radiation. The radiation energy absorbed by a unit mass of material is referred to as the absorbed dose. The absorbing material can be either inanimate matter or living tissue.

Alpha particles leave a dense track of ionization as they travel through tissue and thus deliver the most dose per unit path-length. However, alpha particles are not penetrating and must be taken into the body by inhalation or ingestion to cause harm. Beta and gamma radiation can penetrate the protective dead skin layer of the body from the outside, resulting in exposure of the internal organs to radiation.

Because beta and gamma radiations deposit much less energy in tissue per unit path-length relative to alpha radiation, they produce fewer biological effects for the same absorbed dose. To allow for the different biological effects of different kinds of radiation, the absorbed dose is multiplied by a quality factor to yield a unit called the dose equivalent. A radiation dose expressed as a dose equivalent, rather than as an absorbed dose, permits the risks from different types of radiation exposure to be compared with each other (e.g., exposure to alpha radiation compared with exposure to gamma radiation). For this reason, regulatory agencies limit the dose to individuals in terms of total dose equivalent.

\section{Units of Dose Measurement}

The unit for dose equivalent in common use in the U.S. is the rem, which stands for roentgenequivalent-man. The international unit of dose equivalent is the sievert $(\mathrm{Sv})$, which is equal to 100 rem. The millirem (mrem) and millisievert $(\mathrm{mSv})$, used more frequently to report the low dose equivalents encountered in environmental exposures, are equal to one-thousandth of a rem or sievert, respectively. Other radioactivity unit conversions are found on p. UOM-2 at the back of this report.

The effective dose equivalent (EDE), also expressed in units of rem or sievert, provides a means of combining unequal organ and tissue doses into a single "effective" whole body dose that represents a comparable risk probability. The probability that a given dose will result in the induction of a fatal cancer is referred to as the risk associated with that dose. The EDE is calculated by multiplying the organ dose equivalent by the organ-weighting factors developed by the International Commission on Radiological Protection (ICRP) in Publications 26 (1977) and 30 (1979). The weighting factor is a ratio of the risk from a specific organ or tissue dose to the total risk resulting from an equal whole body dose. All organ-weighted dose equivalents are then summed to obtain the EDE.

The dose from internally-deposited radionuclides calculated for a fifty-year period following intake is called the fifty-year committed effective dose equivalent (CEDE). The CEDE sums the dose to an individual over fifty years to account for the biological retention of radionuclides in the body. The total EDE for one year of exposure to radioactivity is calculated by adding the CEDE to the dose equivalent from external, penetrating radiation received during the year. Unless otherwise specified, all doses discussed here are total EDE values, which include the CEDE for internal emitters.

A collective population dose is expressed in units of person-rem or person-sievert because the individual doses are summed over the entire potentially-exposed population. The average individual dose can therefore be obtained by dividing the collective dose by the population. 


\section{Predicted Dose From Airborne Emissions}

Airborne emissions of radionuclides are regulated by the EPA under the Clean Air Act and its implementing regulations. DOE facilities are subject to 40 Code of Federal Regulations (CFR) 61, Subpart H, NESHAP. Subpart H contains the national emission standards for emissions of radionuclides other than radon from DOE facilities. The applicable standard for radionuclides is a maximum of 10 mrem $(0.1 \mathrm{mSv})$ effective dose equivalent to any member of the public in any year.

Releases of airborne radioactive materials in 2003 from nominal ground-level stacks ( 1 to 24 meters high) and from the main 60-meter-high stack were modeled using the EPA-approved CAP88-PC computer code (Parks, June 1997). This air dispersion code estimates effective dose equivalents for the ingestion, inhalation, air immersion, and ground surface pathways.

Site-specific data for CY 2003 non-radon radionuclide releases in curies per year are listed in Tables D-1 through D-9C. Applicable information from these tables was used as input to the CAP88PC code, as were wind data collected from the on-site meteorological tower during 2003 and current local population distribution numbers.

Resulting output from the CAP88-PC code was then used to determine the total EDE from air emissions to a maximally exposed individual and the collective dose to the population within a 50mile $(80-\mathrm{km})$ radius of the WVDP.

Maximum Dose to an Off-Site Individual. Based on the non-radon airborne radioactivity released from all sources at the site during 2003, it was estimated that a person living in the vicinity of the WVDP could have received a total EDE of $0.0017 \mathrm{mrem}(0.000017 \mathrm{mSv})$ from airborne re- leases. The computer model estimated that this MEOSI was located 0.8 miles $(1.3 \mathrm{~km})$ northnorthwest of the site and was assumed to eat only locally-produced foods. More than $90 \%$ of the dose from main plant stack emissions was from iodine129. (See Iodine Emissions From the Main Stack [this page].)

The maximum total EDE of 0.0011 mrem $(0.000011 \mathrm{mSv})$ from the permitted stacks and vents is far below levels that could be directly measured at the exposed individual's residence. This dose is comparable to about two and one-half minutes of natural background radiation received by an average member of the U.S. population and is well below the $10 \mathrm{mrem}(0.1 \mathrm{mSv})$ NESHAP limit promulgated by the EPA and mandated by DOE Order 5400.5.

Collective Population Dose. The CAP88-PC program was used to estimate the collective EDE to the population. Based upon the latest U.S. census population data collected in CY 2000, 1.54 million people were estimated to reside within 50 miles $(80 \mathrm{~km})$ of the WVDP. This population received an estimated 0.0093 person-rem $(0.000093$ person-Sv) total EDE from radioactive non-radon airborne effluents released from WVDP point and diffuse sources during 2003. The resulting average EDE per individual was 0.000006 mrem $(0.00000006 \mathrm{mSv})$.

Iodine Emissions From the Main Stack. In the ten-year period before the startup of vitrification, iodine-129, a long-lived radionuclide, was found in main stack emissions at levels of approximately 0.003 to $0.034 \mathrm{mCi} /$ year. In 1996, when vitrification operations began, $1.20 \mathrm{mCi}$ of iodine129 were released and in 1997, the first full year of vitrification, a maximum release of $7.4 \mathrm{mCi}$ was observed. (See Fig. 2-10 [p. 2-29].) The increase occurred because gaseous iodine was not as efficiently removed by the vitrification process off- 


\section{Table 2-6}

\section{Summary of Annual Effective Dose Equivalents to an Individual and Population From WVDP Releases in 2003}

Exposure Pathways

\section{Annual Effective Dose Equivalent}

Maximally-Exposed
Off-Site Individual
mrem (mSv)

Airborne Releases ${ }^{3}$

$\%$ EPA standard (10 mrem)

$1.7 \mathrm{E}-03(1.7 \mathrm{E}-05)$
$0.02 \%$

Waterborne Releases ${ }^{4}$

Effluents only

Effluents plus north plateau drainage

Total from all Pathways

$\%$ DOE standard (100 mrem) -

air and water combined

$\%$ of natural background

(295 mrem; 453,000 person-rem) -

received from air and water combined

Estimated Radon-220
$1.8 \mathrm{E}-02(1.8 \mathrm{E}-04)$

3.2E-02 (3.2E-04)

3.3E-02 (3.3E-04)

$0.03 \%$

$0.01 \%$

$1.4 \mathrm{E}-02(1.4 \mathrm{E}-04)^{6}$
Collective Effective

Dose Equivalent ${ }^{2}$

person-rem (person-Sv)

9.3E-03 (9.3E-05)

NA

$1.9 \mathrm{E}-02(1.9 \mathrm{E}-04)$

9.5E-02 (9.5E-04)

$1.0 \mathrm{E}-01(1.0 \mathrm{E}-03)$

NA

3.9E-01 (3.9E-03)
$0.00002 \%$

NA - Not applicable. Numerical regulatory standards are not set for the collective EDE to the population.

1 The maximum exposure to air discharges is estimated to occur at a residence 1.3 kilometers northwest of the main plant building.

2 A population of 1.54 million is estimated to reside within 80 kilometers of the site.

3 Releases are from atmospheric non-radon point and diffuse sources. Calculations use CAP88-PC to estimate individual and population doses. EPA and DOE limits for individual airborne dose are the same.

4 Estimates are calculated using the methodology described in the WVDP Manual for Radiological Assessment of Environmental Releases at the WVDP (WVNSCO, 2003).

5 Estimated releases are based on indicator measurements and vitrification processing values. Dose estimates are calculated using CAP88-PC.

6 The estimated dose from radon-220 is specifically excluded by rule from NESHAP totals. (See p. 2-33.) 


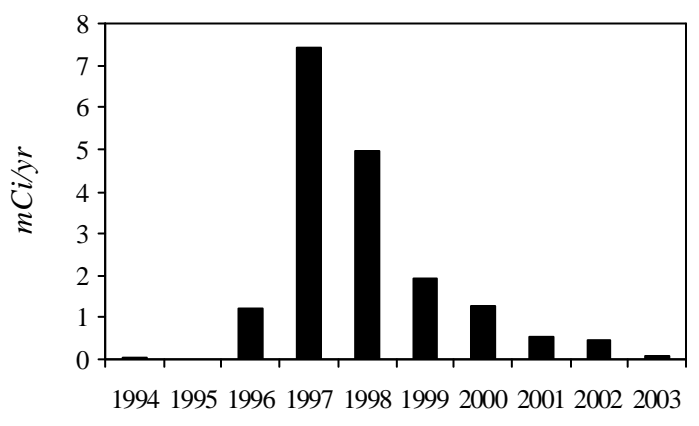

Figure 2-10. Estimated Iodine-129 Releases From the WVDP Main Plant Stack

gas treatment system as were most other radionuclides. As more high-level waste was vitrified, iodine-129 levels decreased and in 2003, the first full year since vitrification was completed, the total annual release had dropped to $0.065 \mathrm{mCi}$. Even so, in 2003, iodine- 129 continued to account for the largest proportion of dose to an off-site individual from main stack airborne emissions.

\section{Predicted Dose From Waterborne Releases}

Currently there are no EPA standards establishing limits on the radiation dose to members of the public from liquid effluents except as applied in 40 CFR 141 and 40 CFR 143, Drinking Water Guidelines (EPA, 1984a; 1984b). Corollary limits for community water supplies are set by NYSDOH in the New York State Sanitary Code (Title 10 of the Official Compilation of Codes, Rules, and Regulations of the State of New York [NYCRR] 5-1.52). The private residential potablewater wells sampled for radionuclides are upgradient of the WVDP and therefore do not represent a potential source of exposure to radiation from routine Project activities.

Since Cattaraugus Creek is not used as a drinking water supply, a comparison of the predicted con- centrations and doses with the 4-mrem/year (0.04$\mathrm{mSv} /$ year) EPA and NYSDOH drinking water limits established in 40 CFR 141 and 40 CFR 143, and in 10 NYCRR \$5-1.52, respectively, is not truly appropriate (although the values in creek samples are well below the EPA drinking water limits). The estimated radiation dose was compared to the applicable guidelines provided in DOE Order 5400.5. The EDE to the MEOSI and the collective EDE to the population due to routine waterborne releases and natural drainage are calculated using dose conversion factors as tabulated in the WVDP Manual for Radiological Assessment of Environmental Releases at the WVDP (WVNSCO, 2003).

Since the Project's liquid effluents eventually reach Cattaraugus Creek, which is not used directly as a source of drinking water, the most important individual exposure pathway is the consumption of fish from this creek by local sportsmen. It is conservatively assumed that a person may consume annually as much as 46 pounds $(21 \mathrm{~kg})$ of fish caught in the creek. Exposure to external radiation from shoreline or water contamination is also included in the model for estimating radiation dose. Population dose estimates assume that radionuclides are further diluted in Lake Erie before reaching municipal drinking water supplies.

The computer codes GENII version $1.485(\mathrm{~Pa}-$ cific Northwest Laboratory, 1988), which implements the models in NRC Regulatory Guide 1.109 (NRC, 1977), and LADTAP II (Simpson and McGill, 1980) were used to calculate site-specific unit dose factors for routine waterborne releases and dispersion of these effluents. Input data included local stream flow and dilution, drinking water usage, and stream usage factors. (See WVDP Manual for Radiological Assessment of Environmental Releases at the WVDP [WVNSCO, 2003] for a detailed description of the GENII code.) 
Seven batches of liquid effluents were released from lagoon 3 (point WNSP001) during 2003. (See LowLevel Waste Treatment Facility Effluent [p. 2-6].) Measurements of the radioactivity discharged in these effluents, listed in Table C-2 $\mathrm{A}^{\mathrm{C}}$, were combined with the unit dose factors to calculate the EDE to the MEOSI and the collective EDE to the population living within a 50-mile $(80-\mathrm{km})$ radius of the WVDP.

In addition to measurements from WNSP001, radioactivity measurements from sewage treatment facility effluents (WNSP007) were included in the EDE calculations. Results from the sewage treatment facility are presented in Table $\mathrm{C}-2 \mathrm{M}^{\mathrm{C}}$. (The french drain at WNSP008, a third release point, has been sealed off since 2001 and was not included in this evaluation.)

Besides the two release points at WNSP001 and WNSP007, waters from two natural drainage channels originating on the Project premises contain measurable concentrations of radioactivity: the northeast swamp (WNSWAMP) and north swamp (WNSW74A). (See Northeast Swamp and North Swamp Drainage [p. 2-6].) The measured radioactivity from these points is reported in Tables $\mathrm{C}-3 \mathrm{C}$ and $\mathrm{C}-3 \mathrm{D}^{\mathrm{C}}$. These results are included in the EDE calculations for the MEOSI and the collective population.

There were no unplanned releases of waterborne radioactivity in 2003.

\section{Maximum Dose to an Off-Site Individual.} Based on the radioactivity in liquid effluents discharged from the WVDP (lagoon 3 and the sewage treatment plant) during 2003, an off-site individual could have received a maximum EDE of $0.018 \mathrm{mrem}(0.00018 \mathrm{mSv})$. More than $85 \%$ of this dose was from cesium-137. The maximum offsite individual EDE due to drainage from the north plateau (north swamp and northeast swamp) was 0.014 mrem $(0.00014 \mathrm{mSv})$.
The combined EDE to the maximally-exposed individual from liquid effluents and drainage was $0.032 \mathrm{mrem}(0.00032 \mathrm{mSv})$. This annual dose is very small in comparison to the 295 mrem (2.95 $\mathrm{mSv}$ ) dose that is received by an average member of the U.S. population from natural background radiation.

Collective Dose to the Population. As a result of radioactivity released in liquid effluents from the WVDP (primarily from lagoon 3) during 2003, the population living within 50 miles $(80 \mathrm{~km})$ of the site received a collective EDE of 0.019 person-rem (0.00019 person-Sv). The collective dose to the population from the effluents plus the north plateau drainage was 0.095 person-rem $(0.00095$ person-Sv). The resulting average EDE from effluent releases and north plateau drainage (north swamp and northeast swamp) per individual is $0.000062 \mathrm{mrem}(0.00000062 \mathrm{mSv})$. This dose is an inconsequential addition to the dose that an average person receives in one year from natural background radiation.

\section{Calculated Dose From Local Foodstuff Tests}

As noted earlier in the discussion of food chain monitoring (p. 2-20), most radionuclide concentrations in near-site food samples were statistically indistinguishable from concentrations in background samples. Strontium- 90 concentrations higher than background were noted in fish taken in Cattaraugus Creek downstream of the WVDP (BFFCATC). Strontium-90 and cesium-137 concentrations above background were both seen in near-site apples. Even so, estimates of dose due to consuming near-site fish, deer, beef, milk, beans, corn, and apples were all less than $0.1 \mathrm{mrem} /$ year. These independent estimates confirm the dose estimates based on air and water effluent sampling results as summarized in Table 2-6 (p. 2-28). 


\section{Predicted Dose From All Pathways}

The potential dose to the public from both airborne and liquid effluents released from the Project during 2003 is the sum of the individual dose contributions. The calculated maximum EDE from all pathways to a nearby resident was 0.033 mrem $(0.00033 \mathrm{mSv})$. This dose is $0.03 \%$ of the 100 mrem (1-mSv) annual limit in DOE Order 5400.5. The estimated dose from radon-220 to the same nearby resident was about $0.01 \mathrm{mrem}$.

The total collective EDE to the population within 50 miles $(80 \mathrm{~km})$ of the site was 0.10 person-rem (0.0010 person-Sv), with an average EDE of $0.00007 \mathrm{mrem}(0.0000007 \mathrm{mSv})$ per individual. The estimated radon-220 dose to the population was approximately 0.4 person-rem.

Table 2-6 (p. 2-28) summarizes the dose contributions from all pathways and compares the individual doses with the applicable standards. The low doses calculated using computer modeling were corroborated by the low or non-detectable doses calculated from local foodstuff test data.
Figure 2-11 (below) shows the calculated annual dose to the hypothetical maximally-exposed individual over the last ten years. The estimated dose for $2003(0.03 \mathrm{mrem})$ is lower than the annual dose reported for 2002 (0.06 mrem). The decrease in dose fraction from air emissions in 2002 is attributed to the continuing decrease in iodine-129 emissions. Liquid doses were also lower in 2003 than in 2002 ( 0.032 versus 0.057 mrem, respectively).

Figure 2-12 (p. 2-32) shows the collective dose to the population over the last ten years. (See Fig. A-14 [p. A-14] for a map of the population sectors.) Collective effective dose equivalent, elevated during vitrification activities, is trending toward previtrification levels.

The overall radioactivity represented by these data confirms the continued inconsequential addition to the natural background radiation dose that individuals and population around the WVDP receive from Project activities.

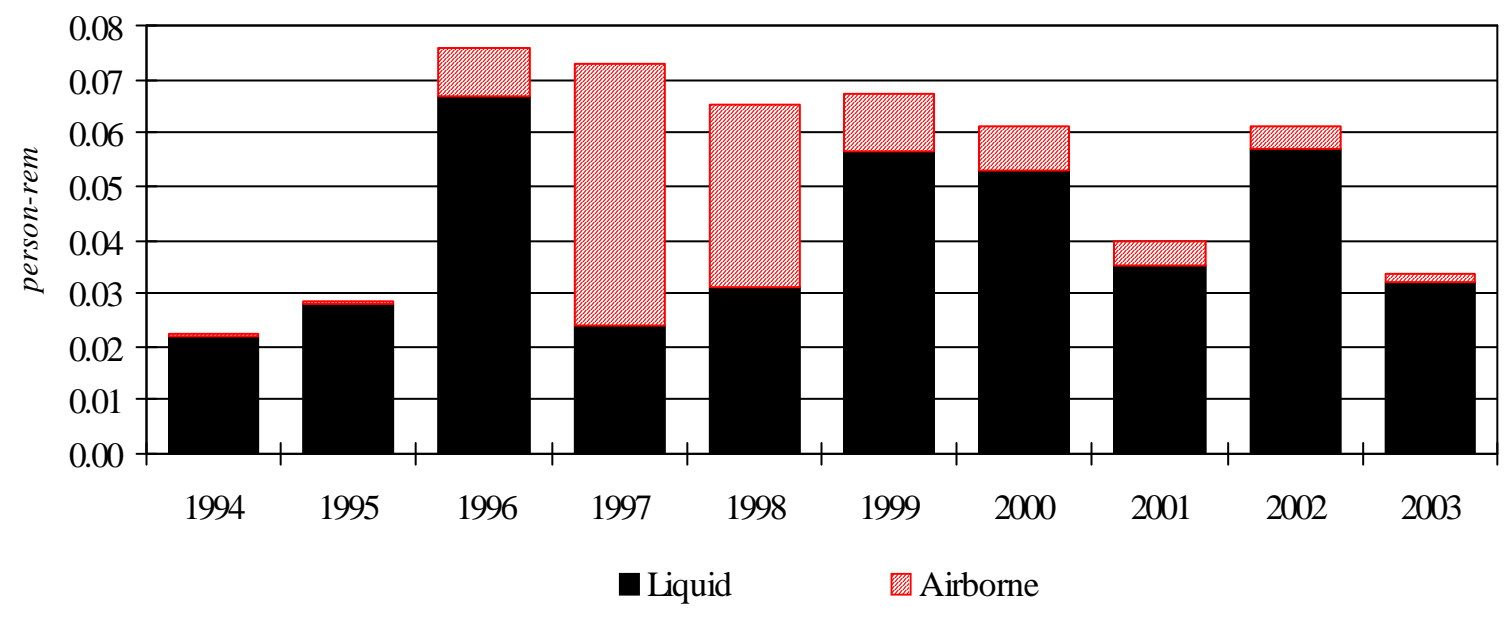

Figure 2-11. Effective Dose Equivalent From Liquid and Airborne Effluents to a Maximally Exposed Individual Residing Near the WVDP 


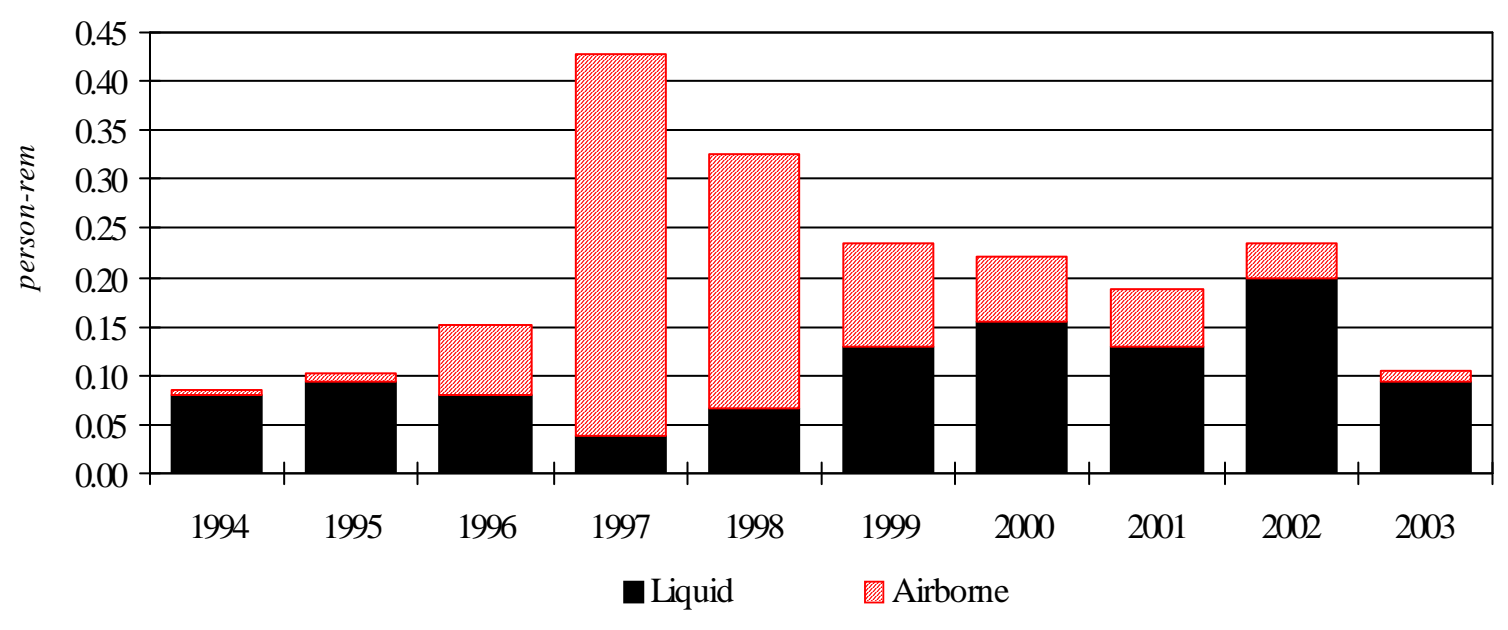

Figure 2-12. Collective Effective Dose Equivalent From Liquid and Airborne Effluents to the Population Residing Within 50 Miles $(80 \mathrm{~km})$ of the WVDP

\section{Risk Assessment}

Estimates of cancer risk from ionizing radiation have been presented by the NCRP (1987b) and the National Research Council's Committee on Biological Effects of Ionizing Radiation (1990).

These reports estimate that the probability of fatal cancer induction to the public, averaged over all ages, ranges from 0.0001 to 0.0005 cancer fatalities per rem. DOE guidance has, in the past, recommended using a risk coefficient of 0.0005 (ICRP, 1991) to estimate risk to a MEOSI. Recent DOE guidance recommends using an even more conservative risk coefficient of 0.0006 provided by the Interagency Steering Committee on Radiation Standards (January 2003). The resulting estimated risk to this hypothetical individual residing near the WVDP from airborne and waterborne releases in 2003 was a 0.00000002 probability of a cancer fatality ( 1 chance in 50 million). This risk is well below the range of 0.000001 to 0.00001 per year considered by the ICRP in Report Number 26 (1977) to be a reasonable risk for any individual member of the public.

\section{Dose to Biota: Aquatic and Terrestrial Wildlife}

Radionuclides from both natural and man-made sources may be found in environmental media such as water, sediments, and soils. In the past, it has been assumed that if radiological controls are sufficient to protect humans, other living things are also likely to be sufficiently protected. This assumption is no longer considered adequate, since populations of plants and animals residing in or near these media or taking food or water from these media may be exposed to a greater extent than are humans. For this reason, the DOE prepared a technical standard which provides methods and guidance to be used to evaluate doses of ionizing radiation to populations of aquatic animals, terrestrial plants, and terrestrial animals.

Methods in this technical standard, A Graded Approach for Evaluating Radiation Doses to Aquatic and Terrestrial Biota (DOE-STD-11532002, July 2002), were used in 2003 to evaluate radiation doses to aquatic and terrestrial biota within the confines of the WNYNSC, which in- 


\section{Radon-220}

Radon-220 is a naturally-occurring gaseous decay product of thorium-232 present in the airborne emissions from the WVDP main plant. Radon-220, also known as thoron, is associated with the thorium reduction extraction (THOREX)-related thorium-232 and uranium-232 in the high-level waste.

As reported in Chapter 2 of the 1996 WVDP Site Environmental Report (WVNSCO and Dames \& Moore, June 1997), thoron levels were observed to increase during startup of the 1996 high-level waste vitrification process. An estimate of the thoron released during each waste concentration cycle was developed and used to determine a theoretical annual release. During the vitrification phase, an average of about 12 curies per day were released. In 2003, the first full year since vitrification was completed, the average was about three curies of thoron released per day.

Although large numbers of curies were released relative to other radionuclides, the calculated dose from thoron is quite small because of its short decay half-life and other characteristics. The NESHAP rule specifically excludes thoron from air emission dose calculations, so a dose estimate using CAP88-PC was calculated separately. The theoretical dose to the MEOSI located 0.8 miles $(1.3 \mathrm{~km})$ north-northwest of the site in 2003 would have been 0.014 mrem, and the collective dose to the population within an 80-kilometer radius would have been 0.39 person-rem. (See Table 2-6 [p. 2-28].) These theoretical doses are within the same range as doses from the man-made radionuclides found in WVDP effluents.

With vitrification completed, thoron releases have decreased to pre-vitrification levels. The figure presented here provides a relative indication of recent trends in the estimated annual thoron releases.

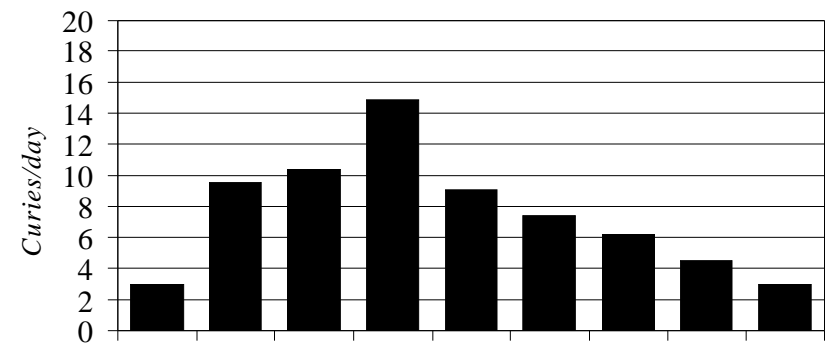

199519961997199819992000200120022003

Estimated Radon-220 Releases From the WVDP

cludes the WVDP. Doses were assessed for compliance with the limit in DOE Order 5400.5 for native aquatic animal organisms ( $1 \mathrm{rad}$ per day) and for compliance with the thresholds for terrestrial plants (also $1 \mathrm{rad}$ per day) and for terrestrial animals (0.1 rad per day), as proposed in DOESTD-1153-2002. Note that the absorbed dose unit (rad) is used for biota instead of the units used for indicating human risk (rem).

The RESRAD-BIOTA Code, a calculation tool provided by the DOE for implementing the tech- nical standard, was used to compare existing radionuclide concentration data from environmental sampling with biota concentration guide (BCG) screening values and to estimate upper bounding doses to biota. Data collected from surface waters, sediments, and soils on and around the WNYNSC over a ten-year period (1991-2000) were used as a baseline. For a more near-term assessment, a second evaluation was completed using surface water data from 2003, sediment data from the last five years (1999-2003), and soil data from the last ten years (1994-2003). Differing time 
periods were used because radionuclide concentrations change more rapidly over time in surface waters than in sediments and soils, as reflected in their sampling frequencies (weekly or monthly for water, annually for sediments and soils). Longer time periods were also required for sediments and soils to obtain sufficient data points to produce reliable annual averages. (See Appendices A and $\mathrm{B}^{\mathrm{C}}$ for maps and descriptions of monitoring and surveillance locations. Radionuclides analyzed for each medium at each location are listed in Appen$\operatorname{dix} B^{C}$. See Appendices $C$ and $G^{C}$ for a summary of results from these locations in 2003.)

Concentration data for radionuclides in each medium were entered into the RESRAD-BIOTA Code. The value for each radionuclide was automatically divided by the BCG in order to calculate a partial fraction for each nuclide for each medium. Partial fractions for each medium were added to produce a sum of fractions.

It was found that the isotopes with the highest sums of fractions - the radionuclides that contributed the largest component of both aquatic and terrestrial dose to biota - were strontium-90 and cesium- 137 . Per guidance in DOE-STD-1153-2002, the populations of organisms most sensitive to strontium-90 and cesium-137 in this evaluation - that is, those populations residing on the WNYNSC that were most likely to be adversely affected via the aquatic and terrestrial pathways - were determined to be populations of the raccoon (aquatic dose) and the deer mouse (terrestrial dose). As such, this study does not pertain to pathways to humans, which are addressed elsewhere. (See Dose Assessment Methodology [p. 2-25].)

The aquatic dose limit from DOE Order 5400.5 may be assumed to have been met if the sum of fractions for the water medium plus that for the sediment medium is less than 1.0. Similarly, proposed dose limits for both terrestrial plants and animals may be assumed to have been met if the sum of fractions for the water medium plus that for the soil medium is less than 1.0.

In accordance with the approach described in DOE-STD-1153-2002, a general screening was first conducted using the maximum radionuclide concentrations from surface waters, sediments, and soils. Maximum radionuclide concentrations exceeded applicable general screening BCG limits for both aquatic and terrestrial evaluations.

As recommended in DOE-STD-1153-2002, a sitespecific screening was then done using estimates of average radionuclide concentrations derived from measurements in surface waters, sediments, and soils. Results are summarized in Table 2-7 (p. 2-36).

At the site-specific screening level for the full tenyear period, the sums of fractions for the aquatic and terrestrial system evaluations were 0.31 and 0.57 , respectively. The comparable sums of fractions using the more near-term data were 0.16 and 0.58 , respectively. The sum of fractions for each assessment was less than 1.0, indicating that applicable BCGs were met for both the aquatic and terrestrial evaluations.

Upper bounding doses associated with the aquatic system evaluation were $0.0059 \mathrm{rad} /$ day to an aquatic animal and $0.016 \mathrm{rad} /$ day to a riparian animal, far below the $1 \mathrm{rad} /$ day standard from DOE Order 5400.5 for dose to a native aquatic animal. Upper bounding doses associated with the terrestrial system evaluation were 0.058 and $0.0047 \mathrm{rad} /$ day to terrestrial animals and plants, again well below the guidance thresholds ( 0.1 and $1.0 \mathrm{rad} /$ day, respectively).

It was therefore concluded that populations of aquatic and terrestrial biota (both plants and animals) on the WNYNSC are not being exposed to 
doses in excess of the existing DOE dose standard for aquatic animals and the recommended standards for terrestrial biota.

\section{Summary}

Predictive computer modeling of airborne and waterborne releases resulted in estimated hypothetical doses to the maximally-exposed individual that were orders of magnitude below all applicable EPA standards and DOE Orders, which place limitations on the release of radioactive materials and dose to individual members of the public. The collective population dose was also assessed and found to be orders of magnitude below the natural background radiation dose. Additionally, estimates of dose to biota indicated that biota at the WVDP are exposed at a fraction of the DOE and IAEA guidelines for dose to biota.

Based on the overall dose assessment, the WVDP was found to be in compliance with applicable effluent radiological guidelines and standards during calendar year 2003. Table 2-8 (p. 2-37) provides a summary of WVDP releases and calculated doses in specified DOE format. 
Table 2-7

\section{Evaluation of Dose to Aquatic and Terrestrial Biota}

Based on average radionuclide concentrations in waters, sediments, and soils from ten years of monitoring, the sum of fractions for the aquatic system evaluation was 0.45 and that for the terrestrial system evaluation was 0.57 . Evaluations using more recent data - surface water data from 2003, sediment data from 1999-2003, and soils data from 1994-2003 - resulted in aquatic and terrestrial sums of fractions of 0.16 and 0.58, respectively. Each sum of fractions was less than 1.0, indicating that applicable biota concentration guides (BCGs) were met for both the aquatic and terrestrial evaluations. The calculated sum of fractions for the aquatic system for the near-term assessment was less than the sum of fractions calculated for the 10-year baseline. Results of this study supported the conclusion that populations of aquatic and terrestrial biota on the WNYNSC are not being exposed to doses in excess of the existing DOE limit for native aquatic animal organisms (U.S. Department of Energy, February 1990) and the international standards for terrestrial organisms (International Atomic Energy Agency, 1992).

Aquatic System Evaluation (Near-Term Data Set)

\begin{tabular}{|c|c|c|c|c|c|c|c|}
\hline Nuclide & $\begin{array}{c}\text { Water } \\
\text { BCG* } \\
(\mathbf{p C i} / \mathrm{L})\end{array}$ & $\begin{array}{c}\text { Mean Water } \\
\text { Value } \\
(\mathbf{p C i} / \mathrm{L})\end{array}$ & $\begin{array}{c}\text { Water } \\
\text { Partial } \\
\text { Fraction }\end{array}$ & $\begin{array}{l}\text { Sediment } \\
\text { BCG* } \\
\text { (pCi/g) }\end{array}$ & $\begin{array}{c}\text { Mean Sediment } \\
\text { Value } \\
(\mathbf{p C i} / \mathrm{g})\end{array}$ & $\begin{array}{l}\text { Sediment } \\
\text { Partial } \\
\text { Fraction }\end{array}$ & $\begin{array}{c}\text { Water and } \\
\text { Sediment } \\
\text { Sum of Fractions }\end{array}$ \\
\hline Cesium-137 & 42.6 & 3.73 & $8.75 \mathrm{E}-02$ & 3,120 & 9.66 & 3.09E-03 & 0.09 \\
\hline Strontium-90 & 278 & 19.2 & $6.89 \mathrm{E}-02$ & 582 & 0.828 & $1.42 \mathrm{E}-03$ & 0.07 \\
\hline All Others & NA & NA & $1.60 \mathrm{E}-03$ & NA & NA & $5.30 \mathrm{E}-04$ & $<0.01$ \\
\hline \multicolumn{3}{|c|}{ Sum of Fractions (Near-Term Data) } & $1.58 \mathrm{E}-01$ & & & $5.04 \mathrm{E}-03$ & 0.16 \\
\hline \multicolumn{6}{|c|}{ Sum of Fractions (Long-Term [10-Yr] Data) 4.47E-01 } & $5.65 \mathrm{E}-03$ & 0.45 \\
\hline \multicolumn{8}{|c|}{ Estimated upper bounding dose to an aquatic animal $=0.0059 \mathrm{rad} /$ day; to a riparian animal $=0.016 \mathrm{rad} / \mathrm{day}$} \\
\hline \multicolumn{8}{|c|}{$\underline{\text { Terrestrial System Evaluation (Near-Term Data Set) }}$} \\
\hline Nuclide & $\begin{array}{c}\text { Water } \\
\text { BCG* } \\
(\mathbf{p C i} / \mathrm{L})\end{array}$ & $\begin{array}{c}\text { Mean Water } \\
\text { Value } \\
(\mathbf{p C i} / \mathbf{L})\end{array}$ & $\begin{array}{c}\text { Water } \\
\text { Partial } \\
\text { Fraction }\end{array}$ & $\begin{array}{c}\text { Soil } \\
\text { BCG* } \\
\text { (pCi/g) }\end{array}$ & $\begin{array}{c}\text { Mean Soil } \\
\text { Value } \\
(\mathbf{p C i} / g)\end{array}$ & $\begin{array}{c}\text { Soil } \\
\text { Partial } \\
\text { Fraction }\end{array}$ & $\begin{array}{c}\text { Water and } \\
\text { Soil } \\
\text { Sum of Fractions }\end{array}$ \\
\hline Cesium-137 & 599,000 & 3.73 & $6.23 \mathrm{E}-06$ & 20.8 & 6.26 & $3.02 \mathrm{E}-01$ & 0.30 \\
\hline Strontium-90 & 54,500 & 19.2 & $3.53 \mathrm{E}-04$ & 22.5 & 6.23 & $2.77 \mathrm{E}-01$ & 0.28 \\
\hline All Others & NA & NA & $1.77 \mathrm{E}-06$ & $\mathrm{NA}$ & $\mathrm{NA}$ & $7.20 \mathrm{E}-04$ & $<0.01$ \\
\hline \multicolumn{3}{|c|}{ Sum of Fractions (Near-Term Data) } & $3.61 \mathrm{E}-04$ & & & $5.79 \mathrm{E}-01$ & 0.58 \\
\hline \multicolumn{3}{|c|}{ Sum of Fractions (Long-Term [10-Yr] Data) } & $7.20 \mathrm{E}-04$ & & & $5.66 \mathrm{E}-01$ & 0.57 \\
\hline
\end{tabular}

* The BCGs are calculated values. Except for the sums of fractions, which are rounded to two significant digits, all values are expressed to three significant digits.

$$
2-36
$$


Table 2-8

WVDP Radiological Dose and Release Summary

WVDP Radiological Dose Reporting Table CY 2003

\begin{tabular}{|c|c|c|c|c|}
\hline $\begin{array}{c}\text { Dose to the } \\
\text { Maximally Exposed } \\
\text { Individual }\end{array}$ & $\begin{array}{c}\text { \% of DOE } \\
\text { 100-mrem Limit }\end{array}$ & $\begin{array}{c}\text { Estimated } \\
\text { Population Dose }\end{array}$ & $\begin{array}{c}\text { Population Within } \\
\text { 50 Miles } \\
\text { (2000 census })\end{array}$ & $\begin{array}{c}\text { Estimated Natural } \\
\text { Radiation Population } \\
\text { Dose }\end{array}$ \\
\hline $\begin{array}{cc}0.033 \\
\mathrm{mrem} \quad(\mathrm{mSv})\end{array}$ & 0.033 & $\begin{array}{c}0.10 \\
\text { person-rem } \\
(\text { person-Sv) }\end{array}$ & $1,536,000$ & $\begin{array}{c}0.0010 \\
\text { person-rem }\end{array}$ \\
\hline
\end{tabular}

\section{WVDP Radiological Atmospheric Emissions ${ }^{+}$CY 2003 in Curies (Bq)}

\begin{tabular}{|c|c|c|c|c|c|c|c|c|c|c|}
\hline Tritium & Kr-85 & $\begin{array}{c}\text { Noble Gases } \\
\left(\mathbf{T}_{1 / 2}<40 \mathrm{dy}\right)\end{array}$ & $\begin{array}{c}\text { Short-Lived } \\
\text { Fission and } \\
\text { Activation } \\
\text { Products } \\
\left(\mathrm{T}_{1 / 2}<3 \mathrm{hr}\right)\end{array}$ & $\begin{array}{c}\text { Fission and } \\
\text { Activation } \\
\text { Products } \\
\left(\mathrm{T}_{1 / 2}>\mathbf{3 ~ h r}\right)\end{array}$ & $\begin{array}{c}\text { Total } \\
\text { Radioiodine }\end{array}$ & $\begin{array}{c}\text { Total } \\
\text { Radiostrontium }\end{array}$ & $\begin{array}{c}\text { Total } \\
\text { Uranium* }\end{array}$ & $\begin{array}{c}\text { Total } \\
\text { Plutonium }\end{array}$ & \begin{tabular}{|c|} 
Total \\
Other \\
Actinides
\end{tabular} & $\begin{array}{c}\text { Other } \\
(\mathbf{R n}-220)\end{array}$ \\
\hline $\begin{array}{c}2.46 \mathrm{E}-03 \\
(9.12 \mathrm{E}+07)\end{array}$ & $\mathrm{NA}$ & NA & NA & $\begin{array}{c}1.25 \mathrm{E}-05 \\
(4.62 \mathrm{E}+05)\end{array}$ & $\begin{array}{c}8.15 \mathrm{E}-05 \\
(3.01 \mathrm{E}+06)\end{array}$ & $\begin{array}{c}4.34 \mathrm{E}-06 \\
(1.61 \mathrm{E}+05)\end{array}$ & $\begin{array}{c}2.74 \mathrm{E}-07 \\
(1.01 \mathrm{E}+04)\end{array}$ & $\begin{array}{c}3.96 \mathrm{E}-07 \\
(1.47 \mathrm{E}+04)\end{array}$ & $\begin{array}{c}5.35 \mathrm{E}-07 \\
(1.98 \mathrm{E}+04)\end{array}$ & $\begin{array}{c}1.10 \mathrm{E}+03 \\
(4.05 \mathrm{E}+13)\end{array}$ \\
\hline
\end{tabular}

WVDP Liquid Effluent Releases ${ }^{+}$of Radionuclide Material CY 2003 in Curies (Bq)

\begin{tabular}{|c|c|c|c|c|c|c|}
\hline Tritium & $\begin{array}{c}\text { Fission and } \\
\text { Activation } \\
\text { Products } \\
\left(\mathbf{T}_{1 / 2}>\mathbf{3} \mathbf{~ h r}\right)\end{array}$ & $\begin{array}{c}\text { Total } \\
\text { Radioiodine }\end{array}$ & $\begin{array}{c}\text { Total } \\
\text { Radiostrontium }\end{array}$ & $\begin{array}{c}\text { Total } \\
\text { Uranium** }\end{array}$ & $\begin{array}{c}\text { Total } \\
\text { Plutonium }\end{array}$ & $\begin{array}{c}\text { Total } \\
\text { Other } \\
\text { Actinides }\end{array}$ \\
\hline $2.51 \mathrm{E}-01$ & $\begin{array}{c}7.80 \mathrm{E}-03 \\
(2.88 \mathrm{E}+08)\end{array}$ & $\begin{array}{c}2.73 \mathrm{E}-04 \\
(1.01 \mathrm{E}+07)\end{array}$ & $\begin{array}{c}8.73 \mathrm{E}-02 \\
(3.23 \mathrm{E}+09)\end{array}$ & $\begin{array}{c}1.36 \mathrm{E}-03 \\
(5.02 \mathrm{E}+07)\end{array}$ & $\begin{array}{c}7.40 \mathrm{E}-05 \\
(2.74 \mathrm{E}+06)\end{array}$ & $\begin{array}{c}3.98 \mathrm{E}-05 \\
(1.47 \mathrm{E}+06)\end{array}$ \\
\hline
\end{tabular}

NA - Not applicable

+ The WVDP air and water releases are from point source and controlled liquid effluent releases, respectively.

$*$ Total uranium $($ grams $)=2.80 \mathrm{E}-01$

** Total uranium $($ grams $)=7.45 \mathrm{E}+02$

\section{$2-37$}


This page intentionally left blank

$2-38$ 


\section{ENVIRONMENTAL NONRADIOLOGICAL PROGRAM INFORMATION}

Overview of New York State Water Classifications, Water Quality Standards, and Water Effluent Limits

The objective of the Clean Water Act of 1972 (CWA) (as stated in Section 101 of the Act) is to restore and maintain the integrity of the nation's waters and ensure that, wherever attainable, waters be made useful for fishing and swimming. To achieve this goal, New York State is delegated with authority under Sections 118, 303, and 510 of the CWA to (1) classify and designate the best uses for receiving waters, such as streams and rivers, within its jurisdiction; and (2) establish and assign water quality standards - goals for achieving the designated best uses for these classified waters. In addition to achieving CWA goals for fishing and swimming, New York has further classified its jurisdictional waters and established ambient water standards, guidelines, and maximum contaminant levels (MCLs) to achieve objectives under the Safe Drinking Water Act for drinking water. These standards serve as the basis for periodic evaluation of the integrity of the receiving waters and identification of needed controls, such as New York State Pollutant Discharge Elimination System (SPDES) permits and effluent limitations.
The definitions for best usage classifications of New York's jurisdictional waters and the water quality standard goals for these classifications are provided in Title 6 of the Official Compilation of Codes, Rules, and Regulations of the State of New York (NYCRR) Parts 701-704. Mapping of the Cattaraugus Creek drainage basin and assignment of best usage designations and classification to each receiving water segment within this drainage basin are described in 6 NYCRR Part 838. According to these regulations, Frank's Creek, Quarry Creek, and segments of Buttermilk Creek under the influence of West Valley Demonstration Project (WVDP) water effluents are identified as Class " $C$ " receiving waters with a minimum designated best usage for fishing with conditions suitable for fish survival. Cattaraugus Creek, in the immediate downstream vicinity of the Western New York Nuclear Service Center (WNYNSC), is identified as a Class " $\mathrm{B}$ " receiving water with best designated usages for swimming and fishing. All fresh (non-saline) groundwaters within New York are assigned a "GA" classification with a designated best usage as a potable water supply source.

Presented in Appendix $\mathrm{C}-1^{\mathrm{C}}$ is a summary of the numerical water quality standards, guidelines, and MCLs assigned to these water classifications for those substances and parameters that are included 
in the WVDP environmental monitoring program for ambient water. Also included in Appendix $\mathrm{C}-1^{\mathrm{C}}$ are SPDES Permit discharge limits for site effluents.

\section{Surface Water, Subsurface Drainage Water, and Water Effluent Monitoring}

Appendix C-2 ${ }^{C}$ contains process effluent data with SPDES Permit limits provided for comparison with these data. Appendices C-3 through C-5 ${ }^{C}$ present data for ambient surface water, subsurface drainage water, contained water, and potable water monitoring locations. Also provided for side-by-side comparison with these data are reference values, where available, including background ambient water monitoring data and/or pertinent ambient water quality standards (AWQS), guidelines, or MCLs.

SPDES Permit-Required Monitoring. Liquid discharges are regulated under the State Pollutant Discharge Elimination System. The WVDP holds a SPDES Permit that identifies the outfalls where liquid effluents are released to Erdman Brook (Fig. A-2 [p. A-2]) and specifies the sampling and analytical requirements for each outfall. In August 2003, the WVDP filed an application with the New York State Department of Environmental Conservation (NYSDEC) for renewal of the SPDES Permit. In October 2003, NYSDEC issued a renewed permit, which will expire in 2009. The conditions and requirements of the SPDES Permit are summarized in Table C-1 $\mathrm{A}^{\mathrm{C}}$ in Appendix C-1. The permit identifies five outfalls:

- outfall WNSP001, discharge from the low-level waste treatment facility (LLWTF)

- outfall WNSP007, discharge from the sanitary and industrial wastewater treatment facility
- outfall WNSP008, groundwater effluent from the perimeter of the LLWTF storage lagoons (closed in May 2001 but still in the permit)

- outfall 116, a location in Frank's Creek that represents the confluence of outfalls WNSP001, WNSP007, and WNSP008, as well as storm water runoff, groundwater seepage, and augmentation water. (Samples from upstream sources are used to calculate total dissolved solids at this location and to demonstrate compliance with the SPDES Permit limit for this parameter. Outfall 116 is referred to as a "pseudo-monitoring" point on the SPDES Permit. See p. GLO-8 in the Glossary.)

- outfall WNSP01B, an internal monitoring point for the liquid waste treatment system evaporator effluent, being monitored for flow and total mercury.

Some of the more significant features of the SPDES Permit are the requirements to report fiveday biochemical oxygen demand $\left(\mathrm{BOD}_{5}\right)$, total dissolved solids (TDS), iron, and ammonia data as flow-weighted concentrations and to apply a net discharge limit for iron. The net limit allows the Project to account for the iron that is naturally present in the site's incoming water. The flowweighted limits apply to the flow-proportioned sum of the Project effluents.

The SPDES monitoring data for 2003 are displayed in Tables C-2C through C-2MC. The WVDP reported three permit excursions in 2003, all due to exceeded holding times for sample analysis at the off-site laboratory.

Mercury Analytical Method Study. The modified SPDES Permit received by the WVDP in July 2002 required a comparison study of mercury determination by two analytical methods: Environmental Protection Agency (EPA) Method 245.1 
(or 245.2) with a detection level of $0.2 \mu \mathrm{g} / \mathrm{L}$ (parts per billion [ppb]) and EPA Method 1631, which allows determination of mercury at a minimum level of $0.5 \mathrm{ng} / \mathrm{L}$ (parts per trillion [ppt]). The latter ("ultraclean") method supports EPA's effort to make available an additional analytical method capable of measuring mercury accurately at ambient water quality criteria levels.

Since the SPDES Permit enforcement compliance limit of $0.2 \mu \mathrm{g} / \mathrm{L}$ for total mercury is several orders of magnitude higher than the AWQS of 0.0007 $\mu \mathrm{g} / \mathrm{L}$ for dissolved mercury, the WVDP is required to conduct a mercury study using both methods (1631 and 245.1 or 245.2) whenever mercury samples are required under the terms of the SPDES Permit. A report summarizing the analytical results from these two methods and its findings is required to be submitted quarterly to NYSDEC.

Fourteen sets of samples from outfall 001 and five sets of samples from outfall 01B were analyzed for mercury by the two test methods in 2003 . Samples were analyzed at Severn Trent Laboratories or Lionville Laboratories using Method 245.1 and at Frontier Geosciences, Inc. or General Engineering Laboratories using Method 1631.

All sample results from Method 245.1 were less than $0.2 \mu \mathrm{g} / \mathrm{L}$, the practical quantitation limit for Method 245.1. Results generated with Method 1631 were consistent with results generated with Method 245.1. That is, all sample results generated with Method 1631 were reported at levels below $0.2 \mu \mathrm{g} / \mathrm{L}$. The average concentration for samples collected at outfall 001 was $0.0164 \mu \mathrm{g} / \mathrm{L}$ and that for outfall $01 \mathrm{~B}$ was $0.00889 \mu \mathrm{g} / \mathrm{L}$.

South Plateau Surface and Subsurface Water. An inactive underground radioactive waste disposal site, the U.S. Nuclear Regulatory Commission-Licensed Disposal Area (NDA), lies on the south plateau of the site. Surface waters, which flow from the south to the north, are routinely monitored at several points around this area. (See Fig. A-2 [p. A-2].) Two of these points, WNNDATR and WNNDADR, are used to monitor (respectively) waters within the NDA water collection trench system and surface runoff and seepage immediately downstream of the NDA. Sampling point WNNDATR is an underground sump at the lowest point in the collection trench system that intercepts groundwater from the NDA. If radiological or nonradiological contamination were to migrate through the NDA, it would most likely be first detected in samples from WNNDATR.

Interceptor Trench and Pretreatment System. Radioactively-contaminated n-dodecane (similar to kerosene) in combination with tributyl phosphate (TBP) was discovered at the northern boundary of the NDA in 1983. To contain migration of this subsurface radioactive organic contaminant, an interceptor trench and a liquid pretreatment system (LPS) were built. (See NRC-Licensed Disposal Area [NDA] Interceptor Trench and Pretreatment System in Chapter 1 [p. 1-11].)

The trench was designed to intercept and collect subsurface water, which could be carrying ndodecane/TBP, to prevent the material from entering the surface water drainage ditch leading into Erdman Brook and to prevent contamination of downgradient groundwater. The LPS was installed to separate the n-dodecane/TBP and to remove iodine-129 from the collected water before its transfer to the LLWTF. The separated ndodecane/TBP would be stored for subsequent treatment and disposal.

In 2003, as in previous years, no water containing TBP was encountered in the trench. Results of surface and groundwater monitoring in the vicinity of the trench are discussed in Chapter 2 (South 
Plateau Surface Water and NDA Interceptor Trench [p. 2-9]) and in Chapter 4 (Results of Monitoring at the NDA [p. 4-11]).

Total Organic Halides. Total organic halides (TOX) measurements are used as a screening mechanism to detect the presence of certain organic compounds and associated radionuclides. In 2003, concentrations of TOX at both WNNDATR and WNNDADR remained within the range of historical values.

Other On-Site and Off-Site Surface Water Monitoring. As part of the routine monitoring program, two sets of grab samples for nonradiological parameters at WNSP006 (Frank's Creek at the security fence), WNSWAMP (northeast swamp drainage), WNSW74A (north swamp drainage), and WFBCBKG (Buttermilk Creek at Fox Valley) were taken in 2003. These samples were screened for organic and inorganic constituents and selected anions, cations, and metals. Results of measurements for these locations are found in Tables C-4C, C-3C, and C-3D .

In 2003 the parameter list for nonradiological analyses and surface water monitoring locations was modified from a groundwater-oriented to a surface-water-oriented program. At locations WNSP006, WFBCBKG, and WFBCTCB, analyses were added to assess water quality with respect to applicable New York Water Quality Standards for Class C waters. At locations WNSWAMP and WNSW74A, the parameter list was modified so as to better define ambient surface water conditions at these outfalls.

At surface water monitoring location points WNSW74A and WFBCTCB, monitoring location WNSP006, and background reference location WFBCBKG, the maximum concentrations of total iron exceeded the water quality standard $(0.30$ $\mathrm{mg} / \mathrm{L})$. NYSDEC, in its 2002 CWA 303(d) report to the EPA, indicated it found the scientific basis for the $0.30 \mathrm{mg} / \mathrm{L}$ standard to be insufficient. NYSDEC also indicated that the upcoming standards review is expected to include a proposed replacement of the $0.30 \mathrm{mg} / \mathrm{L}$ with a $1.0 \mathrm{mg} / \mathrm{L}$ guidance value, based on 1976 U.S. EPA criteria. Nonetheless, the elevated iron concentrations, in particular at WNSW74A, which also exceeds this replacement guidance value, is indicative of typical concentrations in water runoff from areas where industrial activities are occurring.

At water monitoring locations WNSW74A and WNSWAMP, the maximum TDS concentration exceeded the water quality standard of $500 \mathrm{mg} /$ L. Elevated TDS can result from runoff containing residuals from application of deicing materials (i.e., road salt). The elevated TDS concentrations at WNSW74A and WNSWAMP are believed to have resulted from runoff from site service roads and walkways where deicing materials are applied.

The maximum observed concentration of dissolved aluminum at surface water location WFBCTCB exceeded the water quality standard for this parameter. The elevated concentration at this location is indicative of, and is typical for, surface waters receiving water discharges from areas where industrial activities are occurring or have occurred.

Monitoring results for the standing water locations (WNSTAW series) are presented in Table C-4 $\mathrm{H}^{\mathrm{C}}$. The total iron concentration at WNSTAW5 (0.62 $\mathrm{mg} / \mathrm{L}$ ) exceeded the $0.3 \mathrm{mg} / \mathrm{L}$ standard for class "D" surface waters. The elevated iron concentration at this standing water location is thought to be attributable to naturally-elevated background concentrations of iron.

Monitoring results for $\mathrm{pH}$ at locations WNSP005, WFFELBR, WFBCTCB, WNFRC67, and 
WNDCELD are provided in Appendix $\mathrm{C}^{\mathrm{C}}$, Tables C-3A, C-4A, C-4B, C-4F, and C-4G. Although most $\mathrm{pH}$ values were within applicable standards, minimum results at WFFELBR, WNFRC67, and WNDCELD in 2003 were all below the lower pH limit of 6.5.

Low $\mathrm{pH}$ of precipitation in the western New York region may suppress $\mathrm{pH}$ in ambient surface waters, especially during times of high rainfall when precipitation runoff may account for a large proportion of stream flow. Average precipitation $\mathrm{pH}$, as measured near and on the WVDP in 2003, was about 4.5, with a low $\mathrm{pH}$ of 3.85. (See Appendix $\mathrm{D}^{\mathrm{C}}$, Tables D-22 through D-26 ${ }^{\mathrm{C}}$.)

\section{Drinking Water Monitoring}

Site drinking water is monitored to verify compliance with EPA and New York State Department of Health (NYSDOH) regulations. (See Safe Drinking Water Act [p. ECS-13] in the Environmental Compliance Summary.) Samples are collected annually and analyzed for nitrate, fluoride, cyanide, and metals concentrations. In addition, an annual sample was obtained for principal organic contaminants. The 2003 monitoring results indicated that the Project's drinking water met NYSDOH, EPA, and Cattaraugus County Health Department MCLs and drinking water quality standards.

Conductivity and $\mathrm{pH}$ in off-site and on-site drinking water are presented in Tables $\mathrm{C}-5 \mathrm{~A}^{\mathrm{C}}$ and $\mathrm{C}-5 \mathrm{~B}^{\mathrm{C}}$, respectively. Except for a $\mathrm{pH}$ of 6.42 at WFWEL05, below the lower limit of 6.5, all results were within applicable limits.

Results for inorganic, organic, and indicator analyses of utility room potable water at the distribution system entry point, location WNDNKUR, are listed in Table C-5C $\mathrm{C}^{\mathrm{C}}$. Monthly results for biological and residual chlorine analyses at site tap wa- ter locations are provided in Table $\mathrm{C}-5 \mathrm{E}^{\mathrm{C}}$. All results were within NYSDOH MCLs and EPA maximum contaminant level goals. The annual result for nitrate-nitrogen in a tap water sample from the WVDP restroom sink, as analyzed by the Cattaraugus County Department of Health (Table $\mathrm{C}-5 \mathrm{~F}^{\mathrm{C}}$ ), was also below the MCL.

\section{Soil and Sediment Monitoring}

Sediments are found at the bottom of surface waters, including streams located within the WVDP and WNYNSC premises. Sediments provide habitat for a wide variety of benthic organisms, as well as juvenile forms of pelagic organisms. These organisms in sediments are in constant contact with substances that may be adsorbed to sediment particles. Contaminated sediments are also potential diffuse sources of contamination to the overlying water body.

In 1999, NYSDEC issued updated guidance for screening contaminated aquatic sediments. This guidance includes sediment quality criteria correlated to the severity of environmental impact. These criteria, which are derived from National Oceanic and Atmospheric Administration (Long and Morgan, 1990) and 1992 Ministry of Ontario Guidelines for the Protection and Management of Aquatic Sediment Quality in Ontario (Persaud et al., 1992), are presented in Appendix G-1 ${ }^{\mathrm{C}}$, Table G-1B.

Contaminants in soils are potential sources for contamination of groundwater, ambient air, flora, and fauna. Table G-1 $\mathrm{A}^{\mathrm{C}}$ gives a summary of reference criteria, including background concentration ranges for eastern United States soils and sediment screening levels. Data for soil and sediment monitoring locations are provided in Appendix G-2 ${ }^{C}$. Also, provided for side-by-side comparison with these data, are reference val- 
ues, where available, including background concentrations and/or sediment screening levels.

At SNSP006, all analytical results for sediments were below the Severe Effect Level and No Appreciable Contaminant Levels specified in the NYSDEC guidance. According to the NYSDEC "Technical Guidance for Screening Contaminated Sediments," these results suggest there is no pronounced disturbance of the sediment-dwelling biological community and that there is no significant harm to benthic aquatic life at this location.

Results for arsenic, copper, manganese, and nickel in the sediment sample obtained at SNSP006 exceeded the Lowest Effect Level but were below the Severe Effect Level. Based on the NYSDEC sediment screening guidance, moderate impacts to benthic life could be expected at this location.

At SNSW74A and SNSWAMP, concentrations of zinc exceeded the eastern United States background soil concentration range identified in the NYSDEC Technical Administrative Guidance Memorandum \#4046 for "Determination of Soil Clean-Up Objectives and Clean-Up Levels." Calcium and magnesium at SNSW74A also exceeded the eastern background soil concentration range. Concentrations of these naturally-occurring metals above the natural background ranges may be indicative of localized, naturally-elevated background concentrations of metals in soils or deposition of sediment from runoff from areas where industrial activities are occurring.

\section{Air Emission Monitoring}

Nonradiological air emissions are permitted under NYSDEC and EPA regulations. (The regulations that apply to the WVDP are listed in Appendix $\mathrm{K}^{\mathrm{C}}$, Table K-2. The New York State Facility Air Permit held by the WVDP is described in Table ECS-8, West Valley Demonstration Project Envi- ronmental Permits [pp. ECS-26 and ECS-27] in the Environmental Compliance Summary.)

The nonradiological air permits are for emissions of regulated pollutants that include particulates, ammonia, nitrogen oxides, and sulfur dioxide. Emissions of oxides of nitrogen and sulfur are each limited to 99 tons per year.

The main contributing source of oxides of nitrogen and sulfur at the WVDP was the vitrification system melter, which was shut down in September 2002. Site boilers and standby diesel generators were left as the only contributors of nitrogen and sulfur oxides, at levels greatly reduced from those emitted by the melter. 


\section{SITE HYDROLOGY AND GROUNDWATER MONITORING}

\section{Groundwater Monitoring Program Overview}

Groundwater at the West Valley Demonstration Project (WVDP or Project) is monitored to comply with all applicable state and federal regulations and to meet the requirements of U.S. Department of Energy (DOE) Order 450.1. The program enables the WVDP to obtain data to determine baseline conditions, to allow the early detection of groundwater contamination, to identify existing and potential groundwater contamination sources and maintain surveillance of these sources, and to provide data for decision-making.

The WVDP's Groundwater Monitoring Plan outlines groundwater characterization, current groundwater sampling requirements, and support of long-term monitoring requirements identified in the Resource Conservation and Recovery Act (RCRA) facilities investigation (RFI) and DOE programs. The Groundwater Protection Management Program Plan provides additional information regarding protection of groundwater from on-site activities.

\section{Geologic History of the West Valley Site}

The Western New York Nuclear Service Center (WNYNSC) comprises approximately 3,345 acres
(1,354 hectares [ha]) and is located on the Allegheny Plateau near the northern border of Cattaraugus County in Western New York. The 164-acre (66-ha) WVDP site is located within the WNYNSC. Beneath the WNYNSC site is a sequence of Holocene (recent age) and Pleistocene (ice age) sediments filling a steep-sided valley incised in the bedrock. The bedrock is composed of shales and interbedded siltstones of the upper Devonian Canadaway and Conneaut Groups that dip southward at about $5 \mathrm{~m} / \mathrm{km}$ (Rickard, 1975).

Pleistocene sediments overlying the bedrock typically consist of a sequence of three glacial tills of Lavery, Kent, and possibly Olean age. The tills are separated by stratified fluvio-lacustrine deposits. In the northern part of the site, the Lavery till is capped by coarse-grained alluvial-fluvial deposits.

A summary of site hydrology is presented below. Hydrologic conditions of the site are more fully described in Environmental Information Document, Volume III: Hydrology, Part 4 (West Valley Nuclear Services Co. [WVNSCO], March 1996) and in the RCRAFacility Investigation Report Vol. 1: Introduction and General Site Overview (WVNSCO and Dames \& Moore, July 1997). 


\section{Surface Water Hydrology of the West Valley Site}

The WNYNSC lies within the Cattaraugus Creek watershed, which empties into Lake Erie about 27 miles (43 km) southwest of Buffalo. Buttermilk Creek, a tributary of Cattaraugus Creek, drains most of the WNYNSC and all of the WVDP site.

The WVDP lies within the watershed of Frank's Creek, which is a tributary of Buttermilk Creek and forms the eastern and southern boundary of the WVDP; Quarry Creek, a tributary of Frank's Creek, forms the northern boundary. (See Fig. A1 [p. A-1].)

Another tributary of Frank's Creek, Erdman Brook, bisects the WVDP into a north and south plateau. The main plant, waste tanks, and lagoons are located on the north plateau. The drum cell, the U.S. Nuclear Regulatory Commission (NRC)Licensed Disposal Area (NDA), and the New York State-Licensed Disposal Area (SDA) are located on the south plateau.

\section{Hydrogeology of the West Valley Site}

The WVDP site area is underlain by a sequence of glacial tills comprised primarily of clays and silts separated by coarser-grained interstadial sediments. Because the bottommost layer, the Kent till, is less permeable than the other geological units and does not provide a pathway for contaminant movement from the WVDP, it is not discussed here.

The sediments above the Kent till - the Kent recessional sequence, the Lavery till and the intraLavery till-sand, and the surficial sand and gravel - are generally regarded as containing all of the potential routes for the migration of contaminants (via groundwater) from the WVDP site. (Figs. 4-1 and 4-2 [facing page] show the relative loca- tions of these sediments on the north and south plateaus.) The Lavery till, the Kent recessional sequence, and the Kent till are common to both the north and south plateaus.

The WVDP does not use groundwater for drinking or operational purposes, nor does it discharge effluent directly to groundwater. No public water supplies are drawn from groundwater downgradient of the WVDP or from Cattaraugus Creek downstream of the WVDP. However, groundwater upgradient of the WVDP is used for drinking water by local residents.

Kent Recessional Sequence. The Kent recessional sequence consists of a fine-grained lacustrine unit of interbedded clay and silty clay layers locally overlain by coarse-grained sands and gravels. These deposits underlie the Lavery till beneath most of the site, pinching out along the southwestern margin of the site where the walls of the bedrock valley intersect the sequence.

Groundwater flow in the Kent recessional sequence is predominantly to the northeast, toward Buttermilk Creek. Hydraulic conductivity testing completed during the last several years indicates a mean value of $2 \mathrm{E}-01 \mathrm{ft} /$ day $(8 \mathrm{E}-05 \mathrm{~cm} / \mathrm{sec})$ or 2.6 in/day. Recharge comes from the overlying Lavery till and in-flow from the bedrock in the southwest, and discharge is to Buttermilk Creek.

Lavery Till. The Lavery till is predominantly an olive-gray, silty clay glacial till with scattered lenses of silt and sand. It underlies both the north and south plateaus and ranges up to 130 feet $(40 \mathrm{~m})$ in thickness beneath the active areas of the site, slightly increasing northeastward toward Buttermilk Creek and the center of the bedrock valley. Groundwater flow in the unweathered Lavery till is predominantly vertically downward at a relatively slow rate; recent hydraulic conductivity testing in the Lavery till during the last several years 
Hydrogeology of the West Valley Site

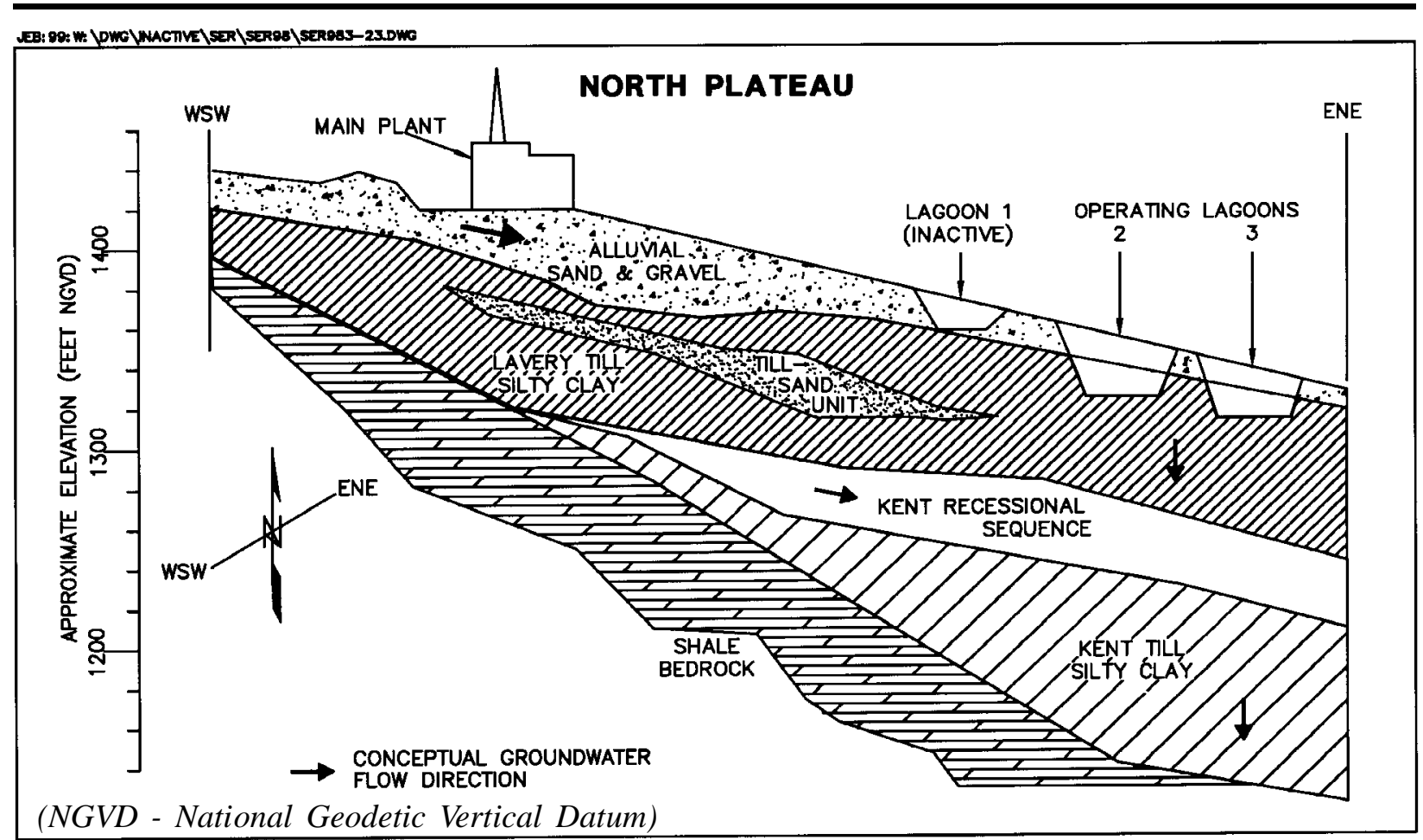

Figure 4-1. Geologic Cross Section Through the North Plateau (Vertical Exaggeration Approx. 2:1)

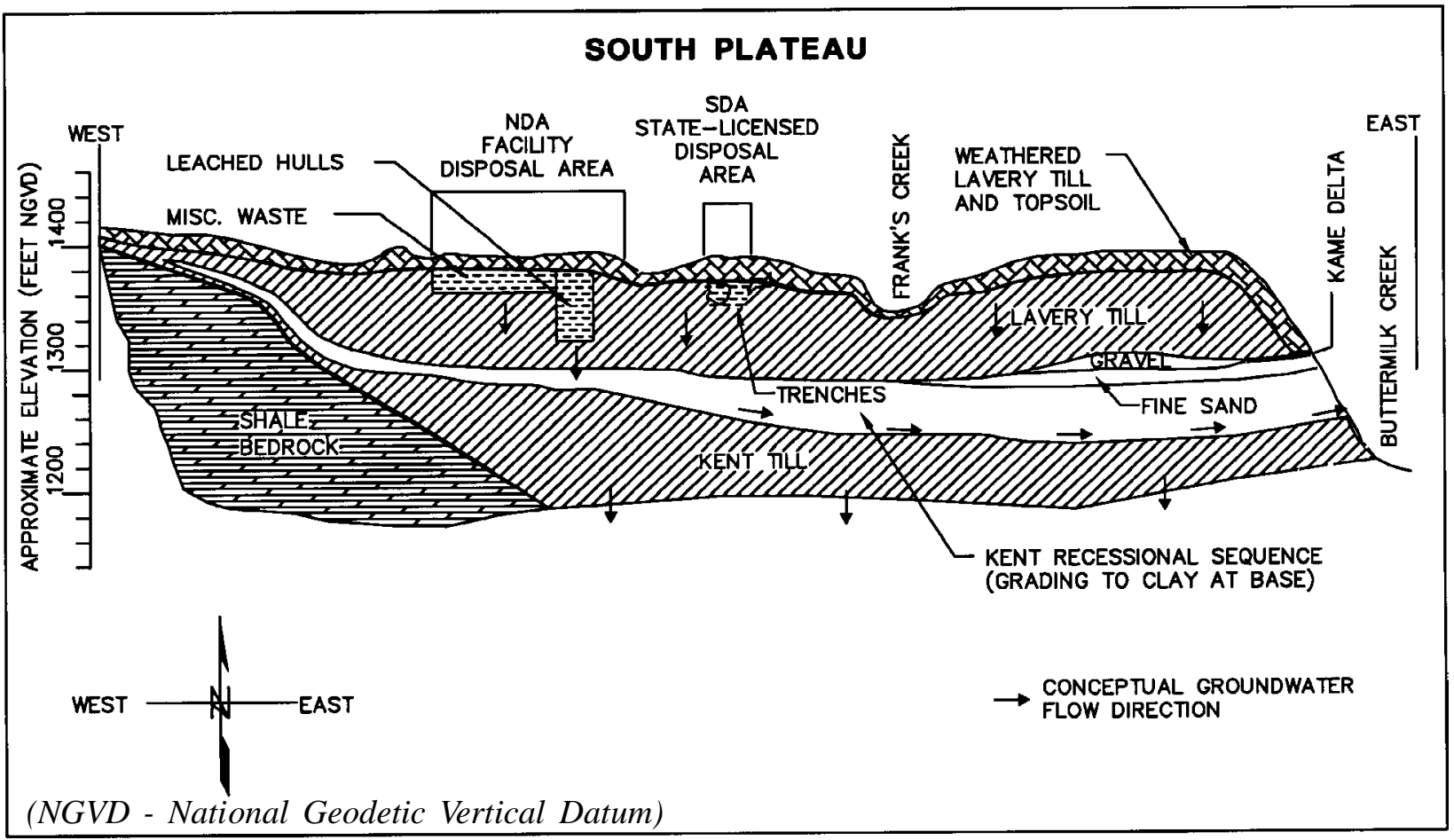

Figure 4-2. Geologic Cross Section Through the South Plateau (Vertical Exaggeration Approx. 2.5:1)

$$
4-3
$$


indicates a mean value of approximately $1 \mathrm{E}-04 \mathrm{ft} /$ day $(3.5 \mathrm{E}-08 \mathrm{~cm} / \mathrm{sec})$ or $0.001 \mathrm{in} /$ day. Some wells have produced hydraulic conductivity values as high as $3 \mathrm{E}-04 \mathrm{~cm} / \mathrm{sec}$, which may indicate the presence of sand lenses within the till.

On the south plateau, the upper zone of the Lavery till is exposed at the ground surface and is weathered and fractured to a depth of 3 to 16 feet $(0.9$ to $4.9 \mathrm{~m}$ ). This layer is referred to as the weathered Lavery till and is unique to the south plateau. The weathered Lavery till has been oxidized to a brown color and contains numerous desiccation cracks and root tubes.

Groundwater flow in the weathered till has both horizontal and vertical components. This enables groundwater to move laterally across the south plateau before moving downward into the unweathered Lavery till or discharging to nearby incised stream channels. Recent hydraulic conductivity testing in the weathered Lavery till indicates a mean value of $5 \mathrm{E}-02 \mathrm{ft} /$ day $(2 \mathrm{E}-05 \mathrm{~cm} /$ $\mathrm{sec}$ ) or $0.6 \mathrm{in} /$ day. The highest conductivities are associated with dense fracture zones found within the upper 7 feet $(2 \mathrm{~m})$ of the unit.

On the north plateau, the weathered till layer is much thinner or nonexistent and the unweathered Lavery till is overlain by the sand and gravel unit.

Sand and Gravel and Till-Sand Units. The sand and gravel unit and the Lavery till-sand are unique to the north plateau. The sand and gravel unit is a silty sand and gravel layer composed of younger Holocene alluvial deposits that overlie older Pleistocene-age glaciofluvial deposits. Together these two layers range up to 41 feet $(12.5 \mathrm{~m})$ in thickness near the center of the plateau and pinch out along the northern, eastern, and southern edges of the plateau, where they have been truncated by downward erosion of stream channels.
Groundwater in this unit generally flows northeastward across the plateau toward Frank's Creek. Groundwater near the northwestern and southeastern margins of the sand and gravel layer also flows radially outward toward Quarry Creek and Erdman Brook, respectively. There is minimal groundwater flow downward into the underlying Lavery till. Mean hydraulic conductivity is $\mathbf{1 6 . 4}$ feet/day $(6 \mathrm{E}-03 \mathrm{~cm} / \mathrm{sec})$ or $200 \mathrm{in} /$ day, based on recent testing.

Within the unweathered Lavery till on the north plateau is another unit, the Lavery till-sand. This thin, sandy unit of limited areal extent and variable thickness is found primarily beneath the southeastern portion of the north plateau. Groundwater flows through this unit in an east-southeast direction. Surface discharge locations have not been observed. The mean hydraulic conductivity of $3.8 \mathrm{ft} /$ day $(1 \mathrm{E}-03 \mathrm{~cm} / \mathrm{sec})$ or $46 \mathrm{in} /$ day for this unit is based on testing completed during the last several years.

\section{Routine Groundwater Monitoring Program}

Groundwater is monitored in the five hydrogeologic units previously described: the sand and gravel, the weathered Lavery till, the unweathered Lavery till, the Lavery till-sand, and the Kent recessional sequence. In 2003, a total of 69 groundwater monitoring locations were sampled. These locations included 63 monitoring wells (including driven well points), five groundwater seepage points, and one sump/manhole. (See Tables 4-1 and 4-2 [facing page] for a summary of groundwater monitoring activities in 2003.)

Monitoring Well Network. Most of the routine groundwater monitoring wells were originally assigned to monitor one (or more) of the super solid waste management units (SSWMUs) on the WVDP site. (See RCRA §3008(h) Administrative Order on Consent [p. ECS-4] and super solid 


\section{Table 4-1}

\section{Summary of Groundwater Monitoring Program by Geographic Area; Monitoring Year 2003}

\begin{tabular}{|l|c|c|c|c|}
\hline \multicolumn{1}{|c|}{ NUMBER OF... } & $\begin{array}{c}\text { TOTAL } \\
\text { WVDP* }\end{array}$ & $\begin{array}{c}\text { NORTH } \\
\text { PLATEAU }\end{array}$ & $\begin{array}{c}\text { SOUTH } \\
\text { PLATEAU }\end{array}$ & $\begin{array}{c}\text { OFF-SITE } \\
\text { RESIDENTIAL }\end{array}$ \\
\hline Monitoring Points Sampled - Analytical* & 79 & 54 & 15 & 10 \\
\hline Monitoring Points - Water Elevations Only & 42 & 26 & 16 & 0 \\
\hline Monitoring Events & 5 & 4 & 4 & 1 \\
\hline Analyses & 1,146 & 939 & 158 & 49 \\
\hline Results & 8,295 & 6,988 & 1,197 & 110 \\
\hline Percent of Nondetectable Results & $81 \%$ & $81 \%$ & $86 \%$ & $64 \%$ \\
\hline Water Elevation Measurements & 400 & 276 & 124 & 0 \\
\hline
\end{tabular}

* Total number of monitoring points sampled includes WVDP on-site (69 wells) and off-site (10 wells).

Table 4-2

\section{Summary of Groundwater Monitoring Program by Monitoring Purpose; Monitoring Year 2003}

\begin{tabular}{|l|c|c|}
\hline \multicolumn{1}{|c|}{ NUMBER OF... } & $\begin{array}{c}\text { REGULATORY/ } \\
\text { WASTE MANAGEMENT }\end{array}$ & $\begin{array}{c}\text { ENVIRONMENTAL } \\
\text { SURVEILLANCE }\end{array}$ \\
\hline Monitoring Points Sampled - Analytical & 34 & 45 \\
\hline Monitoring Points - Water Elevations Only & 0 & 42 \\
\hline Monitoring Events & 4 & 5 \\
\hline Analyses & 271 & 875 \\
\hline Results & 4,936 & 3,359 \\
\hline Percent of Nondetectable Results & $92 \%$ & $86 \%$ \\
\hline Water Elevation Measurements & 128 & 272 \\
\hline
\end{tabular}

* Total number of monitoring points sampled includes WVDP on-site (69 wells) and off-site (10 wells).

$4-5$ 
waste management unit in the Glossary [p. GLO12].)

Figures A-7 and A-8 (pp. A-7 and A-8) show boundaries of ten of the SSWMUs at the WVDP. Twenty-one additional wells in an eleventh SSWMU monitor the SDA and are the responsibility of the New York State Energy Research and Development Authority (NYSERDA). The SDA, a closed radioactive waste landfill, is contiguous with the Project premises and is owned and managed by NYSERDA. Groundwater monitoring results from the SDA are reported in Appendix $\mathrm{L}^{\mathrm{C}}$ but are not discussed here.

Table E-1 ${ }^{\mathrm{C}}$ in Appendix E lists the 11 SSWMUs monitored by the well network, the hydraulic position of each well relative to the SSWMU, the geologic unit monitored, and the analytes measured in 2003. The wells monitoring a given hydrogeologic unit (e.g., sand and gravel, weathered Lavery till) also are arranged in a generalized upgradient to downgradient order, based upon their location within the entire hydrogeologic unit. The hydraulic position of a well relative to an SSWMU (upgradient or downgradient) is independent of the same well's position within its hydrogeologic unit. For example, a well that is upgradient in relation to an SSWMU may be located at any position within its hydrogeologic unit within the boundaries of the WVDP, depending on the geographic position of the SSWMU relative to the hydrogeologic unit. Note that monitoring of certain wells, marked by an asterisk, was specified in RFI reports prepared in accordance with the RCRA $\$ 3008(\mathrm{~h})$ Administrative Order on Consent for the WVDP.

Potentiometric (water level) measurements also are collected from wells listed in Table E- $1^{\mathrm{C}}$ in conjunction with the quarterly analytical sampling schedule. (See Appendix E ${ }^{\mathrm{C}}$ [p. E-3].) Groundwater elevation data are used to produce groundwater contour maps, which delineate flow directions and gradients, and long-term trend graphs, which illustrate seasonal fluctuations and other changes in the groundwater system. In 2003, water levels were routinely measured at 42 locations in addition to those that were sampled.

Surface water elevation measurements are also collected at 11 locations on the north plateau where the water table in the sand and gravel unit intersects the ground surface in the form of standing water. These measurements are correlated with groundwater elevation measurements taken at monitoring wells, and are used to help define groundwater flow direction and gradients in the sand and gravel unit in areas where monitoring well coverage is sparse or nonexistent.

\section{Groundwater Monitoring Program Highlights} 1982 Through 2003. Program content is dictated by regulatory requirements in conjunction with current operating practices and historical knowledge of previous site activities.

- Groundwater monitoring at the WVDP began in 1982 with sampling for tritium in the sand and gravel unit in the area of the lagoon system.

- By 1984, 20 wells in the vicinity of the main plant and the NDA provided monitoring coverage.

- Fourteen new wells, a groundwater seep location, and the french drain outfall were added in 1986 to monitor additional site facilities.

- In 1990, 96 new wells were installed for data collection for the environmental impact statement and RCRA facility investigations.

- ARCRA facility investigation expanded-characterization program was conducted during 1993 and 1994 to fully assess potential releases of hazardous wastes or constituents from on-site SSWMUs. This investigation, which consisted of two rounds of sam- 
pling for a wide range of radiological and chemical parameters, provided valuable information regarding the presence or absence of groundwater contamination near each SSWMU and was also used to guide later monitoring program modifications.

- In 1993, monitoring results indicated elevated gross beta activity in groundwater in the sand and gravel unit on the north plateau. Subsequent investigation of this area delineated a plume of contamination with a southwest to northeast orientation. (See Special Groundwater Monitoring [p. 4-12] for more detail.)

- Long-term monitoring needs were the focus of a 1995 groundwater monitoring program evaluation. After a comprehensive assessment, the number of sampling locations was reduced from 91 to 65 and analytical parameters were tailored for each sampling location for a more focused, efficient, and cost-effective program.

- In 1996, several groundwater seep monitoring locations on the northeast edge of the north plateau were added to the monitoring program.

- From 1996 through 2003, in response to current sampling results and DOE and RCRA monitoring requirements, specific monitoring locations, analytes, and sampling frequencies were modified.

- Four new groundwater monitoring wells were installed during August 2003 in the vicinity of the remote-handled waste facility (RHWF). Two of the new wells provide monitoring coverage upgradient of the RHWF in the sand and gravel and unweathered Lavery till units. The two remaining new wells, in conjunction with existing wells, provide downgradient coverage of the RHWF within hydrogeologic units. Initial sampling of the new wells took place as part of the fourthquarter 2003 monitoring event to establish pre-operational conditions. Initial monitoring parameters included radiological indicators; Title 6 of the New York Official Compilation of Codes, Rules, and Regulations (NYCRR), Appendix 33 volatile organic compounds (VOCs), semivolatile organic compounds (SVOCs), and metals; and selected radioisotopes.

Annual Analytical Trigger Level Review. A computerized data-evaluation program using "trigger levels" for chemical and radiological analytes was instituted in 1995. These pre-set levels - conservative values for chemical or radiological concentrations - were developed to identify and expedite a prompt focus on any anomalies in monitoring results. These values are based on regulatory limits, detection limits, or statistically-derived levels. Trigger levels are reviewed and updated annually. Upper and lower trigger levels for groundwater elevation measurements were introduced in 1999.

\section{Results of Routine Groundwater Monitoring}

Tables in Appendix $\mathrm{E}^{\mathrm{C}}$ group the results of groundwater monitoring within the five hydrogeologic units monitored: the sand and gravel unit, the Lavery till-sand unit, the weathered Lavery till unit, the unweathered Lavery till unit, and the Kent recessional sequence. These tables contain results of sampling for radiological and nonradiological analytes. In addition, Table E- $14^{\mathrm{C}}$ lists the practical quantitation limits (PQLs) for individual NYCRR Title 6, Appendix 33 analytes. The PQL is the lowest level of an analyte that can be measured within specified limits of precision during routine laboratory operations (New York State Department of Environmental Conservation, 1991).

Appendix $\mathrm{E}^{\mathrm{C}}$ tables also provide each well's hydraulic position relative to other wells within the same hydrogeologic unit. Wells identified as UP 
refer to either background wells or wells that are upgradient of other wells in the same hydrogeologic unit. Wells identified as DOWN are downgradient of other wells in that unit. In each table, wells are presented from upgradient to furthest downgradient. Grouping the wells by hydraulic position provides the basis for presenting groundwater monitoring data in the tables and figures in this report.

Data Tables. Groundwater monitoring data for 2003 are presented in Tables E-2 through E-13 C in Appendix $E^{C}$. Where positive results were obtained, a bolding convention was applied to the data series indicating the high and low values, with a "positive" defined as a result exceeding the PQL for the particular analysis. Additional details regarding the bolding convention are presented on page $\mathrm{E}-2^{\mathrm{C}}$.

Trend-Line Graphs. Trend-line graphs are shown for monitoring locations that have historically shown radiological concentrations above background values, or VOC or SVOC concentrations above PQLs.

Long-Term Trends of Gross Beta and Tritium at Selected Groundwater Monitoring Locations. Figures 4-5 through 4-8 (pp. 4-16 and 4-17) show the trends of gross beta and tritium concentrations at selected monitoring locations in the sand and gravel unit. Use of a logarithmic scale allows locations having widely differing concentrations to be compared to average background concentrations plotted on each graph.

Gross Beta. The groundwater plume of gross beta activity in the sand and gravel unit on the north plateau (Fig. 4-3 [facing page]) continues to be monitored closely. The source of the plume's activity can be traced to the subsurface beneath the southwest corner of the former process building. In 2003, 11 wells $(104,105,111,408,501,502$, $801,8603,8604,8605$, and 8609) showed gross

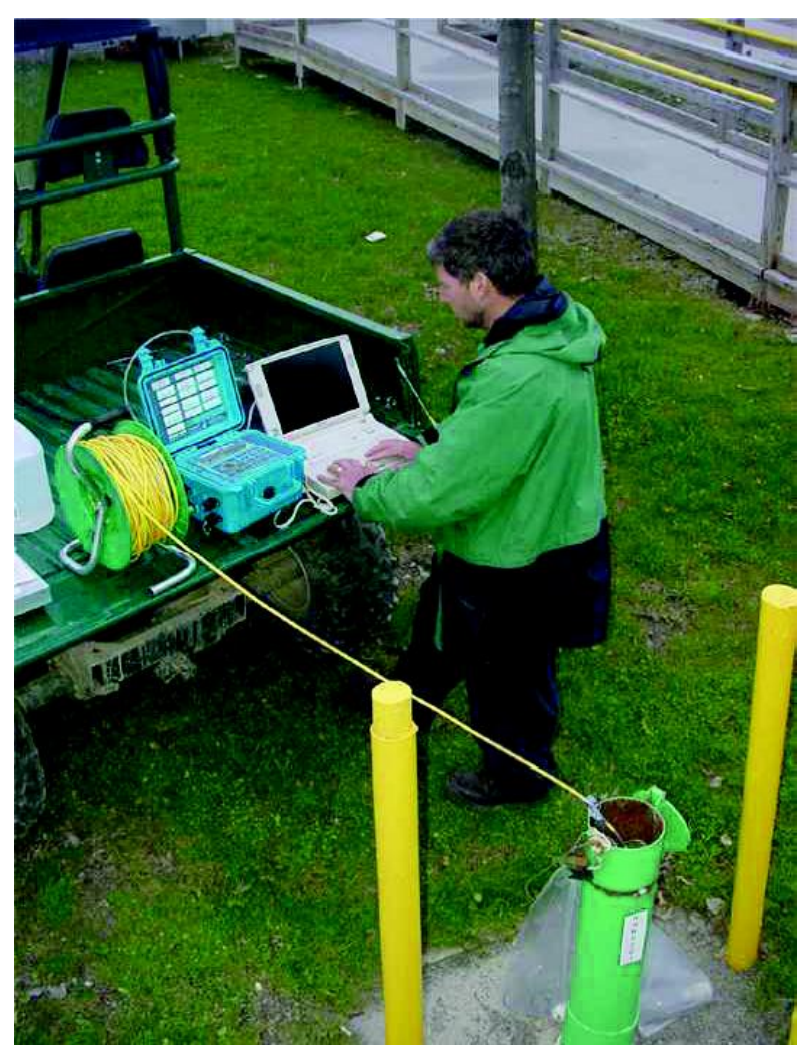

Using a Datalogger to Record Hydraulic Conductivity Data From an On-Site Monitoring Well

beta concentrations that exceeded the DOE derived concentration guide (DCG) for strontium$90(1.0 \mathrm{E}-06 \mu \mathrm{Ci} / \mathrm{mL})$. Lagoon 1 , formerly part of the low-level waste treatment facility, has been identified as a source of the gross beta activity at wells 8605 and 111 .

- Figures 4-5 and 4-6 (p. 4-15) show gross beta in wells 408, 501, 502, 8604, and 8609 (which are somewhat centrally located on the north plateau and are closer to the plume's suspected source beneath the main plant) and wells 104, 105, 116, 801 , and 8603 (which are located generally further northeast, nearer the leading edges of the gross beta plume), respectively. As in previous years, samples from well 408 continued to show the highest gross beta concentrations of all the wells within the north plateau gross beta plume 


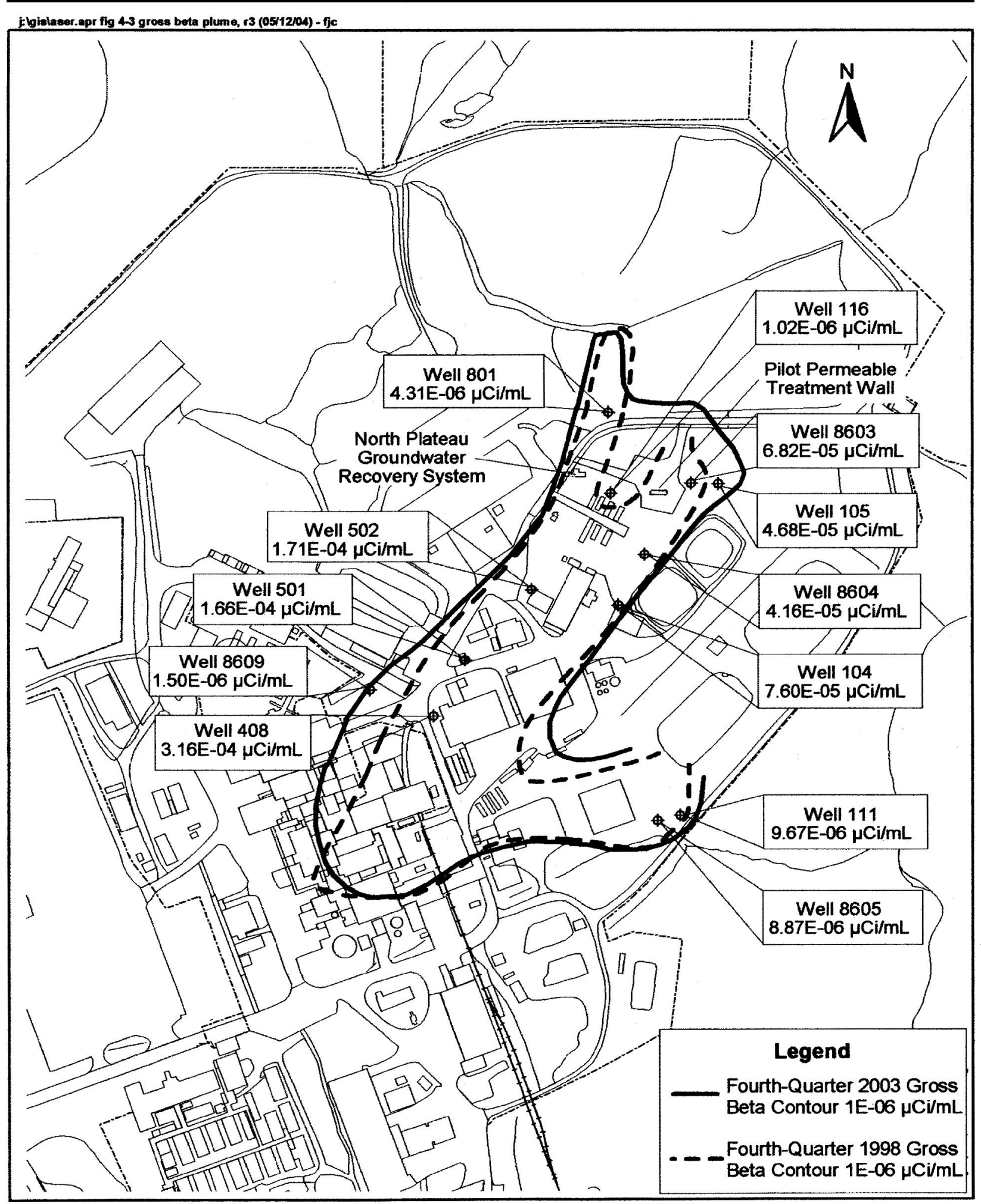

Figure 4-3. North Plateau Gross Beta Plume Area: Fourth-Quarter 2003 Results

$4-9$ 
area. Gross beta results for well 408 in 2003 were somewhat lower than 2002 results.

Wells 501, 502, and 801 showed slight decreases relative to 2002 . Wells $104,105,116,8603,8604$, and 8609 showed increases relative to 2002 values. Well 105 shows the largest overall increase over the last ten years.

- Figure 4-7 (p. 4-17) is a graph of gross beta concentrations at sand and gravel unit monitoring locations 111 and 8605 , located near the eastern edge of the north plateau adjacent to former lagoon 1. Gross beta concentrations at well 111 were slightly higher in 2003 than in 2002 . In well 8605 , gross beta results for 2003 were similar to 2002 results, but overall a decreasing trend is evident from 1994 to the present.

Tritium. Tritium in sand and gravel wells also is routinely monitored as part of the groundwater program.

- Figure 4-8 (p. 4-17) shows the tritium concentrations in wells $111,8603,8604,8605$, and 8609. The figure indicates that tritium concentrations in these wells mainly show slight decreases or relatively consistent trends. Well 111 has had slight increases during the last two years.

North Plateau Seeps. Analytical results of sampling for radiological parameters from the sand and gravel unit seepage monitoring locations were compared with results from GSEEP, a seep monitored since 1991 that has not been affected by the gross beta plume. (Seep monitoring locations are noted on Figs. A-6 and A-7 [pp. A-6 and A-7].)

Gross Beta. Radiological monitoring results continue to indicate that the gross beta groundwater plume has not migrated to these seepage areas. With the exception of SP11, gross beta concentrations from all seep monitoring locations were less than or similar to GSEEP concentrations during 2003. Gross beta concentrations at SP11 show a slightly increasing trend since early 1999 and somewhat steeper increases during 2001 through 2003. Contamination observed at SP11 is believed to be attributable to re-infiltration of contaminated water that has surfaced from the strontium-90 groundwater plume. Although somewhat greater than values typically obtained at GSEEP, it is still well below the strontium-90 DCG. (See Table E-7 ${ }^{\mathrm{C}}$.)

Gross Alpha. Gross alpha concentrations at all of the seep sampling locations were very low - generally below the associated uncertainty or less than the detection limit.

Tritium. Tritium concentrations at the seeps remained similar in magnitude or were less than concentrations at GSEEP. Tritium concentrations in the north plateau seeps, including GSEEP, are slightly above levels reported in background wells of the sand and gravel unit. Concentrations are similar to those seen in sand and gravel unit wells monitoring the lagoon areas of the north plateau, but are still far below the DCG for tritium.

North Plateau Well Points. Sampling at well points A, C, and H (Fig. A-6 [p. A-6]) monitors tritium concentrations in the area east of the process building and fuel receiving and storage facility and west of former lagoon 1. Samples from these three locations have yielded concentrations of tritium that, while elevated with respect to historical monitoring of wells in the area, are well below the DCG of $2.0 \mathrm{E}-03 \mu \mathrm{Ci} / \mathrm{mL}$. (See Table E- $8^{C}$.) Data from downgradient monitoring wells have not indicated similarly elevated levels of tritium.

Results of Radioisotopic Sampling. Groundwater samples for radioisotopic analyses are collected regularly from selected monitoring points in the sand and gravel unit and the weathered 


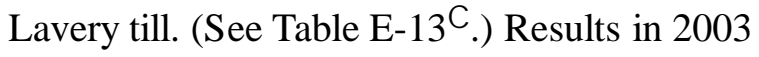
were generally similar to historical findings. Strontium-90 remained the major contributor to elevated gross beta activity in the plume on the north plateau, as indicated by the similarity between strontium-90 trends and gross beta trends in wells showing elevated gross beta results.

Carbon-14, technetium-99, and iodine-129, which have been detected at several monitoring locations at concentrations above background levels, contribute very small percentages to total gross beta concentrations. These detections have occurred at locations within the gross beta plume and downgradient of former lagoon 1 and the NDA. None of the concentrations of carbon-14, technetium-99, or iodine-129 have been above DCGs, and gross beta analyses continue to provide appropriate trend surveillance on a quarterly basis.

Results of Monitoring at the NDA. A trench system was constructed along the northeast and northwest sides of the NDA to collect groundwater that may be contaminated with a mixture of ndodecane and tributyl phosphate (TBP). (See also Chapter 1, Environmental Program Information, NRC-Licensed Disposal Area [NDA] Interceptor Trench and Pretreatment System [p. 1-11].) There were no monitoring results in 2003 that indicated the presence of TBP or n-dodecane in groundwater in the vicinity of the NDA. Groundwater levels are monitored quarterly in and around the trench to ensure that an inward gradient is maintained, thereby minimizing outward migration of potentially-contaminated groundwater.

Gross beta and tritium concentrations in samples from location WNNDATR, a sump at the lowest point of the interceptor trench, and from well 909 (Fig. A-6 [p. A-6]), which is downgradient of WNNDATR, continued to be elevated with respect to background monitoring locations on the south plateau but were still well below the DCGs.
WNNDATR. During 2003, gross beta concentrations at WNNDATR were similar to those seen during 2002, but tritium, while still higher than at other NDA monitoring locations, shows an overall decrease.

Well 909. Radiological indicator results have historically fluctuated at this location but, in general, upward long-term trends in both gross beta and tritium were discernible at well 909 until 1999, when both trends declined, followed by relatively consistent results during recent years. Gross beta concentrations from well 909 are somewhat higher than at NDATR. Residual soil contamination near well 909 is the suspected source of elevated gross beta concentrations.

Off-Site Groundwater Monitoring. Groundwater is used as a potable water supply at off-site private residences near the WVDP. Nine off-site residential supply wells located within 4.3 miles $(7 \mathrm{~km})$ of the facility were sampled for radiological parameters in 2003. A tenth private well, located 18 miles $(29 \mathrm{~km})$ south of the site, provided a background location. These monitoring results are discussed in Chapter 2 (p. 2-12), Overview of Drinking Water Monitoring.

Results for Volatile and Semivolatile Organic Compounds. VOCs and SVOCs were sampled at specific locations (wells 8612, 8609, 803, 8605, 111, and seep sampling location SP12 [Fig. A-6, p. A-6]) that have shown historical results above their respective practical quantitation limits. (See Table E-14 ${ }^{\mathrm{C}}$ for a list of PQLs.) Other monitoring locations are sampled for VOCs and/or SVOCs because they are downgradient of locations that have shown positive results or to comply with the RCRA §3008(h) Administrative Order on Consent.

1,1-Dichloroethane (1,1-DCA). Concentrations of 1,1-DCA at well 8612 decreased during 19951998 and then leveled off during 1999-2003. (See 
Fig. 4-9 [p. 4-18].) The compound was not detected at wells 8609,803 , or groundwater seep SP12 during 2003. (See Table E-9C.)

Dichlorodifluoromethane (DCDFMeth). DCDFMeth was detected at wells 803 and 8612 during 2003 at estimated concentration levels below the PQL. (See Table E-9C.)

1,1,1-Trichloroethane (1,1,1-TCA). The compound 1,1,1-TCA was detected in wells 8609 and 8612 during 2003 at levels below the PQL, but was not detected in well 803 or in seep SP12. (See Table E-9 ${ }^{C}$ for VOC concentrations at these locations and Fig. 4-9 [p. 4-18] for a graph of 1,1,1TCA concentrations at well 8612.)

Total 1,2-Dichloroethylene (1,2-DCE-t). Positive detections of 1,2-DCE-t were first noticed at well 8612 in 1995. Concentrations of 1,2-DCE-t increased from 1995 through 2002, but the trend has leveled from 2002 through 2003, and during 2003 concentrations were similar to or slightly lower than those measured during 2002. (See Fig. 4-9 [p. 4-18].)

The VOCs 1,1-DCA, DCDFMeth, and 1,1,1-TCA are often found in combination with each other and with 1,2-DCE-t. In well 8612, each of these three compounds first exhibited an increasing trend that, over the past few years, was then followed by a decreasing trend. It is expected that 1,2DCE-t will exhibit similar behavior, and continued routine monitoring will evaluate future trends.

Tributyl Phosphate. Concentrations of TBP were detected in 2003 groundwater samples from well 8605 , near former lagoon 1 , at concentrations similar to those in 2002, and within the range of historical results. TBP also was previously detected in well 111, located near well 8605 , but at levels much lower than those at well 8605 . However, there were no positive detections of TBP at well
111 during 2003. (See Figure 4-10 [p. 4-18] and Table E-10 ${ }^{\mathrm{C}}$.)

Ongoing detection of TBP in this localized area maybe related to previously-detected, positive concentrations of iodine-129 and uranium-232 in wells 111 and 8605, as noted in previous Annual Site Environmental Reports. The presence of these three contaminants may reflect residual contamination from liquid waste management activities in the former lagoon 1 area during earlier nuclear fuel reprocessing. Future trends of TBP will be evaluated as part of the routine groundwater monitoring program.

\section{Special Groundwater Monitoring}

Gross Beta Plume on the North Plateau. Elevated gross beta activity has been detected in groundwater from the surficial sand and gravel unit in areas north and east of the building where Nuclear Fuel Services, Inc. reprocessed nuclear fuel (Fig. 4-3 [p. 4-9]). In December 1993, elevated gross beta concentrations were detected in surface water at former sampling location WNDMPNE, located near the edge of the plateau. This detection initiated a subsurface groundwater and soil investigation in 1994 using a Geoprobe ${ }^{\circledR}$ mobile sampling system, which helped to identify the location and extent of the gross beta plume beneath and downgradient of the former process building.

The highest gross beta concentrations in groundwater and soil were found near the southeast corner of the process building. Strontium-90 and its daughter product, yttrium-90, were identified as the major isotopic components of this elevated gross beta activity (WVNSCO, 1995).

In 1995, the north plateau groundwater recovery system (NPGRS) was installed to minimize the advance of the gross beta plume. The NPGRS is 
located near the leading edge of the western lobe of the plume where groundwater flows preferentially toward the edge of the plateau, seeps into a ditch, and flows as surface water toward monitoring location WNSWAMP. (See Northeast Swamp Drainage Monitoring [this page].) The NPGRS consists of three wells that extract contaminated groundwater, which is then treated by ion exchange to remove strontium-90. Treated water is transferred to the lagoon system and ultimately is discharged to Erdman Brook.

The north plateau groundwater recovery system operated successfully throughout 2003 , processing about 4.5 million gallons (17.0 million liters). The system has recovered and processed approximately 34 million gallons (128 million liters) since November 1995.

More attention was given in 1998 to the core area of the plume, determined to be beneath and immediately downgradient of the former process building. The 1998 study noted that, while the overall distribution of strontium-90 in groundwater within the plume was similar to 1994 , concentrations detected in 1998 samples were generally lower than in 1994 samples, due to radioactive decay and continuing migration and dispersion of the plume (WVNSCO, June 1999).

Permeable Treatment Wall. A pilot-scale permeable treatment wall (PTW) was completed in 1999 in the eastern lobe of the north plateau plume in order to test this passive, in-situ remediation technology. The PTW is a trench constructed in the subsurface and backfilled with clinoptilolite, a medium selected for its ability to adsorb strontium90 ions from groundwater. The PTW extends vertically downward through the sand and gravel unit to the top of the underlying Lavery till and is approximately 30 feet long and 10 feet wide ( 9 meters long by 3 meters wide).
Monitoring and evaluation of water levels and radiological concentrations upgradient, within, and downgradient of the PTW continued during 2003 in order to assess its effectiveness. Additional test borings and monitoring well installations were completed in the vicinity of the PTW during the fall of 2001 to obtain improved definition of hydrogeologic conditions. Hydraulic testing in the new wells was completed during 2002. The evaluation concluded that complex hydrogeologic conditions and disturbances from the installation are influencing groundwater flow into and around the pilot PTW.

Northeast Swamp Drainage Monitoring. Routine surface water sampling during 2003 continued to monitor radioactivity levels in surface water flowing through the outlet location WNSWAMP. (See Appendix $\mathrm{C}^{\mathrm{C}}$, Table C-3D ${ }^{\mathrm{C}}$.) Gross beta and strontium-90 concentrations continued to fluctuate due to seasonal effects. Annualized average strontium-90 concentrations steadily decreased during most of the year, dropping below the DOE DCG by about mid-summer. (See Fig. 4-4 [p. 414].) This decreasing trend may be due to a combination of factors, including the operation of the NPGRS, which removes groundwater containing strontium-90 from the subsurface, thereby decreasing the amount of radioactivity migrating to WNSWAMP, and dilution (from groundwater recharge and surface runoff) of any existing radioactivity present in the subsurface prior to NPGRS operations. The main source of the elevated strontium-90 is seepage of groundwater affected by the north plateau plume into a ditch upstream of WNSWAMP.

Although the annualized average concentration of strontium-90 in surface water decreased at sampling location WNSWAMP (on the WVDP premises), concentrations remained elevated with respect to background. Even so, monitoring downstream at the first point of public access (WFFELBR) continued to show strontium-90 con- 
centrations that were not significantly different from background (WFBIGBR) concentrations. (See also Northeast Swamp and North Swamp Drainage [p. 2-6] in Chapter 2, Environmental Radiological Program Information.)

\section{North Plateau Groundwater Quality Early} Warning Monitoring. Early-warning monitoring of water recovered by the NPGRS is important because this water is ultimately discharged off-site via the New York State Pollutant Discharge Elimination System (SPDES) outfall 001. Quarterly monitoring results from well 502, located directly upgradient of the NPGRS, can be used to identify analytical concentrations in groundwater that may affect compliance with the SPDES-permitted effluent limits. Results of sampling for metals at well 502 can be found in Tables E-11 and E-12C.

Investigation of Chromium and Nickel in the Sand and Gravel Unit and Evaluation of Corrosion in Groundwater Monitoring Wells. A 1997 and 1998 study of the effect of modifying sampling equipment and methodology on concen- trations of chromium and nickel in samples of groundwater from the sand and gravel unit noted that such modifications did produce decreases in chromium and nickel concentrations. This supported the hypothesis (which is documented in the technical literature) that elevated concentrations were not representative of actual groundwater conditions, but were caused by release of metals from subsurface corrosion of stainless-steel well materials (WVNSCO and Dames \& Moore, June 1998).

To ensure continued monitoring-well integrity and collection of high-quality samples representative of actual groundwater conditions, wells are periodically inspected for corrosion. Approximately threefourths of the stainless-steel wells monitoring the sand and gravel unit were internally inspected for corrosion during 2001. Wells containing corrosion were cleaned using simple brushing and purging techniques. Cleaned wells were reinspected to verify that corrosion had been removed.

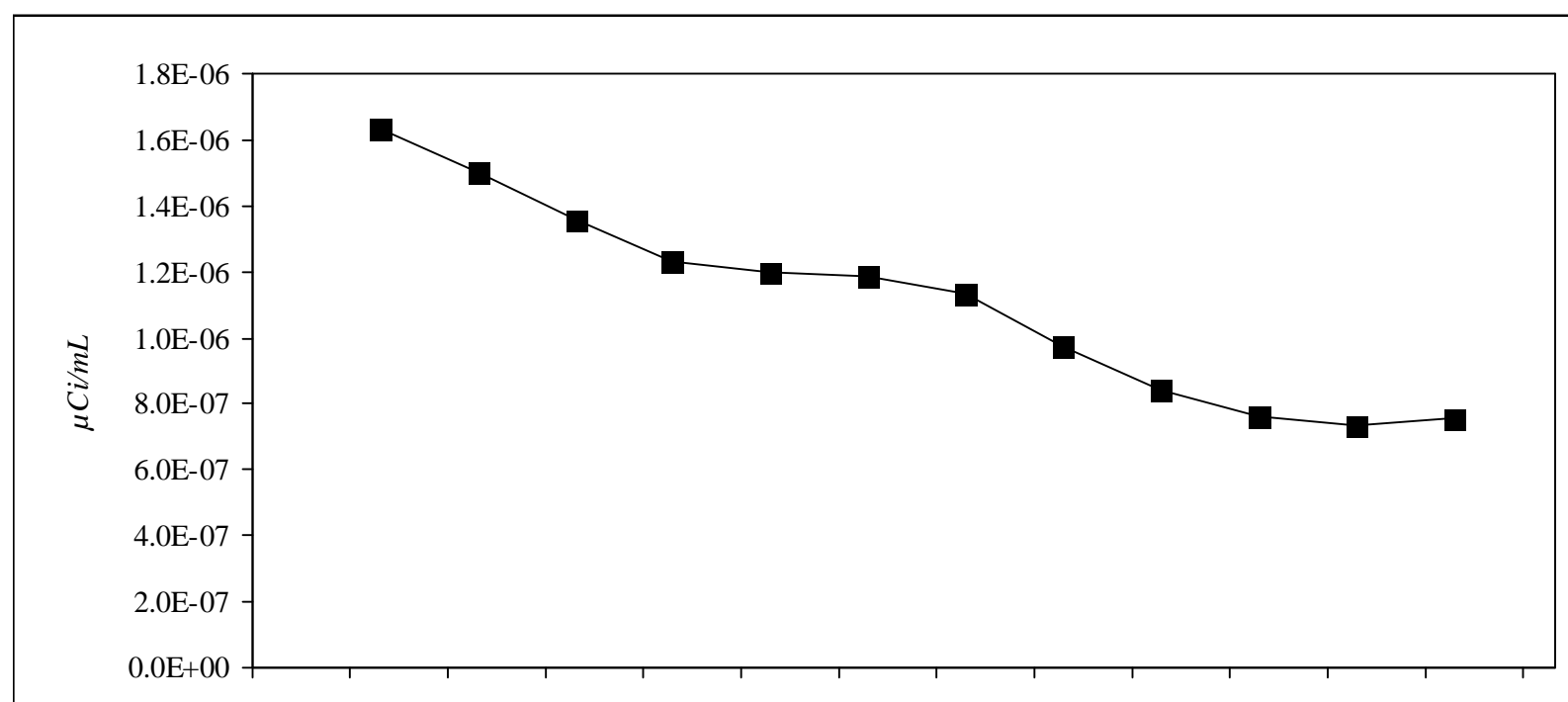

Dec-02 Jan-03 Feb-03 Mar-03 Apr-03 May-03 Jun-03 Jul-03 Aug-03 Sep-03 Oct-03 Nov-03 Dec-03 Jan-04

Strontium-90

Figure 4-4. Annualized Average Strontium-90 Concentrations at WNSWAMP

$$
4-14
$$


Ten-Year Sampling Pump Inspections. Dedicated bladder pumps were installed in many WVDP monitoring wells in 1991. (See Groundwater Sampling Methodology [Appendix $E^{C}$, $p$. E-2].) Pumps in all actively sampled wells were removed and inspected during 2001 to evaluate pump conditions after ten years of use. All pumps were found to be in good, serviceable condition during the 2001 inspection and during routine quarterly sampling activities in 2002 and 2003.

$4-15$ 
Chapter 4. Site Hydrology and Groundwater Monitoring

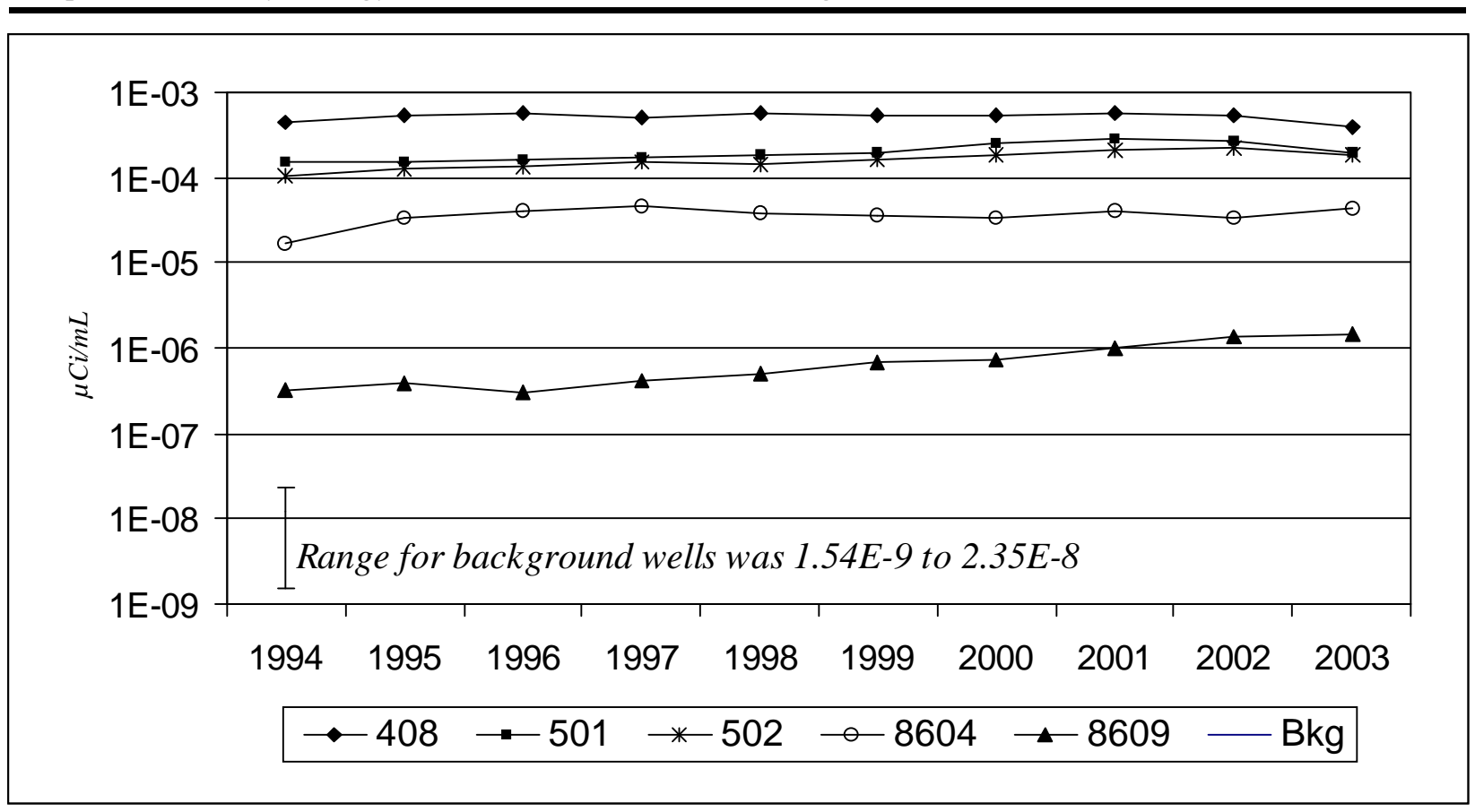

Figure 4-5. Average Yearly Gross Beta Concentrations at Selected Locations in the Sand and Gravel Unit

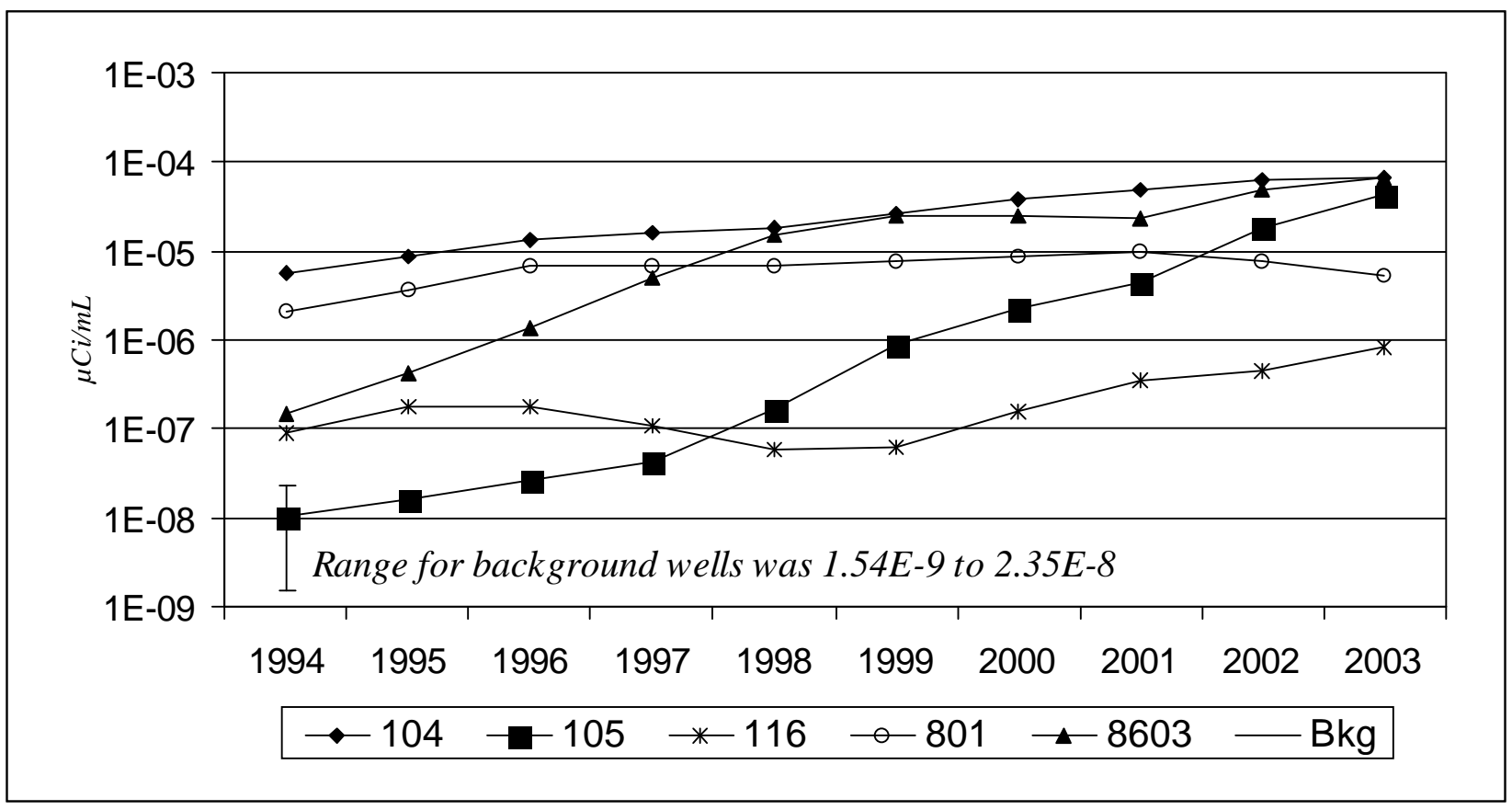

Figure 4-6. Average Yearly Gross Beta Concentrations at Selected Locations in the Sand and Gravel Unit 


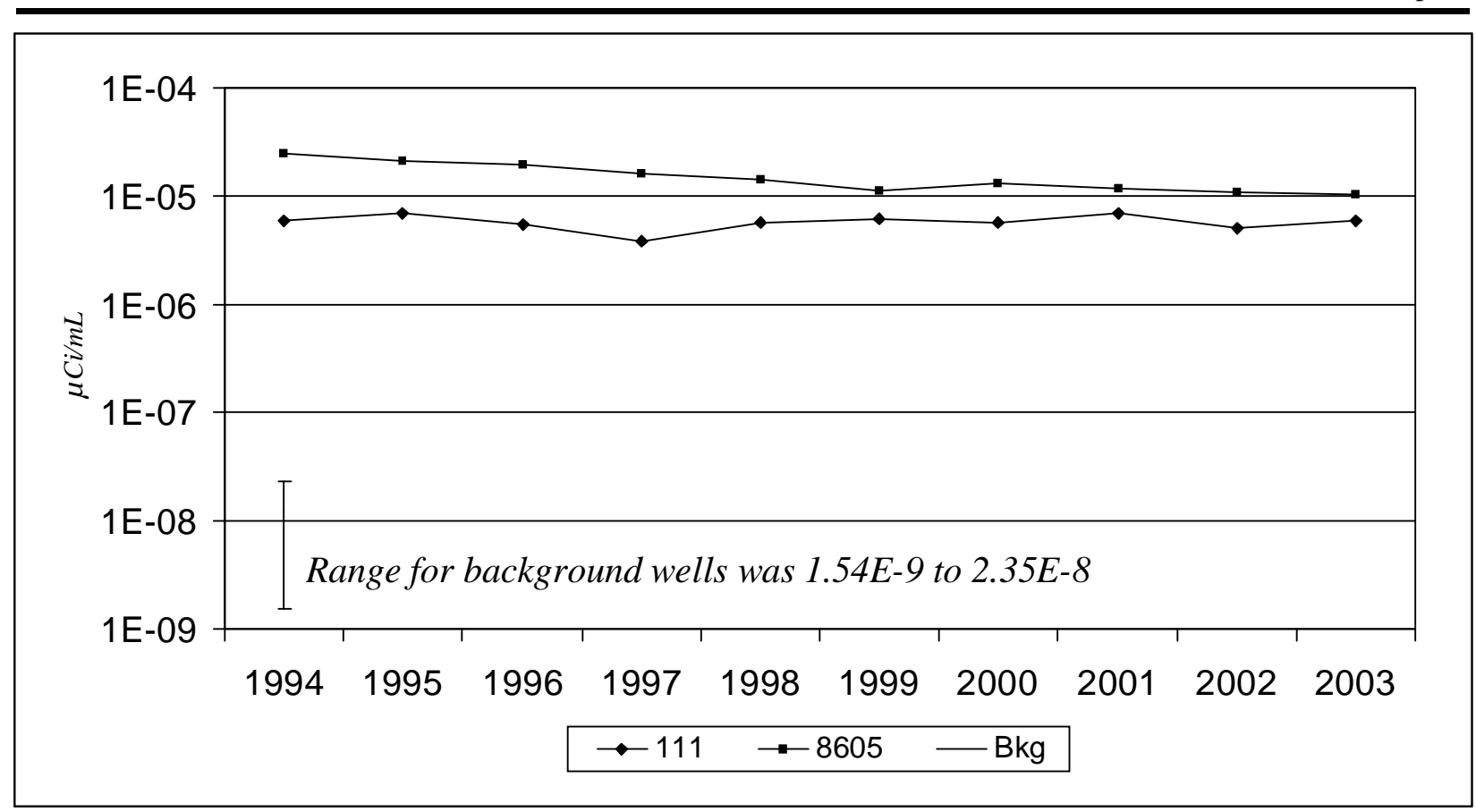

Figure 4-7. Average Yearly Gross Beta Concentrations at Selected Locations in the Sand and Gravel Unit

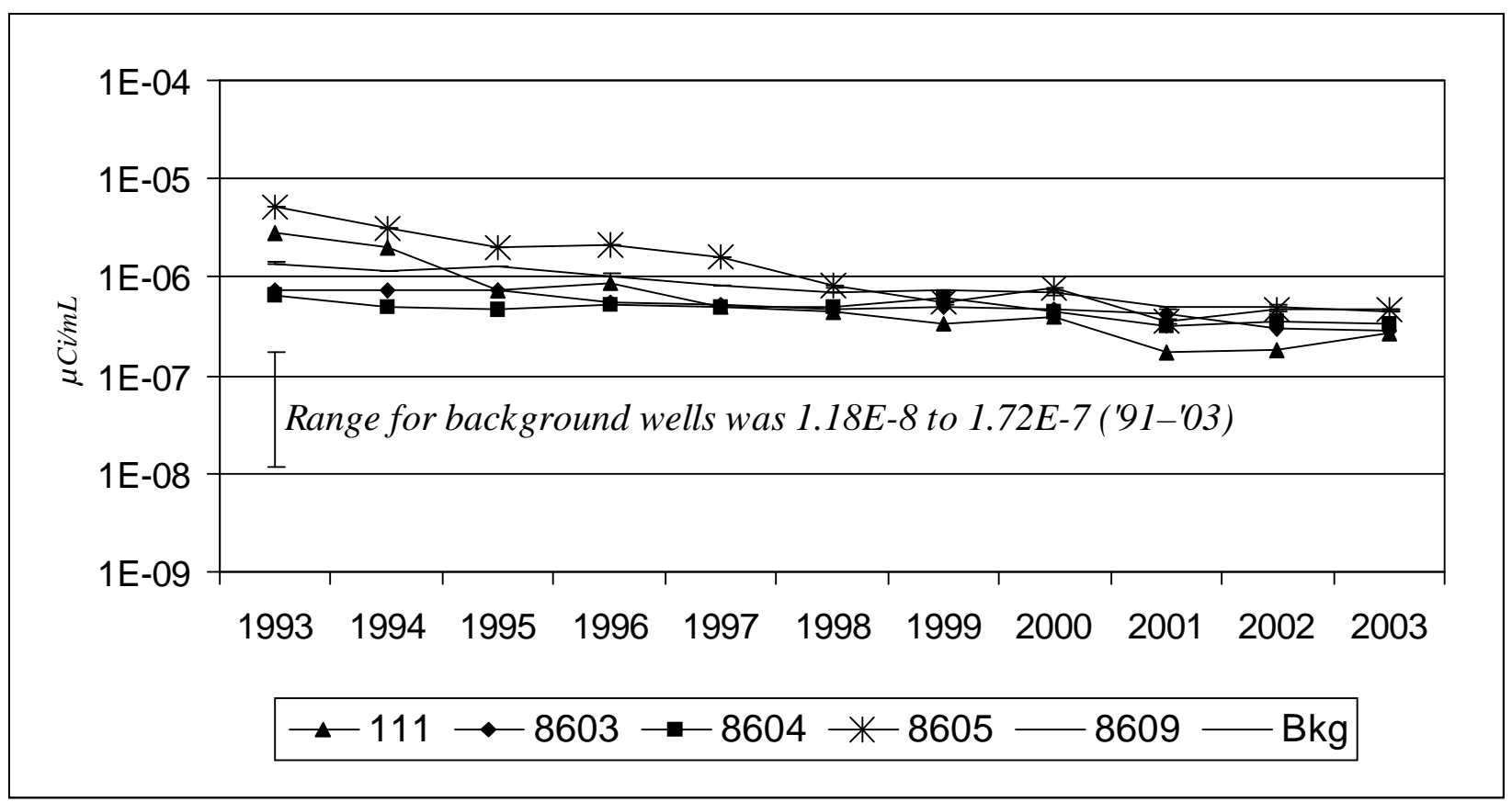

Figure 4-8. Average Yearly Tritium Concentrations at Selected Locations in the Sand and Gravel Unit 


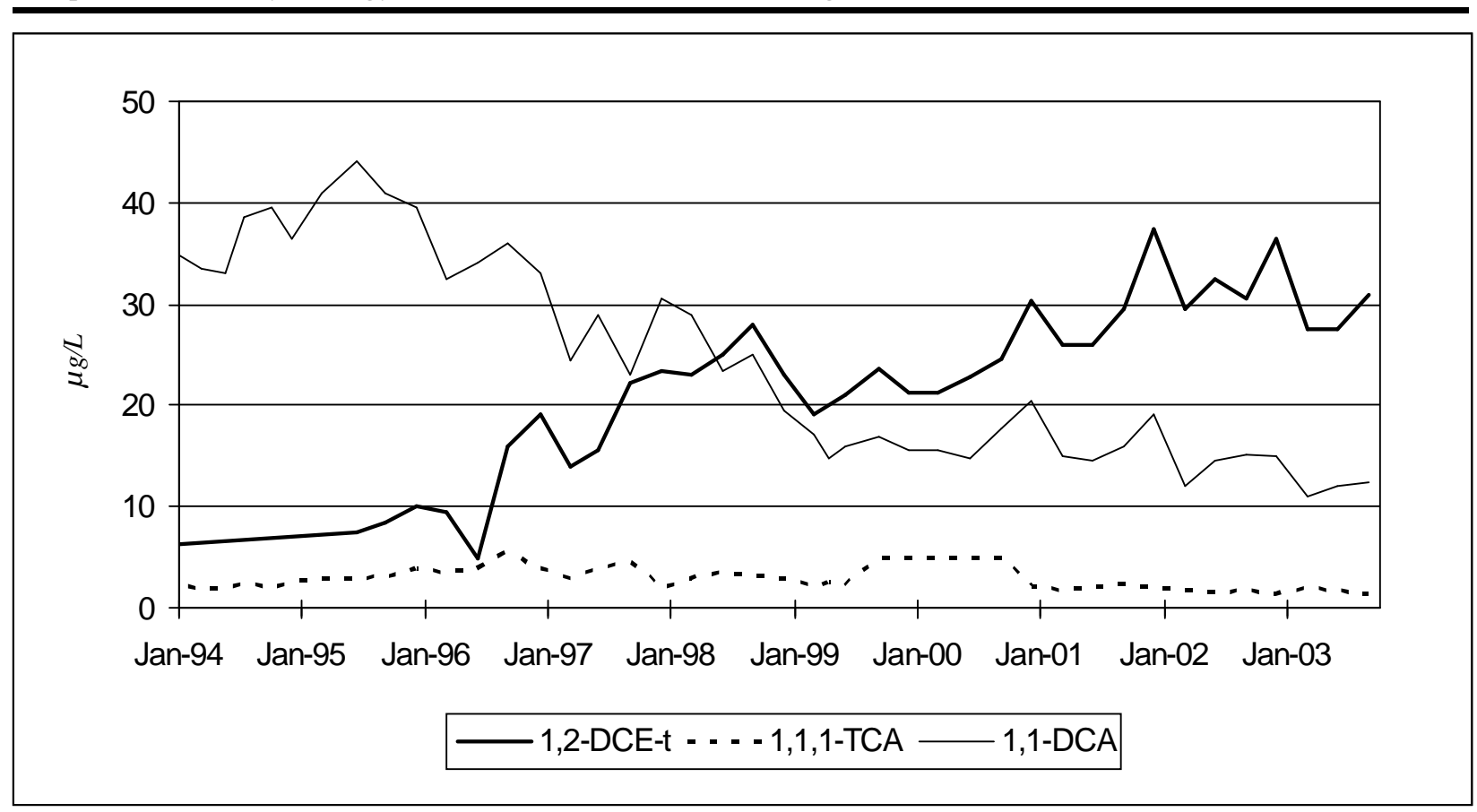

Figure 4-9. Concentrations of 1,2-DCE-t, 1,1,1-TCA, and 1,1-DCA at Well 8612 in the Sand and Gravel Unit

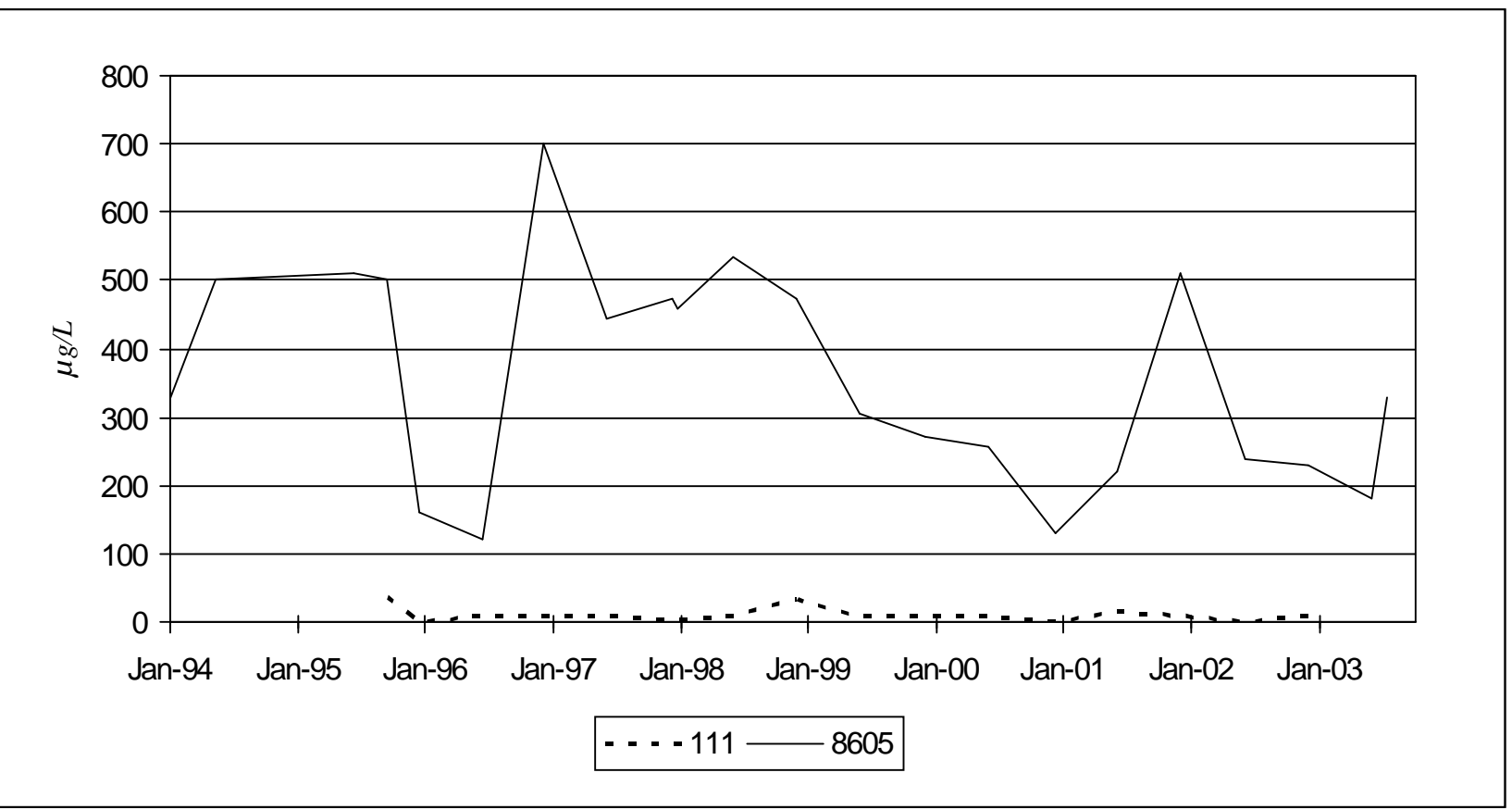

Figure 4-10. Concentrations of Tributyl Phosphate at Selected Locations in the Sand and Gravel Unit 


\section{QUALITY ASSURANCE}

The quality assurance (QA) program at the West Valley Demonstration Project (WVDP or Project) provides for and documents consistency, precision, and accuracy in collecting and analyzing environmental samples and in interpreting and reporting environmental monitoring data.

\section{Organizational Responsibilities}

West Valley Nuclear Services Co. (WVNSCO) is contractually obligated to implement a QA program at the WVDP. Managers of programs, projects, and tasks are responsible for determining and documenting the applicability of QA requirements to their activities and for implementing those requirements. For example, the Project Environmental Laboratory management and staff are directly responsible for carrying out sampling and analytical activities in a manner consistent with good quality assurance practices and for following approved procedures.

\section{Program Design}

The quality requirements of rule 10 Code of Federal Regulations (CFR) Part 830.122, Quality Assurance Criteria (U.S. Department of Energy [DOE]), and DOE Order 414.1A, Quality Assurance (DOE, 2001) provide the QA program poli- cies and requirements applicable to activities at the WVDP.

The integrated quality assurance program applicable to environmental monitoring at the WVDP also incorporates requirements from Quality Assurance Program Requirements for Nuclear Facilities (American Society of Mechanical Engineers [ASME] NQA-1, 1989) and Specifications and Guidelines for Quality Systems for Environmental Data Collection and Environmental Technology Programs (American National Standards Institute and American Society for Quality Control [ANSI/ ASQC E4-1994], 1994).

The QA program focuses upon assigning responsibilities and upon thorough planning, specification, control, and documentation of all aspects of an activity to ensure the quality of both radiological and nonradiological monitoring data. The quality assurance program includes requirements in the areas listed below.

Responsibility. Responsibilities for overseeing, managing, and conducting an activity must be clearly defined. Personnel who verify that the activity has been completed correctly must be independent of those who performed it. 
Planning. An activity must be planned beforehand and the plan followed. All activities must be documented. Similarly, purchases of any equipment or items must be planned, specified precisely, and verified for correctness upon receipt.

Control of Design, Procedures, Items, and Documents. Any activity, equipment, or construction must be clearly described or defined and tested. Changes in the design must be tested and documented. Procedures must clearly state how activities will be conducted. Only approved procedures may be used. Equipment or particular items affecting the quality of environmental data must be identified, inspected, calibrated, and tested before use. Calibration status must be clearly indicated. Items that do not conform to requirements must be identified and separated from other items and the nonconformity documented.

Documentation. Records of all activities must be kept in order to verify what was done and by whom. Records must be clearly traceable to an item or activity.

Corrective Action. Conditions adverse to quality shall be promptly identified and corrected. The cause of a problem must be identified, a corrective action planned, responsibility assigned, and the problem remedied.

Audits. Scheduled audits and assessments must be conducted to verify compliance with all aspects of the QA program and determine its effectiveness.

Subcontractor laboratories providing analytical services for the environmental monitoring program are contractually required to maintain a QA program consistent with WVNSCO requirements. They provide analytical data reports and any supplementary documentation necessary to validate the data.

\section{Procedures}

Those activities that affect the quality of environmental monitoring data are conducted according to approved procedures that clearly describe how the activity should be performed and what precautions are to be taken in connection with the activity. Any person performing an activity that could affect the quality of environmental monitoring data must be trained and must demonstrate proficiency in procedures applicable to the activity.

New procedures are developed each time an activity is added to the monitoring program. Procedures are reviewed periodically and updated when necessary. Documents are controlled so that only current procedures are used.

\section{Quality Control in the Field}

Quality control (QC), an integral part of quality assurance, is used to verify that sample analysis and collection are consistent and repeatable. QC methods are applied in the laboratory (analytical or laboratory QC) and in the field (field QC).

To ensure that samples are collected correctly, appropriate sampling procedures are followed for each type of sample being collected. For example, sample locations at the WVDP are clearly marked in the field to ensure that future samples are collected in the same locations; collection equipment in place in the field is routinely inspected, calibrated, and maintained; and automated sampling stations are kept locked to prevent tampering and to ensure sample integrity. Samples are collected into certified pre-cleaned containers of an appropriate material and capacity. Containers are labeled immediately with the pertinent information - date, time, person doing the collecting, and special field sampling conditions. Collection information is documented and kept as part of the record for that sample. 
Chain-of-custody protocols are followed to ensure that samples are controlled and tracked for traceability. If necessary, samples are preserved as soon as possible after collection.

To assess quality problems that might be introduced by the sampling process, duplicate field samples, field blank samples, and trip blank samples are collected. Background samples are collected for baseline environmental information.

Field Duplicates. Field duplicates are samples collected from the same matrix in the same manner at the same time and place. When processed and analyzed identically, but as independent samples, they provide information on sample homogeneity and sampling precision. Field duplicates are collected at frequencies specified in applicable sampling plans.

Field Blanks. A field blank is a sample of laboratory-deionized water that is put into a sample container at a field collection site and is processed from that point as a routine sample. Field blanks are used to detect contamination that may be introduced by the sampling procedure or the sampling environment. They are processed at a minimum rate of one per 20 samples.

If samples are collected with non-dedicated sampling equipment, the laboratory-deionized water is poured over the collection equipment and into the sample container. This type of field blank is called an equipment blank.

Trip Blanks. Trip blanks are prepared by pouring laboratory-deionized water into sample bottles in the laboratory. The bottles are then placed into sample coolers where they remain throughout the sampling process. Trip blanks are collected to detect any volatile organic contamination that may be introduced from handling during collection, storage, or shipping. Trip blanks are prepared once per day when volatile organic samples are being collected.

Environmental Background Samples. To monitor each pathway for possible radiological contamination, samples of air, water, vegetation, meat, and milk are taken from locations remote from the site for comparison with samples from nearsite locations. Samples that are clearly outside site influence show ambient radiological concentrations and serve as backgrounds or "controls," another form of field quality control sample. Background samples are collected at the same frequencies, as are samples from their counterpart near-site locations and provide baseline information to compare with information from near-site or on-site samples so that site influences can be evaluated.

\section{Quality Control in the Laboratory}

More than 13,500 samples were handled as part of site monitoring in 2003. Samples for routine indicator radiological analysis were analyzed on-site, with the rest being sent to subcontract laboratories.

Off-site subcontract laboratories must maintain a level of QC as specified in contracts with WVNSCO and are required to participate in all applicable crosscheck programs and to maintain all relevant certifications.

To monitor the accuracy and precision of data, laboratory QC practices specific to each analytical method are clearly described in approved references or procedures. Examples of laboratory QC activities at the WVDP include proper training of analysts, maintaining and calibrating measuring equipment and instrumentation, and processing samples in accordance with specific methods as a means of monitoring laboratory performance. 
Analytical instruments and counting systems are calibrated at specified frequencies, and logs of instrument calibration and maintenance are kept. Calibration methods for each instrument are specified in procedures or in manufacturers' directions. Standards traceable to the National Institute of Standards and Technology (NIST) are used to calibrate counting and test instrumentation.

Laboratory quality control samples consist of three general types: standards (including spikes), used to assess accuracy; blanks, used to assess the possibility of contamination; and duplicates, used to assess precision.

Standards. A standard is a material having a known property that can accurately be established based upon its physical or chemical characteristics. Standards are usually NIST-traceable materials or standard reference materials of known quantity or concentration.

At a minimum, one reference standard is analyzed for every 20 sample analyses. The results of the analyses are plotted on control charts, which specify acceptable limits. If the results lie within these limits, then analysis of actual environmental samples may proceed and the results are deemed usable.

Spikes. Another form of standard analysis is a laboratory spike. In a spike, a known amount of analyte is added to a sample (matrix spike) or blank (blank spike) before the sample is analyzed to assess percent recovery. The percent recovery of the analyte indicates how much of the analyte of interest is being detected in the analysis of actual samples; hence, a spike also is an assessment of the accuracy of the method. Spike recoveries are recorded on control charts with documented acceptance limits.
Blanks. Laboratory blanks, also called method blanks, are prepared from a matrix similar to that of the sample, but known to contain none of the analyte of interest. For instance, deionized water, taken through the same preparatory procedure as a sample, may serve as a blank for both radiological and chemical analyses of water samples. A positive result for an analyte in a blank indicates that something is wrong with the analysis and that corrective action should be taken. In general, one laboratory blank is processed daily or with each batch of samples for a given analyte.

The instrument background count for radiological samples, a count taken of a planchet or vial containing no sample, is another form of laboratory blank. The count serves three purposes: to determine if contamination is present in the counting instrument; to determine if the instrument is responding in an acceptable manner; and to determine the background correction that should be applied when calculating radiological activity in certain samples.

Environmental samples containing little or no radioactivity must be measured with very sensitive instruments. For example, gross alpha and gross beta measurements must be made with a lowbackground proportional counter. An instrument background count is taken before each day's counting or with each batch of 20 samples. Background counts are recorded on control charts with defined acceptance limits. An unacceptable count requires corrective action before analyses can proceed.

Duplicates. Laboratory duplicates are created by splitting existing samples before analysis and treating each portion as a separate sample. Laboratory duplicates are used to assess precision in the analytical process. 
To allow independent determination of environmental monitoring data, samples of air filters, water, milk, fish, vegetation, and sediments are split or separately collected and sent to the New York State Department of Health (NYSDOH) for measurement and independent reporting to the public. Co-located samples are listed in Appendix $\mathrm{B}^{\mathrm{C}}$ of this report.

Crosschecks. Crosscheck samples contain a concentration of an analyte known to the agency conducting the crosscheck. However, the concentration is unknown to the participating laboratory. Crosscheck programs provide an additional means of testing accuracy of environmental measurements. WVNSCO participates in formal crosscheck programs for both radiological and nonradiological analyses.

Radiological. The DOE recommends that all organizations performing radiological analyses as part of effluent or environmental monitoring participate in the semiannual Environmental Measurements Laboratory Quality Assessment Program. This program is designed to test the quality of environmental measurements being reported to the DOE by its contractors.

Crosscheck samples for radiological constituents are analyzed by the on-site Environmental Laboratory and by a subcontract laboratory in accordance with contractual requirements. A total of 113 radiological crosscheck analyses were performed by or for the WVDP and reported in 2003. All but three of those results (97.4\% overall) were within acceptance limits.

Results from radiological crosschecks are summarized in Appendix $\mathrm{J}$, Tables $\mathrm{J}-1$ and $\mathrm{J}-2^{\mathrm{C}}$.

The Environmental Laboratory analyzed and reported 34 samples in 2003; all results (100\%) were within control limits. General Engineering Labo- ratory submitted 79 results, of which 76 (96.2\%) were within control limits.

Nonradiological. Analytical laboratories must demonstrate evidence of satisfactory analytical performance on samples provided by the NYSDOH Environmental Laboratory Approval Program (ELAP). The laboratory must also participate in U.S. Environmental Protection Agency (EPA) Discharge Monitoring Report-Quality Assurance performance evaluation studies. Analytical procedures are to be consistent with the principles and methodologies in 40 CFR Part 136, Methodology, Chemical Analysis of Water and Waste, EPA-600/4-79-020, EPA as updated, or methods cited in the NYSDOH-ELAP manual.

Two nonradiological crosscheck samples (from Environmental Research Associates) for the National Pollutant Discharge Elimination System Discharge Monitoring Report-Quality Assurance Study \#23 were analyzed for $\mathrm{pH}$ and residual chlorine by the WVDP wastewater facility laboratory in 2003.

Twenty-one crosscheck analyses were performed by Severn Trent Laboratories, an off-site vendor laboratory, for additional parameters in 2003 . Nonradiological crosscheck results are summarized in Appendix $\mathrm{J}^{\mathrm{C}}$, Table $\mathrm{J}-3^{\mathrm{C}}$.

Results from both samples analyzed at the WVDP were within acceptance limits (100\%). Of the 21 results reported by the vendor laboratory, 20 were within acceptance limits (95.2\%). Combining WVDP and vendor results for nonradiological crosschecks, $97.7 \%$ were within control limits.

WVNSCO subcontracted laboratories are required to perform satisfactorily on crosschecks, defined as at least $80 \%$ or more of results falling within control limits. Crosscheck results that fall outside control limits are addressed by formal corrective actions to determine any conditions that could ad- 
versely affect sample data and to ensure that actual sample results are reliable.

\section{Personnel Training}

Anyone performing environmental monitoring program activities is trained in the appropriate procedures and qualified accordingly before carrying out the activity as part of the site environmental monitoring program.

\section{Recordkeeping}

Control of records is an integral part of the environmental monitoring program. Field data sheets, chain-of-custody forms, requests for analysis, sample-shipping documents, sample logs, bench logs, laboratory data sheets, equipment maintenance $\log s$, calibration $\log s$, training records, crosscheck performance records, data packages, and weather measurements, in addition to other records, are maintained as documentation of the environmental monitoring program.

Records pertaining to the environmental monitoring program are also maintained electronically. A laboratory information management system (LIMS) is used to log samples, print labels, store and process data, track QC samples, track samples, produce sampling and analytical worklists, and generate reports. All records pertaining to the program are routinely reviewed and securely stored and, for electronic records, routinely backed-up.

\section{Chain-of-Custody Procedures}

Chain-of-custody procedures are used to trace sample possession from time of collection through analysis and maintain the appropriate documentation. Chain-of-custody records begin with sample collection. Samples brought in from the field are transferred under signature from the sampler to the sample custodian and are logged at the sample receiving station, after which they are stored in a sample lockup before analysis or shipping. Samples sent off-site for analysis are accompanied by an additional chain-of-custody/analytical request form. Subcontract laboratories are required by contract to maintain internal chain-of-custody records and to store the samples under secure conditions.

\section{Audits and Appraisals}

The New York State Department of Environmental Conservation performed an inspection of WVDP's wastewater treatment facilities and State Pollutant Discharge Elimination System (SPDES) discharge monitoring program in 2003. The inspection resulted in no reported findings or observations.

\section{Self-Assessments}

Two routine self-assessments of the environmental monitoring program were conducted in 2003. The primary topics addressed by the first assessment were worker safety, QA, trend analysis, and incident reporting. Topics addressed in the second assessment were data validation and sample preservation.

No findings or observations were noted. (See finding and observation under self-assessment [p. GLO-11].) Recommended actions were proposed to improve the program. Nothing was found during the course of these routine self-assessments that would compromise the reliability of the environmental monitoring program in general or the quality of the data in this report.

\section{Lessons Learned Program}

Lessons learned data from audits, appraisals, and self-assessments are shared internally and externally through the WVDP lessons learned program. 
The WVDP maintains this system in order to promote the recurrence of desirable events or to prevent the recurrence of undesirable events.

\section{Data Management}

The laboratory information management system is a database system used for maintaining the sample data log, tracking samples, managing field and analytical data, and recording status and results of data validation. The LIMS is used as a controlled-source database for generating reports and evaluations of data sets to support environmental surveillance activities. Subcontract laboratories are asked to, where possible, provide data in electronic form for direct entry into the LIMS by WVDP personnel.

All software packages used to generate data are verified and validated before use. All analytical data produced in the Environmental Laboratory at the bench level are reviewed and signed off by a qualified person other than the one who performed the analysis. A similar in-house review is contractually required from subcontractor laboratories.

\section{Data Verification and Validation}

The data validation process is used to generate validated summary data, including technical qualifications or limitations of these data as based upon regulatory and contract-compliance criteria. Analytical data from both on- and off-site laboratories are reviewed to verify proper documentation of sample processing and data reporting, and to determine the quality and usability of the data. A graded approach is applied that, based upon data quality objectives, dictates the rigor of sample collection and/or sample analysis review. In the WVDP environmental program, each data point is validated per approved standard procedures be- fore it is assigned approval status and made available to the end user.

Control measures, such as chain-of-custody and sample identification numbering and collection dates, are checked to ensure that the correct sample has been analyzed using the appropriate test procedures. The analytical process log information may be reviewed to verify the number and accuracy of quality-check samples and tests. Other quality requirements, such as meeting minimum testing sensitivity and precision levels, are checked for the data being examined.

If the contractually-defined data package deliverables are not met, the data may be either flagged as estimated (useful, for example, as supporting information) or as rejected (not-to-be-used) data. When a sample does not provide a valid data point and analytical or calculation errors cannot be identified and corrected, a retest is often requested on either a remaining sample portion or a similar sample.

After validation is complete, the approved data package contains all of the data from the data generator as well as the qualifier codes affixed to results, where applicable, thereby making the data ready for assessment.

\section{Data Assessment and Reporting}

Validated radiological and nonradiological analytical data, field information, and historical project data are integrated and evaluated to assess the specific data usability in determining presence or absence of analytical constituents and, if present, the levels of the constituents. Data problems identified at this level are further investigated and appropriately resolved. 
Data from the environmental monitoring program are then processed to assess the effect, if any, of the site on the environment and the public. Data from each sampling location are compared to historical results from the same location, comparable background measurements, and (if applicable) regulatory or guidance standards.

- Radiological concentrations in liquid effluent releases or air emissions are compared with DOE derived concentration guides (DCGs) for release of water or air to an unrestricted environment. DCGs for specific radionuclides are listed in Table $\mathrm{K}-1^{\mathrm{C}}$.

- Calculated doses from air emissions are compared with National Emission Standards for Hazardous Air Pollutants limits.

- Nonradiological releases from liquid effluents covered by the SPDES Permit are compared with the limits specified in the permit. (See Table $\mathrm{C}-1 \mathrm{~A}^{\mathrm{C}}$.)

- Data trends over time are assessed on a monthly basis and identified trends are investigated.

- Near-site radiological results are compared to results from background locations far from the site.

- Results from surface waters downgradient of the site are compared with results from upgradient locations.

- Groundwater monitoring results are compared to background data for each super solid waste management unit and to background data for the north and south plateaus.

Standard statistical methods are used to compare the data. Where possible, the underlying distribu- tion of the data set is assessed before determining the appropriate statistical tests to be used.

Once the data have been evaluated, reports are prepared. Calculations summarizing the data, for instance, summing the total curies released from an effluent point, averaging the annual concentration of a radionuclide at a monitoring point, or pooling confidence intervals from a series of measurements, are made in accordance with formally-approved procedures. Final data are reported as described elsewhere in this report. (See Data Reporting in Chapter 1 [p. 1-4] and the section on Scientific Notation at the back of this report [p. UOM-2].)

Before each technical report is issued, the document, including the data on which the report was based, is comprehensively reviewed by one or more persons who are knowledgeable in the necessary technical aspects of the field of work.

\section{Summary}

The multiple levels of scrutiny built into generating, validating, evaluating, and reporting data from the environmental monitoring program ensure that reliable data are reported. The quality assurance elements described in this chapter ensure that environmental monitoring data are consistent, precise, and accurate. The effectiveness of the monitoring program is evidenced by continuing favorable quality assurance assessments. 


\section{REFERENCES AND BIBLIOGRAPHY}

\section{(Some documents listed in this section are basis documents and may not specifically be cited in the text.)}

Albanese, J.R. et al. 1984. Geological and Hydrogeologic Research at the Western New York Nuclear Service Center, West Valley, New York. Final Report, August 1982-December 1983. U.S. Nuclear Regulatory Commission Report. NUREG/CR-3782.

American National Standards Institute/American Society for Quality Control. 1994. Specifications and Guidelines for Quality Systems for Environmental Data Collection and Environmental Technology Programs. ANSI/ASQC E4-1994.

American National Standards Institute, Inc. August 20, 1975. American National Standard: Performance Testing, and Procedural Specifications for Thermoluminescent Dosimetry (Environmental Applications). ANSI N545-1975.

American Society of Mechanical Engineers. 1989. Quality Assurance Program Requirements for Nuclear Facilities. ASME-NQA-1. New York: The American Society of Mechanical Engineers.

Bergeron, M.P. et al. 1987. Geohydrologic Conditions at the Nuclear Fuels Reprocessing Plant and Waste Management Facilities at the Western New York Nuclear Services Center, Cattaraugus County, New York. U.S. Geological Survey Water Resources Investigations Report 85-4145.

Citizen Task Force. July 29, 1998. West Valley Citizen Task Force Final Report.

Dames \& Moore. 1995. Early Warning System for Evaluation of Groundwater Monitoring Results from the Vicinity of the Proposed Groundwater Extraction System. Letter: CDF1004:CDF0.01. AR \#95-692.

December 22, 1998. 1998 Wetlands Investigation and Delineation of the West Valley Assessment Area. AR \#99-117.

$R \& B-1$ 
Spur.

December 1999. Wetlands Investigation and Delineation of the West Valley Railroad

Dunning, Donald E. nd. Estimates of Internal Dose Equivalent from Inhalation and Ingestion of Selected Radionuclides. Revised. WIPP-DOE-176.

Executive Order 11988. May 25, 1977. Floodplain Management. 42 FR 26951.

Executive Order 11990. May 25, 1977. Protection of Wetlands. 42 FR 26961.

Executive Order 13101. September 16, 1998. Greening the Government Through Waste Prevention, Recycling, and Federal Acquisition. 63 FR 49643.

Executive Order 13148. April 26, 2000. Greening the Government Through Leadership in Environmental Management. 65 FR 24595.

International Atomic Energy Agency (IAEA). 1992. Effects of Ionizing Radiation on Plants and Animals at Levels Implied by Current Radiation Protection Standards. Technical Report Series No. 332, IAEA, Vienna, Austria.

International Commission on Radiological Protection. 1959. Recommendations of the International Commission on Radiological Protection - Permissible Dose for Internal Radiation. ICRP Publication 2. Oxford: Pergamon Press.

. 1975. Report of the Task Group on Reference Man. ICRP Publication 23. Oxford: Pergamon Press.

. 1977. Recommendations of the International Commission on Radiological Protection. ICRP Publication 26. Oxford: Pergamon Press.

1979. Recommendations of the International Commission on Radiological Protection - Limits for Intakes of Radionuclides by Workers. ICRP Publication 30. Oxford: Pergamon Press.

1991. 1990 Recommendations of the International Commission on Radiological Protection. ICRP Publication 60. Oxford: Pergamon Press.

International Organization for Standardization. 1996. Environmental Management Systems. ISO 14001:1996.

LaFleur, R.G. 1979. Glacial Geology and Stratigraphy of Western New York Nuclear Service Center and Vicinity, Cattaraugus and Erie Counties, New York. U.S. Geological Survey Open File Report 79-989.

$R \& B-2$ 
Long, E.R., and L.G. Morgan. 1990. The Potential for Biological Effects of Sediment-Sorbed Contaminants Tested in the National States and Trends Program. National Oceanic Atmospheric Administration (NOAA) Technical Memorandum No. 5, OMA52, NOAA National Ocean Service, Seattle, Washington.

Moore, R.E. et al. June 1979. AIRDOS-EPA: A Computerized Methodology for Estimating Environmental Concentrations and Dose to Man from Airborne Releases of Radionuclides. ORNL-5532.

National Council on Radiation Protection and Measurements. December 1979. Environmental Radiation Measurements. NCRP-50. Washington, D.C.

. 1987a. Recommendations on Limits for Exposure to Ionizing Radiation. NCRP-91. Bethesda, Maryland.

1987b. Ionizing Radiation Exposure of the Population of the United States. NCRP-93. Bethesda, Maryland.

National Research Council. 1990. Health Effects of Exposure to Low Levels of Ionizing Radiation. BEIR V. Washington: National Academy Press.

New York State Department of Environmental Conservation. nd. Title 6, New York Codes, Rules, and Regulations (6 NYCRR). Environmental Conservation Rules and Regulations. 1991. Draft Cleanup Policy and Guidelines, Appendix B - Water Cleanup Criteria. . January 24, 1994. Determination of Soil Cleanup Objectives and Cleanup Levels. Technical and Administrative Guidance Memorandum (TAGM) \#4046. . 1995. Appendix 33 - Groundwater Monitoring List. Title 6 NYCRR Subpart 373-2. . September 3, 1996. Federal Facility Compliance Act: Order on Consent. . June 1998. Ambient Water Quality Standards and Guidance Values and Groundwater Effluent Limitations. Technical and Operational Guidance Series (TOGS) 1.1.1. . January 25, 1999. Technical Guidance for Screening Contaminated Sediments. . March 19, 1999. Stipulation of Agreement Pursuant to Section 17-0303 of the Environmental Conservation Law and Section 176 of the Navigation Law.

. July 15, 2002. State Pollutant Discharge Elimination System (SPDES) Discharge Permit NY0000973.

$R \& B-3$ 
. January 2003. Draft Technical and Operational Guidance Series (TOGS) \#5.1.9.

In-Water and Riparian Management of Sediment and Dredge Material.

New York State Department of Health. nd. Environmental Laboratory Approval Program (ELAP) Certification Manual.

. nd. Title 10, New York Code, Rules, and Regulations (10 NYCRR). Sources of Water Supply. Part 5 (Drinking Water Supplies) and Part 170 (Sources of Water Supply).

Oak Ridge National Laboratory. May 1980. User's Manual for LADTAP II - A Computer Program for Calculating Radiation Exposure to Man from Routine Release of Nuclear Reactor Liquid Effluents. NUREG/CR-1276.

Pacific Northwest Laboratory (PNL). November 1988. Napier, B.A., Strenge, D.L., Pelequin, R.A., and Ramsdell, J.V. GENII - The Hanford Environmental Radiation Dosimetry Software System. Version 1.485, PNL-6584.

Parks B.L. March 1992. User's Guide for CAP88-PC. Version 1.0. Las Vegas, NV: U.S. Environmental Protection Agency Office of Radiation Programs. 402-B-92-001.

June 1997. CAP88-PC Version 2.0 User's Guide. Germantown, Maryland. U.S. Department of Energy.

Persaud, D., Jaagumagi, R., and A. Hayton. 1992. Guidelines for the Protection and Management of Aquatic Sediment Quality in Ontario. Ontario Ministry of the Environment, Queen's Printer for Ontario.

Rickard, L.V. 1975. Correlation of the Silurian and Devonian Rocks in New York State. New York State Museum and Science Service Map and Chart Series No. 24.

Sheppard, M.I., and D.H. Thibault. 1990. Default Soil Solid/Liquid Partition Coefficients, $K_{d}$ s, for Four Major Soil Types: A Compendium. Health Physics. 59 (No. 4): 471-482.

Shleien, B. et al. 1998. Handbook of Health Physics and Radiological Health Safety. 3rd ed. Baltimore, Maryland: Williams \& Wilkens.

Simpson, D.B., and B.L. McGill. 1980. LADTAP II: A Computer Program for Calculating Radiation Exposure to Man from Routine Release of Nuclear Reactor Liquid Effluents. Technical Data Management Center. ORNL/NUREG/TDMC-1.

Standish, P.N. 1985. Closure of the Construction Landfill Site. Letter (WD:85:0434) to W.H. Hannum, Department of Energy, West Valley Project Office.

$R \& B-4$ 
Tesmer, I.H. 1975. Geology of Cattaraugus County, New York. Buffalo Society of Natural Sciences Bulletin, Vol. 27.

Tseng, J.C. November 4, 1975. Clarification of Applicable Radiation Protection Standards for the Public and the Environment. Memorandum from EH-231, Office of Environmental Guidance and Compliance. Washington, D.C.

U.S. Congress. 1954. Atomic Energy Act of 1954. 42 United States Code (USC) §2011 et seq. . 1955. Clean Air Act. 42 USC $\S 7401$ et seq.

. 1966. National Historic Preservation Act of 1966. 16 USC $\$ 470$ et seq. 1969. National Environmental Policy Act of 1969. 42 USC $\$ 4321$ et seq. . 1973. Endangered Species Act of 1973. 16 USC $\$ 1531$ et seq. 1974. Safe Drinking Water Act. 42 USC $\$ 300 f$ et seq.

. October 23, 1976. Resource Conservation and Recovery Act of 1976. Public Law 94-580, 90 Stat. 2795, 42 USC $\$ 6901$ et seq.

. November 1976. Migratory Bird Treaty Act. 16 USC $§ 703$ et seq.

1977. Federal Water Pollution Control Act. 33 USC \$1251 et seq. (Also known as the Clean Water Act)

. October 1, 1980. An Act to Authorize the Department of Energy to Carry Out a High-Level Liquid Nuclear Waste Management Demonstration Project at the Western New York Service Center in West Valley, New York. Public Law 96-368 [S. 2443]. Congressional Record, Vol. 126. (Also known as the WVDP Act)

. December 11, 1980. Comprehensive Environmental Response, Compensation, and Liability Act of 1980. Public Law 96-510, 42 USC $\$ 9601$ et seq.

. 1986a. Toxic Substances Control Act. 15 USC §2601 et seq.

. 1986b. Emergency Planning and Community Right-to-Know Act of 1986. 42 USC $\S 11001$ et seq.

. October 17, 1986. Superfund Amendments and Reauthorization Act (SARA) of 1986. Public Law 99-499, 100 Stat. 1613, Title 10.

$$
R \& B-5
$$


U.S. Department of Commerce. U.S. Census Bureau. Census 2000.

U.S. Department of Energy. nd. Quality Assurance Criteria. 10 CFR 830.122.

July 1981. A Guide for Environmental Radiological Surveillance at U.S.

Department of Energy Installations. DOE/EP-0023. Washington, D.C.

. June 1982. Final Environmental Impact Statement: Long-Term Management of Liquid High-Level Radioactive Wastes Stored at the Western New York Nuclear Services Center, West Valley. DOE/EIS-0081.

July 1983. A Guide for Effluent Radiological Measurements at DOE Installations. DOE/EP-0096. Washington, D.C.

. May 15, 1984. Environmental Protection, Safety, and Health Protection Standards, including Change 4 (January 7, 1993). DOE Order 5480.4. Washington, D.C.

. July 1988. Internal Dose Conversion Factors for Calculation of Dose to the Public. DOE/EH-0071.

. February 8, 1990. Radiation Protection of the Public and the Environment. DOE Order 5400.5, including Change 2 (January 7, 1993). Washington, D.C.

. January 1991. Environmental Regulatory Guide for Radiological Effluent Monitoring and Environmental Surveillance. DOE/EH-0173T. Washington, D.C.

. January 1996. Draft Environmental Impact Statement for Completion of the West Valley Demonstration Project and Closure or Long-Term Management of Facilities at the Western New York Nuclear Services Center. DOE/EIS-0226-D.

May 1997. Final Waste Management Programmatic Impact Statement for Managing Treatment, Storage, and Disposal of Radioactive and Hazardous Waste. DOE/ EIS-0200-F.

. January 23, 1998. Record of Decision for the Department of Energy's Waste Isolation Pilot Plant Disposal Phase.

. March 27, 1998. Worker Protection Management for DOE Federal and Contractor Employees. DOE Order 440.1A. Washington, D.C.

June 23, 1998. DOE/EIS-0081. Supplement Analysis II of Environmental Impacts Resulting from Modifications in the West Valley Demonstration Project. WVDP-321.

$R \& B-6$ 
. August 5, 1998. Record of Decision for the Department of Energy's Waste Management Program: Treatment of Non-Wastewater Hazardous Waste.

. July 9, 1999. Radioactive Waste Management. DOE Order 435.1, including Change 1 (August 28, 2001). Washington, D.C.

August 26, 1999. Record of Decision for the Department of Energy's Waste Management Program: Storage of High-Level Radioactive Waste.

. September 29, 1999. Quality Assurance. DOE Order 414.1A, including Change 1 (July 12, 2001). Washington, D.C.

. December 10, 1999. Identification of Preferred Alternatives for the Department of Energy's Waste Management Program: Low-Level Waste and Mixed Low-Level Waste Disposal Sites.

. February 25, 2000. Record of Decision for the DOE's Waste Management Program: Treatment and Disposal of Low-Level Waste and Mixed Low-Level Waste; Amendment of the Record of Decision for the Nevada Test Site. 65 FR 10061.

. October 26, 2000. National Environmental Policy Act Compliance Program. DOE Order 451.1B, including Change 1 (September 28, 2001). Washington, D.C.

. March 26, 2001. Revised Strategy for the Environmental Impact Statement for Completion of the West Valley Demonstration Project and Closure or Long-Term Management of Facilities at the Western New York Nuclear Service Center and Solicitation of Scoping Comments. 66 FR 16447.

. November 6, 2001. Advance Notice of Intent to Prepare an Environmental Impact Statement to Evaluate Decommissioning and/or Long-Term Stewardship at the West Valley Demonstration Project and Western New York Nuclear Service Center. 66 FR 56090.

. July 2002. DOE Standard: A Graded Approach for Evaluating Radiation Doses to Aquatic and Terrestrial Biota. DOE-STD-1153-2002. Washington, D.C.

. September 23, 2002. Radioactive Material Transportation Practices Manual.

DOE M 460.2-1.

. January 2003. Estimating Radiation Risk from Total Effective Dose Equivalent (TEDE). ISCORS Technical Report No. 1. DOE/EH-412/0015/0502, Rev. 1.

$R \& B-7$ 
. January 15, 2003. Environmental Protection Program. DOE Order 450.1.

Washington, D.C. (Canceled DOE Order 5400.1, General Environmental Protection Program, November 9, 1988, including Change 1 [June 29, 1990].)

March 13, 2003. Notice of Intent to Prepare an Environmental Impact Statement for Decommissioning and/or Long-Term Stewardship at the West Valley Demonstration Project and Western New York Nuclear Services Center. 68 FR 12044.

. May 16, 2003. Notice of Availability of the West Valley Demonstration Project Draft Waste Management Environmental Impact Statement. 68 FR 26587.

August 19, 2003. Environment, Safety, and Health Reporting. DOE Order 231.1A. Washington, D.C.

December 2003. West Valley Demonstration Project Waste Management Environmental Impact Statement. DOE/EIS-0337F.

U.S. Department of Energy and New York State Energy Research and Development Authority. 1981. Cooperative Agreement between United States Department of Energy and New York State Energy Research and Development Authority on the Western New York Nuclear Service Center at West Valley, New York, effective October 1, 1980, as amended September 18.

U.S. Environmental Protection Agency. nd. 40 Code of Federal Regulations, Protection of the Environment, Chapter 1, Environmental Protection Agency.

. 1976. National Interim Primary Drinking Water Regulations. EPA-570/9-76-003. Washington, D.C.: Office of Water Supply.

. March 1983. Mercury, Method 245.1 (Manual Cold Vapor Technique). Methods for Chemical Analysis of Water and Wastes. Environmental Monitoring and Support Laboratory. Cincinnati, Ohio.

1984a. Drinking Water Guidelines. 40 CFR 141, National Secondary Drinking Water Regulations, Subpart B, Maximum Contaminant Levels.

1984b. Drinking Water Guidelines. 40 CFR 143, National Secondary Drinking Water Regulations, Section 143.3, Secondary Maximum Contaminant Levels.

September 1986. Groundwater Monitoring Technical Enforcement Guidance Document. OWSER-9950.1. Washington, D.C.

$R \& B-8$ 
. November 1986. Test Methods for Evaluating Solid Waste. Vol. IA: Laboratory Manual,Physical Chemical Methods. EPA Manual, SW-846, 3rd ed. Update II, September 1994. Washington, D.C.: Office of Solid Waste and Emergency Response.

December 15, 1989. National Emission Standards for Hazardous Air Pollutants: Standards for Radionuclides. 40 CFR 61, including update of September 9, 2002. Washington, D.C.: U.S. Government Printing Office.

. 1992. Region II Administrative Order on Consent. Docket No. II RCRA 3008(h) 92-0202. In the Matter of: Western New York Nuclear Service Center.

. October 16, 1996. Code of Environmental Management Principles. 61 FR 54062.

. August 2002. Method 1631, Revision E: Mercury in Water by Oxidation, Purge and Trap, and Cold Vapor Atomic Fluorescence Spectrometry. EPA-821-R-02-019.

U.S. Nuclear Regulatory Commission. July 1977. Regulatory Guide 1.111: Methods for Estimating Atmospheric Transport and Dispersion of Gaseous Effluents in Routine Releases from Light-Water-Cooled Reactors.

October 1977. Regulatory Guide 1.109: Calculation of Annual Doses to Man from Routine Releases of Reactor Effluents for the Purpose of Evaluating Compliance with 10 CFR Part 50, Appendix I.

. July 1997. Radiological Criteria for License Termination. 10 CFR Part 20, Appendix E.

1998. Decommissioning Criteria for West Valley. SECY-98-251.

. 1999. Supplement to SECY-98-251, Decommissioning Criteria for West Valley. SECY-99-057.

. December 3, 1999. Decommissioning Criteria for the West Valley Demonstration Project (M-32) and West Valley Site; Draft Policy Statement and Notice of Public Meeting. 64 FR 67952.

. February 1, 2002. Decommissioning Criteria for the West Valley Demonstration Project (M-32) at the West Valley Site; Final Policy Statement. 67 FR 5003.

URS Group, Inc. April 8, 2002. Land Use Survey. Rev. 0. AR \#2002-171.

West Valley Demonstration Project. 1986. WVDP Radioactive Air Emissions Permit Application General Information. Submitted to EPA Region II.

$R \& B-9$ 
West Valley Nuclear Services Co., Inc. January 1992. Environmental Media Management Plan at the West Valley Demonstration Project.

. December 16, 1993. RCRA Facility Investigation (RFI) Work Plan. West Valley Demonstration Project. Rev. 0. WVDP-RFI-014.

. May 1, 1995. Subsurface Probing Investigation on the North Plateau at the West Valley Demonstration Project. Rev. 0. WVDP-220.

. May 10, 1995. Groundwater Seep Investigation Report: 1,1,1-Trichloroethane Detection. Rev. 0. WVDP-RFI-002.

. March 1996. Environmental Information Document, Volume III: Hydrology, Part 4. WVDP-EIS-009.

. June 23, 1998. Supplement Analysis II of Environmental Impacts Resulting from Modifications in the West Valley Demonstration Project. WVDP-321. (This document is an update to DOE/EIS-0081.)

. August 19, 1998 and March 26, 2003. Documentation and Reporting of Environmental Monitoring Data. Rev. 2 and Rev. 3. EMP-11.

June 11, 1999. 1998 Geoprobe ${ }^{\circledR}$ Investigation in the Core Area of the North Plateau Groundwater Plume. Rev. 0. WVDP-346.

. October 22, 1999. WVDP Air Emission Inventory. Rev. 2. WVDP-288.

. October 26, 1999. Asbestos Management Plan. Rev. 5. WVDP-072.

. March 6, 2000, March 14, 2003, and December 2, 2003. Environmental Monitoring Program Plan. Rev. 10, Rev. 11, and Rev. 12. WVDP-098.

. May 2, 2000 and December 2, 2003. WVDP Groundwater Protection Management Program Plan. Rev. 4 and Rev. 5. WVDP-091.

. March 21, 2001. PCB and PCB-Contaminated Material Management Plan. Rev. 6. WVDP-080.

. September 27, 2001, October 24, 2003, and December 3, 2003. Groundwater Monitoring Plan. Rev. 5, Rev. 6, and Rev. 7. WVDP-239.

. December 20, 2001, June 2, 2003, and December 23, 2003. Waste Minimization/ Pollution Prevention Awareness Plan. Rev. 5, Rev. 6, and Rev. 7. WVDP-087. 
. May 14, 2002 and July 10, 2003. WVDP Environmental Management System. Rev. 14 and Rev. 15. WV-980.

. July 1, 2003. Annual Status Report for the Hazardous Waste Reduction Program.

. November 22, 2002 and November 25, 2003. WVDP Safety Management System (SMS) Description. Rev. 8 and Rev. 9. WVDP-310.

. February 26, 2004. New York State Department of Environmental Conservation Hazardous Waste Report for 2003.

February 5, 2003. Site Treatment Plan: Fiscal Year 2003 Update. Rev. 6.

WVDP-299.

. April 15, 2003. Manual for Radiological Assessment of Environmental Releases at the WVDP. Rev. 4. WVDP-065.

West Valley Nuclear Services Co., Inc. and Dames \& Moore. June 1997. West Valley Demonstration Project Site Environmental Report, Calendar Year 1996.

July 1997. Resource Conservation and Recovery Act Facility Investigation Report, Vol.1: Introduction and General Site Overview. WVDP-RFI-017.

June 1998. Final Report: Evaluation of the Pilot Program to Investigate Chromium and Nickel Concentrations in Groundwater in the Sand and Gravel Unit.

West Valley Nuclear Services Co. and URS Group, Inc. January 2001. Results of Corrosion Evaluation in Selected Stainless Steel Monitoring Wells on the North Plateau and Recommendations for Long-Term Management.

August 2001. West Valley Demonstration Project Site Environmental Report, Calendar Year 2000.

August 2002. West Valley Demonstration Project Annual Site Environmental Report, Calendar Year 2001.

August 2003. West Valley Demonstration Project Annual Site Environmental Report, Calendar Year 2002.

Williams, A.C. August 20, 2002. Elimination of Air Sampling at the Old Low-Level Waste Treatment Facility and Laundry Facility. Correspondence to W.M. Wierzbicki. DW:2002:0349.

$$
R \& B-11
$$


Wilson, J.W. April 1998. Overview of Radiation Environments and Human Exposures. NASA Langley Research Center. 34th Annual Meeting of the National Council on Radiation Protection. Washington, D.C.

Yager, R.M. 1987. Simulation of Groundwater Flow near the Nuclear Fuel Reprocessing Facility at the Western New York Nuclear Service Center, Cattaraugus County, New York. 85-4308. Ithaca, New York: U.S. Geological Survey. 


\section{GLOSSARY}

\section{A}

accuracy. The degree of agreement between a measurement and its true value. The accuracy of a data set is assessed by evaluating results from standards or sample spikes containing known quantities of an analyte.

action plan. An action plan addresses assessment findings and root causes that have been identified in an audit or an assessment report. It is intended to define specific actions that the responsible group will undertake to remedy deficiencies. The plan includes a timetable and funding requirements for implementation of the planned activities.

alluvial fan. A cone-shaped deposit of alluvium made by a stream where it runs out onto a level plain.

alluvium. Sedimentary material deposited by flowing water, such as a river.

aquifer. A water-bearing unit of permeable rock or soil that will yield water in usable quantities to wells. Confined aquifers are bounded above and below by less permeable layers. Groundwater in a confined aquifer is under a pressure greater than the atmospheric pressure. Unconfined aquifers are bounded below by less permeable material, but are not bounded above. The pressure on the groundwater at the surface of an unconfined aquifer is equal to that of the atmosphere.

as low as reasonably achievable (ALARA). An approach to radiation protection that advocates controlling or managing exposures (both individual and collective) to the work force and the general public and releases of radioactive material to the environment as low as social, technical, economic, practical, and public policy considerations permit. As used in DOE Order 5400.5, ALARA is not a dose limit but, rather, a process that has as its objective the attainment of dose levels as far below the applicable limits of the Order as practicable.

$G L O-1$ 
B

background radiation. Natural and man-made radiation such as cosmic radiation and radiation from naturally radioactive elements and from commercial sources and medical procedures.

becquerel (Bq). A unit of radioactivity equal to one nuclear transformation per second.

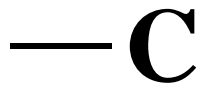

categorical exclusion (CX). A proposed action that normally does not require an environmental assessment or an environmental impact statement and that the Department of Energy has determined does not individually or cumulatively have a significant effect on the human environment. See 10 CFR 1021.410.

Class A, B, and C low-level waste. Waste classifications from the Nuclear Regulatory Commission's 10 CFR Part 61 rule. Maximum concentration limits are set for specific isotopes. Class A waste disposal is minimally restricted with respect to the form of the waste. Class B waste must meet more rigorous requirements to ensure physical stability after disposal. Higher concentration limits are set for the same isotopes in Class $\mathrm{C}$ waste, which also must meet physical stability requirements. Moreover, special measures must be taken at the disposal facility to protect against inadvertent intrusion.

compliance findings. Conditions that may not satisfy applicable environmental or safety and health regulations, DOE Orders and memoranda, enforcement actions, agreements with regulatory agencies, or permit conditions.

confidence coefficient or factor. The chance or probability, usually expressed as a percentage, that a confidence interval includes some defined parameter of a population. The confidence coefficients usually associated with confidence intervals are $90 \%, 95 \%$, and $99 \%$.

confidence interval. The range of values within which some parameter may be expected to lie with a stated degree of confidence. For example, a value of 10 with an uncertainty of 5 calculated at the $95 \%$ confidence level $(10 \pm 5)$ indicates there is a $95 \%$ probability that the true value of the population parameter lies between 5 and 15 .

consistency. The condition of showing steady conformity to practices. In the environmental monitoring program, approved procedures are in place so that data collection activities are carried out in a consistent manner to minimize variability.

cosmic radiation. High-energy subatomic particles from outer space that bombard the earth's atmosphere. Cosmic radiation is part of natural background radiation.

$G L O-2$ 
counting error. The variability caused by the inherent random nature of radioactive disintegration and by the detection process.

curie (Ci). A unit of radioactivity equal to 37 billion $\left(3.7 \times 10^{10}\right)$ nuclear transformations per second.

$-\mathbf{D}$

data set. A group of data (e.g., factual information such as measurements or statistics) used as a basis for reasoning, discussion, or calculation.

decay (radioactive). Disintegration of the nucleus of an unstable nuclide by spontaneous emission of charged particles and/or photons or by spontaneous fission.

derived concentration guide (DCG). The concentration of a radionuclide in air and water that, under conditions of continuous exposure for one year by one exposure mode (i.e., ingestion of water, submersion in air, or inhalation), would result in an effective dose equivalent of 100 mrem $(1 \mathrm{mSv})$. See Table $\mathrm{K}-1^{\mathrm{C}}$ in Appendix $\mathrm{K}^{\mathrm{C}}$.

detection limit or level (DL). This term may also be expressed as "method detection limit" (MDL). The smallest amount of a substance that can be distinguished in a sample by a given measurement procedure at a given confidence level. (See lower limit of detection [p. GLO-7].)

dispersion (groundwater). The process whereby solutes are spread or mixed as they are transported by groundwater as it moves through the subsurface.

dosimeter. A portable device for measuring the total accumulated exposure to ionizing radiation.

downgradient. The direction of water flow from a reference point to a selected point of interest at a lower elevation than the reference point. (See gradient [p. GLO-5].)

$\mathbf{E}$

effective dose. (See effective dose equivalent [p. GLO-10] under radiation dose [p. GLO-9].)

effluent. Any treated or untreated air emission or liquid discharge to the environment, including storm water runoff.

effluent monitoring. Sampling or measuring specific liquid or gaseous effluent streams for the presence of pollutants.

$G L O-3$ 
enhanced work planning. A process used to evaluate and improve the program by which work is identified, planned, approved, controlled, and executed. The key elements are line management ownership, a graded approach to work management based on risk and complexity, worker involvement beginning at the earliest phases of work management, organizationally diverse teams, and organized, institution-wide communication.

environmental assessment. An evaluation that provides sufficient evidence and analysis for determining whether an environmental impact statement or a finding of no significant impact is required. Detailed information found in 40 CFR 1508.9.

environmental impact statement. A detailed statement that includes the environmental impact of the proposed action, any adverse environmental effects that cannot be avoided should the proposal be implemented, and alternatives to the proposed action. Detailed information found in Section 102 (2) (C) of the National Environmental Policy Act.

environmental management system. The systematic application of business management practices to environmental issues, including defining the organizational structure, planning for activities, identifying responsibilities, and defining practices, procedures, processes, and resources.

environmental monitoring. The collection and analysis of samples or the direct measurement of environmental media. Environmental monitoring consists of two major activities: effluent monitoring and environmental surveillance.

environmental surveillance. The collection and analysis of samples or the direct measurement of air, water, soil, foodstuff, and biota in order to determine compliance with applicable standards and permit requirements.

erg. One-billionth (1E-09) of the energy released by a 100-watt bulb in one second.

evapotranspiration. The combined total precipitation returned to the air through direct evaporation and by transpiration of vegetation.

exposure. The subjection of a target (usually living tissue) to radiation.

$\mathbf{F}$

fallout. The settling to earth of radioactive materials mixed into the earth's atmosphere.

finding. A Department of Energy compliance term. A finding is a statement of fact concerning a condition in the Environmental, Safety, and Health program that was investigated during an appraisal. Findings include best management practice findings, compliance findings, and noteworthy practices. A finding may be a

$G L O-4$ 
simple statement of proficiency or a description of deficiency (i.e., a variance from procedures or criteria). (See also self-assessment [p. GLO-11].)

fission. The act or process of splitting into parts. A nuclear reaction in which an atomic nucleus splits into fragments (i.e., fission products, usually fragments of comparable mass) with the evolution of approximately 100 million to several hundred million electron volts of energy.

$-\mathbf{G}$

gamma isotopic (also gamma scan). An analytical method by which the quantity of several gamma rayemitting radioactive isotopes may be determined simultaneously. Typical nuclear fuel cycle isotopes determined by this method include, but are not limited to, cobalt-60, zirconium-95, ruthenium-106, silver-110m, antimony-125, cesium-134, cesium-137, and europium-154. Naturally-occurring isotopes for which samples also often are analyzed are beryllium-7, potassium-40, radium-224, and radium-226.

gradient. Change in value of one variable with respect to another variable, such as a vertical change over a horizontal distance.

groundwater. Subsurface water in the pore spaces and fractures of soil and bedrock units.

$-\mathbf{H}$

half-life. The time in which half the atoms of a radionuclide disintegrate into another nuclear form. The halflife may vary from a fraction of a second to thousands of years.

hazardous waste. A waste or combination of wastes that because of quantity, concentration, or physical, chemical, or infectious characteristics may: a) cause or significantly contribute to an increase in mortality or an increase in serious irreversible or incapacitating reversible illness; or (b) pose a substantial present or potential hazard to human health or the environment when improperly treated, stored, transported, disposed of, or otherwise managed.

high-level waste (HLW). The highly radioactive waste material that results from the reprocessing of spent nuclear fuel, including liquid waste produced directly in reprocessing and any solid waste derived from the liquid, that contains a combination of transuranic waste and fission products in concentrations sufficient to require permanent isolation. (See also transuranic waste [p. GLO-12].)

hydraulic conductivity. The ratio of flow velocity to driving force for viscous flow under saturated conditions of a specified liquid in a porous medium; the ratio describing the rate at which water can move through a permeable medium.

$$
G L O-5
$$


$\mathbf{I}$

integrated safety management system (ISMS). The ISMS describes the programs, policies, and procedures used by WVNSCO and the DOE to ensure that WVNSCO establishes a safe workplace for the employees, the public, and the environment. The guiding principles of ISMS are line management responsibility for safety; clear roles and responsibilities; competence commensurate with responsibilities; balanced priorities; identification of safety standards and requirements; hazard controls; and operations authorization.

interim status. The status of any currently existing facility that becomes subject to the requirement to have a RCRA permit because of a new statutory or regulatory amendment to RCRA.

interstitial. The (annular) space between the inner and outer tank walls in a double-walled storage tank.

ion. An atom or group of atoms with an electric charge.

ion exchange. The reversible exchange of ions contained in solution with other ions that are part of the ionexchange material.

isotope. Different forms of the same chemical element that are distinguished by having the same number of protons but a different number of neutrons in the nucleus. An element can have many isotopes. For example, the three isotopes of hydrogen are protium, deuterium, and tritium, with one, two, and three neutrons in the nucleus, respectively.

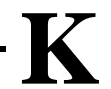

kame delta. A conical hill or short irregular ridge of gravel or sand deposited in contact with glacier ice.

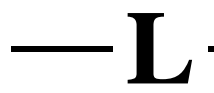

lacustrine sediments. A sedimentary deposit consisting of material pertaining to, produced by, or formed in a lake or lakes.

land disposal restrictions (LDR). Regulations promulgated by the U.S. EPA (and by NYSDEC in New York State) governing the land disposal of hazardous wastes. The wastes must be treated using the best demonstrated available technology or must meet certain treatment standards before being disposed.

$G L O-6$ 
lower limit of detection (LLD). The lowest limit of a given parameter that an instrument is capable of detecting. A measurement of analytical sensitivity.

low-level waste (LLW). Radioactive waste not classified as high-level waste, transuranic waste, spent fuel, or uranium mill tailings. (See Class A, B, and C low-level waste [p. GLO-2].)

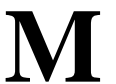

maximally-exposed individual (MEI). On-site (occupational) or off-site (non-occupational) person that receives the highest dose from a release scenario.

maximally-exposed off-site individual (MEOSI). Member of the general public receiving the highest dose from the effluent release.

mean. The average value of a series of measurements.

metric ton. (See ton, metric [p. GLO-12].)

millirem (mrem). A unit of radiation dose equivalent that is equal to one one-thousandth of a rem. An individual member of the public can receive up to $500 \mathrm{mrem}$ per year according to DOE standards. This limit does not include radiation received for medical treatment or the roughly $360 \mathrm{mrem}$, on average, that people receive annually from background radiation.

minimum detectable concentration (MDC) or method detection limit (MDL). Depending on the sample medium, the smallest amount or concentration of a radioactive or nonradioactive analyte that can be reliably detected using a specific analytical method. Calculations of the minimum detectable concentrations are based on the lower limit of detection.

mixed waste (MW). A waste that is both radioactive and hazardous.

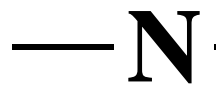

n-Dodecane/tributyl phosphate. An organic solution composed of 30\% tributyl phosphate (TBP) dissolved in n-dodecane used to first separate the uranium and plutonium from the fission products in the dissolved fuel and then to separate the uranium from the plutonium.

neutron. An electrically neutral subatomic particle in the baryon family with a mass 1,839 times that of an electron, stable when bound in an atomic nucleus, and having a mean lifetime of approximately 16.6 minutes as a free particle.

$G L O-7$ 
notice of violation (NOV). A letter of notice from a regional water engineer in response to an instance of significant noncompliance with a SPDES permit. Generally, an official notification from a regulatory agency of noncompliance with permit requirements.

nucleus. The positively-charged central region of an atom, made up of protons and neutrons and containing almost all of the mass of the atom.

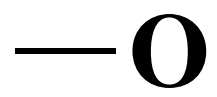

outfall. The discharge end of a drain or pipe that carries wastewater or other effluents into a ditch, pond, or river.

$-\mathbf{P}$

parameter. Any of a set of physical properties whose values determine the characteristics or behavior of something (e.g., temperature, pressure, density of air). In relation to environmental monitoring, a monitoring parameter is a constituent of interest. Statistically, the term "parameter" is a calculated quantity, such as a mean or variance, that describes a statistical population.

particulates. Solid particles and liquid droplets small enough to become airborne.

person-rem. The sum of the individual radiation dose equivalents received by members of a certain group or population. It may be calculated by multiplying the average dose per person by the number of persons exposed. For example, a thousand people each exposed to one millirem would have a collective dose of one person-rem.

plume. The distribution of a pollutant in air or water after being released from a source.

precision. The degree of reproducibility of a measurement under a given set of conditions. Precision in a data set is assessed by evaluating results from duplicate field or analytical samples.

proglacial lake. A lake occupying a basin in front of a glacier, generally in direct contact with the ice.

proton. A stable, positively-charged subatomic particle in the baryon family with a mass 1,836 times that of an electron.

pseudo-monitoring point. A theoretical monitoring location rather than an actual physical location; a calculation based on analytical test results of samples obtained from other associated, tributary, monitored

$G L O-8$ 
locations. (Point 116 at the WVDP is classified as a "pseudo" monitoring point because samples are not physically collected at that location. Rather, using analytical results from samples collected from "real" upstream outfall locations, compliance with the total dissolved solids limit in the WVDP's SPDES permit is calculated for this theoretical point.)

$-\mathbf{Q}$

quality factor (QF). The extent of tissue damage caused by different types of radiation of the same energy. The greater the damage, the higher the quality factor. More specifically, the factor by which absorbed doses are multiplied to obtain a quantity that indicates the degree of biological damage produced by ionizing radiation. See radiation dose [below].) The factor is dependent upon radiation type (alpha, beta, gamma, or $\mathrm{x}$-ray) and exposure (internal or external).

$\mathbf{R}$

rad. Radiation absorbed dose. One hundred ergs of energy absorbed per gram.

radiation. The process of emitting energy in the form of rays or particles that are thrown off by disintegrating atoms. The rays or particles emitted may consist of alpha, beta, or gamma radiation.

alpha radiation. The least penetrating type of radiation. Alpha radiation can be stopped by a sheet of paper or the outer dead layer of skin.

beta radiation. Electrons emitted from a nucleus during fission and nuclear decay. Beta radiation can be stopped by an inch of wood or a thin sheet of aluminum.

gamma radiation. A form of electromagnetic, high-energy radiation emitted from a nucleus. Gamma rays are essentially the same as x-rays and require heavy shielding such as lead, concrete, or steel to be stopped.

internal radiation. Radiation originating from a source within the body as a result of the inhalation, ingestion, or implantation of natural or man-made radionuclides in body tissues.

\section{radiation dose:}

absorbed dose. The amount of energy absorbed per unit mass in any kind of matter from any kind of ionizing radiation. Absorbed dose is measured in rads or grays.

$$
G L O-9
$$


collective dose equivalent. The sum of the dose equivalents for all the individuals comprising a defined population. The per capita dose equivalent is the quotient of the collective dose equivalent divided by the population. The unit of collective dose equivalent is person-rem or personsievert.

collective effective dose equivalent. The sum of the effective dose equivalents for the individuals comprising a defined population. Units of measurement are person-rem or person-sievert. The per capita effective dose equivalent is obtained by dividing the collective dose equivalent by the population. Units of measurement are rem or sievert.

committed dose equivalent. A measure of internal radiation. The predicted total dose equivalent to a tissue or organ over a fifty-year period after a known intake of a radionuclide into the body. It does not include contributions from sources of external penetrating radiation. Committed dose equivalent is measured in rem or sievert.

committed effective dose equivalent. The sum of the committed dose equivalents to various tissues in the body, each multiplied by the appropriate weighting factor. Committed effective dose equivalent is measured in rem or sievert.

effective dose equivalent. The summation of the products of the dose equivalent received by specified tissues of the body and the appropriate weighting factors. It includes the dose from radiation sources internal and/or external to the body. The effective dose equivalent is expressed in units of rem or seivert.

radioactivity. A property possessed by some elements (such as uranium) whereby alpha, beta, or gamma rays are spontaneously emitted.

radioisotope. A radioactive isotope of a specified element. Carbon-14 is a radioisotope of carbon. Tritium is a radioisotope of hydrogen. (See isotope [p. GLO-6].)

radionuclide. A radioactive nuclide. Radionuclides are variations (isotopes) of elements. They have the same number of protons and electrons but different numbers of neutrons, resulting in different atomic masses. There are several hundred known nuclides, both manmade and naturally occurring.

reference man. A hypothetical aggregation of human physical and physiological characteristics arrived at by internal consensus. These characteristics may be used by researchers and public health workers to standardize results of experiments and to relate biological insult to a common base.

rem. An acronym for Roentgen Equivalent Man. A unit of radiation exposure that indicates the potential effect of radiation on human cells.

$G L O-10$ 
remote-handled waste. At the WVDP, waste that has an external surface dose rate that exceeds 100 millirem per hour or a high level of alpha and/or beta surface contamination and, therefore, must be handled in such a manner that a worker does not come into physical contact with it.

roentgen. A unit of exposure to ionizing radiation. It is that quantity of gamma or x-rays required to produce ions carrying one electrostatic unit of electrical charge in one cubic centimeter of dry air under standard conditions. The unit is named after Wilhelm Roentgen, German scientist who discovered x-rays in 1895.

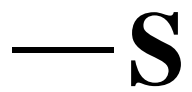

self-assessment. Appraisals of work at the WVDP by individuals, groups, or organizations responsible for overseeing and/or performing the work. Self-assessments are intended to provide an internal review of performance to determine that specific functional areas are in programmatic and site-specific compliance with applicable DOE directives, WVDP procedures, and regulations.

finding. A direct and significant violation of applicable Department of Energy, regulatory, or other procedural or programmatic requirements. A finding requires documented corrective action.

observation. A condition that, while not a direct and significant violation of applicable Department of Energy, regulatory, or other procedural or programmatic requirements, could result in a finding if not corrected. An observation requires documented corrective action.

good practice. A statement of proficiency or confirmed excellence worthy of documenting.

sievert. A unit of dose equivalent from the International System of Units (Systeme Internationale). Equal to one joule per kilogram.

solid waste management unit (SWMU). Any discernible unit at which solid wastes have been placed at any time, irrespective of whether the unit was intended for the management of solid or hazardous waste. Such units include any area at a facility at which solid wastes have been routinely and systematically released. (See also super solid waste management unit [p. GLO-12].)

spent fuel. Nuclear fuel that has been used in a nuclear reactor; this fuel contains uranium, activation products, fission products, and plutonium.

spill. A spill or release is defined as "any spilling, leaking, pumping, pouring, emitting, emptying, discharging, injecting, escaping, leaching, dumping, or otherwise disposing of substances from the ordinary containers employed in the normal course of storage, transfer, processing, or use."

\section{$G L O-11$}


stakeholder. A person or group that has an investment, share, or interest in something. At the WVDP stakeholders include Project management, scientists, other employees, politicians, regulatory agencies, local and national interest groups, and members of the general public.

standard deviation. An indication of the dispersion of a set of results around their average.

super solid waste management unit (SSWMU). Individual solid waste management units that have been grouped and ranked into larger units - super solid waste management units - because some individual units are contiguous or so close together as to make monitoring of separate units impractical. (See also solid waste management unit [p. GLO-11].)

surface water. Water that is exposed to the atmospheric conditions of temperature, pressure, and chemical composition at the surface of the earth.

surveillance. The act of monitoring or observing a process or activity to verify conformance with specified requirements.

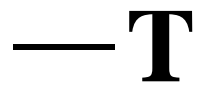

thermoluminescent dosimeter (TLD). A device that luminesces upon heating after being exposed to radiation. The amount of light emitted is proportional to the amount of radiation to which the luminescent material has been exposed.

ton, metric (also tonne). A unit of mass equal to 1,000 kilograms.

ton (short ton). A unit of weight equal to 2,000 pounds or 907.1847 kilograms.

transuranic (TRU) waste. Waste containing transuranic elements, that is, those elements with an atomic number greater than 92, including neptunium, plutonium, americium, and curium.

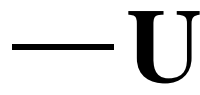

universal wastes. Wastes subject to special management provisions that are intended to ease the management burden and facilitate recycling of such materials. Four types of waste are currently covered under the universal waste regulations: hazardous waste batteries, hazardous waste pesticides that are either recalled or collected in waste pesticide collection programs, hazardous waste thermostats, and hazardous waste lamps.

$G L O-12$ 
upgradient. Referring to the flow of water or air, "upgradient" is analogous to upstream. Upgradient is a point that is "before" an area of study that is used as a baseline for comparison with downstream or downgradient data. (See gradient [p. GLO-5] and downgradient [p. GLO-3].)

\section{$\mathbf{W}$}

watershed. The area contained within a drainage divide above a specified point on a stream or river.

water table. The upper surface in a body of groundwater; the surface in an unconfined aquifer or confining bed at which the pore water pressure is equal to atmospheric pressure.

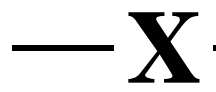

x-ray. Penetrating electromagnetic radiations having wave lengths shorter than those of visible light. They are usually produced by bombarding a metallic target with fast electrons in a high vacuum. In nuclear reactions it is customary to refer to photons originating in the nucleus as gamma rays and those originating in the extranuclear part of the atom as x-rays. These rays are sometimes called roentgen rays after their discoverer, W.C. Roentgen.

$G L O-13$ 
This page intentionally left blank

$$
G L O-14
$$




\section{ACRONYMS AND ABBREVIATIONS}

$\begin{array}{ll}\text { ACM } & \text { Asbestos-Containing Material } \\ \text { ACOE } & \text { (U.S.) Army Corps of Engineers } \\ \text { ALARA } & \text { As Low As Reasonably Achievable } \\ \text { ANSI } & \text { American National Standards Institute } \\ \text { ASER } & \text { Annual Site Environmental Report } \\ \text { ASME } & \text { American Society of Mechanical Engineers } \\ \text { ASQ } & \text { American Society for Quality (formerly American Society for Quality Co } \\ \text { AWQS } & \text { [ASQC]) } \\ \text { BAT } & \text { Ambient Water Quality Standard } \\ \text { BCG } & \text { Best Available Technology } \\ \text { BEIR } & \text { Biota Concentration Guide } \\ \text { BOD } & \text { Biological Effects of Ionizing Radiation } \\ \text { BSW } & \text { Biochemical Oxygen Demand (5-day) } \\ \text { CAA } & \text { Bulk Storage Warehouse } \\ \text { CD } & \\ \text { CDDL } & \text { Clean Air Act } \\ \text { CEDE } & \text { Compact Disk } \\ \text { CEMP } & \text { Construction and Demolition Debris Landfill } \\ \text { CERCLA } & \text { Committed Effective Dose Equivalent } \\ \text { CFR } & \text { Code of Environmental Management Principles (for Federal Agencies) } \\ \text { CO } & \text { Comprehensive Environmental Response, Compensation, and Liability Act } \\ \text { CPC } & \text { Code of Federal Regulations } \\ \text { CPC-WSA } & \text { Certificate-to-Operate } \\ \text { CSPF } & \text { Chemical Process Cell } \\ \text { CSRF } & \text { Chemical Process Cell Waste Storage Area } \\ \text { CSS } & \text { Container Sorting and Packaging Facility } \\ \text { CWA } & \text { Contact Size-Reduction Facility } \\ & \text { Cement Solidification System } \\ \text { Clean Water Act }\end{array}$

$A \& A-1$ 


CWAP
CX
CY
DCDFMeth
DCG
DL
DMR
DOE
DOE-EM
DOE-HQ
DOE-OH
DOT

\section{EA}

EDE

EHS

EIS

ELAB

EML

EMS

EO

EPA

EPCRA

ERA

ES\&H

ESR

EWP

FFC Act

FONSI

FR

FRS

FY

GEL

GET

GPC

HAA5

HEPA

HLW

HPIC
Clean Water Action Plan

Categorical Exclusion

Calendar Year

Dichlorodifluoromethane

Derived Concentration Guide

Detection Limit or Detection Level

Discharge Monitoring Report

(U.S.) Department of Energy

Department of Energy, Office of Environmental Restoration and Waste Management

Department of Energy, Headquarters Office

Department of Energy, Ohio Field Office

(U.S.) Department of Transportation

Environmental Assessment

Effective Dose Equivalent

Extremely Hazardous Substance

Environmental Impact Statement

(WVDP) Environmental Laboratory

(DOE) Environmental Measurements Laboratory

Environmental Management System

Executive Order

(U.S.) Environmental Protection Agency

Emergency Planning and Community Right-to-Know Act

Environmental Research Associates

Environmental, Safety, and Health

(WVDP) Effluent Summary Report

Enhanced Work Planning

Federal Facility Compliance Act

Finding of No Significant Impact

Federal Register

Fuel Receiving and Storage

Fiscal Year

General Engineering Laboratory

General Employee Training

General Purpose Cell

Haloacetic Acid

High-Efficiency Particulate Air (filter)

High-Level (radioactive) Waste

High-Pressure Ion Chamber

$A \& A-2$ 


\begin{tabular}{|c|c|}
\hline HTO & Hydrogen Tritium Oxide \\
\hline HVAC & Heating, Ventilation, and Air Conditioning \\
\hline ICRP & International Commission on Radiological Protection \\
\hline ID & Identification Number (samples, wells, or monitoring locations) \\
\hline INEEL & Idaho National Engineering and Environmental Laboratory \\
\hline INL & Idaho National Laboratory (prior name for INEEL) \\
\hline IRTS & Integrated Radwaste Treatment System \\
\hline ISCORS & Interagency Steering Committee on Radiation Standards \\
\hline ISMS & Integrated Safety Management System \\
\hline ISO & International Organization for Standardization \\
\hline LAS & Linear Alkylate Sulfonate \\
\hline LDR & Land Disposal Restriction \\
\hline LIMS & Laboratory Information Management System \\
\hline LLD & Lower Limit of Detection \\
\hline LLW & Low-Level (radioactive) Waste \\
\hline LLW2 & Low-Level(liquid) Waste Treatment Facility (new) \\
\hline LLWTF & Low-Level(liquid) Waste Treatment Facility (old) \\
\hline LPS & Liquid Pretreatment System \\
\hline LSA & Lag Storage Area \\
\hline LTR & License Termination Rule \\
\hline LWTS & Liquid Waste Treatment System \\
\hline MCL & Maximum Contaminant Level \\
\hline MCLG & Maximum Contaminant Level Goal \\
\hline MDC & Minimum Detectable Concentration \\
\hline MDL & Method Detection Limit (also Minimum Detection Level) \\
\hline MEI & Maximally-Exposed Individual \\
\hline MEOSI & Maximally-Exposed Off-Site Individual \\
\hline MGD & Million Gallons per Day \\
\hline ML & Minimum Level \\
\hline MSDS & Material Safety Data Sheet \\
\hline MTAR & Monthly Trend Analysis Report \\
\hline MW & (Radioactive and Hazardous) Mixed Waste \\
\hline NCRP & National Council on Radiation Protection and Measurements \\
\hline NDA & Nuclear Regulatory Commission (NRC)-Licensed Disposal Area \\
\hline NEPA & National Environmental Policy Act \\
\hline NESHAP & National Emission Standards for Hazardous Air Pollutants \\
\hline NFS & Nuclear Fuel Services, Inc. \\
\hline NGVD & National Geodetic Vertical Datum \\
\hline $\mathbf{N H}_{3}$ & Ammonia \\
\hline
\end{tabular}

$A \& A-3$ 
NIST

NOAA

NOI

NOV

$\mathrm{NO}_{\mathrm{x}}$

NPDES

NPGRS

NPOC

NRC

NTS

NTU

NYCRR

NYS

NYSDEC

NYSDOH

NYSDOH ELAP

NYSDOL

NYSERDA

NYSGS

OH/WVDP

OSHA

OVE

P2

PCB

PMC

PNNL

PPC

PQL

PSOSS

PTW

PUREX

PVS

PVU

QA

QAP

QC

QF

RCRA

REM
National Institute of Standards and Technology

National Oceanic and Atmospheric Administration

Notice of Intent

Notice of Violation

Nitrogen Oxides

National Pollutant Discharge Elimination System

North Plateau Groundwater Recovery System

Nonpurgeable Organic Carbon

(U.S.) Nuclear Regulatory Commission

Nevada Test Site

Nephelometric Turbidity Unit

New York Official Compilation of Codes, Rules, and Regulations

New York State

New York State Department of Environmental Conservation

New York State Department of Health

(NYSDOH) Environmental Laboratory Approval Program

New York State Department of Labor

New York State Energy Research and Development Authority

New York State Geological Survey

Department of Energy, West Valley Demonstration Project

Occupational Safety and Health Administration

Outdoor Ventilated Enclosure

Pollution Prevention

Polychlorinated Biphenyl

Process Mechanical Cell

Pacific Northwest National Laboratory

Product Purification Cell

Practical Quantitation Limit

Plant Systems Operations Shift Supervisor

Permeable Treatment Wall

Plutonium Uranium Reduction Extraction

Permanent Ventilation System

Portable Ventilation Unit

Quality Assurance

Quality Assessment Program (also Quality Assurance Program)

Quality Control

Quality Factor

Resource Conservation and Recovery Act

Roentgen Equivalent Man

$A \& A-4$ 
RFI

RHWF

SAR

SARA

SD

SDA

SDWA

SI

$\mathrm{SO}_{2}$

SPDES

SRM

SRR

SSWMU

STL

STP

STS

SVOC

SWMU

TAGM

TBP

TCE

TDS

TFA

THOREX

TLD

TOC

TOGS

TOX

TRI

TRU

TSCA

TSDF

TSS

U.S.

URS

USC

USGS
RCRA Facility Investigation

Remote-Handled Waste Facility

Safety Analysis Report

Superfund Amendments and Reauthorization Act

Standard Deviation

(New York) State-Licensed Disposal Area

Safe Drinking Water Act

Systeme Internationale (International System of Units)

Sulfur Dioxide

(New York) State Pollutant Discharge Elimination System

Standard Reference Material

Scrap Removal Room

Super Solid Waste Management Unit

Severn Trent Laboratories

Site Treatment Plan

Supernatant Treatment System

Semivolatile Organic Compound

Solid Waste Management Unit

Technical and Administrative Guidance Memorandum

Tributyl Phosphate

Trichloroethylene

TotalDissolved Solids

Tank Focus Area

Thorium Reduction Extraction

Thermoluminescent Dosimeter

Total Organic Carbon

Technical and Operational Guidance Series

Total Organic Halides

Toxic Release Inventory

Transuranic

Toxic Substances Control Act

Treatment, Storage, and Disposal Facility

Total Suspended Solids

United States

URS Group, Inc.

United States Code

United States Geological Survey

A\&A - 5 


VF
VOC
VPP
WNYNSC
WVDP
WVNS
WVNSCO
WWTF

XC-2
Vitrification Facility

Volatile Organic Compound

(U.S. DOE) Voluntary Protection Program

Western New York Nuclear Service Center

West Valley Demonstration Project

West Valley Nuclear Services Company (now WVNSCO)

West Valley Nuclear Services Company

Wastewater Treatment Facility

Extraction Cell \#2

$A \& A-6$ 


\section{Units of Measure}

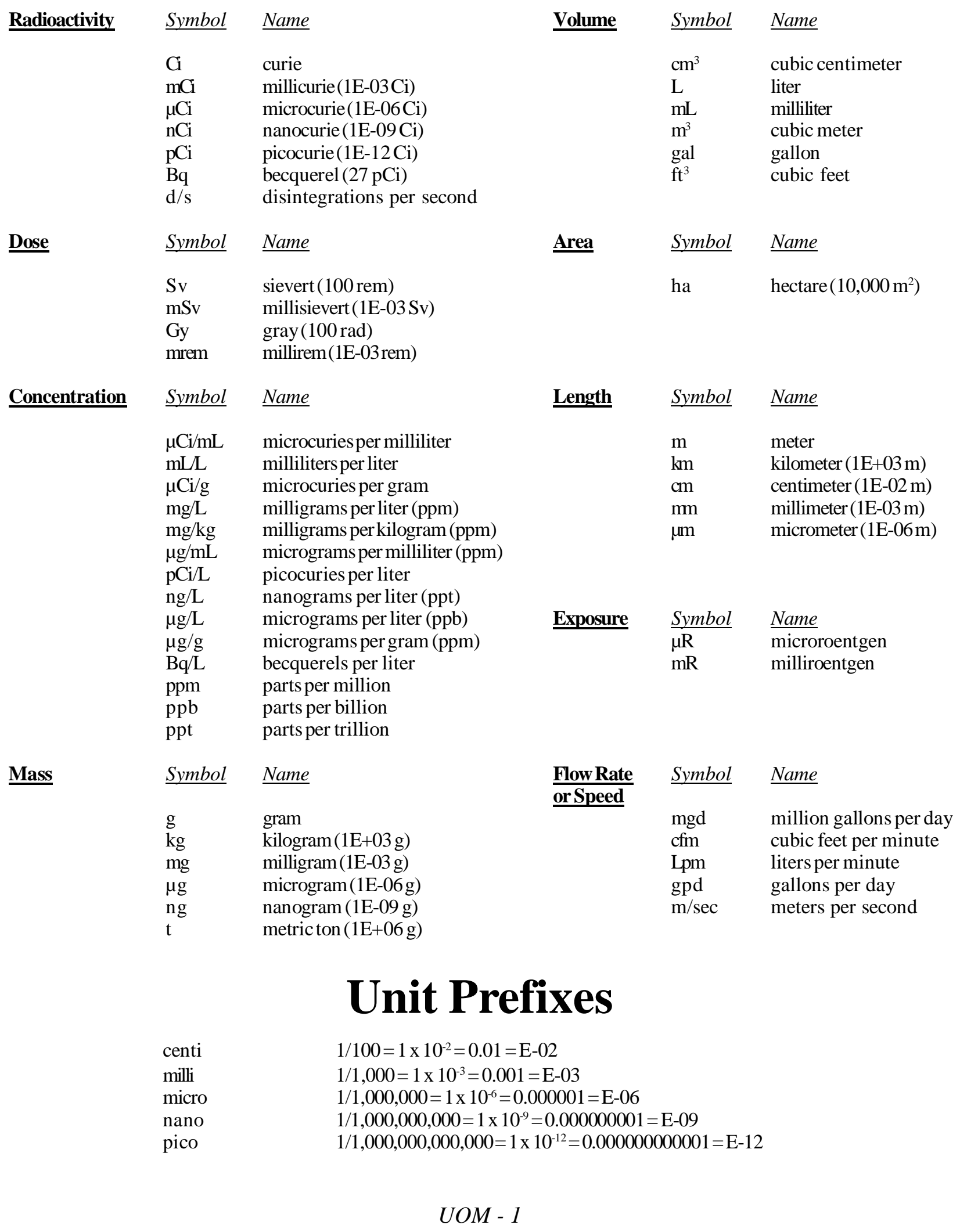




\section{Scientific Notation}

Scientific notation may be used to express very large or very small numbers. A number smaller than 1 is expressed with a negative exponent (e.g., $1.3 \times 10^{-6}$ ). To convert this number to decimal form, the decimal point is moved left by the number of places equal to the exponent. Thus, $1.3 \times 10^{-6}$ becomes 0.0000013 .

A number larger than 10 is expressed with a positive exponent (e.g., $\left.1.3 \times 10^{6}\right)$. To convert this number to decimal form, the decimal point is moved right by the number of places equal to the exponent. Thus, $1.3 \times 10^{6}$ becomes $1,300,000$.

The power of 10 also is expressed as E. For example, $1.3 \times 10^{-6}$ also can be written as $1.3 \mathrm{E}-06$. The chart below shows equivalent exponential and decimal values.

$$
\begin{array}{lllll}
1.0 \times 10^{2}= & 1 \mathrm{E}+02= & 100 \\
1.0 \times 10^{1}= & 1 \mathrm{E}+01= & 10 \\
1.0 \times 10^{0}= & 1 \mathrm{E}+00= & 1 \\
1.0 \times 10^{-1}= & 1 \mathrm{E}-01= & 0.1 \\
1.0 \times 10^{-2}= & 1 \mathrm{E}-02= & 0.01 \\
1.0 \times 10^{-3}= & 1 \mathrm{E}-03= & & \\
1.0 \times 10^{-4}= & 1 \mathrm{E}-04= & 0.001 & \\
1.0 \times 10^{-5}= & 1 \mathrm{E}-05= & 0.00001 & \\
1.0 \times 10^{-6}= & 1 \mathrm{E}-06= & 0.000001 & \text { One millionth } \\
1.0 \times 10^{-7}= & 1 \mathrm{E}-07= & 0.0000001 & \\
1.0 \times 10^{-8}= & 1 \mathrm{E}-08= & 0.00000001 & \\
& & & &
\end{array}
$$

\section{Conversion Chart}

Both traditional radiological units (curie, roentgen, rad, rem) and the Systeme Internationale (S.I.) units (becquerel, gray, sievert) are used in this report. Nonradiological measurements are presented in both English and metric units. Frequently-used radioactivity and dose conversions are bolded.

$\begin{array}{lll}1 \text { centimeter }(\mathrm{cm}) & = & 0.3937 \text { inches }(\mathrm{in}) \\ 1 \text { meter }(\mathrm{m}) & = & 39.37 \text { inches }(\mathrm{in})=3.28 \text { feet }(\mathrm{ft}) \\ 1 \text { kilometer }(\mathrm{km}) & = & 0.62 \text { miles }(\mathrm{mi}) \\ 1 \text { milliliter }(\mathrm{mL}) & = & 0.0338 \text { ounces }(\mathrm{oz}) \\ & = & 0.061 \text { cubic inches }\left(\mathrm{in}^{3}\right) \\ & = & 1 \text { cubic centimeter }\left(\mathrm{cm}^{3}\right) \\ 1 \text { liter }(\mathrm{L}) & = & 1.057 \text { quarts }(\mathrm{qt}) \\ & = & 61.02 \text { cubic inches }\left(\mathrm{in}^{3}\right) \\ 1 \text { gram }(\mathrm{g}) & = & 0.0353 \text { ounces }(\mathrm{oz}) \\ & = & 0.0022 \text { pounds }(\mathrm{lbs}) \\ 1 \text { kilogram }(\mathrm{kg}) & = & 2.2 \text { pounds }(\mathrm{lbs}) \\ 1 \text { curie }(\mathrm{Ci}) & = & 3.7 \mathrm{E}+10 \text { disintegrations per second }(\mathrm{d} / \mathrm{s}) \\ \mathbf{1} \text { becquerel }(\mathbf{B q}) & = & \mathbf{1} \text { disintegration per second }(\mathbf{d} / \mathbf{s}) \\ & = & \mathbf{2 7} \text { picocuries }(\mathbf{p C i}) \\ 1 \text { roentgen }(\mathrm{R}) & = & 2.58 \mathrm{E}-04 \text { coulombs per kilogram of air }(\mathrm{C} / \mathrm{kg}) \\ \mathbf{1} \text { rad } & = & \mathbf{0 . 0 1} \text { gray }(\mathbf{G y}) \\ \mathbf{1} \text { rem } & = & \mathbf{0 . 0 1} \text { sievert }(\mathbf{S v}) \\ 1 \text { millirem }(\mathrm{mrem}) & = & 0.001 \text { rem } \\ 1 \text { sievert }(\mathbf{S v}) & = & \mathbf{1 0 0} \text { rem }\end{array}$




\section{Distribution}

$\underline{\text { Recipient }}$

DOE Office of Scientific and Technical Information

\begin{tabular}{|c|c|}
\hline R. Hardwick & DOE - HQ \\
\hline R. Natoli & DOE - HQ \\
\hline G. Podonsky & DOE - HQ \\
\hline M. Rawlings & DOE - HQ \\
\hline J. Craig & $\mathrm{DOE}-\mathrm{OH}$ \\
\hline R. Tormey & $\mathrm{DOE}-\mathrm{OH}$ \\
\hline C. Glenn & NRC - HQ \\
\hline J. Greeves & NRC - HQ \\
\hline J. Kottan & NRC - Region 1 \\
\hline R. Chaput & U.S. EPA - Region II \\
\hline J. Eng & U.S. EPA - Region II \\
\hline P. Giardina & U.S. EPA - Region II \\
\hline W. Kappel & USGS \\
\hline T. Reynolds & U.S. Congressman, 26th Dist. \\
\hline J. Quinn & U.S. Congressman, 30th Dist. \\
\hline A. Houghton & U.S. Congressman, 31st Dist. \\
\hline H. Clinton & U.S. Senator, New York \\
\hline C. Schumer & U.S. Senator, New York \\
\hline
\end{tabular}

\section{$\underline{\text { Recipient }}$}

E. Wohlers

G. Felton

G. Fitzpatrick

J. Burrell

\begin{abstract}
A. Billittier IV
R. Armstrong

L. Maybee
\end{abstract}

Federal Organization

U.S. Senator, New York

\begin{abstract}
Cattaraugus County Legislator
Cattaraugus County Legislator

Cattaraugus County Legislator
\end{abstract}

Erie County Health Department

President, Seneca Nation of Indians $\underline{\text { Recipient }}$

J. Austin

E. Dassatti

R. Phaneuf

T. Rice

M. Wang

L. Winterberger

B. Youngberg

B. Bartz

S. Doleski

J. Sciascia

D. D'Angelo

M. Jackson

J. Strickland

G. Baker

B. Ignatz

A. Salame Alfie

P. Piciulo

H. Brodie

R. Fakundiny

D. Burling

C. Young

P. McGee

W. Stachowski

D. Volker

$\underline{\text { Recipient }}$ $\underline{\text { State Organization }}$

Executive Chamber, State Capitol, Albany

NYSDEC - Albany

NYSDEC - Albany

NYSDEC - Albany

NYSDEC - Albany

NYSDEC - Albany

NYSDEC - Albany

NYSDEC - Buffalo

NYSDEC - Buffalo

NYSDEC - Buffalo

NYSDEC - Region 9

NYSDEC - Region 9

NYSDEC - Region 9

NYSDOH - Buffalo

NYSDOH - Buffalo

NYSDOH - Troy

NYSERDA

NYSERDA - Albany

NYSGS

New York Assemblyman, 147th Dist.

New York Assemblywoman, 149th Dist.

New York Senator, 57th Dist.

New York Senator, 58th Dist.

New York Senator, 59th Dist.

\section{$\underline{\text { Local Organization }}$}

Mayor, Village of Springville

Supervisor, Town of Ashford

Supervisor, Town of Concord
G. Eppolito
W. King
M. Steffan

Seneca Nation of Indians Environmental Protection Department

DST - 1 


\section{Distribution}

\section{Publication}

Buffalo News, Buffalo, New York*

Salamanca Republican Press, Salamanca, New York *

Springville Journal, Springville, New York*

\section{Library}

Olean Public Library, Olean, New York

West Valley Central School Library, West Valley, New York Town of Concord Hulbert Library, Springville, New York

Central Buffalo Public Library, Buffalo, New York

Seneca Nation of Indians Library, Cattaraugus Reservation, Irving, New York

Seneca Nation of Indians Library, Allegheny Reservation, Salamanca, New York

* Notice of public availability

DST - 2 


\section{Appendix A \\ Environmental Monitoring Program Maps}

$A-i$ 
This page intentionally left blank

$A-i i$ 


\section{Environmental Monitoring Program Sample Points}

The following maps contain points sampled as part of the West Valley Demonstration Project (WVDP) routine environmental monitoring program for 2003. This program met or exceeded the requirements of DOE Order 450.1, DOE Order 5400.5, and DOE/EH-0173T. Specific methods and recommended monitoring program elements are found in DOE/EP-0096, A Guide for Effluent Radiological Measurements at DOE Installations, and DOE/EP-0023, A Guide for Environmental Radiological Surveillance at U.S. Department of Energy Installations, which were the bases for selecting most of the sampling locations. Additional monitoring was mandated by air and water discharge permits (40 CFR 61 and SPDES).

The index on pages A-iv through A-vii is a list of the codes used to identify the various sampling locations, which are shown on Figures A-2 through A-13 (pp. A-2 through A-13). The sample location code describes the physical location where the sample is collected. The code consists of seven or eight characters: The first character identifies the sample medium as Air, Water, Soil/Sediment, Biological, or Direct Measurement. The second character specifies oN-site or oFf-site. The remaining characters describe the specific location (e.g., AFGRVAL is Air oFf-site at GReat VALley). Distances noted at sampling locations are as measured in a straight line from the main stack on-site. Sampling points located inside buildings (e.g., on-site drinking water locations) or points that do not have a fixed location (e.g., outdoor ventilated enclosures) are not shown on these maps. Areas labeled as "wetlands" on the figures in Appendix A do not depict the WVDP's formallydelineated wetlands inventory. As an aid to the reader, these polygons indicate relatively low-lying areas that almost always contain wet surface soils or standing water during years with typical precipitation totals.

\section{List of Maps}

A-1. West Valley Demonstration Project Base Map A-1

A-2. On-Site Surface Water and Soil/Sediment Sampling Locations A-2

A-3. Off-Site Surface Water and Soil/Sediment Sampling Locations A-3

A-4. On-Site Air Monitoring and Sampling Locations ____ A-4

A-5. Off-Site Air and Fallout Sampling Locations ___ A-5

A-6. Active WVDP Groundwater Monitoring Locations ____ A-6

A-7. North Plateau On-Site Groundwater Monitoring Network ___ A-7

A-8. South Plateau On-Site Groundwater Monitoring Network ____ A-8

A-9. Near-Site Drinking Water and Biological Sampling Locations ___ A-9

A-10. Location of On-Site Thermoluminescent Dosimeters (TLDs) ___ A-10

A-11. Location of Off-Site Thermoluminescent Dosimeters (TLDs) Within 5 Kilometers of the WVDP _ A-11

A-12. Environmental Sampling Locations Between 5 and 10 Kilometers From the WVDP ___ A-12

A-13. Environmental Sampling Locations More Than 10 Kilometers From the WVDP____ A-13

A-14. Projected 2002 Population by Sector Within 80 Kilometers of the WVDP___ A-14 


\section{List of Sampling Locations}

On-Site Surface Water and Soil/Sediment Sampling Locations (Fig. A-2 [p. A-2])

WNSP001

WNSP006

SNSP006

WNSP116

WNSP007

WNSWAMP

SNSWAMP

WNSW74A

SNSW74A

WNSDADR

WNSP008

WNSP005

WNCOOLW

WNFRC67

WNERB53

WNNDADR

WNDCELD

WNNDATR

WNSTAW6
Lagoon 3 Weir Point

Facility Main Drainage

Soil at WNSP006

Pseudo Monitoring Point in Frank's Creek

Sanitary Waste Discharge

Northeast Swamp Drainage Point

Soil at WNSWAMP

North Swamp Drainage Point

Soil at WNSW74A

SDA Run-Off

French Drain LLWTF Area

South Facility Drainage

Cooling Tower

Frank's Creek East

Erdman Brook

Disposal Area Drainage

Drum Cell Drainage

NDA Trench Interceptor Project

Standing Water

\section{Off-Site Surface Water and Soil/Sediment Sampling Locations (Fig. A-3 [p. A-3])}

$\begin{array}{ll}\text { WFBCBKG } & \text { Buttermilk Creek near Fox Valley, Background } \\ \text { WFBCTCB } & \text { Buttermilk Creek at Thomas Corners } \\ \text { WFBIGBR } & \text { Cattaraugus Creek at Bigelow Bridge, Background } \\ \text { SFBISED } & \text { Cattaraugus Creek at Bigelow Bridge, Background Sediment } \\ \text { WFFELBR } & \text { Cattaraugus Creek at Felton Bridge } \\ \text { SFTCORD } & \text { Soil at Thomas Corners Air Sampler } \\ \text { SFSDSED } & \text { Cattaraugus Creek at Springville Dam, Sediment } \\ \text { SFCCSED } & \text { Cattaraugus Creek at Felton Bridge, Sediment } \\ \text { SFTCSED } & \text { Buttermilk Creek at Thomas Corners, Sediment } \\ \text { SFBCSED } & \text { Buttermilk Creek at Fox Valley Road, Background Sediment } \\ \text { SFRSPRD } & \text { Soil at Rock Springs Road Air Sampler } \\ \text { SFRT240 } & \text { Soil at Route 240 Air Sampler } \\ \text { SFBLKST } & \text { Soil at Bulk Storage Warehouse Air Sampler } \\ \text { SFFXVRD } & \text { Soil at Fox Valley Road Air Sampler } \\ \text { SFBOEHN } & \text { Soil at Dutch Hill Road Air Sampler } \\ \text { WNSTAW4 } & \text { Standing Water } \\ \text { WNSTAW5 } & \text { Standing Water } \\ \text { WNSTAW9 } & \text { Standing Water }\end{array}$

$A-i v$ 


\section{List of Sampling Locations (continued)}

On-Site Air Monitoring and Sampling Locations (Fig. A-4 [p. A-4])

$\begin{array}{ll}\text { ANSTACK } & \text { Main Plant } \\ \text { ANSTSTK } & \text { Supernatant Treatment System } \\ \text { ANCSSTK } & \text { 01-14 Building } \\ \text { ANCSRFK } & \text { Size-Reduction Facility } \\ \text { ANCSPFK } & \text { Container Sorting and Packaging Facility } \\ \text { ANVITSK } & \text { Vitrification Heating, Ventilation, and Air Conditioning } \\ \text { ANSEISK } & \text { Seismic Sampler (Vitrification backup) } \\ \text { ANLLW2V } & \text { Low-Level Waste Treatment Ventilation } \\ \text { ANLAGAM } & \text { Lag Storage Area (ambient air) } \\ \text { ANNDAAM } & \text { NDAArea (ambient air) } \\ \text { ANSDAT9 } & \text { SDA Trench 9 (ambient air) } \\ \text { ANRGFOP } & \text { Rain Gauge Fallout }\end{array}$

Off-Site Air and Fallout Sampling Locations (Fig. A-5 [p. A-5])

$\begin{array}{ll}\text { AFFXVRD } & \text { Fox Valley Sampler } \\ \text { AFFXFOP } & \text { Fox Valley Fallout } \\ \text { AFTCORD } & \text { Thomas Corners Sampler } \\ \text { AFTCFOP } & \text { Thomas Corners Fallout } \\ \text { AFRT240 } & \text { Route 240 Sampler } \\ \text { AF24FOP } & \text { Route 240 Fallout } \\ \text { AFBOEHN } & \text { Dutch Hill Road Sampler } \\ \text { AFDHFOP } & \text { Dutch Hill Fallout } \\ \text { AFRSPRD } & \text { Rock Springs Road Sampler } \\ \text { AFBLKST } & \text { Bulk Storage Warehouse Sampler }\end{array}$

$A-v$ 


\section{List of Sampling Locations (continued)}

Active WVDP Groundwater Monitoring Locations (Fig. A-6 [p. A-6])

North Plateau On-Site Groundwater Monitoring Network (Fig. A-7 [p. A-7])

South Plateau On-Site Groundwater Monitoring Network (Fig. A-8 [p. A-8])

$\begin{array}{ll}\text { SSWMU\#1 } & \text { Low-Level Waste Treatment Facility Wells } \\ \text { SSWMU\#2 } & \text { Miscellaneous Small Units Wells } \\ \text { SSWMU \#3 } & \text { Liquid Waste Treatment System Wells } \\ \text { SSWMU \#4 } & \text { HLW Storage and Processing Tank Wells } \\ \text { SSWMU \#5 } & \text { Maintenance Shop Leach Field Wells } \\ \text { SSWMU\#6 } & \text { Low-Level Waste Storage Area Wells } \\ \text { SSWMU\#7 } & \text { CPC Waste Storage Area Wells } \\ \text { SSWMU \#8 } & \text { CDDL Wells } \\ \text { SSWMU\#9 } & \text { NDA Units Wells and NDATR } \\ \text { SSWMU\#10 } & \text { IRTS Drum Cell Wells } \\ \text { RHWF } & \text { Remote-Handled Waste Facility Wells } \\ \text { SSWMU\#11 } & \text { SDA Unit Wells } \\ \text { North Plateau Seeps } & \text { Northeastern Edge of North Plateau } \\ \text { Well Points } & \text { Downgradient of Main Plant } \\ \text { WNWNB1S } & \text { Former North Plateau Background Well }\end{array}$

Near-Site Drinking Water and Biological Sampling Locations (Fig. A-9 [p. A-9])

$\begin{array}{ll}\text { BFFCATC } & \text { Cattaraugus Creek Fish, Downstream } \\ \text { BFFCATD } & \text { Cattaraugus Creek Fish, Downstream of Springville Dam } \\ \text { BFMREED } & \text { North-Northwest Milk, Near-Site } \\ \text { BFMWIDR } & \text { Southeast Milk, Near-Site } \\ \text { BFMSCHT } & \text { South Milk, Near-Site } \\ \text { BFVNEAR } & \text { Produce, Near-Site } \\ \text { BFBNEAR } & \text { Beef, Near-Site } \\ \text { BFDNEAR } & \text { Venison, Near-Site } \\ \text { WFWEL Series } & \text { Private Wells }\end{array}$

Location of On-Site Thermoluminescent Dosimeters (TLDs) (Fig. A-10 [p. A-10])

DNTLD Series $\quad$ On-Site Direct Radiation

Location of Off-Site Thermoluminescent Dosimeters (TLDs) Within 5 Kilometers of the WVDP (Fig. A-11 [p. A-11])

DFTLD Series $\quad$ Off-Site Direct Radiation

$$
A-v i
$$




\section{List of Sampling Locations (concluded)}

Environmental Sampling Locations Between 5 and 10 Kilometers From the WVDP(Fig. A-12 [p. A-12])

$\begin{array}{ll}\text { AFSPRVL } & \text { Springville Sampler } \\ \text { SFSPRVL } & \text { Soil at Springville Air Sampler } \\ \text { DFTLD21 } & \text { TLD at Springville Air Sampler } \\ \text { WFWEL10 } & \text { Drinking Water at Springville Air Sampler } \\ \text { BFVNEAR } & \text { Produce, Near-site } \\ \text { DFTLD22 } & \text { TLD at West Valley Air Sampler } \\ \text { SFWEVAL } & \text { Soil at West Valley Air Sampler } \\ \text { AFWEVAL } & \text { West Valley Sampler }\end{array}$

Environmental Sampling Locations More Than 10 Kilometers From the WVDP(Fig. A-13 [p. A-13])

BFMCTLS

BFVCTRL

AFNASHV

SFNASHV

DFTLD37

WNSTAWB

DFTLD41

BFFCTRL

DFTLD17

BFDCTRL

AFGRVAL

SFGRVAL

DFTLD23

WFWEL06

BFBCTRL
Milk, South, Background

Produce, Background

Nashville Sampler, Background

Soil at Nashville Air Sampler

TLD, Background

Standing Water, Background

TLD, Background

Cattaraugus Creek Fish, Background

TLD, Background

Venison, Background

Great Valley Sampler, Background

Soil at Great Valley Air Sampler, Background

TLD at Great Valley Air Sampler

Drinking Water at Great Valley Air Sampler

Beef, Background

$A-v i i$ 
This page intentionally left blank

A - viii 


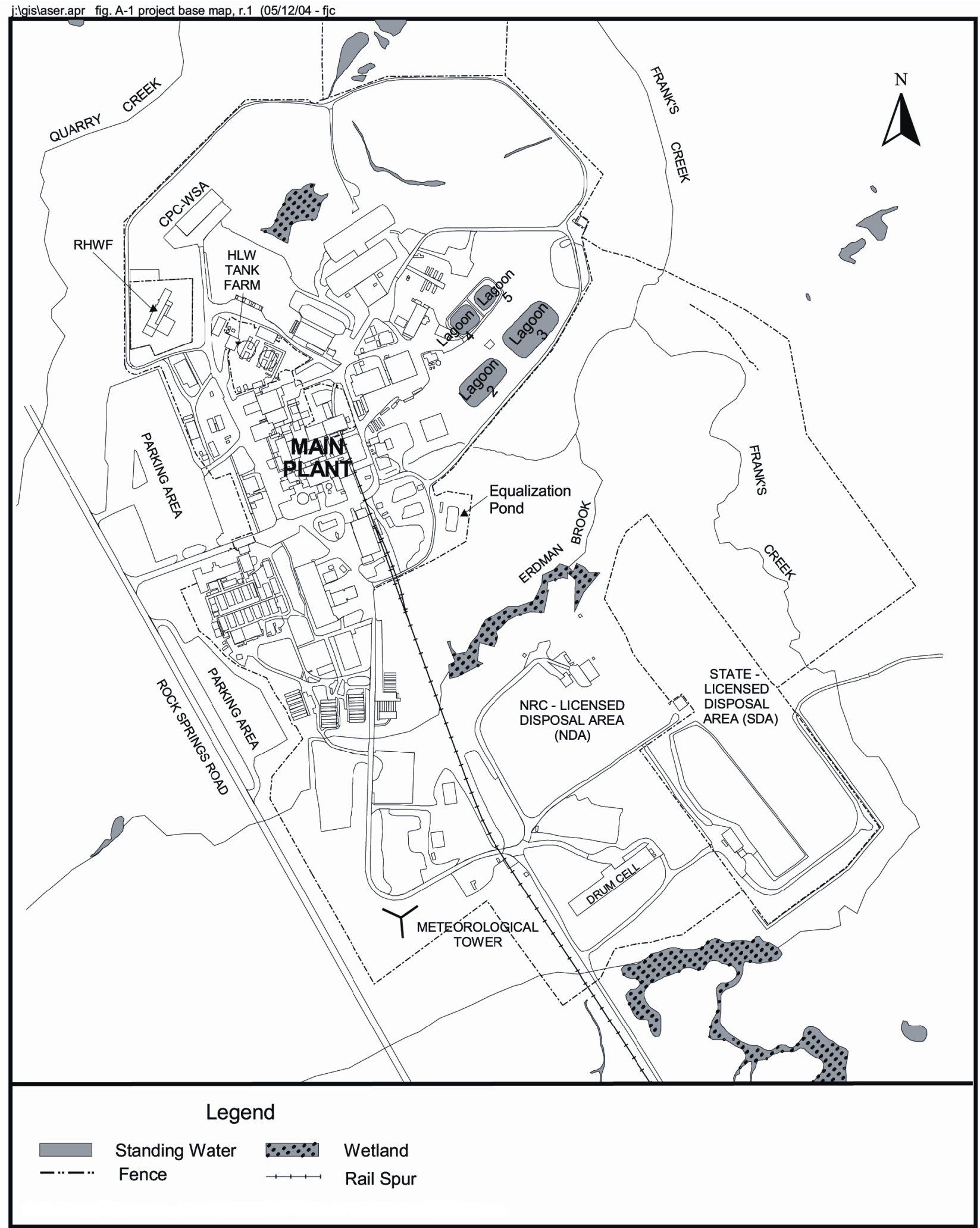

Figure A-1. West Valley Demonstration Project Base Map

$A-1$ 


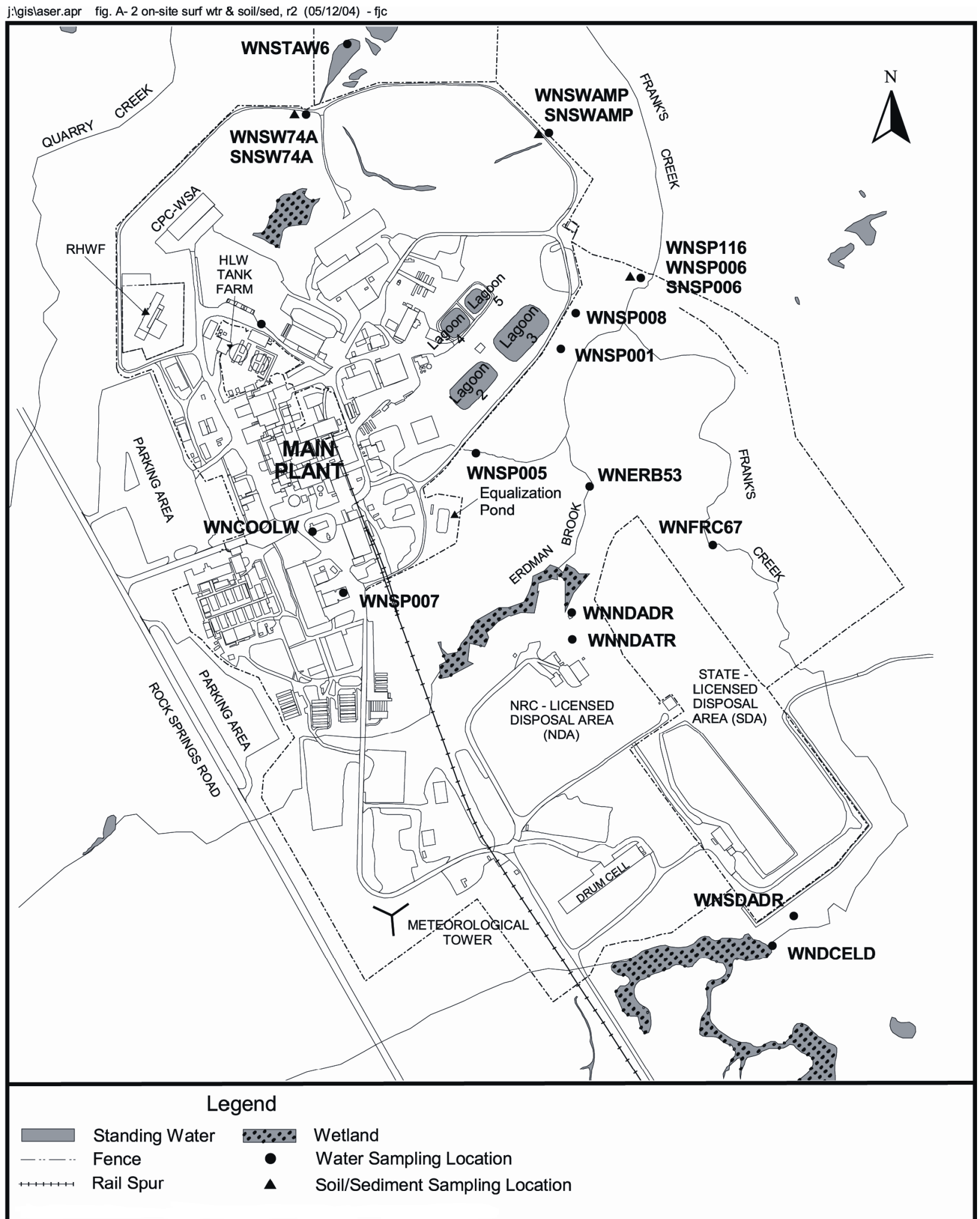

Figure A-2. On-Site Surface Water and Soil/Sediment Sampling Locations

A - 2 
j:lgislaser.apr fig. A-3 off-site surface water \& soil/sed, r2 (05/19/04) - fjc

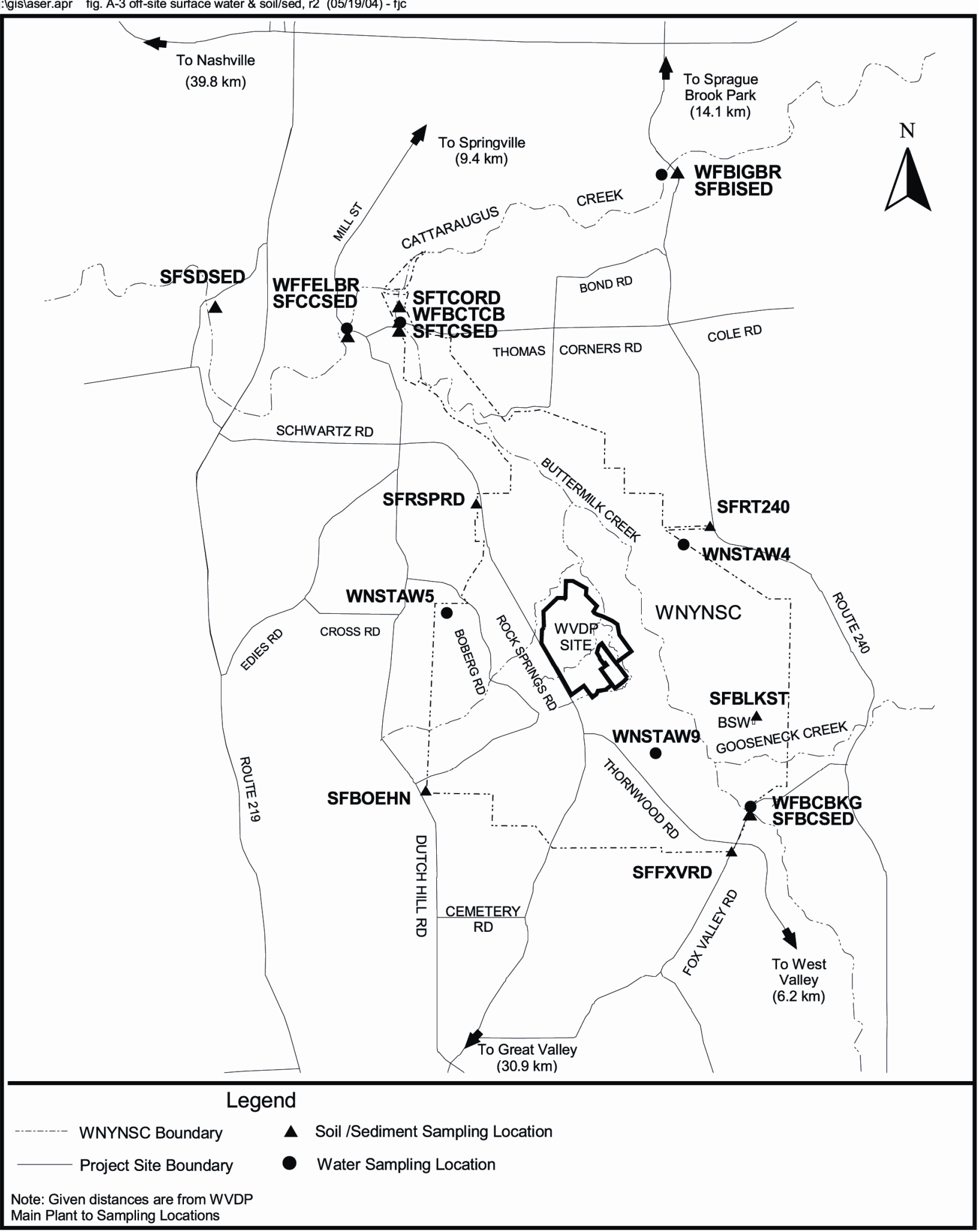

Figure A-3. Off-Site Surface Water and Soil/Sediment Sampling Locations

$$
\text { A - } 3
$$




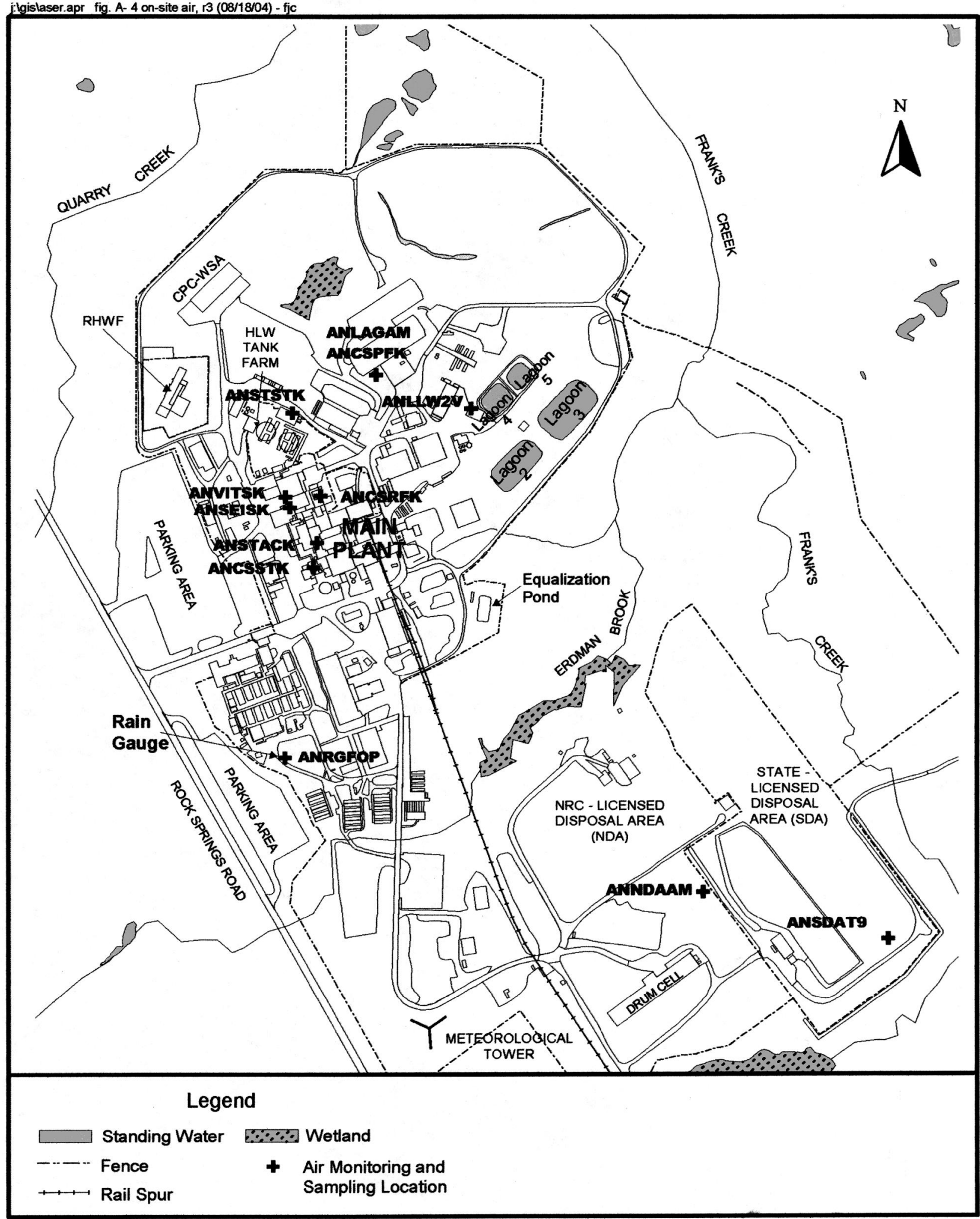

Figure A-4. On-Site Air Monitoring and Sampling Locations

$$
\text { A - } 4
$$




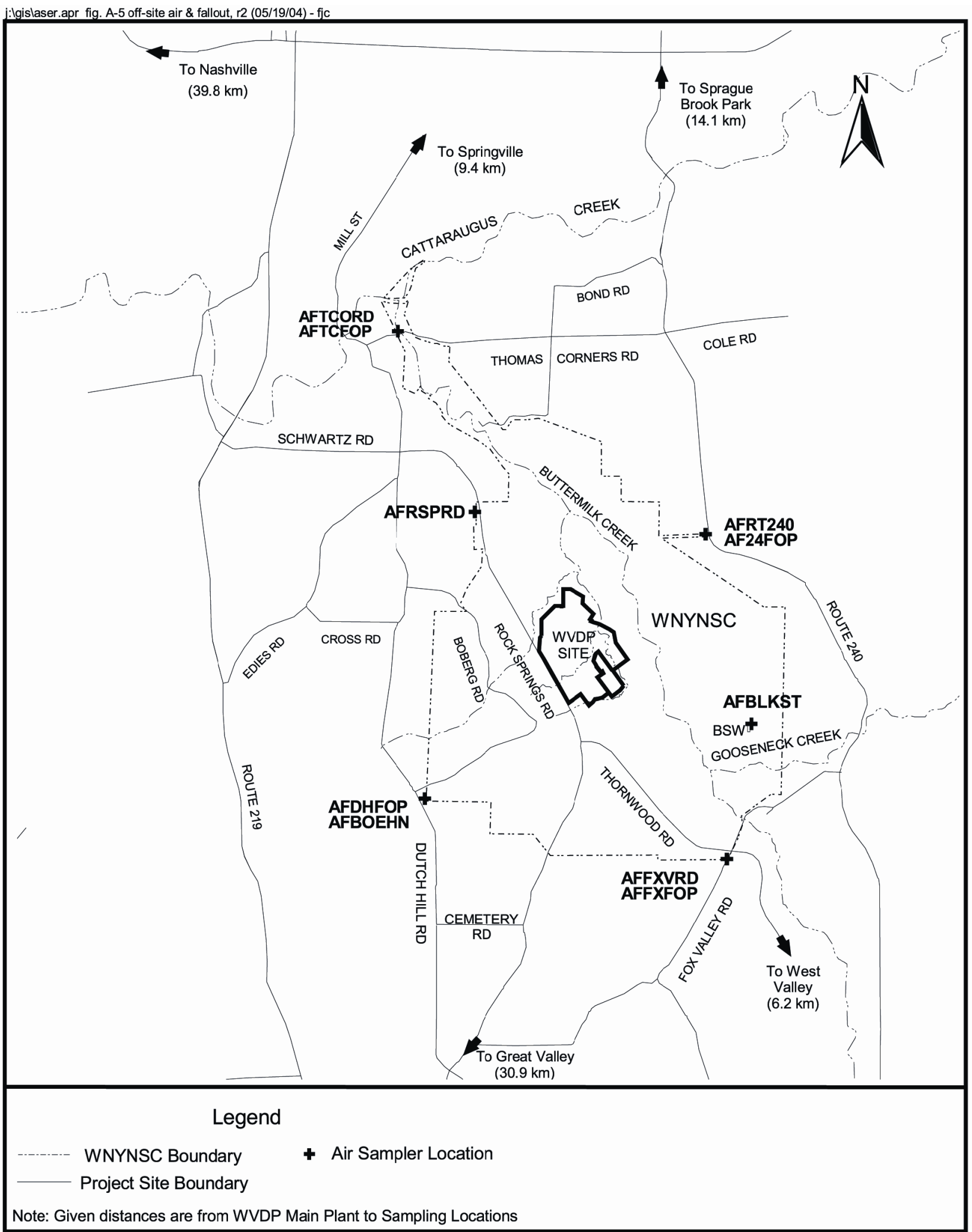

Figure A-5. Off-Site Air and Fallout Sampling Locations

A - 5 


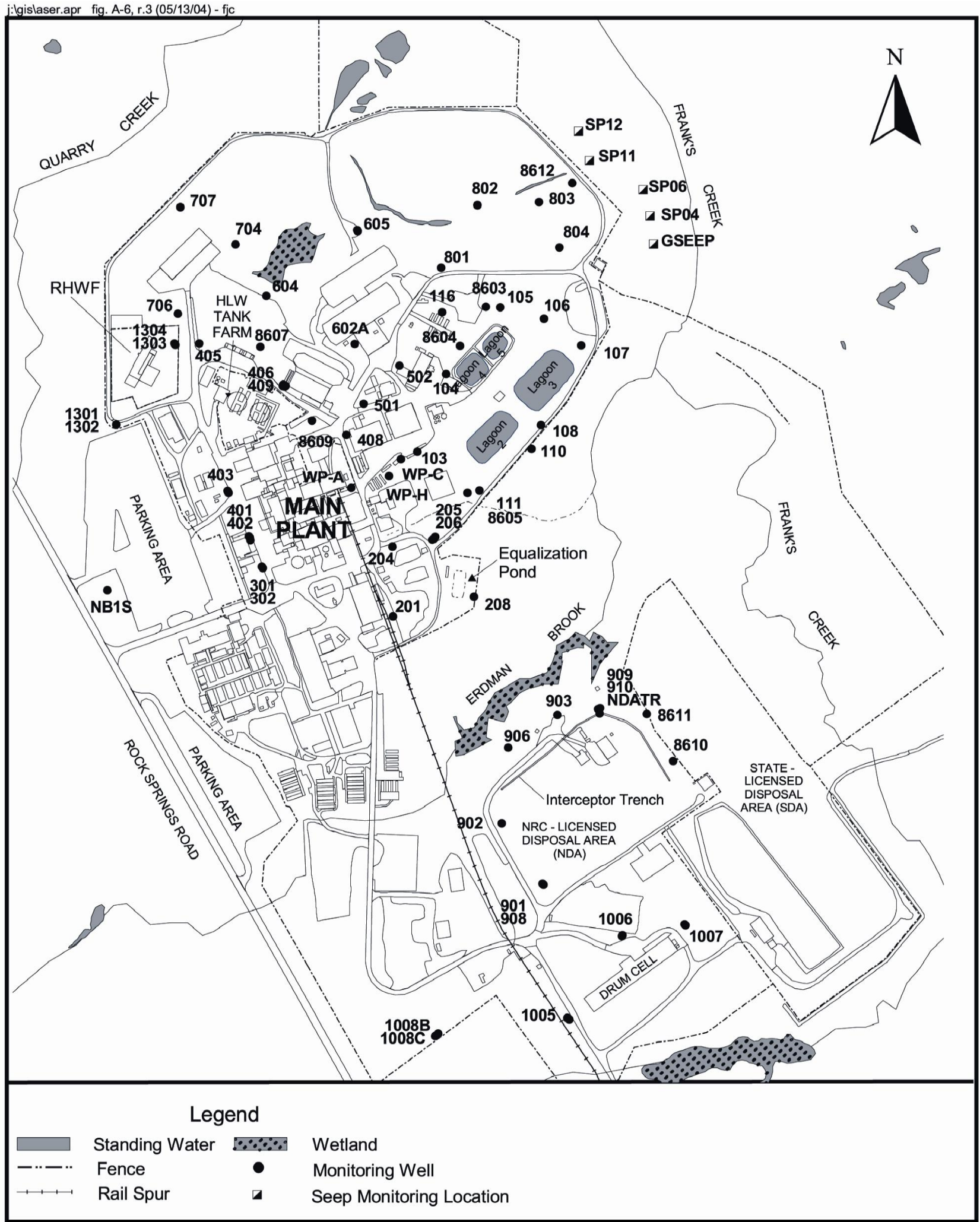

Figure A-6. Active WVDP Groundwater Monitoring Locations

A - 6 


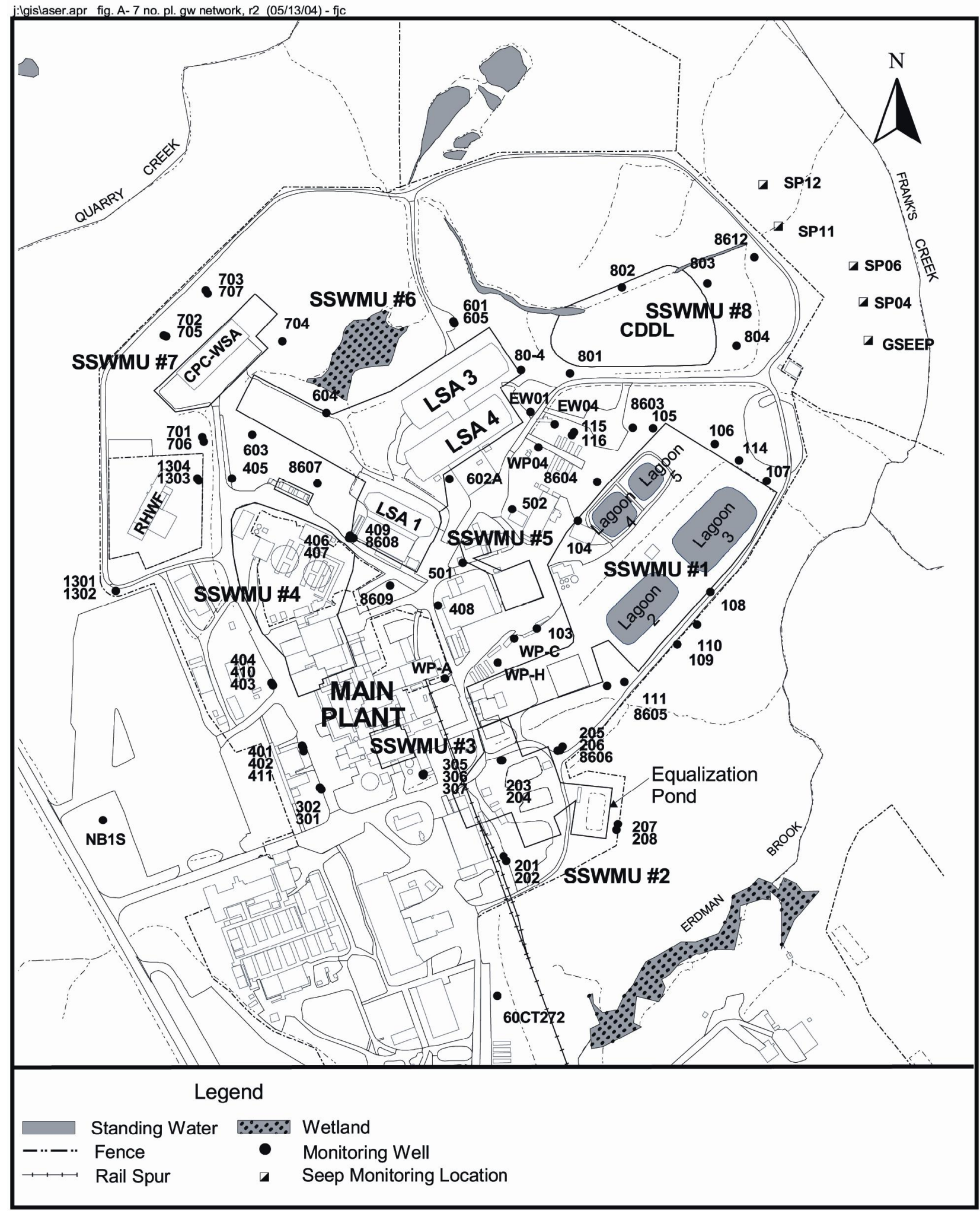

Figure A-7. North Plateau On-Site Groundwater Monitoring Network (Includes Wells Used for Water-Level Measurements)

$$
\text { A - } 7
$$




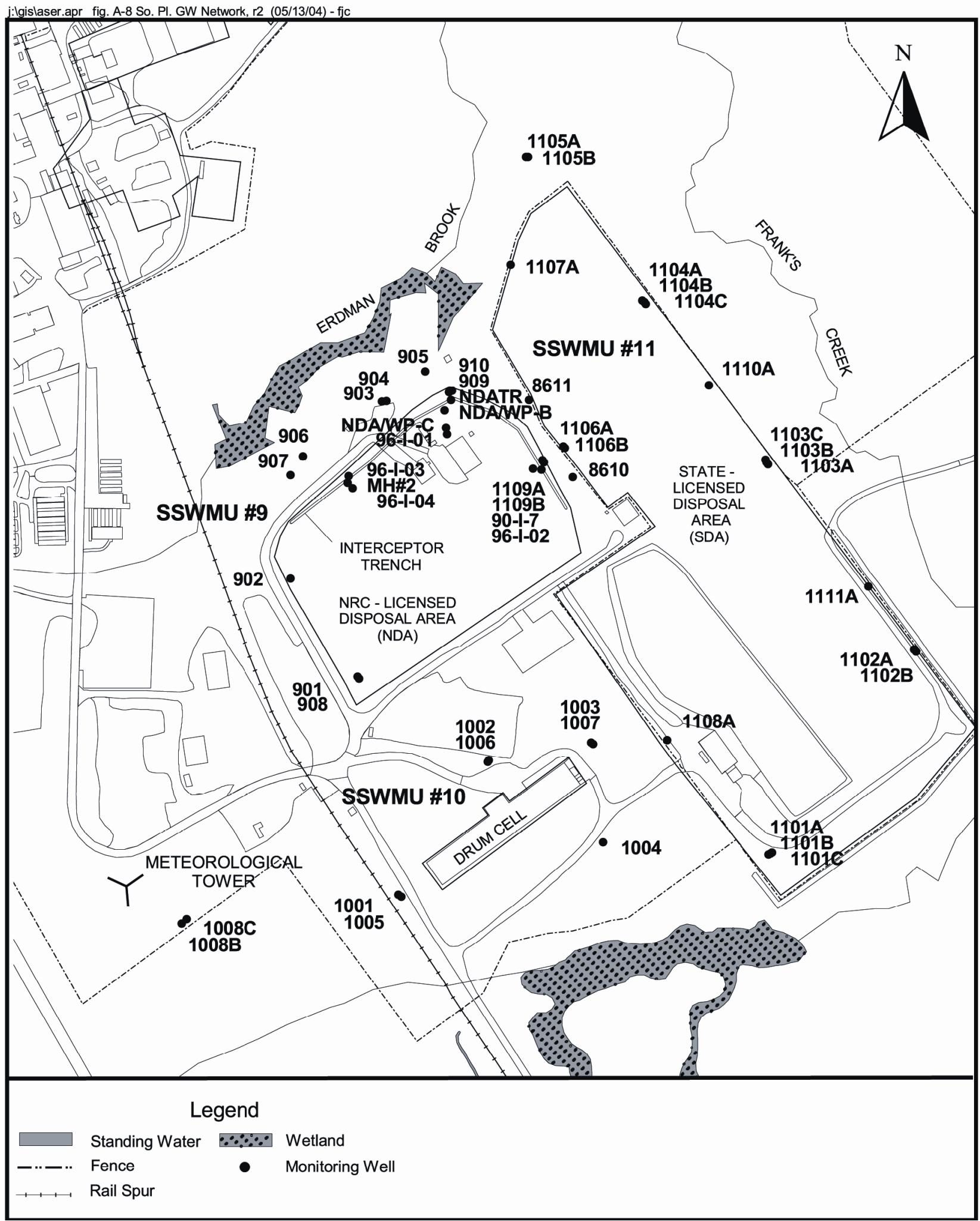

Figure A-8. South Plateau On-Site Groundwater Monitoring Network (Includes Wells Used for Water-Level Measurements [WVDP] and SDA Wells [NYSERDA])

$$
\text { A - } 8
$$




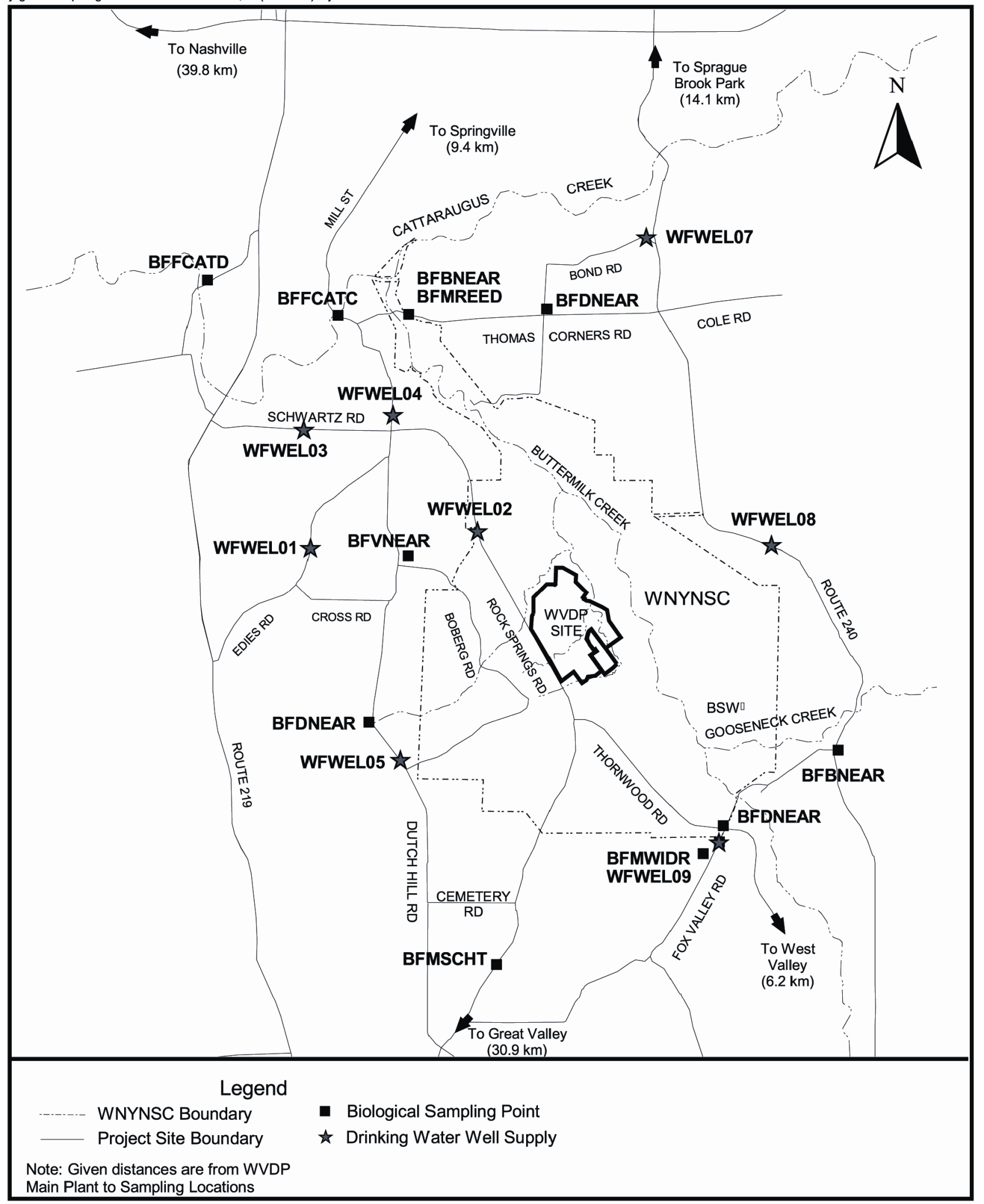

Figure A-9. Near-Site Drinking Water and Biological Sampling Locations

$$
\text { A - } 9
$$




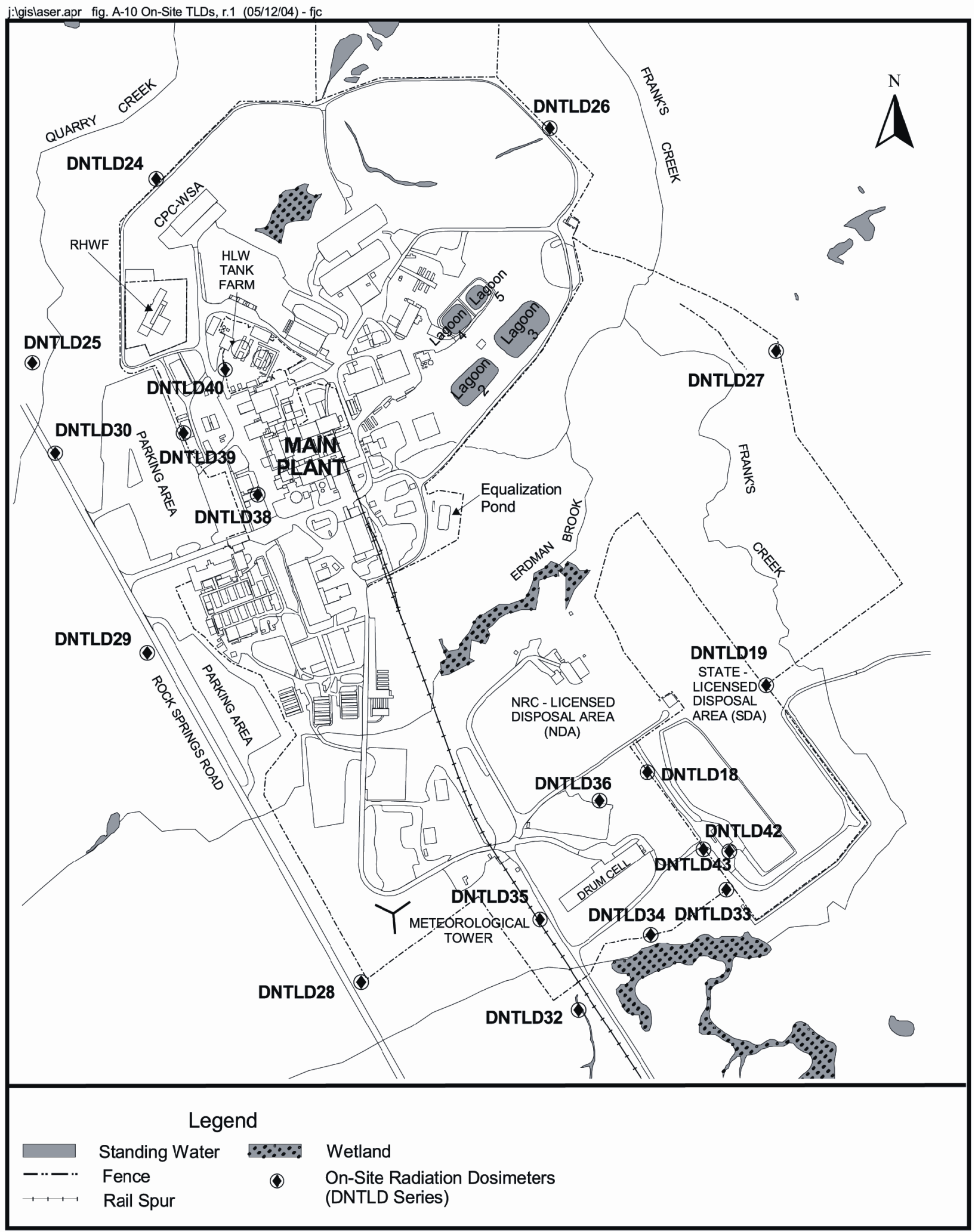

Figure A-10. Location of On-Site Thermoluminescent Dosimeters (TLDs)

$$
\text { A - } 10
$$




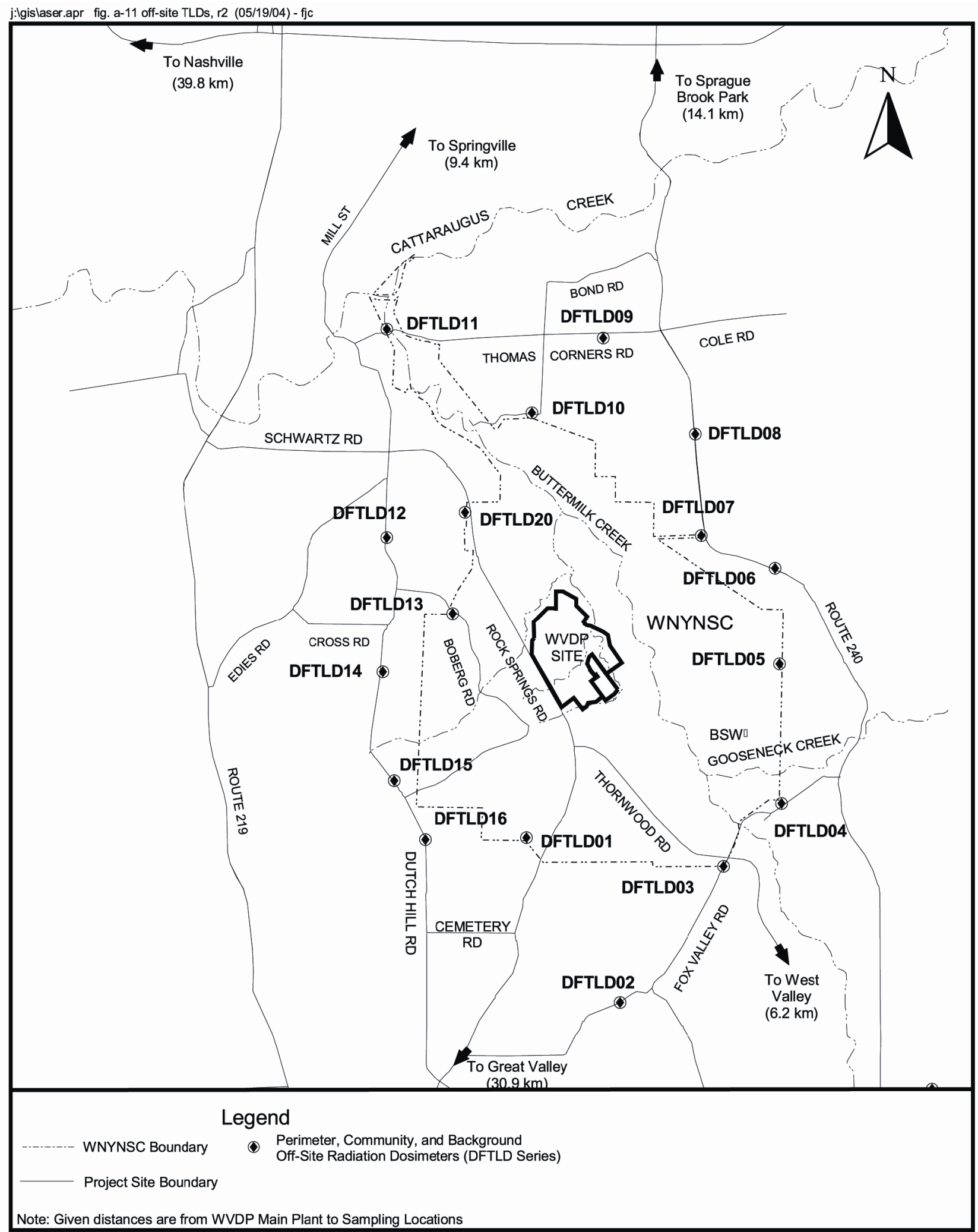

Figure A-11. Location of Off-Site Thermoluminescent Dosimeters (TLDs) Within 5 Kilometers of the WVDP

$$
\text { A - } 11
$$


j: lgislaser.apr fig A-12 regional points > $5 \mathrm{~km}$ from s/te, r3 (05/20/04) - fjc

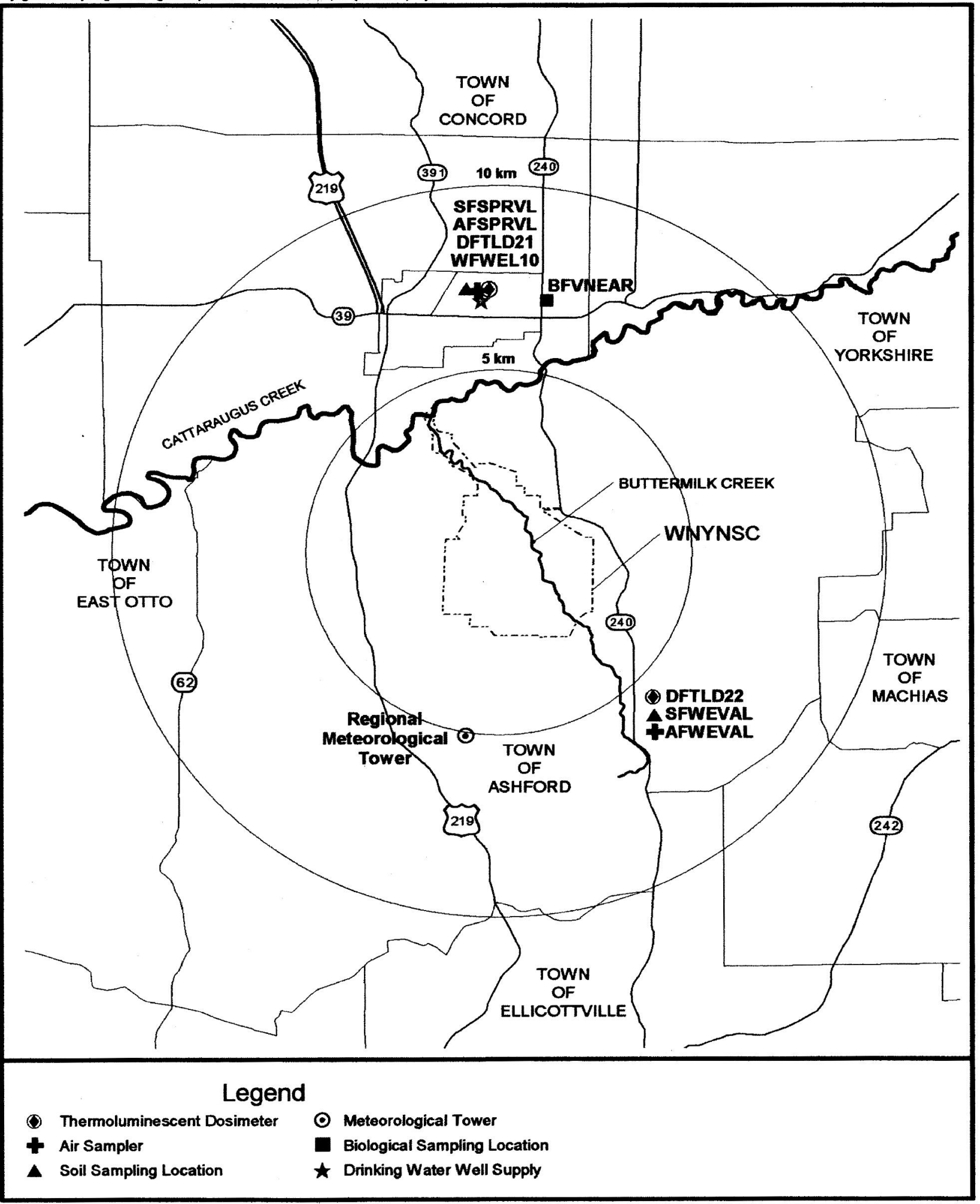

Figure A-12. Environmental Sampling Locations Between 5 and 10 Kilometers From the WVDP

$$
A-12
$$




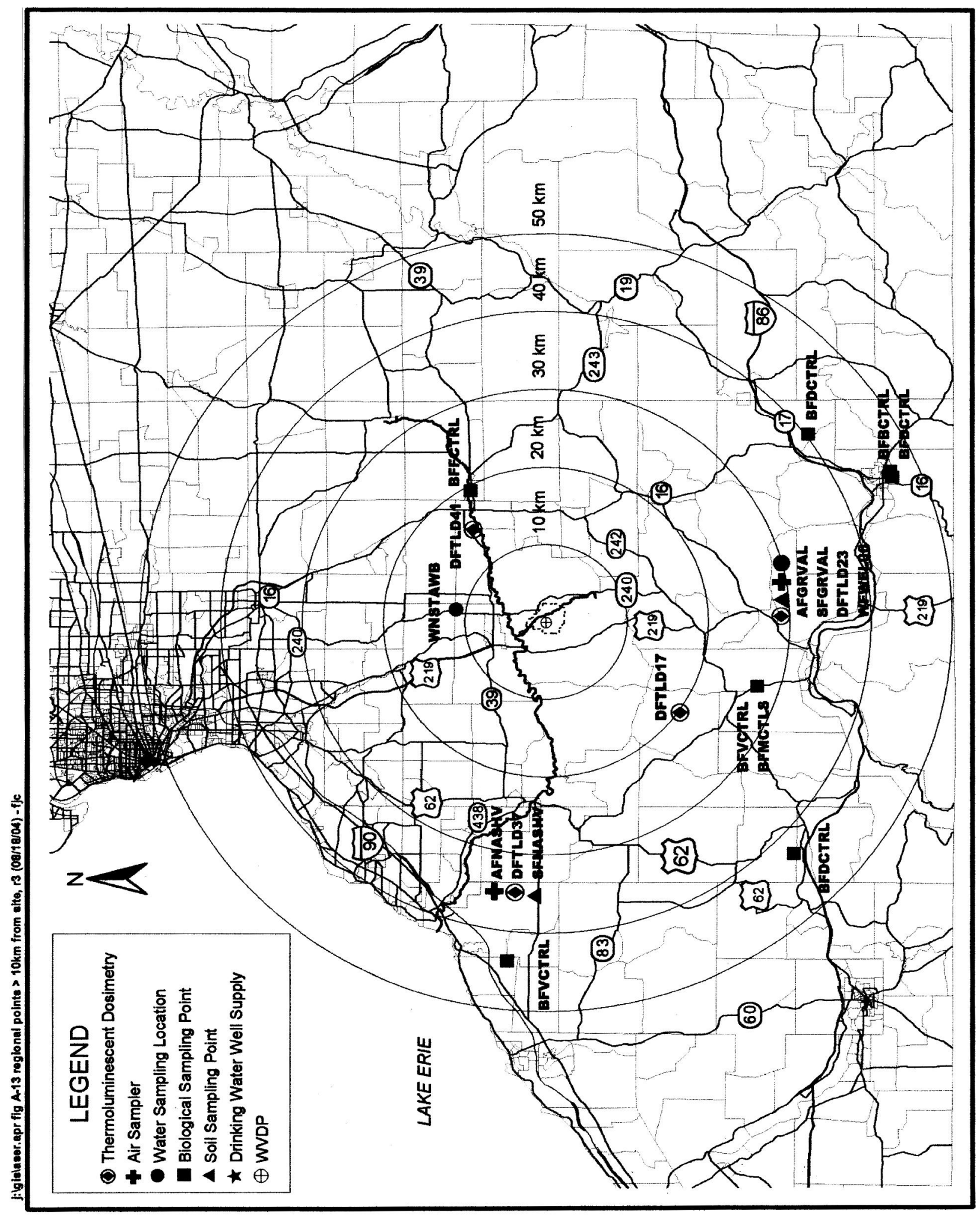

Figure A-13. Environmental Sampling Locations More Than 10 Kilometers From the WVDP

$$
\text { A - } 13
$$




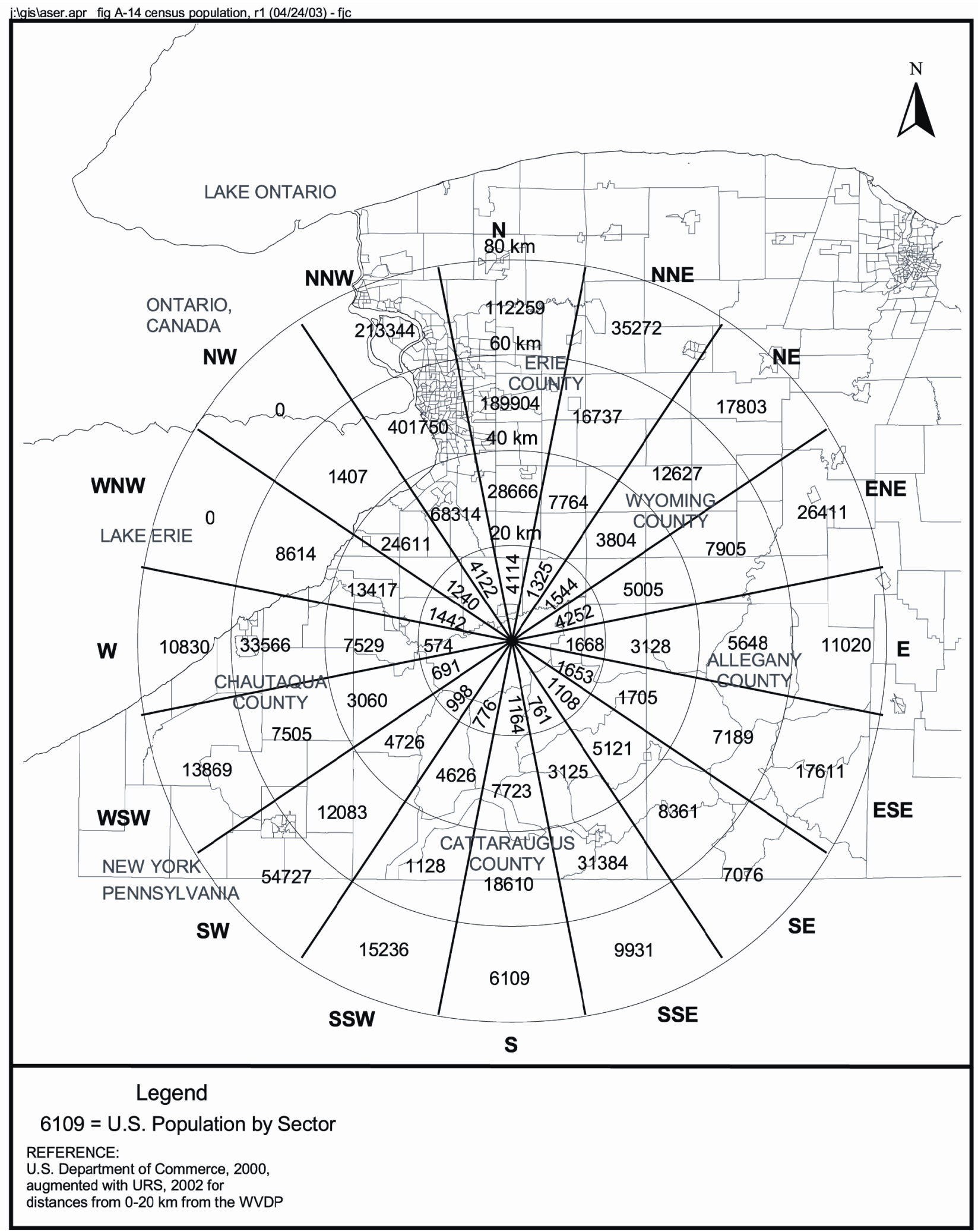

Figure A-14. Estimated 2002 Population by Sector Within 80 Kilometers of the WVDP

$$
\text { A - } 14
$$




\section{Appendix B 2003 Environmental Monitoring Program}

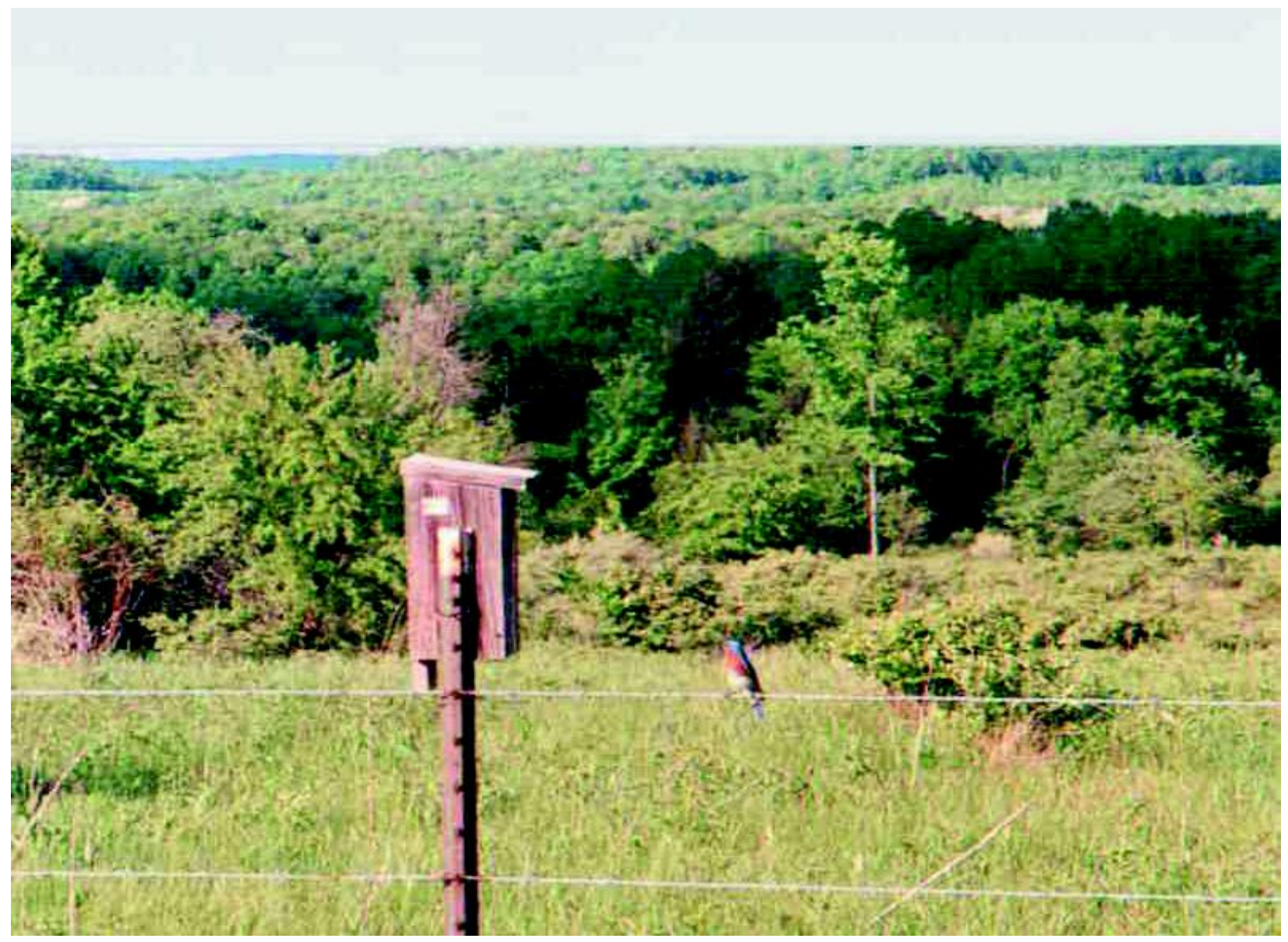

The WVDP Supports a Bluebird and Wood Duck Nesting-Box Program Sponsored by the Springville Field and Stream Club

$B-i$ 
This page intentionally left blank

$B-i i$ 


\section{Environmental Monitoring Program}

The following schedule represents the West Valley Demonstration Project (WVDP) routine environmental monitoring program for 2003. This schedule met or exceeded the requirements of DOE Order 450.1, DOE Order 5400.5, and DOE/EH-0173T. Specific methods and recommended monitoring program elements are found in DOE/EP-0096, A Guide for Effluent Radiological Measurements at DOE Installations, and DOE/EP-0023, A Guide for Environmental Radiological Surveillance at U.S. Department of Energy Installations, which were the bases for selecting most of the schedule specifics. Additional monitoring was mandated by air and water discharge permits (40 CFR 61 and SPDES), which also required formal reports. Specifics are identified in the schedule under Monitoring/Reporting Requirements.

A computerized environmental data-screening system identifies analytical data that exceed pre-set limits. All locations are checked monthly for trends or notable results in accordance with criteria established in Documentation and Reporting of Environmental Monitoring Data (West Valley Nuclear Services Co., March 26, 2003). Reportable results are then described in a Monthly Trend Analysis Report (MTAR) together with possible causes and corrective actions, if indicated. A WVDP Effluent Summary Report (ESR) is transmitted with each MTAR.

\section{Schedule of Environmental Sampling}

The index on pages B-vi through B-viii is a list of the codes used to identify the various sampling locations, which are shown on Figures A-1 through A-13 (pp. A-1 through A-13 in Appendix A). The schedule of environmental sampling at the WVDP is found in this appendix on pages B-1 through B-52. Table headings in the schedule are as follows:

- Sample Location Code. Describes the physical location where the sample is collected. The code consists of seven or eight characters: The first character identifies the sample medium as Air, Water, Soil/Sediment, Biological, or Direct Measurement. The second character specifies oN-site or oFf-site. The remaining characters describe the specific location (e.g., AFGRVAL is Air oFf-site at GReat VALley). Distances noted at sampling locations are as measured in a straight line from the main stack on-site.

- Monitoring/Reporting Requirements. Notes the bases for monitoring the location, any additional references to permits, and the reports that are generated from the sample data. Routine reports cited in this appendix are the Effluent Summary Report (ESR), the Monthly Trend Analysis Report (MTAR), the State Pollutant Discharge Elimination System Discharge Monitoring Report (SPDES DMR), the Air Emissions Report (NESHAP), and the Annual Site Environmental Report (ASER).

- Sampling Type/Medium. Describes the collection method and the physical characteristics of the medium.

- Collection Frequency. Indicates how often the samples are collected or retrieved.

- Total Annual Sample Collections. Specifies the number of discrete physical samples collected annually for each group of analytes.

- Analyses Performed/Composite Frequency. Notes the type of analyses of the samples taken at each collection, the frequency of composite, and the analytes determined for the composite samples.

$B-i i i$

WVDP Annual Site Environmental Report

Calendar Year 2003 


\section{Summary of Monitoring Program Changes in 2003}

Location Code

ANSEISK

ANLLW2V

WNSP006

WFBCBKG

WFBCTCB

WNSP007

WNSWAMP

WNSW74A

WNSP005

WNERB53

WNFRC67

WNCOOLW

WNSTAW Series

WVDP Annual Site Environmental Report

\section{Description of Changes}

Sampling at ANSEISK, backup for the vitrification facility heating, ventilation, and air-conditioning system, was discontinued in March 2003. (The sampling system at ANSEISK was retained and is now the sampler of record at location ANVITSK.)

Sample collection was discontinued in March 2003 at the end of the 1st quarter. No releases higher than background have been noted at this location in more than thirteen years of monitoring. Releases may be estimated using process knowledge.

The parameter list for nonradiological analyses was modified from a groundwater-oriented program to a surface-water-oriented program. Analyses were added to assess compliance with New York Water Quality Standards for Class C Waters.

Strontium-90 analysis of sanitary waste discharge samples was added on a quarterly basis beginning with the second quarter of 2003.

The parameter list for nonradiological analyses was modified from a groundwater-oriented program to a surface-water-oriented program in order to define ambient conditions at these outfalls.

Strontium-90 and gamma-isotopic analyses were added on a quarterly basis beginning with the second quarter of 2003.

Sampling of cooling water from plant systems was reduced from monthly to quarterly and strontium-90 analysis was added beginning with the second quarter of 2003.

Strontium-90 and gamma-isotopic analyses were added on an annual basis.

$B-i v$ 


\section{Summary of Monitoring Program Changes in 2003 (concluded)}

Location Code

WNDNKEL

WNDNKMP

WNDNKMS

WFBCTCB

WFFELBR

WFWEL01 through

WFWEL10

AFNASHV

SFNASHV

BFFCATC

BFFCTRL

BFMCTLN

BFHCTLN

BFHCTLS

BFHNEAR

DFTLD17

DFTLD37

DFTLD41

\section{Description of Changes}

Beginning in the second quarter of 2003, sampling frequency for these potable water locations was reduced from monthly to every third month, on a rotating basis. (Full monthly and annual sampling was retained at the entry point for site potable water, WNDNKUR.)

Technetium-99 analysis was added on a quarterly basis, beginning with the second quarter of 2003.

Strontium-90 analysis was added on an annual basis.

Air and soil sampling at the secondary background location (Nashville) was discontinued at the end of the 1st quarter of 2003, in March. (The primary background location, Great Valley, was retained.)

The number of fish collected at each location was reduced from ten to five for each sampling period in consideration of safety of field sampling personnel and to reduce pressure on the fish population. Statistical assessment indicated that this reduction does not impact the ability to evaluate radionuclide concentrations in fish.

Sampling for milk was discontinued at the northern background location at the end of the 1st quarter of 2003, in March. (The southern background location is still being sampled.)

Sampling of hay was deleted from the program. Data from these samples are not directly used in dose estimates.

Redundant background thermoluminescent dosimeter (TLD) locations at Five-Points Landfill (DFTLD17), Nashville (DFTLD37), and Sardinia (DFTLD41) were deleted from the program after the 1 st quarter of 2003, in March. The primary background location at Great Valley was retained.

$$
B-v
$$




\section{Index of Environmental Monitoring Program Sample Points}

\begin{tabular}{lll}
\multicolumn{2}{l}{ Air Effluent and On-Site Ambient Air (Fig. A-4 [p. A-4]) } & \\
& & \\
ANSTACK & Main Plant & B-1 \\
ANSTSTK & Supernatant Treatment System & B-1 \\
ANCSSTK & 01-14 Building & B-1 \\
ANCSRFK & Size-Reduction Facility & B-1 \\
ANCSPFK & Container Sorting and Packaging Facility & B-1 \\
ANVITSK & Vitrification Heating, Ventilation, and Air Conditioning & B-1 \\
ANSEISK & Seismic Sampler(Vitrification backup) & B-1 \\
OVES/PVUs* & Outdoor Ventilated Enclosures/Portable Ventilation Units & B-3 \\
ANLLW2V & Low-Level Waste Treatment Ventilation & B-5 \\
ANLAGAM & Lag Storage Area (ambient air) & B-5 \\
ANNDAAM & NDA Area (ambient air) & B-5 \\
ANSDAT9 & SDA Trench 9 (ambient air) & B-5
\end{tabular}

\section{Liquid Effluent and On-Site Water (Fig. A-2 [p. A-2])}

WNSP001

WNSP01B*

WNSP116

WNSP006

WNURRAW*

WNSP007

WNSWAMP

WNSW74A

WNSDADR

WNSP008

WNSP005

WNCOOLW

WNFRC67

WNERB53

WNNDADR

WNDCELD

WNNDATR

WNSTAW Series

WNDNK Series*
Lagoon 3 Weir Point

B-7

Internal Process Monitoring Point

B-9

Pseudo-Monitoring Point Outfall 116

B-9

Facility Main Drainage

Utility Room Raw Water

Sanitary Waste Discharge

Northeast Swamp Drainage Point

North Swamp Drainage Point

SDA Run-Off

B-11

B-11

B-13

B-15

B-15

B-17

B-19

B-19

B-19

B-21

B-21

B-21

B-21

B-21

B-23

B-25

* Not detailed on map.

$B-v i$ 


\section{Index of Environmental Monitoring Program Sample Points (continued)}

\begin{tabular}{lll}
\multicolumn{2}{l}{ On-Site Groundwater and Seeps (Figs. A-6 through A-8 [pp. A-6 through A-8]) } & \\
SSWMU \#1 & Low-Level Waste Treatment Facility Wells & B-27 \\
SSWMU \#2 & Miscellaneous Small Units Wells & B-27 \\
SSWMU \#3 & Liquid Waste Treatment System Wells & B-27 \\
SSWMU \#4 & HLW Storage and Processing Tank Wells & B-29 \\
SSWMU \#5 & Maintenance Shop Leach Field Wells & B-29 \\
SSWMU \#6 & Low-Level Waste Storage Area Wells & B-29 \\
SSWMU \#7 & CPC Waste Storage Area Wells & B-29 \\
SSWMU \#8 & CDDLWells & B-31 \\
SSWMU \#9 & NDAUnits Wells and NDATR & B-31 \\
SSWMU \#10 & IRTS Drum Cell Wells & B-31 \\
RHWF & Remote-Handled Waste Facility Wells & B-31 \\
SSWMU \#11 & SDA Unit Wells & B-33 \\
North Plateau Seeps & Northeastern Edge of North Plateau & B-33 \\
Well Points & Downgradient of Main Plant & B-33 \\
WNWNB1S & Former North Plateau Background Well & B-33
\end{tabular}

Off-Site Surface Water (Fig. A-3 [p. A-3])

WFBCBKG Buttermilk Creek near Fox Valley (background) B-35

$\begin{array}{lll}\text { WFBCTCB Buttermilk Creek at Thomas Corners } & \text { B-35 }\end{array}$

$\begin{array}{lll}\text { WFBIGBR } & \text { Cattaraugus Creek at Bigelow Bridge (background) } & \text { B-37 }\end{array}$

$\begin{array}{llr}\text { WFFELBR } & \text { Cattaraugus Creek at Felton Bridge } & \text { B-37 }\end{array}$

Off-Site Drinking Water (Figs. A-9, A-12, and A-13 [pp. A-9, A-12, and A-13])

$\begin{array}{lll}\text { WFWEL Series } & \text { Private Local Wells } & \text { B-39 }\end{array}$

Off-Site Ambient Air (Figs. A-5, A-12, and A-13 [pp. A-5, A-12, and A-13])

$\begin{array}{llr}\text { AFFXVRD } & \text { Fox Valley Sampler } & \text { B-41 } \\ \text { AFTCORD } & \text { Thomas Corners Sampler } & \text { B-41 } \\ \text { AFRT240 } & \text { Route 240 Sampler } & \text { B-41 } \\ \text { AFSPRVL } & \text { Springville Sampler } & \text { B-41 } \\ \text { AFWEVAL } & \text { West Valley Sampler } & \text { B-41 } \\ \text { AFNASHV } & \text { Nashville Sampler (background) } & \text { B-41 } \\ \text { AFBOEHN } & \text { Dutch Hill Road Sampler } & \text { B-41 } \\ \text { AFRSPRD } & \text { Rock Springs Road Sampler } & \text { B-41 } \\ \text { AFGRVAL } & \text { Great Valley Sampler (background) } & \text { B-41 } \\ \text { AFBLKST } & \text { Bulk Storage Warehouse Sampler } & \text { B-41 }\end{array}$

$$
B-v i i
$$




\section{Index of Environmental Monitoring Program Sample Points (concluded)}

Fallout, Sediment, and Soil (Figs. A-2 through A-5 [pp. A-2 through A-5], A-12, and A-13 [pp. A12 and $A-13]$ )

\begin{tabular}{llr} 
AFDHFOP & Dutch Hill Fallout & B-43 \\
AFFXFOP & Fox Valley Fallout & B-43 \\
AFTCFOP & Thomas Corners Fallout & B-43 \\
AF24FOP & Route 240 Fallout & B-43 \\
ANRGFOP & Rain Gauge Fallout & B-43 \\
SF Soil Series & Air Sampler Area Soil & B-43 \\
SFCCSED & Cattaraugus Creek at Felton Bridge, Sediment & B-43 \\
SFSDSED & Cattaraugus Creek at Springville Dam, Sediment & B-43 \\
SFBISED & Cattaraugus Creek at Bigelow Bridge, Background Sediment & B-43 \\
SFTCSED & Buttermilk Creek at Thomas Corners, Sediment & B-43 \\
SFBCSED & Buttermilk Creek at Fox Valley Road, Background Sediment & B-43 \\
SN Soil Series: & On-Site Soils/Sediments & B-43 \\
\multicolumn{1}{|c|}{ SNSW74A } & & B-43 \\
SNSWAMP & & B-43 \\
SNSP006 & & B-43
\end{tabular}

Off-Site Biological (Figs. A-9, A-12, and A-13 [pp. A-9, A-12, and A-13])

$\begin{array}{llr}\text { BFFCATC } & \text { Cattaraugus Creek Fish, Downstream } & \text { B-45 } \\ \text { BFFCATD } & \text { Cattaraugus Creek Fish, Downstream of Springville Dam } & \text { B-45 } \\ \text { BFFCTRL } & \text { Cattaraugus Creek Fish, Background } & \text { B-45 } \\ \text { BFMREED } & \text { North-Northwest Milk, Near-Site } & \text { B-45 } \\ \text { BFMCTLS } & \text { Milk, South, Background } & \text { B-45 } \\ \text { BFMCTLN } & \text { Milk, North, Background } & \text { B-45 } \\ \text { BFMWIDR } & \text { Southeast Milk, Near-Site } & \text { B-45 } \\ \text { BFMSCHT } & \text { South Milk, Near-Site } & \text { B-45 } \\ \text { BFVNEAR* } & \text { Produce, Near-Site } & \text { B-47 } \\ \text { BFVCTRL* } & \text { Produce, Background } & \text { B-47 } \\ \text { BFBNEAR } & \text { Beef, Near-Site } & \text { B-47 } \\ \text { BFBCTRL } & \text { Beef, Background } & \text { B-47 } \\ \text { BFDNEAR } & \text { Venison, Near-Site } & \text { B-47 } \\ \text { BFDCTRL } & \text { Venison, Background } & \text { B-47 }\end{array}$

Direct Measurement Dosimetry (Figs. A-10 through A-13 [pp. A-10 through A-13])

DFTLD Series $\quad$ Off-Site Direct Radiation B-49

$\begin{array}{lll}\text { DNTLD Series } \quad \text { On-Site Direct Radiation } & \text { B-51 }\end{array}$

* Near-site and background produce samples (corn, apples, and beans) are identified specifically as follows: corn = BFVNEAC and BFVCTRC; apples = BFVNEAAF and BFVCTRA; beans = BFVNEAB and BFVCTRB . 
This page intentionally left blank

$B-i x$ 


\section{Monitoring Program \\ On-Site Effluent Monitoring}

Air Effluents

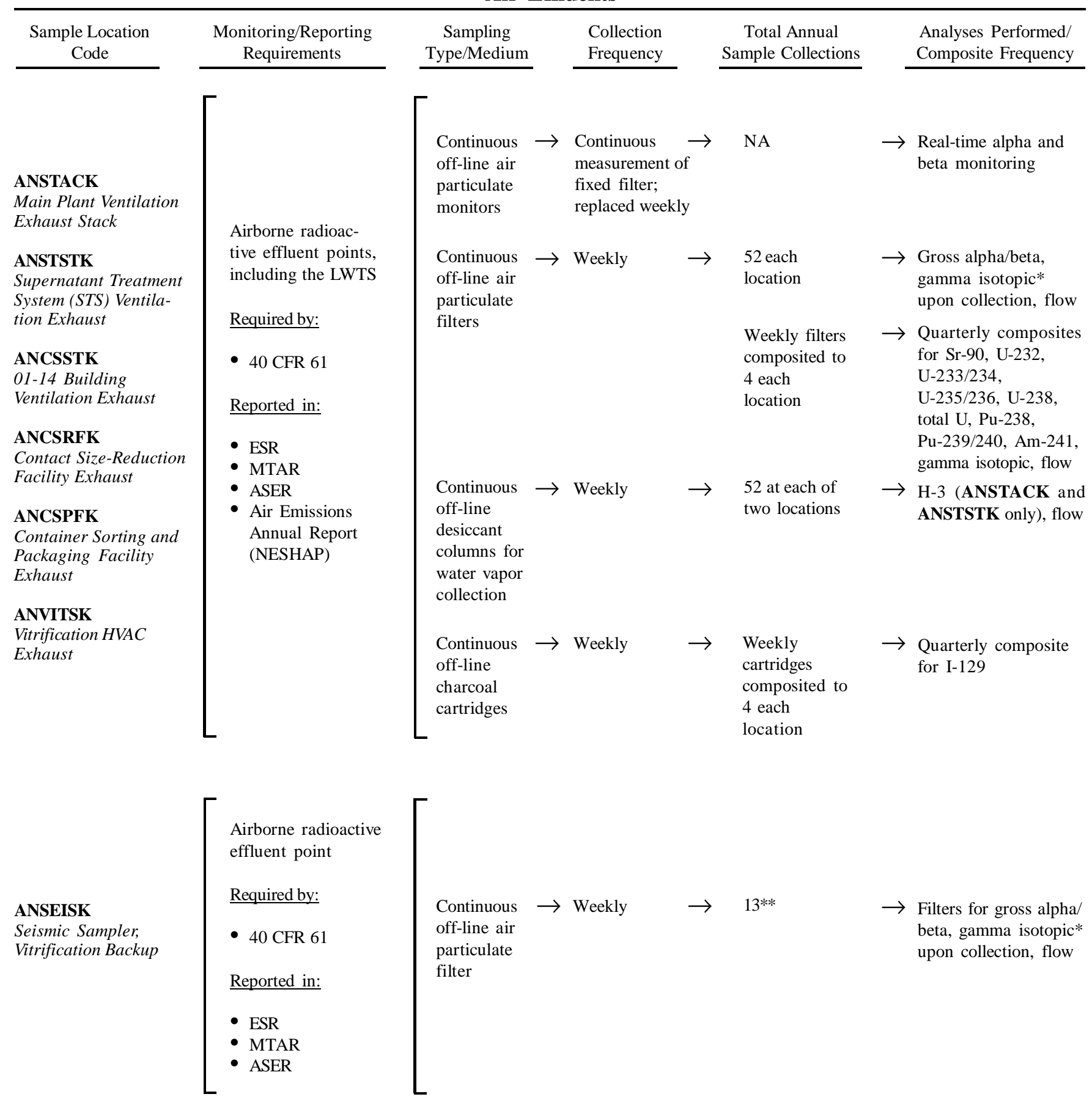

* Weekly gamma isotopic only if gross activity rises significantly.

** Sampling at ANSEISK was discontinued after the first quarter of 2003, so only 13 samples were collected.

NA - Not applicable.

$$
B-1
$$




\section{Sampling Rationale}

ANSTACK

ANSTSTK

ANCSPFK

ANVITSK

ANSEISK
ANCSRFK

DOE/EH-0173T, 3.0; DOE/EP-0096, 3.3

Monitors and samples HEPA-filtered ventilation from most process areas, including cell ventilation, vessel offgas, fuel receiving and storage (FRS), head end ventilation, and an analytical aisle. Requires continuous effluent monitoring per 40 CFR Subpart H, Section 61.93(b) because potential emissions may exceed the 0.1 mrem limit.

DOE/EH-0173T, 3.0; DOE/EP-0096, 3.3

Monitors and samples HEPA-filtered ventilation (permanent ventilation system [PVS]) from building areas involved in treatment of high-level waste supernatant. Requires continuous effluent monitoring per 40 CFR Subpart H, Section 61.93(b) because potential emissions may exceed the $0.1 \mathrm{mrem}$ limit.

DOE/EH-0173T, 3.0; DOE-EP-0096, 3.3

Monitors and samples HEPA-filtered ventilation from the 01-14 building, which houses equipment used to treat the ceramic melter off-gas. Requires effluent monitoring per 40 CFR Subpart H, Section 61.93(b) to confirm that emissions are less than the 0.1 mrem limit.

DOE/EH-0173T, 3.0; DOE-EP-0096, 3.3

Monitors and samples HEPA-filtered ventilation from a process area where radioactive tanks, pipes, and other equipment are cut up with a plasma torch to reduce volume.

DOE/EH-0173T, 3.0; DOE-EP-0096, 3.3

Monitors and samples ventilation from lag storage area 4, the container sorting and packaging facility.

DOE/EH-0173T, 3.0; DOE-EP-0096, 3.3

Vitrification facility heating, ventilation, and air conditioning (HVAC) effluent exhaust stack. Sampler brought online in late 1995 when nonradioactive operations began. Radioactive operation began with the first high-level waste transfer in June 1996 and vitrification startup in July 1996. Monitors and samples HEPA-filtered ventilation from building areas involved in treatment of high-level waste supernatant. Requires effluent monitoring per 40 CFR Subpart H, Section 61.93(b) because potential emissions may exceed the $0.1 \mathrm{mrem}$ limit.

DOE/EH-0173T, 3.0; DOE-EP-0096, 3.3

Vitrification system back-up filter for catastrophic-event monitoring in case the primary vitrification HVAC stack ventilation fails. Since vitrification was completed, backup sampling was discontinued. The sampling equipment from ANVITSK and ANSEISK draw air from the same emission point. Sample point ANSEISK was deleted from the monitoring program after the first quarter of 2003. However, since the sampling equipment formerly used as the seismic sampler (ANSEISK) is more accessible for maintenance and sample changing, the equipment was returned to service as ANVITSK, the sampler of record, in October 2003.

n Sampling locations are shown on Figure A-4 (p. A-4).

$$
B-2
$$




\section{Monitoring Program \\ On-Site Effluent Monitoring}

\section{Air Effluents}

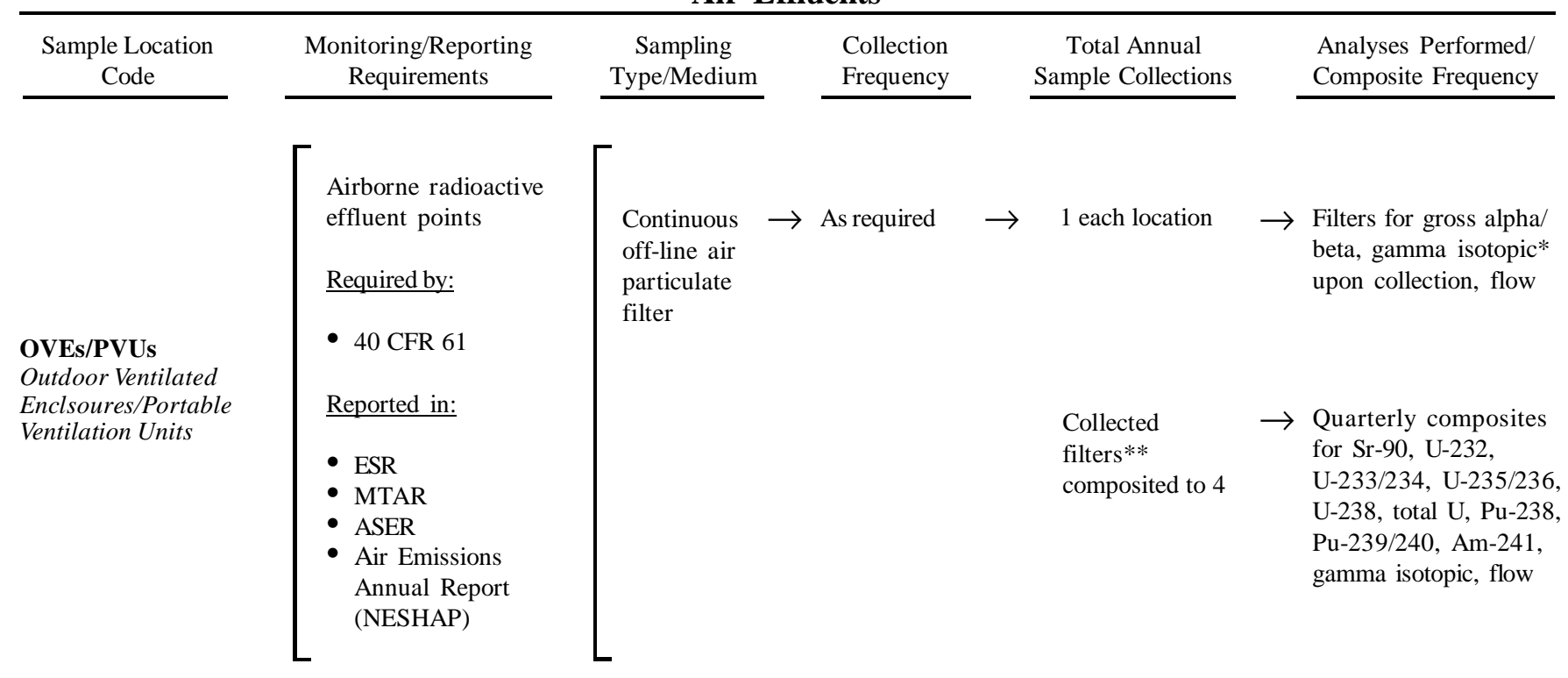

* Gamma isotopic only if gross activity rises significantly.

** If gross determination of individual filter is significantly higher than background, the individual sample would be submitted immediately for isotopic analysis.

$$
B-3
$$




\section{Sampling Rationale}

\section{OVEs/PVUs DOE/EH-0173T, 3.0; DOE/EP-0096, 3.3}

Outdoor ventilated enclosures; portable ventilation units used for handling radioactive materials or for decontamination in areas not having containment ventilation. Emissions are monitored to confirm that they are below the 0.1 mrem limit.

$\mathrm{n} \quad$ Sampling locations are not shown on figures.

$$
B-4
$$




\section{Monitoring Program \\ On-Site Effluent Monitoring}

Air Effluents and On-Site Ambient Air

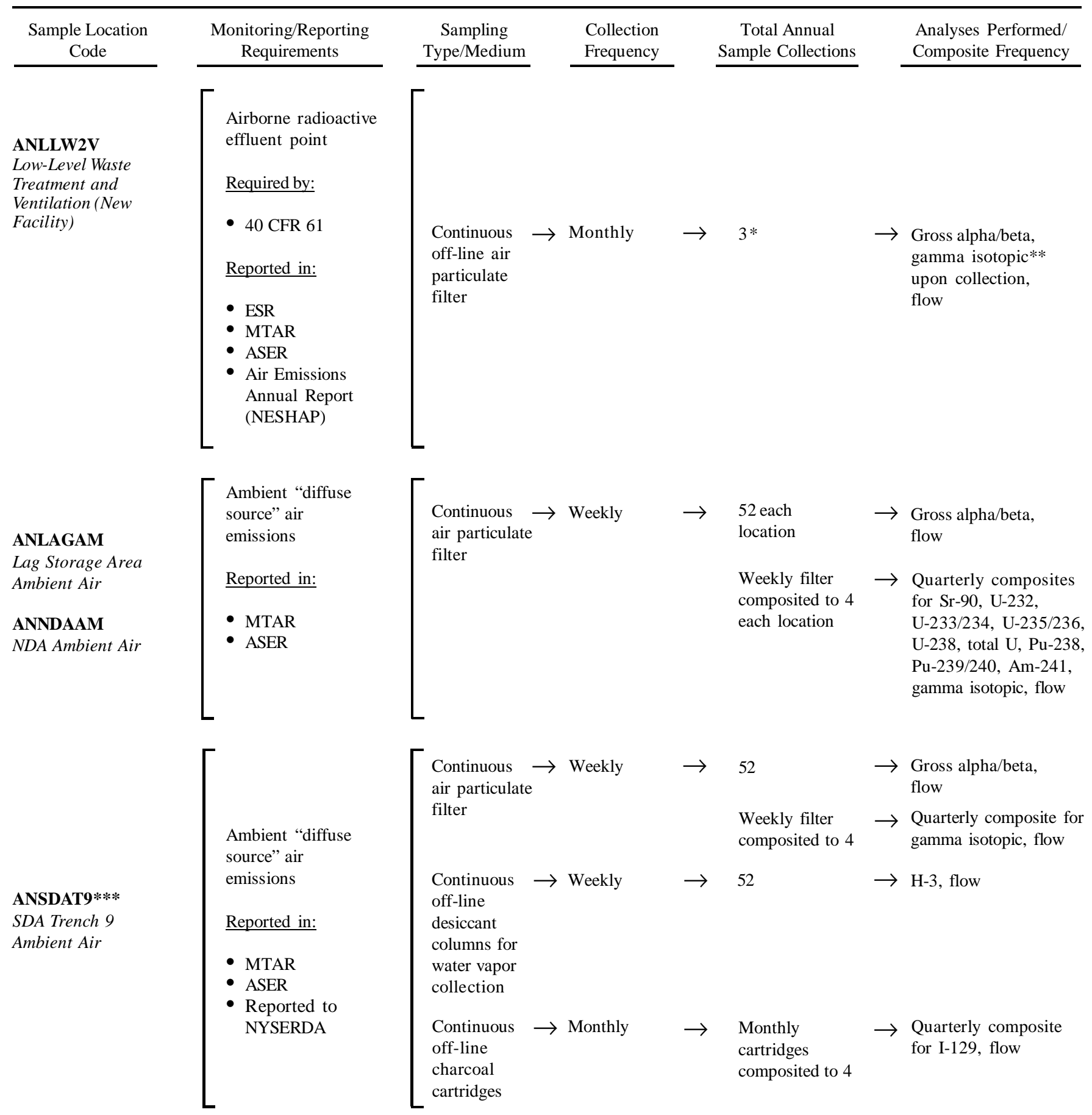

* Sampling at ANLLW2V was discontinued after the first quarter of 2003, so only three samples were collected.

** Gamma isotopic only if gross activity rises significantly.

*** Sampling frequency and analytical parameters as directed by NYSERDA.

$$
B-5
$$




\section{Sampling Rationale}

ANLLW2V DOE/EH-0173T, 3.0; DOE/EP-0096, 3.3

Samples ventilation exhaust from the new low-level waste treatment facility. System started up in April 1998.

Sampling was discontinued at the end of the 1st quarter of 2003, in March.

ANLAGAM

DOE/EH-0173T, 3.3.2

Monitors ambient air in the lag storage area, a possible diffuse source of air emissions.

ANNDAAM

DOE/EH-0173T, 3.3.2

Monitors ambient air in the NDA area, a possible diffuse source of air emissions.

ANSDAT9 DOE/EH-0173T, 3.3.2

Monitors potential diffuse sources of air emissions at the SDA and south plateau area. WVDP support of NYSERDA.

n Sampling locations are shown on Figure A-4 (p. A-4).

$B-6$ 


\section{Monitoring Program \\ On-Site Effluent Monitoring}

\section{Liquid Effluents}

\begin{tabular}{|c|c|c|c|c|c|c|c|c|}
\hline $\begin{array}{l}\text { Sample Location } \\
\text { Code } \\
\end{array}$ & $\begin{array}{c}\text { Monitoring/Reporting } \\
\text { Requirements }\end{array}$ & $\begin{array}{c}\text { Sampling } \\
\text { Type/Medium } \\
\end{array}$ & & $\begin{array}{l}\text { Collection } \\
\text { Frequency }\end{array}$ & & $\begin{array}{c}\text { Total Annual } \\
\text { Sample Collection }\end{array}$ & & $\begin{array}{l}\text { Analyses Performed/ } \\
\text { Composite Frequency }\end{array}$ \\
\hline \multirow{6}{*}{$\begin{array}{l}\text { WNSP001 } \\
\text { Lagoon } 3 \text { Discharge } \\
\text { Weir }\end{array}$} & \multirow{6}{*}{$\begin{array}{l}\text { Primary point of } \\
\text { liquid effluent batch } \\
\text { release } \\
\text { Required by: } \\
\text { - SPDES permit } \\
\text { Reported in: } \\
\text { - Monthly SPDES } \\
\text { - DMR } \\
\text { - MTR } \\
\text { - ASER }\end{array}$} & Grab liquid & $\rightarrow$ & $\begin{array}{l}\text { Daily, during } \\
\text { lagoon } 3 \\
\text { discharge* }\end{array}$ & $\rightarrow$ & $\begin{array}{l}\text { Composite of } \\
\text { daily samples } \\
\text { for each } \\
\text { discharge, } 4-8\end{array}$ & $\rightarrow$ & $\begin{array}{l}\text { Daily for gross beta, } \\
\text { conductivity, flow } \\
\text { Near the start, middle, and } \\
\text { end of each discharge, a } \\
\text { sample is analyzed for } \\
\text { gross alpha/beta, H-3, Sr- } \\
\text { 90, gamma isotopic } \\
\text { Weighted composite for } \\
\text { gross alpha/beta, H-3, } \\
\text { C-14, Sr-90, Tc-99, } \\
\text { I-129, gamma isotopic, } \\
\text { U-232, U-233/234, } \\
\text { U-235/236, U-238, total } \\
\text { U, Pu-238, Pu-239/240, } \\
\text { and Am-241 for each } \\
\text { month of discharge }\end{array}$ \\
\hline & & Grab liquid & $\rightarrow$ & $\begin{array}{l}\text { Twice during } \\
\text { discharge, } \\
\text { near start and } \\
\text { near end }\end{array}$ & $\rightarrow$ & $8-16$ & $\rightarrow$ & $\begin{array}{l}\text { Settleable solids, total } \\
\text { dissolved solids, pH, cyanide } \\
\text { amenable to chlorination, } \\
\text { oil \& grease, surfactant (as } \\
\text { LAS), total recoverable Co, } \\
\mathrm{Cr}^{+6} \text {, Se, and V, 3,3- } \\
\text { dichlorobenzidine, tributyl } \\
\text { phosphate, hexachloro- } \\
\text { benzene, alpha-BHC, } \\
\text { heptachlor, xylene, 2- } \\
\text { butanone }\end{array}$ \\
\hline & & $\begin{array}{l}\text { Composite } \\
\text { liquid }\end{array}$ & $\rightarrow$ & Semiannual** & $\rightarrow$ & 4 & $\rightarrow$ & $\begin{array}{l}\text { A 24-hour composite } \\
\text { for titanium }\end{array}$ \\
\hline & & $\begin{array}{l}\text { Composite } \\
\text { liquid }\end{array}$ & $\rightarrow$ & Annual** & $\rightarrow$ & 2 & $\rightarrow$ & $\begin{array}{l}\text { A 24-hour composite for } \\
\mathrm{Ba} \text { and } \mathrm{Sb}\end{array}$ \\
\hline & & Grab liquid & $\rightarrow$ & Semiannual** & $\rightarrow$ & 4 & $\rightarrow$ & $\begin{array}{l}\text { Bis(2-ethylhexyl) } \\
\text { phthalate, 4-dodecene }\end{array}$ \\
\hline & & Grab liquid & $\rightarrow$ & Annual** & $\rightarrow$ & 2 & $\rightarrow$ & $\begin{array}{l}\text { Chloroform, dichlorodi- } \\
\text { fluoromethane, } \\
\text { trichlorofluoromethane }\end{array}$ \\
\hline
\end{tabular}

* Lagoon 3 is discharged four to eight times per year, as necessary, averaging six to seven days per discharge.

** Two samples are collected, one near the start and one near the end of the discharge.

$$
B-7
$$




\section{Sampling Rationale}

WNSP001 DOE Order 5400.5; DOE/EH-0173T, 2.3.3; New York State SPDES Permit no. NY0000973

By DOE Order all liquid effluent streams from DOE facilities shall be evaluated and their potential for release of radionuclides addressed. These requirements for radiological parameters are met by daily grab sampling during periods of lagoon 3 discharge.

Sampling for chemical constituents is performed near the beginning and end of each discharge period to meet the site SPDES Permit. Both grab samples and 24-hour composite samples are collected.

For permit requirements, total $\mathrm{Hg}$ is analyzed by U.S. EPA Method 245.1. For mercury studies, samples are analyzed by EPA Method 1631.

$\mathrm{n} \quad$ Sampling location is shown on Figure A-2 (p. A-2).

$$
B-8
$$




\section{Monitoring Program \\ On-Site Effluent Monitoring}

\section{Liquid Effluents}

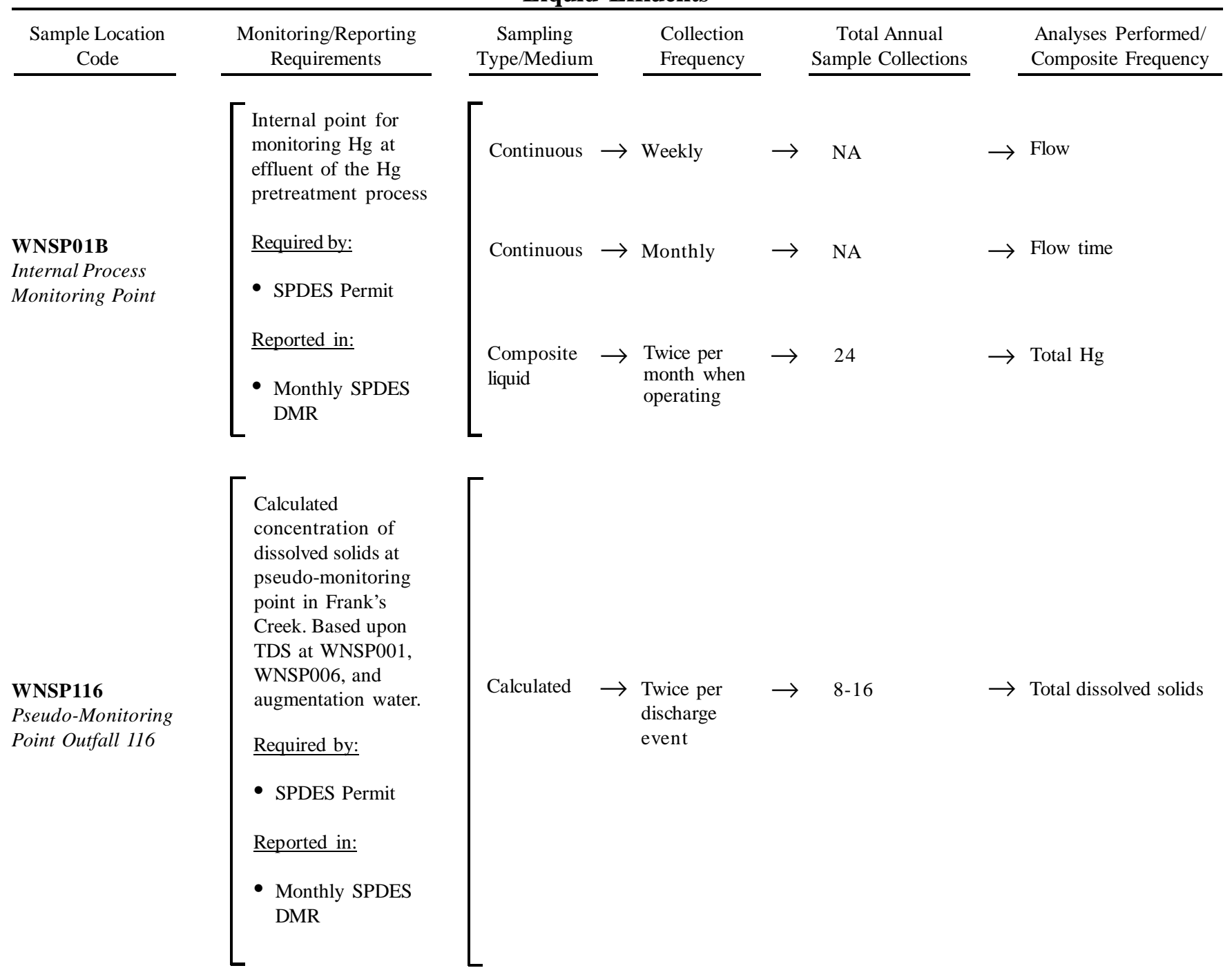

NA - Not applicable

$$
B-9
$$




\section{Sampling Rationale}

WNSP01B New York State SPDES Permit no. NY0000973

This internal point is used to monitor mercury in effluent from the proposed mercury pretreatment process. Effluent from this point is subsequently released to lagoon 3, which is monitored at point WNSP001.

For permit requirements, total $\mathrm{Hg}$ is analyzed by U.S. EPA Method 245.1. For mercury studies, samples are analyzed by EPA Method 1631.

WNSP116 New York State SPDES Permit no. NY0000973

This "pseudo-monitoring point," assumed to be in Frank's Creek, is calculated from actual total dissolved solids (TDS) measurements and flow measurements from points WNSP001 and WNSP006 and from augmentation water.

$\mathrm{n}$ Sampling location WNSP116 is shown on Figure A-2 (p. A-2). Sampling location WNSP01B is not shown on the figures.

$$
\text { B - } 10
$$




\section{Monitoring Program \\ On-Site Effluent Monitoring}

\section{Liquid Effluents}

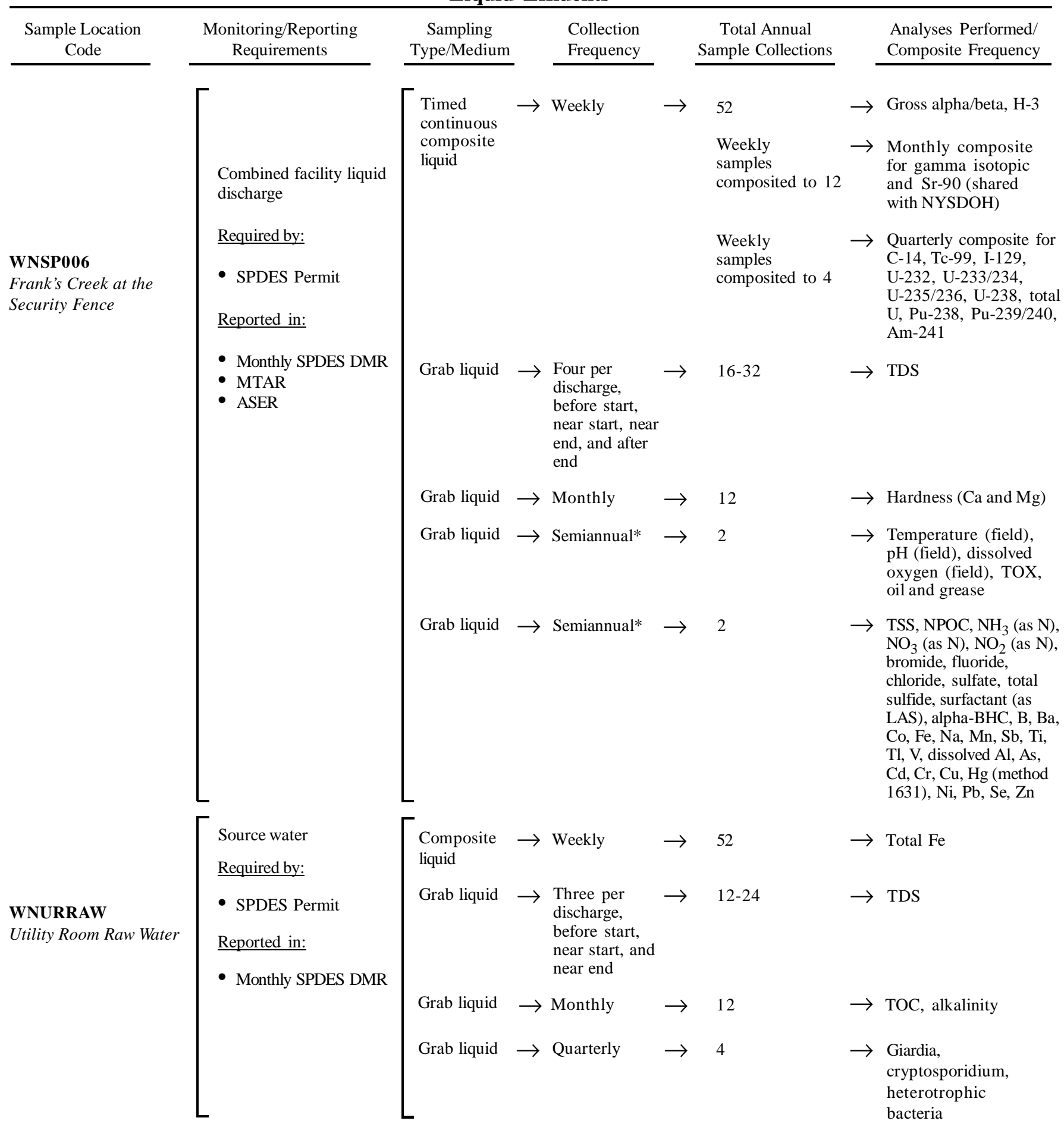

* Semiannual samples collected when points WNSP001 and WNSP007 are discharging.

$$
B-11
$$




\section{Sampling Rationale}

WNSP006 DOE/EH-0173T, 5.10.1.1; New York State SPDES Permit no. NY0000973; 6 NYCRR, Parts 702-704

By DOE Order all liquid effluent streams from DOE facilities shall be evaluated and their potential for release of radionuclides addressed.

The monitoring program on the facing page was put into place at the end of March 2003.

The parameter list for nonradiological analyses was modified in 2003 from a groundwater-oriented program to a surface-water-oriented program. Analyses were added to ensure compliance with New York State Water Quality Standards for Class C Waters.

TDS is measured before the discharge begins, shortly after it begins, near the end, and after the end of each lagoon 3 discharge period to meet requirements of the site SPDES Permit. Measurements of TDS and flow are used to calculate TDS at pseudo-monitoring point outfall 116 in Frank's Creek.

Semiannual samples are collected when WNSP001 and WNSP007 are discharging.

WNURRAW New York State SPDES Permit no. NY0000973; 10 NYCRR, Part 5, Subpart 5-1

TDS is measured near the beginning and end of each lagoon 3 discharge. Results are used for outfall 116 calculations. (See WNSP006 above.)

n Sampling location WNSP006 is shown on Figure A-2 (p. A-2). Sampling location WNURRAW is not shown on the figures.

$B-12$ 


\section{Monitoring Program \\ On-Site Effluent Monitoring}

\section{Liquid Effluents}

\begin{tabular}{|c|c|c|c|c|c|c|c|c|}
\hline $\begin{array}{l}\text { Sample Location } \\
\text { Code }\end{array}$ & $\begin{array}{l}\text { Monitoring/Reporting } \\
\text { Requirements }\end{array}$ & $\begin{array}{c}\text { Sampling } \\
\text { Type/Medium }\end{array}$ & & $\begin{array}{l}\text { Collection } \\
\text { Frequency }\end{array}$ & & $\begin{array}{c}\text { Total Annual } \\
\text { Sample Collections }\end{array}$ & & $\begin{array}{l}\text { Analyses Performed/ } \\
\text { Composite Frequency }\end{array}$ \\
\hline \multirow{6}{*}{$\begin{array}{l}\text { WNSP007 } \\
\text { Sanitary Waste } \\
\text { Discharge }\end{array}$} & {$\left[\begin{array}{l}\text { Liquid effluent point } \\
\text { for sanitary and utility } \\
\text { plant combined } \\
\text { discharge }\end{array}\right.$} & $\begin{array}{l}\text { 24-hour } \\
\text { composite } \\
\text { liquid }\end{array}$ & $\rightarrow$ & 3 each month & $\rightarrow$ & 36 & $\rightarrow$ & $\begin{array}{l}\text { Gross alpha/beta, } \mathrm{H}-3 \text {, } \\
\mathrm{pH} \text {, total suspended } \\
\text { solids, } \mathrm{NH}_{3}, \mathrm{NO}_{2}-\mathrm{N} \text {, } \\
\mathrm{BOD}_{5} \text {, total } \mathrm{Fe} \text {, flow }\end{array}$ \\
\hline & $\begin{array}{l}\text { Required by: } \\
\text { - SPDES Permit }\end{array}$ & & & & & $\begin{array}{l}\text { Monthly } \\
\text { samples } \\
\text { composited to } 4\end{array}$ & $\rightarrow$ & $\begin{array}{l}\text { Quarterly composite } \\
\text { for gamma isotopic } \\
\text { and } \mathrm{Sr}-90\end{array}$ \\
\hline & & Grab liquid & $\rightarrow$ & 3 each month & $\rightarrow$ & 36 & $\rightarrow$ & Oil \& grease \\
\hline & $\begin{array}{ll}\text { - } & \text { Monthly SPDES DMR } \\
\text { - } & \text { ESR } \\
\text { - } & \text { MTAR } \\
\text { - } & \text { ASER }\end{array}$ & Grab liquid & $\rightarrow$ & Weekly & $\rightarrow$ & 52 & $\rightarrow$ & $\begin{array}{l}\mathrm{pH} \text {, settleable solids, } \\
\text { total residual chlorine, } \\
\text { temperature }\end{array}$ \\
\hline & & Grab liquid & $\rightarrow$ & Annual & $\rightarrow$ & 1 & $\rightarrow$ & Chloroform \\
\hline & & Grab liquid & $\rightarrow$ & Monthly & $\rightarrow$ & 12 & $\rightarrow$ & Flow, flow time \\
\hline
\end{tabular}

$B-13$ 


\section{Sampling Rationale}

WNSP007 DOE Order 5400.5; DOE/EH-0173T, 2.3.3; New York State SPDES Permit no. NY0000973

Monitoring of treated effluent from the sanitary and industrial wastewater treatment facility is performed in accordance with the New York State SPDES Permit no. NY0000973 and DOE Order 5400.5 criteria.

Strontium-90 analysis was added in a quarterly basis beginning in the 2nd quarter of 2003 .

n Sampling location WNSP007 is shown on Figure A-2 (p. A-2).

$B-14$ 
2003 Monitoring Program

Environmental Surveillance

On-Site Surface Water

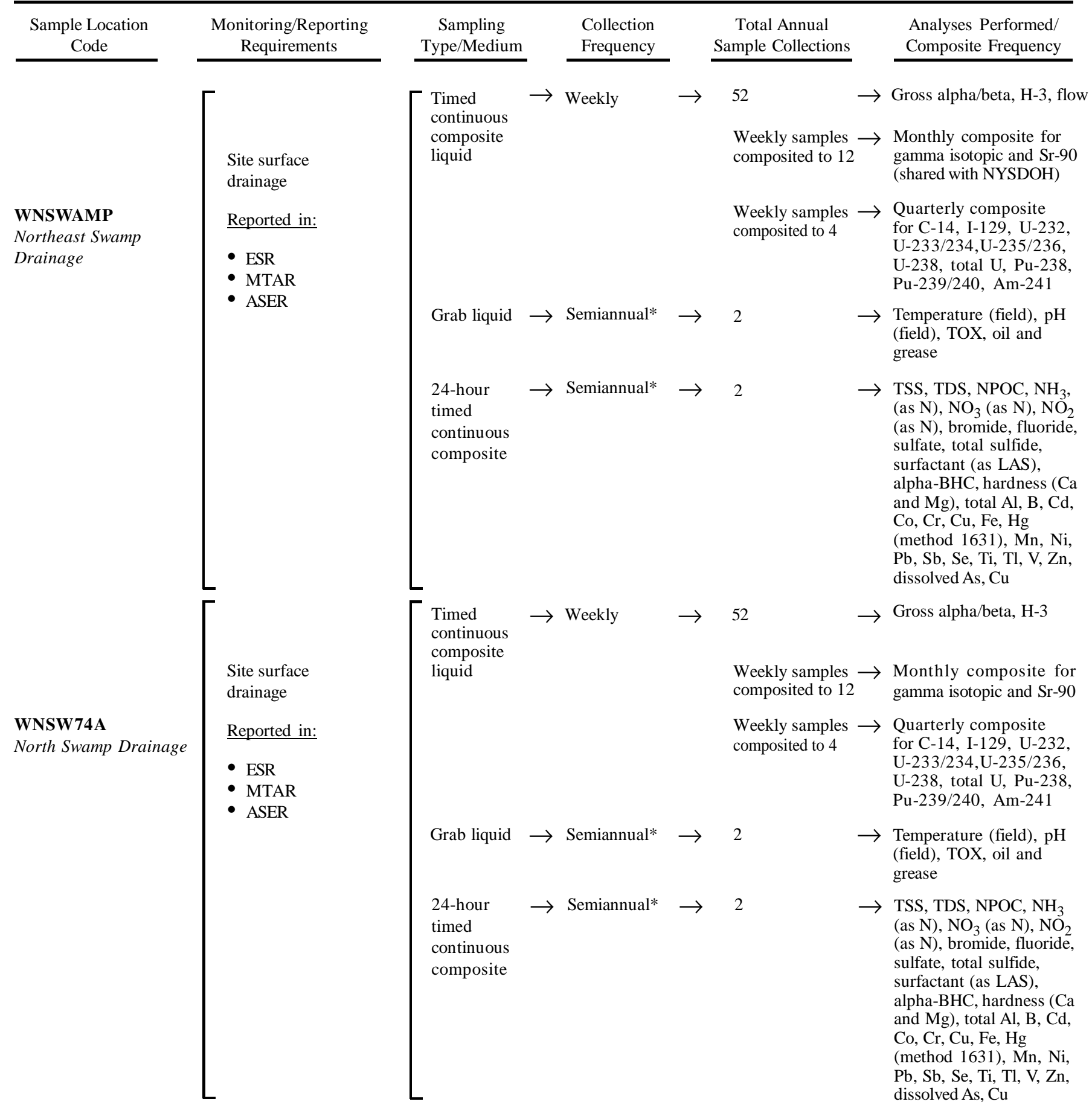

* Sampled during ambient (i.e., non-wet weather) conditions.

$B-15$

WVDP Annual Site Environmental Report

Calendar Year 2003 


\section{Sampling Rationale}

\section{WNSWAMP DOE/EH-0173T, 5.10.1.1; 40 CFR, Part 122.26}

Northeast site surface water drainage; provides for sampling of uncontrolled surface waters from this discrete drainage path just before they leave the site's controlled boundary. Waters represent surface and subsurface drainages from the construction and demolition debris landfill (CDDL), old hardstand areas, and other possible north plateau sources of radiological or nonradiological contamination on the north plateau.

The monitoring program on the facing page was put into place at the end of the first quarter of 2003, in March. The parameter list for nonradiological analyses was modified from a groundwater-oriented program to a surface-wateroriented program in order to define ambient conditions at these outfalls.

Monitoring for nonradiological parameters is performed during ambient conditions to verify authorized non-storm water flows. Storm water monitoring is performed per WVDP-233, "Sampling and Analysis Plan for Storm Water Discharges at the West Valley Demonstration Project."

WNSW74A DOE/EH-0173T, 5.10.1.1; 40 CFR, Part 122.26

North site surface water drainage; provides for sampling of uncontrolled surface waters from this discrete drainage path just before they leave the site's controlled boundary. Waters represent surface and subsurface drainages from lag storage areas and other possible sources of radiological or nonradiological contamination on the north plateau.

The monitoring program on the facing page was put into place at the end of the first quarter of 2003, in March. The parameter list for nonradiological analyses was modified from a groundwater-oriented program to a surface-wateroriented program in order to define ambient conditions at these outfalls.

Monitoring for nonradiological parameters is performed during ambient conditions to verify authorized non-storm water flows. Storm water monitoring is performed per WVDP-233, "Sampling and Analysis Plan for Storm Water Discharges at the West Valley Demonstration Project."

$\mathrm{n} \quad$ Sampling locations are shown on Figure A-2 (p. A-2).

\section{$B-16$}


2003 Monitoring Program

Environmental Surveillance

On-Site Surface Water

\begin{tabular}{|c|c|c|c|c|c|c|c|c|}
\hline $\begin{array}{l}\text { Sample Location } \\
\text { Code }\end{array}$ & $\begin{array}{l}\text { Monitoring/Reporting } \\
\text { Requirements }\end{array}$ & $\begin{array}{c}\text { Sampling } \\
\text { Type/Medium }\end{array}$ & & $\begin{array}{l}\text { Collection } \\
\text { Frequency }\end{array}$ & & $\begin{array}{c}\text { Total Annual } \\
\text { Sample Collections }\end{array}$ & & $\begin{array}{l}\text { Analyses Performed/ } \\
\text { Composite Frequency }\end{array}$ \\
\hline $\begin{array}{l}\text { WNSDADR } \\
\text { SDA Run-Off }\end{array}$ & {$\left[\begin{array}{l}\begin{array}{l}\text { Surface water run-off } \\
\text { from south portion } \\
\text { of SDA }\end{array} \\
\text { Required by: } \\
\text { - Interim Measures } \\
\text { Compliance } \\
\text { Reported in: } \\
\text { - MTAR } \\
\text { - ASER } \\
\text { - Reported to } \\
\text { NYSERDA }\end{array}\right.$} & Grab liquid & $\rightarrow$ & Monthly & $\rightarrow$ & 12 maximum & $\rightarrow$ & $\begin{array}{l}\mathrm{pH} \text {, total suspended } \\
\text { solids, oil \& grease, flow, } \\
\text { gross alpha/beta, H-3, } \\
\text { gamma isotopic, } \\
\text { precipitation }\end{array}$ \\
\hline
\end{tabular}

$B-17$ 


\section{Sampling Rationale}

WNSDADR NYSERDA interim measures compliance.

n Sampling location WNSDADR is shown on Figure A-2 (p. A-2).

$$
\text { B }-18
$$




\section{Monitoring Program \\ Environmental Surveillance}

\section{On-Site Surface Water}

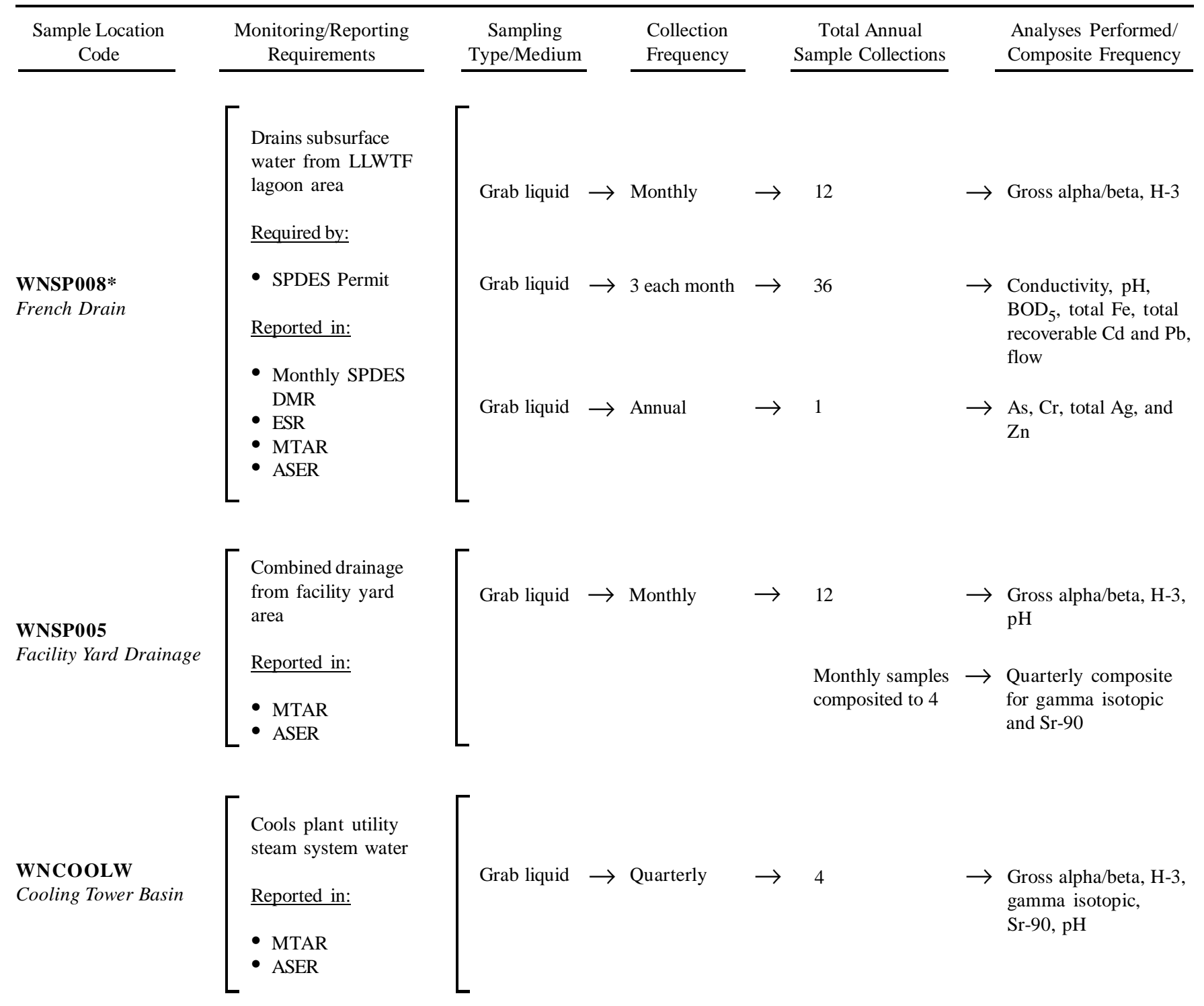

\footnotetext{
* Although WNSP008 is listed in the SPDES Permit, it was capped off in May 2001 and is no longer being sampled.
} 


\section{Sampling Rationale}

WNSP008 DOE/EH-0173T, 5.10.1.3; New York State SPDES Permit no. NY0000973

French drain of subsurface water from lagoon (LLWTF) area. The SPDES Permit also provides for sampling of uncontrolled subsurface water from this discrete drainage path before these waters flow into Erdman Brook. Waters represent subsurface drainages from downward infiltration around the LLWTF and lagoon systems. This point would also monitor any subsurface spillover from the overfilling of lagoons 2 and 3. Sampling is of significance for both radiological and nonradiological contamination. This point was capped off in May 2001 and is routinely checked to verify that there is no discharge.

WNSP005 Generally in accordance with DOE/EH-0173T, 5.10.1.1 (previously in accordance with SPDES permit no. NY0000973)

Provides for the sampling of uncontrolled surface waters from this discrete drainage path after outfall 007 discharge into the drainage and before these waters flow into Erdman Brook. Waters represent surface and subsurface drainages primarily from the main plant yard area. Historically, this point was used to monitor sludge pond and utility room discharges to the drainage. These two sources have been rerouted. Migration of residual site contamination around the main plant dictates surveillance of this point, primarily for radiological parameters. Sr-90 and gamma-isotopic analyses were added on a quarterly basis beginning in the 2nd quarter of 2003.

WNCOOLW Generally in accordance with DOE/EH-0173T, 5.10.1.1

Operational sampling carried out to confirm that radiological contamination is not migrating into the primary coolant loop of the high-level waste treatment facility and/or plant utility steam systems. Migration from either source might indicate radiological control failure. Sampling was reduced from monthly to quarterly at the end of the 1st quarter of 2003 (March) and Sr-90 analysis was added.

n Sampling locations are shown on Figure A-2 (p. A-2).

B - 20 


\section{Monitoring Program \\ Environmental Surveillance}

On-Site Surface Water

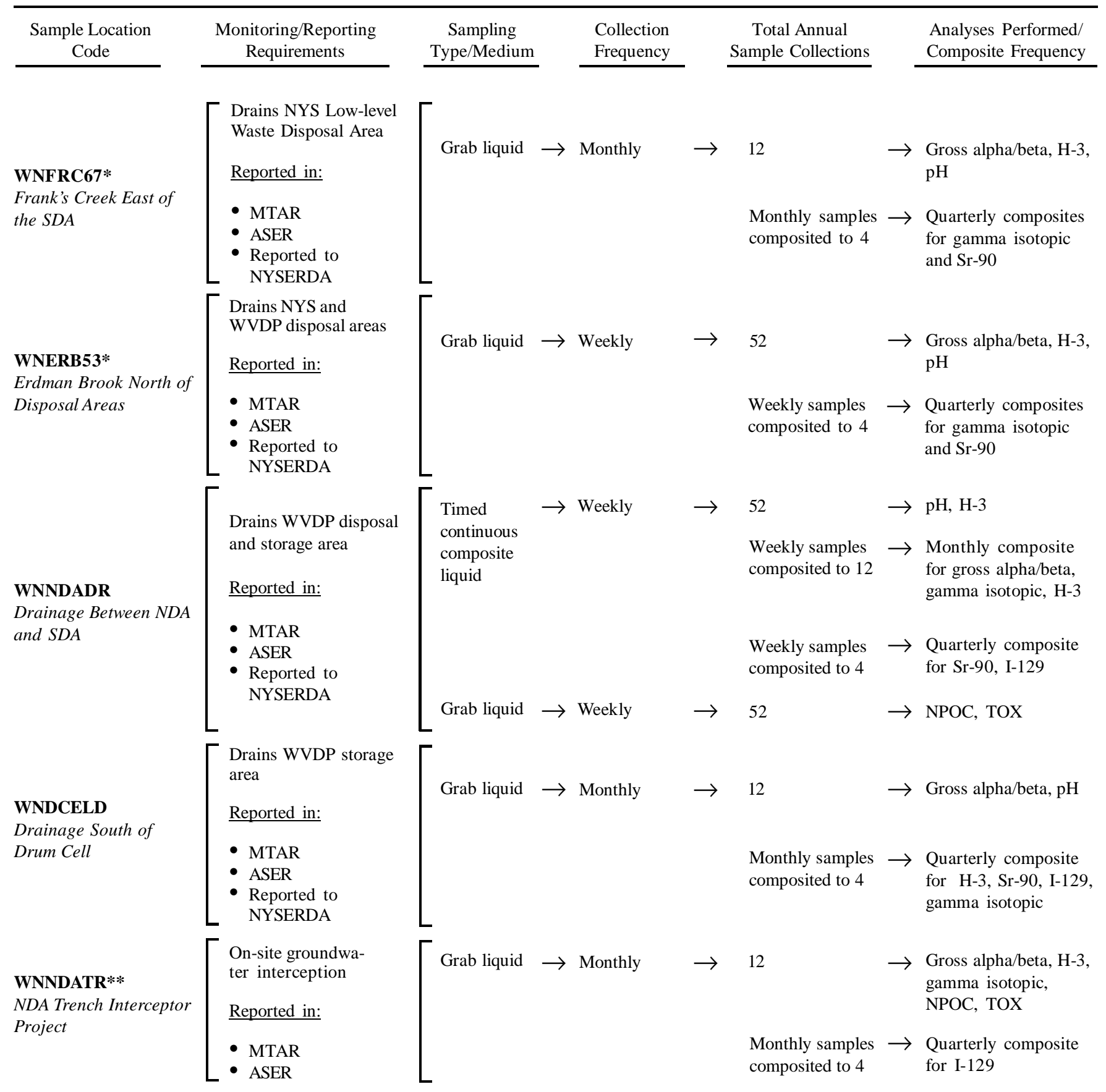

\footnotetext{
* Monthly sample also collected by NYSDOH

** Coordinated with Main Plant Operations
}

B - 21 


\section{Sampling Rationale}

WNFRC67 DOE/EH-0173T, 5.10.1.1

Monitors the potential influence of both the SDA and drum cell drainage into Frank's Creek east of the SDA and upstream of its confluence with Erdman Brook. Strontium-90 and gamma isotopic analysis were added on a quarterly basis at the beginning of the 2nd quarter of 2003.

WNERB53 DOE/EH-0173T, 5.10.1.1

Monitors the potential influence of the drainages from the SDA and the WVDP storage and disposal area into Erdman Brook upstream of its confluence with Frank's Creek. Strontium- 90 and gamma isotopic analysis were added on a quarterly basis at the beginning of the 2nd quarter of 2003.

WNNDADR $\quad$ DOE/EH-0173T, 5.10.1.1

Monitors the potential influence of the drainages from the SDA and the WVDP storage and disposal area into Lagoon Road Creek upstream of the creek's confluence with Erdman Brook.

WNDCELD DOE/EH-0173T, 5.10.1.1

Monitors the potential influence of drum cell drainage into Frank's Creek south of the SDA and upstream of WNFRC67.

WNNDATR Generally in accordance with DOE/EH-0173T, 5.10.1.1

Monitors groundwater in the vicinity of the NDA interceptor trench project. The grab sample is taken directly from the trench collection system.

n Sampling locations are shown on Figure A-2 (p. A-2).

$B-22$ 
2003 Monitoring Program

Environmental Surveillance

On-Site Surface Water

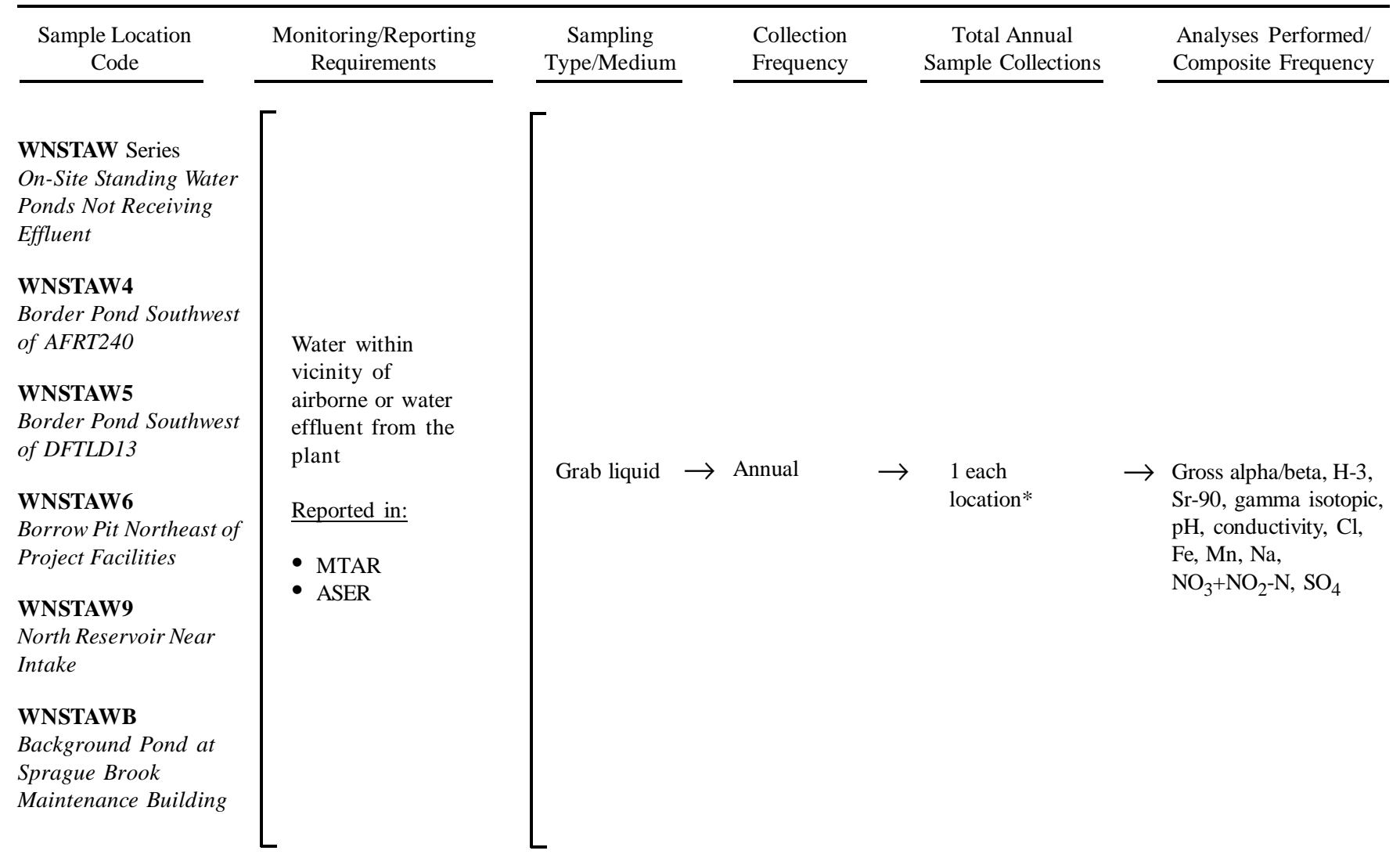

* Sampling depends upon on-site ponding conditions during the year.

B - 23 


\section{Sampling Rationale}

WNSTAW Series DOE/EH-0173T, 5.10.1.1

Monitoring of on- and off-site standing waters at locations listed below. Although none receive effluent directly, the potential for contamination is present except at the background location. Former collecting sites 1,2,3,7, and 8 were deleted from the monitoring program because they were either built over or are now dry. Strontium-90 and gamma isotopic were added on an annual basis beginning in 2003.

WNSTAW4 Border pond located south of AFRT240. Chosen as a location for showing potentially high concentrations, based on meteorological data. This perimeter location is next to a working farm. Drainage extends through private property and is accessible by the public.

WNSTAW5 Border pond located west of Project facilities near the perimeter fence and DFTLD13. Chosen as a location for showing potentially high concentrations, based on meteorological data. Location is next to a private residence and potentially accessible by the general public.

WNSTAW6 Borrow pit northeast of Project facilities just outside the inner security fence. Considered the closest standing water to the main plant and high-level waste facilities.

WNSTAW9 North reservoir near intake. Chosen to provide data in the event of potentially contaminated site potable water supply. Location is south of main plant facilities.

WNSTAWB Pond located near the Sprague Brook maintenance building. Considered a background location; approximately 14 kilometers north of the WVDP.

n Sampling locations are shown on Figures A-2, A-3, and A-13 (pp. A-2, A-3, and A-13).

$B-24$ 


\section{Monitoring Program \\ Environmental Surveillance}

On-Site Potable Water

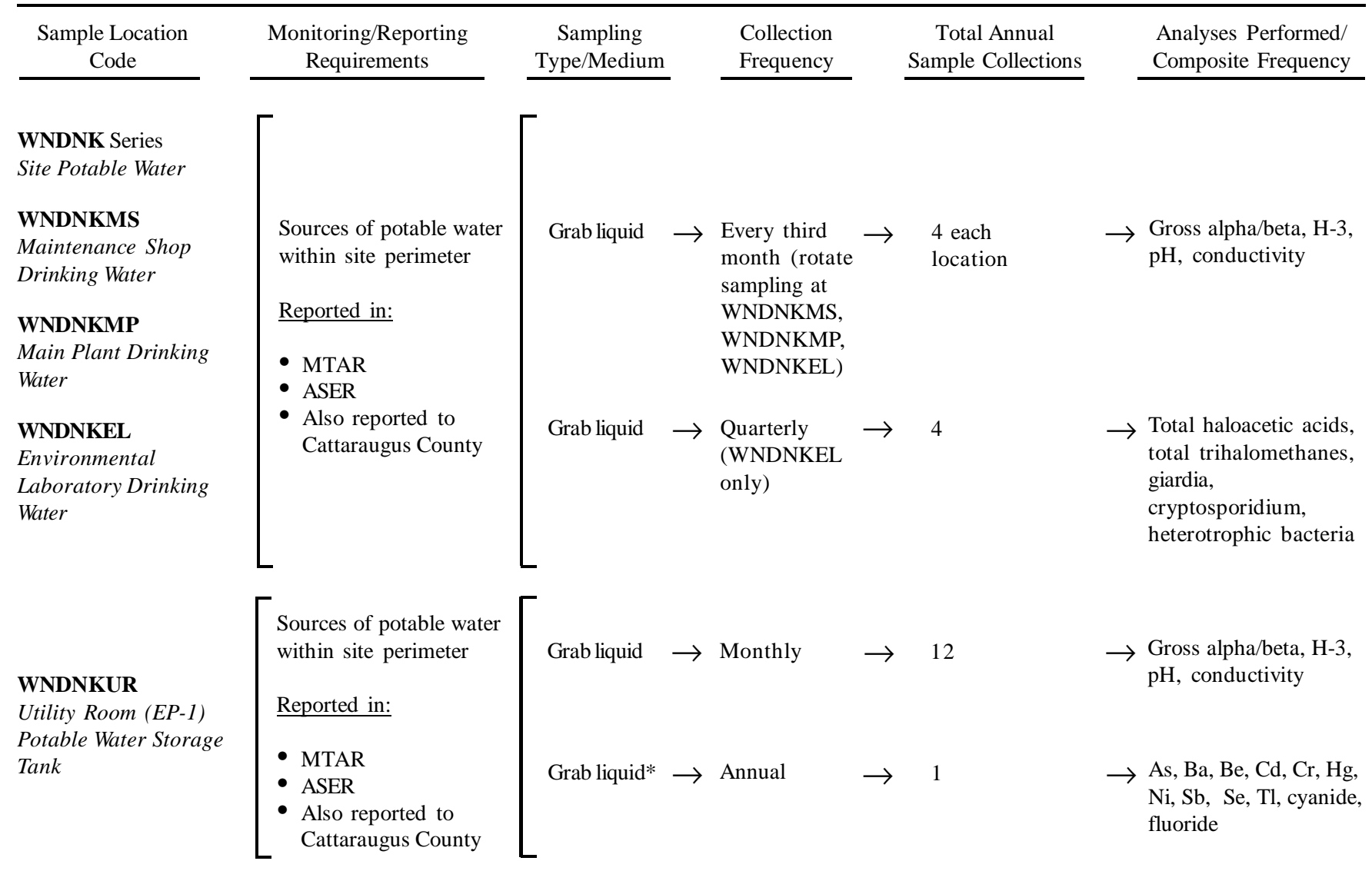
$*$ Sample for $\mathrm{NO}_{3}$ (as total nitrate) is collected by the Cattaraugus County Health Department. $\mathrm{Pb}$ and $\mathrm{Cu}$ also are sampled at this site based upon
Cattaraugus County Health Department guidance.

$$
\text { B }-25
$$




\section{Sampling Rationale}

WNDNK Series Site drinking water; generally according to DOE/EH-0173T, 5.10.1.2; 10 NYCRR, Part 5, Subpart 5-1

Potable-water sampling to confirm no migration of radiological and/or nonradiological contamination into the site's drinking water supply. Sampling at WNDNKMS, WNDNKMP, and WNDNKEL was reduced from monthly to every third month on a rotating basis at the end of the 1st quarter of 2003.

WNDNKMS Potable water sampled at the maintenance shop in order to monitor a point that is an intermediate distance from the point of potable water generation and that is used heavily by site personnel.

WNDNKMP Same rationale as WNDNKMS but sampled at the break room sink in the main plant.

WNDNKEL Potable water sampled at the Environmental Laboratory. Disinfectant by-products are sampled at WNDNKEL, the furthest location from the entry point (WNDNKUR).

WNDNKUR Sampled at the utility room potable water storage tank before the site drinking water distribution system. Sample location is entry point EP-1.

$\mathrm{n} \quad$ Sampling locations are within the site facilities and are not detailed on figures.

$B-26$ 
2003 Monitoring Program

Environmental Surveillance

On-Site Groundwater

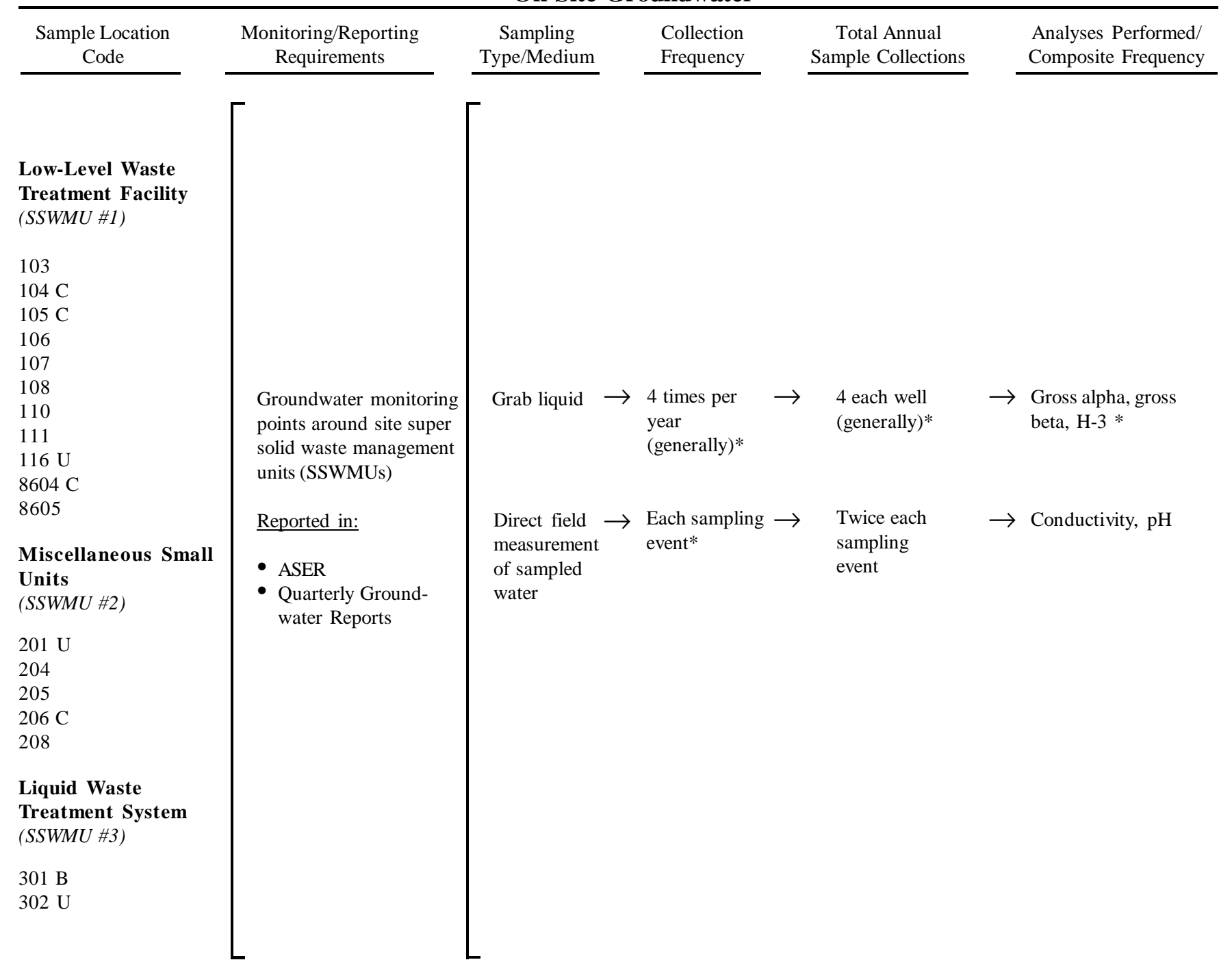

NOTE: "U" designates upgradient, "B" designates background, and "C" designates crossgradient wells. The remainder are downgradient.

* Sampling frequency and analytes vary from point to point. See p. E-3 for a summary listing of all monitored analytes and Table E-1 (Appendix E [p. E-4 $C_{\text {] }}$ ) for a listing of analytes monitored at each location. See Appendix $\mathrm{E}^{\mathrm{C}}$ for results from each location.

$$
B-27
$$




\title{
Sampling Rationale
}

\begin{abstract}
On-Site DOE/EH-0173T, 5.10.1.3; 40 CFR, Parts 264 and 265, Subpart F
Groundwater

The on-site WVDP groundwater monitoring program provides for the determination of water quality, focusing on radiological and chemical surveillance of both active and inactive super solid waste management units (SSWMUs). In addition, using wells situated hydraulically upgradient (background) and downgradient of SSWMUs allows both detection of groundwater contamination and evaluation of the effects associated with the individual SSWMUs. Groundwater protection was addressed in the "Groundwater Protection Management Program Plan," WVDP-091. Groundwater monitoring was detailed in the "Groundwater Monitoring Plan," WVDP-239.
\end{abstract}

SSWMU \#1 Low-level waste treatment facilities, including four active lagoons - lagoons 2, 3, 4, and 5 - and an inactive, filledin lagoon - lagoon 1.

SSWMU \#2 Miscellaneous small units, including the sludge pond, the solvent dike, the paper incinerator, the equalization basin, and the kerosene tank.

SSWMU \#3 Liquid waste treatment system containing effluent from the supernatant treatment system.

n Sampling locations are shown on Figures A-6 and A-7 (pp. A-6 and A-7).

B - 28 
2003 Monitoring Program

Environmental Surveillance

On-Site Groundwater

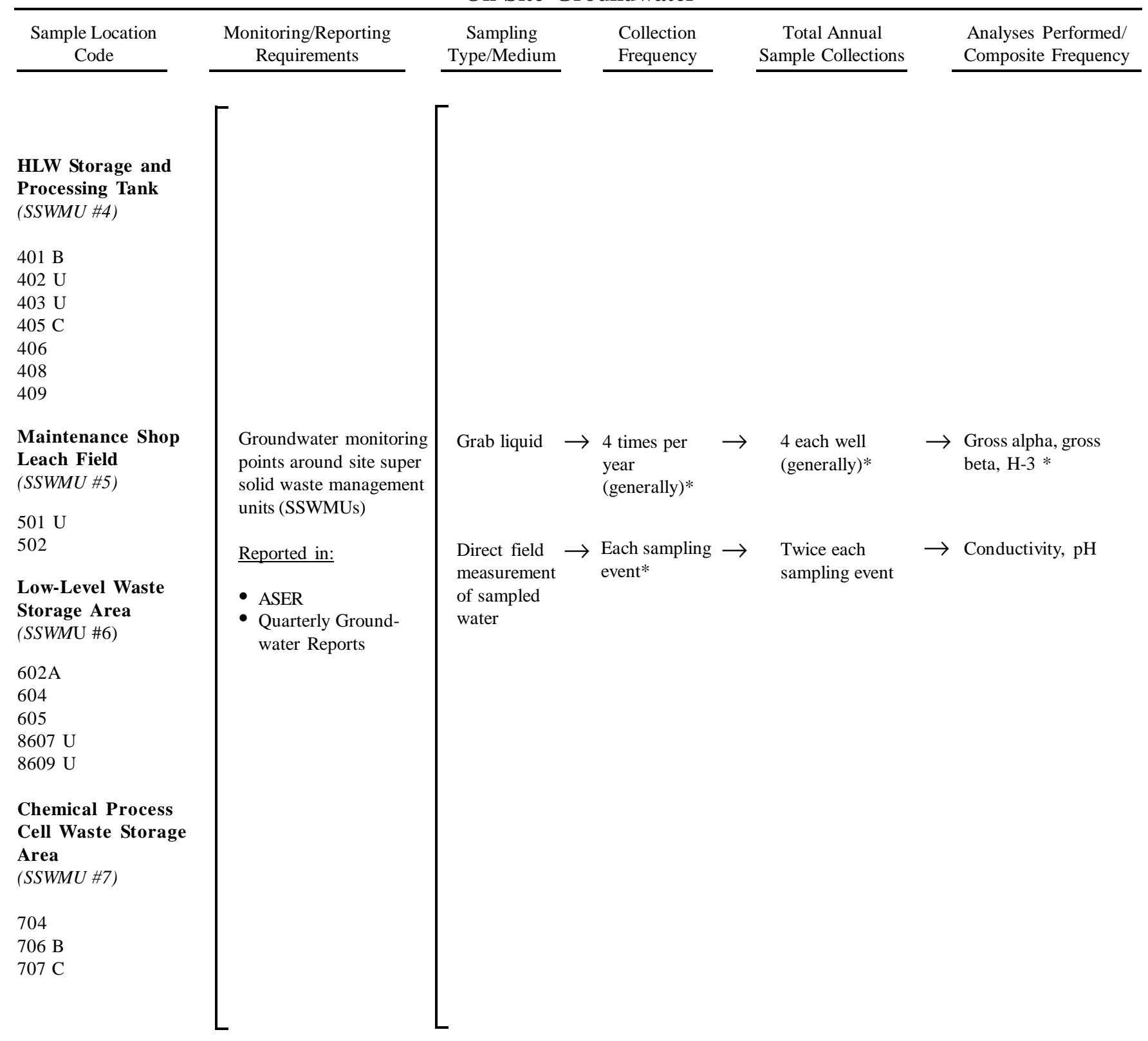

NOTE: "U" designates upgradient, "B" designates background, and "C" designates crossgradient wells. The remainder are downgradient.

* Sampling frequency and analytes vary from point to point. See p. E-3 for a summary listing of all monitored analytes and Table E-1 (Appendix E [p. E-4 $\mathrm{C}_{\text {] }}$ ) for a listing of analytes monitored at each location. See Appendix $\mathrm{E}^{\mathrm{C}}$ for results from each location.

$$
\text { B - } 29
$$




\title{
Sampling Rationale
}

\author{
On-Site DOE/EH-0173T, 5.10.1.3; 40 CFR, Parts 264 and 265, Subpart F \\ Groundwater \\ The on-site WVDP groundwater monitoring program provides for the determination of water quality, focusing on \\ radiological and chemical surveillance of both active and inactive super solid waste management units (SSWMUs). In \\ addition, using wells situated hydraulically upgradient (background) and downgradient of SSWMUs allows both detection \\ of groundwater contamination and evaluation of the effects associated with the individual SSWMUs. Groundwater \\ protection was addressed in the "Groundwater Protection Management Program Plan," WVDP-091. Groundwater \\ monitoring was detailed in the "Groundwater Monitoring Plan," WVDP-239. \\ SSWMU \#4 High-level waste storage and processing area, including the high-level radioactive waste tanks, the supernatant \\ treatment system, and the vitrification facility. \\ SSWMU \#5 Maintenance shop sanitary leach field, formerly used by NFS and the WVDP to process domestic sewage generated by \\ the maintenance shop. \\ SSWMU \#6 Low-level waste storage area; includes metal and fabric structures housing low-level radioactive waste being stored for \\ future disposal. \\ SSWMU \#7 Chemical process cell (CPC) waste storage area, which contains packages of pipes, vessels, and debris from \\ decontamination and cleanup of the chemical process cell in the former reprocessing plant.
}

n Sampling locations are shown on Figures A-6 and A-7 (pp. A-6 and A-7).

$B-30$ 
2003 Monitoring Program

Environmental Surveillance

On-Site Groundwater

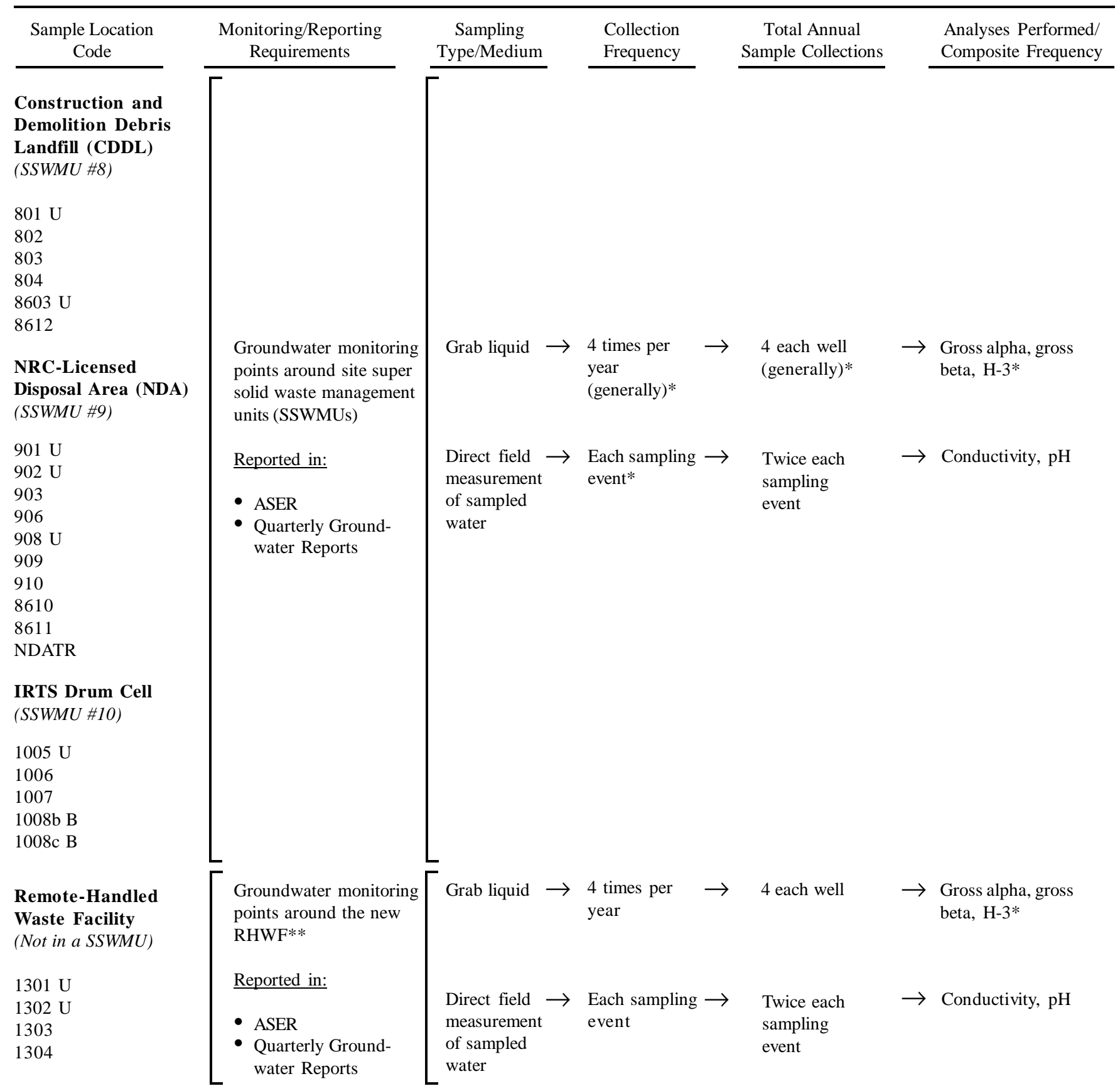

NOTE: "U" designates upgradient, "B" designates background, and "C" designates crossgradient wells. The remainder are downgradient.

* Sampling frequency and analytes vary from point to point. See p. E-3 for a summary listing of all monitored analytes. See Table E-1 (Appendix E [p. E-4 $]$ ) for a listing of analytes monitored at each location. See Appendix $\mathrm{E}^{\mathrm{C}}$ for results from each location.

** These wells were installed in August 2003 and sampling initiated during the fourth quarter of 2003 (September 2003).

$$
B-31
$$


Sampling Rationale

\begin{abstract}
On-Site DOE/EH-0173T, 5.10.1.3; 40 CFR, Parts 264 and 265, Subpart F
Groundwater

The on-site WVDP groundwater monitoring program provides for the determination of water quality, focusing on radiological and chemical surveillance of both active and inactive super solid waste management units (SSWMUs). In addition, using wells situated hydraulically upgradient (background) and downgradient of SSWMUs allows both detection of groundwater contamination and evaluation of the effects associated with the individual SSWMUs. Groundwater protection was addressed in the "Groundwater Protection Management Program Plan," WVDP-091. Groundwater monitoring was detailed in the "Groundwater Monitoring Plan," WVDP-239.

SSWMU \#8 The construction and demolition debris landfill (CDDL); used by NFS and the WVDP to dispose of nonhazardous and nonradioactive materials.

SSWMU \#9 The NRC-licensed disposal area (NDA); contains radioactive wastes generated by NFS and the WVDP. The NDA is bounded on its downgradient (northwest and northeast) perimeters by the interceptor trench, which is sampled at monitoring point NDATR.
\end{abstract}

SSWMU \#10 The integrated radioactive waste system (IRTS) treatment drum cell; stores cement-stablized low-level radioactive waste.

Remote-Handled Establish pre-operational baseline groundwater conditions in the area of the newly constructed remote-handled waste Waste Facility facility (RHWF). Monitor groundwater in the vicinity of the RHWF.

$\mathrm{n}$ Sampling locations are shown on Figures A-6 through A-8 (pp. A-6 through A-8).

B - 32 
2003 Monitoring Program

Environmental Surveillance

\section{On-Site Groundwater and Seeps}

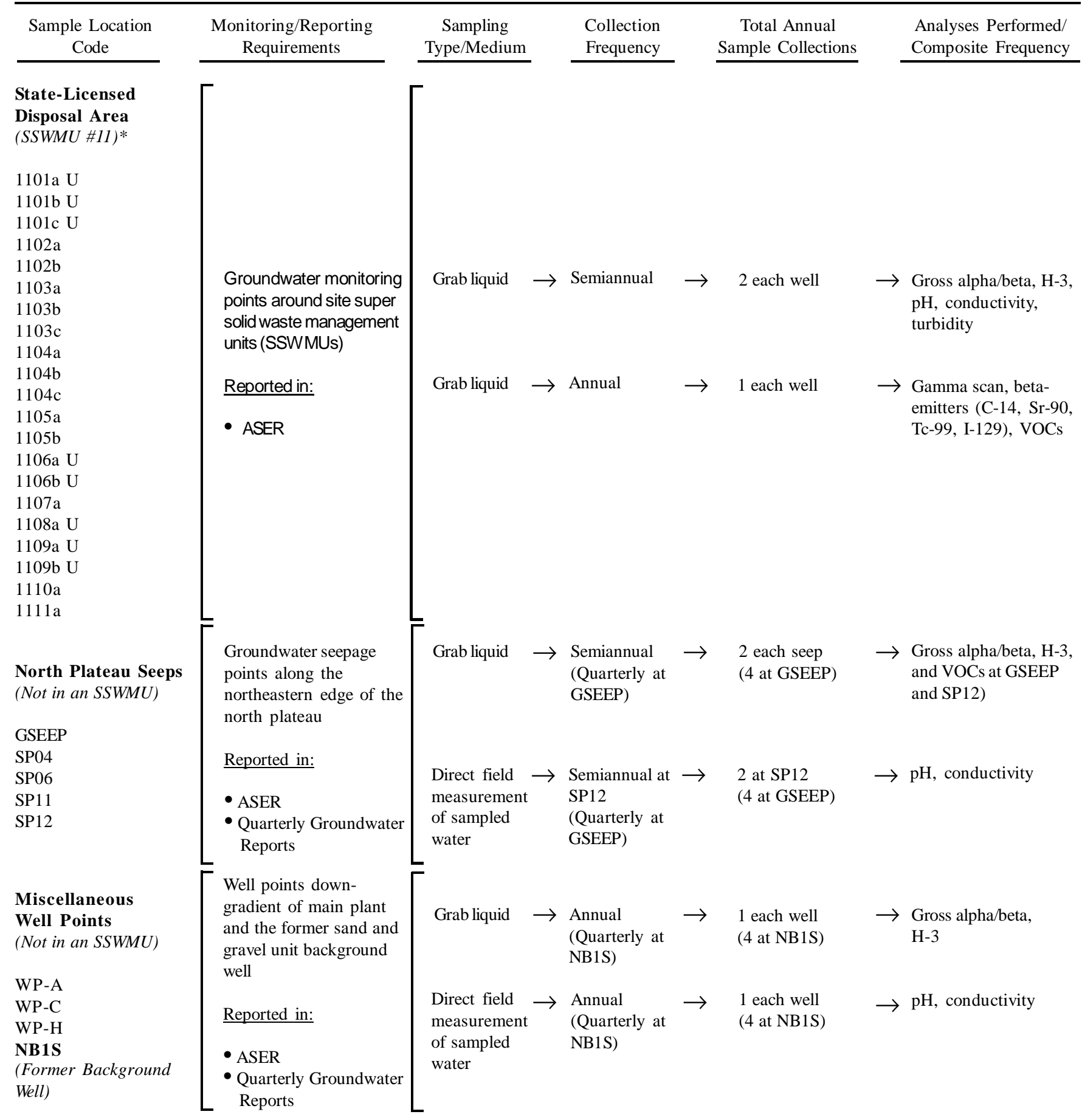

NOTE: "U" designates upgradient, "B" designates background, and "C" designates crossgradient wells. The remainder are downgradient.

* SSWMU \#11 is sampled by NYSERDA under a separate program.

$$
\text { B - } 33
$$




\title{
Sampling Rationale
}

\begin{abstract}
On-Site DOE/EH-0173T, 5.10.1.3; 40 CFR, Parts 264 and 265, Subpart F
Groundwater

The on-site WVDP groundwater monitoring program provides for the determination of water quality, focusing on radiological and chemical surveillance of both active and inactive super solid waste management units (SSWMUs). In addition, using wells situated hydraulically upgradient (background) and downgradient of SSWMUs allows both detection of groundwater contamination and evaluation of the effects associated with the individual SSWMUs. Groundwater protection was addressed in the "Groundwater Protection Management Program Plan," WVDP-091. Groundwater monitoring was detailed in the "Groundwater Monitoring Plan," WVDP-239.
\end{abstract}

SSWMU \#11 The New York State-licensed disposal area (SDA) was operated by NFS as a commercial low-level disposal facility; it also received wastes from NFS reprocessing operations.

North Plateau

Monitor groundwater emanating from the ground surface along the edge of the site's north plateau.

Seeps

Well Points

Monitor groundwater of known subsurface contamination in the north plateau area. All well points are downgradient of the main plant.

WNWNB1S Former background well on the north plateau.

$\mathrm{n} \quad$ Sampling locations are shown on Figures A-6 through A-8 (pp. A-6 through A-8).

$$
B-34
$$


2003 Monitoring Program

Environmental Surveillance

Off-Site Surface Water

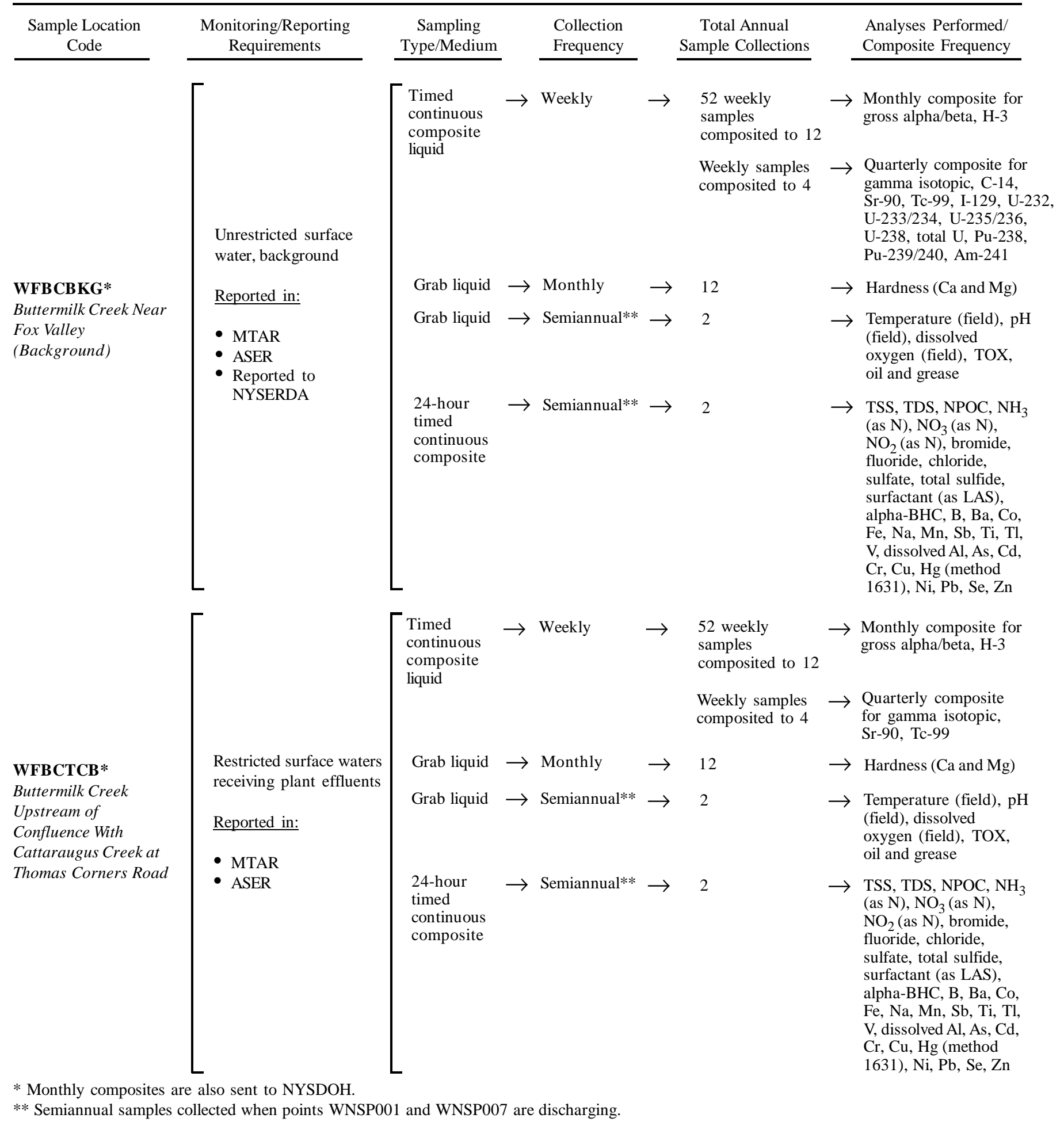

$$
B-35
$$




\section{Sampling Rationale}

WFBCBKG DOE/EH-0173T, 5.10.1.1; 6 NYCRR, Part 702-704

Monitors background conditions of Buttermilk Creek upstream of the WVDP; allows for comparison to downstream conditions. Monitoring for nonradiological parameters performed during discharges from WNSP001 and WNSP007 for comparison with downstream conditions.

The parameter list for nonradiological analyses was modified in 2003 from a groundwater-oriented program to a surface-water-oriented program. Analyses were added to ensure compliance with New York State Water Quality Standards for Class C Waters.

The monitoring program on the facing page was put into effect at the end of the 1st quarter of 2003, in March.

WFBCTCB DOE/EH-0173T, 5.10.1.1; 6 NYCRR, Part 702-704

Buttermilk Creek is the surface water that receives all WVDP effluents. WFBCTCB monitors the potential influence of WVDP drainage into Buttermilk Creek upstream of Buttermilk Creek's confluence with Cattaraugus Creek. Monitoring for nonradiological parameters performed during discharges from WNSP001 and WNSP007 for comparison with New York State ambient water quality standards (6 NYCRR, Part 702-704).

The parameter list for nonradiological analyses was modified in 2003 from a groundwater-oriented program to a surface-water-oriented program. Analyses were added to ensure compliance with New York State Water Quality Standards for Class C Waters.

Technetium-99 analysis was added on a quarterly basis at the beginning of the 2nd quarter of 2003 .

The monitoring program on the facing page was put into effect at the end of the 1st quarter of 2003, in March.

$\mathrm{n} \quad$ Sampling locations are shown on Figure A-3 (p. A-3).

$$
B-36
$$




\section{Monitoring Program \\ Environmental Surveillance}

Off-Site Surface Water

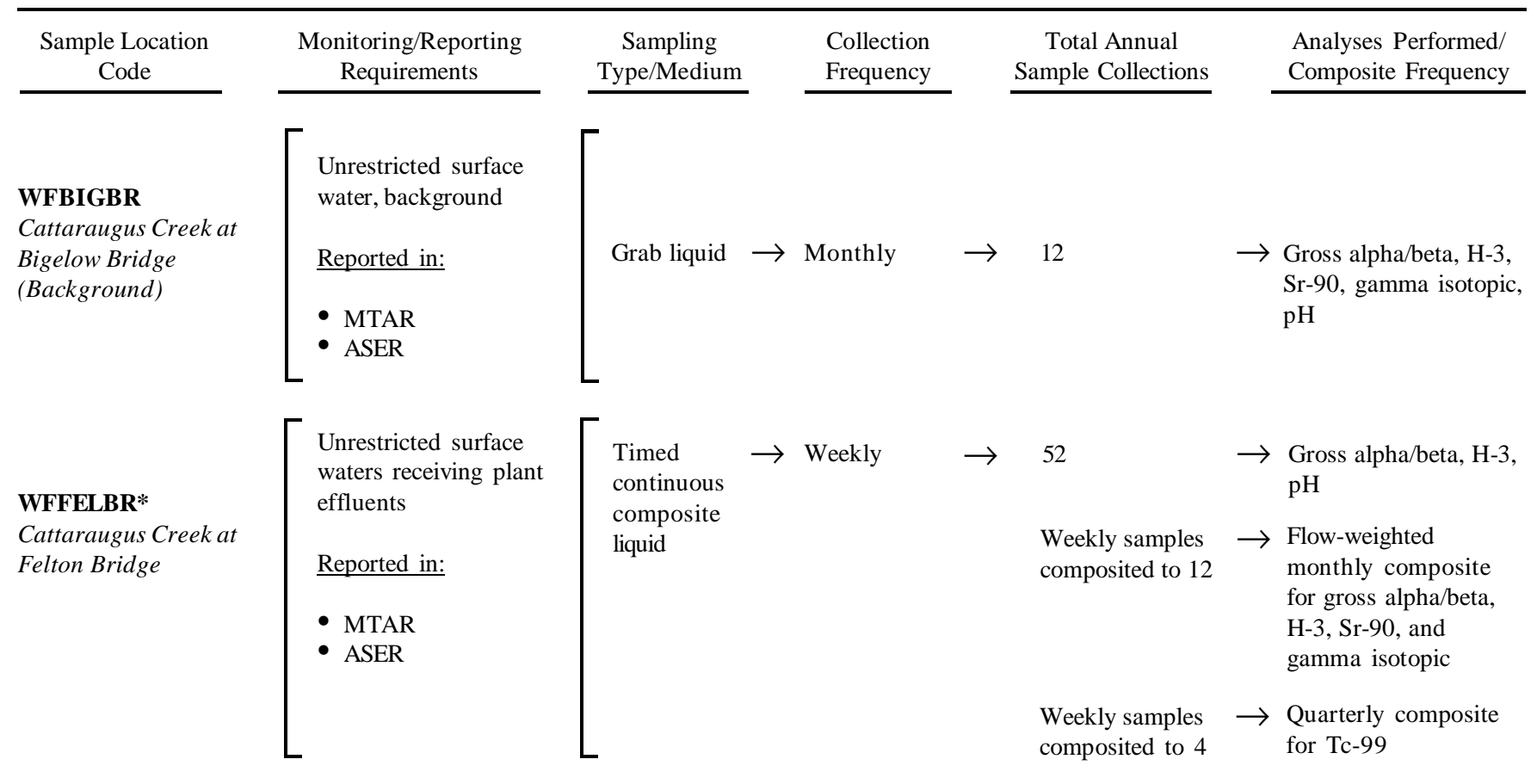

* Monthly composites are also sent to NYSDOH.

$B-37$ 


\section{Sampling Rationale}

WFBIGBR $\quad$ DOE/EH-0173T, 5.10.1.1

Monitors background conditions of Cattaraugus Creek at Bigelow Bridge, upstream of the WVDP; allows for comparison to downstream conditions.

WFFELBR

DOE/EH-0173T, 5.10.1.1

Because Buttermilk Creek empties into Cattaraugus Creek, WFFELBR monitors the potential influence of WVDP drainage into Cattaraugus Creek directly downstream of the Cattaraugus Creek confluence with Buttermilk Creek.

Technetium-99 analysis was added on a quarterly basis at the beginning of the 2nd quarter of 2003 .

n Sampling locations are shown on Figure A-3 (p. A-3).

$B-38$ 
2003 Monitoring Program

Environmental Surveillance

Off-Site Drinking Water

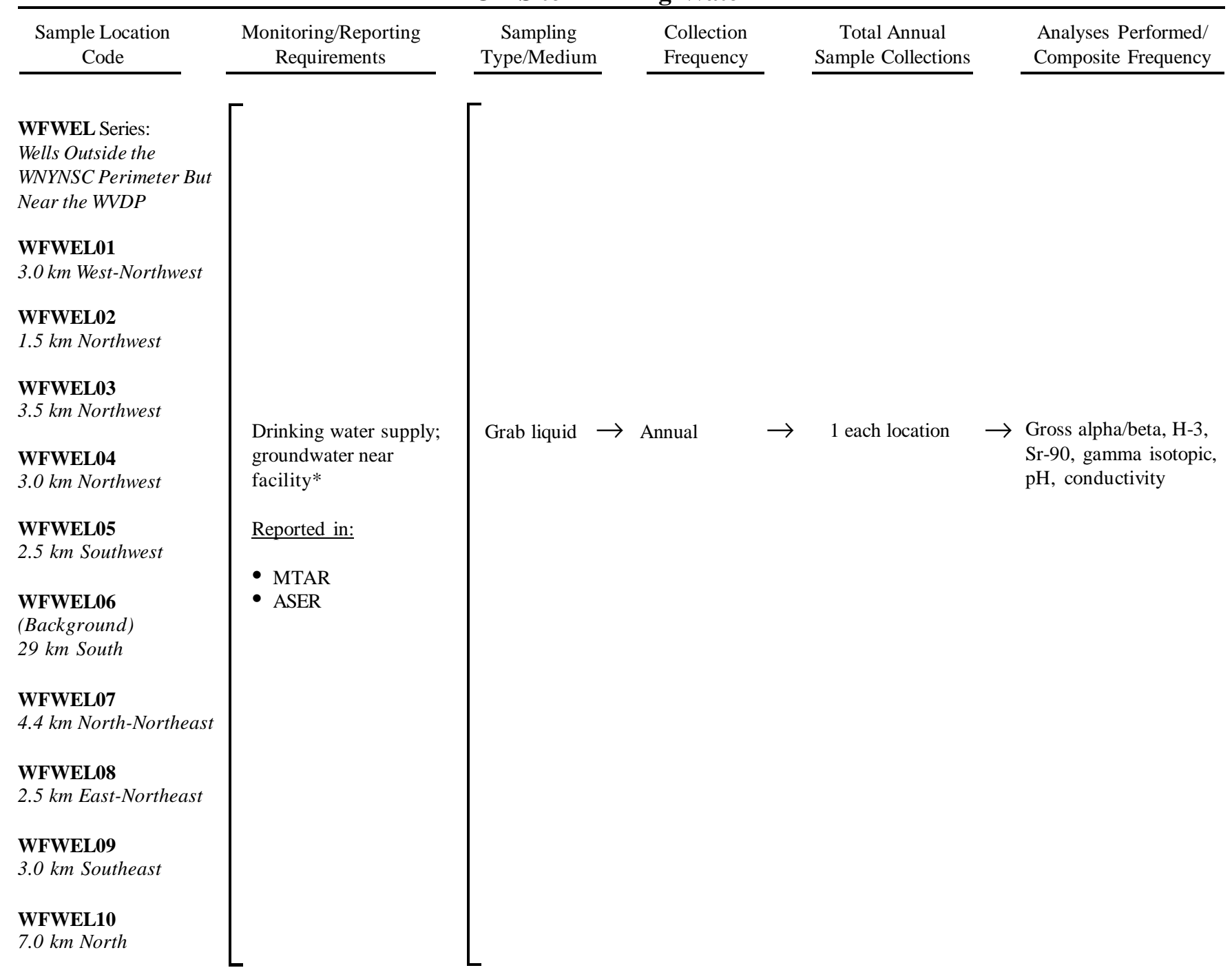

* No drinking water wells are located in hydrogeological units affected by site activity.

B - 39 


\section{Sampling Rationale}

Off-Site DOE/EH-0173T, 5.10.1.2

Drinking Water

WFWEL Series

Eight of the ten listed off-site private residential drinking water wells represent the nearest unrestricted uses of groundwater close to the WVDP. The ninth sample (WFWEL10) is taken from a public water supply from deep wells. The tenth drinking water well, WFWEL06, is located 29 kilometers south of the Project and is considered a background drinking water source.

Strontium-90 analysis was added on an annual basis during 2003.

n Sampling locations are shown on Figures A-9, A-12, and A-13 (pp. A-9, A-12, and A-13).

$$
B-40
$$




\section{Monitoring Program}

\section{Environmental Surveillance}

\section{Off-Site Air}

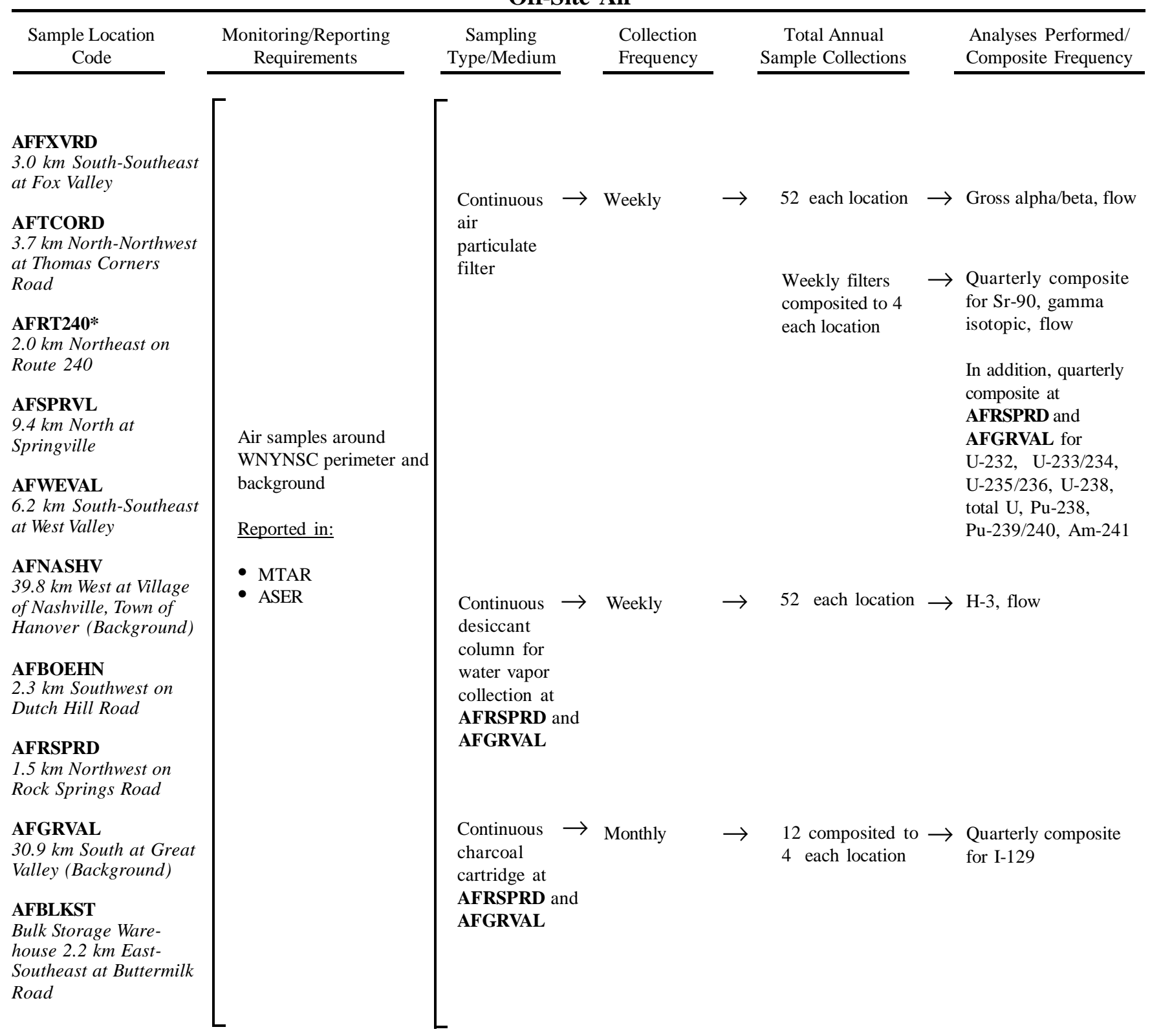

* Filter from duplicate sampler sent to NYSDOH.

B -41 


\section{Sampling Rationale}

\section{AFFXVRD \\ AFTCORD \\ AFRT240}

AFSPRVL

AFNASHV

AFRSPRD

AFBLKST

DOE/EH-0173T, 5.7.4

Air samplers put into service by NFS as part of the site's original monitoring program at perimeter locations chosen to obtain data from places most likely to provide highest concentrations. Choice of location based on meteorological data.

DOE/EH-0173T, 5.7.4; DOE/EP-0023, 4.2.3

Off-site (remote) sampler located on private property in a nearby community within 15 kilometers of the site (north).

DOE/EH-0173T, 5.7.4; DOE/EP-0023, 4.2.3

Off-site (remote) sampler located in a nearby community within 15 kilometers of the site (southeast).

DOE/EH-0173T, 5.7.4; DOE/EP-0023, 4.2.3

Off-site (remote) sampler considered representative of natural background radiation. Located 39.8 kilometers west of the site (upwind) on privately owned property.

Sampling at this location was discontinued after the 1st quarter of 2003 (March).

DOE/EH-0173T, 5.7.4; DOE/EP-0023, 4.2.3

Perimeter location chosen to obtain data from the place most likely to provide the highest elevated release concentrations. AFBOEHN is located on NYSERDA property at the perimeter. Choice of location based on meteorological data.

DOE/EH-0173T, 5.7.4

Perimeter location chosen to obtain data from the place most likely to provide the highest ground-level release concentrations. AFRSPRD is on WNYNSC property outside the main plant operations fenceline. H-3 and I-129 are sampled here because the sampling trains were easy to incorporate and the location was most likely to receive effluent releases. Choice of location based on meteorological data.

\section{AFGRVAL DOE/EH-0173T, 5.7.4; DOE/EP-0023, 4.2.3}

Off-site (remote) sampler considered representative of natural background radiation. Located on privately owned property 30.9 kilometers south of the site (typically upwind). H-3 and I-129 sampled here also.

DOE/EH-0173T, 5.7.4

Off-site monitoring of bulk storage warehouse, near the site perimeter.

n Sampling locations are shown on Figures A-5, A-12, and A-13 (pp. A-5, A-12, and A-13).

$$
B-42
$$


2003 Monitoring Program

Environmental Surveillance

Fallout, Sediment, and Soil

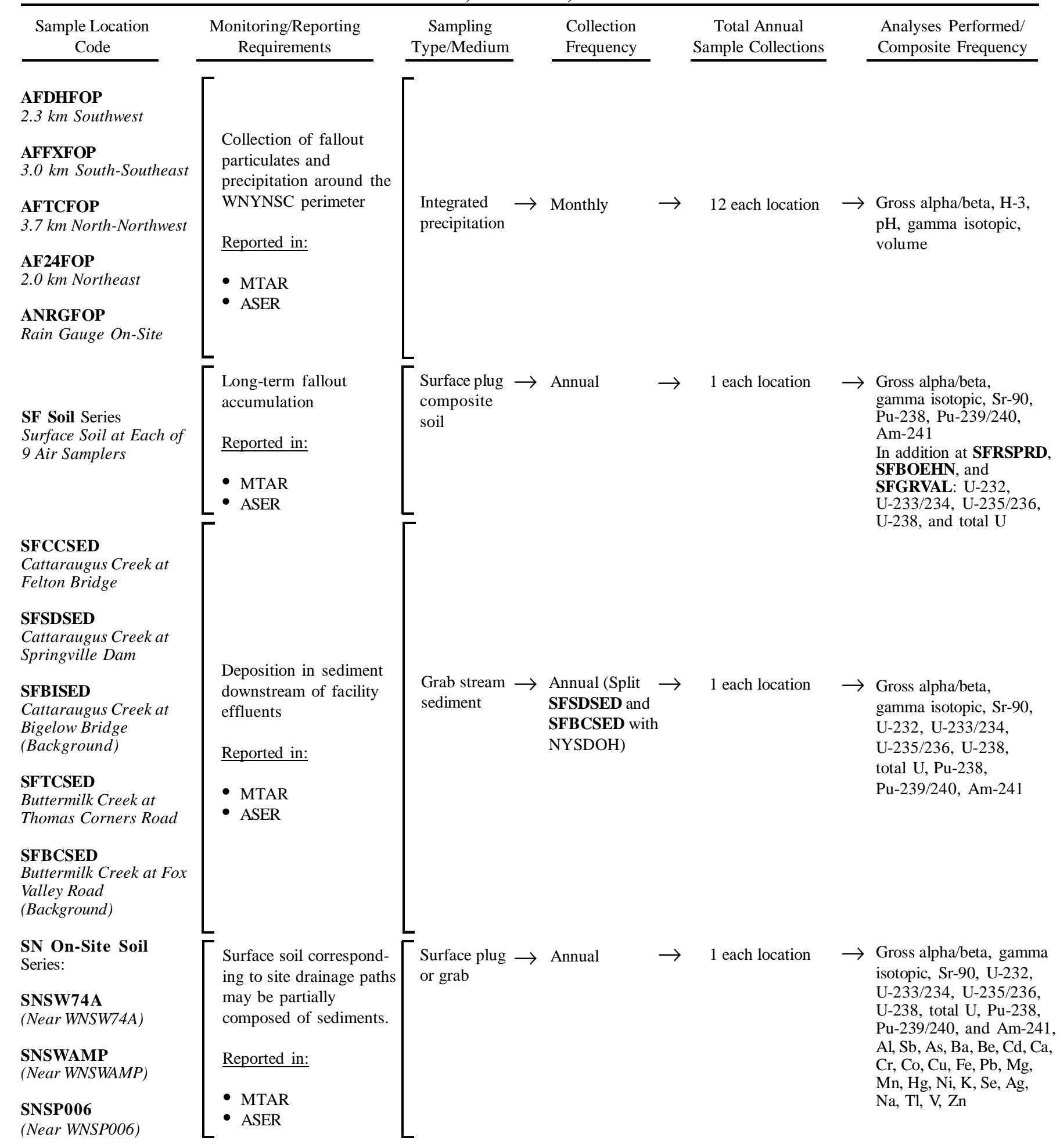

$$
\text { B - } 43
$$




\section{Sampling Rationale}

\section{AFDHFOP \\ AFFXFOP \\ AFTCFOP \\ AF 24FOP}

ANRGFOP

SF Soil Series

SFSDSED

SFTCSED

SN Soil Series
SFBISED

SFBCSED

DOE/EP-0023, 4.7

Collection of fallout particles and precipitation around the site perimeter at established air sampling locations: AFDHFOP (Dutch Hill at Boehn Road), AFFXFOP (Fox Valley Road), AFTCFOP (Thomas Corners), AF24FOP (Route 240). Indicates short-term effects.

Fallout particles and precipitation collected on-site by the Environmental Laboratory at the rain gauge. Indicates short-term effects.

DOE/EH-0173T, 5.9.1

Off-site soils collected at air sampling locations: SFWEVAL (West Valley), SFFXVRD (Fox Valley Road), SFSPRVL (Springville), SFTCORD (Thomas Corners), SFRT240 (Route 240), SFBOEHN (Boehn Road-Dutch Hill), SFGRVAL (Great Valley), SFRSPRD (Rock Springs Road), and SFBLKST (bulk storage warehouse): Collection of long-term fallout data at established air sampler locations via soil sampling.

DOE/EH-0173T, 5.12.1

Sediment deposition in Cattaraugus Creek at Felton Bridge. Location is the first point of public access to Cattaraugus Creek downstream of its confluence with Buttermilk Creek.

DOE/EH-0173T, 5.12.1

Sediment deposition in Cattaraugus Creek at Springville Dam. Reservoir provides ideal settling and collection location for sediments downstream of the Buttermilk Creek confluence with Cattaraugus Creek. Located downstream of SFCCSED.

DOE/EH-0173T, 5.12.1

Sediment deposition in Cattaraugus Creek at Bigelow Bridge. Location is upstream of the Buttermilk Creek confluence with Cattaraugus Creek and serves as the Cattaraugus Creek background location.

DOE/EH-0173T, 5.12.1

Sediment deposition in Buttermilk Creek at Thomas Corners immediately downstream of all facility liquid effluents.

DOE/EH-0173T, 5.12.1

Sediment deposition in Buttermilk Creek upsteam of facility effluents (background).

DOE/EH-0173T, 5.9.1.

On-site soil. (Samples may be partially composed of sediments.) SNSW74A (surface soil near WNSW74A), SNSWAMP (surface soil near WNSWAMP), and SNSP006 (surface soil near WNSP006): Locations to be specifically defined by geographic coordinates. Correspond to site drainage pattern flows (i.e., most likely area of radiological deposition/accumulation).

n Sampling locations are shown on Figures A-2 through A-5, A-12, and A-13 (pp. A-2 through A-5, A-12, and A-13). 


\section{Monitoring Program}

\section{Environmental Surveillance}

\section{Off-Site Biological}

\begin{tabular}{|c|c|c|c|c|c|c|c|c|}
\hline $\begin{array}{l}\text { Sample Location } \\
\text { Code }\end{array}$ & $\begin{array}{l}\text { Monitoring/Reporting } \\
\text { Requirements }\end{array}$ & $\begin{array}{c}\text { Sampling } \\
\text { Type/Medium }\end{array}$ & & $\begin{array}{l}\text { Collection } \\
\text { Frequency }\end{array}$ & & $\begin{array}{c}\text { Total Annual } \\
\text { Sample Collections }\end{array}$ & & $\begin{array}{l}\text { Analyses Performed/ } \\
\text { Composite Frequency }\end{array}$ \\
\hline $\begin{array}{l}\text { BFFCATC } \\
\text { Fish From Cattaraugus } \\
\text { Creek Downstream of } \\
\text { Its Confluence With } \\
\text { Buttermilk Creek } \\
\text { BFFCATD } \\
\text { Fish From Cattaraugus } \\
\text { Creek Downstream of the } \\
\text { Springville Dam }\end{array}$ & $\begin{array}{l}\text { Fish in waters up- and } \\
\text { downstream of facility } \\
\text { effluents } \\
\text { Reported in: }\end{array}$ & $\begin{array}{l}\text { Individual } \\
\text { collection, } \\
\text { biological }\end{array}$ & $\rightarrow$ & $\begin{array}{l}\text { Semiannual } \\
\text { (samples at } \\
\text { BFFCATC } \\
\text { and } \\
\text { BFFCTRL } \\
\text { shared with } \\
\text { NYSDOH) }\end{array}$ & $\rightarrow$ & $\begin{array}{l}10 \text { fish each } \\
\text { location }\end{array}$ & $\rightarrow$ & $\begin{array}{l}\text { Gamma isotopic and } \\
\text { Sr-90 in edible } \\
\text { portions of each } \\
\text { individual fish, \% } \\
\text { moisture }\end{array}$ \\
\hline $\begin{array}{l}\text { BFFCTRL } \\
\text { Control Fish Sample } \\
\text { From Nearby Stream } \\
\text { Not Affected by the } \\
\text { WVDP ( } 7 \text { km or More } \\
\text { Upstream of Site } \\
\text { Effluent Point; } \\
\text { Background) }\end{array}$ & $\begin{array}{l}\text { - } \text { MTAR } \\
\text { - } \text { ASER }\end{array}$ & & & $\begin{array}{l}\text { Annual } \\
\text { (BFFCATD } \\
\text { only) }\end{array}$ & $\rightarrow$ & 10 fish & $\rightarrow$ & $\begin{array}{l}\text { Gamma isotopic and } \\
\text { Sr-90 in edible } \\
\text { portions of each } \\
\text { individual fish, \% } \\
\text { moisture }\end{array}$ \\
\hline $\begin{array}{l}\text { BFMREED } \\
\text { Dairy Farm } \\
\text { 3.8 km North-Northwest } \\
\text { BFMCTLS } \\
\text { Control Location } 25 \mathrm{~km} \\
\text { South (Background) } \\
\text { BFMCTLN } \\
\text { Control Location } 30 \mathrm{~km} \\
\text { North (Background) }\end{array}$ & $\begin{array}{l}\text { Milk from animals } \\
\text { foraging at locations } \\
\text { near the facility } \\
\text { perimeter and at } \\
\text { background sites } \\
\text { Reported in: } \\
\text { - MTAR } \\
\text { - ASER }\end{array}$ & $\begin{array}{l}\text { Grab } \\
\text { biological }\end{array}$ & $\rightarrow$ & $\begin{array}{l}\text { Monthly } \\
\text { (samples at } \\
\text { BFMREED } \\
\text { shared with } \\
\text { NYSDOH) }\end{array}$ & $\rightarrow$ & $\begin{array}{l}12 \text { monthly } \\
\text { samples } \\
\text { composited to } \\
4 \text { each location }\end{array}$ & $\rightarrow$ & $\begin{array}{l}\text { Quarterly composite } \\
\text { for gamma isotopic, } \\
\mathrm{H}-3 \text {, Sr-90, and I-129 }\end{array}$ \\
\hline $\begin{array}{l}\text { BFMWIDR } \\
\text { Dairy Farm } \\
3.0 \mathrm{~km} \text { Southeast } \\
\text { BFMSCHT } \\
\text { Dairy Farm } \\
4.8 \mathrm{~km} \text { South }\end{array}$ & $\begin{array}{l}\text { Milk from animals } \\
\text { foraging near the site } \\
\text { perimeter } \\
\text { Reported in: } \\
\text { - MTAR } \\
\text { - ASER }\end{array}$ & $\begin{array}{l}\text { Grab } \\
\text { biological }\end{array}$ & $\rightarrow$ & Annual & $\rightarrow$ & $\begin{array}{l}1 \text { each } \\
\text { location }\end{array}$ & $\rightarrow$ & $\begin{array}{l}\text { Gamma isotopic, } \mathrm{H}-3 \text {, } \\
\mathrm{Sr}-90 \text {, and I-129 }\end{array}$ \\
\hline
\end{tabular}

$$
B-45
$$




\section{Sampling Rationale}

$\begin{array}{ll}\begin{array}{l}\text { BFFCATC } \\ \text { BFTCATD }\end{array} & \text { DOE/EH-0173T, 5.11.1.1 } \\ & \begin{array}{l}\text { Radioactivity may enter a food chain in which fish are a major component and are consumed by the local } \\ \text { population. }\end{array} \\ \text { BFFCTRL } & \begin{array}{l}\text { Control fish sample; provides background data for comparison with data from fish caught downstream of facility } \\ \text { effluents. }\end{array} \\ \text { BFMREED } & \text { DOE/EH-0173T, 5.8.2.1 } \\ \text { BFMCTLS } & \text { Milk is consumed by all age groups and is frequently the most important food that could contribute to the } \\ \text { BFMCTLN } & \text { radiation dose. Dairy animals pastured near the site allow adequate monitoring. Control milk samples are collected } \\ \text { BFMSCHT } & \text { far from the site to provide background data for comparison with data from near-site milk samples. Sampling at } \\ \text { the northern background location (BFMCTLN) was discontinued at the end of the 1st quarter of } 2003, \text { in March. }\end{array}$

$\mathrm{n}$ Sampling locations are shown on Figures A-9, A-12, and A-13 (pp. A-9, A-12, and A-13).

$B-46$ 


\section{Monitoring Program \\ Environmental Surveillance}

Off-Site Biological

\begin{tabular}{|c|c|c|c|c|c|c|c|c|}
\hline $\begin{array}{l}\text { Sample Location } \\
\text { Code }\end{array}$ & $\begin{array}{l}\text { Monitoring/Reporting } \\
\text { Requirements }\end{array}$ & $\begin{array}{c}\text { Sampling } \\
\text { Type/Medium }\end{array}$ & & $\begin{array}{l}\text { Collection } \\
\text { Frequency }\end{array}$ & & $\begin{array}{c}\text { Total Annual } \\
\text { Sample Collections }\end{array}$ & & $\begin{array}{l}\text { Analyses Performed/ } \\
\text { Composite Frequency }\end{array}$ \\
\hline $\begin{array}{l}\text { BFVNEAR* } \\
\text { Nearby Locations } \\
\text { BFVCTRL* } \\
\text { Remote Locations (16 } \\
\text { km or More From } \\
\text { Facility; Background) }\end{array}$ & $\begin{array}{l}\text { Fruit and vegetables } \\
\text { grown near facility } \\
\text { perimeter, downwind if } \\
\text { possible, and at back- } \\
\text { ground locations } \\
\text { Reported in: } \\
\text { - MTAR } \\
\text { - ASER }\end{array}$ & $\begin{array}{l}\text { Grab } \\
\text { biological } \\
\text { (fruits and } \\
\text { vegetables) }\end{array}$ & $\rightarrow$ & $\begin{array}{l}\text { Annual } \\
\text { (at harvest) }\end{array}$ & $\rightarrow$ & $\begin{array}{l}3 \text { each (split with } \\
\text { NYSDOH) }\end{array}$ & $\rightarrow$ & $\begin{array}{l}\text { Gamma isotopic and } \\
\text { Sr-90 analysis of } \\
\text { edible portions, H-3 in } \\
\text { free moisture, } \% \\
\text { moisture }\end{array}$ \\
\hline $\begin{array}{l}\text { BFBNEAR } \\
\text { Beef Animal From } \\
\text { Nearby Farm in } \\
\text { Downwind Direction } \\
\text { BFBCTRL } \\
\text { Beef Animal From } \\
\text { Control Location } 16 \mathrm{~km} \\
\text { or More From Facility } \\
\text { (Background) }\end{array}$ & $\begin{array}{l}\text { Meat (beef foraging } \\
\text { near facility perim- } \\
\text { eter, downwind if } \\
\text { possible, and a } \\
\text { background location) } \\
\text { Reported in: } \\
\text { - MTAR } \\
\text { - ASER }\end{array}$ & $\begin{array}{l}\text { Grab } \\
\text { biological }\end{array}$ & $\rightarrow$ & Semiannual & $\rightarrow$ & 2 each location & $\rightarrow$ & $\begin{array}{l}\text { Gamma isotopic and } \\
\text { Sr-90 analysis of } \\
\text { meat, } \mathrm{H}-3 \text { in free } \\
\text { moisture, \% moisture }\end{array}$ \\
\hline $\begin{array}{l}\text { BFDNEAR } \\
\text { Deer in Vicinity of the } \\
\text { Site }\end{array}$ & $\begin{array}{l}\text { Venison (deer foraging } \\
\text { near facility perimeter } \\
\text { and at background } \\
\text { locations) }\end{array}$ & $\begin{array}{l}\text { Individual } \\
\text { collection, } \\
\text { biological }\end{array}$ & $\rightarrow$ & $\begin{array}{l}\text { Annual, during } \\
\text { hunting season } \\
\text { (BFDNEAR } \\
\text { sample split } \\
\text { with NYSDOH) }\end{array}$ & $\rightarrow$ & 3 & $\rightarrow$ & $\begin{array}{l}\text { Gamma isotopic and } \\
\text { Sr-90 analysis of } \\
\text { meat, } \mathrm{H}-3 \text { in free } \\
\text { moisture, } \% \text { moisture }\end{array}$ \\
\hline $\begin{array}{l}\text { BFDCTRL } \\
\text { Control Deer } 16 \text { km or } \\
\text { More From the Facility } \\
\text { (Background) }\end{array}$ & $\begin{array}{l}\text { Reported in: } \\
\text { - MTAR } \\
\text { - ASER }\end{array}$ & & & $\begin{array}{l}\text { During year as } \\
\text { available } \\
\text { (BFDCTRL } \\
\text { sample split } \\
\text { with NYSDOH) }\end{array}$ & $\rightarrow$ & 3 & $\rightarrow$ & $\begin{array}{l}\text { Gamma isotopic and } \\
\text { Sr-90 analysis of } \\
\text { meat, H-3 in free } \\
\text { moisture, \% moisture }\end{array}$ \\
\hline
\end{tabular}

\footnotetext{
* Near-site and control corn, apple, and bean samples are identified specifically as follows: corn = BFVNEAC and BFVCTRC; apples =
} BFVNEAAF and BFVCTRA; beans = BFVNEAB and BFVCTRB.

$$
B-47
$$




\section{Sampling Rationale}

\section{BFVNEAR DOE/EH-0173T, 5.8.2.2}

Fruits and vegetables (corn, apples, and beans or leafy vegetables, if available) collected from areas near the site. These samples are collected, if possible, from areas near the site predicted to have worst-case downwind concentrations of radionuclides in air and soil. Sample analysis reflects steady state/chronic uptake or contamination of foodstuffs as a result of site activities. Possible pathway directly to humans or indirectly through animals.

BFVCTRL

DOE/EH-0173T, 5.8.2.2

Fruits and vegetables collected from an area remote from the site. Background fruits and vegetables collected for comparison with near-site samples. Collected in area(s) of no possible site effects.

BFBNEAR

BFBCTRL

BFDNEAR

BFDCTRL
DOE/EH-0173T, 5.8.2.3

Beef collected from animals raised near the site and foraging downwind of the site in areas of maximum probable effects. Following the rationale for vegetable matter collected near the site (BFVNEAR), edible flesh portion of beef animals is analyzed to determine possible radionuclide content passable directly to humans.

DOE/EH-0173T, 5.8.2.3

Beef collected from animals raised far from the site. Background beef collected for comparison with near-site samples. Collected in area(s) of no possible site effects.

\section{DOE/EH-0173T, 5.8.3}

Venison from near-site deer. Samples are taken from deer killed in collisions with vehicles. Sample rationale is similar to BFBNEAR.

\section{DOE/EH-0173T, 5.8.3}

Venison from deer living far from the site. Background deer meat collected for comparison with near-site samples. Collected in area(s) of no possible site effects.

$\mathrm{n}$ Sampling locations are shown on Figures A-9, A-12, and A-13 (pp. A-9, A-12, and A-13). 
2003 Monitoring Program

Environmental Surveillance

Off-Site Direct Radiation

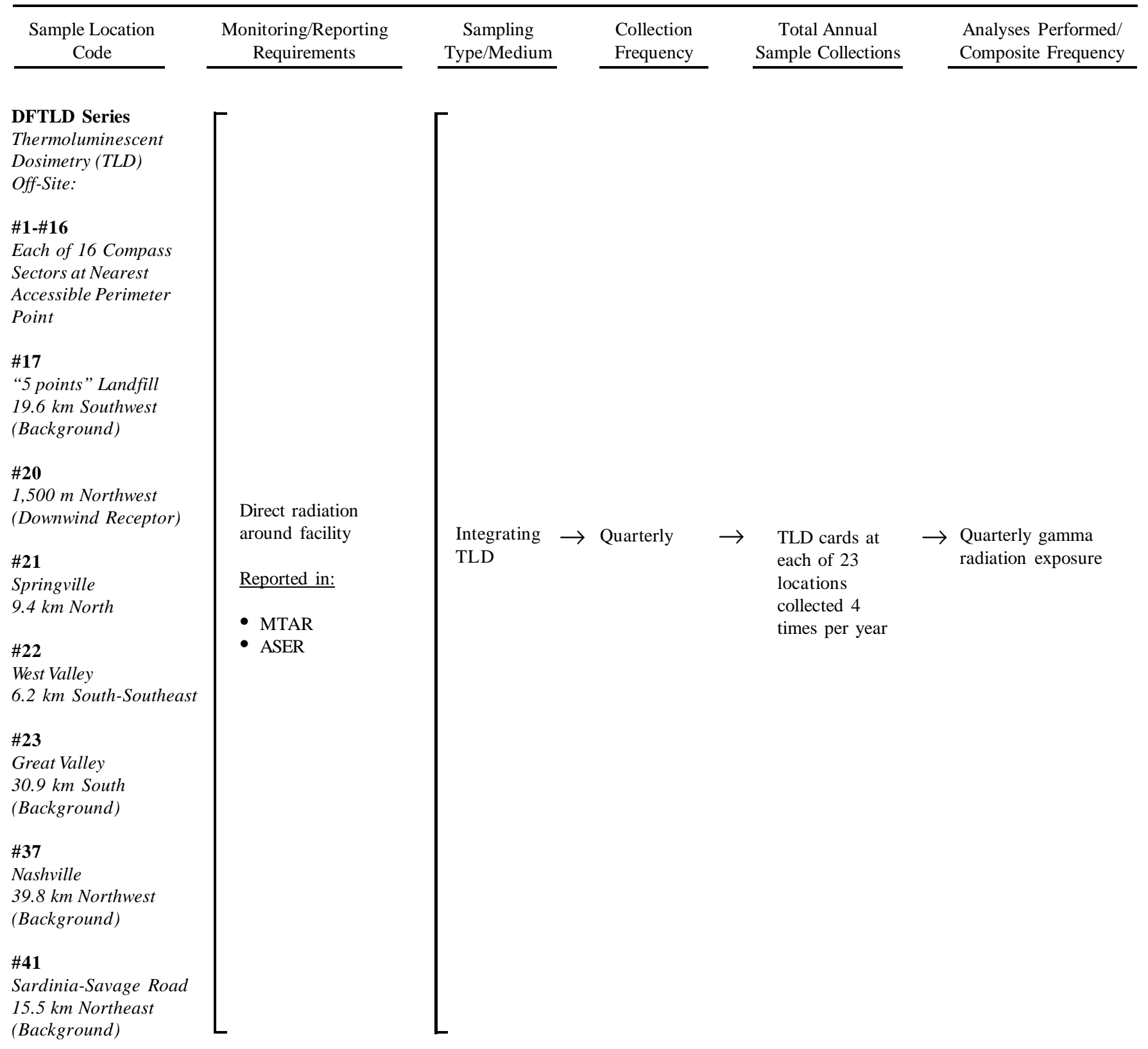

$B-49$ 


\section{Sampling Rationale}

Direct Radiation DOE/EH-0173T, 5.5; DOE/EP-0023, 4.6.3

Off-Site

TLDs offer continuous integrated environmental gamma-ray monitoring and have been deployed systematically about the site. Off-site TLDs are used to verify that site activities have not adversely affected the surrounding environs.

An annual high-pressure ion chamber (HPIC) gamma radiation measurement was completed at all locations in order to confirm TLD measurements.

Sampling at redundant background locations \#17, \#37, and \#41 was discontinued in March 2003.

n Sampling locations are shown on Figures A-11 through A-13 (pp. A-11 through A-13).

$$
B-50
$$




\section{Monitoring Program}

Environmental Surveillance

On-Site Direct Radiation

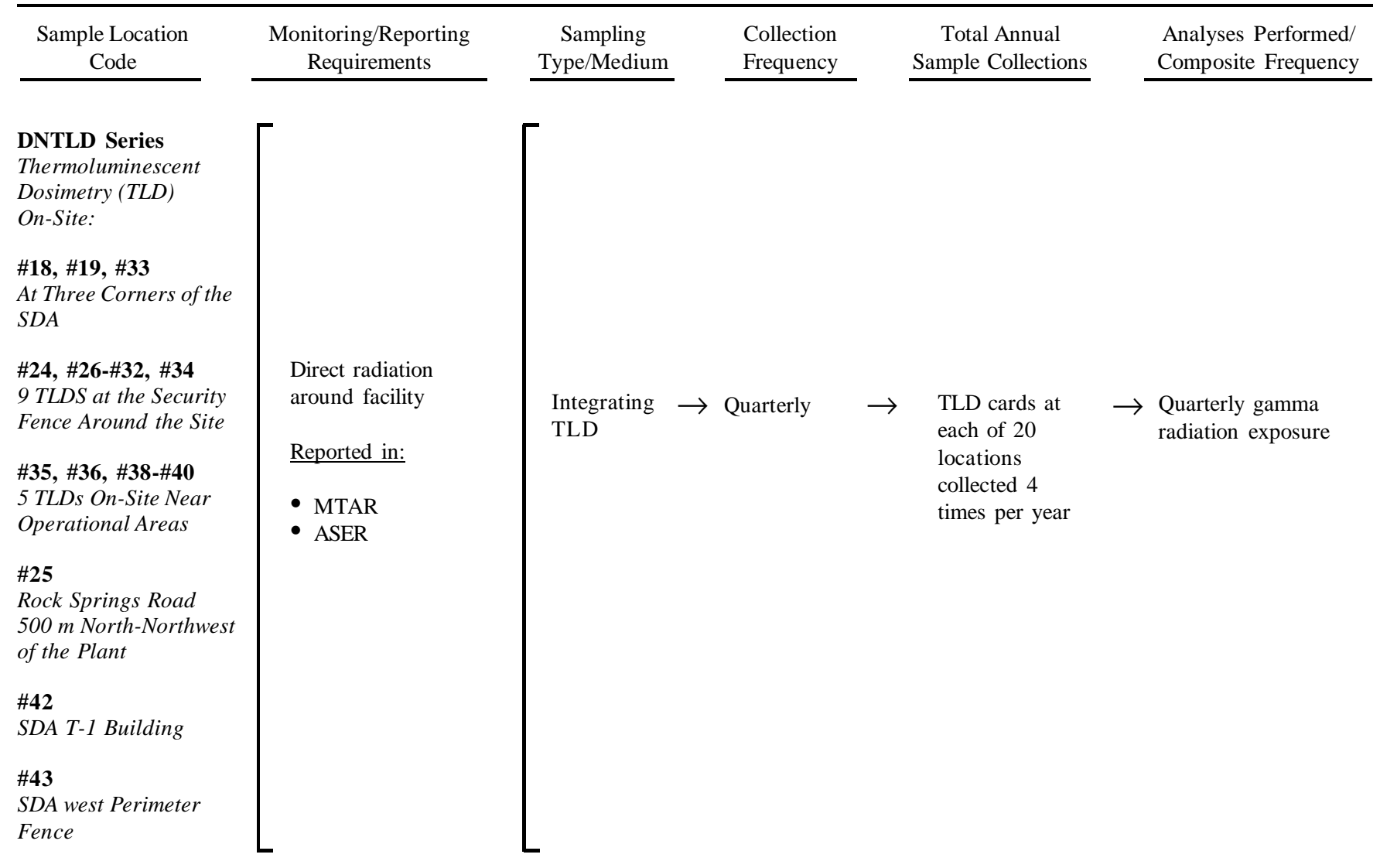

$B-51$ 


\section{Sampling Rationale}

\section{Direct Radiation DOE/EH-0173T, 5.4 and 5.5 \\ On-Site}

On-site TLDs monitor waste management units and verify that the potential dose rate to the general public (i.e., at Rock Springs Road) is below $100 \mathrm{mrem} /$ year $(1 \mathrm{mSv} / \mathrm{year})$ from site activities.

An annual high-pressure ion chamber (HPIC) gamma radiation measurement is completed at all locations in order to confirm TLD measurements.

Potential TLD sampling locations are continually evaluated with respect to site activities.

n Sampling locations are shown on Figure A-10 (p. A-10).

$B-52$ 
This page intentionally left blank

$$
\text { B - } 53
$$




\section{Appendix C-1 \\ Summary of Water Limits, Guidelines, and Standards}

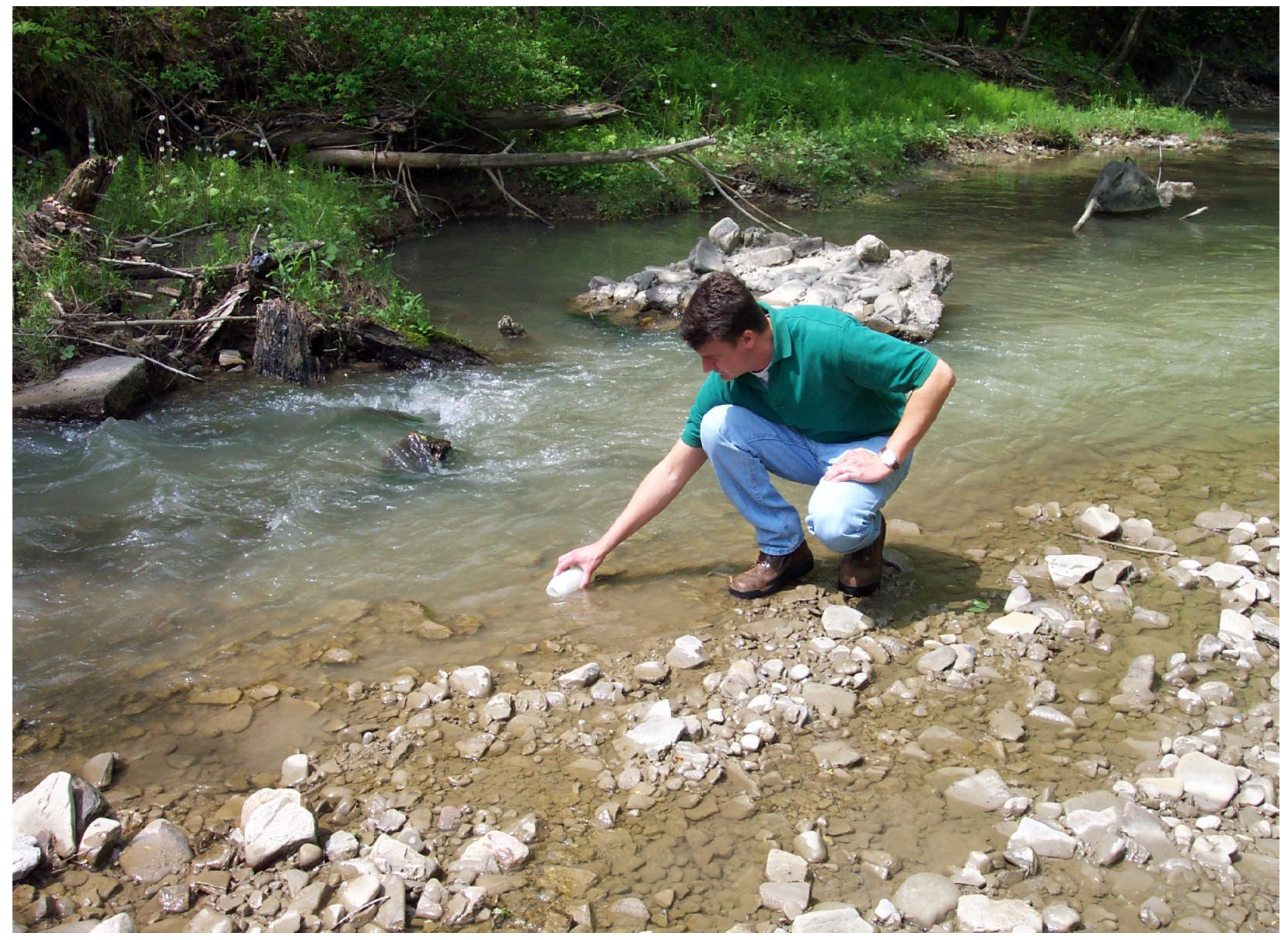

Collecting a Sample at a WVDP Stream Sampling Location

$C-1$ 
This page intentionally left blank

$C-2$ 


\section{Table C-1A \\ West Valley Demonstration Project State Pollutant Discharge Elimination System (SPDES) Sampling Program}

Outfall

001 (Process and Storm Flow Wastewater)

\section{Para}

Aluminum, total

Ammonia $\left(\mathrm{NH}_{3}\right)$

Arsenic, dissolved

$\mathrm{BOD}_{5}$

Iron, total

Zinc, total recoverable

Suspended solids

Cyanide, amenable to chlorination

Settleable solids

$\mathrm{pH}$ (range)

Oil and grease

Sulfate (as S)

Sulfide, dissolved

Manganese, total

Nitrate (as N)

Nitrite (as N)

Chromium, total recoverable

Chromium, hexavalent, total recoverable

Cadmium, total recoverable

Copper, total recoverable

Copper, dissolved

Lead, total recoverable

Nickel, total recoverable

Dichlorodifluoromethane

Trichlorofluoromethane

3,3-dichlorobenzidine

Tributyl phosphate

Vanadium, total recoverable

Cobalt, total recoverable

Selenium, total recoverable

Hexachlorobenzene

Alpha - BHC

Heptachlor

Surfactants (as LAS)

Xylene

2-butanone

Total dissolved solids

Mercury, total
Daily Maximum Limit*

Monitor

$14.0 \mathrm{mg} / \mathrm{L}$

Monitor

$0.15 \mathrm{mg} / \mathrm{L}$

$10.0 \mathrm{mg} / \mathrm{L}$

Monitor

$0.48 \mathrm{mg} / \mathrm{L}$

$45.0 \mathrm{mg} / \mathrm{L}$

$0.022 \mathrm{mg} / \mathrm{L}$

$0.30 \mathrm{~mL} / \mathrm{L}$

6.5-8.5

$15.0 \mathrm{mg} / \mathrm{L}$

Monitor

$0.4 \mathrm{mg} / \mathrm{L}$

$2.0 \mathrm{mg} / \mathrm{L}$

Monitor

$0.1 \mathrm{mg} / \mathrm{L}$

$0.3 \mathrm{mg} / \mathrm{L}$

$0.011 \mathrm{mg} / \mathrm{L}$

$0.002 \mathrm{mg} / \mathrm{L}$

$0.030 \mathrm{mg} / \mathrm{L}$

Monitor

$0.006 \mathrm{mg} / \mathrm{L}$

$0.14 \mathrm{mg} / \mathrm{L}$

$0.01 \mathrm{mg} / \mathrm{L}$

$0.01 \mathrm{mg} / \mathrm{L}$

$0.01 \mathrm{mg} / \mathrm{L}$

$32 \mathrm{mg} / \mathrm{L}$

$0.014 \mathrm{mg} / \mathrm{L}$

$0.005 \mathrm{mg} / \mathrm{L}$

$0.004 \mathrm{mg} / \mathrm{L}$

$0.02 \mathrm{mg} / \mathrm{L}$

$0.00001 \mathrm{mg} / \mathrm{L}$

$0.00001 \mathrm{mg} / \mathrm{L}$

$0.4 \mathrm{mg} / \mathrm{L}$

$0.05 \mathrm{mg} / \mathrm{L}$

$0.5 \mathrm{mg} / \mathrm{L}$

Monitor

$0.0002 \mathrm{mg} / \mathrm{L}$
Sample Frequency

2 per discharge

2 per discharge

2 per discharge

2 per discharge

2 per discharge

2 per discharge

2 per discharge

2 per discharge

2 per discharge

2 per discharge

2 per discharge

2 per discharge

2 per discharge

2 per discharge

2 per discharge

2 per discharge

2 per discharge

2 per discharge

2 per discharge

2 per discharge

2 per discharge

2 per discharge

2 per discharge

2 per discharge

annual

annual

2 per discharge

2 per discharge

2 per discharge

2 per discharge

2 per discharge

2 per discharge

2 per discharge

2 per discharge

2 per discharge

2 per discharge

2 per discharge

2 per discharge

2 per discharge

\footnotetext{
* Daily average limitations are also identified in the permit but require only monitoring for all parameters except total aluminum (daily average limit $-7.0 \mathrm{mg} / \mathrm{L}$ ); suspended solids (daily average limit - $30.0 \mathrm{mg} / \mathrm{L}$ ); $B O D_{5}$ for the sum of outfalls 001, 007, and 008 (daily average limit $-5.0 \mathrm{mg} / \mathrm{L}$ ); and ammonia for the sum of outfalls 001 and 007 (daily average limit $-1.49 \mathrm{mg} / \mathrm{L}$ ).
}

$$
\text { C - } 3
$$




\section{Table C-1A (concluded) \\ West Valley Demonstration Project State Pollutant Discharge Elimination System (SPDES) Sampling Program}

\begin{tabular}{|c|c|c|c|}
\hline Outfall & Parameter & Daily Maximum Limit* & Sample Frequency \\
\hline 001 (concluded) & $\begin{array}{l}\text { Barium } \\
\text { Antimony } \\
\text { Chloroform } \\
\text { Bis(2-ethylhexyl)phthalate } \\
\text { 4-Dodecene } \\
\text { Titanium } \\
\text { Bromide } \\
\text { Boron }\end{array}$ & $\begin{array}{l}0.5 \mathrm{mg} / \mathrm{L} \\
1.0 \mathrm{mg} / \mathrm{L} \\
0.3 \mathrm{mg} / \mathrm{L} \\
1.6 \mathrm{mg} / \mathrm{L} \\
0.6 \mathrm{mg} / \mathrm{L} \\
0.65 \mathrm{mg} / \mathrm{L} \\
5.0 \mathrm{mg} / \mathrm{L} \\
2.0 \mathrm{mg} / \mathrm{L}\end{array}$ & $\begin{array}{l}\text { annual } \\
\text { annual } \\
\text { annual } \\
\text { semiannual } \\
\text { semiannual } \\
\text { semiannual } \\
\text { quarterly } \\
\text { quarterly }\end{array}$ \\
\hline $\begin{array}{l}\text { 01B (Internal Process } \\
\text { Monitoring Point) }\end{array}$ & $\begin{array}{l}\text { Flow } \\
\text { Mercury, total }\end{array}$ & $\begin{array}{l}\text { Monitor } \\
10.0 \mu \mathrm{g} / \mathrm{L}\end{array}$ & $\begin{array}{l}\text { weekly } \\
2 \text { per month }\end{array}$ \\
\hline $\begin{array}{l}007 \text { (Sanitary and } \\
\text { Utility Wastewater) }\end{array}$ & $\begin{array}{l}\text { Flow } \\
\text { Ammonia }\left(\text { as NH}_{3}\right) \\
\mathrm{BOD}_{5} \\
\text { Iron, total } \\
\text { Solids, suspended } \\
\text { Solids, settleable } \\
\text { pH(range) } \\
\text { Nitrite (as N) } \\
\text { Oil and grease } \\
\text { Chlorine, total residual } \\
\text { Chloroform }\end{array}$ & $\begin{array}{l}\text { Monitor } \\
\text { Monitor } \\
10 \mathrm{mg} / \mathrm{L} \\
\text { Monitor } \\
45.0 \mathrm{mg} / \mathrm{L} \\
0.3 \mathrm{~mL} / \mathrm{L} \\
6.5-8.5 \\
0.1 \mathrm{mg} / \mathrm{L} \\
15 \mathrm{mg} / \mathrm{L} \\
0.1 \mathrm{mg} / \mathrm{L} \\
0.20 \mathrm{mg} / \mathrm{L}\end{array}$ & $\begin{array}{l}3 \text { per month } \\
3 \text { per month } \\
3 \text { per month } \\
3 \text { per month } \\
3 \text { per month } \\
\text { weekly } \\
\text { weekly } \\
3 \text { per month } \\
3 \text { per month } \\
\text { weekly } \\
\text { annual }\end{array}$ \\
\hline $\begin{array}{l}\text { 008 (French Drain } \\
\text { Wastewater) }\end{array}$ & $\begin{array}{l}\text { Flow } \\
\text { BOD }_{5} \\
\text { Iron, total } \\
\text { pH(range) } \\
\text { Cadmium, total recoverable } \\
\text { Lead, total recoverable } \\
\text { Silver, total } \\
\text { Zinc, total } \\
\text { Arsenic } \\
\text { Chromium }\end{array}$ & $\begin{array}{l}\text { Monitor } \\
5.0 \mathrm{mg} / \mathrm{L} \\
\text { Monitor } \\
6.5-8.5 \\
0.002 \mathrm{mg} / \mathrm{L} \\
0.006 \mathrm{mg} / \mathrm{L} \\
0.008 \mathrm{mg} / \mathrm{L} \\
0.100 \mathrm{mg} / \mathrm{L} \\
0.17 \mathrm{mg} / \mathrm{L} \\
0.13 \mathrm{mg} / \mathrm{L}\end{array}$ & $\begin{array}{l}3 \text { per month } \\
3 \text { per month } \\
3 \text { per month } \\
3 \text { per month } \\
3 \text { per month } \\
3 \text { per month } \\
\text { annual } \\
\text { annual } \\
\text { annual } \\
\text { annual }\end{array}$ \\
\hline $\begin{array}{l}\text { Sum of Outfalls 001, } \\
007 \text {, and } 008\end{array}$ & $\begin{array}{l}\text { Iron, total } \\
\text { BOD }_{5}\end{array}$ & $\begin{array}{l}0.30 \mathrm{mg} / \mathrm{L} \\
\text { Monitor }\end{array}$ & $\begin{array}{l}3 \text { per month } \\
3 \text { per month }\end{array}$ \\
\hline $\begin{array}{l}\text { Sum of Outfalls } 001 \\
\text { and } 007\end{array}$ & Ammonia $\left(\right.$ as $\mathrm{NH}_{3}$ ) & $2.1 \mathrm{mg} / \mathrm{L}$ & 3 per month \\
\hline $\begin{array}{l}\text { Pseudo-monitoring } \\
\text { point (116) }\end{array}$ & Solids, total dissolved & $500 \mathrm{mg} / \mathrm{L}$ & 2 per discharge \\
\hline
\end{tabular}

\footnotetext{
* Daily average limitations are also identified in the permit but require only monitoring for all parameters except total aluminum (daily average limit - $7.0 \mathrm{mg} / \mathrm{L}$ ); suspended solids (daily average limit - $30.0 \mathrm{mg} / \mathrm{L}$ ); $B O D_{5}$ for the sum of outfalls 001, 007, and 008 (daily average limit $-5.0 \mathrm{mg} / \mathrm{L}$ ); and ammonia for the sum of outfalls 001 and 007 (daily average limit $-1.49 \mathrm{mg} / \mathrm{L}$ ).
}

$$
\text { C - } 4
$$


Table C-1B

New York Water Quality Standards and Guidelines ${ }^{a}$

\begin{tabular}{|c|c|c|c|c|c|c|}
\hline Parameter & Units & Class A & Class B & Class C & Class D & Class GA \\
\hline Gross Alphab & $\mathrm{pCi} / \mathrm{L}(\mu \mathrm{Ci} / \mathrm{mL})$ & $15(1.5 \mathrm{E}-08)$ & -- & -- & -- & $15(1.5 \mathrm{E}-08)$ \\
\hline Gross Beta ${ }^{c}$ & pCi/L $(\mu \mathrm{Ci} / \mathrm{mL})$ & $1,000(1 \mathrm{E}-06)$ & -- & -- & -- & $1,000(1 \mathrm{E}-06)$ \\
\hline Tritium (H-3) & $\mathrm{pCi} / \mathrm{L}(\mu \mathrm{Ci} / \mathrm{mL})$ & $20,000(2 \mathrm{E}-05)$ & -- & -- & -- & -- \\
\hline Strontium-90 & $\mathrm{pCi} / \mathrm{L}(\mu \mathrm{Ci} / \mathrm{mL})$ & $8(8 \mathrm{E}-09)$ & -- & -- & -- & -- \\
\hline Alpha BHC & $\mathrm{mg} / \mathrm{L}$ & 0.000002 & 0.000002 & 0.000002 & 0.000002 & 0.00001 \\
\hline Aluminum, Dissolved & $\mathrm{mg} / \mathrm{L}$ & 0.10 & 0.10 & 0.10 & -- & -- \\
\hline Aluminum, Total & $\mathrm{mg} / \mathrm{L}$ & -- & -- & -- & -- & -- \\
\hline Ammonia, Total as $\mathbf{N}$ & $\mathrm{mg} / \mathrm{L}$ & $0.09-2.1$ & $0.09-2.1$ & $0.09-2.1$ & $0.67-29$ & 2.0 \\
\hline Antimony, Total & $\mathrm{mg} / \mathrm{L}$ & 0.003 & -- & -- & -- & 0.003 \\
\hline Arsenic, Dissolved & $\mathrm{mg} / \mathrm{L}$ & 0.050 & 0.150 & 0.150 & 0.340 & -- \\
\hline Arsenic, Total & $\mathrm{mg} / \mathrm{L}$ & 0.050 & -- & -- & -- & 0.025 \\
\hline Barium, Total & $\mathrm{mg} / \mathrm{L}$ & 1.00 & -- & -- & -- & 1.00 \\
\hline Beryllium, Total & $\mathrm{mg} / \mathrm{L}$ & 0.003 & d & d & -- & 0.003 \\
\hline Bicarbonate Alkalinity (as $\mathrm{CaCO}_{3}$ ) & $\mathrm{mg} / \mathrm{L}$ & -- & -- & -- & -- & -- \\
\hline Boron, Total & $\mathrm{mg} / \mathrm{L}$ & 10.0 & 10.0 & 10.0 & -- & 1.00 \\
\hline Bromide & $\mathrm{mg} / \mathrm{L}$ & 2.00 & -- & -- & -- & 2.00 \\
\hline Cadmium, Dissolved $^{\mathrm{e}}$ & $\mathrm{mg} / \mathrm{L}$ & -- & -- & -- & -- & -- \\
\hline Cadmium, Total & $\mathrm{mg} / \mathrm{L}$ & 0.005 & -- & -- & -- & 0.005 \\
\hline Calcium, Total & $\mathrm{mg} / \mathrm{L}$ & -- & -- & -- & -- & -- \\
\hline Carbonate Alkalinity (as $\mathrm{CaCO}_{3}$ ) & $\mathrm{mg} / \mathrm{L}$ & -- & -- & -- & -- & -- \\
\hline Chloride & $\mathrm{mg} / \mathrm{L}$ & 250 & -- & -- & -- & 250 \\
\hline Chromium, Dissolved $^{\mathrm{e}}$ & $\mathrm{mg} / \mathrm{L}$ & -- & -- & -- & -- & -- \\
\hline Chromium, Total & $\mathrm{mg} / \mathrm{L}$ & 0.05 & -- & -- & -- & 0.05 \\
\hline Cobalt, Total $^{\text {h }}$ & $\mathrm{mg} / \mathrm{L}$ & 0.005 & 0.005 & 0.005 & 0.110 & -- \\
\hline Conductivity & $\mu \mathrm{mhos} / \mathrm{cm} @ 25^{\circ} \mathrm{C}$ & -- & -- & -- & -- & -- \\
\hline Copper, Dissolved $^{\mathrm{e}}$ & $\mathrm{mg} / \mathrm{L}$ & -- & -- & -- & -- & -- \\
\hline Copper, Total & $\mathrm{mg} / \mathrm{L}$ & 0.20 & -- & -- & -- & 0.20 \\
\hline Cyanide & $\mathrm{mg} / \mathrm{L}$ & 0.0052 & 0.0052 & 0.0052 & 0.22 & 0.200 \\
\hline Dissolved Oxygen (minimum) & $\mathrm{mg} / \mathrm{L}$ & 4.0 & 4.0 & 4.0 & 3.0 & -- \\
\hline Fluoride $^{\mathrm{e}}$ & $\mathrm{mg} / \mathrm{L}$ & -- & -- & -- & -- & 1.5 \\
\hline Hardness & $\mathrm{mg} / \mathrm{L}$ & -- & -- & -- & -- & -- \\
\hline Iron and Manganese (sum) & $\mathrm{mg} / \mathrm{L}$ & -- & -- & -- & -- & 0.500 \\
\hline
\end{tabular}

-- No applicable guideline or reference standard available

Note: All water quality and metals standards are presented in $\mathrm{mg} / \mathrm{L}(\mathrm{ppm})$ to provide consistency in comparisons.

a Source: 6 NYCRR Parts 701-704; The most stringent applicable pathway (e.g., wildlife, aquatic, human health,

etc.) values are reported.

${ }^{b}$ Gross alpha standard includes radium-226, but excludes radon and uranium; however WVDP results include

these isotopes.

${ }^{c}$ Gross beta standard excludes strontium-90 and alpha emitters, however WVDP results include these isotopes.

${ }^{d}$ Beryllium standard for classes " $B$ " and " $C$ " are based on stream hardness.

${ }^{e}$ Standards for these constituents vary according to stream location hardness values.

${ }^{f} \mathrm{pH}$ shall not be lower than 6.5 or the $\mathrm{pH}$ of natural groundwater, whichever is lower, nor shall pH be greater than 8.5 or the $\mathrm{pH}$ of the natural groundwater, whichever is greater.

${ }^{g}$ Applies to the sum of those organic substances which have individual human health water source standards listed at $0.100 \mathrm{mg} / \mathrm{L}$ or less in 6 NYCRR Part 703.5

${ }^{h}$ Standards for cobalt, thallium, and vanadium are acid-soluble. 


\section{Table C-1B (concluded) \\ New York Water Quality Standards and Guidelines ${ }^{a}$}

\begin{tabular}{|c|c|c|c|c|c|c|}
\hline Parameter & Units & Class A & Class B & Class C & Class D & Class GA \\
\hline Iron, Total & $\mathrm{mg} / \mathrm{L}$ & 0.30 & 0.30 & 0.30 & 0.30 & 0.30 \\
\hline Lead, Dissolved $^{\mathrm{e}}$ & $\mathrm{mg} / \mathrm{L}$ & -- & -- & -- & -- & -- \\
\hline Lead, Total & $\mathrm{mg} / \mathrm{L}$ & 0.050 & -- & -- & -- & 0.025 \\
\hline Magnesium, Total & $\mathrm{mg} / \mathrm{L}$ & 35.0 & -- & -- & -- & 35.0 \\
\hline Manganese, Total & $\mathrm{mg} / \mathrm{L}$ & 0.30 & -- & -- & -- & 0.30 \\
\hline Mercury, Dissolved & $\mathrm{mg} / \mathrm{L}$ & 0.0000007 & 0.0000007 & 0.0000007 & 0.0000007 & -- \\
\hline Mercury, Total & $\mathrm{mg} / \mathrm{L}$ & 0.0007 & -- & -- & -- & 0.0007 \\
\hline Nickel, Dissolved ${ }^{\mathrm{e}}$ & $\mathrm{mg} / \mathrm{L}$ & -- & -- & -- & -- & -- \\
\hline Nickel, Total & $\mathrm{mg} / \mathrm{L}$ & 0.10 & -- & -- & -- & 0.10 \\
\hline Nitrate-N & $\mathrm{mg} / \mathrm{L}$ & 10.0 & -- & -- & -- & 10.0 \\
\hline Nitrate + Nitrite & $\mathrm{mg} / \mathrm{L}$ & 10.0 & 10.0 & 10.0 & 10.0 & 10.0 \\
\hline Nitrite-N & $\mathrm{mg} / \mathrm{L}$ & 0.10 & 0.10 & 0.10 & -- & 1.00 \\
\hline NPOC $^{\mathrm{g}}$ & $\mathrm{mg} / \mathrm{L}$ & 0.10 & -- & -- & -- & -- \\
\hline Oil \& Grease & $\mathrm{mg} / \mathrm{L}$ & -- & -- & -- & -- & -- \\
\hline pH & SU & $6.5-8.5^{\mathrm{f}}$ & $6.5-8.5^{\mathrm{f}}$ & $6.5-8.5^{\mathrm{f}}$ & $6.0-9.5$ & $6.5-8.5^{\mathrm{f}}$ \\
\hline Potassium, Total & $\mathrm{mg} / \mathrm{L}$ & -- & -- & -- & -- & -- \\
\hline Selenium, Dissolved & $\mathrm{mg} / \mathrm{L}$ & 0.0046 & 0.0046 & 0.0046 & -- & -- \\
\hline Selenium, Total & $\mathrm{mg} / \mathrm{L}$ & 0.01 & -- & -- & -- & 0.01 \\
\hline Silver, Total & $\mathrm{mg} / \mathrm{L}$ & 0.05 & -- & -- & -- & 0.05 \\
\hline Sodium, Total & $\mathrm{mg} / \mathrm{L}$ & -- & -- & -- & -- & 20.0 \\
\hline Solids, Settleable & $\mathrm{mg} / \mathrm{L}$ & -- & -- & -- & -- & -- \\
\hline Solids, Total Dissolved & $\mathrm{mg} / \mathrm{L}$ & 500 & 500 & 500 & -- & 500 \\
\hline Solids, Total Suspended & $\mathrm{mg} / \mathrm{L}$ & -- & -- & -- & -- & -- \\
\hline Sulfate & $\mathrm{mg} / \mathrm{L}$ & 250 & -- & -- & -- & 250 \\
\hline Sulfide (undissociated form) & $\mathrm{mg} / \mathrm{L}$ & 0.002 & 0.002 & 0.002 & -- & 0.050 (as HS) \\
\hline Surfactants (as LAS) & $\mathrm{mg} / \mathrm{L}$ & 0.04 & 0.04 & 0.04 & -- & -- \\
\hline Thallium, Total $^{\mathrm{h}}$ & $\mathrm{mg} / \mathrm{L}$ & 0.0005 & 0.008 & 0.008 & 0.020 & 0.0005 \\
\hline Titanium, Total & $\mathrm{mg} / \mathrm{L}$ & -- & -- & -- & -- & -- \\
\hline TOX (total organic halides) ${ }^{\mathrm{g}}$ & $\mathrm{mg} / \mathrm{L}$ & 0.10 & -- & -- & -- & -- \\
\hline Vanadium, Total $^{\mathrm{h}}$ & $\mathrm{mg} / \mathrm{L}$ & 0.014 & 0.014 & 0.014 & 0.190 & -- \\
\hline Zinc, Dissolved $^{\mathrm{e}}$ & $\mathrm{mg} / \mathrm{L}$ & -- & -- & -- & -- & -- \\
\hline Zinc, Total & $\mathrm{mg} / \mathrm{L}$ & 2.00 & -- & -- & -- & 2.00 \\
\hline
\end{tabular}

-- No applicable guideline or reference standard available

Note: All water quality and metals standards are presented in $\mathrm{mg} / \mathrm{L}(\mathrm{ppm})$ to provide consistency in comparisons.

$H S$ - Hydrogen sulfide

$S U$ - Standard units

${ }^{a}$ Source: 6 NYCRR Parts 701-704; The most stringent applicable pathway (e.g., wildlife, aquatic, human health, etc.) values are reported.

${ }^{b}$ Gross alpha standard includes radium-226, but excludes radon and uranium; however WVDP results include these isotopes.

${ }^{c}$ Gross beta standard excludes strontium-90 and alpha emitters, however WVDP results include these isotopes.

"Beryllium standard for classes " $B$ " and "C" are based on stream hardness.

"Standards for these constituents vary according to stream location hardness values.

${ }^{f} \mathrm{pH}$ shall not be lower than 6.5 or the $\mathrm{pH}$ of natural groundwater, whichever is lower, nor shall $\mathrm{pH}$ be greater than 8.5 or the $\mathrm{pH}$ of the natural groundwater, whichever is greater.

${ }^{g}$ Applies to the sum of those organic substances which have individual human health water source standards listed at $0.100 \mathrm{mg} / \mathrm{L}$ or less in 6 NYCRR Part 703.5

${ }^{h}$ Standards for cobalt, thallium, and vanadium are acid-soluble. 


\section{Table C-1C \\ New York State Department of Health/U.S. Environmental Protection Agency MCLs, MCLGs, and Raw Water Standards}

\begin{tabular}{|c|c|c|c|c|}
\hline Parameter & Units & $\begin{array}{l}\text { NYSDOH or } \\
\text { EPA MCL }^{\text {a }}\end{array}$ & EPA MCLG & $\begin{array}{c}\text { NYSDOH Raw Water } \\
\text { Standards }^{\mathrm{c}}\end{array}$ \\
\hline Gross Alpha & $\mathrm{pCi} / \mathrm{L}(\mu \mathrm{Ci} / \mathrm{mL})$ & $15(1.5 \mathrm{E}-08)^{\mathrm{d}}$ & 0 & -- \\
\hline Gross Beta & $\mathrm{pCi} / \mathrm{L}(\mu \mathrm{Ci} / \mathrm{mL})$ & $50(5 \mathrm{E}-08)^{\mathrm{e}}$ & 0 & $1,000(1 \mathrm{E}-06)$ \\
\hline Tritium (H-3) & $\mathrm{pCi} / \mathrm{L}(\mu \mathrm{Ci} / \mathrm{mL})$ & $20,000(2 \mathrm{E}-05)$ & -- & -- \\
\hline Strontium-90 & $\mathrm{pCi} / \mathrm{L}(\mu \mathrm{Ci} / \mathrm{mL})$ & $8(8 \mathrm{E}-09)$ & -- & $10(1 \mathrm{E}-08)$ \\
\hline Antimony, Total & $\mathrm{mg} / \mathrm{L}$ & 0.006 & 0.006 & -- \\
\hline Arsenic, Total & $\mathrm{mg} / \mathrm{L}$ & 0.05 & -- & 0.05 \\
\hline Barium, Total & $\mathrm{mg} / \mathrm{L}$ & 2 & 2 & 1 \\
\hline Beryllium, Total & $\mathrm{mg} / \mathrm{L}$ & 0.004 & 0.004 & -- \\
\hline Cadmium, Total & $\mathrm{mg} / \mathrm{L}$ & 0.005 & 0.005 & 0.01 \\
\hline Chromium, Total & $\mathrm{mg} / \mathrm{L}$ & 0.1 & 0.1 & -- \\
\hline Conductivity & $\mu \mathrm{mhos} / \mathrm{cm} @ 25^{\circ} \mathrm{C}$ & -- & -- & -- \\
\hline Cyanide & $\mathrm{mg} / \mathrm{L}$ & 0.2 & 0.2 & $<0.1$ \\
\hline E. Coli & NA & one positive sample & 0 & -- \\
\hline Fluoride & $\mathrm{mg} / \mathrm{L}$ & 2.2 & -- & 1.5 \\
\hline Free Residual Chlorine & $\mathrm{mg} / \mathrm{L}$ & $0.02(\min ) \quad 4.0(\max )$ & -- & -- \\
\hline Haloacetic Acids -Five (5) & $\mathrm{mg} / \mathrm{L}$ & 0.060 & -- & -- \\
\hline Iron, Total & $\mathrm{mg} / \mathrm{L}$ & 0.3 & -- & -- \\
\hline Mercury, Total & $\mathrm{mg} / \mathrm{L}$ & 0.002 & 0.002 & 0.005 \\
\hline Nickel, Total & $\mathrm{mg} / \mathrm{L}$ & -- & -- & -- \\
\hline Nitrate-N & $\mathrm{mg} / \mathrm{L}$ & 10 & 10 & -- \\
\hline pH & SU & -- & -- & $6.5-8.5$ \\
\hline POC $^{f}$ & $\mathrm{mg} / \mathrm{L}$ & -- & 0.0005 & -- \\
\hline Selenium, Total & $\mathrm{mg} / \mathrm{L}$ & 0.05 & 0.05 & 0.01 \\
\hline Solids, Total Dissolved & $\mathrm{mg} / \mathrm{L}$ & -- & -- & 500 \\
\hline Thallium, Total & $\mathrm{mg} / \mathrm{L}$ & 0.002 & 0.0005 & -- \\
\hline Total Coliform & NA & 2 or more positive samples & zero & -- \\
\hline Total Trihalomethanes & $\mathrm{mg} / \mathrm{L}$ & 0.080 & -- & -- \\
\hline Turbidity & NTU & 1 (max) & -- & -- \\
\hline
\end{tabular}

-- No applicable guideline or reference standard available

Note: All water quality and metals standards are presented in $\mathrm{mg} / \mathrm{L}(\mathrm{ppm})$ to provide consistency in comparisons.

NA - Not applicable

$N T U$ - Nephelometric turbidity units

$S U$ - Standard units

${ }^{a}$ MCL - Listed is NYSDOH or EPA Maximum Contaminant Levels. Sources: 40 CFR 141 and/or 5 NYCRR 5-1.52,

whichever is more stringent.

${ }^{b}$ MCLG - Maximum Contaminant Level Goal (non-enforceable) as listed in 40 CFR Part 141

${ }^{c}$ Source: 10 NYCRR Part 170.4

${ }^{d}$ Alpha guideline includes radium-226, but excludes uranium; however, WVDP results include these isotopes.

${ }^{e}$ Average annual concentration assumed to produce a total body organ dose of $4 \mathrm{mrem} /$ year

${ }^{f}$ POC - Principle Organic Contaminant

$$
\text { C - } 7
$$


Table C-1D

\section{U.S. Department of Energy Derived Concentration Guides $(D C G s)^{a}$}

\begin{tabular}{|c|c|c|}
\hline Radionuclide & Units & Concentration in Ingested Water \\
\hline Gross Alpha (as Am-241) $^{\text {b }}$ & $\mu \mathrm{Ci} / \mathrm{mL}$ & $3 \mathrm{E}-08$ \\
\hline Gross Beta (as Sr-90) ${ }^{b}$ & $\mu \mathrm{Ci} / \mathrm{mL}$ & $1 \mathrm{E}-06$ \\
\hline Tritium (H-3) & $\mu \mathrm{Ci} / \mathrm{mL}$ & $2 \mathrm{E}-03$ \\
\hline Carbon-14 (C-14) & $\mu \mathrm{Ci} / \mathrm{mL}$ & 7E-05 \\
\hline Potassium-40 (K-40) & $\mu \mathrm{Ci} / \mathrm{mL}$ & 7E-06 \\
\hline Cobalt-60 (Co-60) & $\mu \mathrm{Ci} / \mathrm{mL}$ & $5 \mathrm{E}-06$ \\
\hline Strontium-90 (Sr-90) & $\mu \mathrm{Ci} / \mathrm{mL}$ & $1 \mathrm{E}-06$ \\
\hline Technetium-99 (Tc-99) & $\mu \mathrm{Ci} / \mathrm{mL}$ & $1 \mathrm{E}-04$ \\
\hline Iodine-129(I-129) & $\mu \mathrm{Ci} / \mathrm{mL}$ & $5 \mathrm{E}-07$ \\
\hline Cesium-137 (Cs-137) & $\mu \mathrm{Ci} / \mathrm{mL}$ & $3 \mathrm{E}-06$ \\
\hline Europium-154 (Eu-154) & $\mu \mathrm{Ci} / \mathrm{mL}$ & $2 \mathrm{E}-05$ \\
\hline Uranium-232 (U-232) & $\mu \mathrm{Ci} / \mathrm{mL}$ & $1 \mathrm{E}-07$ \\
\hline Uranium-233 (U-233) & $\mu \mathrm{Ci} / \mathrm{mL}$ & 5E-07 \\
\hline Uranium-234 (U-234) & $\mu \mathrm{Ci} / \mathrm{mL}$ & $5 \mathrm{E}-07$ \\
\hline Uranium-235 (U-235) & $\mu \mathrm{Ci} / \mathrm{mL}$ & $6 \mathrm{E}-07$ \\
\hline Uranium-236 (U-236) & $\mu \mathrm{Ci} / \mathrm{mL}$ & 5E-07 \\
\hline Uranium-238(U-238) & $\mu \mathrm{Ci} / \mathrm{mL}$ & $6 \mathrm{E}-07$ \\
\hline Plutonium-238 (Pu-238) & $\mu \mathrm{Ci} / \mathrm{mL}$ & $4 \mathrm{E}-08$ \\
\hline Plutonium-239 (Pu-239) & $\mu \mathrm{Ci} / \mathrm{mL}$ & 3E-08 \\
\hline Plutonium-240 (Pu-240) & $\mu \mathrm{Ci} / \mathrm{mL}$ & 3E-08 \\
\hline Americium-241 (Am-241) & $\mu \mathrm{Ci} / \mathrm{mL}$ & $3 \mathrm{E}-08$ \\
\hline
\end{tabular}

${ }^{a}$ DCGs are established in DOE Order 5400.5 and are defined as the concentration of a radionuclide that, under conditions of continuous exposure for one year by one exposure mode, would result in an effective dose equivalent of $100 \mathrm{mrem}(1 \mathrm{mSv})$.

${ }^{b}$ Because there are no DCGs for gross alpha and gross beta concentrations, the DCGs for the most restrictive alpha and beta emitters at the WVDP, americium-241 and strontium-90 (3E-08 and $1 \mathrm{E}-06 \mu \mathrm{Ci} / \mathrm{mL}$, respectively) are used as a conservative basis for comparison at locations for which there are no radionuclide-specific data, in which case a more appropriate DCG may be applied.

C- 8 


\section{Appendix C-2 Process Effluent Data}

C- 9 
Table C-2A contains a bolding convention devised to help the reader, when viewing the data, to quickly see the range of detectable measurements within a data series. A data series is a set of chemical or radionuclide measurements (e.g., gross alpha, gross beta, tritium) from a single location or from similar locations. Note that some tables contain data that should not be technically evaluated under this convention.

\section{Key to bolding convention:}

Results for each constituent constitute a single data series. If a radiological result is larger than the uncertainty term, the measurement is considered positive. Otherwise, a result is considered non-detectable. Chemical results preceded by "less than" $(<)$ are considered nondetectable.

If all results in a data series are positive, the lowest and highest values are bolded. If a data series contains some positive results, the highest value is bolded.

If all values in a data series are nondetectable, no values are bolded. 


\section{Table C-2A}

\section{Total Radioactivity (curies) of Liquid Effluents Released From Lagoon 3}

(WNSP001) in 2003

\begin{tabular}{|c|c|c|c|c|c|}
\hline Isotope & 1st Quarter & 2nd Quarter & 3rd Quarter & 4th Quarter & Annual Total \\
\hline Gross Alpha & $7.62 \pm 0.74 \mathrm{E}-04$ & $2.27 \pm 0.35 \mathrm{E}-04$ & $7.18 \pm 2.96 \mathrm{E}-05$ & $4.99 \pm 0.55 \mathrm{E}-04$ & $1.56 \pm 0.10 \mathrm{E}-03$ \\
\hline Gross Beta & $5.43 \pm 0.14 \mathrm{E}-03$ & $3.00 \pm 0.09 \mathrm{E}-03$ & $1.30 \pm 0.07 E-03$ & $3.30 \pm 0.10 \mathrm{E}-03$ & $1.30 \pm 0.02 \mathrm{E}-02$ \\
\hline H-3 & $4.62 \pm 0.14 \mathrm{E}-02$ & $9.55 \pm 0.26 \mathrm{E}-02$ & $3.16 \pm 0.14 \mathrm{E}-02$ & $5.65 \pm 0.19 \mathrm{E}-02$ & $2.30 \pm 0.04 \mathrm{E}-01$ \\
\hline C-14 & $2.64 \pm 1.40 \mathrm{E}-04$ & $2.28 \pm 1.95 \mathrm{E}-04$ & $0.23 \pm 2.11 \mathrm{E}-04$ & $5.62 \pm 3.97 \mathrm{E}-04$ & $1.08 \pm 0.51 \mathrm{E}-03$ \\
\hline K-40 & $7.74 \pm 7.46 \mathrm{E}-04$ & $-2.65 \pm 5.44 \mathrm{E}-04$ & $-2.49 \pm 3.44 \mathrm{E}-04$ & $1.01 \pm 0.51 \mathrm{E}-03$ & $1.27 \pm 1.11 \mathrm{E}-03$ \\
\hline Co-60 & $2.08 \pm 2.54 \mathrm{E}-05$ & $0.44 \pm 2.23 \mathrm{E}-05$ & $0.72 \pm 1.41 \mathrm{E}-05$ & $4.29 \pm 5.02 \mathrm{E}-05$ & $7.53 \pm 6.22 \mathrm{E}-05$ \\
\hline $\mathrm{Sr}-90$ & $2.01 \pm 0.10 \mathrm{E}-03$ & $1.04 \pm 0.07 \mathrm{E}-03$ & $4.75 \pm 0.25 \mathrm{E}-04$ & $1.15 \pm 0.06 \mathrm{E}-03$ & $4.66 \pm 0.14 \mathrm{E}-03$ \\
\hline Tc-99 & $6.65 \pm 0.47 \mathrm{E}-04$ & $6.58 \pm 0.29 \mathrm{E}-04$ & $2.40 \pm 0.27 \mathrm{E}-04$ & $5.72 \pm 0.38 \mathrm{E}-04$ & $2.13 \pm 0.07 \mathrm{E}-03$ \\
\hline I-129 & $1.00 \pm 1.22 \mathrm{E}-05$ & $2.65 \pm 2.03 \mathrm{E}-05$ & $0.00 \pm 1.42 \mathrm{E}-05$ & $8.28 \pm 2.85 \mathrm{E}-05$ & $1.19 \pm 0.40 \mathrm{E}-04$ \\
\hline Cs-137 & $1.44 \pm 0.08 \mathrm{E}-03$ & $7.02 \pm 0.58 \mathrm{E}-04$ & $3.94 \pm 0.43 E-04$ & $7.46 \pm 1.03 \mathrm{E}-04$ & $3.28 \pm 0.15 \mathrm{E}-03$ \\
\hline U-232 & $2.92 \pm 0.06 \mathrm{E}-04$ & $9.95 \pm 0.37 \mathrm{E}-05$ & $4.69 \pm 0.41 \mathrm{E}-05$ & $2.02 \pm 0.06 \mathrm{E}-04$ & $6.41 \pm 0.10 \mathrm{E}-04$ \\
\hline U-233/234 & $1.76 \pm 0.14 \mathrm{E}-04$ & $6.43 \pm 0.41 \mathrm{E}-05$ & $2.70 \pm 0.31 E-05$ & $1.21 \pm 0.05 \mathrm{E}-04$ & $3.88 \pm 0.16 \mathrm{E}-04$ \\
\hline U-235/236 & $4.00 \pm 1.82 \mathrm{E}-06$ & $3.65 \pm 1.12 \mathrm{E}-06$ & $1.93 \pm 0.86 \mathrm{E}-06$ & $7.48 \pm 1.32 \mathrm{E}-06$ & $1.71 \pm 0.27 \mathrm{E}-05$ \\
\hline U-238 & $9.46 \pm 1.01 \mathrm{E}-05$ & $4.33 \pm 0.34 \mathrm{E}-05$ & $1.76 \pm 0.25 \mathrm{E}-05$ & $7.61 \pm 0.39 \mathrm{E}-05$ & $2.32 \pm 0.12 \mathrm{E}-04$ \\
\hline Total U (g) & $2.32 \pm 0.08 \mathrm{E}+02$ & $1.39 \pm 0.02 \mathrm{E}+02$ & $5.60 \pm 0.09 \mathrm{E}+01$ & $2.46 \pm 0.09 \mathrm{E}+02$ & $6.73 \pm 0.12 \mathrm{E}+02$ \\
\hline Pu-238 & $2.50 \pm 0.16 \mathrm{E}-05$ & $1.74 \pm 0.61 \mathrm{E}-06$ & $2.42 \pm 1.04 \mathrm{E}-06$ & $5.59 \pm 1.28 \mathrm{E}-06$ & $3.47 \pm 0.24 \mathrm{E}-05$ \\
\hline Pu-239/240 & $2.09 \pm 0.15 \mathrm{E}-05$ & $2.74 \pm 0.77 \mathrm{E}-06$ & $2.75 \pm 1.07 \mathrm{E}-06$ & $1.06 \pm 0.16 \mathrm{E}-05$ & $3.70 \pm 0.25 \mathrm{E}-05$ \\
\hline Am-241 & $1.46 \pm 0.12 \mathrm{E}-05$ & $1.46 \pm 0.61 \mathrm{E}-06$ & $1.82 \pm 0.84 \mathrm{E}-06$ & $5.32 \pm 1.35 \mathrm{E}-06$ & $2.32 \pm 0.21 \mathrm{E}-05$ \\
\hline
\end{tabular}

Note: Bolding convention applied to these data. See page C-10. 
Table C-2B

\section{Comparison of 2003 Lagoon 3 (WNSP001) Liquid Effluent Radioactivity Concentrations With U.S. Department of Energy Guidelines}

\begin{tabular}{|c|c|c|c|c|c|}
\hline Isotope $^{a}$ & Discharge Activity $^{b}$ & Radioactivity $^{\mathrm{c}}$ & Concentration & DCG & \% of DCG \\
\hline & (Ci) & (Becquerels) & $(\mu \mathrm{Ci} / \mathrm{mL})$ & $(\mu \mathrm{Ci} / \mathrm{mL})$ & \\
\hline Alpha & $1.56 \pm 0.10 \mathrm{E}-03$ & $5.77 \pm 0.38 \mathrm{E}+07$ & $2.75 \pm 0.18 \mathrm{E}-08$ & $\mathrm{NA}^{\mathrm{d}}$ & NA \\
\hline Beta & $1.30 \pm 0.02 \mathrm{E}-02$ & $4.82 \pm 0.08 \mathrm{E}+08$ & $2.30 \pm 0.04 \mathrm{E}-07$ & $N A^{\mathrm{d}}$ & NA \\
\hline H-3 & $2.30 \pm 0.04 \mathrm{E}-01$ & $8.51 \pm 0.14 \mathrm{E}+09$ & $4.05 \pm 0.07 \mathrm{E}-06$ & $2.00 \mathrm{E}-03$ & 0.20 \\
\hline C-14 & $1.08 \pm 0.51 \mathrm{E}-03$ & $3.99 \pm 1.89 \mathrm{E}+07$ & $1.90 \pm 0.90 \mathrm{E}-08$ & $7.00 \mathrm{E}-05$ & 0.03 \\
\hline K-40 & $1.27 \pm 1.11 \mathrm{E}-03$ & $4.71 \pm 4.11 \mathrm{E}+07$ & $2.24 \pm 1.96 \mathrm{E}-08$ & $\mathrm{NA}^{\mathrm{e}}$ & NA \\
\hline Co-60 & $7.53 \pm 6.22 \mathrm{E}-05$ & $2.79 \pm 2.30 \mathrm{E}+06$ & $1.33 \pm 1.10 \mathrm{E}-09$ & $5 \mathrm{E}-06$ & 0.03 \\
\hline Sr-90 & $4.66 \pm 0.14 \mathrm{E}-03$ & $1.73 \pm 0.05 \mathrm{E}+08$ & $8.22 \pm 0.24 \mathrm{E}-08$ & 1E-06 & 8.22 \\
\hline Tc-99 & $2.13 \pm 0.07 \mathrm{E}-03$ & $7.90 \pm 0.27 \mathrm{E}+07$ & $3.76 \pm 0.13 \mathrm{E}-08$ & $1 \mathrm{E}-04$ & 0.04 \\
\hline I-129 & $1.19 \pm 0.40 \mathrm{E}-04$ & $4.41 \pm 1.47 \mathrm{E}+06$ & $2.10 \pm 0.70 \mathrm{E}-09$ & $5 \mathrm{E}-07$ & 0.42 \\
\hline Cs-137 & $3.28 \pm 0.15 \mathrm{E}-03$ & $1.21 \pm 0.05 \mathrm{E}+08$ & $5.79 \pm 0.26 \mathrm{E}-08$ & 3E-06 & 1.93 \\
\hline $\mathrm{U}-232^{\mathrm{f}}$ & $6.41 \pm 0.10 \mathrm{E}-04$ & $2.37 \pm 0.04 \mathrm{E}+07$ & $1.13 \pm 0.02 \mathrm{E}-08$ & $1 \mathrm{E}-07$ & 11.29 \\
\hline$U-233 / 234^{f}$ & $3.88 \pm 0.16 \mathrm{E}-04$ & $1.44 \pm 0.06 \mathrm{E}+07$ & $6.85 \pm 0.28 \mathrm{E}-09$ & $5 \mathrm{E}-07$ & 1.37 \\
\hline$U-235 / 236^{f}$ & $1.71 \pm 0.27 \mathrm{E}-05$ & $6.31 \pm 0.98 \mathrm{E}+05$ & $3.01 \pm 0.47 \mathrm{E}-10$ & $5 \mathrm{E}-07^{\mathrm{g}}$ & 0.06 \\
\hline $\mathrm{U}-238^{\mathrm{f}}$ & $2.32 \pm 0.12 \mathrm{E}-04$ & $8.57 \pm 0.43 \mathrm{E}+06$ & $4.08 \pm 0.20 \mathrm{E}-09$ & $6 \mathrm{E}-07$ & 0.68 \\
\hline Pu-238 & $3.47 \pm 0.24 \mathrm{E}-05$ & $1.29 \pm 0.09 \mathrm{E}+06$ & $6.12 \pm 0.42 \mathrm{E}-10$ & 4E-08 & 1.53 \\
\hline Pu-239/240 & $3.70 \pm 0.25 \mathrm{E}-05$ & $1.37 \pm 0.09 \mathrm{E}+06$ & $6.51 \pm 0.45 \mathrm{E}-10$ & 3E-08 & 2.17 \\
\hline Am-241 & $2.32 \pm 0.21 \mathrm{E}-05$ & $8.58 \pm 0.78 \mathrm{E}+05$ & $4.09 \pm 0.37 \mathrm{E}-10$ & $3 \mathrm{E}-08$ & 1.36 \\
\hline \multicolumn{5}{|c|}{ Total \% of DCGs } & 29.33 \\
\hline
\end{tabular}

${ }^{a}$ Half-lives are listed in Table $K-1 \mathrm{C}$.

${ }^{b}$ Total volume released: $5.67 E+10 \mathrm{~mL}(1.50 \mathrm{E}+07 \mathrm{gal})$

${ }^{c} 1$ curie $(\mathrm{Ci})=3.7 E+10$ becquerels $(\mathrm{Bq}) ; 1 \mathrm{~Bq}=2.7 \mathrm{E}-11 \mathrm{Ci}$

${ }^{d}$ DOE-derived concentration guides (DCGs) do not exist for indicator parameters gross alpha and gross beta.

${ }^{e}$ Potassium-40 activity is not applicable because of its natural origin.

${ }^{f}$ Total $U(g)=6.73 \pm 0.12 E+02$; Average $U(\mu \mathrm{g} / \mathrm{mL})=1.19 \pm 0.02 E-02$

${ }^{g}$ DCG for $U-236$ is used for this comparison. 
Table C-2C

2003 SPDES Results for Outfall 001 (WNSP001):

Water Quality

\begin{tabular}{|c|c|c|c|c|c|c|c|c|}
\hline & \multicolumn{2}{|c|}{$\begin{array}{c}\text { Ammonia } \\
(\mathrm{mg} / \mathrm{L})\end{array}$} & \multicolumn{2}{|c|}{$\begin{array}{c}\text { BOD }_{5} \text { day } \\
(\mathrm{mg} / \mathrm{L})\end{array}$} & \multicolumn{2}{|c|}{$\begin{array}{c}\text { Cyanide } \\
\text { (amenable to chlorination) } \\
(\mathrm{m} / \mathrm{L})\end{array}$} & \multicolumn{2}{|c|}{$\begin{array}{l}\text { Discharge Rate } \\
\text { (MGD) }\end{array}$} \\
\hline Permit limit & \multicolumn{2}{|c|}{ Monitor } & \multicolumn{2}{|c|}{$\begin{array}{l}10.0 \mathrm{mg} / \mathrm{L} \text { daily } \\
\text { maximum }\end{array}$} & \multicolumn{2}{|c|}{$\begin{array}{l}0.022 \mathrm{mg} / \mathrm{L} \text { daily } \\
\text { maximum }\end{array}$} & \multicolumn{2}{|c|}{ Monitor } \\
\hline Month & Avg & Max & Avg & Max & Avg & Max & Avg & Max \\
\hline January & 0.23 & 0.29 & $<2.0$ & $<2.0$ & $<0.010$ & $<0.010$ & 0.282 & 0.485 \\
\hline February $^{a}$ & -- & -- & -- & -- & - & -- & -- & -- \\
\hline March & 0.29 & 0.29 & $<2.0$ & $<2.0$ & $<0.010$ & $<0.010$ & 0.305 & 0.726 \\
\hline April & $<0.012$ & $<0.012$ & $<2.0$ & $<2.0$ & $<0.010$ & $<0.010$ & 0.302 & 0.775 \\
\hline $\operatorname{May}^{a}$ & -- & -- & -- & -- & - & -- & -- & -- \\
\hline June & $<0.07$ & 0.091 & $<2.1$ & 2.1 & $<0.010$ & $<0.010$ & 0.308 & 0.736 \\
\hline$J_{u l y}{ }^{a}$ & -- & -- & -- & -- & - & -- & -- & -- \\
\hline August & $<0.050$ & $<0.050$ & $<2.6$ & 3.2 & $<0.010$ & $<0.010$ & 0.163 & 0.189 \\
\hline September ${ }^{a}$ & -- & -- & -- & -- & - & -- & -- & -- \\
\hline October & $<0.050$ & $<0.050$ & $<2.3$ & 2.5 & $<0.010$ & $<0.010$ & 0.174 & 0.206 \\
\hline November $^{a}$ & -- & -- & -- & -- & - & -- & -- & -- \\
\hline December & $<0.067$ & 0.084 & $<2.0$ & $<2.0$ & $<0.010$ & $<0.010$ & 0.397 & 0.422 \\
\hline
\end{tabular}

\begin{tabular}{|c|c|c|c|c|c|c|}
\hline & \multicolumn{2}{|c|}{$\begin{array}{c}\text { Nitrate (as N) } \\
\quad(\mathrm{mg} / \mathrm{L})\end{array}$} & \multicolumn{2}{|c|}{$\begin{array}{c}\text { Nitrite (as N) } \\
(\mathrm{mg} / \mathrm{L})\end{array}$} & \multicolumn{2}{|c|}{$\begin{array}{l}\text { Oil \& Grease } \\
(\mathrm{mg} / \mathrm{L})\end{array}$} \\
\hline Permit limit & \multicolumn{2}{|c|}{ Monitor } & \multicolumn{2}{|c|}{$\begin{array}{l}0.1 \mathrm{mg} / \mathrm{L} \text { daily } \\
\text { maximum }\end{array}$} & \multicolumn{2}{|c|}{$\begin{array}{l}15.0 \mathrm{mg} / \mathrm{L} \text { daily } \\
\text { maximum }\end{array}$} \\
\hline Month & Avg & Max & Avg & Max & Avg & Max \\
\hline January & 1.0 & 1.0 & $<0.05$ & $<0.05$ & $<5.0$ & $<5.0$ \\
\hline February $^{a}$ & -- & -- & -- & -- & - & - \\
\hline March & 0.99 & 1.1 & $<0.05$ & $<0.05$ & $<5.0$ & $<5.0$ \\
\hline April & 0.69 & 0.75 & $<0.05$ & $<0.05$ & $<5.0$ & $<5.0$ \\
\hline $\operatorname{May}^{a}$ & -- & -- & -- & -- & - & -- \\
\hline June & 0.21 & 0.23 & $<0.05$ & $<0.05$ & $<5.0$ & $<5.0$ \\
\hline$J_{u l y}{ }^{a}$ & -- & -- & -- & -- & - & -- \\
\hline August & $<0.05$ & $<0.05$ & $<0.05$ & $<0.05$ & $<5.0$ & $<5.0$ \\
\hline September $^{a}$ & -- & -- & -- & -- & - & -- \\
\hline October & $<0.05$ & $<0.05$ & $<0.05$ & $<0.05$ & $<5.0$ & $<5.0$ \\
\hline November $^{a}$ & -- & -- & -- & -- & - & -- \\
\hline December & 0.50 & 0.55 & $<0.05$ & $<0.05$ & $<5.0$ & $<5.0$ \\
\hline
\end{tabular}

Note: No results exceeded the permit limits.

${ }^{a}$ No discharge this month 
Table C-2C (concluded)

2003 SPDES Results for Outfall 001 (WNSP001):

Water Quality

\begin{tabular}{|c|c|c|c|c|c|c|c|c|}
\hline \multirow{3}{*}{$\begin{array}{l}\text { Permit limit } \\
\text { Month }\end{array}$} & \multicolumn{2}{|c|}{$\begin{array}{c}\mathbf{p H} \\
\text { (standard units) }\end{array}$} & \multicolumn{2}{|c|}{$\begin{array}{c}\text { Solids } \\
\text { Settleable } \\
(\mathrm{mL} / \mathrm{L})\end{array}$} & \multicolumn{2}{|c|}{$\begin{array}{c}\text { Solids } \\
\text { Total Dissolved } \\
(\mathrm{mg} / \mathrm{L})\end{array}$} & \multicolumn{2}{|c|}{$\begin{array}{c}\text { Solids } \\
\text { Total Suspended } \\
(\mathrm{mg} / \mathrm{L})\end{array}$} \\
\hline & \multicolumn{2}{|c|}{$6.5-8.5$} & \multicolumn{2}{|c|}{$\begin{array}{l}0.30 \mathrm{~mL} / \mathrm{L} \text { daily } \\
\text { maximum }\end{array}$} & \multicolumn{2}{|c|}{ Monitor } & \multicolumn{2}{|c|}{$\begin{array}{c}45.0 \mathrm{mg} / \mathrm{L} \text { daily maximum; } \\
30.0 \text { daily average }\end{array}$} \\
\hline & Min & Max & Avg & Max & Avg & Max & Avg & Max \\
\hline Jaпиагу & 7.3 & 7.8 & $<0.1$ & $<0.1$ & 823 & 839 & $<2.0$ & $<2.0$ \\
\hline February $^{a}$ & -- & -- & -- & -- & - & -- & -- & -- \\
\hline March & 7.9 & 7.9 & $<0.1$ & $<0.1$ & 789 & 820 & $<2.0$ & $<2.0$ \\
\hline April & 7.6 & 7.9 & $<0.1$ & $<0.1$ & 817 & 824 & 13.0 & 17.0 \\
\hline May $^{a}$ & -- & -- & -- & -- & - & -- & -- & -- \\
\hline June & 8.0 & 8.4 & $<0.1$ & $<0.1$ & 757 & 761 & $<2.0$ & $<2.0$ \\
\hline July $^{a}$ & -- & -- & -- & -- & - & -- & -- & -- \\
\hline August & 7.5 & 8.1 & $<0.1$ & $<0.1$ & 836 & 855 & $<2.0$ & $<2.0$ \\
\hline September $^{a}$ & -- & -- & -- & -- & - & -- & -- & -- \\
\hline October & 7.7 & 8.2 & $<0.1$ & $<0.1$ & 798 & 808 & $<2.0$ & $<2.0$ \\
\hline November $^{a}$ & -- & -- & -- & -- & - & -- & -- & -- \\
\hline December & 7.7 & 7.8 & $<0.1$ & $<0.1$ & 728 & 735 & $<3.0$ & 4.0 \\
\hline
\end{tabular}

\begin{tabular}{|c|c|c|c|c|c|c|}
\hline & \multicolumn{2}{|c|}{$\begin{array}{c}\text { Sulfate (as S) } \\
(\mathrm{mg} / \mathrm{L})\end{array}$} & \multicolumn{2}{|c|}{$\begin{array}{c}\text { Sulfide (as S) } \\
\text { Dissolved } \\
(\mathrm{mg} / \mathrm{L})\end{array}$} & \multicolumn{2}{|c|}{$\begin{array}{c}\text { Surfactants } \\
\text { as LAS } \\
(\mathrm{mg} / \mathrm{L})\end{array}$} \\
\hline Permit limit & \multicolumn{2}{|c|}{ Monitor } & \multicolumn{2}{|c|}{$\begin{array}{l}0.4 \mathrm{mg} / \mathrm{L} \text { daily } \\
\text { maximum }\end{array}$} & \multicolumn{2}{|c|}{$\begin{array}{l}0.4 \mathrm{mg} / \mathrm{L} \text { daily } \\
\text { maximum }\end{array}$} \\
\hline Month & Avg & Max & Avg & Max & Avg & Max \\
\hline January & 47 & 53 & $<0.2$ & $<0.2$ & $<0.1$ & $<0.1$ \\
\hline February $^{a}$ & -- & -- & -- & -- & - & -- \\
\hline March & 53 & 55 & $<0.2$ & $<0.2$ & $<0.1$ & $<0.1$ \\
\hline April & 54 & 55 & $<0.2$ & $<0.2$ & $<0.1$ & $<0.1$ \\
\hline$M a y^{a}$ & -- & -- & -- & -- & - & -- \\
\hline June & 56 & 59 & $<0.2$ & $<0.2$ & $>0.1$ & $>0.1$ \\
\hline July $^{a}$ & -- & -- & -- & -- & - & -- \\
\hline August & 48 & 53 & $<0.2$ & $<0.2$ & $<0.1$ & $<0.1$ \\
\hline September $^{a}$ & - & -- & -- & - & - & -- \\
\hline October & 44 & 49 & $<0.2$ & 0.3 & $<0.1$ & $<0.1$ \\
\hline November $^{a}$ & -- & -- & -- & -- & - & -- \\
\hline December & 35 & 46 & $<0.2$ & $<0.2$ & $<0.1$ & $<0.1$ \\
\hline
\end{tabular}

Note: No results exceeded the permit limits.

${ }^{a}$ No discharge this month 
Table C-2D

2003 SPDES Results for Outfall 001 (WNSP001):

Metals

\begin{tabular}{|c|c|c|c|c|c|c|c|c|}
\hline \multirow{3}{*}{$\begin{array}{l}\text { Permit limit } \\
\text { Month }\end{array}$} & \multicolumn{2}{|c|}{$\begin{array}{l}\text { Aluminum } \\
\text { Total } \\
(\mathrm{mg} / \mathrm{L})\end{array}$} & \multicolumn{2}{|c|}{$\begin{array}{c}\text { Arsenic } \\
\text { Dissolved } \\
(\mathrm{mg} / \mathrm{L})\end{array}$} & \multicolumn{2}{|c|}{$\begin{array}{c}\text { Cadmium } \\
\text { Total Recoverable } \\
(\mathrm{mg} / \mathrm{L})\end{array}$} & \multicolumn{2}{|c|}{$\begin{array}{c}\text { Cobalt } \\
\text { Total Recoverable } \\
(\mathrm{mg} / \mathrm{L})\end{array}$} \\
\hline & $\begin{array}{r}14.0 \mathrm{mg} / \mathrm{L} \\
7.0 \mathrm{mg} / \mathrm{L}\end{array}$ & $\begin{array}{l}\text { maximum; } \\
\text { y average }\end{array}$ & $\begin{array}{r}0.15 \\
\mathrm{~m}\end{array}$ & $\begin{array}{l}\text { daily } \\
\text { Im }\end{array}$ & $\begin{array}{r}0.002 \\
\mathrm{~m}\end{array}$ & $\begin{array}{l}\text { daily } \\
\text { um }\end{array}$ & $\begin{array}{r}0.005 \\
\mathrm{~m}\end{array}$ & $\begin{array}{l}\text { daily } \\
\text { m }\end{array}$ \\
\hline & Avg & Max & Avg & Max & Avg & Max & Avg & Max \\
\hline January & $<0.200$ & $<0.200$ & $<0.002$ & $<0.002$ & $<0.001$ & $<0.001$ & $<0.004$ & $<0.004$ \\
\hline February $^{a}$ & -- & -- & -- & -- & -- & -- & -- & -- \\
\hline March & 0.275 & 0.344 & 0.002 & 0.002 & $<0.001$ & $<0.001$ & $<0.004$ & $<0.004$ \\
\hline April & 0.260 & 0.278 & 0.0016 & 0.0016 & $<0.001$ & $<0.001$ & $<0.004$ & $<0.004$ \\
\hline May $^{a}$ & -- & -- & -- & -- & -- & -- & -- & -- \\
\hline June & $<0.254$ & 0.307 & 0.0017 & 0.0018 & $<0.001$ & $<0.001$ & $<0.004$ & $<0.004$ \\
\hline July $^{a}$ & -- & -- & -- & -- & -- & -- & -- & -- \\
\hline August & $<0.200$ & $<0.200$ & 0.0035 & 0.0039 & $<0.001$ & $<0.001$ & $<0.004$ & $<0.004$ \\
\hline September $^{a}$ & -- & -- & -- & -- & -- & -- & -- & -- \\
\hline October & $<0.200$ & $<0.200$ & 0.003 & 0.003 & $<0.001$ & $<0.001$ & $<0.004$ & $<0.004$ \\
\hline November $^{a}$ & -- & -- & -- & -- & -- & -- & -- & -- \\
\hline December & $<0.258$ & 0.316 & 0.0022 & 0.0027 & $<0.001$ & $<0.001$ & $<0.004$ & $<0.004$ \\
\hline
\end{tabular}

\begin{tabular}{|c|c|c|c|c|c|c|c|c|}
\hline \multirow{3}{*}{$\begin{array}{l}\text { Permit limit } \\
\text { Month }\end{array}$} & \multirow{2}{*}{\multicolumn{2}{|c|}{$\begin{array}{c}\begin{array}{c}\text { Chromium } \\
\text { Total Recoverable } \\
(\mathrm{mg} / \mathrm{L})\end{array} \\
\begin{array}{c}0.3 \mathrm{mg} / \mathrm{L} \text { daily } \\
\text { maximum }\end{array} \\
\end{array}$}} & \multirow{2}{*}{\multicolumn{2}{|c|}{$\begin{array}{c}\text { Chromium VI } \\
\text { Total Recoverable } \\
(\mathrm{mg} / \mathrm{L})\end{array}$}} & \multirow{2}{*}{\multicolumn{2}{|c|}{$\begin{array}{c}\begin{array}{c}\text { Copper } \\
\text { Dissolved } \\
(\mathrm{mg} / \mathrm{L})\end{array} \\
\text { Monitor }\end{array}$}} & \multirow{2}{*}{\multicolumn{2}{|c|}{$\begin{array}{c}\begin{array}{c}\text { Copper } \\
\text { Total Recoverable } \\
(\mathrm{mg} / \mathrm{L})\end{array} \\
\begin{array}{c}0.030 \mathrm{mg} / \mathrm{L} \text { daily } \\
\text { maximum }\end{array}\end{array}$}} \\
\hline & & & & & & & & \\
\hline & Avg & Max & Avg & Max & Avg & $\operatorname{Max}$ & Avg & Max \\
\hline Janиary & $<0.002$ & $<0.002$ & $<0.010$ & $<0.010$ & $<0.010$ & $<0.010$ & $<0.010$ & $<0.010$ \\
\hline February $^{a}$ & -- & -- & -- & -- & -- & -- & -- & -- \\
\hline March & $<0.002$ & $<0.002$ & $<0.010$ & $<0.010$ & $<0.010$ & $<0.010$ & $<0.010$ & $<0.010$ \\
\hline April & $<0.002$ & $<0.002$ & $<0.010$ & $<0.010$ & $<0.010$ & $<0.010$ & $<0.010$ & $<0.010$ \\
\hline $\operatorname{May}^{a}$ & -- & -- & -- & - & - & -- & -- & -- \\
\hline June & $<0.002$ & $<0.002$ & $<0.010$ & $<0.010$ & $<0.010$ & $<0.010$ & $<0.010$ & $<0.010$ \\
\hline$J_{u l y}{ }^{a}$ & -- & -- & -- & -- & -- & -- & -- & -- \\
\hline August & $<0.002$ & $<0.002$ & $<0.010$ & $<0.010$ & $<0.010$ & $<0.010$ & $<0.010$ & $<0.010$ \\
\hline September $^{a}$ & -- & -- & -- & -- & -- & -- & -- & -- \\
\hline October & $<0.002$ & $<0.002$ & $<0.010$ & $<0.010$ & $<0.010$ & $<0.010$ & $<0.010$ & $<0.010$ \\
\hline November $^{a}$ & -- & -- & -- & -- & -- & -- & -- & -- \\
\hline December & $<0.002$ & $<0.002$ & $<0.010$ & $<0.010$ & $<0.010$ & $<0.010$ & $<0.010$ & $<0.010$ \\
\hline
\end{tabular}

Note: No results exceeded the permit limits.

${ }^{a}$ No discharge this month 
Table C-2D (concluded)

2003 SPDES Results for Outfall 001 (WNSP001): Metals

\begin{tabular}{|c|c|c|c|c|c|c|c|c|c|c|}
\hline \multirow{3}{*}{$\begin{array}{l}\text { Permit limit } \\
\text { Month }\end{array}$} & \multicolumn{2}{|c|}{$\begin{array}{l}\text { Iron } \\
\text { Total } \\
(\mathrm{mg} / \mathrm{L})\end{array}$} & \multicolumn{2}{|c|}{$\begin{array}{c}\text { Lead } \\
\text { Total Recoverable } \\
(\mathrm{mg} / \mathrm{L})\end{array}$} & \multicolumn{2}{|c|}{$\begin{array}{l}\text { Manganese } \\
\text { Total } \\
(\mathrm{mg} / \mathrm{L})\end{array}$} & \multicolumn{2}{|c|}{$\begin{array}{c}\text { Mercury, Total } \\
\text { (per EPA Method 245.1) } \\
(\mathrm{mg} / \mathrm{L})\end{array}$} & \multicolumn{2}{|c|}{$\begin{array}{c}\text { Mercury, Total } \\
\text { (per EPA Method 1631) } \\
(\mu \mathrm{g} / \mathrm{L})\end{array}$} \\
\hline & \multicolumn{2}{|c|}{ Monitor } & \multicolumn{2}{|c|}{$\begin{array}{l}0.006 \mathrm{mg} / \mathrm{L} \text { daily } \\
\text { maximum }\end{array}$} & \multicolumn{2}{|c|}{$\begin{array}{l}2.0 \mathrm{mg} / \mathrm{L} \text { daily } \\
\text { maximum }\end{array}$} & \multicolumn{2}{|c|}{$\begin{array}{l}0.0002 \mathrm{mg} / \mathrm{L} \text { daily } \\
\text { maximum }\end{array}$} & \multicolumn{2}{|c|}{ Monitor } \\
\hline & Avg & Max & Avg & Max & Avg & Max & Avg & Max & Avg & Max \\
\hline January & 0.236 & 0.342 & 0.0007 & 0.0007 & 0.096 & 0.14 & $<0.0002$ & $<0.0002$ & 0.0455 & 0.0567 \\
\hline February $^{a}$ & - & - & -- & -- & - & - & - & - & - & - \\
\hline March & 0.235 & 0.254 & 0.0009 & 0.001 & 0.069 & 0.11 & $<0.0002$ & $<0.0002$ & 0.0224 & 0.0274 \\
\hline April & 0.177 & 0.228 & $<0.0005$ & $<0.0005$ & 0.013 & 0.016 & $<0.0002$ & .0002 & 0.0145 & 0.0170 \\
\hline May $^{a}$ & - & - & -- & -- & - & 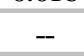 & - & - & - & - \\
\hline June & 0.222 & 0.281 & $<0.0005$ & $<0.0005$ & 0.038 & 0.038 & $<0.0002$ & $<0.0002$ & 0.00475 & 0.00554 \\
\hline$J_{u l y}{ }^{a}$ & - & - & -- & -- & - & - & - & - & - & - \\
\hline August & 0.0727 & 0.0861 & $<0.0005$ & $<0.0005$ & 0.027 & 0.037 & $<0.0002$ & $<0.0002$ & 0.00619 & 0.00715 \\
\hline September $^{a}$ & - & - & -- & -- & - & - & - & - & - & - \\
\hline October & 0.139 & 0.169 & $<0.0005$ & $<0.0005$ & 0.014 & 0.016 & $<0.0002$ & $<0.0002$ & 0.0135 & 0.0159 \\
\hline November $^{a}$ & - & - & -- & -- & - & - & - & - & - & - \\
\hline December & 0.197 & 0.235 & 0.0005 & 0.0006 & 0.019 & 0.022 & $<0.0002$ & $<0.0002$ & 0.00836 & 0.00881 \\
\hline
\end{tabular}

\begin{tabular}{|c|c|c|c|c|c|c|c|c|}
\hline \multirow{3}{*}{$\begin{array}{l}\text { Permit limit } \\
\text { Month }\end{array}$} & \multirow{2}{*}{\multicolumn{2}{|c|}{$\begin{array}{c}\text { Nickel } \\
\text { Total Recoverable } \\
(\mathrm{mg} / \mathrm{L})\end{array}$}} & \multirow{2}{*}{\multicolumn{2}{|c|}{$\begin{array}{c}\text { Selenium } \\
\text { Total Recoverable } \\
(\mathrm{mg} / \mathrm{L})\end{array}$}} & \multirow{2}{*}{\multicolumn{2}{|c|}{$\begin{array}{c}\text { Vanadium } \\
\text { Total Recoverable } \\
(\mathrm{mg} / \mathrm{L})\end{array}$}} & \multirow{2}{*}{\multicolumn{2}{|c|}{$\begin{array}{c}\text { Zinc } \\
\text { Total Recoverable } \\
(\mathrm{mg} / \mathrm{L})\end{array}$}} \\
\hline & & & & & & & & \\
\hline & Avg & Max & Avg & Max & Avg & Max & Avg & Max \\
\hline January & $<0.010$ & $<0.010$ & 0.001 & 0.001 & $<0.010$ & $<0.010$ & $<0.010$ & $<0.010$ \\
\hline February $^{a}$ & - & - & -- & -- & - & - & - & - \\
\hline March & $<0.010$ & $<0.010$ & 0.003 & 0.003 & $<0.010$ & $<0.010$ & $<0.027$ & 0.041 \\
\hline April & $<0.010$ & $<0.010$ & 0.003 & 0.003 & $<0.010$ & $<0.010$ & $<0.010$ & $<0.010$ \\
\hline $\operatorname{May}^{a}$ & - & - & -- & -- & - & - & - & - \\
\hline June & $<0.010$ & $<0.010$ & 0.003 & 0.003 & $<0.010$ & $<0.010$ & $<0.010$ & $<0.010$ \\
\hline July $^{a}$ & - & - & -- & -- & - & - & - & - \\
\hline August & $<0.010$ & $<0.010$ & 0.003 & 0.003 & $<0.010$ & $<0.010$ & $<0.010$ & $<0.010$ \\
\hline September $^{a}$ & - & - & -- & -- & - & - & - & - \\
\hline October & $<0.010$ & $<0.010$ & 0.003 & 0.003 & $<0.010$ & $<0.010$ & $<0.010$ & $<0.010$ \\
\hline November $^{a}$ & - & - & -- & -- & - & - & - & - \\
\hline December & $<0.010$ & $<0.010$ & $<0.003$ & 0.004 & $<0.010$ & $<0.010$ & $<0.010$ & $<0.010$ \\
\hline
\end{tabular}

Note: No results exceeded the permit limits.

${ }^{a}$ No discharge this month 
Table C-2E

\section{SPDES Results for Outfall 001 (WNSP001): Organics}

SEMIVOLATILES

\begin{tabular}{|c|c|c|c|c|c|c|c|c|}
\hline \multirow{3}{*}{$\begin{array}{l}\text { Permit limit } \\
\text { Month }\end{array}$} & \multicolumn{2}{|c|}{$\begin{array}{l}\text { 3,3-Dichlorobenzidine } \\
(\mathrm{mg} / \mathrm{L})\end{array}$} & \multicolumn{2}{|c|}{$\begin{array}{c}\text { Hexachlorobenzene } \\
(\mathrm{mg} / \mathrm{L})\end{array}$} & \multicolumn{2}{|c|}{$\begin{array}{l}\text { Heptachlor } \\
(\mathrm{mg} / \mathrm{L})\end{array}$} & \multicolumn{2}{|c|}{$\begin{array}{c}\text { Tributyl Phosphate } \\
(\mathrm{mg} / \mathrm{L})\end{array}$} \\
\hline & $\begin{array}{r}0.01 \\
\mathrm{~m}\end{array}$ & $\begin{array}{l}\text { daily } \\
\text { um }\end{array}$ & $\begin{array}{r}0.02 \\
\mathrm{n}\end{array}$ & $\begin{array}{l}\text { daily } \\
\mathrm{m}\end{array}$ & $\begin{array}{r}0.00001 \\
\max \end{array}$ & $\begin{array}{l}\text { g/L daily } \\
\text { num }\end{array}$ & & \\
\hline & Avg & Max & Avg & Max & Avg & Max & Avg & Max \\
\hline January & $<0.0099$ & $<0.0099$ & $<0.01$ & $<0.01$ & $<0.000009$ & $<0.000009$ & $<0.010$ & $<0.010$ \\
\hline February $^{a}$ & -- & -- & -- & -- & -- & -- & -- & -- \\
\hline March & $<0.0099$ & $<0.0099$ & $<0.01$ & $<0.01$ & $<0.000009$ & $<0.000009$ & $<0.010$ & $<0.010$ \\
\hline April & $<0.0099$ & $<0.0099$ & $<0.01$ & $<0.01$ & $<0.000009$ & $<0.000009$ & $<0.010$ & $<0.010$ \\
\hline May $^{a}$ & -- & -- & -- & -- & -- & -- & -- & -- \\
\hline June & $<0.0099$ & $<0.0099$ & $<0.01$ & $<0.01$ & $<0.000009$ & $<0.000009$ & $<0.010$ & $<0.010$ \\
\hline$J_{u l y}{ }^{a}$ & -- & -- & -- & -- & -- & -- & -- & -- \\
\hline August & $<0.0099$ & $<0.0099$ & $<0.01$ & $<0.01$ & $<0.000009$ & $<0.000009$ & $<0.010$ & $<0.010$ \\
\hline September $^{a}$ & -- & -- & -- & -- & -- & -- & -- & -- \\
\hline October & $<0.0099$ & $<0.0099$ & $<0.01$ & $<0.01$ & $<0.000009$ & $<0.000009$ & $<0.010$ & $<0.010$ \\
\hline November $^{a}$ & -- & -- & -- & -- & -- & -- & -- & -- \\
\hline December & $<0.0099$ & $<0.0099$ & $<0.01$ & $<0.01$ & $<0.000009$ & $<0.000009$ & $<0.010$ & $<0.010$ \\
\hline
\end{tabular}

VOLATILES

\begin{tabular}{|c|c|c|c|c|c|c|}
\hline & \multirow{2}{*}{\multicolumn{2}{|c|}{$\begin{array}{c}\text { 2-Butanone } \\
(\mathrm{mg} / \mathrm{L})\end{array}$}} & \multirow{2}{*}{\multicolumn{2}{|c|}{$\begin{array}{c}\text { Xylene } \\
(\mathrm{mg} / \mathrm{L})\end{array}$}} & \multirow{2}{*}{\multicolumn{2}{|c|}{$\begin{array}{c}\begin{array}{c}\text { Alpha-BHC } \\
(\mathrm{mg} / \mathrm{L})\end{array} \\
\begin{array}{c}0.00001 \mathrm{mg} / \mathrm{L} \text { daily } \\
\text { maximum }\end{array}\end{array}$}} \\
\hline Permit limit & & & & & & \\
\hline Month & Avg & Max & Avg & Max & Avg & Max \\
\hline January & $<0.01$ & $<0.01$ & $<0.005$ & $<0.005$ & $<0.000009$ & $<0.000009$ \\
\hline February $^{a}$ & -- & -- & -- & -- & -- & -- \\
\hline March & $<0.01$ & $<0.01$ & $<0.005$ & $<0.005$ & $<0.000009$ & $<0.000009$ \\
\hline April & $<0.01$ & $<0.01$ & $<0.005$ & $<0.005$ & $<0.000009$ & $<0.000009$ \\
\hline May $^{a}$ & -- & -- & -- & -- & -- & -- \\
\hline June & $<0.01$ & $<0.01$ & $<0.005$ & $<0.005$ & $<0.000009$ & $<0.000009$ \\
\hline July $^{a}$ & -- & -- & -- & -- & - & -- \\
\hline August & $<0.01$ & $<0.01$ & $<0.01$ & $<0.01$ & $<0.000009$ & $<0.000009$ \\
\hline September $^{a}$ & -- & -- & -- & -- & -- & -- \\
\hline October & $<0.01$ & $<0.01$ & $<0.01$ & $<0.01$ & $<0.000009$ & $<0.000009$ \\
\hline November $^{a}$ & -- & -- & -- & -- & -- & -- \\
\hline December & $<0.01$ & $<0.01$ & $<0.01$ & $<0.01$ & $<0.000009$ & $<0.000009$ \\
\hline
\end{tabular}

${ }^{a}$ No discharge this month

Note: No results exceeded the permit limits.

$C-17$

WVDP Annual Site Environmental Report

Calendar Year 2003 
Table C-2F

2003 SPDES Results for Outfall 007 (WNSP007):

Water Quality and Iron

\begin{tabular}{|c|c|c|c|c|c|c|c|c|c|c|}
\hline \multirow{3}{*}{$\begin{array}{l}\text { Permit limit } \\
\text { Month }\end{array}$} & \multicolumn{2}{|c|}{$\begin{array}{c}\text { Ammonia } \\
\left(\operatorname{as~} \mathbf{N H}_{\mathbf{3}}\right) \\
(\mathrm{mg} / \mathrm{L})\end{array}$} & \multicolumn{2}{|c|}{$\begin{array}{l}\mathbf{B O D}_{\mathbf{5}} \\
(\mathrm{mg} / \mathrm{L})\end{array}$} & \multicolumn{2}{|c|}{$\begin{array}{c}\text { Chlorine } \\
\text { Total Residual } \\
(\mathrm{mg} / \mathrm{L})\end{array}$} & \multicolumn{2}{|c|}{$\begin{array}{l}\text { Discharge Rate } \\
\text { (MGD) }\end{array}$} & \multicolumn{2}{|c|}{$\begin{array}{l}\text { Iron } \\
\text { Total } \\
(\mathrm{mg} / \mathrm{L})\end{array}$} \\
\hline & \multicolumn{2}{|c|}{ Monitor } & \multicolumn{2}{|c|}{$\begin{array}{l}10 \mathrm{mg} / \mathrm{L} \text { daily } \\
\text { maximum }\end{array}$} & \multicolumn{2}{|c|}{$\begin{array}{l}0.1 \mathrm{mg} / \mathrm{L} \text { daily } \\
\text { maximum }\end{array}$} & \multicolumn{2}{|c|}{ Monitor } & \multicolumn{2}{|c|}{ Monitor } \\
\hline & Avg & Max & Avg & Max & Avg & Max & Avg & Max & Avg & Max \\
\hline January & $<0.012$ & $<0.012$ & $<2.0$ & $<2.0$ & 0.02 & 0.03 & 0.025 & 0.044 & 0.147 & 0.201 \\
\hline February & $<0.016$ & 0.022 & $<2.0$ & $<2.0$ & 0.03 & 0.04 & 0.031 & 0.035 & $<0.166$ & 0.253 \\
\hline March & 0.029 & 0.049 & $<2.1$ & 2.3 & 0.03 & 0.05 & 0.029 & 0.038 & 0.138 & 0.198 \\
\hline April & $<0.017$ & 0.028 & 3.0 & 4.1 & 0.03 & 0.04 & 0.026 & 0.017 & $<0.049$ & 0.065 \\
\hline May & $<0.035$ & 0.062 & $<2.2$ & 2.6 & 0.01 & 0.03 & 0.021 & 0.042 & 0.124 & 0.169 \\
\hline June & $<0.050$ & $<0.066$ & $>2.0$ & $>2.0$ & 0.02 & 0.04 & 0.022 & 0.022 & 0.079 & 0.092 \\
\hline July & $<0.050$ & $<0.050$ & 3.6 & 4.0 & 0.01 & 0.02 & 0.020 & 0.032 & $<0.051$ & 0.0521 \\
\hline August & $<0.050$ & $<0.050$ & 2.6 & 3.0 & 0.02 & 0.02 & 0.018 & 0.020 & $<0.068$ & 0.0782 \\
\hline September & $<0.050$ & $<0.050$ & $<2.3$ & 2.8 & 0.01 & 0.02 & 0.020 & 0.031 & $<0.050$ & $<0.050$ \\
\hline October & $<0.050$ & $<0.050$ & $<2.0$ & $<2.0$ & 0.02 & 0.04 & 0.026 & 0.045 & $<0.088$ & 0.112 \\
\hline November & $<0.050$ & $<0.050$ & $<2.2$ & 2.5 & 0.02 & 0.03 & 0.038 & 0.048 & 0.112 & 0.141 \\
\hline December & $<0.087$ & 0.16 & $<2.1$ & 2.2 & 0.03 & 0.04 & 0.041 & 0.043 & 0.0975 & 0.144 \\
\hline
\end{tabular}

\begin{tabular}{|c|c|c|c|c|c|c|c|c|c|c|}
\hline \multirow{3}{*}{\begin{tabular}{|l} 
Permit limit \\
Month \\
\end{tabular}} & \multirow{2}{*}{\multicolumn{2}{|c|}{$\begin{array}{c}\begin{array}{c}\text { Nitrite } \\
(\text { as } \mathbf{N})\end{array} \\
(\mathrm{mg} / \mathrm{L}) \\
0.1 \mathrm{mg} / \mathrm{L} \text { daily } \\
\text { maximum }\end{array}$}} & \multirow{2}{*}{\multicolumn{2}{|c|}{ 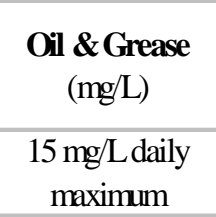 }} & \multirow{2}{*}{\multicolumn{2}{|c|}{$\begin{array}{c}\mathbf{p H} \\
\text { (standard units) } \\
6.5 \text { to } 8.5\end{array}$}} & \multirow{2}{*}{\multicolumn{2}{|c|}{$\begin{array}{c}\text { Solids } \\
\text { Settleable } \\
(\mathrm{mL} / \mathrm{L})\end{array}$}} & \multirow{2}{*}{\multicolumn{2}{|c|}{$\begin{array}{c}\text { Solids } \\
\text { Total } \text { Suspended } \\
(\mathrm{mg} / \mathrm{L})\end{array}$}} \\
\hline & & & & & & & & & & \\
\hline & Avg & Max & Avg & Max & Min & Max & Avg & Max & Avg & Max \\
\hline January & $<0.05$ & $<0.05$ & $<5.0$ & $<5.0$ & 7.7 & 7.9 & $<0.1$ & $<0.1$ & $<2.0$ & $<2.0$ \\
\hline February & $<0.05$ & $<0.05$ & $<5.0$ & $<5.0$ & 7.5 & 7.7 & $<0.2$ & $<0.3$ & $<2.7$ & 3.0 \\
\hline March & $<0.05$ & $<0.05$ & $<5.0$ & $<5.0$ & 7.5 & 7.8 & $<0.1$ & $<0.1$ & $<2.3$ & 3.0 \\
\hline April & $<0.05$ & $<0.05$ & $<5.0$ & $<5.0$ & 7.3 & 7.7 & $<0.1$ & $<0.1$ & $<3.3$ & 6.0 \\
\hline May & $<0.05$ & $<0.05$ & $<5.0$ & $<5.0$ & 7.1 & 7.7 & $<0.1$ & $<0.1$ & $<2.7$ & 4.0 \\
\hline June & $<0.05$ & $<0.05$ & $<5.0$ & $<5.0$ & 7.5 & 7.6 & $<0.1$ & $<0.1$ & $>2.0$ & $>2.0$ \\
\hline July & $<0.05$ & $<0.05$ & $<5.0$ & $<5.0$ & 7.3 & 7.6 & $<0.1$ & $<0.1$ & $<2.0$ & $<2.0$ \\
\hline August & $<0.05$ & $<0.05$ & $<5.0$ & $<5.0$ & 7.4 & 7.5 & $<0.2$ & $<0.3$ & $<4.7$ & 10.0 \\
\hline September & $<0.05$ & $<0.05$ & $<5.0$ & $<5.0$ & 7.4 & 7.8 & $<0.2$ & $<0.3$ & $<2.0$ & 2.0 \\
\hline October & $<0.05$ & $<0.05$ & $<5.0$ & $<5.0$ & 7.0 & 8.0 & $<0.1$ & $<0.2$ & $<3.0$ & 5.0 \\
\hline November & $<0.05$ & $<0.05$ & $<5.0$ & $<5.0$ & 7.7 & 7.9 & $<0.1$ & $<0.1$ & $<2.0$ & $<2.0$ \\
\hline December & $<0.05$ & $<0.05$ & $<5.0$ & $<5.0$ & 7.5 & 7.8 & $<0.1$ & $<0.1$ & $<3.0$ & 5.0 \\
\hline
\end{tabular}

Note: No results exceeded the permit limits. 
Table C-2G

2003 SPDES Results for Outfall 008 (WNSP008):

Water Quality

\author{
NO DISCHARGE FROM THE \\ FRENCH DRAIN (WNSP008) SINCE MAY 2001
}

C -19 
Table C-2H

2003 SPDES Results for Sums of Outfalls 001, 007, 008, and 116:

Water Quality

$\underline{2003 \text { Results for Sums of Outfalls } 001,007 \text { and } 008}$

\begin{tabular}{|c|c|c|c|c|c|}
\hline & \multicolumn{2}{|c|}{$\begin{array}{c}\text { Ammonia }^{\mathbf{a}} \\
\text { Flow-Weighted Average } \\
(\mathrm{mg} / \mathrm{L})\end{array}$} & \multicolumn{2}{|c|}{$\begin{array}{c}\mathbf{B O D}_{\mathbf{5}} \text { day } \\
(\mathrm{mg} / \mathrm{L})\end{array}$} & $\begin{array}{c}\text { Iron } \\
\text { Flow-Weighted Average } \\
(\mathrm{mg} / \mathrm{L})\end{array}$ \\
\hline Permit limit & \multicolumn{2}{|c|}{$\begin{array}{l}2.1 \text { daily maximum; } \\
1.49 \text { daily average }\end{array}$} & \multicolumn{2}{|c|}{5.0 daily average } & 0.30 daily average \\
\hline Month & Avg & Max & Avg & Max & Avg \\
\hline January & $<0.14$ & $<0.27$ & $<2.0$ & $<2.0$ & 0.00 \\
\hline February $^{b}$ & $<0.016$ & 0.022 & $<2.0$ & $<2.0$ & 0.00 \\
\hline March & 0.19 & 0.28 & $<2.0$ & $<2.0$ & 0.00 \\
\hline April & $<0.012$ & $<0.012$ & $<2.2$ & 2.4 & 0.00 \\
\hline$M a y^{b}$ & $<0.035$ & 0.062 & $<2.2$ & 2.6 & 0.00 \\
\hline June & $<0.058$ & $<0.088$ & $>2.1$ & $>2.1$ & 0.00 \\
\hline$J_{u l y}{ }^{b}$ & $<0.050$ & $<0.050$ & 3.6 & 4.0 & 0.00 \\
\hline August & $<0.050$ & $<0.050$ & $<2.5$ & 3.2 & 0.00 \\
\hline September ${ }^{b}$ & $<0.050$ & $<0.050$ & $<2.3$ & 2.8 & 0.00 \\
\hline October & $<0.050$ & $<0.050$ & $<2.1$ & $<2.4$ & 0.00 \\
\hline November $^{b}$ & $<0.050$ & $<0.050$ & $<2.2$ & 2.5 & 0.00 \\
\hline December & $<0.063$ & 0.089 & $<2.1$ & 2.2 & 0.00 \\
\hline
\end{tabular}

\section{$\underline{2003}$ Results for Outfall 116}

\begin{tabular}{|l|c|c|}
\hline \multirow{2}{*}{ Permit limit } & \multicolumn{2}{|c|}{$\begin{array}{c}\text { Total Dissolved Solids } \\
\text { (mg/L) }\end{array}$} \\
\hline Month & \multicolumn{2}{|c|}{ Avg } \\
maximum
\end{tabular}

Note: No results exceeded the permit limits.

a Sum of Outfalls 001 and 007 only

${ }^{b}$ No discharge this month 
Table C-2I

2003 Quarterly/Semiannual/Annual SPDES Results for Outfall 001 (WNSP001): Water Quality, Metals, and Organics

\begin{tabular}{|c|c|c|c|c|}
\hline & $\begin{array}{c}\text { Action } \\
\text { Level }\end{array}$ & $\begin{array}{l}\text { Monitoring } \\
\text { Frequency }\end{array}$ & $\begin{array}{l}\text { Collection } \\
\text { Date }\end{array}$ & $\begin{array}{l}\text { Maximum } \\
\text { Measured }\end{array}$ \\
\hline $\begin{array}{l}\text { Boron, Total } \\
\quad(\mathrm{mg} / \mathrm{L})\end{array}$ & $\begin{array}{l}2.0 \mathrm{mg} / \mathrm{L} \text { daily } \\
\text { maximum }\end{array}$ & Quarterly & $\begin{array}{c}\text { March } 2003 \\
\text { June } 2003 \\
\text { August } 2003 \\
\text { December } 2003\end{array}$ & $\begin{array}{l}0.038 \\
0.051 \\
0.051 \\
0.042\end{array}$ \\
\hline $\begin{array}{l}\text { Bromide, Total } \\
(\mathrm{mg} / \mathrm{L})\end{array}$ & $\begin{array}{l}5.0 \mathrm{mg} / \mathrm{L} \text { daily } \\
\text { maximum }\end{array}$ & Quarterly & $\begin{array}{c}\text { March } 2003 \\
\text { June } 2003 \\
\text { August } 2003 \\
\text { December } 2003\end{array}$ & $\begin{array}{l}1.1 \\
<0.5 \\
0.95 \\
0.88\end{array}$ \\
\hline $\begin{array}{l}\text { Titanium, Total } \\
(\mathrm{mg} / \mathrm{L})\end{array}$ & $\begin{array}{l}0.65 \mathrm{mg} / \mathrm{L} \text { daily } \\
\text { maximum }\end{array}$ & Semiannual & $\begin{array}{l}\text { March } 2003 \\
\text { August } 2003\end{array}$ & $\begin{array}{l}<0.005 \\
<0.005\end{array}$ \\
\hline $\begin{array}{l}\text { Bis(2-ethylhexyl)phthalate } \\
(\mathrm{mg} / \mathrm{L})\end{array}$ & $\begin{array}{l}1.6 \mathrm{mg} / \mathrm{L} \text { daily } \\
\text { maximum }\end{array}$ & Semiannual & $\begin{array}{l}\text { March } 2003 \\
\text { August } 2003\end{array}$ & $\begin{array}{l}<0.010 \\
<0.010\end{array}$ \\
\hline $\begin{array}{c}\text { 4-dodecene } \\
(\mathrm{mg} / \mathrm{L})\end{array}$ & $\begin{array}{l}0.6 \mathrm{mg} / \mathrm{L} \text { daily } \\
\text { maximum }\end{array}$ & Semiannual & $\begin{array}{l}\text { March } 2003 \\
\text { August } 2003\end{array}$ & $\begin{array}{l}<0.060 \\
<0.060\end{array}$ \\
\hline $\begin{array}{l}\text { Chloroform } \\
(\mathrm{mg} / \mathrm{L})\end{array}$ & $\begin{array}{l}0.3 \mathrm{mg} / \mathrm{L} \text { daily } \\
\text { maximum }\end{array}$ & Annual & March 2003 & $<0.005$ \\
\hline $\begin{array}{l}\text { Antimony, Total } \\
(\mathrm{mg} / \mathrm{L})\end{array}$ & $\begin{array}{l}1.0 \mathrm{mg} / \mathrm{L} \text { daily } \\
\text { maximum }\end{array}$ & Annual & March 2003 & $<0.02$ \\
\hline $\begin{array}{l}\text { Barium, Total } \\
(\mathrm{mg} / \mathrm{L})\end{array}$ & $\begin{array}{l}0.5 \mathrm{mg} / \mathrm{L} \text { daily } \\
\text { maximum }\end{array}$ & Annual & March 2003 & 0.04 \\
\hline $\begin{array}{l}\text { Dichlorodifluoromethane } \\
(\mathrm{mg} / \mathrm{L})\end{array}$ & $\begin{array}{l}0.01 \mathrm{mg} / \mathrm{L} \text { daily } \\
\text { maximum }\end{array}$ & Annual & March 2003 & $<0.005$ \\
\hline $\begin{array}{c}\text { Trichlorofluoromethane } \\
(\mathrm{mg} / \mathrm{L})\end{array}$ & $\begin{array}{l}0.01 \mathrm{mg} / \mathrm{L} \text { daily } \\
\text { maximum }\end{array}$ & Annual & March 2003 & $<0.005$ \\
\hline
\end{tabular}

Note: No results exceeded the permit limits.

$C-21$ 
Table C-2J

2003 Annual SPDES Results for Outfall 007 (WNSP007):

Water Quality

\begin{tabular}{|c|c|c|c|c|}
\hline & $\begin{array}{c}\text { Action } \\
\text { Level }\end{array}$ & $\begin{array}{c}\text { Monitoring } \\
\text { Frequency }\end{array}$ & $\begin{array}{c}\text { Collection } \\
\text { Date }\end{array}$ & $\begin{array}{c}\text { Maximum } \\
\text { Measured }\end{array}$ \\
\hline $\begin{array}{c}\text { Chloroform } \\
(\mathrm{mg} / \mathrm{L})\end{array}$ & $\begin{array}{c}0.20 \mathrm{mg} / \mathrm{L} \text { daily } \\
\text { maximum }\end{array}$ & Annual & January 2004 & $<0.005$ \\
\hline
\end{tabular}

Table C-2K

2003 Annual SPDES Results for Outfall 008 (WNSP008):

Water Quality

NO DISCHARGE FROM THE

FRENCH DRAIN (WNSP008) SINCE MAY 2001

$C-22$ 
Table C-2L

2003 SPDES Results for Outfall 01B (WNSP01B):

Water Quality

\begin{tabular}{|c|c|c|c|c|c|c|c|}
\hline \multirow{3}{*}{$\begin{array}{l}\text { Permit limit } \\
\text { Month }\end{array}$} & \multirow{2}{*}{\multicolumn{2}{|c|}{$\begin{array}{l}\text { Discharge Rate } \\
\text { (GPD) }\end{array}$}} & \multirow[t]{3}{*}{$\mathbf{N}$} & \multirow{2}{*}{\multicolumn{2}{|c|}{ 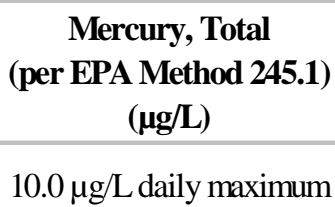 }} & \multirow{2}{*}{\multicolumn{2}{|c|}{$\begin{array}{c}\begin{array}{c}\text { Mercury, Total } \\
\text { (per EPA Method 1631 } \\
(\mu \mathrm{g} / \mathrm{L})\end{array} \\
\text { No Limit }\end{array}$}} \\
\hline & & & & & & & \\
\hline & Avg & Max & & Avg & Max & Avg & Max \\
\hline Janиагу & 6,846 & 7,663 & 2 & $<0.2$ & $<0.2$ & 0.00682 & 0.00734 \\
\hline February & 7,811 & 9,395 & 2 & $<0.2$ & $<0.2$ & 0.0110 & 0.0129 \\
\hline March & -- & -- & -- & - & -- & -- & -- \\
\hline April & -- & -- & -- & - & -- & -- & -- \\
\hline May & -- & -- & -- & - & -- & -- & -- \\
\hline June & -- & -- & -- & - & -- & -- & -- \\
\hline July & -- & -- & -- & - & -- & -- & -- \\
\hline August & -- & -- & -- & - & -- & -- & -- \\
\hline September & -- & -- & -- & - & -- & -- & -- \\
\hline October & -- & -- & -- & - & -- & -- & -- \\
\hline November & -- & -- & -- & - & -- & -- & -- \\
\hline December & -- & -- & -- & - & -- & -- & -- \\
\hline
\end{tabular}

Note: No results exceeded the permit limits.

$N$ - Number of samples

-- No discharge through the internal monitoring location during this month

\section{Table C-2M}

\section{Results at Sewage Treatment Outfall (WNSP007)}

\begin{tabular}{|l|c|c|c|c|c|c|}
\hline \multirow{2}{*}{\multicolumn{1}{|c|}{ Analyte }} & \multirow{2}{*}{ Units } & \multirow{2}{*}{$\mathbf{N}$} & \multicolumn{3}{c|}{ WNSP007 Concentrations } & \multirow{2}{*}{ Guideline $^{\text {a }}$} \\
\cline { 4 - 6 } & & & Minimum & Average & Maximum & \\
\hline Gross Alpha & $\mu \mathrm{Ci} / \mathrm{mL}$ & 36 & $<1.52 \mathrm{E}-09$ & $0.23 \pm 3.24 \mathrm{E}-09$ & $3.78 \mathrm{E}-09$ & $3 \mathrm{E}-08^{\mathrm{b}}$ \\
\hline Gross Beta & $\mu \mathrm{Ci} / \mathrm{mL}$ & 36 & $5.88 \mathrm{E}-09$ & $1.65 \pm 0.50 \mathrm{E}-08$ & $2.76 \mathrm{E}-08$ & $1 \mathrm{E}-06^{\mathrm{c}}$ \\
\hline Tritium & $\mu \mathrm{Ci} / \mathrm{mL}$ & 36 & $<5.90 \mathrm{E}-08$ & $3.78 \pm 8.11 \mathrm{E}-08$ & $1.46 \mathrm{E}-07$ & $2 \mathrm{E}-03$ \\
\hline Sr-90 & $\mu \mathrm{Ci} / \mathrm{mL}$ & 3 & $3.13 \mathrm{E}-09$ & $6.93 \pm 2.74 \mathrm{E}-09$ & $1.17 \mathrm{E}-08$ & $1 \mathrm{E}-06$ \\
\hline Cs-137 & $\mu \mathrm{Ci} / \mathrm{mL}$ & 4 & $<2.01 \mathrm{E}-09$ & $1.97 \pm 2.83 \mathrm{E}-09$ & $4.09 \mathrm{E}-09$ & $3 \mathrm{E}-06$ \\
\hline
\end{tabular}

$N$ - Number of samples

${ }^{a}$ DOE ingestion-based DCGs for $100 \mathrm{mrem} / \mathrm{yr}$ dose limit are provided as a guideline for radiological results.

${ }^{b}$ Alpha as Am-241

${ }^{c}$ Beta as $\operatorname{Sr}-90$

WVDP Annual Site Environmental Report

$$
\text { C - } 23
$$

Calendar Year 2003 
This page intentionally left blank

$$
\text { C }-24
$$




\section{Appendix C-3 \\ Site Surface Drainage, Subsurface Drainage, and Contained Water}

$C-25$ 
This page intentionally left blank

$$
\text { C }-26
$$


Table C-3A

2003 Results in Surface Water at Facility Yard Drainage (WNSP005)

\begin{tabular}{|c|c|c|c|c|c|c|}
\hline \multirow{2}{*}{ Analyte } & \multirow{2}{*}{ Units } & \multirow{2}{*}{$\mathbf{N}$} & \multicolumn{3}{|c|}{ WNSP005 Concentrations } & \multirow{2}{*}{$\begin{array}{c}\text { Guideline }^{\mathrm{a}} \text { or } \\
\text { Standard }^{\mathrm{b}}\end{array}$} \\
\hline & & & Minimum & Average & Maximum & \\
\hline Gross Alpha & $\mu \mathrm{Ci} / \mathrm{mL}$ & 12 & $<1.08 \mathrm{E}-09$ & $1.77 \pm 2.95 \mathrm{E}-09$ & 8.48E-09 & $3 \mathrm{E}-08^{\mathrm{c}}$ \\
\hline Gross Beta & $\mu \mathrm{Ci} / \mathrm{mL}$ & 12 & $2.50 \mathrm{E}-08$ & $1.99 \pm 0.10 \mathrm{E}-07$ & $4.53 \mathrm{E}-07$ & $1 \mathrm{E}-06^{\mathrm{d}}$ \\
\hline Tritium & $\mu \mathrm{Ci} / \mathrm{mL}$ & 12 & $<5.93 \mathrm{E}-08$ & $3.60 \pm 8.13 \mathrm{E}-08$ & $1.26 \mathrm{E}-07$ & $2 \mathrm{E}-03$ \\
\hline Sr-90 & $\mu \mathrm{Ci} / \mathrm{mL}$ & 3 & 4.99E-08 & $7.37 \pm 0.56 \mathrm{E}-08$ & 1.07E-07 & $1 \mathrm{E}-06$ \\
\hline Cs-137 & $\mu \mathrm{Ci} / \mathrm{mL}$ & 3 & $<1.90 \mathrm{E}-09$ & $2.06 \pm 2.57 \mathrm{E}-09$ & $<3.54 \mathrm{E}-09$ & $3 \mathrm{E}-06$ \\
\hline pH & SU & 12 & 6.63 & 7.18 & 7.85 & $6.0-9.5$ \\
\hline
\end{tabular}

$N$ - Number of samples

$S U$ - Standard units

${ }^{a}$ DOE ingestion-based DCGs for $100 \mathrm{mrem} / \mathrm{yr}$ dose limit are provided as a guideline for radiological results.

${ }^{b}$ New York State Water Quality Standards for Class “D” as a comparative reference for nonradiological results

${ }^{c}$ Alpha as Am-241

${ }^{d}$ Beta as Sr-90

Table C-3B

2003 Results in Surface Water at French Drain (WNSP008)

NO DISCHARGE FROM THE

FRENCH DRAIN DURING CY 2003

$C-27$ 
Table C-3C

2003 Results in Surface Water at the North Swamp (WNSW74A)

RADIOACTIVITY CONCENTRATIONS

\begin{tabular}{|c|c|c|c|c|c|c|c|}
\hline \multirow{3}{*}{ Analyte } & \multirow{3}{*}{ Units } & \multirow{3}{*}{$\mathbf{N}$} & \multirow{2}{*}{\multicolumn{2}{|c|}{$\begin{array}{c}\text { WNSW74A } \\
\text { Concentrations }\end{array}$}} & \multirow{3}{*}{$\mathbf{N}$} & \multicolumn{2}{|c|}{ Reference Values } \\
\hline & & & & & & \multirow{2}{*}{$\begin{array}{l}\text { Background Range } \\
\text { WFBCBKG }^{\mathrm{a}}\end{array}$} & \multirow{2}{*}{ Guideline $^{\mathrm{b}}$} \\
\hline & & & Average & Maximum & & & \\
\hline Gross Alpha & $\mu \mathrm{Ci} / \mathrm{mL}$ & 52 & $-0.17 \pm 3.19 \mathrm{E}-09$ & $3.26 \mathrm{E}-09$ & 12 & $<5.80 \mathrm{E}-10-1.08 \mathrm{E}-09$ & $3 \mathrm{E}-08^{\mathrm{c}}$ \\
\hline Gross Beta & $\mu \mathrm{Ci} / \mathrm{mL}$ & 52 & $1.38 \pm 0.50 \mathrm{E}-08$ & 2.87E-08 & 12 & $<1.23 \mathrm{E}-09-4.76 \mathrm{E}-09$ & $1 \mathrm{E}-06^{\mathrm{d}}$ \\
\hline Tritium & $\mu \mathrm{Ci} / \mathrm{mL}$ & 52 & $3.15 \pm 8.32 \mathrm{E}-08$ & $2.80 \mathrm{E}-07$ & 12 & $<8.06 \mathrm{E}-08-2.29 \mathrm{E}-07$ & $2 \mathrm{E}-03$ \\
\hline C-14 & $\mu \mathrm{Ci} / \mathrm{mL}$ & 4 & $-0.59 \pm 1.89 \mathrm{E}-08$ & $<2.65 \mathrm{E}-08$ & 4 & $<1.34 \mathrm{E}-08-<2.66 \mathrm{E}-08$ & $7 \mathrm{E}-05$ \\
\hline Sr-90 & $\mu \mathrm{Ci} / \mathrm{mL}$ & 12 & $6.13 \pm 2.20 \mathrm{E}-09$ & $8.69 \mathrm{E}-09$ & 4 & $<9.20 \mathrm{E}-10-1.76 \mathrm{E}-09$ & 1E-06 \\
\hline I-129 & $\mu \mathrm{Ci} / \mathrm{mL}$ & 4 & $5.44 \pm 6.80 \mathrm{E}-10$ & $1.31 \mathrm{E}-09$ & 4 & $<5.25 \mathrm{E}-10-1.42 \mathrm{E}-09$ & $5 \mathrm{E}-07$ \\
\hline Cs-137 & $\mu \mathrm{Ci} / \mathrm{mL}$ & 12 & $1.16 \pm 8.51 \mathrm{E}-09$ & $1.18 \mathrm{E}-08$ & 4 & $<1.84 \mathrm{E}-09-<3.33 \mathrm{E}-09$ & 3E-06 \\
\hline U-232 & $\mu \mathrm{Ci} / \mathrm{mL}$ & 4 & $1.35 \pm 4.53 \mathrm{E}-11$ & $<4.89 \mathrm{E}-11$ & 4 & $<3.14 \mathrm{E}-11-<5.23 \mathrm{E}-11$ & $1 \mathrm{E}-07$ \\
\hline U-233/234 & $\mu \mathrm{Ci} / \mathrm{mL}$ & 4 & $1.61 \pm 0.82 \mathrm{E}-10$ & $2.35 \mathrm{E}-10$ & 4 & $<6.60 \mathrm{E}-11-1.20 \mathrm{E}-10$ & $5 \mathrm{E}-07$ \\
\hline U-235/236 & $\mu \mathrm{Ci} / \mathrm{mL}$ & 4 & $3.48 \pm 4.41 \mathrm{E}-11$ & $3.85 \mathrm{E}-11$ & 4 & $<1.76 \mathrm{E}-11-2.88 \mathrm{E}-11$ & $5 \mathrm{E}-07^{\mathrm{e}}$ \\
\hline U-238 & $\mu \mathrm{Ci} / \mathrm{mL}$ & 4 & $1.06 \pm 0.63 \mathrm{E}-10$ & $1.29 \mathrm{E}-10$ & 4 & $<1.57 \mathrm{E}-11-5.63 \mathrm{E}-11$ & $6 \mathrm{E}-07$ \\
\hline Total U & $\mu \mathrm{g} / \mathrm{mL}$ & 4 & $2.96 \pm 0.11 \mathrm{E}-04$ & 3.63E-04 & 4 & 2.18E-04-4.61E-04 & -- \\
\hline Pu-238 & $\mu \mathrm{Ci} / \mathrm{mL}$ & 4 & $0.82 \pm 2.22 \mathrm{E}-11$ & $1.47 \mathrm{E}-11$ & 4 & $<1.74 \mathrm{E}-11-<3.11 \mathrm{E}-11$ & 4E-08 \\
\hline Pu-239/240 & $\mu \mathrm{Ci} / \mathrm{mL}$ & 4 & $0.47 \pm 2.08 \mathrm{E}-11$ & $<2.78 \mathrm{E}-11$ & 4 & $<2.24 \mathrm{E}-11-1.98 \mathrm{E}-10$ & $3 \mathrm{E}-08$ \\
\hline Am-241 & $\mu \mathrm{Ci} / \mathrm{mL}$ & 4 & $0.77 \pm 2.74 \mathrm{E}-11$ & $<3.14 \mathrm{E}-11$ & 4 & $<2.19 \mathrm{E}-11-3.23 \mathrm{E}-11$ & $3 \mathrm{E}-08$ \\
\hline
\end{tabular}

$N$ - Number of samples

-- No guideline or standard available for these analytes

${ }^{a}$ Background location

${ }^{b}$ DOE ingestion-based DCGs for $100 \mathrm{mrem} / y \mathrm{r}$ dose limits are provided as a guideline for radiological results.

${ }^{c}$ Alpha as Am-241

${ }^{d}$ Beta as $\mathrm{Sr}-90$

${ }^{e} D C G$ for U-236 is used for this comparison. 


\section{Table C-3C (continued) 2003 Results in Surface Water at the North Swamp (WNSW74A)}

CHEMICAL CONSTITUENTS

\begin{tabular}{|c|c|c|c|c|c|c|c|}
\hline \multirow{3}{*}{ Analyte } & \multirow{3}{*}{ Units } & \multirow{3}{*}{$\mathbf{N}$} & \multirow{2}{*}{\multicolumn{2}{|c|}{$\begin{array}{c}\text { WNSW74A } \\
\text { Concentrations }\end{array}$}} & \multirow{3}{*}{$\mathbf{N}$} & \multicolumn{2}{|c|}{ Reference Values } \\
\hline & & & & & & \multirow{2}{*}{$\begin{array}{c}\text { Background Range } \\
\text { WFBCBKG }^{\text {a }}\end{array}$} & \multirow{2}{*}{ Standard $^{\mathrm{b}}$} \\
\hline & & & Average & Maximum & & & \\
\hline Alpha-BHC & $\mathrm{mg} / \mathrm{L}$ & 2 & $<0.000009$ & $<0.000009$ & 2 & $<0.000009-<0.000009$ & 0.000002 \\
\hline Aluminum, Total & $\mathrm{mg} / \mathrm{L}$ & 2 & $<0.20$ & 0.29 & 0 & NA & -- \\
\hline Ammonia-N & $\mathrm{mg} / \mathrm{L}$ & 2 & $<0.05$ & $<0.05$ & 2 & $<0.05-<0.05$ & $0.67-29$ \\
\hline Antimony, Total & $\mathrm{mg} / \mathrm{L}$ & 2 & $<0.003$ & $<0.003$ & 2 & $<0.003-<0.003$ & -- \\
\hline Arsenic, Dissolved & $\mathrm{mg} / \mathrm{L}$ & 2 & $<0.005$ & $<0.005$ & 2 & $<0.005-<0.005$ & 0.340 \\
\hline Boron, Total & $\mathrm{mg} / \mathrm{L}$ & 2 & 0.03 & 0.04 & 2 & $0.01-0.02$ & -- \\
\hline Bromide & $\mathrm{mg} / \mathrm{L}$ & 2 & $<0.50$ & $<0.50$ & 2 & $<0.50-<0.50$ & -- \\
\hline Cadmium, Total & $\mathrm{mg} / \mathrm{L}$ & 2 & $<0.001$ & $<0.001$ & 0 & NA & -- \\
\hline Calcium, Total & $\mathrm{mg} / \mathrm{L}$ & 2 & 101 & 117 & 9 & $21.9-43.2$ & -- \\
\hline Chromium, Total & $\mathrm{mg} / \mathrm{L}$ & 2 & $<0.01$ & $<0.01$ & 0 & NA & -- \\
\hline Cobalt, Total & $\mathrm{mg} / \mathrm{L}$ & 2 & $<0.005$ & $<0.005$ & 2 & $<0.005-<0.005$ & $0.110^{c}$ \\
\hline Conductivity & $\mu \mathrm{mhos} / \mathrm{cm} @ 25^{\circ} \mathrm{C}$ & 22 & 1,679 & 2,470 & 22 & $145-279$ & -- \\
\hline Copper, Dissolved & $\mathrm{mg} / \mathrm{L}$ & 2 & $<0.005$ & $<0.005$ & 2 & $<0.005-<0.005$ & $0.044^{\mathrm{d}}$ \\
\hline Copper, Total & $\mathrm{mg} / \mathrm{L}$ & 2 & $<0.005$ & $<0.005$ & 0 & NA & -- \\
\hline Fluoride & $\mathrm{mg} / \mathrm{L}$ & 2 & $<0.12$ & 0.13 & 2 & $<0.10-<0.10$ & $33.5^{\mathrm{d}}$ \\
\hline Hardness & $\mathrm{mg} / \mathrm{L}$ & 2 & 306 & 356 & 9 & 69-132 & -- \\
\hline Iron, Total & $\mathrm{mg} / \mathrm{L}$ & 2 & 0.27 & 0.39 & 2 & $0.23-3.28$ & 0.30 \\
\hline Lead, Total & $\mathrm{mg} / \mathrm{L}$ & 2 & $<0.0005$ & $<0.0005$ & 0 & NA & -- \\
\hline Magnesium, Total & $\mathrm{mg} / \mathrm{L}$ & 2 & 13.0 & 15.4 & 9 & $3.51-5.94$ & -- \\
\hline Manganese, Total & $\mathrm{mg} / \mathrm{L}$ & 2 & 0.07 & 0.08 & 2 & $0.02-0.10$ & -- \\
\hline Mercury, Total, Method 1631 & $\mathrm{mg} / \mathrm{L}$ & 2 & 0.000001 & 0.000002 & 0 & NA & -- \\
\hline Nickel, Total & $\mathrm{mg} / \mathrm{L}$ & 2 & $<0.04$ & $<0.04$ & 0 & NA & -- \\
\hline Nitrate-N & $\mathrm{mg} / \mathrm{L}$ & 2 & 0.52 & 0.52 & 2 & $<0.05-0.16$ & -- \\
\hline Nitrite-N & $\mathrm{mg} / \mathrm{L}$ & 2 & $<0.05$ & $<0.05$ & 2 & $<0.05-<0.05$ & -- \\
\hline NPOC & $\mathrm{mg} / \mathrm{L}$ & 2 & 2.6 & 3.3 & 2 & $2.0-2.4$ & -- \\
\hline Oil \& Grease & $\mathrm{mg} / \mathrm{L}$ & 2 & $<5$ & $<5$ & 2 & $<5-<5$ & -- \\
\hline pH & SU & 24 & 7.17 & 8.81 & 24 & $6.56-8.24$ & $6.0-9.5$ \\
\hline Selenium, Total & $\mathrm{mg} / \mathrm{L}$ & 2 & $<0.001$ & $<0.001$ & 0 & NA & -- \\
\hline Solids, Total Dissolved & $\mathrm{mg} / \mathrm{L}$ & 2 & 812 & 1,050 & 2 & $125-176$ & -- \\
\hline Solids, Total Suspended & $\mathrm{mg} / \mathrm{L}$ & 2 & $<82$ & 160 & 2 & $<4-<4$ & -- \\
\hline
\end{tabular}

$N$ - Number of samples

NA - No data available

$S U$ - Standard units

-- No guideline or standard available for these analytes

a Background location

${ }^{b}$ New York State Water Quality Standards, Class “D” as a comparative reference for nonradiological results at WNSW74A

${ }^{c}$ Standards for cobalt, thallium, and vanadium are acid-soluble.

${ }^{d}$ Calculated from maximum measurement of hardness of surface water stream at WNSW74A 
Table C-3C (concluded)

2003 Results in Surface Water at the North Swamp (WNSW74A)

CHEMICAL CONSTITUENTS (concluded)

\begin{tabular}{|c|c|c|c|c|c|c|c|}
\hline \multirow{3}{*}{ Analyte } & \multirow{3}{*}{ Units } & \multirow{3}{*}{$\mathbf{N}$} & \multirow{2}{*}{\multicolumn{2}{|c|}{$\begin{array}{c}\text { WNSW74A } \\
\text { Concentrations }\end{array}$}} & \multirow{3}{*}{$\mathbf{N}$} & \multicolumn{2}{|c|}{ Reference Values } \\
\hline & & & & & & \multirow{2}{*}{$\begin{array}{c}\text { Background Range } \\
\text { WFBCBKG }^{\mathrm{a}}\end{array}$} & \multirow{2}{*}{ Standard $^{\mathrm{b}}$} \\
\hline & & & Average & Maximum & & & \\
\hline Sulfate & $\mathrm{mg} / \mathrm{L}$ & 2 & 61.7 & 68.0 & 2 & $15.8-21.4$ & -- \\
\hline Sulfide & $\mathrm{mg} / \mathrm{L}$ & 2 & $<0.04$ & $<0.04$ & 2 & $<0.04-0.62$ & - \\
\hline Surfactants & $\mathrm{mg} / \mathrm{L}$ & 2 & $<0.05$ & 0.08 & 2 & $0.04-0.04$ & -- \\
\hline Thallium, Total & $\mathrm{mg} / \mathrm{L}$ & 2 & $<0.008$ & $<0.008$ & 2 & $<0.008-<0.008$ & $0.020^{c}$ \\
\hline Titanium, Total & $\mathrm{mg} / \mathrm{L}$ & 2 & $<0.05$ & $<0.05$ & 2 & $<0.05-<0.05$ & -- \\
\hline TOX & $\mathrm{mg} / \mathrm{L}$ & 2 & 0.04 & 0.04 & 2 & $0.01-0.02$ & -- \\
\hline Vanadium, Total & $\mathrm{mg} / \mathrm{L}$ & 2 & $<0.01$ & $<0.01$ & 2 & $<0.01-<0.01$ & $0.190^{c}$ \\
\hline Zinc, Total & $\mathrm{mg} / \mathrm{L}$ & 2 & $<0.02$ & $<0.02$ & 0 & NA & -- \\
\hline
\end{tabular}

$N$ - Number of samples

NA - No data available

-- No guideline or standard available for these analytes

a Background location

${ }^{b}$ New York State Water Quality Standards, Class “D” as a comparative reference for nonradiological results at WNSW74A

${ }^{c}$ Standards for cobalt, thallium, and vanadium are acid-soluble. 
Table C-3D

2003 Results in Surface Water at the Northeast Swamp (WNSWAMP)

RADIOACTIVITY CONCENTRATIONS

\begin{tabular}{|c|c|c|c|c|c|c|c|}
\hline \multirow{3}{*}{ Analyte } & \multirow{3}{*}{ Units } & \multirow{3}{*}{$\mathbf{N}$} & \multirow{2}{*}{\multicolumn{2}{|c|}{$\begin{array}{l}\text { WNSWAMP } \\
\text { Concentrations }\end{array}$}} & \multirow{3}{*}{$\mathbf{N}$} & \multicolumn{2}{|c|}{ Reference Values } \\
\hline & & & & & & \multirow{2}{*}{$\begin{array}{c}\text { WFBCBKG }^{\mathrm{a}} \\
\text { Background Range }\end{array}$} & \multirow{2}{*}{ Guideline $^{b}$} \\
\hline & & & Average & Maximum & & & \\
\hline Gross Alpha & $\mu \mathrm{Ci} / \mathrm{mL}$ & 52 & $0.20 \pm 2.11 \mathrm{E}-09$ & $2.67 \mathrm{E}-09$ & 12 & $<5.80 \mathrm{E}-10-1.08 \mathrm{E}-09$ & $3 \mathrm{E}-08^{\mathrm{c}}$ \\
\hline Gross Beta & $\mu \mathrm{Ci} / \mathrm{mL}$ & 52 & $1.44 \pm 0.02 \mathrm{E}-06$ & $3.83 \mathrm{E}-06$ & 12 & $<1.23 \mathrm{E}-09-4.76 \mathrm{E}-09$ & $1 \mathrm{E}-06^{\mathrm{d}}$ \\
\hline Tritium & $\mu \mathrm{Ci} / \mathrm{mL}$ & 52 & $1.05 \pm 0.83 \mathrm{E}-07$ & $2.92 \mathrm{E}-07$ & 12 & $<8.06 \mathrm{E}-08-2.29 \mathrm{E}-07$ & $2 \mathrm{E}-03$ \\
\hline C-14 & $\mu \mathrm{Ci} / \mathrm{mL}$ & 4 & $-0.18 \pm 2.04 \mathrm{E}-08$ & $<2.63 \mathrm{E}-08$ & 4 & $<1.34 \mathrm{E}-08-<2.66 \mathrm{E}-08$ & 7E-05 \\
\hline Sr-90 & $\mu \mathrm{Ci} / \mathrm{mL}$ & 12 & $7.08 \pm 0.24 \mathrm{E}-07$ & $1.58 \mathrm{E}-06$ & 4 & $<9.20 \mathrm{E}-10-1.76 \mathrm{E}-09$ & $1 \mathrm{E}-06$ \\
\hline I-129 & $\mu \mathrm{Ci} / \mathrm{mL}$ & 4 & $9.33 \pm 9.71 \mathrm{E}-10$ & $1.29 \mathrm{E}-09$ & 4 & $<5.25 \mathrm{E}-10-1.42 \mathrm{E}-09$ & $5 \mathrm{E}-07$ \\
\hline Cs-137 & $\mu \mathrm{Ci} / \mathrm{mL}$ & 12 & $0.99 \pm 2.43 \mathrm{E}-09$ & 2.12E-09 & 4 & $<1.84 \mathrm{E}-09-<3.33 \mathrm{E}-09$ & $3 \mathrm{E}-06$ \\
\hline U-232 & $\mu \mathrm{Ci} / \mathrm{mL}$ & 4 & $0.23 \pm 7.42 \mathrm{E}-11$ & $<8.84 \mathrm{E}-11$ & 4 & $<3.14 \mathrm{E}-11-<5.23 \mathrm{E}-11$ & $1 \mathrm{E}-07$ \\
\hline U-233/234 & $\mu \mathrm{Ci} / \mathrm{mL}$ & 4 & $2.31 \pm 1.32 \mathrm{E}-10$ & $2.67 \mathrm{E}-10$ & 4 & $<6.60 \mathrm{E}-11-1.20 \mathrm{E}-10$ & $5 \mathrm{E}-07$ \\
\hline U-235/236 & $\mu \mathrm{Ci} / \mathrm{mL}$ & 4 & $3.75 \pm 6.42 \mathrm{E}-11$ & $<9.51 \mathrm{E}-11$ & 4 & $<1.76 \mathrm{E}-11-2.88 \mathrm{E}-11$ & $5 \mathrm{E}-07^{\mathrm{e}}$ \\
\hline U-238 & $\mu \mathrm{Ci} / \mathrm{mL}$ & 4 & $1.36 \pm 0.94 \mathrm{E}-10$ & $1.63 \mathrm{E}-10$ & 4 & $<1.57 \mathrm{E}-11-5.63 \mathrm{E}-11$ & $6 \mathrm{E}-07$ \\
\hline Total U & $\mu \mathrm{Ci} / \mathrm{mL}$ & 4 & $4.02 \pm 0.15 \mathrm{E}-04$ & $6.51 \mathrm{E}-04$ & 4 & $2.18 \mathrm{E}-04-4.61 \mathrm{E}-04$ & -- \\
\hline Pu-238 & $\mu \mathrm{Ci} / \mathrm{mL}$ & 4 & $1.07 \pm 2.96 \mathrm{E}-11$ & $<4.58 \mathrm{E}-11$ & 4 & $<1.74 \mathrm{E}-11-<3.11 \mathrm{E}-11$ & 4E-08 \\
\hline Pu-239/240 & $\mu \mathrm{Ci} / \mathrm{mL}$ & 4 & $0.69 \pm 2.44 \mathrm{E}-11$ & $2.99 \mathrm{E}-11$ & 4 & $<2.24 \mathrm{E}-11-1.98 \mathrm{E}-10$ & $3 \mathrm{E}-08$ \\
\hline Am-241 & $\mu \mathrm{Ci} / \mathrm{mL}$ & 4 & $1.54 \pm 3.33 \mathrm{E}-11$ & $<5.47 \mathrm{E}-11$ & 4 & $<2.19 \mathrm{E}-11-3.23 \mathrm{E}-11$ & $3 \mathrm{E}-08$ \\
\hline
\end{tabular}

$N$ - Number of samples

-- No guideline or standard available for these analytes

${ }^{a}$ Background location

${ }^{b}$ DOE ingestion-based DCGs for $100 \mathrm{mrem} / \mathrm{yr}$ dose limit are provided as a guideline for radiological results.

${ }^{c}$ Alpha as Am-241

${ }^{d}$ Beta as $\mathrm{Sr}-90$

${ }^{e} D C G$ for $U-236$ is used for this comparison 
Table C-3D (continued)

2003 Results in Surface Water at the Northeast Swamp (WNSWAMP)

CHEMICAL CONSTITUENTS

\begin{tabular}{|c|c|c|c|c|c|c|c|}
\hline \multirow{3}{*}{ Analyte } & \multirow{3}{*}{ Units } & \multirow{3}{*}{$\mathbf{N}$} & \multirow{2}{*}{\multicolumn{2}{|c|}{$\begin{array}{c}\text { WNSWAMP } \\
\text { Concentrations }\end{array}$}} & \multirow{3}{*}{$\mathbf{N}$} & \multicolumn{2}{|c|}{ Reference Values } \\
\hline & & & & & & \multirow{2}{*}{$\begin{array}{c}\text { WFBCBKG } \\
\text { Background Range }\end{array}$} & \multirow{2}{*}{ Standard } \\
\hline & & & Average & Maximum & & & \\
\hline Alpha-BHC & $\mathrm{mg} / \mathrm{L}$ & 2 & $<0.000007$ & $<0.000009$ & 2 & $<0.000009-<0.000009$ & 0.000002 \\
\hline Aluminum, Total & $\mathrm{mg} / \mathrm{L}$ & 2 & 0.06 & 0.06 & 0 & NA & -- \\
\hline Ammonia-N & $\mathrm{mg} / \mathrm{L}$ & 2 & $<0.10$ & $<0.10$ & 2 & $<0.05-<0.05$ & $0.67-29$ \\
\hline Antimony, Total & $\mathrm{mg} / \mathrm{L}$ & 2 & $<0.003$ & $<0.003$ & 2 & $<0.003-<0.003$ & -- \\
\hline Arsenic, Dissolved & $\mathrm{mg} / \mathrm{L}$ & 2 & $<0.004$ & $<0.004$ & 2 & $<0.005-<0.005$ & 0.340 \\
\hline Boron, Total & $\mathrm{mg} / \mathrm{L}$ & 2 & 0.05 & 0.05 & 2 & $0.01-0.02$ & -- \\
\hline Bromide & $\mathrm{mg} / \mathrm{L}$ & 2 & 0.80 & 0.90 & 2 & $<0.50-<0.50$ & -- \\
\hline Cadmium, Total & $\mathrm{mg} / \mathrm{L}$ & 2 & $<0.0004$ & $<0.0004$ & 0 & NA & - \\
\hline Calcium, Total & $\mathrm{mg} / \mathrm{L}$ & 2 & 112 & 118 & 9 & $21.9-43.2$ & -- \\
\hline Chloride & $\mathrm{mg} / \mathrm{L}$ & 1 & 130 & 130 & 2 & $10-16$ & -- \\
\hline Chromium, Total & $\mathrm{mg} / \mathrm{L}$ & 2 & $<0.001$ & $<0.001$ & 0 & NA & - \\
\hline Cobalt, Total & $\mathrm{mg} / \mathrm{L}$ & 2 & $<0.001$ & $<0.001$ & 2 & $<0.005-<0.005$ & $0.110^{\mathrm{c}}$ \\
\hline Conductivity & $\mu \mathrm{mhos} / \mathrm{cm} @ 25^{\circ} \mathrm{C}$ & 22 & 1,187 & 1,390 & 22 & $145-279$ & -- \\
\hline Copper, Dissolved & $\mathrm{mg} / \mathrm{L}$ & 2 & $<0.001$ & $<0.001$ & 2 & $<0.005-<0.005$ & $0.045^{\mathrm{d}}$ \\
\hline Copper, Total & $\mathrm{mg} / \mathrm{L}$ & 2 & 0.002 & 0.002 & 0 & NA & -- \\
\hline Fluoride & $\mathrm{mg} / \mathrm{L}$ & 2 & $<0.10$ & $<0.10$ & 2 & $<0.10-<0.10$ & $33.6^{\mathrm{d}}$ \\
\hline Hardness & $\mathrm{mg} / \mathrm{L}$ & 2 & 341 & 357 & 9 & 69-132 & -- \\
\hline Iron, Total & $\mathrm{mg} / \mathrm{L}$ & 2 & 0.12 & 0.19 & 2 & $0.23-3.28$ & 0.30 \\
\hline Lead, Total & $\mathrm{mg} / \mathrm{L}$ & 2 & $<0.002$ & $<0.002$ & 0 & NA & -- \\
\hline Magnesium, Total & $\mathrm{mg} / \mathrm{L}$ & 2 & 14.6 & 15.1 & 9 & $3.51-5.94$ & -- \\
\hline Manganese, Total & $\mathrm{mg} / \mathrm{L}$ & 2 & 0.17 & 0.23 & 2 & $0.02-0.10$ & -- \\
\hline Mercury, Total, Method 1631 & $\mathrm{mg} / \mathrm{L}$ & 2 & 0.000005 & 0.000009 & 0 & NA & -- \\
\hline Nickel, Total & $\mathrm{mg} / \mathrm{L}$ & 2 & $<0.002$ & $<0.002$ & 0 & NA & -- \\
\hline Nitrate-N & $\mathrm{mg} / \mathrm{L}$ & 2 & 0.10 & 0.16 & 2 & $<0.05-0.16$ & -- \\
\hline Nitrite-N & $\mathrm{mg} / \mathrm{L}$ & 2 & $<0.02$ & $<0.02$ & 2 & $<0.05-<0.05$ & -- \\
\hline NPOC & $\mathrm{mg} / \mathrm{L}$ & 2 & 5.4 & 5.5 & 2 & $2.0-2.4$ & -- \\
\hline Oil \& Grease & $\mathrm{mg} / \mathrm{L}$ & 2 & $<1$ & $<1$ & 2 & $<5-<5$ & -- \\
\hline pH & $\mathrm{SU}$ & 24 & 7.01 & 7.39 & 24 & $6.56-8.24$ & $6.0-9.5$ \\
\hline
\end{tabular}

$N$ - Number of samples

NA - No data available

$S U$ - Standard units

-- No guideline or standard available for these analytes

a Background location

${ }^{b}$ New York State Water Quality Standards, Class “D” as a comparative reference for nonradiological results at WNSWAMP

${ }^{c}$ Standards for cobalt, thallium, and vanadium are acid-soluble.

${ }^{d}$ Calculated from maximum measurement of hardness of surface water stream at WNSWAMP 


\section{Table C-3D (concluded) \\ 2003 Results in Surface Water at the Northeast Swamp (WNSWAMP) \\ CHEMICAL CONSTITUENTS (concluded)}

\begin{tabular}{|c|c|c|c|c|c|c|c|}
\hline \multirow{3}{*}{ Analyte } & \multirow{3}{*}{ Units } & \multirow{3}{*}{$\mathbf{N}$} & \multirow{2}{*}{\multicolumn{2}{|c|}{$\begin{array}{c}\text { WNSWAMP } \\
\text { Concentrations }\end{array}$}} & \multirow{3}{*}{$\mathbf{N}$} & \multicolumn{2}{|c|}{ Reference Values } \\
\hline & & & & & & \multirow{2}{*}{$\begin{array}{c}\text { WFBCBKG } \\
\text { Background Range }\end{array}$} & \multirow{2}{*}{ Standard $^{\mathrm{b}}$} \\
\hline & & & Average & Maximum & & & \\
\hline Selenium, Total & $\mathrm{mg} / \mathrm{L}$ & 2 & $<0.004$ & $<0.004$ & 0 & NA & -- \\
\hline Solids, Total Dissolved & $\mathrm{mg} / \mathrm{L}$ & 2 & 770 & 833 & 2 & $125-176$ & -- \\
\hline Solids, Total Suspended & $\mathrm{mg} / \mathrm{L}$ & 2 & $<5$ & $<5$ & 2 & $<4-<4$ & -- \\
\hline Sulfate & $\mathrm{mg} / \mathrm{L}$ & 2 & 22.1 & 23.4 & 2 & $15.8-21.4$ & -- \\
\hline Sulfide & $\mathrm{mg} / \mathrm{L}$ & 2 & $<1.20$ & 1.40 & 2 & $<0.04-0.62$ & -- \\
\hline Surfactants & $\mathrm{mg} / \mathrm{L}$ & 2 & $<0.10$ & $<0.10$ & 2 & $0.04-0.04$ & -- \\
\hline Thallium, Total & $\mathrm{mg} / \mathrm{L}$ & 2 & $<0.005$ & 0.006 & 2 & $<0.008-<0.008$ & $0.020^{c}$ \\
\hline Titanium, Total & $\mathrm{mg} / \mathrm{L}$ & 2 & $<0.001$ & 0.003 & 2 & $<0.050-<0.050$ & -- \\
\hline TOX & $\mathrm{mg} / \mathrm{L}$ & 2 & $<0.02$ & 0.04 & 2 & $0.01-0.02$ & -- \\
\hline Vanadium, Total & $\mathrm{mg} / \mathrm{L}$ & 2 & $<0.001$ & $<0.001$ & 2 & $<0.010<<0.010$ & $0.190^{c}$ \\
\hline Zinc, Total & $\mathrm{mg} / \mathrm{L}$ & 2 & 0.01 & 0.01 & 0 & NA & -- \\
\hline
\end{tabular}

$N$ - Number of samples

NA - No data available

-- No guideline or standard available for these analytes

${ }^{a}$ Background location

${ }^{b}$ New York State Water Quality Standards, Class "D" as a comparative reference for nonradiological results at WNSWAMP

${ }^{c}$ Standards for cobalt, thallium, and vanadium are acid-soluble. 
Table C-3E

2003 Results at Storage and Disposal Area Drainage (WNNDADR)

\begin{tabular}{|c|c|c|c|c|c|c|}
\hline \multirow{2}{*}{ Analyte } & \multirow{2}{*}{ Units } & \multirow{2}{*}{$\mathbf{N}$} & \multicolumn{3}{|c|}{ WNNDADR Concentrations } & \multirow{2}{*}{ Standard $^{\mathrm{a}}$} \\
\hline & & & Minimum & Average & Maximum & \\
\hline Gross Alpha & $\mu \mathrm{Ci} / \mathrm{mL}$ & 12 & $<9.16 \mathrm{E}-10$ & $0.86 \pm 1.34 \mathrm{E}-09$ & $1.24 \mathrm{E}-09$ & -- \\
\hline Gross Beta & $\mu \mathrm{Ci} / \mathrm{mL}$ & 12 & $1.50 \mathrm{E}-07$ & $1.83 \pm 0.06 \mathrm{E}-07$ & $2.26 \mathrm{E}-07$ & -- \\
\hline Tritium & $\mu \mathrm{Ci} / \mathrm{mL}$ & 12 & 4.39E-07 & $1.00 \pm 0.10 \mathrm{E}-06$ & $1.60 \mathrm{E}-06$ & -- \\
\hline Sr-90 & $\mu \mathrm{Ci} / \mathrm{mL}$ & 4 & 7.92E-08 & $9.10 \pm 0.63 \mathrm{E}-08$ & $9.69 \mathrm{E}-08$ & -- \\
\hline I-129 & $\mu \mathrm{Ci} / \mathrm{mL}$ & 4 & $<8.46 \mathrm{E}-10$ & $0.55 \pm 1.17 \mathrm{E}-09$ & $<1.49 \mathrm{E}-09$ & -- \\
\hline Cs-137 & $\mu \mathrm{Ci} / \mathrm{mL}$ & 12 & $<4.41 \mathrm{E}-09$ & $0.51 \pm 7.79 \mathrm{E}-09$ & $<1.25 \mathrm{E}-08$ & -- \\
\hline NPOC & $\mathrm{mg} / \mathrm{L}$ & 52 & 2.1 & $<6.7$ & 14.9 & -- \\
\hline pH & SU & 52 & 5.97 & 7.06 & 7.98 & $6.0-9.5$ \\
\hline TOX & $\mathrm{mg} / \mathrm{L}$ & 50 & $<0.005$ & $<0.022$ & 0.074 & -- \\
\hline
\end{tabular}

$N$ - Number of samples

SU - Standard units

-- No applicable reference standard available

${ }^{a}$ New York State Water Quality Standards, Class “D” as a comparative reference for nonradiological results at WNNDADR

Table C-3F

2003 Results in Subsurface Water at the NDA Interceptor Trench (WNNDATR)

\begin{tabular}{|l|c|c|c|c|c|}
\hline \multirow{2}{*}{\multicolumn{1}{c|}{ Analyte }} & \multirow{2}{*}{ Units } & N & \multicolumn{3}{c|}{ WNNDATR Concentrations } \\
\cline { 4 - 6 } & & & Minimum & Average & Maximum \\
\hline Gross Alpha & $\mu \mathrm{Ci} / \mathrm{mL}$ & 12 & $<1.17 \mathrm{E}-09$ & $2.17 \pm 2.11 \mathrm{E}-09$ & $4.26 \mathrm{E}-09$ \\
\hline Gross Beta & $\mu \mathrm{Ci} / \mathrm{mL}$ & 12 & $9.74 \mathrm{E}-08$ & $1.38 \pm 0.06 \mathrm{E}-07$ & $1.68 \mathrm{E}-07$ \\
\hline Tritium & $\mu \mathrm{Ci} / \mathrm{mL}$ & 12 & $1.32 \mathrm{E}-06$ & $4.83 \pm 0.21 \mathrm{E}-06$ & $1.00 \mathrm{E}-05$ \\
\hline I-129 & $\mu \mathrm{Ci} / \mathrm{mL}$ & 4 & $6.64 \mathrm{E}-10$ & $1.30 \pm 1.05 \mathrm{E}-09$ & $2.58 \mathrm{E}-09$ \\
\hline Cs-137 & $\mu \mathrm{Ci} / \mathrm{mL}$ & 12 & $<5.35 \mathrm{E}-09$ & $0.39 \pm 1.05 \mathrm{E}-08$ & $1.50 \mathrm{E}-08$ \\
\hline NPOC & $\mathrm{mg} / \mathrm{L}$ & 12 & 2.5 & 4.9 & 7.0 \\
\hline TOX & $\mathrm{mg} / \mathrm{L}$ & 12 & 0.012 & 0.022 & 0.030 \\
\hline
\end{tabular}

Note: No standards applicable for this location, these waters are pumped and treated at the LLWTF prior to discharge at outfall WNSP001.

$N$ - Number of samples 
Table C-3G

2003 Results at SDA Drainage (WNSDADR)

\begin{tabular}{|l|c|c|c|c|c|c|}
\hline \multirow{2}{*}{\multicolumn{1}{c|}{ Analyte }} & \multirow{2}{*}{ Units } & \multirow{2}{*}{$\mathbf{N}$} & \multicolumn{3}{c|}{ WNSDADR Concentrations } & \multirow{2}{*}{$\begin{array}{c}\text { Guideline or } \\
\text { Standard }\end{array}$} \\
\cline { 4 - 7 } & & & Minimum & Average & Maximum & - \\
\hline Gross Alpha & $\mu \mathrm{Ci} / \mathrm{mL}$ & 12 & $<3.33 \mathrm{E}-10$ & $5.68 \pm 4.46 \mathrm{E}-10$ & $1.26 \mathrm{E}-09$ & - \\
\hline Gross Beta & $\mu \mathrm{Ci} / \mathrm{mL}$ & 12 & $8.69 \mathrm{E}-10$ & $5.91 \pm 1.11 \mathrm{E}-09$ & $3.80 \mathrm{E}-08$ & - \\
\hline Tritium & $\mu \mathrm{Ci} / \mathrm{mL}$ & 12 & $<8.64 \mathrm{E}-08$ & $2.89 \pm 0.84 \mathrm{E}-07$ & $4.68 \mathrm{E}-07$ & -- \\
\hline Cs-137 & $\mu \mathrm{Ci} / \mathrm{mL}$ & 12 & $<3.65 \mathrm{E}-09$ & $-0.33 \pm 6.79 \mathrm{E}-09$ & $<1.16 \mathrm{E}-08$ & - \\
\hline pH & $\mathrm{SU}$ & 12 & 6.93 & 7.32 & 7.90 & $6.5-8.5$ \\
\hline
\end{tabular}

$N$ - Number of samples

$S U$ - Standard units

-- No applicable reference standard available

${ }^{a}$ New York State Water Quality Standards, Class “ $C$ ” as a comparative reference for nonradiological results at WNSDADR

Table $\mathrm{C}-3 \mathrm{H}$

\section{Results in Surface Water at Cooling Tower Basin (WNCOOLW)}

\begin{tabular}{|l|c|c|c|c|c|}
\hline \multirow{2}{*}{\multicolumn{1}{c|}{ Analyte }} & \multirow{2}{*}{ Units } & \multirow{2}{*}{ N } & \multicolumn{3}{c|}{ WNCOOLW Concentrations } \\
\cline { 4 - 6 } & & & Minimum & Average & Maximum \\
\hline Gross Alpha & $\mu \mathrm{Ci} / \mathrm{mL}$ & 6 & $<1.00 \mathrm{E}-09$ & $0.77 \pm 1.50 \mathrm{E}-09$ & $2.57 \mathrm{E}-09$ \\
\hline Gross Beta & $\mu \mathrm{Ci} / \mathrm{mL}$ & 6 & $<3.57 \mathrm{E}-09$ & $5.71 \pm 2.94 \mathrm{E}-09$ & $9.70 \mathrm{E}-09$ \\
\hline Tritium & $\mu \mathrm{Ci} / \mathrm{mL}$ & 6 & $<8.10 \mathrm{E}-08$ & $0.08 \pm 8.43 \mathrm{E}-08$ & $1.60 \mathrm{E}-07$ \\
\hline Sr-90 & $\mu \mathrm{Ci} / \mathrm{mL}$ & 3 & $1.50 \mathrm{E}-09$ & $2.95 \pm 1.78 \mathrm{E}-09$ & $4.68 \mathrm{E}-09$ \\
\hline Cs-137 & $\mu \mathrm{Ci} / \mathrm{mL}$ & 4 & $<4.15 \mathrm{E}-09$ & $1.42 \pm 6.93 \mathrm{E}-09$ & $<1.08 \mathrm{E}-08$ \\
\hline pH & $\mathrm{SU}$ & 6 & 7.80 & 8.07 & 8.55 \\
\hline
\end{tabular}

Note: No standards are applicable for this location, these waters are pumped and treated at the LLWTF prior to discharge at outfall WNSPOO1.

$N$ - Number of samples

$S U$ - Standard units 
This page intentionally left blank

$$
\text { C }-36
$$




\section{Appendix C-4 Ambient Surface Water Data}

$C-37$ 
This page intentionally left blank

$$
\text { C }-38
$$




\section{Table C-4A}

\section{Results in Surface Water Downstream of the WVDP in Cattaraugus Creek at Felton Bridge (WFFELBR)}

\begin{tabular}{|c|c|c|c|c|c|c|c|}
\hline \multirow{3}{*}{ Analyte } & \multirow{3}{*}{ Units } & \multirow{3}{*}{$\mathbf{N}$} & \multirow{2}{*}{\multicolumn{2}{|c|}{$\begin{array}{c}\text { WFFELBR } \\
\text { Concentrations }\end{array}$}} & \multirow{3}{*}{$\mathbf{N}$} & \multicolumn{2}{|c|}{ Reference Values } \\
\hline & & & & & & \multirow{2}{*}{$\begin{array}{c}\text { WFBIGBR }^{\mathrm{a}} \\
\text { Background Range }\end{array}$} & \multirow{2}{*}{$\begin{array}{c}\text { Guideline }^{b} \\
\text { or Standard }^{c}\end{array}$} \\
\hline & & & Average & Maximum & & & \\
\hline Gross Alpha & $\mu \mathrm{Ci} / \mathrm{mL}$ & 12 & $0.92 \pm 1.17 \mathrm{E}-09$ & $2.55 \mathrm{E}-09$ & 12 & $<7.06 \mathrm{E}-10-1.29 \mathrm{E}-09$ & $3 \mathrm{E}-08^{\mathrm{d}}$ \\
\hline Gross Beta & $\mu \mathrm{Ci} / \mathrm{mL}$ & 12 & $3.77 \pm 1.78 \mathrm{E}-09$ & 7.10E-09 & 12 & $<1.24 \mathrm{E}-09-6.00 \mathrm{E}-09$ & $1 \mathrm{E}-06^{\mathrm{e}}$ \\
\hline Tritium & $\mu \mathrm{Ci} / \mathrm{mL}$ & 12 & $2.10 \pm 8.58 \mathrm{E}-08$ & $<9.06 \mathrm{E}-08$ & 12 & $<5.75 \mathrm{E}-08-2.65 \mathrm{E}-07$ & $2 \mathrm{E}-03$ \\
\hline Sr-90 & $\mu \mathrm{Ci} / \mathrm{mL}$ & 12 & $2.05 \pm 1.75 \mathrm{E}-09$ & 3.74E-09 & 12 & $<1.23 \mathrm{E}-09-1.10 \mathrm{E}-08$ & $1 \mathrm{E}-06$ \\
\hline Tc-99 & $\mu \mathrm{Ci} / \mathrm{mL}$ & 3 & $1.36 \pm 2.64 \mathrm{E}-09$ & $5.78 \mathrm{E}-09$ & 0 & NA & $1 \mathrm{E}-04$ \\
\hline Cs-137 & $\mu \mathrm{Ci} / \mathrm{mL}$ & 12 & $1.22 \pm 2.48 \mathrm{E}-09$ & 3.94E-09 & 12 & $<1.34 \mathrm{E}-09-5.29 \mathrm{E}-09$ & $3 \mathrm{E}-06$ \\
\hline pH & SU & 52 & 7.17 & 8.27 & 12 & $6.49-8.15$ & $6.5-8.5$ \\
\hline
\end{tabular}

$N$ - Number of samples

NA - Data not available

SU - Standard units

a Background location

${ }^{b}$ DOE ingestion-based DCGs for 100 mrem/yr dose limit are provided as a guideline for radiological results in the absence of water quality standards.

"New York State Water Quality Standards, Class “B” as a comparative reference for nonradiological results

${ }^{d}$ Alpha as Am-241

e Beta as $\mathrm{Sr}-90$

Table C-4B

2003 Results in Surface Water Downstream of the WVDP in Buttermilk Creek at Thomas Corners Bridge (WFBCTCB)

RADIOACTIVITY CONCENTRATIONS

\begin{tabular}{|c|c|c|c|c|c|c|c|}
\hline \multirow{3}{*}{ Analyte } & \multirow{3}{*}{ Units } & \multirow{3}{*}{$\mathbf{N}$} & \multirow{2}{*}{\multicolumn{2}{|c|}{$\begin{array}{c}\text { WFBCTCB } \\
\text { Concentrations }\end{array}$}} & \multirow{3}{*}{$\mathbf{N}$} & \multicolumn{2}{|c|}{ Reference Values } \\
\hline & & & & & & \multirow{2}{*}{$\begin{array}{c}\text { WFBCBKG }^{\mathrm{a}} \\
\text { Background Range }\end{array}$} & \multirow{2}{*}{ Guideline $^{b}$} \\
\hline & & & Average & Maximum & & & \\
\hline Gross Alpha & $\mu \mathrm{Ci} / \mathrm{mL}$ & 12 & $5.75 \pm 7.62 \mathrm{E}-10$ & $1.44 \mathrm{E}-09$ & 12 & $<5.80 \mathrm{E}-10-1.08 \mathrm{E}-09$ & $3 \mathrm{E}-08^{\mathrm{c}}$ \\
\hline Gross Beta & $\mu \mathrm{Ci} / \mathrm{mL}$ & 12 & $7.84 \pm 1.53 \mathrm{E}-09$ & $9.98 \mathrm{E}-09$ & 12 & $<1.23 \mathrm{E}-09-4.76 \mathrm{E}-09$ & $1 \mathrm{E}-06^{\mathrm{d}}$ \\
\hline Tritium & $\mu \mathrm{Ci} / \mathrm{mL}$ & 12 & $6.61 \pm 8.50 \mathrm{E}-08$ & $1.65 \mathrm{E}-07$ & 12 & $<8.06 \mathrm{E}-08-2.29 \mathrm{E}-07$ & $2 \mathrm{E}-03$ \\
\hline Sr-90 & $\mu \mathrm{Ci} / \mathrm{mL}$ & 4 & $3.77 \pm 1.81 \mathrm{E}-09$ & 4.45E-09 & 4 & $<9.20 \mathrm{E}-10-1.76 \mathrm{E}-09$ & $1 \mathrm{E}-06$ \\
\hline Tc-99 & $\mu \mathrm{Ci} / \mathrm{mL}$ & 3 & $5.24 \pm 2.63 \mathrm{E}-09$ & $1.04 \mathrm{E}-08$ & 4 & $<9.90 \mathrm{E}-10-7.25 \mathrm{E}-09$ & $1 \mathrm{E}-04$ \\
\hline Cs-137 & $\mu \mathrm{Ci} / \mathrm{mL}$ & 4 & $2.11 \pm 2.02 \mathrm{E}-09$ & 3.04E-09 & 4 & $<1.84 \mathrm{E}-09-<3.33 \mathrm{E}-09$ & $3 \mathrm{E}-06$ \\
\hline
\end{tabular}

$N$ - Number of samples

a Background location

${ }^{b}$ DOE ingestion-based DCGs for $100 \mathrm{mrem} / \mathrm{yr}$ dose limit are provided as a guideline for radiological results in the absence of water quality standards.

${ }^{c}$ Alpha as Am-241

${ }^{d}$ Beta as $\operatorname{Sr}-90$ 
Table C-4B (continued)

2003 Results in Surface Water Downstream of the WVDP in Buttermilk Creek at Thomas Corners Bridge (WFBCTCB)

CHEMICAL CONSTITUENTS

\begin{tabular}{|c|c|c|c|c|c|c|c|}
\hline \multirow{3}{*}{ Analyte } & \multirow{3}{*}{ Units } & \multirow{3}{*}{$\mathbf{N}$} & \multirow{2}{*}{\multicolumn{2}{|c|}{$\begin{array}{c}\text { WFBCTCB } \\
\text { Concentrations }\end{array}$}} & \multirow{3}{*}{$\mathbf{N}$} & \multicolumn{2}{|c|}{ Reference Values } \\
\hline & & & & & & \multirow{2}{*}{$\begin{array}{c}\text { WFBCBKG }^{\mathrm{a}} \\
\text { Background Range }\end{array}$} & \multirow{2}{*}{ Standard $^{\mathrm{b}}$} \\
\hline & & & Average & Maximum & & & \\
\hline Alpha-BHC & $\mathrm{mg} / \mathrm{L}$ & 2 & $<0.000009$ & $<0.000009$ & 2 & $<0.000009-<0.000009$ & 0.000002 \\
\hline Aluminum, Dissolved & $\mathrm{mg} / \mathrm{L}$ & 2 & $<0.25$ & 0.4 & 2 & $<0.10-<0.10$ & 0.10 \\
\hline Ammonia-N & $\mathrm{mg} / \mathrm{L}$ & 2 & $<0.05$ & $<0.05$ & 2 & $<0.05-<0.05$ & $0.09-2.1$ \\
\hline Antimony, Total & $\mathrm{mg} / \mathrm{L}$ & 2 & $<0.003$ & $<0.003$ & 2 & $<0.003-<0.003$ & -- \\
\hline Arsenic, Dissolved & $\mathrm{mg} / \mathrm{L}$ & 2 & $<0.005$ & $<0.005$ & 2 & $<0.005-<0.005$ & 0.150 \\
\hline Barium, Total & $\mathrm{mg} / \mathrm{L}$ & 2 & 0.06 & 0.06 & 2 & $0.07-0.10$ & -- \\
\hline Boron, Total & $\mathrm{mg} / \mathrm{L}$ & 2 & 0.03 & 0.04 & 2 & $0.01-0.02$ & 10.0 \\
\hline Bromide & $\mathrm{mg} / \mathrm{L}$ & 2 & $<0.50$ & $<0.50$ & 2 & $<0.50-<0.50$ & -- \\
\hline Cadmium, Dissolved & $\mathrm{mg} / \mathrm{L}$ & 2 & $<0.001$ & $<0.001$ & 2 & $<0.001-<0.001$ & $0.003^{\mathrm{c}}$ \\
\hline Calcium, Total & $\mathrm{mg} / \mathrm{L}$ & 9 & 38.9 & 50.9 & 9 & $21.9-43.2$ & -- \\
\hline Chloride & $\mathrm{mg} / \mathrm{L}$ & 2 & 23 & 25 & 2 & $10-16$ & -- \\
\hline Chromium, Dissolved & $\mathrm{mg} / \mathrm{L}$ & 2 & $<0.01$ & $<0.01$ & 2 & $<0.01-<0.01$ & $0.114^{\mathrm{c}}$ \\
\hline Cobalt, Total & $\mathrm{mg} / \mathrm{L}$ & 2 & $<0.005$ & $<0.005$ & 2 & $<0.005-<0.005$ & $0.005^{\mathrm{d}}$ \\
\hline Conductivity & $\mu \mathrm{mhos} / \mathrm{cm} @ 25^{\circ} \mathrm{C}$ & 22 & 266 & 326 & 22 & $145-279$ & -- \\
\hline Copper, Dissolved & $\mathrm{mg} / \mathrm{L}$ & 2 & $<0.005$ & $<0.005$ & 2 & $<0.005-<0.005$ & $0.014^{\mathrm{c}}$ \\
\hline Dissolved, Oxygen & $\mathrm{mg} / \mathrm{L}$ & 2 & 11 & 12 & 2 & $9-12$ & $4.0(\min )$ \\
\hline Fluoride & $\mathrm{mg} / \mathrm{L}$ & 4 & $<0.10$ & $<0.10$ & 4 & $<0.10-<0.10$ & $3.4^{\mathrm{c}}$ \\
\hline Hardness & $\mathrm{mg} / \mathrm{L}$ & 9 & 123 & 168 & 9 & $69-132$ & -- \\
\hline Iron, Total & $\mathrm{mg} / \mathrm{L}$ & 2 & 0.30 & 0.32 & 2 & $0.23-3.28$ & 0.30 \\
\hline Lead, Dissolved & $\mathrm{mg} / \mathrm{L}$ & 2 & $<0.0005$ & $<0.0005$ & 2 & $<0.0005-<0.0005$ & $0.007^{\mathrm{c}}$ \\
\hline Magnesium, Total & $\mathrm{mg} / \mathrm{L}$ & 9 & 6.39 & 10.0 & 9 & $3.51-5.94$ & -- \\
\hline Manganese, Total & $\mathrm{mg} / \mathrm{L}$ & 2 & 0.01 & 0.01 & 2 & $0.02-0.10$ & -- \\
\hline Mercury, Dissolved, Method 1631 & $\mathrm{mg} / \mathrm{L}$ & 2 & 0.000001 & 0.000001 & 2 & 0.000001 & -- \\
\hline Nickel, Dissolved & $\mathrm{mg} / \mathrm{L}$ & 2 & $<0.04$ & $<0.04$ & 2 & $<0.04-<0.04$ & $0.081^{\mathrm{c}}$ \\
\hline Nitrate-N & $\mathrm{mg} / \mathrm{L}$ & 2 & 0.26 & 0.34 & 2 & $<0.05-0.16$ & -- \\
\hline Nitrite-N & $\mathrm{mg} / \mathrm{L}$ & 2 & $<0.05$ & $<0.05$ & 2 & $<0.05-<0.05$ & 0.10 \\
\hline NPOC & $\mathrm{mg} / \mathrm{L}$ & 2 & 3.1 & 3.6 & 2 & $2.0-2.4$ & -- \\
\hline
\end{tabular}

$N$ - Number of samples

-- No reference standard available for this analyte

${ }^{a}$ Background location

${ }^{b}$ New York State Water Quality Standards, Class “C” as a comparative reference for nonradiological results

${ }^{c}$ Calculated from maximum measurement of hardness of surface water stream at WFBCTCB

${ }^{d}$ Standards for cobalt, thallium, and vanadium are acid-soluble. 


\section{Table C-4B (concluded) \\ 2003 Results in Surface Water Downstream of the WVDP in Buttermilk Creek at Thomas Corners Bridge (WFBCTCB)}

CHEMICAL CONSTITUENTS (concluded)

\begin{tabular}{|c|c|c|c|c|c|c|c|}
\hline \multirow{3}{*}{ Analyte } & \multirow{3}{*}{ Units } & \multirow{3}{*}{$\mathbf{N}$} & \multirow{2}{*}{\multicolumn{2}{|c|}{$\begin{array}{c}\text { WFBCTCB } \\
\text { Concentrations }\end{array}$}} & \multirow{3}{*}{$\mathbf{N}$} & \multicolumn{2}{|c|}{ Reference Values } \\
\hline & & & & & & \multirow{2}{*}{$\begin{array}{c}\text { WFBCBKG } \\
\text { Background Range }\end{array}$} & \multirow{2}{*}{ Standard $^{\mathrm{b}}$} \\
\hline & & & Average & Maximum & & & \\
\hline Oil \& Grease & $\mathrm{mg} / \mathrm{L}$ & 2 & $<5$ & $<5$ & 2 & $<5-<5$ & -- \\
\hline pH & SU & 24 & 7.10 & 8.19 & 24 & $6.56-8.24$ & $6.5-8.5$ \\
\hline Selenium, Dissolved & $\mathrm{mg} / \mathrm{L}$ & 2 & $<0.001$ & $<0.001$ & 2 & $<0.001-0.002$ & 0.0046 \\
\hline Sodium, Total & $\mathrm{mg} / \mathrm{L}$ & 2 & 15.6 & 15.7 & 2 & $8.53-8.55$ & -- \\
\hline Solids, Total Dissolved & $\mathrm{mg} / \mathrm{L}$ & 2 & 176 & 206 & 2 & $125-176$ & 500 \\
\hline Solids, Total Suspended & $\mathrm{mg} / \mathrm{L}$ & 2 & $<4$ & $<4$ & 2 & $<4-<4$ & -- \\
\hline Sulfate & $\mathrm{mg} / \mathrm{L}$ & 2 & 23.1 & 26.2 & 2 & $15.8-21.4$ & -- \\
\hline Sulfide & $\mathrm{mg} / \mathrm{L}$ & 2 & $<0.04$ & $<0.04$ & 2 & $<0.04-0.62$ & 0.002 \\
\hline Surfactants & $\mathrm{mg} / \mathrm{L}$ & 2 & 0.04 & 0.05 & 2 & $0.04-0.04$ & 0.04 \\
\hline Thallium, Total & $\mathrm{mg} / \mathrm{L}$ & 2 & $<0.008$ & $<0.008$ & 2 & $<0.008-<0.008$ & $0.008^{\mathrm{d}}$ \\
\hline Titanium, Total & $\mathrm{mg} / \mathrm{L}$ & 2 & $<0.05$ & $<0.05$ & 2 & $<0.05-<0.05$ & -- \\
\hline TOX & $\mathrm{mg} / \mathrm{L}$ & 2 & 0.01 & 0.02 & 2 & $0.01-0.02$ & -- \\
\hline Vanadium, Total & $\mathrm{mg} / \mathrm{L}$ & 2 & $<0.01$ & $<0.01$ & 2 & $<0.01-<0.01$ & $0.014^{\mathrm{d}}$ \\
\hline Zinc, Dissolved & $\mathrm{mg} / \mathrm{L}$ & 2 & $<0.02$ & $<0.02$ & 2 & $<0.02-<0.02$ & $0.129^{c}$ \\
\hline
\end{tabular}

$N$ - Number of samples

$S U$ - Standard units

-- No reference standard available for this analyte

${ }^{a}$ Background location

${ }^{b}$ New York State Water Quality Standards, Class "C" as a comparative reference for nonradiological results

${ }^{c}$ Calculated from maximum measurement of hardness of surface water stream at WFBCTCB

${ }^{d}$ Standards for cobalt, thallium, and vanadium are acid-soluble. 


\section{Table C-4C}

\section{Results in Surface Water Downstream of the WVDP at Frank's Creek (WNSP006)}

RADIOACTIVITY CONCENTRATIONS

\begin{tabular}{|c|c|c|c|c|c|c|c|}
\hline \multirow{3}{*}{ Analyte } & \multirow{3}{*}{ Units } & \multirow{3}{*}{$\mathbf{N}$} & \multirow{2}{*}{\multicolumn{2}{|c|}{$\begin{array}{c}\text { WNSP006 } \\
\text { Concentrations }\end{array}$}} & \multirow{3}{*}{$\mathbf{N}$} & \multicolumn{2}{|c|}{ Reference Values } \\
\hline & & & & & & \multirow{2}{*}{$\begin{array}{c}\text { WFBCBKG }^{\mathrm{a}} \\
\text { Background Range }\end{array}$} & \multirow{2}{*}{ Guideline $^{\text {b }}$} \\
\hline & & & Average & Maximum & & & \\
\hline Gross Alpha & $\mu \mathrm{Ci} / \mathrm{mL}$ & 52 & $0.94 \pm 1.44 \mathrm{E}-09$ & 8.05E-09 & 12 & $<5.80 \mathrm{E}-10-1.08 \mathrm{E}-09$ & $3 \mathrm{E}-08^{\mathrm{c}}$ \\
\hline Gross Beta & $\mu \mathrm{Ci} / \mathrm{mL}$ & 52 & $3.82 \pm 0.38 \mathrm{E}-08$ & $1.08 \mathrm{E}-07$ & 12 & $<1.23 \mathrm{E}-09-4.76 \mathrm{E}-09$ & $1 \mathrm{E}-06^{\mathrm{d}}$ \\
\hline Tritium & $\mu \mathrm{Ci} / \mathrm{mL}$ & 52 & $1.89 \pm 0.84 \mathrm{E}-07$ & $1.51 \mathrm{E}-06$ & 12 & $<8.06 \mathrm{E}-08-2.29 \mathrm{E}-07$ & $2 \mathrm{E}-03$ \\
\hline C-14 & $\mu \mathrm{Ci} / \mathrm{mL}$ & 4 & $-0.18 \pm 1.92 \mathrm{E}-08$ & $<2.64 \mathrm{E}-08$ & 4 & $<1.34 \mathrm{E}-08-<2.66 \mathrm{E}-08$ & $7 \mathrm{E}-05$ \\
\hline Sr-90 & $\mu \mathrm{Ci} / \mathrm{mL}$ & 12 & $1.84 \pm 0.34 \mathrm{E}-08$ & $2.93 \mathrm{E}-08$ & 4 & $<9.20 \mathrm{E}-10-1.76 \mathrm{E}-09$ & $1 \mathrm{E}-06$ \\
\hline Tc-99 & $\mu \mathrm{Ci} / \mathrm{mL}$ & 4 & $6.51 \pm 2.65 \mathrm{E}-09$ & $1.19 \mathrm{E}-08$ & 4 & $<9.90 \mathrm{E}-10-7.25 \mathrm{E}-09$ & $1 \mathrm{E}-04$ \\
\hline I-129 & $\mu \mathrm{Ci} / \mathrm{mL}$ & 4 & $2.10 \pm 9.75 \mathrm{E}-10$ & $1.11 \mathrm{E}-09$ & 4 & $<5.25 \mathrm{E}-10-1.42 \mathrm{E}-09$ & 5E-07 \\
\hline Cs-137 & $\mu \mathrm{Ci} / \mathrm{mL}$ & 12 & $5.74 \pm 8.98 \mathrm{E}-09$ & $1.53 \mathrm{E}-08$ & 4 & $<1.84 \mathrm{E}-09-<3.33 \mathrm{E}-09$ & $3 \mathrm{E}-06$ \\
\hline U-232 & $\mu \mathrm{Ci} / \mathrm{mL}$ & 4 & $4.56 \pm 1.31 \mathrm{E}-10$ & $5.86 \mathrm{E}-10$ & 4 & $<3.14 \mathrm{E}-11-<5.23 \mathrm{E}-11$ & $1 \mathrm{E}-07$ \\
\hline U-233/234 & $\mu \mathrm{Ci} / \mathrm{mL}$ & 4 & $3.88 \pm 1.50 \mathrm{E}-10$ & $4.82 \mathrm{E}-10$ & 4 & $<6.60 \mathrm{E}-11-1.20 \mathrm{E}-10$ & $5 \mathrm{E}-07$ \\
\hline U-235/236 & $\mu \mathrm{Ci} / \mathrm{mL}$ & 4 & $1.96 \pm 4.77 \mathrm{E}-11$ & $<6.69 \mathrm{E}-11$ & 4 & $<1.76 \mathrm{E}-11-2.88 \mathrm{E}-11$ & $5 \mathrm{E}-07^{\mathrm{e}}$ \\
\hline U-238 & $\mu \mathrm{Ci} / \mathrm{mL}$ & 4 & $2.56 \pm 1.24 \mathrm{E}-10$ & 3.47E-10 & 4 & $<1.57 \mathrm{E}-11-5.63 \mathrm{E}-11$ & $6 \mathrm{E}-07$ \\
\hline Total U & $\mu \mathrm{g} / \mathrm{mL}$ & 4 & $8.08 \pm 0.20 \mathrm{E}-04$ & $1.00 \mathrm{E}-03$ & 4 & 2.18E-04-4.61E-04 & -- \\
\hline Pu-238 & $\mu \mathrm{Ci} / \mathrm{mL}$ & 4 & $3.21 \pm 3.43 \mathrm{E}-11$ & $5.20 \mathrm{E}-11$ & 4 & $<1.74 \mathrm{E}-11-<3.11 \mathrm{E}-11$ & $4 \mathrm{E}-08$ \\
\hline Pu-239/240 & $\mu \mathrm{Ci} / \mathrm{mL}$ & 4 & $2.02 \pm 3.83 \mathrm{E}-11$ & $<4.85 \mathrm{E}-11$ & 4 & $<2.24 \mathrm{E}-11-1.98 \mathrm{E}-10$ & 3E-08 \\
\hline Am-241 & $\mu \mathrm{Ci} / \mathrm{mL}$ & 4 & $4.87 \pm 4.37 \mathrm{E}-11$ & $6.67 \mathrm{E}-11$ & 4 & $<2.19 \mathrm{E}-11-3.23 \mathrm{E}-11$ & $3 \mathrm{E}-08$ \\
\hline
\end{tabular}

$N$ - Number of samples

-- No guideline or standard available for these analytes

${ }^{a}$ Background location

${ }^{b}$ DOE ingestion-based DCGs for $100 \mathrm{mrem} / \mathrm{yr}$ dose limit are provided as a guideline for radiological results.

${ }^{c}$ Alpha as Am-241

${ }^{d}$ Beta as $\mathrm{Sr}-90$

${ }^{e} D C G$ for U-236 is used for this comparison. 


\section{Table C-4C (continued)}

\section{Results in Surface Water Downstream of the WVDP at Frank's Creek (WNSP006)}

\section{CHEMICAL CONSTITUENTS}

\begin{tabular}{|c|c|c|c|c|c|c|c|}
\hline \multirow{3}{*}{ Analyte } & \multirow{3}{*}{ Units } & \multirow{3}{*}{$\mathbf{N}$} & \multirow{2}{*}{\multicolumn{2}{|c|}{$\begin{array}{c}\text { WNSP006 } \\
\text { Concentrations }\end{array}$}} & \multirow{3}{*}{$\mathbf{N}$} & \multicolumn{2}{|c|}{ Reference Values } \\
\hline & & & & & & \multirow{2}{*}{$\begin{array}{c}\text { WFBCBKG }^{\mathrm{a}} \\
\text { Background Range }\end{array}$} & \multirow{2}{*}{ Standard $^{\mathbf{b}}$} \\
\hline & & & Average & Maximum & & & \\
\hline Alpha-BHC & $\mathrm{mg} / \mathrm{L}$ & 2 & $<0.000009$ & $<0.000009$ & 2 & $<0.000009-<0.000009$ & 0.000002 \\
\hline Aluminum, Dissolved & $\mathrm{mg} / \mathrm{L}$ & 2 & 0.6 & 0.68 & 2 & $<0.10-<0.10$ & 0.10 \\
\hline Ammonia-N & $\mathrm{mg} / \mathrm{L}$ & 2 & $<0.05$ & $<0.05$ & 2 & $<0.05-<0.05$ & $0.09-2.1$ \\
\hline Antimony, Total & $\mathrm{mg} / \mathrm{L}$ & 2 & $<0.003$ & $<0.003$ & 2 & $<0.003-<0.003$ & -- \\
\hline Arsenic, Dissolved & $\mathrm{mg} / \mathrm{L}$ & 2 & $<0.005$ & $<0.005$ & 2 & $<0.005-<0.005$ & 0.150 \\
\hline Barium, Total & $\mathrm{mg} / \mathrm{L}$ & 2 & 0.06 & 0.07 & 2 & $0.07-0.11$ & -- \\
\hline Boron, Total & $\mathrm{mg} / \mathrm{L}$ & 2 & 0.03 & 0.04 & 2 & $0.01-0.02$ & 10.0 \\
\hline Bromide & $\mathrm{mg} / \mathrm{L}$ & 2 & $<0.50$ & $<0.50$ & 2 & $<0.50-<0.50$ & -- \\
\hline Cadmium, Dissolved & $\mathrm{mg} / \mathrm{L}$ & 2 & $<0.001$ & $<0.001$ & 2 & $<0.001-<0.001$ & $0.004^{c}$ \\
\hline Calcium, Total & $\mathrm{mg} / \mathrm{L}$ & 9 & 47.1 & 71.1 & 9 & $21.9-43.2$ & -- \\
\hline Chloride & $\mathrm{mg} / \mathrm{L}$ & 2 & 114 & 127 & 2 & $10-16$ & -- \\
\hline Chromium, Dissolved & $\mathrm{mg} / \mathrm{L}$ & 2 & $<0.01$ & $<0.01$ & 2 & $<0.01-<0.01$ & $0.143^{c}$ \\
\hline Cobalt, Total & $\mathrm{mg} / \mathrm{L}$ & 2 & $<0.005$ & $<0.005$ & 2 & $<0.005-<0.005$ & $0.005^{\mathrm{d}}$ \\
\hline Conductivity & $\mu \mathrm{mhos} / \mathrm{cm} @ 25^{\circ} \mathrm{C}$ & 47 & 614 & 1,520 & 22 & $145-279$ & -- \\
\hline Copper, Dissolved & $\mathrm{mg} / \mathrm{L}$ & 2 & $<0.005$ & $<0.005$ & 2 & $<0.005-<0.005$ & $0.018^{\mathrm{c}}$ \\
\hline Dissolved Oxygen & $\mathrm{mg} / \mathrm{L}$ & 2 & 13 & 18 & 2 & $9-12$ & 4.0 (min) \\
\hline Fluoride & $\mathrm{mg} / \mathrm{L}$ & 2 & $<0.10$ & $<0.10$ & 2 & $<0.10-<0.10$ & $4.38^{\mathrm{c}}$ \\
\hline Hardness & $\mathrm{mg} / \mathrm{L}$ & 9 & 150 & 223 & 9 & 69-132 & -- \\
\hline Iron, Total & $\mathrm{mg} / \mathrm{L}$ & 2 & 5.52 & 7.59 & 2 & $0.23-3.28$ & 0.30 \\
\hline Lead, Dissolved & $\mathrm{mg} / \mathrm{L}$ & 2 & $<0.0005$ & $<0.0005$ & 2 & $<0.0005-<0.0005$ & $0.009^{c}$ \\
\hline Magnesium, Total & $\mathrm{mg} / \mathrm{L}$ & 9 & 7.77 & 11 & 9 & $3.51-5.94$ & -- \\
\hline Manganese, Total & $\mathrm{mg} / \mathrm{L}$ & 2 & 0.17 & 0.22 & 2 & $0.02-0.10$ & -- \\
\hline Mercury, Dissolved, Method 1631 & $\mathrm{mg} / \mathrm{L}$ & 2 & 0.000008 & 0.000015 & 2 & 0.000001 & -- \\
\hline Nickel, Dissolved & $\mathrm{mg} / \mathrm{L}$ & 2 & $<0.04$ & $<0.04$ & 2 & $<0.04-<0.04$ & $0.10^{\mathrm{c}}$ \\
\hline Nitrate-N & $\mathrm{mg} / \mathrm{L}$ & 2 & 0.72 & 0.77 & 2 & $<0.05-0.16$ & -- \\
\hline Nitrite-N & $\mathrm{mg} / \mathrm{L}$ & 2 & $<0.05$ & $<0.05$ & 2 & $<0.05-<0.05$ & 0.10 \\
\hline NPOC & $\mathrm{mg} / \mathrm{L}$ & 2 & 3.8 & 3.9 & 2 & $2.0-2.4$ & -- \\
\hline Oil \& Grease & $\mathrm{mg} / \mathrm{L}$ & 3 & $<5$ & $<5$ & 2 & $<5-<5$ & -- \\
\hline pH & SU & 24 & 7.17 & 8.26 & 24 & $6.56-8.24$ & $6.5-8.5$ \\
\hline
\end{tabular}

$N$ - Number of samples

$S U$ - Standard units

-- No guideline or standard available for these analytes

${ }^{a}$ Background location

${ }^{b}$ New York Water Quality Standards for Class "C" surface waters as a comparative reference for nonradiological results.

${ }^{c}$ Calculated from maximum measured hardness of surface water stream at WNSP006.

${ }^{d}$ Standards for cobalt, thallium, and vanadium are acid-soluble. 
Table C-4C (concluded)

2003 Results in Surface Water Downstream of the WVDP at Frank's Creek

(WNSP006)

CHEMICAL CONSTITUENTS (concluded)

\begin{tabular}{|c|c|c|c|c|c|c|c|}
\hline \multirow{3}{*}{ Analyte } & \multirow{3}{*}{ Units } & \multirow{3}{*}{$\mathbf{N}$} & \multirow{2}{*}{\multicolumn{2}{|c|}{$\begin{array}{c}\text { WNSP006 } \\
\text { Concentrations }\end{array}$}} & \multirow{3}{*}{$\mathbf{N}$} & \multicolumn{2}{|c|}{ Reference Values } \\
\hline & & & & & & \multirow{2}{*}{$\begin{array}{c}\text { WFBCBKG } \\
\text { Background Range }\end{array}$} & \multirow{2}{*}{ Standard $^{\mathbf{b}}$} \\
\hline & & & Average & Maximum & & & \\
\hline Selenium, Dissolved & $\mathrm{mg} / \mathrm{L}$ & 2 & 0.002 & 0.002 & 2 & $<0.001-0.002$ & 0.0046 \\
\hline Sodium, Total & $\mathrm{mg} / \mathrm{L}$ & 2 & 100 & 106 & 2 & $8.53-8.55$ & - \\
\hline Solids, Total Dissolved & $\mathrm{mg} / \mathrm{L}$ & 35 & 321 & 436 & 2 & $125-176$ & 500 \\
\hline Solids, Total Suspended & $\mathrm{mg} / \mathrm{L}$ & 2 & 112 & 175 & 2 & $<4-<4$ & - \\
\hline Sulfate & $\mathrm{mg} / \mathrm{L}$ & 2 & 65.8 & 79.4 & 2 & $15.8-21.4$ & -- \\
\hline Sulfide & $\mathrm{mg} / \mathrm{L}$ & 2 & $<0.04$ & $<0.04$ & 2 & $<0.04-0.62$ & 0.002 \\
\hline Surfactants & $\mathrm{mg} / \mathrm{L}$ & 2 & $<0.02$ & $<0.02$ & 2 & $0.04-0.04$ & 0.40 \\
\hline Thallium, Total & $\mathrm{mg} / \mathrm{L}$ & 2 & $<0.008$ & $<0.008$ & 2 & $<0.008-<0.008$ & $0.008^{\mathrm{d}}$ \\
\hline Titanium, Total & $\mathrm{mg} / \mathrm{L}$ & 2 & $<0.06$ & 0.07 & 2 & $<0.05-<0.05$ & -- \\
\hline TOX & $\mathrm{mg} / \mathrm{L}$ & 2 & 0.03 & 0.03 & 2 & $0.01-0.02$ & -- \\
\hline Vanadium, Total & $\mathrm{mg} / \mathrm{L}$ & 2 & $<0.01$ & $<0.01$ & 2 & $<0.01-<0.01$ & $0.014^{\mathrm{d}}$ \\
\hline Zinc, Dissolved & $\mathrm{mg} / \mathrm{L}$ & 2 & $<0.02$ & $<0.02$ & 2 & $<0.02-<0.02$ & $0.16^{\mathrm{c}}$ \\
\hline
\end{tabular}

$N$ - Number of samples

-- No guideline or standard available for these analytes

${ }^{a}$ Background location

${ }^{b}$ New York Water Quality Standards for Class "C" surface waterse as a comparative reference for nonradiological results.

${ }^{c}$ Calculated from maximum measured hardness of surface water stream at WNSP006.

${ }^{d}$ Standards for cobalt, thallium, and vanadium are acid-soluble. 
Table C-4D

2003 Results From Outfall WNSP116

\begin{tabular}{|c|c|c|c|c|c|}
\hline \multirow{2}{*}{ Month } & \multirow{2}{*}{ Units } & \multirow{2}{*}{$\mathbf{N}$} & \multicolumn{2}{|c|}{ Total Dissolved Solids } & \multirow{2}{*}{$\begin{array}{c}\text { Daily Maximum } \\
\text { Limit }\end{array}$} \\
\hline & & & Average & Maximum & \\
\hline January & $\mathrm{mg} / \mathrm{L}$ & 2 & 365 & 399 & 500 \\
\hline February $^{b}$ & $\mathrm{mg} / \mathrm{L}$ & 0 & -- & -- & 500 \\
\hline March & $\mathrm{mg} / \mathrm{L}$ & 2 & 321 & 388 & 500 \\
\hline April & $\mathrm{mg} / \mathrm{L}$ & 2 & 364 & 367 & 500 \\
\hline May $^{b}$ & $\mathrm{mg} / \mathrm{L}$ & 0 & -- & -- & 500 \\
\hline June & $\mathrm{mg} / \mathrm{L}$ & 2 & 351 & 364 & 500 \\
\hline July $^{\mathbf{b}}$ & $\mathrm{mg} / \mathrm{L}$ & 0 & - & -- & 500 \\
\hline August & $\mathrm{mg} / \mathrm{L}$ & 2 & 326 & 336 & 500 \\
\hline September $^{b}$ & $\mathrm{mg} / \mathrm{L}$ & 0 & -- & -- & 500 \\
\hline October & $\mathrm{mg} / \mathrm{L}$ & 2 & 320 & 339 & 500 \\
\hline November $^{b}$ & $\mathrm{mg} / \mathrm{L}$ & 0 & -- & -- & 500 \\
\hline December & $\mathrm{mg} / \mathrm{L}$ & 2 & 329 & 412 & 500 \\
\hline
\end{tabular}

$N$ - Number of samples

${ }^{a}$ SPDES Permit limit; $500 \mathrm{mg} / \mathrm{L}$ daily maximum

${ }^{b}$ No discharge this month

Table C-4E

2003 Results in Surface Water at Erdman Brook (WNERB53)

\begin{tabular}{|c|c|c|c|c|c|c|}
\hline \multirow{2}{*}{ Analyte } & \multirow{2}{*}{ Units } & \multirow{2}{*}{$\mathbf{N}$} & \multicolumn{3}{|c|}{ WNERB53 Concentrations } & \multirow{2}{*}{$\begin{array}{c}\text { Reference } \\
\text { Guideline }^{\mathrm{a}} \text { or } \\
\text { Standard }^{\mathbf{b}}\end{array}$} \\
\hline & & & Minimum & Average & Maximum & \\
\hline Gross Alpha & $\mu \mathrm{Ci} / \mathrm{mL}$ & 50 & $<8.14 \mathrm{E}-10$ & $0.26 \pm 1.77 \mathrm{E}-09$ & $2.42 \mathrm{E}-09$ & $3 \mathrm{E}-08^{\mathrm{c}}$ \\
\hline Gross Beta & $\mu \mathrm{Ci} / \mathrm{mL}$ & 50 & $9.14 \mathrm{E}-09$ & $2.09 \pm 0.31 \mathrm{E}-08$ & 4.37E-08 & $1 \mathrm{E}-06^{\mathrm{d}}$ \\
\hline Tritium & $\mu \mathrm{Ci} / \mathrm{mL}$ & 52 & $<6.14 \mathrm{E}-08$ & $6.19 \pm 8.21 \mathrm{E}-08$ & $3.74 \mathrm{E}-07$ & $2 \mathrm{E}-03$ \\
\hline Sr-90 & $\mu \mathrm{Ci} / \mathrm{mL}$ & 3 & $9.30 \mathrm{E}-09$ & $9.70 \pm 2.75 \mathrm{E}-09$ & 9.91E-09 & $1 \mathrm{E}-06$ \\
\hline Cs-137 & $\mu \mathrm{Ci} / \mathrm{mL}$ & 3 & $<1.77 \mathrm{E}-09$ & $-0.50 \pm 2.08 \mathrm{E}-09$ & $<2.38 \mathrm{E}-09$ & $3 \mathrm{E}-06$ \\
\hline pH & SU & 52 & 6.23 & 7.14 & 8.04 & $6.0-9.5$ \\
\hline
\end{tabular}

$N$ - Number of samples

$S U$ - Standard units

${ }^{a}$ DOE ingestion-based DCGs for 100 mrem/yr dose limit are provided as a guideline for radiological results.

${ }^{b}$ New York State Water Quality Standards, Class “D” for surface waters as a standard for nonradiological results

${ }^{c}$ Alpha as Am-241

${ }^{d}$ Beta as $\mathrm{Sr}-90$ 
Table $\mathrm{C}-\mathbf{4 F}$

2003 Results in Surface Water at Frank's Creek East of the SDA (WNFRC67)

\begin{tabular}{|l|c|c|c|c|c|c|}
\hline \multirow{2}{*}{\multicolumn{1}{c|}{ Analyte }} & \multirow{2}{*}{ Units } & \multirow{2}{*}{$\mathbf{N}$} & \multicolumn{3}{c|}{ WNFRC67 Concentrations } & Reference \\
\cline { 4 - 7 } & & & Minimum & Average & Maximum & $\begin{array}{c}\text { Guideline } \\
\text { Standard }^{\text {or }}\end{array}$ \\
\hline Gross Alpha & $\mu \mathrm{Ci} / \mathrm{mL}$ & 12 & $<5.06 \mathrm{E}-10$ & $5.45 \pm 7.07 \mathrm{E}-10$ & $3.89 \mathrm{E}-09$ & $3 \mathrm{E}-08^{\mathrm{c}}$ \\
\hline Gross Beta & $\mu \mathrm{Ci} / \mathrm{mL}$ & 12 & $1.42 \mathrm{E}-09$ & $3.22 \pm 1.22 \mathrm{E}-09$ & $8.88 \mathrm{E}-09$ & $1 \mathrm{E}-066^{\mathrm{d}}$ \\
\hline Tritium & $\mu \mathrm{Ci} / \mathrm{mL}$ & 12 & $<5.80 \mathrm{E}-08$ & $4.35 \pm 8.40 \mathrm{E}-08$ & $2.59 \mathrm{E}-07$ & $2 \mathrm{E}-03$ \\
\hline Sr-90 & $\mu \mathrm{Ci} / \mathrm{mL}$ & 3 & $<1.42 \mathrm{E}-09$ & $0.95 \pm 1.52 \mathrm{E}-09$ & $3.42 \mathrm{E}-09$ & $1 \mathrm{E}-06$ \\
\hline Cs-137 & $\mu \mathrm{Ci} / \mathrm{mL}$ & 3 & $<1.97 \mathrm{E}-09$ & $1.00 \pm 2.55 \mathrm{E}-09$ & $<3.40 \mathrm{E}-09$ & $3 \mathrm{E}-06$ \\
\hline pH & $\mathrm{SU}$ & 12 & 6.22 & 7.02 & 7.98 & $6.5-8.5$ \\
\hline
\end{tabular}

$N$ - Number of samples

SU - Standard units

${ }^{a}$ DOE ingestion-based DCGs for $100 \mathrm{mrem} / \mathrm{yr}$ dose limit are provided as a guideline for radiological results in the absence of water quality standards.

${ }^{b}$ New York State Water Quality Standards for Class “ C" surface waters as a comparative reference for nonradiological results.

c Alpha as Am-241

${ }^{d}$ Beta as $\mathrm{Sr}-90$

Table C-4G

2003 Results in Surface Water at Drum Cell Drainage (WNDCELD)

\begin{tabular}{|c|c|c|c|c|c|c|}
\hline \multirow{2}{*}{ Analyte } & \multirow{2}{*}{ Units } & \multirow{2}{*}{$\mathbf{N}$} & \multicolumn{3}{|c|}{ WNDCELD Concentrations } & \multirow{2}{*}{$\begin{array}{c}\text { Reference } \\
\text { Guideline }^{\mathrm{a}} \\
\text { or Standard }\end{array}$} \\
\hline & & & Minimum & Average & Maximum & \\
\hline Gross Alpha & $\mu \mathrm{Ci} / \mathrm{mL}$ & 12 & $<4.66 \mathrm{E}-10$ & $2.53 \pm 6.43 \mathrm{E}-10$ & $1.20 \mathrm{E}-09$ & $3 \mathrm{E}-08^{\mathrm{c}}$ \\
\hline Gross Beta & $\mu \mathrm{Ci} / \mathrm{mL}$ & 12 & $<1.13 \mathrm{E}-09$ & $2.46 \pm 1.19 \mathrm{E}-09$ & $6.88 \mathrm{E}-09$ & $1 \mathrm{E}-06^{\mathrm{d}}$ \\
\hline Tritium & $\mu \mathrm{Ci} / \mathrm{mL}$ & 4 & $<7.74 \mathrm{E}-08$ & $5.53 \pm 8.46 \mathrm{E}-08$ & $1.04 \mathrm{E}-07$ & $2 \mathrm{E}-03$ \\
\hline Sr-90 & $\mu \mathrm{Ci} / \mathrm{mL}$ & 4 & $<1.59 \mathrm{E}-09$ & $1.39 \pm 1.70 \mathrm{E}-09$ & $1.85 \mathrm{E}-09$ & $1 \mathrm{E}-06$ \\
\hline I-129 & $\mu \mathrm{Ci} / \mathrm{mL}$ & 4 & $<3.81 \mathrm{E}-10$ & $3.93 \pm 8.38 \mathrm{E}-10$ & $1.68 \mathrm{E}-09$ & $5 \mathrm{E}-07$ \\
\hline Cs-137 & $\mu \mathrm{Ci} / \mathrm{mL}$ & 4 & $<4.27 \mathrm{E}-09$ & $3.61 \pm 6.96 \mathrm{E}-09$ & $<1.06 \mathrm{E}-08$ & $3 \mathrm{E}-06$ \\
\hline pH & SU & 12 & 6.45 & 6.98 & 7.97 & $6.5-8.5$ \\
\hline
\end{tabular}

$N$ - Number of samples

$S U$ - Standard units

${ }^{a}$ DOE ingestion-based DCGs for $100 \mathrm{mrem} / \mathrm{yr}$ dose limit are provided as a guideline for radiological results in the absence of water quality standards.

${ }^{b}$ New York State Water Quality Standards for Class “C” surface waters as a comparative reference for nonradiological results.

${ }^{c}$ Alpha as Am-241

${ }^{d}$ Beta as $\mathrm{Sr}-90$

WVDP Annual Site Environmental Report

$C-46$

Calendar Year 2003 
Table $\mathrm{C}-4 \mathrm{H}$

\section{Results in Surface Water at the Standing Water (WNSTAW-Series) Locations}

\begin{tabular}{|c|c|c|c|c|c|c|}
\hline \multirow[b]{2}{*}{ Analyte } & \multirow[b]{2}{*}{ Units } & \multirow[b]{2}{*}{$\mathbf{N}$} & \multirow[b]{2}{*}{ WNSTAW4 } & \multirow[b]{2}{*}{ WNSTAW5 } & \multicolumn{2}{|c|}{ Reference Values } \\
\hline & & & & & $\begin{array}{c}\text { WNSTAWB }^{\mathrm{a}} \\
\text { Background Location }\end{array}$ & $\begin{array}{c}\text { Guideline }^{\text {b }} \\
\text { or Standard }\end{array}$ \\
\hline Gross Alpha & $\mu \mathrm{Ci} / \mathrm{mL}$ & 1 & $4.26 \pm 3.29 \mathrm{E}-10$ & $2.89 \pm 2.86 \mathrm{E}-10$ & $4.68 \pm 6.80 \mathrm{E}-10$ & $3 \mathrm{E}-08^{\mathrm{d}}$ \\
\hline Gross Beta & $\mu \mathrm{Ci} / \mathrm{mL}$ & 1 & $3.37 \pm 0.98 \mathrm{E}-09$ & $2.30 \pm 0.92 \mathrm{E}-09$ & $2.78 \pm 1.03 \mathrm{E}-09$ & $1 \mathrm{E}-06^{\mathrm{e}}$ \\
\hline Tritium & $\mu \mathrm{Ci} / \mathrm{mL}$ & 1 & $1.14 \pm 0.85 \mathrm{E}-07$ & $-1.30 \pm 5.94 \mathrm{E}-08$ & $-1.01 \pm 0.82 \mathrm{E}-07$ & $2 \mathrm{E}-03$ \\
\hline Sr-90 & $\mu \mathrm{Ci} / \mathrm{mL}$ & 1 & $0.49 \pm 1.19 \mathrm{E}-09$ & $9.80 \pm 8.78 \mathrm{E}-10$ & $1.22 \pm 1.26 \mathrm{E}-09$ & $1 \mathrm{E}-06$ \\
\hline Cs-137 & $\mu \mathrm{Ci} / \mathrm{mL}$ & 1 & $-0.06 \pm 4.46 \mathrm{E}-09$ & $-0.69 \pm 5.11 \mathrm{E}-09$ & $3.05 \pm 6.11 \mathrm{E}-09$ & $3 \mathrm{E}-06$ \\
\hline Chloride & $\mathrm{mg} / \mathrm{L}$ & 1 & 8 & $<1$ & 39 & -- \\
\hline Conductivity & $\mu \mathrm{mhos} / \mathrm{cm} @ 25^{\circ} \mathrm{C}$ & 1 & 81 & 52 & 359 & -- \\
\hline Iron, Total & $\mathrm{mg} / \mathrm{L}$ & 1 & 0.14 & 0.62 & 0.19 & 0.3 \\
\hline Manganese, Total & $\mathrm{mg} / \mathrm{L}$ & 1 & 0.02 & 0.15 & 0.07 & -- \\
\hline Nitrate+Nitrite & $\mathrm{mg} / \mathrm{L}$ & 1 & $<0.05$ & $<0.05$ & $<0.05$ & -- \\
\hline pH & SU & 1 & 7.77 & 7.38 & 7.37 & $6.0-9.5$ \\
\hline Sodium, Total & $\mathrm{mg} / \mathrm{L}$ & 1 & 4.5 & 1.0 & 20.6 & -- \\
\hline Sulfate & $\mathrm{mg} / \mathrm{L}$ & 1 & 7.3 & 5.6 & 13.3 & -- \\
\hline
\end{tabular}

\begin{tabular}{|c|c|c|c|c|c|}
\hline \multirow[b]{2}{*}{ Analyte } & \multirow[b]{2}{*}{ Units } & \multirow[b]{2}{*}{$\mathbf{N}$} & \multirow[b]{2}{*}{ WNSTAW6 } & \multicolumn{2}{|c|}{ Reference Values } \\
\hline & & & & $\begin{array}{c}\text { WNSTAWB }^{\text {a }} \\
\text { Background Location }\end{array}$ & $\begin{array}{c}\text { Guideline }^{\mathrm{b}} \text { or } \\
\text { Standard }^{\mathrm{c}}\end{array}$ \\
\hline Gross Alpha & $\mu \mathrm{Ci} / \mathrm{mL}$ & 1 & $3.46 \pm 6.20 \mathrm{E}-10$ & $4.68 \pm 6.80 \mathrm{E}-10$ & $3 \mathrm{E}-08^{\mathrm{d}}$ \\
\hline Gross Beta & $\mu \mathrm{Ci} / \mathrm{mL}$ & 1 & 4.22 $\pm 1.07 \mathrm{E}-09$ & $2.78 \pm 1.03 \mathrm{E}-09$ & $1 \mathrm{E}-06^{\mathrm{e}}$ \\
\hline Tritium & $\mu \mathrm{Ci} / \mathrm{mL}$ & 1 & $0.33 \pm 8.33 \mathrm{E}-08$ & $-1.01 \pm 0.82 \mathrm{E}-07$ & $2 \mathrm{E}-03$ \\
\hline Sr-90 & $\mu \mathrm{Ci} / \mathrm{mL}$ & 1 & $1.28 \pm 1.19 \mathrm{E}-09$ & $1.22 \pm 1.26 \mathrm{E}-09$ & $1 \mathrm{E}-06$ \\
\hline Cs-137 & $\mu \mathrm{Ci} / \mathrm{mL}$ & 1 & $-0.79 \pm 8.90 \mathrm{E}-09$ & $3.05 \pm 6.11 \mathrm{E}-09$ & $3 \mathrm{E}-06$ \\
\hline Chloride & $\mathrm{mg} / \mathrm{L}$ & 1 & 2 & 39 & -- \\
\hline Conductivity & $\mu \mathrm{mhos} / \mathrm{cm} @ 25^{\circ} \mathrm{C}$ & 1 & 190 & 359 & -- \\
\hline Iron, Total & $\mathrm{mg} / \mathrm{L}$ & 1 & $<0.10$ & 0.19 & 0.3 \\
\hline Manganese, Total & $\mathrm{mg} / \mathrm{L}$ & 1 & $<0.02$ & 0.07 & -- \\
\hline Nitrate+Nitrite & $\mathrm{mg} / \mathrm{L}$ & 1 & $<0.05$ & $<0.05$ & -- \\
\hline pH & SU & 1 & 7.43 & 7.37 & $6.0-9.5$ \\
\hline Sodium, Total & $\mathrm{mg} / \mathrm{L}$ & 1 & $<1.0$ & 20.6 & -- \\
\hline Sulfate & $\mathrm{mg} / \mathrm{L}$ & 1 & 8.9 & 13.3 & -- \\
\hline
\end{tabular}

$N$ - Number of samples

SU - Standard units

-- No guideline or standard available for these analytes

${ }^{a}$ Background location

${ }^{b}$ DOE ingestion-based DCGs for $100 \mathrm{mrem} / \mathrm{yr}$ dose limit are provided as a guideline for radiological results.

"New York State Water Quality Standards Class “D” surface waters as a comparative standard for nonradiological results

${ }^{d}$ Alpha as Am-241

e Beta as $\mathrm{Sr}-90$ 
Table C-4H (concluded)

2003 Results in Surface Water at the Standing Water (WNSTAW-Series)

Locations

\begin{tabular}{|c|c|c|c|c|c|}
\hline \multirow{3}{*}{ Analyte } & \multirow{3}{*}{ Units } & \multirow{3}{*}{$\mathbf{N}$} & \multirow{3}{*}{ WNSTAW9 } & \multicolumn{2}{|c|}{ Reference Values } \\
\hline & & & & \multirow{2}{*}{\begin{tabular}{|c|} 
WNSTAWB $^{\mathrm{a}}$ \\
Background Location $^{-}$
\end{tabular}} & \multirow{2}{*}{$\begin{array}{c}\text { Guideline }^{\mathrm{b}} \text { or } \\
\text { Standard }^{\mathrm{c}}\end{array}$} \\
\hline & & & & & \\
\hline Gross Alpha & $\mu \mathrm{Ci} / \mathrm{mL}$ & 1 & $4.74 \pm 5.76 \mathrm{E}-10$ & $4.68 \pm 6.80 \mathrm{E}-10$ & $3 \mathrm{E}-08^{\mathrm{d}}$ \\
\hline Gross Beta & $\mu \mathrm{Ci} / \mathrm{mL}$ & 1 & $2.72 \pm 0.96 \mathrm{E}-09$ & $2.78 \pm 1.03 \mathrm{E}-09$ & $1 \mathrm{E}-06^{\mathrm{e}}$ \\
\hline Tritium & $\mu \mathrm{Ci} / \mathrm{mL}$ & 1 & $8.18 \pm 8.44 \mathrm{E}-08$ & $-1.01 \pm 0.82 \mathrm{E}-07$ & $2 \mathrm{E}-03$ \\
\hline K-40 & $\mu \mathrm{Ci} / \mathrm{mL}$ & 1 & $-9.79 \pm 9.72 \mathrm{E}-08$ & $-0.54 \pm 1.04 \mathrm{E}-07$ & $7 \mathrm{E}-06$ \\
\hline Co-60 & $\mu \mathrm{Ci} / \mathrm{mL}$ & 1 & $3.61 \pm 4.17 \mathrm{E}-09$ & $-1.01 \pm 5.21 \mathrm{E}-09$ & $5 \mathrm{E}-06$ \\
\hline Sr-90 & $\mu \mathrm{Ci} / \mathrm{mL}$ & 1 & $1.02 \pm 0.82 \mathrm{E}-09$ & $1.22 \pm 1.26 \mathrm{E}-09$ & $1 \mathrm{E}-06$ \\
\hline Cs-137 & $\mu \mathrm{Ci} / \mathrm{mL}$ & 1 & $2.39 \pm 6.28 \mathrm{E}-09$ & $3.05 \pm 6.11 \mathrm{E}-09$ & $3 \mathrm{E}-06$ \\
\hline Chloride & $\mathrm{mg} / \mathrm{L}$ & 1 & 8 & 39 & -- \\
\hline Conductivity & $\mu$ mhos/cm@25 $5^{\circ} \mathrm{C}$ & 1 & 236 & 359 & -- \\
\hline Iron, Total & $\mathrm{mg} / \mathrm{L}$ & 1 & 0.22 & 0.19 & 0.3 \\
\hline Manganese, Total & $\mathrm{mg} / \mathrm{L}$ & 1 & 0.12 & 0.07 & -- \\
\hline Nitrate+Nitrite & $\mathrm{mg} / \mathrm{L}$ & 1 & $<0.05$ & $<0.05$ & -- \\
\hline pH & SU & 1 & 7.52 & 7.37 & $6.5-8.5$ \\
\hline Sodium, Total & $\mathrm{mg} / \mathrm{L}$ & 1 & 5.2 & 20.6 & -- \\
\hline Sulfate & $\mathrm{mg} / \mathrm{L}$ & 1 & 15.9 & 13.3 & -- \\
\hline
\end{tabular}

$N$ - Number of samples

SU - Standard units

-- No guideline or standard available for these analytes

${ }^{a}$ Background location

${ }^{b}$ DOE ingestion-based DCGs for 100 mrem/yr dose limit are provided as a guideline for radiological results.

' New York State Water Quality Standards Class “C”" surface waters as a comparative standard for nonradiological results at WNSTAW9

${ }^{d}$ Alpha as Am-241

${ }^{e}$ Beta as Sr-90 


\section{Appendix C-5 \\ Potable Water (Drinking Water) Data}


This page intentionally left blank

$$
\text { C - } 50
$$




\section{Table C-5A}

\section{Results in Potable Well Water Around the WVDP}

\begin{tabular}{|c|c|c|c|c|c|c|c|}
\hline \multirow{3}{*}{ Analyte } & \multirow{3}{*}{ Units } & \multirow{3}{*}{$\mathbf{N}$} & \multirow{2}{*}{\multicolumn{3}{|c|}{ Annual Concentrations at Potable Wells }} & \multicolumn{2}{|c|}{ Reference Values } \\
\hline & & & & & & \multirow{2}{*}{$\begin{array}{c}\text { Background }^{\mathrm{a}} \\
\text { WFWELO6 }^{-}\end{array}$} & \multirow{2}{*}{ Standard ${ }^{b,}$} \\
\hline & & & WFWEL01 & WFWEL02 & WFWEL03 & & \\
\hline Gross Alpha & $\mu \mathrm{Ci} / \mathrm{mL}$ & 1 & $8.68 \pm 7.76 \mathrm{E}-10$ & $4.26 \pm 8.00 \mathrm{E}-10$ & $1.16 \pm 0.92 \mathrm{E}-09$ & $-0.92 \pm 5.84 \mathrm{E}-10$ & $1.5 \mathrm{E}-08^{\mathrm{d}}$ \\
\hline Gross Beta & $\mu \mathrm{Ci} / \mathrm{mL}$ & 1 & $2.24 \pm 1.26 \mathrm{E}-09$ & $1.13 \pm 1.44 \mathrm{E}-09$ & $1.92 \pm 1.47 \mathrm{E}-09$ & $5.25 \pm 8.00 \mathrm{E}-10$ & $1 \mathrm{E}-06^{\mathrm{e}}$ \\
\hline Tritium & $\mu \mathrm{Ci} / \mathrm{mL}$ & 1 & $0.03 \pm 8.23 \mathrm{E}-08$ & $-4.57 \pm 8.15 \mathrm{E}-08$ & $-4.75 \pm 5.64 \mathrm{E}-08$ & $-8.11 \pm 5.65 \mathrm{E}-08$ & -- \\
\hline Sr-90 & $\mu \mathrm{Ci} / \mathrm{mL}$ & 1 & $2.41 \pm 2.89 \mathrm{E}-09$ & $1.53 \pm 1.52 \mathrm{E}-09$ & $1.23 \pm 1.24 \mathrm{E}-09$ & $-0.36 \pm 1.33 \mathrm{E}-09$ & -- \\
\hline Cs-137 & $\mu \mathrm{Ci} / \mathrm{mL}$ & 1 & $1.61 \pm 7.55 \mathrm{E}-09$ & $0.75 \pm 6.42 \mathrm{E}-09$ & $0.10 \pm 1.10 \mathrm{E}-08$ & $1.54 \pm 4.63 \mathrm{E}-09$ & -- \\
\hline Conductivity & $\mu \mathrm{mhos} / \mathrm{cm} @ 25^{\circ} \mathrm{C}$ & 1 & 432 & 469 & 425 & 273 & -- \\
\hline pH & SU & 1 & 7.81 & 7.20 & 8.12 & 8.08 & $6.5-8.5$ \\
\hline
\end{tabular}

\begin{tabular}{|c|c|c|c|c|c|c|c|}
\hline \multirow{3}{*}{ Analyte } & \multirow{3}{*}{ Units } & \multirow{3}{*}{$\mathbf{N}$} & \multirow{2}{*}{\multicolumn{3}{|c|}{ Annual Concentrations at Potable Wells }} & \multicolumn{2}{|c|}{ Reference Values } \\
\hline & & & & & & \multirow{2}{*}{$\begin{array}{c}\text { Background }^{\mathrm{a}} \\
\text { WFWEL06 }\end{array}$} & \multirow{2}{*}{ Standard ${ }^{\mathrm{b}, \mathbf{c}}$} \\
\hline & & & WFWEL04 & WFWEL05 & WFWEL07 & & \\
\hline Gross Alpha & $\mu \mathrm{Ci} / \mathrm{mL}$ & 1 & $0.95 \pm 1.80 \mathrm{E}-09$ & $1.08 \pm 5.57 \mathrm{E}-10$ & $8.53 \pm 6.75 \mathrm{E}-10$ & $-0.92 \pm 5.84 \mathrm{E}-10$ & $1.5 \mathrm{E}-08^{\mathrm{d}}$ \\
\hline Gross Beta & $\mu \mathrm{Ci} / \mathrm{mL}$ & 1 & $2.98 \pm 2.59 \mathrm{E}-09$ & $2.84 \pm 1.03 \mathrm{E}-09$ & $-3.71 \pm 8.43 \mathrm{E}-10$ & $5.25 \pm 8.00 \mathrm{E}-10$ & $1 \mathrm{E}-06^{\mathrm{e}}$ \\
\hline Tritium & $\mu \mathrm{Ci} / \mathrm{mL}$ & 1 & $3.65 \pm 5.85 \mathrm{E}-08$ & $0.56 \pm 7.94 \mathrm{E}-08$ & $2.19 \pm 8.20 \mathrm{E}-08$ & $-8.11 \pm 5.65 \mathrm{E}-08$ & -- \\
\hline Sr-90 & $\mu \mathrm{Ci} / \mathrm{mL}$ & 1 & $0.10 \pm 1.37 \mathrm{E}-09$ & $1.30 \pm 1.31 \mathrm{E}-09$ & $2.27 \pm 2.92 \mathrm{E}-09$ & $-0.36 \pm 1.33 \mathrm{E}-09$ & -- \\
\hline Cs-137 & $\mu \mathrm{Ci} / \mathrm{mL}$ & 1 & $3.02 \pm 7.58 \mathrm{E}-09$ & 2.14 $\pm 7.37 \mathrm{E}-09$ & $-0.27 \pm 1.15 \mathrm{E}-08$ & $1.54 \pm 4.63 \mathrm{E}-09$ & -- \\
\hline Conductivity & $\mu \mathrm{mhos} / \mathrm{cm} @ 25^{\circ} \mathrm{C}$ & 1 & 1,424 & 266 & 297 & 273 & -- \\
\hline pH & SU & 1 & 8.11 & 6.42 & 7.80 & 8.08 & $6.5-8.5$ \\
\hline
\end{tabular}

\begin{tabular}{|c|c|c|c|c|c|c|c|}
\hline \multirow{3}{*}{ Analyte } & \multirow{3}{*}{ Units } & \multirow{3}{*}{$\mathbf{N}$} & \multirow{2}{*}{\multicolumn{3}{|c|}{ Annual Concentrations at Potable Wells }} & \multicolumn{2}{|c|}{ Reference Values } \\
\hline & & & & & & \multirow{2}{*}{$\begin{array}{c}\text { Background }^{\mathrm{a}} \\
\text { WFWELO6 }\end{array}$} & \multirow{2}{*}{ Standard $d^{\mathrm{b}, \mathrm{c}}$} \\
\hline & & & WFWEL08 & WFWEL09 & WFWEL10 & & \\
\hline Gross Alpha & $\mu \mathrm{Ci} / \mathrm{mL}$ & 1 & $1.29 \pm 0.92 \mathrm{E}-09$ & $2.03 \pm 1.30 \mathrm{E}-09$ & $-0.43 \pm 1.33 \mathrm{E}-09$ & $-0.92+5.84 \mathrm{E}-10$ & $1.5 \mathrm{E}-08^{\mathrm{d}}$ \\
\hline Gross Beta & $\mu \mathrm{Ci} / \mathrm{mL}$ & 1 & $2.46 \pm 1.51 \mathrm{E}-09$ & $2.07 \pm 1.52 \mathrm{E}-09$ & $1.85 \pm 1.40 \mathrm{E}-09$ & $5.25 \pm 8.00 \mathrm{E}-10$ & $1 \mathrm{E}-06^{\mathrm{e}}$ \\
\hline Tritium & $\mu \mathrm{Ci} / \mathrm{mL}$ & 1 & $0.21 \pm 8.33 \mathrm{E}-08$ & $3.88 \pm 8.05 \mathrm{E}-08$ & $-5.63 \pm 7.99 \mathrm{E}-08$ & $-8.11 \pm 5.65 \mathrm{E}-08$ & -- \\
\hline Sr-90 & $\mu \mathrm{Ci} / \mathrm{mL}$ & 1 & $2.61 \pm 1.43 \mathrm{E}-09$ & $1.16 \pm 1.85 \mathrm{E}-09$ & $0.09 \pm 1.51 \mathrm{E}-09$ & $-0.36 \pm 1.33 \mathrm{E}-09$ & -- \\
\hline Cs-137 & $\mu \mathrm{Ci} / \mathrm{mL}$ & 1 & $1.97 \pm 7.36 \mathrm{E}-09$ & $3.08 \pm 6.12 \mathrm{E}-09$ & $6.42 \pm 6.60 \mathrm{E}-09$ & $1.54 \pm 4.63 \mathrm{E}-09$ & -- \\
\hline Conductivity & $\mu \mathrm{mhos} / \mathrm{cm} @ 25^{\circ} \mathrm{C}$ & 1 & 381 & 560 & 589 & 273 & -- \\
\hline pH & SU & 1 & 7.92 & 8.05 & 7.55 & 8.08 & $6.5-8.5$ \\
\hline
\end{tabular}

$N$ - Number of samples

$S U$ - Standard units

-- No guideline or standard available for these analytes

${ }^{a}$ Background location

${ }^{b}$ New York State Water Quality Standard for Class “GA” for fresh groundwater

${ }^{c}$ NYSDOH raw water supply standards (10 NYCRR Part 170.4)

${ }^{d}$ Alpha standard excludes radon and uranium, however, the WVDP results include these isotopes.

${ }^{e}$ Beta standard excludes strontium and alpha emitters, however, the WVDP results include these isotopes. 


\section{Table C-5B}

\section{Results in Main Plant Potable Water (WNDNKMP)}

\begin{tabular}{|l|c|c|c|c|c|c|}
\hline \multirow{2}{*}{\multicolumn{1}{|c|}{ Analyte }} & \multirow{2}{*}{ Units } & \multirow{2}{*}{$\mathbf{N}$} & \multicolumn{3}{c|}{ Annual Concentration } & \multirow{2}{*}{ Standard $^{\text {a }}$} \\
\cline { 4 - 6 } & & & Minimum & Average & Maximum & \\
\hline Gross Alpha & $\mu \mathrm{Ci} / \mathrm{mL}$ & 6 & $<3.33 \mathrm{E}-10$ & $0.27 \pm 4.19 \mathrm{E}-10$ & $<5.74 \mathrm{E}-10$ & $1.5 \mathrm{E}-08$ \\
\hline Gross Beta & $\mu \mathrm{Ci} / \mathrm{mL}$ & 6 & $7.81 \mathrm{E}-10$ & $1.59 \pm 0.74 \mathrm{E}-09$ & $1.98 \mathrm{E}-09$ & $5 \mathrm{E}-08$ \\
\hline Tritium & $\mu \mathrm{Ci} / \mathrm{mL}$ & 6 & $<8.16 \mathrm{E}-08$ & $-1.94 \pm 8.46 \mathrm{E}-08$ & $1.21 \mathrm{E}-07$ & $2 \mathrm{E}-05$ \\
\hline Conductivity & $\mu \mathrm{mhos} / \mathrm{cm} @ 25^{\circ} \mathrm{C}$ & 6 & 158 & 212 & 244 & -- \\
\hline pH & $\mathrm{SU}$ & 6 & 7.21 & 7.62 & 8.01 & - \\
\hline
\end{tabular}

\section{Results in Environmental Laboratory Potable Water (WNDNKEL)}

\begin{tabular}{|c|c|c|c|c|c|c|}
\hline \multirow{2}{*}{ Analyte } & \multirow{2}{*}{ Units } & \multirow{2}{*}{$\mathbf{N}$} & \multicolumn{3}{|c|}{ Annual Concentration } & \multirow{2}{*}{ Standard } \\
\hline & & & Minimum & Average & Maximum & \\
\hline Gross Alpha & $\mu \mathrm{Ci} / \mathrm{mL}$ & 6 & $<3.38 \mathrm{E}-10$ & $-0.06 \pm 4.23 \mathrm{E}-10$ & $<5.54 \mathrm{E}-10$ & $1.5 \mathrm{E}-08$ \\
\hline Gross Beta & $\mu \mathrm{Ci} / \mathrm{mL}$ & 6 & $9.98 \mathrm{E}-10$ & $1.69 \pm 0.75 \mathrm{E}-09$ & 2.88E-09 & $5 \mathrm{E}-08$ \\
\hline Tritium & $\mu \mathrm{Ci} / \mathrm{mL}$ & 6 & $<8.01 \mathrm{E}-08$ & $3.45 \pm 8.33 \mathrm{E}-08$ & $1.74 \mathrm{E}-07$ & $2 \mathrm{E}-05$ \\
\hline Conductivity & $\mu \mathrm{mhos} / \mathrm{cm} @ 25^{\circ} \mathrm{C}$ & 6 & 195 & 208 & 232 & -- \\
\hline HAA5 & $\mathrm{mg} / \mathrm{L}$ & 4 & $<0.013$ & $<0.023$ & $<0.038$ & 0.06 \\
\hline pH & SU & 6 & 6.79 & 7.21 & 8.00 & -- \\
\hline TTHM & $\mathrm{mg} / \mathrm{L}$ & 4 & $<0.017$ & $<0.029$ & $<0.046$ & 0.08 \\
\hline
\end{tabular}

\section{Results in Maintenance Shop Potable Water (WNDNKMS)}

\begin{tabular}{|l|c|c|c|c|c|c|}
\hline \multirow{2}{*}{ Analyte } & \multirow{2}{*}{ Units } & \multirow{2}{*}{$\mathbf{N}$} & \multicolumn{3}{c|}{ Annual Concentration } & \multirow{2}{*}{ Standard $^{\mathbf{a}}$} \\
\cline { 4 - 6 } & & & Minimum & Average & Maximum & \\
\hline Gross Alpha & $\mu \mathrm{Ci} / \mathrm{mL}$ & 6 & $<3.59 \mathrm{E}-10$ & $0.64 \pm 4.03 \mathrm{E}-10$ & $<4.77 \mathrm{E}-10$ & $1.5 \mathrm{E}-08$ \\
\hline Gross Beta & $\mu \mathrm{Ci} / \mathrm{mL}$ & 6 & $1.04 \mathrm{E}-09$ & $1.45 \pm 0.76 \mathrm{E}-09$ & $1.80 \mathrm{E}-09$ & $5 \mathrm{E}-08$ \\
\hline Tritium & $\mu \mathrm{Ci} / \mathrm{mL}$ & 6 & $<5.80 \mathrm{E}-08$ & $1.29 \pm 8.00 \mathrm{E}-08$ & $1.04 \mathrm{E}-07$ & $2 \mathrm{E}-05$ \\
\hline Conductivity & $\mu \mathrm{mhos} / \mathrm{cm} @ 25^{\circ} \mathrm{C}$ & 6 & 198 & 229 & 315 & -- \\
\hline pH & $\mathrm{SU}$ & 6 & 7.25 & 7.62 & 8.57 & -- \\
\hline
\end{tabular}

$N$ - Number of samples

$S U$ - Standard units

-- No guideline or standard available for these analytes

${ }^{a}$ New York State Department of Health MCLs for drinking water used as a comparative reference 
Table C-5C

2003 Results in Utility Room Potable Water (WNDNKUR)

\begin{tabular}{|c|c|c|c|c|c|c|}
\hline \multirow{2}{*}{ Analyte } & \multirow{2}{*}{ Units } & \multirow{2}{*}{$\mathbf{N}$} & \multicolumn{3}{|c|}{ WNDNKUR Concentrations } & \multirow{2}{*}{$\begin{array}{c}\text { Standard } \\
\text { or } \\
\text { Guideline }^{\mathrm{a}}\end{array}$} \\
\hline & & & Minimum & Average & Maximum & \\
\hline Gross Alpha & $\mu \mathrm{Ci} / \mathrm{mL}$ & 12 & $<3.33 \mathrm{E}-10$ & $1.07 \pm 4.55 \mathrm{E}-10$ & $<6.17 \mathrm{E}-10$ & $1.5 \mathrm{E}-08$ \\
\hline Gross Beta & $\mu \mathrm{Ci} / \mathrm{mL}$ & 12 & 7.71E-10 & $1.64 \pm 0.75 \mathrm{E}-09$ & $2.65 \mathrm{E}-09$ & $5 \mathrm{E}-08$ \\
\hline Tritium & $\mu \mathrm{Ci} / \mathrm{mL}$ & 12 & $<4.32 \mathrm{E}-08$ & $0.83 \pm 7.95 \mathrm{E}-08$ & $1.18 \mathrm{E}-07$ & $2 \mathrm{E}-05$ \\
\hline Antimony, Total & $\mathrm{mg} / \mathrm{L}$ & 1 & NA & NA & $<0.001$ & 0.006 \\
\hline Arsenic, Total & $\mathrm{mg} / \mathrm{L}$ & 1 & NA & NA & $<0.001$ & 0.05 \\
\hline Barium, Total & $\mathrm{mg} / \mathrm{L}$ & 1 & NA & NA & $<0.20$ & 2 \\
\hline Beryllium, Total & $\mathrm{mg} / \mathrm{L}$ & 1 & NA & NA & $<0.0003$ & 0.004 \\
\hline Cadmium, Total & $\mathrm{mg} / \mathrm{L}$ & 1 & NA & NA & $<0.002$ & 0.005 \\
\hline Chromium, Total & $\mathrm{mg} / \mathrm{L}$ & 1 & NA & NA & $<0.010$ & 0.1 \\
\hline Conductivity & $\mu$ mhos $/ \mathrm{cm} @ 25^{\circ} \mathrm{C}$ & 12 & 107 & 198 & 248 & -- \\
\hline Cyanide, Total & $\mathrm{mg} / \mathrm{L}$ & 1 & NA & NA & $<0.01$ & 0.2 \\
\hline Fluoride & $\mathrm{mg} / \mathrm{L}$ & 1 & NA & NA & $<0.20$ & 2.2 \\
\hline Free Residual Chlorine & $\mathrm{mg} / \mathrm{L}$ & 1,095 & 0.45 & NA & 2.20 & $0.2-4.0$ \\
\hline Mercury, Total & $\mathrm{mg} / \mathrm{L}$ & 1 & NA & NA & $<0.0004$ & 0.002 \\
\hline Nickel, Total & $\mathrm{mg} / \mathrm{L}$ & 1 & NA & NA & $<0.005$ & -- \\
\hline pH & SU & 12 & 7.35 & 7.82 & 8.56 & -- \\
\hline POC $^{b}$ & $\mathrm{mg} / \mathrm{L}$ & 52 & NA & NA & $<0.0005$ & $<0.0005$ \\
\hline Selenium, Total & $\mathrm{mg} / \mathrm{L}$ & 1 & NA & NA & $<0.002$ & 0.050 \\
\hline Thallium, Total & $\mathrm{mg} / \mathrm{L}$ & 1 & NA & NA & $<0.001$ & 0.0005 \\
\hline Turbidity & NTU & 2,190 & 0.08 & NA & 0.46 & $1.0^{\mathrm{c}}$ \\
\hline
\end{tabular}

$N$ - Number of samples

NA - Not available, constituents sampled annually

NTU - Nephelometric turbidity units

$S U$ - Standard units

-- No guideline or standard available for these analytes

${ }^{a}$ New York State Department of Health MCLs for drinking water or EPA MCLGs, whichever is more stringent

${ }^{b}$ Principal organic contaminant

${ }^{c}$ A treatment standard of 0.3 NTU applies to the 95th percentile on a monthly basis. 
Table C-5D

2003 Results in Utility Room Raw (Untreated) Water (WNURRAW)

\begin{tabular}{|l|c|c|c|c|c|}
\hline \multirow{2}{*}{ Analyte } & \multirow{2}{*}{ Units } & \multirow{2}{*}{ N } & \multicolumn{3}{c|}{ WNURRAW Concentrations } \\
\cline { 4 - 6 } & & Minimum & Average & Maximum \\
\hline Iron, Total & $\mathrm{mg} / \mathrm{L}$ & 53 & 0.11 & 0.60 & 162 \\
\hline Solids, Total Dissolved & $\mathrm{mg} / \mathrm{L}$ & 21 & 82 & 106 & \\
\hline
\end{tabular}

$N$ - Number of samples

-- No guideline applicable to this location

\section{Table C-5E \\ Various Site Tap Water Locations \\ (Analyzed by Cattaraugus County Department of Health)}

\begin{tabular}{|l|c|c|c|c|}
\hline \multicolumn{1}{|c|}{ Analyte } & Units & N & $\begin{array}{c}\text { Various Site Tap Water Locations } \\
\text { Results }\end{array}$ & Standard $^{\mathbf{a}}$ \\
\hline E. coli & NA & 12 & Negative & one positive sample \\
\hline Free Residual Chlorine & $\mathrm{mg} / \mathrm{L}$ & 12 & Range: $0.04-1.16 \mathrm{mg} / \mathrm{L}$ & $0.02(\mathrm{~min})-4.0(\max )$ \\
\hline Total Coliform & NA & 12 & Negative & two or more positive samples \\
\hline
\end{tabular}

$N$ - Number of samples

NA - Not applicable

${ }^{a}$ New York State Department of Health MCLs for drinking water or EPA MCLGs, whichever is more stringent

Table C-5F

Tap Water Sample Results From WVDP Restroom Sink

(Analyzed by Cattaraugus County Department of Health)

\begin{tabular}{|c|c|c|c|c|c|}
\hline \multicolumn{1}{|c|}{ Analyte } & Units & $\mathbf{N}$ & Date Collected & Annual Concentration & Standard $^{\mathrm{a}}$ \\
\hline Nitrate-N & $\mathrm{mg} / \mathrm{L}$ & 1 & $3 / 11 / 03$ & 1.01 & 10 \\
\hline
\end{tabular}

$N$ - Number of samples

${ }^{a}$ New York State Department of Health MCLs for drinking water or EPA MCLGs, whichever is more stringent 


\section{Appendix D}

\section{Summary of Air Monitoring Data}

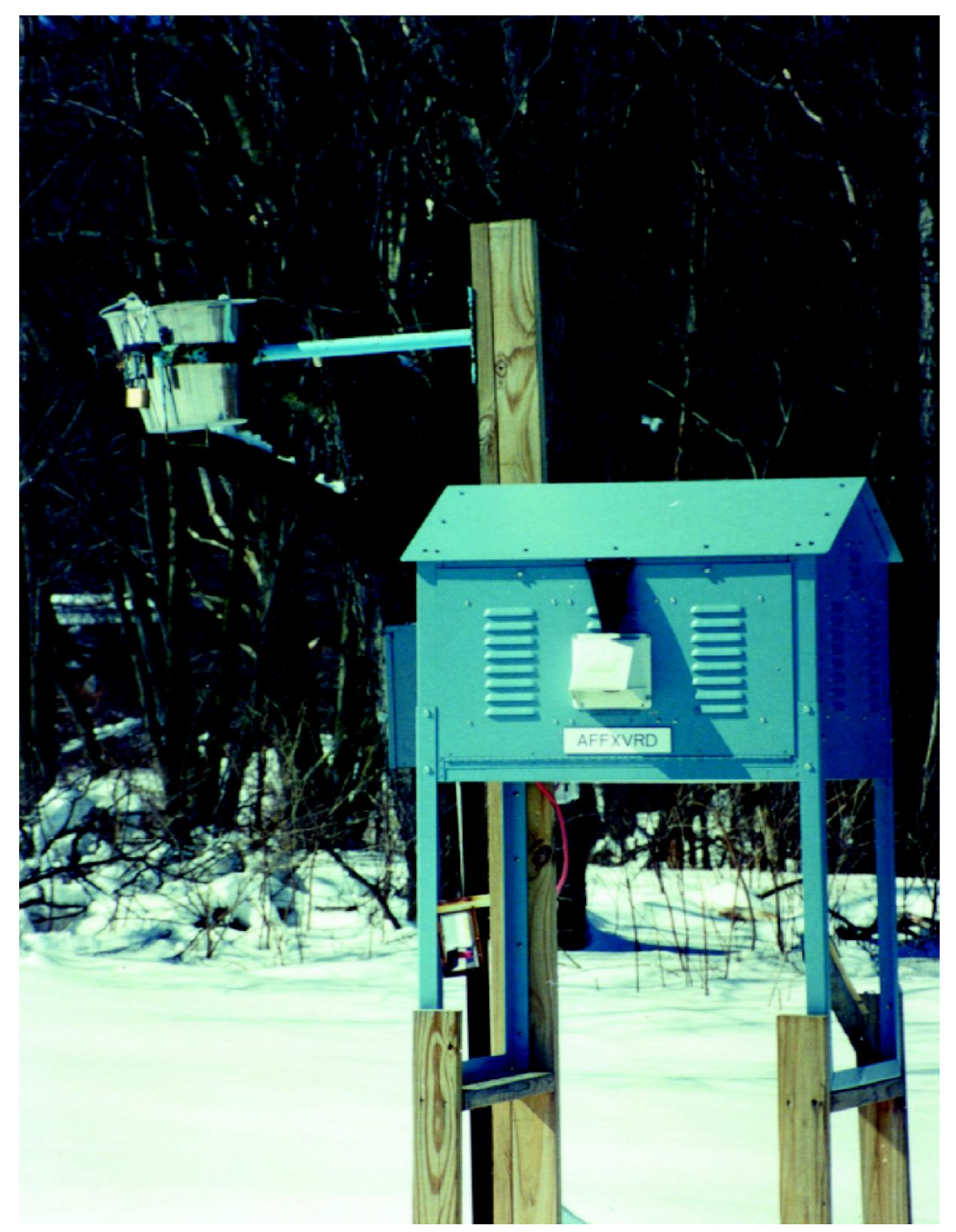

Ambient Air and Atmospheric Fallout Samples are Collected From Numerous Locations in the West Valley Area

$D-1$ 
This page intentionally left blank

$D-2$ 
Table D-1

2003 Airborne Radioactivity at Main Stack (ANSTACK)

\begin{tabular}{|c|c|c|c|c|c|c|}
\hline Isotope $^{\mathbf{a}}$ & $\mathbf{N}$ & $\begin{array}{c}\text { Exhaust } \\
\text { Activity Released }^{\mathbf{b}} \\
\text { (Ci) }\end{array}$ & $\begin{array}{c}\text { Average } \\
\text { Concentration } \\
(\mu \mathrm{Ci} / \mathrm{mL})\end{array}$ & $\begin{array}{c}\text { Maximum } \\
\text { Concentration } \\
(\mu \mathrm{Ci} / \mathrm{mL})\end{array}$ & $\begin{array}{c}D^{2} G^{c} \\
(\mu \mathrm{Ci} / \mathbf{m L})\end{array}$ & $\begin{array}{c}\text { Average } \\
\text { \% DCG }\end{array}$ \\
\hline Gross Alpha & 52 & $1.68 \pm 0.13 \mathrm{E}-06$ & $2.28 \pm 0.17 \mathrm{E}-15$ & $3.30 \mathrm{E}-14$ & -- & -- \\
\hline Gross Beta & 52 & $5.46 \pm 0.05 \mathrm{E}-05$ & $7.39 \pm 0.07 \mathrm{E}-14$ & $1.16 \mathrm{E}-12$ & -- & -- \\
\hline H-3 & 52 & $2.41 \pm 0.20 \mathrm{E}-03$ & $3.27 \pm 0.27 \mathrm{E}-12$ & $2.16 \mathrm{E}-11$ & 1E-07 & $<0.01$ \\
\hline Co-60 & 4 & $4.62 \pm 5.88 \mathrm{E}-08$ & $6.26 \pm 7.97 \mathrm{E}-17$ & $3.37 \mathrm{E}-16$ & $8 \mathrm{E}-11$ & $<0.01$ \\
\hline Sr-90 & 4 & $4.31 \pm 0.15 \mathrm{E}-06$ & $5.84 \pm 0.21 \mathrm{E}-15$ & $8.89 \mathrm{E}-15$ & $9 \mathrm{E}-12$ & 0.06 \\
\hline I-129 & 4 & $6.49 \pm 0.44 \mathrm{E}-05$ & $8.79 \pm 0.60 \mathrm{E}-14$ & $1.20 \mathrm{E}-13$ & 7E-11 & 0.13 \\
\hline Cs-137 & 4 & $1.22 \pm 0.05 \mathrm{E}-05$ & $1.65 \pm 0.07 \mathrm{E}-14$ & 3.63E-14 & $4 \mathrm{E}-10$ & $<0.01$ \\
\hline Eu-154 & 4 & $0.00 \pm 1.53 \mathrm{E}-07$ & $0.00 \pm 2.07 \mathrm{E}-16$ & $<4.57 \mathrm{E}-16$ & $5 \mathrm{E}-11$ & $<0.01$ \\
\hline$U-232^{d}$ & 4 & $3.32 \pm 0.99 \mathrm{E}-08$ & $4.49 \pm 1.34 \mathrm{E}-17$ & $6.86 \mathrm{E}-17$ & $2 \mathrm{E}-14$ & 0.22 \\
\hline U-233/234 ${ }^{\mathrm{d}}$ & 4 & $5.75 \pm 0.99 \mathrm{E}-08$ & $7.80 \pm 1.34 \mathrm{E}-17$ & 7.34E-17 & 9E-14 & 0.09 \\
\hline $\mathrm{U}-235 / 236$ & 4 & $6.14 \pm 3.70 \mathrm{E}-09$ & $8.32 \pm 5.01 \mathrm{E}-18$ & $1.43 \mathrm{E}-17$ & $1 \mathrm{E}-13$ & 0.01 \\
\hline U-238 ${ }^{d}$ & 4 & $5.03 \pm 0.89 \mathrm{E}-08$ & $6.82 \pm 1.20 \mathrm{E}-17$ & 7.89E-17 & $1 \mathrm{E}-13$ & 0.07 \\
\hline Pu-238 & 4 & $1.69 \pm 0.17 \mathrm{E}-07$ & $2.29 \pm 0.23 \mathrm{E}-16$ & $5.09 \mathrm{E}-16$ & $3 \mathrm{E}-14$ & 0.76 \\
\hline Pu-239/240 & 4 & $2.19 \pm 0.19 \mathrm{E}-07$ & $2.97 \pm 0.26 \mathrm{E}-16$ & $5.26 \mathrm{E}-16$ & $2 \mathrm{E}-14$ & 1.48 \\
\hline Am-241 & 4 & $5.16 \pm 0.30 \mathrm{E}-07$ & $6.99 \pm 0.41 \mathrm{E}-16$ & $1.15 \mathrm{E}-15$ & 2E-14 & 3.49 \\
\hline Total \% of DCG & & & & & & 6.33 \\
\hline
\end{tabular}

$N$ - Number of samples

-- DCGs are not specified for gross alpha and beta activity.

${ }^{a}$ Half-lives are listed in Table $\mathrm{K}-\mathrm{C} \mathrm{C}$.

${ }^{b}$ Total volume released at 50,000 $\mathrm{cfm}=7.38 \mathrm{E}+14 \mathrm{~mL} / \mathrm{year}$

${ }^{c}$ Derived concentration guides (DCGs) are listed for reference only. They are applicable to average concentrations at the site boundary but not to stack concentrations, as might be inferred from their inclusion in this table.

${ }^{d}$ Total Uranium: $1.56 \pm 0.02 \mathrm{E}-01 \mathrm{~g}$; average $=2.11 \mathrm{E} \pm 0.03 \mathrm{E}-10 \mu \mathrm{g} / \mathrm{mL}$

$D-3$ 
Table D-2

2003 Airborne Radioactivity at Vitrification System (HVAC) (ANVITSK)

\begin{tabular}{|c|c|c|c|c|c|}
\hline Isotope & $\mathbf{N}$ & $\begin{array}{c}\text { Total } \\
\text { Activity Released } \\
\text { (Ci) }\end{array}$ & $\begin{array}{c}\text { Average } \\
\text { Concentration } \\
(\mu \mathrm{Ci} / \mathrm{mL})\end{array}$ & $\begin{array}{c}\text { Maximum } \\
\text { Concentration } \\
\mu \mathrm{Ci} / \mathrm{mL}\end{array}$ & $\begin{array}{c}D G^{\mathrm{a}} \\
\mu \mathrm{Ci} / \mathrm{mL}\end{array}$ \\
\hline Gross Alpha & 52 & $-1.78 \pm 3.44 \mathrm{E}-08$ & $-4.84 \pm 9.33 \mathrm{E}-17$ & $<9.02 \mathrm{E}-16$ & -- \\
\hline Gross Beta & 52 & $4.68 \pm 6.57 \mathrm{E}-08$ & $1.27 \pm 1.78 \mathrm{E}-16$ & $1.65 \mathrm{E}-15$ & -- \\
\hline Co-60 & 4 & $-2.28 \pm 3.94 \mathrm{E}-08$ & $-0.62 \pm 1.07 \mathrm{E}-16$ & $<2.95 \mathrm{E}-16$ & $8 \mathrm{E}-11$ \\
\hline Sr-90 & 4 & $2.70 \pm 1.58 \mathrm{E}-08$ & $7.32 \pm 4.28 \mathrm{E}-17$ & $1.90 \mathrm{E}-16$ & $9 \mathrm{E}-12$ \\
\hline I-129 & 4 & $2.69 \pm 0.89 \mathrm{E}-07$ & $7.30 \pm 2.41 \mathrm{E}-16$ & $8.64 \mathrm{E}-16$ & $7 \mathrm{E}-11$ \\
\hline Cs-137 & 4 & $1.24 \pm 3.68 \mathrm{E}-08$ & $3.36 \pm 9.98 \mathrm{E}-17$ & $<3.00 \mathrm{E}-16$ & $4 \mathrm{E}-10$ \\
\hline Eu-154 & 4 & $-3.61 \pm 8.69 \mathrm{E}-08$ & $-0.98 \pm 2.35 \mathrm{E}-16$ & $<5.06 \mathrm{E}-16$ & $5 \mathrm{E}-11$ \\
\hline $\mathrm{U}^{-232}{ }^{\mathrm{b}}$ & 4 & $0.52 \pm 2.72 \mathrm{E}-09$ & $1.42 \pm 7.37 \mathrm{E}-18$ & $<1.58 \mathrm{E}-16$ & $2 \mathrm{E}-14$ \\
\hline $\mathrm{U}-233 / 234^{\mathrm{b}}$ & 4 & $3.84 \pm 0.54 \mathrm{E}-08$ & $1.04 \pm 0.15 \mathrm{E}-16$ & $1.80 \mathrm{E}-16$ & $9 \mathrm{E}-14$ \\
\hline $\mathrm{U}-235 / 236^{b}$ & 4 & $5.36 \pm 2.53 \mathrm{E}-09$ & $1.45 \pm 0.69 \mathrm{E}-17$ & $5.22 \mathrm{E}-17$ & $1 \mathrm{E}-13$ \\
\hline $\mathrm{U}_{-238}{ }^{\mathrm{b}}$ & 4 & $2.77 \pm 0.56 \mathrm{E}-08$ & $7.49 \pm 1.52 \mathrm{E}-17$ & 9.99E-17 & $1 \mathrm{E}-13$ \\
\hline Pu-238 & 4 & $-0.11 \pm 1.34 \mathrm{E}-09$ & $-0.30 \pm 3.63 \mathrm{E}-18$ & $<1.14 \mathrm{E}-17$ & $3 \mathrm{E}-14$ \\
\hline Pu-239/240 & 4 & $1.70 \pm 1.53 \mathrm{E}-09$ & $4.60 \pm 4.17 \mathrm{E}-18$ & $1.26 \mathrm{E}-17$ & $2 \mathrm{E}-14$ \\
\hline Am-241 & 4 & $4.71 \pm 2.09 \mathrm{E}-09$ & $1.28 \pm 0.57 \mathrm{E}-17$ & $2.45 \mathrm{E}-17$ & $2 \mathrm{E}-14$ \\
\hline
\end{tabular}

Note: The sampler for former air monitoring location ANSEISK, discontinued at the end of March 2003, was restarted in October 2003 for operational reasons and became the primary sampling point ANVITSK. The preexisting location was shut down.

$N$ - Number of samples

-- DCGs are not specified for gross alpha and beta activity.

${ }^{a}$ Derived concentration guides (DCGs) are listed for reference only. They are applicable to average concentrations at the site boundary but not to stack concentrations, as might be inferred from their inclusion in this table.

${ }^{b}$ Total Uranium: 6.86 $\pm 0.07 E$ - $02 \mathrm{~g}$; average $=1.86 \pm 0.02 \mathrm{E}-10 \mu \mathrm{g} / \mathrm{mL}$

Table D-3

2003 Airborne Radioactivity at Seismic Sampler (ANSEISK)

\begin{tabular}{|c|c|c|c|c|c|}
\hline Isotope & $\mathbf{N}$ & $\begin{array}{c}\text { Total } \\
\text { Activity Released } \\
\text { (Ci) }\end{array}$ & $\begin{array}{c}\text { Average } \\
\text { Concentration } \\
(\mu \mathrm{Ci} / \mathrm{mL})\end{array}$ & $\begin{array}{c}\text { Maximum } \\
\text { Concentration } \\
(\mu \mathrm{Ci} / \mathrm{mL})\end{array}$ & $\begin{array}{c}\text { DCG } \\
(\mu \mathrm{Ci} / \mathrm{mL})\end{array}$ \\
\hline Gross Alpha & 13 & $-1.62 \pm 1.93 \mathrm{E}-08$ & $-1.76 \pm 2.10 \mathrm{E}-16$ & $<9.71 \mathrm{E}-16$ & -- \\
\hline Gross Beta & 13 & $1.61 \pm 0.38 \mathrm{E}-07$ & $1.75 \pm 0.41 \mathrm{E}-15$ & 1.93E-14 & -- \\
\hline
\end{tabular}

$N$ - Number of samples; Sampling for ANSEISK was discontinued after the first quarter of 2003.

-- DCGs are not specified for gross alpha and gross beta activity.

$D-4$ 
Table D-4

2003 Airborne Radioactivity at 01-14 Building (ANCSSTK)

\begin{tabular}{|c|c|c|c|c|c|}
\hline \multirow[b]{2}{*}{ Isotope } & \multirow[b]{2}{*}{$\mathbf{N}$} & CSS Stack & Average & Maximum & \multirow[b]{2}{*}{$\begin{array}{c}\mathrm{DCG}^{\mathrm{a}} \\
\mu \mathrm{Ci} / \mathbf{m L}\end{array}$} \\
\hline & & $\begin{array}{c}\text { Activity } \\
\text { Ci }\end{array}$ & $\begin{array}{c}\text { Concentration } \\
\mu \mathrm{Ci} / \mathrm{mL}\end{array}$ & $\begin{array}{c}\text { Concentration } \\
\mu \mathrm{Ci} / \mathrm{mL}\end{array}$ & \\
\hline Gross Alpha & 52 & $-1.48 \pm 1.33 \mathrm{E}-08$ & $1.05 \pm 0.93 \mathrm{E}-16$ & $<9.88 \mathrm{E}-16$ & -- \\
\hline Gross Beta & 52 & $1.39 \pm 2.58 \mathrm{E}-08$ & $0.94 \pm 1.80 \mathrm{E}-16$ & $1.85 \mathrm{E}-15$ & -- \\
\hline Co-60 & 4 & $-0.21 \pm 1.28 \mathrm{E}-08$ & $1.50 \pm 8.92 \mathrm{E}-17$ & $<2.65 \mathrm{E}-16$ & $8 \mathrm{E}-11$ \\
\hline Sr-90 & 4 & $0.64 \pm 5.83 \mathrm{E}-09$ & $0.45 \pm 4.07 \mathrm{E}-17$ & $<9.70 \mathrm{E}-17$ & $9 \mathrm{E}-12$ \\
\hline I-129 & 4 & $4.90 \pm 2.65 \mathrm{E}-08$ & $3.63 \pm 1.98 \mathrm{E}-16$ & $5.24 \mathrm{E}-16$ & 7E-11 \\
\hline Cs-137 & 4 & $0.22 \pm 1.00 \mathrm{E}-08$ & $1.51 \pm 7.00 \mathrm{E}-17$ & $<1.90 \mathrm{E}-16$ & $4 \mathrm{E}-10$ \\
\hline Eu-154 & 4 & $-0.76 \pm 3.77 \mathrm{E}-08$ & $-0.54 \pm 2.63 \mathrm{E}-16$ & $<8.49 \mathrm{E}-16$ & $5 \mathrm{E}-11$ \\
\hline $\mathrm{U}-232^{\mathrm{b}}$ & 4 & $1.35 \pm 1.15 \mathrm{E}-09$ & $9.40 \pm 8.06 \mathrm{E}-18$ & $1.14 \mathrm{E}-17$ & $2 \mathrm{E}-14$ \\
\hline $\mathrm{U}-233 / 234^{\mathrm{b}}$ & 4 & $1.06 \pm 0.18 \mathrm{E}-08$ & $7.37 \pm 1.28 \mathrm{E}-17$ & $1.01 \mathrm{E}-16$ & 9E-14 \\
\hline $\mathrm{U}-235 / 236^{\mathrm{b}}$ & 4 & $1.80 \pm 0.94 \mathrm{E}-09$ & $1.26 \pm 0.66 \mathrm{E}-17$ & 2.61E-17 & $1 \mathrm{E}-13$ \\
\hline U-238 ${ }^{b}$ & 4 & $1.10 \pm 0.17 \mathrm{E}-08$ & $7.70 \pm 1.21 \mathrm{E}-17$ & $9.43 \mathrm{E}-17$ & $1 \mathrm{E}-13$ \\
\hline Pu-238 & 4 & $-0.37 \pm 6.37 \mathrm{E}-10$ & $-0.26 \pm 4.45 E-17$ & $<1.33 \mathrm{E}-17$ & $3 \mathrm{E}-14$ \\
\hline Pu-239/240 & 4 & $0.80 \pm 7.87 \mathrm{E}-10$ & $0.56 \pm 5.49 \mathrm{E}-18$ & $<1.69 \mathrm{E}-17$ & $2 \mathrm{E}-14$ \\
\hline Am-241 & 4 & $1.55 \pm 0.96 \mathrm{E}-09$ & $1.08 \pm 6.69 \mathrm{E}-18$ & $2.44 \mathrm{E}-17$ & $2 \mathrm{E}-14$ \\
\hline
\end{tabular}

$N$ - Number of samples

-- DCGs are not specified for gross alpha and beta activity.

${ }^{a}$ Derived concentration guides (DCGs) are listed for reference only. They are applicable to average concentrations at the site boundary but not to stack concentrations, as might be inferred from their inclusion in this table.

${ }^{b}$ Total Uranium: $2.57 \pm 0.03 E-02 \mathrm{~g} ;$ average $=1.79 \pm 0.02 \mathrm{E}-10 \mu \mathrm{g} / \mathrm{mL}$

Table D-5

2003 Airborne Radioactivity at Contact Size-Reduction (ANCSRFK)

\author{
VENTILATION OFF DURING CY 2003
}

$D-5$ 
Table D-6

2003 Airborne Radioactivity at Supernatant Treatment System (ANSTSTK)

\begin{tabular}{|c|c|c|c|c|c|}
\hline Isotope & $\mathbf{N}$ & $\begin{array}{l}\text { Total } \\
\text { Activity Released } \\
\text { (Ci) }\end{array}$ & $\begin{array}{c}\text { Average } \\
\text { Concentration } \\
(\mu \mathrm{Ci} / \mathrm{mL})\end{array}$ & $\begin{array}{c}\text { Maximum } \\
\text { Concentration } \\
(\mu \mathrm{Ci} / \mathrm{mL})\end{array}$ & $\begin{array}{c}D G^{a} \\
(\mu \mathrm{Ci} / \mathrm{mL})\end{array}$ \\
\hline Gross Alpha & 52 & $0.15 \pm 7.42 \mathrm{E}-09$ & $0.02 \pm 1.10 \mathrm{E}-16$ & $7.86 \mathrm{E}-16$ & -- \\
\hline Gross Beta & 52 & $2.53 \pm 1.41 \mathrm{E}-08$ & $3.80 \pm 2.08 \mathrm{E}-16$ & 2.19E-15 & -- \\
\hline H-3 & 52 & $5.40 \pm 0.55 \mathrm{E}-05$ & $8.14 \pm 0.83 \mathrm{E}-13$ & $2.47 \mathrm{E}-12$ & $1 \mathrm{E}-07$ \\
\hline Co-60 & 4 & $7.23 \pm 7.35 \mathrm{E}-09$ & $1.09 \pm 1.11 \mathrm{E}-16$ & $1.55 \mathrm{E}-16$ & $8 \mathrm{E}-11$ \\
\hline Sr-90 & 4 & $2.49 \pm 3.31 \mathrm{E}-09$ & $3.76 \pm 4.98 \mathrm{E}-17$ & $<1.04 \mathrm{E}-16$ & 9E-12 \\
\hline I-129 & 4 & $1.61 \pm 0.10 \mathrm{E}-05$ & $2.43 \pm 0.15 \mathrm{E}-13$ & $2.54 \mathrm{E}-13$ & 7E-11 \\
\hline Cs-137 & 4 & $1.36 \pm 1.04 \mathrm{E}-08$ & $2.05 \pm 1.56 \mathrm{E}-16$ & $2.24 \mathrm{E}-16$ & $4 \mathrm{E}-10$ \\
\hline Eu-154 & 4 & $0.43 \pm 2.02 \mathrm{E}-08$ & $0.65 \pm 3.04 \mathrm{E}-16$ & $<5.92 \mathrm{E}-16$ & 5E-11 \\
\hline $\mathrm{U}^{-232}{ }^{\mathrm{b}}$ & 4 & $-0.34 \pm 6.60 \mathrm{E}-10$ & $-0.51 \pm 9.94 \mathrm{E}-18$ & $<2.30 \mathrm{E}-17$ & $2 \mathrm{E}-14$ \\
\hline U-233/234 ${ }^{b}$ & 4 & $6.89 \pm 0.99 \mathrm{E}-09$ & $1.04 \pm 0.15 \mathrm{E}-16$ & $1.25 \mathrm{E}-16$ & 9E-14 \\
\hline $\mathrm{U}-235 / 236^{\mathrm{b}}$ & 4 & $1.28 \pm 0.76 \mathrm{E}-09$ & $1.92 \pm 1.14 \mathrm{E}-17$ & $2.39 \mathrm{E}-17$ & 1E-13 \\
\hline $\mathrm{U}-\mathbf{2 3 8}^{\mathrm{b}}$ & 4 & $7.21 \pm 0.95 \mathrm{E}-09$ & $1.09 \pm 0.14 \mathrm{E}-16$ & $1.44 \mathrm{E}-16$ & $1 \mathrm{E}-13$ \\
\hline Pu-238 & 4 & $1.65 \pm 4.37 \mathrm{E}-10$ & $2.48 \pm 6.57 \mathrm{E}-18$ & $<1.51 \mathrm{E}-17$ & $3 \mathrm{E}-14$ \\
\hline Pu-239/240 & 4 & $6.31 \pm 4.01 \mathrm{E}-10$ & $9.49 \pm 6.03 \mathrm{E}-18$ & $1.37 \mathrm{E}-17$ & $2 \mathrm{E}-14$ \\
\hline Am-241 & 4 & $4.28 \pm 4.07 \mathrm{E}-10$ & $6.45 \pm 6.12 \mathrm{E}-18$ & $6.53 \mathrm{E}-18$ & 2E-14 \\
\hline
\end{tabular}

$N$ - Number of samples

-- DCGs are not specified for gross alpha and beta activity.

${ }^{a}$ Derived concentration guides (DCGs) are listed for reference only. They are applicable to average concentrations at the site boundary but not to stack concentrations, as might be inferred from their inclusion in this table.

${ }^{b}$ Total Uranium: $1.51 \pm 0.02 E-02 \mathrm{~g}$; average $=2.27 \pm 0.03 \mathrm{E}-10 \mu \mathrm{g} / \mathrm{mL}$

$D-6$ 
Table D-7

2003 Airborne Radioactivity at Container Sorting and Packaging Facility (ANCSPFK)

\begin{tabular}{|c|c|c|c|c|c|}
\hline Isotope & $\mathbf{N}$ & $\begin{array}{l}\text { Stack } \\
\text { Activity } \\
\text { Ci }\end{array}$ & $\begin{array}{c}\text { Average } \\
\text { Concentration } \\
\mu \mathrm{Ci} / \mathrm{mL}\end{array}$ & $\begin{array}{c}\text { Maximum } \\
\text { Concentration } \\
\mu \mathrm{Ci} / \mathrm{mL}\end{array}$ & $\begin{array}{c}\mathrm{DCG}^{\mathrm{a}} \\
\mu \mathrm{Ci} / \mathrm{mL}\end{array}$ \\
\hline Gross Alpha & 52 & $-1.58 \pm 1.51 \mathrm{E}-09$ & $-9.50 \pm 9.08 \mathrm{E}-17$ & $6.75 \mathrm{E}-16$ & -- \\
\hline Gross Beta & 52 & $2.71 \pm 2.98 \mathrm{E}-09$ & $1.63 \pm 1.79 \mathrm{E}-16$ & $2.12 \mathrm{E}-15$ & -- \\
\hline Co-60 & 4 & $-1.26 \pm 2.71 \mathrm{E}-09$ & $-0.76 \pm 1.63 \mathrm{E}-16$ & $<2.49 \mathrm{E}-16$ & $8 \mathrm{E}-11$ \\
\hline Sr-90 & 4 & $1.73 \pm 1.80 \mathrm{E}-09$ & $1.04 \pm 1.08 \mathrm{E}-16$ & $1.58 \mathrm{E}-16$ & $9 \mathrm{E}-12$ \\
\hline I-129 & 4 & $1.59 \pm 0.36 \mathrm{E}-07$ & $9.66 \pm 2.19 \mathrm{E}-15$ & $1.43 \mathrm{E}-14$ & $7 \mathrm{E}-11$ \\
\hline Cs-137 & 4 & $1.85 \pm 2.55 \mathrm{E}-09$ & $1.11 \pm 1.53 \mathrm{E}-16$ & $2.48 \mathrm{E}-16$ & $4 \mathrm{E}-10$ \\
\hline Eu-154 & 4 & $2.94 \pm 9.47 \mathrm{E}-09$ & $1.77 \pm 5.69 \mathrm{E}-16$ & $<6.88 \mathrm{E}-16$ & $5 \mathrm{E}-11$ \\
\hline $\mathrm{U}-232^{\mathrm{D}}$ & 4 & $0.58 \pm 3.05 \mathrm{E}-10$ & $0.35 \pm 1.83 \mathrm{E}-17$ & $<2.59 \mathrm{E}-17$ & $2 \mathrm{E}-14$ \\
\hline $\mathrm{U}-233 / 234^{\mathrm{b}}$ & 4 & $9.98 \pm 3.93 \mathrm{E}-10$ & $6.00 \pm 2.37 \mathrm{E}-17$ & $8.71 \mathrm{E}-17$ & $9 \mathrm{E}-14$ \\
\hline $\mathrm{U}-235 / 236^{\mathrm{b}}$ & 4 & $1.52 \pm 2.71 \mathrm{E}-10$ & $0.91 \pm 1.63 \mathrm{E}-17$ & $1.97 \mathrm{E}-17$ & $1 \mathrm{E}-13$ \\
\hline $\mathrm{U}-\mathbf{2 3 8}^{\mathrm{b}}$ & 4 & $1.08 \pm 0.38 \mathrm{E}-09$ & $6.48 \pm 2.26 \mathrm{E}-17$ & $1.00 \mathrm{E}-16$ & $1 \mathrm{E}-13$ \\
\hline Pu-238 & 4 & $0.20 \pm 1.89 \mathrm{E}-10$ & $0.12 \pm 1.14 \mathrm{E}-17$ & $<2.39 \mathrm{E}-17$ & 3E-14 \\
\hline Pu-239/240 & 4 & $0.01 \pm 1.45 \mathrm{E}-10$ & $0.08 \pm 8.74 \mathrm{E}-18$ & $<1.51 \mathrm{E}-17$ & $2 \mathrm{E}-14$ \\
\hline Am-241 & 4 & $-0.29 \pm 1.87 \mathrm{E}-10$ & $-0.17 \pm 1.12 \mathrm{E}-17$ & $<1.29 \mathrm{E}-17$ & $2 \mathrm{E}-14$ \\
\hline
\end{tabular}

$N$ - Number of samples

-- DCGs are not specified for gross alpha and gross beta activity.

${ }^{a}$ Derived concentration guides (DCGs) are listed for reference only. They are applicable to average concentrations at the site boundary but not to stack concentrations, as might be inferred from their inclusion in this table.

${ }^{b}$ Total Uranium: $2.44 \pm 0.05 E-03 \mathrm{~g}$; average $=1.47 \pm 0.03 E-10 \mu \mathrm{g} / \mathrm{mL}$

Table D-8

2003 Airborne Radioactivity at Low-Level Waste Treatment Facility (ANLLW2V)

\begin{tabular}{|l|c|c|c|c|c|}
\hline \multicolumn{1}{|c|}{ Isotope } & $\mathbf{N}$ & $\begin{array}{c}\text { Stack } \\
\text { Activity } \\
\mathbf{C i}\end{array}$ & $\begin{array}{c}\text { Average } \\
\text { Concentration } \\
\boldsymbol{\mu C i} / \mathbf{m L}\end{array}$ & $\begin{array}{c}\text { Maximum } \\
\text { Concentration } \\
\boldsymbol{\mu C i} / \mathbf{m L}\end{array}$ & $\begin{array}{c}\text { DCG } \\
\boldsymbol{\mu C i} / \mathbf{m L}\end{array}$ \\
\hline Gross Alpha & 13 & $-6.18 \pm 7.90 \mathrm{E}-10$ & $-1.46 \pm 1.86 \mathrm{E}-16$ & $<1.03 \mathrm{E}-15$ & -- \\
\hline Gross Beta & 13 & $-0.85 \pm 1.38 \mathrm{E}-09$ & $-2.01 \pm 3.26 \mathrm{E}-16$ & $1.37 \mathrm{E}-15$ & -- \\
\hline
\end{tabular}

$N$ - Number of samples; Sampling for ANLLW2V was discontinued after the first quarter of 2003.

-- DCGs are not specified for gross alpha and gross beta activity.

$D-7$ 
Table D-9

2003 Airborne Radioactivity at Outdoor Ventilation Enclosures/Portable Ventilation Units (OVEs/PVUs)

\begin{tabular}{|c|c|c|c|c|c|}
\hline Isotope & $\mathbf{N}$ & $\begin{array}{c}\text { Total } \\
\text { Activity Released } \\
\text { (Ci) }\end{array}$ & $\begin{array}{c}\text { Average } \\
\text { Concentration } \\
(\mu \mathrm{Ci} / \mathrm{mL})\end{array}$ & $\begin{array}{c}\text { Maximum } \\
\text { Concentration } \\
(\mu \mathrm{Ci} / \mathrm{mL})\end{array}$ & $\begin{array}{c}\mathrm{DCG}^{\mathrm{a}} \\
(\mu \mathrm{Ci} / \mathrm{mL})\end{array}$ \\
\hline Gross Alpha & 120 & $1.77 \pm 0.41 \mathrm{E}-08$ & $4.18 \pm 0.98 \mathrm{E}-16$ & $5.73 \mathrm{E}-15$ & -- \\
\hline Gross Beta & 120 & $2.39 \pm 0.72 \mathrm{E}-08$ & $5.63 \pm 1.71 \mathrm{E}-16$ & $8.53 \mathrm{E}-15$ & -- \\
\hline Co-60 & 3 & $-0.34 \pm 1.94 \mathrm{E}-09$ & $-0.79 \pm 4.57 \mathrm{E}-17$ & $<5.11 \mathrm{E}-16$ & $8 \mathrm{E}-11$ \\
\hline Sr-90 & 3 & $-0.54 \pm 1.47 \mathrm{E}-09$ & $-1.27 \pm 3.46 \mathrm{E}-17$ & $<3.06 \mathrm{E}-16$ & 9E-12 \\
\hline Cs-137 & 3 & $4.93 \pm 2.20 \mathrm{E}-09$ & $1.16 \pm 5.20 \mathrm{E}-16$ & $<3.99 \mathrm{E}-16$ & $4 \mathrm{E}-10$ \\
\hline Eu-154 & 3 & $-3.04 \pm 5.65 \mathrm{E}-09$ & $-0.72 \pm 1.33 \mathrm{E}-16$ & $<1.39 \mathrm{E}-15$ & $5 \mathrm{E}-11$ \\
\hline $\mathrm{U}-232^{\mathrm{b}}$ & 3 & $5.03 \pm 6.65 \mathrm{E}-10$ & $1.19 \pm 1.57 \mathrm{E}-17$ & $<9.40 \mathrm{E}-17$ & 2E-14 \\
\hline $\mathrm{U}-233 / 234^{\mathrm{b}}$ & 3 & $5.59 \pm 4.92 \mathrm{E}-09$ & $1.32 \pm 1.16 \mathrm{E}-16$ & $<7.10 \mathrm{E}-16$ & 9E-14 \\
\hline U-235/236 ${ }^{b}$ & 3 & $5.65 \pm 3.73 \mathrm{E}-10$ & $1.33 \pm 0.88 \mathrm{E}-17$ & $5.20 \mathrm{E}-17$ & $1 \mathrm{E}-13$ \\
\hline U-238 & 3 & $5.64 \pm 5.18 \mathrm{E}-09$ & $1.33 \pm 1.22 \mathrm{E}-16$ & $<7.48 \mathrm{E}-16$ & $1 \mathrm{E}-13$ \\
\hline Pu-238 & 3 & $2.33 \pm 1.38 \mathrm{E}-09$ & $5.50 \pm 3.25 \mathrm{E}-17$ & 2.14E-16 & 3E-14 \\
\hline Pu-239/240 & 3 & $3.49 \pm 3.06 \mathrm{E}-09$ & $8.23 \pm 7.23 \mathrm{E}-17$ & $<4.41 \mathrm{E}-16$ & $2 \mathrm{E}-14$ \\
\hline Am-241 & 3 & $8.03 \pm 5.05 \mathrm{E}-09$ & $1.98 \pm 1.19 \mathrm{E}-16$ & 7.44E-16 & 2E-14 \\
\hline
\end{tabular}

$N$ - Number of samples; Composite samples to be analyzed for isotopic constituents for the second quarter of 2003 were lost. Estimated releases for the second quarter were based upon releases for the third and fourth quarters, scaled to gross alpha and beta data for the second quarter.

-- DCGs are not specified for gross alpha and gross beta activity.

${ }^{a}$ Derived concentration guides (DCGs) are listed for reference only. They are applicable to average concentrations at the site boundary but not to stack concentrations, as might be inferred from their inclusion in this table.

${ }^{b}$ Total Uranium: $1.20 \pm 0.90 \mathrm{E}-02 \mathrm{~g}$; average $=2.82 \pm 2.12 \mathrm{E}-10 \mu \mathrm{g} / \mathrm{mL}$

$D-8$ 
Table D-10

2003 Airborne Radioactivity at Lag Storage (ANLAGAM)

\begin{tabular}{|c|c|c|c|c|c|c|}
\hline \multirow[t]{2}{*}{ Isotope } & \multirow[t]{2}{*}{$\mathbf{N}$} & \multicolumn{2}{|c|}{$\begin{array}{c}\text { ANLAGAM } \\
\mu \mathrm{Ci} / \mathrm{mL}\end{array}$} & \multirow[t]{2}{*}{$\mathbf{N}$} & \multirow{2}{*}{$\begin{array}{c}\text { AFGRVAL }^{\mathrm{a}} \\
\mu \mathrm{Ci} / \mathrm{mL}\end{array}$} & \multirow[t]{2}{*}{ DCG $^{\mathbf{b}}$} \\
\hline & & Average & Maximum & & & \\
\hline Gross Alpha & 52 & $6.54 \pm 8.76 \mathrm{E}-16$ & $1.69 \mathrm{E}-15$ & 52 & $<7.71 \mathrm{E}-16-6.15 \mathrm{E}-15$ & -- \\
\hline Gross Beta & 52 & $1.89 \pm 0.26 \mathrm{E}-14$ & 3.64E-14 & 52 & 8.97E-15-3.38E-14 & -- \\
\hline K-40 & 3 & $2.10 \pm 3.02 \mathrm{E}-15$ & $3.90 \mathrm{E}-15$ & 3 & $<3.44 \mathrm{E}-15-<6.45 \mathrm{E}-15$ & $9 \mathrm{E}-10$ \\
\hline Co-60 & 3 & $0.24 \pm 1.80 \mathrm{E}-16$ & $<2.11 \mathrm{E}-16$ & 3 & $<2.38 \mathrm{E}-16-<4.80 \mathrm{E}-16$ & $8 \mathrm{E}-11$ \\
\hline Sr-90 & 3 & $3.05 \pm 8.17 \mathrm{E}-17$ & $<9.44 \mathrm{E}-17$ & 3 & $<1.01 \mathrm{E}-16-2.84 \mathrm{E}-16$ & $9 \mathrm{E}-12$ \\
\hline Cs-137 & 3 & $-0.02 \pm 1.59 \mathrm{E}-16$ & $<1.94 \mathrm{E}-16$ & 3 & $<1.87 \mathrm{E}-16-<2.43 \mathrm{E}-16$ & $4 \mathrm{E}-10$ \\
\hline $\mathrm{U}-\mathbf{2 3 2}^{\mathrm{c}}$ & 3 & $0.28 \pm 1.74 \mathrm{E}-17$ & $<2.01 \mathrm{E}-17$ & 3 & $<1.53 \mathrm{E}-17-<2.22 \mathrm{E}-17$ & $2 \mathrm{E}-14$ \\
\hline $\mathrm{U}-233 / 234^{\mathrm{c}}$ & 3 & $5.67 \pm 2.08 \mathrm{E}-17$ & $7.55 \mathrm{E}-17$ & 3 & $6.20 \mathrm{E}-17-1.21 \mathrm{E}-16$ & $9 \mathrm{E}-14$ \\
\hline $\mathrm{U}-235 / 236^{\mathrm{C}}$ & 3 & $0.78 \pm 1.24 \mathrm{E}-17$ & $1.48 \mathrm{E}-17$ & 3 & $<1.09 \mathrm{E}-17-1.95 \mathrm{E}-17$ & $1 \mathrm{E}-13$ \\
\hline $\mathrm{U}-238^{\mathrm{c}}$ & 3 & $1.03 \pm 0.26 \mathrm{E}-16$ & $2.14 \mathrm{E}-16$ & 3 & $7.43 \mathrm{E}-17-1.48 \mathrm{E}-16$ & $1 \mathrm{E}-13$ \\
\hline Pu-238 & 3 & $0.58 \pm 1.21 \mathrm{E}-17$ & $<1.93 \mathrm{E}-17$ & 3 & $<7.06 \mathrm{E}-18-<1.80 \mathrm{E}-17$ & 3E-14 \\
\hline $\mathrm{Pu}-239 / 240$ & 3 & $-1.96 \pm 6.45 \mathrm{E}-18$ & $<8.18 \mathrm{E}-18$ & 3 & $<7.68 \mathrm{E}-18-<2.27 \mathrm{E}-17$ & $2 \mathrm{E}-14$ \\
\hline Am-241 & 3 & $0.62 \pm 1.08 \mathrm{E}-17$ & $<1.58 \mathrm{E}-17$ & 3 & $<4.21 \mathrm{E}-18-9.49 \mathrm{E}-18$ & $2 \mathrm{E}-14$ \\
\hline
\end{tabular}

$N$ - Number of samples; Composite samples to be analyzed for isotopic constituents for the second quarter of 2003 were lost. Averages and Maxima are based on samples from three quarters.

-- DCGs are not specified for gross alpha and gross beta activity.

${ }^{a}$ Background air sampling location

${ }^{b}$ Derived concentration guides (DCGs) are applicable to average concentrations at the site boundary.

${ }^{c}$ Total Uranium: ANLAGAM average $=1.30 \pm 0.03 \mathrm{E}-10 \mu \mathrm{g} / \mathrm{mL} ;$ AFGRVAL average $=2.81 \pm 0.80 \mathrm{E}-10 \mu \mathrm{g} / \mathrm{mL}$

$D-9$ 
Table D-11

2003 Airborne Radioactivity at the NDA (ANNDAAM)

\begin{tabular}{|c|c|c|c|c|c|c|}
\hline \multirow[t]{2}{*}{ Isotope } & \multirow[t]{2}{*}{$\mathbf{N}$} & \multicolumn{2}{|c|}{$\begin{array}{c}\text { ANNDAAM } \\
\mu \mathrm{Ci} / \mathrm{mL}\end{array}$} & \multirow[t]{2}{*}{$\mathbf{N}$} & \multirow{2}{*}{$\begin{array}{c}\text { AFGRVAL }^{\mathrm{a}} \\
\mu \mathrm{Ci} / \mathrm{mL}\end{array}$} & \multirow[t]{2}{*}{$\mathbf{D C G}^{\mathrm{b}}$} \\
\hline & & Average & Maximum & & & \\
\hline Gross Alpha & 52 & $7.13 \pm 8.84 \mathrm{E}-16$ & $2.75 \mathrm{E}-15$ & 52 & $<7.71 \mathrm{E}-16-6.15 \mathrm{E}-15$ & -- \\
\hline Gross Beta & 52 & $1.73 \pm 0.25 \mathrm{E}-14$ & $3.23 \mathrm{E}-14$ & 52 & 8.97E-15-3.38E-14 & -- \\
\hline K-40 & 3 & $1.91 \pm 3.56 \mathrm{E}-15$ & $4.06 \mathrm{E}-15$ & 3 & $<3.44 \mathrm{E}-15-<6.45 \mathrm{E}-15$ & 9E-10 \\
\hline Co-60 & 3 & $-0.22 \pm 2.08 \mathrm{E}-16$ & $<2.54 \mathrm{E}-16$ & 3 & $<2.38 \mathrm{E}-16-<4.80 \mathrm{E}-16$ & $8 \mathrm{E}-11$ \\
\hline Sr-90 & 3 & $7.14 \pm 8.72 \mathrm{E}-17$ & 7.44E-17 & 3 & $<1.01 \mathrm{E}-16-2.84 \mathrm{E}-16$ & 9E-12 \\
\hline Cs-137 & 3 & $-0.42 \pm 1.76 \mathrm{E}-16$ & $<1.88 \mathrm{E}-16$ & 3 & $<1.87 \mathrm{E}-16-<2.43 \mathrm{E}-16$ & $4 \mathrm{E}-10$ \\
\hline $\mathrm{U}-232^{\mathrm{c}}$ & 3 & $0.87 \pm 1.15 \mathrm{E}-17$ & $1.64 \mathrm{E}-17$ & 3 & $<1.53 \mathrm{E}-17-<2.22 \mathrm{E}-17$ & 2E-14 \\
\hline $\mathrm{U}-233 / 234^{\mathrm{c}}$ & 3 & $5.81 \pm 2.04 \mathrm{E}-17$ & $7.79 \mathrm{E}-17$ & 3 & 6.20E-17-1.21E-16 & 9E-14 \\
\hline $\mathrm{U}-235 / 236^{\mathrm{c}}$ & 3 & $0.64 \pm 1.08 \mathrm{E}-17$ & 9.33E-18 & 3 & $<1.09 \mathrm{E}-17-1.95 \mathrm{E}-17$ & $1 \mathrm{E}-13$ \\
\hline $\mathrm{U}-238^{\mathrm{c}}$ & 3 & $5.79 \pm 1.97 \mathrm{E}-17$ & $6.29 \mathrm{E}-17$ & 3 & 7.43E-17-1.48E-16 & $1 \mathrm{E}-13$ \\
\hline Pu-238 & 3 & $-2.73 \pm 9.46 \mathrm{E}-18$ & $<1.25 \mathrm{E}-17$ & 3 & $<7.06 \mathrm{E}-18-<1.80 \mathrm{E}-17$ & $3 \mathrm{E}-14$ \\
\hline Pu-239/240 & 3 & $-0.46 \pm 7.47 \mathrm{E}-18$ & $<8.04 \mathrm{E}-18$ & 3 & $<7.68 \mathrm{E}-18-<2.27 \mathrm{E}-17$ & 2E-14 \\
\hline Am-241 & 3 & $0.89 \pm 1.16 \mathrm{E}-17$ & $1.32 \mathrm{E}-17$ & 3 & $<4.21 \mathrm{E}-18-9.49 \mathrm{E}-18$ & $2 \mathrm{E}-14$ \\
\hline
\end{tabular}

$N$ - Number of samples; Composite samples to be analyzed for isotopic constituents for the second quarter of 2003 were lost. Averages and Maxima are based on samples from three quarters.

-- DCGs are not specified for gross alpha and gross beta activity.

a Background air sampling location

${ }^{b}$ Derived concentration guides (DCGs) are applicable to average concentrations at the site boundary.

${ }^{c}$ Total Uranium: ANNDAAM average $=1.25 \pm 0.03 \mathrm{E}-10 \mu \mathrm{g} / \mathrm{mL} ;$ AFGRVAL average $=2.81 \pm 0.80 \mathrm{E}-10 \mu \mathrm{g} / \mathrm{mL}$

Table D-12

2003 Airborne Radioactivity at SDA Trench 9 (ANSDAT9)

\begin{tabular}{|c|c|c|c|c|c|c|}
\hline \multirow[t]{2}{*}{ Isotope } & \multirow[t]{2}{*}{$\mathbf{N}$} & \multicolumn{2}{|c|}{$\begin{array}{l}\text { ANSDAT9 } \\
\mu \mathrm{Ci} / \mathrm{mL}\end{array}$} & \multirow[t]{2}{*}{$\mathbf{N}$} & \multirow{2}{*}{$\begin{array}{c}\text { AFGRVAL }^{\mathrm{a}} \\
\boldsymbol{\mu \mathrm { Ci } / \mathrm { mL }} \\
\text { Background Range }\end{array}$} & \multirow[t]{2}{*}{ DCG $^{\mathbf{b}}$} \\
\hline & & Average & Maximum & & & \\
\hline Gross Alpha & 52 & $0.24 \pm 1.75 \mathrm{E}-15$ & $1.85 \mathrm{E}-15$ & 52 & $<7.71 \mathrm{E}-16-6.15 \mathrm{E}-15$ & -- \\
\hline Gross Beta & 52 & $1.54 \pm 0.39 \mathrm{E}-14$ & $3.04 \mathrm{E}-14$ & 52 & 8.97E-15-3.38E-14 & -- \\
\hline Tritium & 52 & $7.56 \pm 7.29 \mathrm{E}-13$ & $2.14 \mathrm{E}-12$ & 50 & $<5.41 \mathrm{E}-14-2.95 \mathrm{E}-12$ & 1E-07 \\
\hline K-40 & 3 & $2.51 \pm 4.26 \mathrm{E}-15$ & $<4.82 \mathrm{E}-15$ & 3 & $<3.44 \mathrm{E}-15-<6.45 \mathrm{E}-15$ & 9E-10 \\
\hline Co-60 & 3 & $0.87 \pm 2.17 \mathrm{E}-16$ & $<2.43 \mathrm{E}-16$ & 3 & $<2.38 \mathrm{E}-16-<4.80 \mathrm{E}-16$ & $8 \mathrm{E}-11$ \\
\hline I-129 & 4 & $1.95 \pm 3.26 \mathrm{E}-16$ & $5.96 \mathrm{E}-16$ & 4 & $<2.38 \mathrm{E}-16-3.90 \mathrm{E}-16$ & 7E-11 \\
\hline Cs-137 & 3 & $0.25 \pm 2.14 \mathrm{E}-16$ & $<2.53 \mathrm{E}-16$ & 3 & $<1.87 \mathrm{E}-16-<2.43 \mathrm{E}-16$ & $4 \mathrm{E}-10$ \\
\hline
\end{tabular}

$N$ - Number of samples; Composite samples to be analyzed for isotopic constituents for the second quarter of 2003 were lost. Averages and Maxima are based on samples from three quarters.

-- DCGs are not specified for gross alpha and gross beta activity.

${ }^{a}$ Background air sampling location

${ }^{b}$ Derived concentration guides (DCGs) are applicable to average concentrations at the site boundary.

$D-10$ 
Table D-13

2003 Airborne Radioactivity at Rock Springs Road (AFRSPRD)

\begin{tabular}{|c|c|c|c|c|c|c|}
\hline \multirow[t]{2}{*}{ Isotope } & \multirow[t]{2}{*}{$\mathbf{N}$} & \multicolumn{2}{|c|}{$\begin{array}{c}\text { AFRSPRD } \\
\mu \mathrm{Ci} / \mathrm{mL}\end{array}$} & \multirow[t]{2}{*}{$\mathbf{N}$} & \multirow{2}{*}{$\begin{array}{c}\text { AFGRVAL }^{\mathrm{a}} \\
\mu \mathrm{Ci} / \mathrm{mL} \\
\text { Background Range }\end{array}$} & \multirow[t]{2}{*}{ DCG $^{\mathbf{b}}$} \\
\hline & & Average & Maximum & & & \\
\hline Gross Alpha & 52 & $0.51 \pm 1.16 \mathrm{E}-15$ & $1.73 \mathrm{E}-15$ & 52 & $<7.71 \mathrm{E}-16-6.15 \mathrm{E}-15$ & -- \\
\hline Gross Beta & 52 & $1.71 \pm 0.32 \mathrm{E}-14$ & $3.22 \mathrm{E}-14$ & 52 & 8.97E-15-3.38E-14 & -- \\
\hline Tritium & 52 & $-0.59 \pm 6.91 \mathrm{E}-13$ & $1.66 \mathrm{E}-12$ & 50 & $<5.41 \mathrm{E}-14-2.95 \mathrm{E}-12$ & $1 \mathrm{E}-07$ \\
\hline K-40 & 3 & $2.18 \pm 2.51 \mathrm{E}-15$ & $3.12 \mathrm{E}-15$ & 3 & $<3.44 \mathrm{E}-15-<6.45 \mathrm{E}-15$ & $9 \mathrm{E}-10$ \\
\hline Co-60 & 3 & $-0.41 \pm 2.31 \mathrm{E}-16$ & $<2.52 \mathrm{E}-16$ & 3 & $<2.38 \mathrm{E}-16-<4.80 \mathrm{E}-16$ & $8 \mathrm{E}-11$ \\
\hline Sr-90 & 3 & $-0.32 \pm 1.15 \mathrm{E}-16$ & $<1.37 \mathrm{E}-16$ & 3 & $<1.01 \mathrm{E}-16-2.84 \mathrm{E}-16$ & $9 \mathrm{E}-12$ \\
\hline I-129 & 4 & $1.29 \pm 4.18 \mathrm{E}-16$ & $<4.83 \mathrm{E}-16$ & 4 & $<2.38 \mathrm{E}-16-3.90 \mathrm{E}-16$ & 7E-11 \\
\hline Cs-137 & 3 & $0.10 \pm 1.91 \mathrm{E}-16$ & $<2.21 \mathrm{E}-16$ & 3 & $<1.87 \mathrm{E}-16-<2.43 \mathrm{E}-16$ & $4 \mathrm{E}-10$ \\
\hline Eu-154 & 3 & $1.04 \pm 5.73 \mathrm{E}-16$ & $<6.79 \mathrm{E}-16$ & 3 & $<7.08 \mathrm{E}-16-<1.34 \mathrm{E}-15$ & $5 \mathrm{E}-11$ \\
\hline $\mathrm{U}-232^{\mathrm{c}}$ & 3 & $0.32 \pm 2.01 \mathrm{E}-17$ & $<2.27 \mathrm{E}-17$ & 3 & $<1.53 \mathrm{E}-17-<2.22 \mathrm{E}-17$ & $2 \mathrm{E}-14$ \\
\hline $\mathrm{U}-233 / 234^{\mathrm{c}}$ & 3 & $7.95 \pm 3.24 \mathrm{E}-17$ & $9.33 \mathrm{E}-17$ & 3 & $6.20 \mathrm{E}-17-1.21 \mathrm{E}-16$ & 9E-14 \\
\hline $\mathrm{U}-235 / 236^{c}$ & 3 & $0.23 \pm 2.17 \mathrm{E}-17$ & $<2.69 \mathrm{E}-17$ & 3 & $<1.09 \mathrm{E}-17-1.95 \mathrm{E}-17$ & $1 \mathrm{E}-13$ \\
\hline $\mathrm{U}-238^{\mathrm{c}}$ & 3 & $6.37 \pm 2.45 \mathrm{E}-17$ & $8.27 \mathrm{E}-17$ & 3 & 7.43E-17-1.48E-16 & $1 \mathrm{E}-13$ \\
\hline Pu-238 & 3 & $-0.09 \pm 1.01 \mathrm{E}-17$ & $<1.67 \mathrm{E}-17$ & 3 & $<7.06 \mathrm{E}-18-<1.80 \mathrm{E}-17$ & $3 \mathrm{E}-14$ \\
\hline $\mathrm{Pu}-239 / 240$ & 3 & $-0.11 \pm 9.00 \mathrm{E}-18$ & $<1.06 \mathrm{E}-17$ & 3 & $<7.68 \mathrm{E}-18-<2.27 \mathrm{E}-17$ & 2E-14 \\
\hline Am-241 & 3 & $-0.39 \pm 1.17 \mathrm{E}-17$ & $<1.51 \mathrm{E}-17$ & 3 & $<4.21 \mathrm{E}-18-9.49 \mathrm{E}-18$ & $2 \mathrm{E}-14$ \\
\hline
\end{tabular}

$N$ - Number of samples; Composite samples to be analyzed for isotopic constituents for the second quarter of 2003 were lost. Averages and Maxima are based on samples from three quarters.

-- DCGs are not specified for gross alpha and gross beta activity.

${ }^{a}$ Background air sampling location

${ }^{b}$ Derived concentration guides (DCGs) are applicable to average concentrations at the site boundary.

${ }^{c}$ Total Uranium: AFRSPRD average $=1.85 \pm 0.05 \mathrm{E}-10 \mu \mathrm{g} / \mathrm{mL} ;$ AFGRVAL average $=2.81 \pm 0.80 \mathrm{E}-10 \mu \mathrm{g} / \mathrm{mL}$ 
Table D-14

2003 Airborne Radioactivity at Dutch Hill Road (AFBOEHN)

\begin{tabular}{|c|c|c|c|c|c|c|}
\hline \multirow[t]{2}{*}{ Isotope } & \multirow[t]{2}{*}{$\mathbf{N}$} & \multicolumn{2}{|c|}{$\begin{array}{c}\text { AFBOEHN } \\
\mu \mathrm{Ci} / \mathrm{mL}\end{array}$} & \multirow[t]{2}{*}{$\mathbf{N}$} & \multirow{2}{*}{$\begin{array}{c}\text { AFGRVAL }^{\mathrm{a}} \\
\mu \mathrm{Ci} / \mathrm{mL} \\
\text { Background Range }\end{array}$} & \multirow[t]{2}{*}{ DCG $^{b}$} \\
\hline & & Average & Maximum & & & \\
\hline Gross Alpha & 52 & $0.43 \pm 1.12 \mathrm{E}-15$ & $2.00 \mathrm{E}-15$ & 52 & $<7.71 \mathrm{E}-16-6.15 \mathrm{E}-15$ & -- \\
\hline Gross Beta & 52 & $1.82 \pm 0.32 \mathrm{E}-14$ & $3.39 \mathrm{E}-14$ & 52 & 8.97E-15-3.38E-14 & -- \\
\hline K-40 & 3 & $2.56 \pm 3.87 \mathrm{E}-15$ & $4.28 \mathrm{E}-15$ & 3 & $<3.44 \mathrm{E}-15-<6.45 \mathrm{E}-15$ & 9E-10 \\
\hline Co-60 & 3 & $-0.74 \pm 2.34 \mathrm{E}-16$ & $<2.61 \mathrm{E}-16$ & 3 & $<2.38 \mathrm{E}-16-<4.80 \mathrm{E}-16$ & $8 \mathrm{E}-11$ \\
\hline Sr-90 & 3 & $-0.79 \pm 1.15 \mathrm{E}-16$ & $<1.33 \mathrm{E}-16$ & 3 & $<1.01 \mathrm{E}-16-2.84 \mathrm{E}-16$ & 9E-12 \\
\hline Cs-137 & 3 & $0.33 \pm 2.15 \mathrm{E}-16$ & $<2.48 \mathrm{E}-16$ & 3 & $<1.87 \mathrm{E}-16-<2.43 \mathrm{E}-16$ & $4 \mathrm{E}-10$ \\
\hline
\end{tabular}

$N$ - Number of samples; Composite samples to be analyzed for isotopic constituents for the second quarter of 2003 were lost. Averages and Maxima are based on samples from three quarters.

-- DCGs are not specified for gross alpha and gross beta activity.

${ }^{a}$ Background air sampling location

${ }^{b}$ Derived concentration guides (DCGs) are applicable to average concentrations at the site boundary.

Table D-15

2003 Airborne Radioactivity at Fox Valley Road (AFFXVRD)

\begin{tabular}{|c|c|c|c|c|c|c|}
\hline \multirow[t]{2}{*}{ Isotope } & \multirow[t]{2}{*}{$\mathbf{N}$} & \multicolumn{2}{|c|}{$\begin{array}{c}\text { AFFXVRD } \\
\mu \mathrm{Ci} / \mathrm{mL}\end{array}$} & \multirow[t]{2}{*}{$\mathbf{N}$} & \multirow{2}{*}{$\begin{array}{c}\text { AFGRVAL }^{\mathrm{a}} \\
\boldsymbol{\mu C i} / \mathbf{m L}\end{array}$} & \multirow[t]{2}{*}{ DCG $^{\text {b }}$} \\
\hline & & Average & Maximum & & & \\
\hline Gross Alpha & 52 & $0.50 \pm 1.25 \mathrm{E}-15$ & $2.14 \mathrm{E}-15$ & 52 & $<7.71 \mathrm{E}-16-6.15 \mathrm{E}-15$ & -- \\
\hline Gross Beta & 52 & $1.69 \pm 0.34 \mathrm{E}-14$ & 3.06E-14 & 52 & 8.97E-15-3.38E-14 & -- \\
\hline K-40 & 3 & $5.95 \pm 3.90 \mathrm{E}-15$ & $9.30 \mathrm{E}-15$ & 3 & $<3.44 \mathrm{E}-15-<6.45 \mathrm{E}-15$ & $9 \mathrm{E}-10$ \\
\hline Co-60 & 3 & $-0.17 \pm 2.82 \mathrm{E}-16$ & $<3.37 \mathrm{E}-16$ & 3 & $<2.38 \mathrm{E}-16-<4.80 \mathrm{E}-16$ & $8 \mathrm{E}-11$ \\
\hline Sr-90 & 3 & $0.93 \pm 1.18 \mathrm{E}-16$ & $<1.30 \mathrm{E}-16$ & 3 & $<1.01 \mathrm{E}-16-2.84 \mathrm{E}-16$ & $9 \mathrm{E}-12$ \\
\hline Cs-137 & 3 & $-0.25 \pm 2.36 \mathrm{E}-16$ & $<2.86 \mathrm{E}-16$ & 3 & $<1.87 \mathrm{E}-16-<2.43 \mathrm{E}-16$ & $4 \mathrm{E}-10$ \\
\hline
\end{tabular}

$N$ - Number of samples; Composite samples to be analyzed for isotopic constituents for the second quarter of 2003 were lost. Averages and Maxima are based on samples from three quarters.

-- DCGs are not specified for gross alpha and gross beta activity.

a Background air sampling location

${ }^{b}$ Derived concentration guides (DCGs) are applicable to average concentrations at the site boundary. 
Table D-16

2003 Airborne Radioactivity at the Bulk Storage Warehouse (AFBLKST)

\begin{tabular}{|c|c|c|c|c|c|c|}
\hline \multirow[t]{2}{*}{ Isotope } & \multirow[t]{2}{*}{$\mathbf{N}$} & \multicolumn{2}{|c|}{$\begin{array}{c}\text { AFBLKST } \\
\mu \mathrm{Ci} / \mathrm{mL}\end{array}$} & \multirow[t]{2}{*}{$\mathbf{N}$} & \multirow{2}{*}{$\begin{array}{c}\text { AFGRVAL }^{\mathrm{a}} \\
\mu \mathrm{Ci} / \mathrm{mL} \\
\text { Background Range }\end{array}$} & \multirow[t]{2}{*}{$\mathbf{D C G}^{\mathrm{b}}$} \\
\hline & & Average & Maximum & & & \\
\hline Gross Alpha & 52 & $0.49 \pm 1.13 \mathrm{E}-15$ & $2.50 \mathrm{E}-15$ & 52 & $<7.71 \mathrm{E}-16-6.15 \mathrm{E}-15$ & -- \\
\hline Gross Beta & 52 & $1.74 \pm 0.31 \mathrm{E}-14$ & $3.33 \mathrm{E}-14$ & 52 & 8.97E-15-3.38E-14 & -- \\
\hline K-40 & 3 & $5.67 \pm 3.62 \mathrm{E}-15$ & $6.45 \mathrm{E}-15$ & 3 & $<3.44 \mathrm{E}-15-<6.45 \mathrm{E}-15$ & 9E-10 \\
\hline Co-60 & 3 & $-0.46 \pm 2.75 \mathrm{E}-16$ & $<2.89 \mathrm{E}-16$ & 3 & $<2.38 \mathrm{E}-16-<4.80 \mathrm{E}-16$ & $8 \mathrm{E}-11$ \\
\hline Sr-90 & 3 & $0.81 \pm 1.43 \mathrm{E}-16$ & $<1.65 \mathrm{E}-16$ & 3 & $<1.01 \mathrm{E}-16-2.84 \mathrm{E}-16$ & 9E-12 \\
\hline Cs-137 & 3 & $-0.04 \pm 2.15 \mathrm{E}-16$ & $<2.49 \mathrm{E}-16$ & 3 & $<1.87 \mathrm{E}-16-<2.43 \mathrm{E}-16$ & $4 \mathrm{E}-10$ \\
\hline
\end{tabular}

$N$ - Number of samples; Composite samples to be analyzed for isotopic constituents for the second quarter of 2003 were lost. Averages and Maxima are based on samples from three quarters.

-- DCGs are not specified for gross alpha and gross beta activity.

${ }^{a}$ Background air sampling location

${ }^{b}$ Derived concentration guides (DCGs) are applicable to average concentrations at the site boundary.

Table D-17

2003 Airborne Radioactivity at Route 240 (AFRT240)

\begin{tabular}{|c|c|c|c|c|c|c|}
\hline \multirow[t]{2}{*}{ Isotope } & \multirow[t]{2}{*}{$\mathbf{N}$} & \multicolumn{2}{|c|}{$\begin{array}{c}\text { AFRT240 } \\
\mu \mathrm{Ci} / \mathrm{mL}\end{array}$} & \multirow[t]{2}{*}{$\mathbf{N}$} & \multirow{2}{*}{$\begin{array}{c}\begin{array}{c}\text { AFGRVAL }^{\mathrm{a}} \\
\mu \mathrm{Ci} / \mathrm{mL}\end{array} \\
\text { Background Range }\end{array}$} & \multirow[t]{2}{*}{ DCG $^{b}$} \\
\hline & & Average & Maximum & & & \\
\hline Gross Alpha & 52 & $0.52 \pm 1.14 \mathrm{E}-15$ & $2.39 \mathrm{E}-15$ & 52 & $<7.71 \mathrm{E}-16-6.15 \mathrm{E}-15$ & -- \\
\hline Gross Beta & 52 & $1.66 \pm 0.31 \mathrm{E}-14$ & 3.39E-14 & 52 & 8.97E-15-3.38E-14 & -- \\
\hline K-40 & 3 & $2.64 \pm 4.90 \mathrm{E}-15$ & $5.84 \mathrm{E}-15$ & 3 & $<3.44 \mathrm{E}-15-<6.45 \mathrm{E}-15$ & $9 \mathrm{E}-10$ \\
\hline Co-60 & 3 & $-1.15 \pm 2.63 \mathrm{E}-16$ & $<3.13 \mathrm{E}-16$ & 3 & $<2.38 \mathrm{E}-16-<4.80 \mathrm{E}-16$ & $8 \mathrm{E}-11$ \\
\hline Sr-90 & 3 & $0.97 \pm 1.22 \mathrm{E}-16$ & $1.61 \mathrm{E}-16$ & 3 & $<1.01 \mathrm{E}-16-2.84 \mathrm{E}-16$ & $9 \mathrm{E}-12$ \\
\hline Cs-137 & 3 & $0.80 \pm 4.16 \mathrm{E}-16$ & $2.41 \mathrm{E}-16$ & 3 & $<1.87 \mathrm{E}-16-<2.43 \mathrm{E}-16$ & $4 \mathrm{E}-10$ \\
\hline
\end{tabular}

$N$ - Number of samples; Composite samples to be analyzed for isotopic constituents for the second quarter of 2003 were lost. Averages and Maxima are based on samples from three quarters.

-- DCGs are not specified for gross alpha and gross beta activity.

${ }^{a}$ Background air sampling location

${ }^{b}$ Derived concentration guides (DCGs) are applicable to average concentrations at the site boundary. 
Table D-18

2003 Airborne Radioactivity at Thomas Corners Road (AFTCORD)

\begin{tabular}{|c|c|c|c|c|c|c|}
\hline \multirow[t]{2}{*}{ Isotope } & \multirow[t]{2}{*}{$\mathbf{N}$} & \multicolumn{2}{|c|}{$\begin{array}{c}\text { AFTCORD } \\
\mu \mathrm{Ci} / \mathrm{mL}\end{array}$} & \multirow[t]{2}{*}{$\mathbf{N}$} & \multirow{2}{*}{$\begin{array}{c}\text { AFGRVAL }^{\mathrm{a}} \\
\mu \mathrm{Ci} / \mathrm{mL} \\
\text { Background Range }\end{array}$} & \multirow[t]{2}{*}{ DCG $^{\mathbf{b}}$} \\
\hline & & Average & Maximum & & & \\
\hline Gross Alpha & 52 & $0.52 \pm 1.14 \mathrm{E}-15$ & $2.28 \mathrm{E}-15$ & 52 & $<7.71 \mathrm{E}-16-6.15 \mathrm{E}-15$ & -- \\
\hline Gross Beta & 52 & $1.66 \pm 0.31 \mathrm{E}-14$ & 3.30E-14 & 52 & 8.97E-15-3.38E-14 & -- \\
\hline K-40 & 3 & $1.59 \pm 5.25 \mathrm{E}-15$ & $<6.24 \mathrm{E}-15$ & 3 & $<3.44 \mathrm{E}-15-<6.45 \mathrm{E}-15$ & 9E-10 \\
\hline Co-60 & 3 & $1.42 \pm 1.95 \mathrm{E}-16$ & $3.52 \mathrm{E}-16$ & 3 & $<2.38 \mathrm{E}-16-<4.80 \mathrm{E}-16$ & $8 \mathrm{E}-11$ \\
\hline Sr-90 & 3 & $0.93 \pm 1.27 \mathrm{E}-16$ & $<1.54 \mathrm{E}-16$ & 3 & $<1.01 \mathrm{E}-16-2.84 \mathrm{E}-16$ & 9E-12 \\
\hline Cs-137 & 3 & $0.24 \pm 1.83 \mathrm{E}-16$ & $<2.14 \mathrm{E}-16$ & 3 & $<1.87 \mathrm{E}-16-<2.43 \mathrm{E}-16$ & $4 \mathrm{E}-10$ \\
\hline
\end{tabular}

$N$ - Number of samples; Composite samples to be analyzed for isotopic constituents for the second quarter of 2003 were lost. Averages and Maxima are based on samples from three quarters.

-- DCGs are not specified for gross alpha and gross beta activity.

${ }^{a}$ Background air sampling location

${ }^{b}$ Derived concentration guides (DCGs) are applicable to average concentrations at the site boundary.

Table D-19

2003 Airborne Radioactivity at West Valley (AFWEVAL)

\begin{tabular}{|c|c|c|c|c|c|c|}
\hline \multirow[t]{2}{*}{ Isotope } & \multirow[t]{2}{*}{$\mathbf{N}$} & \multicolumn{2}{|c|}{$\begin{array}{c}\text { AFWEVAL } \\
\mu \mathrm{Ci} / \mathrm{mL}\end{array}$} & \multirow[t]{2}{*}{$\mathbf{N}$} & \multirow{2}{*}{$\begin{array}{c}\text { AFGRVAL }^{\mathrm{a}} \\
\mu \mathrm{Ci} / \mathrm{mL} \\
\text { Background Range }\end{array}$} & \multirow[t]{2}{*}{ DCG $^{\text {b }}$} \\
\hline & & Average & Maximum & & & \\
\hline Gross Alpha & 52 & $0.52 \pm 1.13 \mathrm{E}-15$ & $1.96 \mathrm{E}-15$ & 52 & $<7.71 \mathrm{E}-16-6.15 \mathrm{E}-15$ & -- \\
\hline Gross Beta & 52 & $1.72 \pm 0.31 \mathrm{E}-14$ & $3.09 \mathrm{E}-14$ & 52 & 8.97E-15-3.38E-14 & -- \\
\hline K-40 & 3 & $4.05 \pm 3.04 \mathrm{E}-15$ & $4.56 \mathrm{E}-15$ & 3 & $<3.44 \mathrm{E}-15-<6.45 \mathrm{E}-15$ & 9E-10 \\
\hline Co-60 & 3 & $0.59 \pm 3.09 \mathrm{E}-16$ & $<4.05 \mathrm{E}-16$ & 3 & $<2.38 \mathrm{E}-16-<4.80 \mathrm{E}-16$ & $8 \mathrm{E}-11$ \\
\hline Sr-90 & 3 & $0.04 \pm 1.15 \mathrm{E}-16$ & $<1.26 \mathrm{E}-16$ & 3 & $<1.01 \mathrm{E}-16-2.84 \mathrm{E}-16$ & 9E-12 \\
\hline Cs-137 & 3 & $-0.16 \pm 1.99 \mathrm{E}-16$ & $<2.41 \mathrm{E}-16$ & 3 & $<1.87 \mathrm{E}-16-<2.43 \mathrm{E}-16$ & $4 \mathrm{E}-10$ \\
\hline
\end{tabular}

$N$ - Number of samples; Composite samples to be analyzed for isotopic constituents for the second quarter of 2003 were lost. Averages and Maxima are based on samples from three quarters.

-- DCGs are not specified for gross alpha and gross beta activity.

${ }^{a}$ Background air sampling location

${ }^{b}$ Derived concentration guides (DCGs) are applicable to average concentrations at the site boundary. 
Table D-20

2003 Airborne Radioactivity at Springville (AFSPRVL)

\begin{tabular}{|c|c|c|c|c|c|c|}
\hline \multirow[t]{2}{*}{ Isotope } & \multirow[t]{2}{*}{$\mathbf{N}$} & \multicolumn{2}{|c|}{$\begin{array}{c}\text { AFSPRVL } \\
\mu \mathrm{Ci} / \mathrm{mL}\end{array}$} & \multirow[t]{2}{*}{$\mathbf{N}$} & \multirow{2}{*}{$\begin{array}{c}\text { AFGRVAL }^{\mathrm{a}} \\
\mu \mathrm{Ci} / \mathrm{mL} \\
\text { Background Range }\end{array}$} & \multirow[t]{2}{*}{ DCG $^{\mathbf{b}}$} \\
\hline & & Average & Maximum & & & \\
\hline Gross Alpha & 52 & $0.44 \pm 1.21 \mathrm{E}-15$ & $1.83 \mathrm{E}-15$ & 52 & $<7.71 \mathrm{E}-16-6.15 \mathrm{E}-15$ & -- \\
\hline Gross Beta & 52 & $1.71 \pm 0.32 \mathrm{E}-14$ & $3.76 \mathrm{E}-14$ & 52 & 8.97E-15-3.38E-14 & -- \\
\hline K-40 & 3 & $2.13 \pm 4.09 \mathrm{E}-15$ & $5.02 \mathrm{E}-15$ & 3 & $<3.44 \mathrm{E}-15-<6.45 \mathrm{E}-15$ & $9 \mathrm{E}-10$ \\
\hline Co-60 & 3 & $1.95 \pm 2.31 \mathrm{E}-16$ & $4.27 \mathrm{E}-16$ & 3 & $<2.38 \mathrm{E}-16-<4.80 \mathrm{E}-16$ & $8 \mathrm{E}-11$ \\
\hline Sr-90 & 3 & $-0.05 \pm 1.23 \mathrm{E}-16$ & $1.67 \mathrm{E}-16$ & 3 & $<1.01 \mathrm{E}-16-2.84 \mathrm{E}-16$ & $9 \mathrm{E}-12$ \\
\hline Cs-137 & 3 & $0.62 \pm 1.91 \mathrm{E}-16$ & $<2.16 \mathrm{E}-16$ & 3 & $<1.87 \mathrm{E}-16-<2.43 \mathrm{E}-16$ & $4 \mathrm{E}-10$ \\
\hline
\end{tabular}

$N$ - Number of samples; Composite samples to be analyzed for isotopic constituents for the second quarter of 2003 were lost. Averages and Maxima are based on samples from three quarters.

-- DCGs are not specified for gross alpha and gross beta activity.

${ }^{a}$ Background air sampling location

${ }^{b}$ Derived concentration guides (DCGs) are applicable to average concentrations at the site boundary.

Table D-21

2003 Airborne Radioactivity at the Nashville Background (AFNASHV)

\begin{tabular}{|c|c|c|c|c|c|c|}
\hline \multirow[t]{2}{*}{ Isotope } & \multirow[t]{2}{*}{$\mathbf{N}$} & \multicolumn{2}{|c|}{$\begin{array}{l}\text { AFNASHV } \\
\mu \mathrm{Ci} / \mathrm{mL}\end{array}$} & \multirow[t]{2}{*}{$\mathbf{N}$} & \multirow{2}{*}{$\begin{array}{c}\text { AFGRVAL }^{\mathrm{a}} \\
\mu \mathrm{Ci} / \mathrm{mL} \\
\text { Background Range }\end{array}$} & \multirow[t]{2}{*}{ DCG $^{\text {b }}$} \\
\hline & & Average & Maximum & & & \\
\hline Gross Alpha & 13 & $0.74 \pm 1.33 \mathrm{E}-15$ & $2.07 \mathrm{E}-15$ & 52 & $<7.71 \mathrm{E}-16-6.15 \mathrm{E}-15$ & -- \\
\hline Gross Beta & 13 & $2.06 \pm 0.34 \mathrm{E}-14$ & $3.11 \mathrm{E}-14$ & 52 & 8.97E-15-3.38E-14 & -- \\
\hline K-40 & 1 & $1.64 \pm 2.79 \mathrm{E}-15$ & $<2.79 \mathrm{E}-15$ & 3 & $<3.44 \mathrm{E}-15-<6.45 \mathrm{E}-15$ & $9 \mathrm{E}-10$ \\
\hline Co-60 & 1 & $-0.46 \pm 1.79 \mathrm{E}-16$ & $<1.79 \mathrm{E}-16$ & 3 & $<2.38 \mathrm{E}-16-<4.80 \mathrm{E}-16$ & $8 \mathrm{E}-11$ \\
\hline Sr-90 & 1 & $0.29 \pm 1.38 \mathrm{E}-16$ & $<1.38 \mathrm{E}-16$ & 3 & $<1.01 \mathrm{E}-16-2.84 \mathrm{E}-16$ & 9E-12 \\
\hline Cs-137 & 1 & $0.78 \pm 1.48 \mathrm{E}-16$ & $<1.48 \mathrm{E}-16$ & 3 & $<1.87 \mathrm{E}-16-<2.43 \mathrm{E}-16$ & $4 \mathrm{E}-10$ \\
\hline
\end{tabular}

$N$ - Number of samples; Composite samples to be analyzed for isotopic constituents for the second quarter of 2003 were lost. Averages and Maxima are based on samples from three quarters for AFGRVAL. Sampling for AFNASHV was discontinued after the first quarter of 2003.

-- DCGs are not specified for gross alpha and gross beta activity.

${ }^{a}$ Background air sampling location

${ }^{b}$ Derived concentration guides (DCGs) are applicable to average concentrations at the site boundary. 
Table D-22

2003 Results in Fallout: Dutch Hill (AFDHFOP)

\begin{tabular}{|l|c|c|c|c|c|}
\hline \multicolumn{1}{|c|}{ Analyte } & Units & N & Minimum & Average & Maximum \\
\hline Gross Alpha & $\mathrm{nCi} / \mathrm{m}^{2}$ & 11 & $2.12 \mathrm{E}-02$ & $3.85 \pm 1.23 \mathrm{E}-02$ & $7.07 \mathrm{E}-02$ \\
\hline Gross Beta & $\mathrm{nCi} / \mathrm{m}^{2}$ & 11 & $2.32 \mathrm{E}-01$ & $4.86 \pm 0.41 \mathrm{E}-01$ & $8.27 \mathrm{E}-01$ \\
\hline H-3 & $\mu \mathrm{Ci} / \mathrm{mL}$ & 12 & $4.66 \mathrm{E}-08$ & $2.71 \pm 8.24 \mathrm{E}-08$ & $1.20 \mathrm{E}-07$ \\
\hline K-40 & $\mathrm{nCi} / \mathrm{m}^{2}$ & 12 & $1.68 \mathrm{E}+00$ & $-1.03 \pm 5.34 \mathrm{E}+00$ & $8.47 \mathrm{E}+00$ \\
\hline Cs-137 & $\mathrm{nCi} / \mathrm{m}^{2}$ & 12 & $8.95 \mathrm{E}-02$ & $-0.02 \pm 4.05 \mathrm{E}-01$ & $6.46 \mathrm{E}-01$ \\
\hline pH & standard units & 12 & 3.93 & 4.31 & 7.87 \\
\hline
\end{tabular}

$N$ - Number of samples

Note: Samples taken in June 2003 are rejected for gross alpha and gross beta.

Table D-23

2003 Results in Fallout: Rain Gauge (ANRGFOP)

\begin{tabular}{|l|c|c|c|c|c|}
\hline \multicolumn{1}{|c|}{ Analyte } & Units & N & Minimum & Average & Maximum \\
\hline Gross Alpha & $\mathrm{nCi} / \mathrm{m}^{2}$ & 11 & $1.16 \mathrm{E}-02$ & $4.29 \pm 4.39 \mathrm{E}-02$ & $1.43 \mathrm{E}-01$ \\
\hline Gross Beta & $\mathrm{nCi} / \mathrm{m}^{2}$ & 11 & $2.02 \mathrm{E}-01$ & $5.63 \pm 0.68 \mathrm{E}-01$ & $1.05 \mathrm{E}+00$ \\
\hline H-3 & $\mu \mathrm{Ci} / \mathrm{mL}$ & 12 & $8.12 \mathrm{E}-08$ & $5.10 \pm 8.29 \mathrm{E}-08$ & $1.27 \mathrm{E}-07$ \\
\hline K-40 & $\mathrm{nCi} / \mathrm{m}^{2}$ & 12 & $1.19 \mathrm{E}+00$ & $-0.97 \pm 7.65 \mathrm{E}+00$ & $6.78 \mathrm{E}+00$ \\
\hline Cs-137 & $\mathrm{nCi} / \mathrm{m}^{2}$ & 12 & $2.12 \mathrm{E}-01$ & $0.39 \pm 5.49 \mathrm{E}-01$ & $7.88 \mathrm{E}-01$ \\
\hline $\mathbf{p H}$ & standard units & 12 & 4.43 & 4.82 & 7.10 \\
\hline
\end{tabular}

$N$ - Number of samples

Note: Samples taken in June 2003 are rejected for gross alpha and gross beta.

$D-16$ 
Table D-24

2003 Results in Fallout: Route 240 (AF24FOP)

\begin{tabular}{|l|c|c|c|c|c|}
\hline \multicolumn{1}{|c|}{ Analyte } & Units & N & Minimum & Average & Maximum \\
\hline Gross Alpha & $\mathrm{nCi} / \mathrm{m}^{2}$ & 11 & $1.10 \mathrm{E}-02$ & $3.69 \pm 1.20 \mathrm{E}-02$ & $6.47 \mathrm{E}-02$ \\
\hline Gross Beta & $\mathrm{nCi} / \mathrm{m}^{2}$ & 11 & $2.93 \mathrm{E}-01$ & $5.09 \pm 0.46 \mathrm{E}-01$ & $9.24 \mathrm{E}-01$ \\
\hline H-3 & $\mu \mathrm{Ci} / \mathrm{mL}^{2}$ & 12 & $5.84 \mathrm{E}-08$ & $5.29 \pm 8.33 \mathrm{E}-08$ & $1.68 \mathrm{E}-07$ \\
\hline K-40 & $\mathrm{nCi} / \mathrm{m}^{2}$ & 12 & $1.79 \mathrm{E}+00$ & $-1.50 \pm 6.41 \mathrm{E}+00$ & $9.24 \mathrm{E}+00$ \\
\hline Cs-137 & $\mathrm{nCi} / \mathrm{m}^{2}$ & 12 & $1.26 \mathrm{E}-01$ & $0.17 \pm 4.52 \mathrm{E}-01$ & $3.89 \mathrm{E}-01$ \\
\hline pH & standard units & 12 & 4.14 & 4.45 & 5.35 \\
\hline
\end{tabular}

$N$ - Number of samples

Note: Samples taken in June 2003 are rejected for gross alpha and gross beta.

Table D-25

2003 Results in Fallout: Thomas Corners (AFTCFOP)

\begin{tabular}{|l|c|c|c|c|c|}
\hline \multicolumn{1}{|c|}{ Analyte } & Units & N & Minimum & Average & Maximum \\
\hline Gross Alpha & $\mathrm{nCi} / \mathrm{m}^{2}$ & 11 & $2.27 \mathrm{E}-02$ & $5.58 \pm 1.81 \mathrm{E}-02$ & $1.02 \mathrm{E}-01$ \\
\hline Gross Beta & $\mathrm{nCi} / \mathrm{m}^{2}$ & 11 & $2.31 \mathrm{E}-01$ & $5.42 \pm 0.55 \mathrm{E}-01$ & $1.04 \mathrm{E}+00$ \\
\hline $\mathbf{H}-3$ & $\mathrm{\mu Ci} / \mathrm{mL}$ & 12 & $5.96 \mathrm{E}-08$ & $3.57 \pm 7.90 \mathrm{E}-08$ & $1.09 \mathrm{E}-07$ \\
\hline K-40 & $\mathrm{nCi} / \mathrm{m}^{2}$ & 12 & $2.76 \mathrm{E}+00$ & $0.23 \pm 7.51 \mathrm{E}+00$ & $1.44 \mathrm{E}+01$ \\
\hline Cs-137 & $\mathrm{nCi} / \mathrm{m}^{2}$ & 12 & $2.08 \mathrm{E}-01$ & $-0.79 \pm 6.16 \mathrm{E}-01$ & $1.13 \mathrm{E}+00$ \\
\hline pH & standard units & 12 & 3.85 & 4.56 & 7.04 \\
\hline
\end{tabular}

$N$ - Number of samples

Note: Samples taken in June 2003 are rejected for gross alpha and gross beta.

WVDP Annual Site Environmental Report

$D-17$

Calendar Year 2003 
Table D-26

2003 Results in Fallout: Fox Valley Road (AFFXFOP)

\begin{tabular}{|l|c|c|c|c|c|}
\hline \multicolumn{1}{|c|}{ Analyte } & Units & N & Minimum & Average & Maximum \\
\hline Gross Alpha & $\mathrm{nCi} / \mathrm{m}^{2}$ & 11 & $2.13 \mathrm{E}-02$ & $5.88 \pm 2.38 \mathrm{E}-02$ & $1.16 \mathrm{E}-01$ \\
\hline Gross Beta & $\mathrm{nCi} / \mathrm{m}^{2}$ & 11 & $1.89 \mathrm{E}-01$ & $5.16 \pm 0.56 \mathrm{E}-01$ & $8.67 \mathrm{E}-01$ \\
\hline Tritium & $\mu \mathrm{Ci} / \mathrm{mL}$ & 12 & $7.97 \mathrm{E}-08$ & $2.86 \pm 8.52 \mathrm{E}-08$ & $1.67 \mathrm{E}-07$ \\
\hline K-40 & $\mathrm{nCi} / \mathrm{m}^{2}$ & 12 & $2.06 \mathrm{E}+00$ & $-0.56 \pm 7.67 \mathrm{E}+00$ & $1.41 \mathrm{E}+01$ \\
\hline Cs-137 & $\mathrm{nCi} / \mathrm{m}^{2}$ & 12 & $1.73 \mathrm{E}-01$ & $-0.27 \pm 4.70 \mathrm{E}-01$ & $7.63 \mathrm{E}-01$ \\
\hline $\mathbf{p H}$ & standard units & 12 & 4.50 & 4.85 & 6.96 \\
\hline
\end{tabular}

$N$ - Number of samples

Note: Samples taken in June 2003 are rejected for gross alpha and gross beta.

$D-18$ 


\section{Appendix $E$ Summary of Groundwater Monitoring Data}

E - 1 


\section{Groundwater Sampling Methodology}

Groundwater samples are collected from monitoring wells using either dedicated Teflon ${ }^{\circledR}$ well bailers or bladder pumps. Bailers are used in low-yield wells; bladder pumps are used in wells with good water-yielding characteristics. This sampling equipment is dedicated to an individual well to reduce the likelihood of sample contamination from external materials or cross contamination.

To ensure that only representative groundwater is sampled, three well volumes are removed (purged) from the well before the actual samples are collected. In low-yield wells, pumping or bailing to dryness provides sufficient purging. Conductivity and $\mathrm{pH}$ are measured before and after sampling to confirm the geochemical stability of the groundwater during sampling.

The bailer, a tube with a check valve at the bottom, is lowered slowly into the well to minimize agitation of the water column. The bailer containing the groundwater is then withdrawn from the well and emptied into a sample container. Bladder pumps use compressed air that is pumped from the surface to gently squeeze a Teflon ${ }^{\circledR}$ bladder encased in a stainless-steel tube near the bottom of the well. Groundwater flowing into the bladder is pumped into a sample container, allowing additional groundwater to enter the bladder with a minimum of agitation and mixing. A check valve ensures that the water flows in only one direction.

Groundwater samples are cooled and preserved, with chemicals if required, to minimize chemical and/or biological changes after sample collection. A strict chain-of-custody protocol is followed for all samples collected by the WVDP.

\section{Key to bolding convention:}

The tables on pages E-9 through E-25 (Tables E-2 through E-13C) contain a bolding convention devised to help the reader, when viewing the data, to quickly see the range of detectable measurements within a data series. A data series is a set of chemical or radionuclide measurements (e.g., gross alpha, gross beta, tritium) from a single location or from similar locations. Note that some tables contain data that should not be technically evaluated under this convention.

Results for each analyte constitute a single data series. If a radiological result is larger than the uncertainty term, the measurement is considered positive. Otherwise, a result is considered non-detectable. Chemical results preceded by "less than" $(<)$ are considered nondetectable. The bolding convention is not applied to data series consisting of less than three values.

If all results in a data series are positive, the lowest and highest values are bolded.

If a data series contains some positive results, the highest value is bolded.

If all values in a data series are nondetectable, no values are bolded.

$$
E-2
$$




\section{Groundwater Sampling and Analysis Agenda}

\section{Analyte Group}

Contamination Indicator Parameters (I)

Radiological Indicator Parameters (RI)

Volatile Organic Compounds (V)

Semivolatile Organic Compounds (SV)

NYCRR Appendix 33 Metals (M33)

Special Monitoring Parameters

for Early Warning Wells (SM)

Radioisotopic Analyses:

alpha-, beta-, and gamma-emitters (R)

Strontium-90 (S)

\section{Description of Parameters ${ }^{1}$}

$\mathrm{pH}$, specific conductance (field measurement)

Gross alpha, gross beta, tritium

NYCRR Appendix 33 Volatile Organic Compounds (VOCs) (See Table E-14 ${ }^{\mathrm{C}}$.)

NYCRR Appendix 33 Semi-volatile Organic Compounds (SVOCs) and tributyl phosphate (TBP) (See Table E-14 ${ }^{\mathrm{C}}$.)

Antimony, arsenic, barium, beryllium, cadmium, chromium, cobalt, copper, lead, mercury, nickel, selenium, silver, thallium, tin, vanadium, zinc

Aluminum, iron, manganese

Carbon-14, Strontium-90, Technetium-99, Iodine-129, Cesium-137, Radium-226, Radium-228, Uranium-232, Uranium-233/234, Uranium-235/236, Uranium-238, total uranium

Strontium-90

2003 Quarterly Monitoring Schedule:

1st Qtr - December 1, 2002 to February 28, 2003

2nd Qtr - March 1, 2003 to May 31, 2003

3rd Qtr - June 1, 2003 to August 31, 2003

4th Qtr-September 1, 2003 to November 30, 2003

${ }^{I}$ Analysis completed for selected active monitoring locations only. See Table E-1 ${ }^{\mathrm{C}}$ for the analytes assigned to each monitoring location.

$$
\text { E - } 3
$$


Table E-1

Groundwater Monitoring Network: Super Solid Waste Management Units

\begin{tabular}{|c|c|c|c|c|c|c|}
\hline $\begin{array}{c}\text { SSWMUS } \\
\text { and } \\
\text { Constituent SWMUs }\end{array}$ & \multicolumn{2}{|c|}{$\begin{array}{l}\text { Well } \\
\text { ID } \\
\text { Number }^{1}\end{array}$} & $\begin{array}{c}\text { Additional } \\
\text { Analytes } \\
\text { Measured in } \\
\mathbf{2 0 0 3}^{\mathbf{2}}\end{array}$ & \multicolumn{2}{|c|}{$\begin{array}{c}\text { Well } \\
\text { ID } \\
\text { Number }^{1}\end{array}$} & $\begin{array}{c}\text { Additional } \\
\text { Analytes } \\
\text { Measured in } \\
\mathbf{2 0 0 3}^{\mathbf{2}}\end{array}$ \\
\hline \multicolumn{7}{|l|}{$\begin{array}{l}\text { SSWMU \#1 - } \\
\text { Low-Level Waste Treatment Facilities: }\end{array}$} \\
\hline $\begin{array}{l}\text { - Former Lagoon } 1 \\
\text { - LLWTF Lagoons } \\
\text { - LLWTF Building } \\
\text { - Interceptors } \\
\text { - Neutralization Pit }\end{array}$ & $\begin{array}{l}103 * \\
104 \\
105 \\
106 \\
107 \\
108 \\
109\end{array}$ & $\begin{array}{l}(\mathrm{S}: \mathrm{D}) \\
(\mathrm{S}: \mathrm{C}) \\
(\mathrm{S}: \mathrm{C}) \\
(\mathrm{S}: \mathrm{D}) \\
(\mathrm{T}: \mathrm{D}) \\
(\mathrm{T}: \mathrm{D}) \\
(\mathrm{T}: \mathrm{D})\end{array}$ & $\begin{array}{c}\text { V } \\
\text { SV,V } \\
\text { V } \\
\text { V } \\
\text { V } \\
\text { V } \\
p\end{array}$ & $\begin{array}{l}110^{*} \\
111^{*} \\
114 \\
115 \\
116^{*} \\
8604 \\
8605^{*}\end{array}$ & $\begin{array}{l}\text { (T:D) } \\
(\mathrm{S}: \mathrm{D}) \\
(\mathrm{T}: \mathrm{D}) \\
(\mathrm{T}: \mathrm{U}) \\
(\mathrm{S}: \mathrm{U}) \\
(\mathrm{S}: \mathrm{C}) \\
(\mathrm{S}: \mathrm{D})\end{array}$ & $\begin{array}{c}\mathrm{V} \\
\mathrm{M} 33, \mathrm{~S}, \mathrm{SV}, \mathrm{V} \\
p \\
p \\
\mathrm{~S}, \mathrm{~V} \\
\mathrm{~V} \\
\mathrm{M} 33, \mathrm{~S}, \mathrm{SV}, \mathrm{V}\end{array}$ \\
\hline \multicolumn{7}{|l|}{$\begin{array}{l}\text { SSWMU \#2 - } \\
\text { Miscellaneous Small Units: }\end{array}$} \\
\hline $\begin{array}{l}\text { - Sludge Ponds } \\
\text { - Solvent Dike } \\
\text { - Equalization Mixing Basin } \\
\text { - Paper Incinerator }\end{array}$ & $\begin{array}{l}201 \\
202 \\
203 \\
204 * \\
205\end{array}$ & $\begin{array}{r}\text { (S:U) } \\
(T S: U) \\
(S: D) \\
\text { (TS:D) } \\
\text { (S:D) }\end{array}$ & $\begin{array}{l}\mathrm{V} \\
p \\
p\end{array}$ & $\begin{array}{l}206 \\
207 \\
208 \\
8606\end{array}$ & $\begin{array}{r}\text { (TS:D) } \\
\text { (S:D) } \\
\text { (TS:D) } \\
\text { (S:D) }\end{array}$ & $\begin{array}{l}p \\
\mathrm{~V} \\
p\end{array}$ \\
\hline \multicolumn{7}{|l|}{$\begin{array}{l}\text { SSWMU \#3 - } \\
\text { Liquid Waste Treatment System: }\end{array}$} \\
\hline $\begin{array}{l}\text { - Liquid Waste Treatment System } \\
\text { - Cement Solidification System } \\
\text { - Main Process Building (specific areas) }\end{array}$ & $\begin{array}{l}301^{*} \\
302 \\
305\end{array}$ & $\begin{array}{r}(\mathrm{S}: \mathrm{B}) \\
(\mathrm{TS}: \mathrm{U}) \\
(\mathrm{S}: \mathrm{D})\end{array}$ & $p$ & 307 & $(\mathrm{~S}: \mathrm{D})$ & $p$ \\
\hline
\end{tabular}

\footnotetext{
${ }^{1}$ Hydrogeologic unit monitored and well position in SSWMU follow the well ID in parentheses. Hydrogeologic units monitored are: WT (weathered Lavery till); $T$ (unweathered Lavery till); $S$ (sand and gravel); $K$ (Kent recessional sequence); TS (till-sand). Well position in SSWMU: U (upgradient); D (downgradient); B (background); $C$ (crossgradient). Example: $401^{*}(S: B)$ monitors background conditions in the sand and gravel unit.
}

${ }^{2}$ See p. E-3 for a description of codes and analytes. The parameters listed in this table, Table E-1C, are in addition to the contamination indicator parameters (I) and radiological indicator parameters (RI) routinely scheduled at all monitoring locations for 2003. Wells measured for potentiometric (water-level) data only are designated by "p."

* Monitoring for certain parameters is required by the RCRA $\$ 3008(h)$ Order on Consent. (See p. ECS-4.)

$$
E-4
$$


Table E-1 (continued)

Groundwater Monitoring Network: Super Solid Waste Management Units

SSWMUS
and
Constituent SWMUs

\begin{abstract}
Well
ID
\end{abstract}

Number $^{1}$
Additional

Analytes

Measured in $\mathbf{2 0 0 3}^{2}$
Well

Number $^{1}$
Additional

Analytes

Measured in

$\mathbf{2 0 0 3}^{2}$
SSWMU \#4 -

HLW Storage and Processing Area:

- Vitrification Facility

- Vitrification Test Tanks

- HLW Tanks

- Supernatant Treatment System

Maintenance Shop Leach Field:

- Maintenance Shop Leach Field

$501 *$

(S:U)

(TS:U)

(T:C)

(S:D)

$\mathrm{R}$

V

$p$

$406^{*}$

$\begin{array}{lcc}407 & (\mathrm{~K}: \mathrm{D}) & p \\ 408^{*} & (\mathrm{~S}: \mathrm{D}) & \mathrm{R}, \mathrm{V} \\ 409 & (\mathrm{~T}: \mathrm{D}) & \\ 410 & (\mathrm{~K}: \mathrm{U}) & p \\ 411 & (\mathrm{~K}: \mathrm{U}) & p\end{array}$

$p$
$\mathrm{R}, \mathrm{V}$

$p$

$502 * \quad(S \cdot D)$

(S:D)

S, SM, V

$605 \quad$ (S:D) $\quad$ S

8607* (S:U)

$8608 \quad(\mathrm{~S}: \mathrm{U})$

8609* $\quad(\mathrm{S}: \mathrm{U})$

(S:D)
(S:D)
(S:U)
(S:D)

(LSAs 1, 2, 3, 4)

SSWMU \#7 -

Chemical Process Cell

(CPC) Waste Storage Area:

- CPC Waste Storage Area

$\begin{array}{rr}701 & \text { (TS:U) } \\ 702 & \text { (T:C) } \\ 703 & \text { (T:D) } \\ 704 & \text { (T:D) }\end{array}$

TS:U)
(T:C)
(T:D)
(T:D)

$p$
$\mathrm{~S}$
$p$

S, V
S
V

$\stackrel{p}{\mathrm{~S}, \mathrm{~V}}$

${ }^{1}$ Hydrogeologic unit monitored and well position in SSWMU follow the well ID in parentheses. Hydrogeologic units monitored are: WT (weathered Lavery till); $T$ (unweathered Lavery till); $S$ (sand and gravel); $K$ (Kent recessional sequence); TS (till-sand). Well position in SSWMU: U (upgradient); D (downgradient); B (background); $C$ (crossgradient). Example: 401*(S:B) monitors background conditions in the sand and gravel unit.

${ }^{2}$ See p. E-3 for a description of codes and analytes. The parameters listed in this table, Table E-1C, are in addition to the contamination indicator parameters (I) and radiological indicator parameters (RI) routinely scheduled at all monitoring locations for 2003. Wells measured for potentiometric (water-level) data only are designated by "p."

* Monitoring for certain parameters is required by the RCRA $\$ 3008(h)$ Order on Consent. (See p. ECS-4.)

$$
E-5
$$


Table E-1 (continued)

Groundwater Monitoring Network: Super Solid Waste Management Units

SSWMUS
and
Constituent SWMUs

Well
ID
Number $^{1}$

\author{
Additional \\ Analytes \\ Measured in \\ $\mathbf{2 0 0 3}^{2}$
}

\author{
Well \\ ID \\ Number $^{1}$
}

Additional

Analytes

Measured in

$\mathbf{2 0 0 3}^{2}$
SSWMU \#8 -

Construction and Demolition

Debris Landfill:

- Former Construction and Demolition Debris Landfill

SSWMU \#9 -

NRC-Licensed Disposal Area:

- NRC-Licensed Disposal Area

- Container Storage Area

- Trench Interceptor Project
SSWMU \#10 -

IRTS Drum Cell:

- IRTS Drum Cell

- Background (south plateau)

\begin{abstract}
(2)
\end{abstract}

$\begin{array}{lr}901 * & (\mathrm{~K}: \mathrm{U}) \\ 902 * & (\mathrm{~K}: \mathrm{U}) \\ 903 * & (\mathrm{~K}: \mathrm{D}) \\ 904 & (\mathrm{~T}: \mathrm{D}) \\ 905 & (\mathrm{~S}: \mathrm{D}) \\ 906 * & (\mathrm{WT}: \mathrm{D}) \\ 907 & (\mathrm{WT}: \mathrm{D})\end{array}$

$(\mathrm{S}: \mathrm{U})$

(S:D)

(S:D)

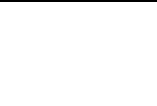

904
905
$906^{*}$
907

$804 * 2$

$\begin{array}{llc}804 * & \text { (S:D) } & \text { V } \\ 8603 & \text { (S:U) } & \text { S } \\ 8612 * & \text { (S:D) } & \text { SV,V }\end{array}$

$\begin{array}{lrr}908 * & \text { (WT:U) } & \\ 909 * & \text { (WT:D) } & \text { M33, R, SV, V } \\ 910 * & \text { (T:D) } & \\ 8610 * & \text { (K:D) } & \\ 8611 * & \text { (K:D) } & \\ \text { NDATR* } & \text { (Inter- } & \\ & \text { ceptor } & \\ \text { Trench } & \\ \text { Manhole } & \\ \text { Sump: D) } & \text { M33, R, SV, V }\end{array}$

1006* (WT:D)

1007 (WT:D)

1008B $\quad(\mathrm{K}: \mathrm{B})$

1008C* (WT:B)

${ }^{1}$ Hydrogeologic unit monitored and well position in SSWMU follow the well ID in parentheses. Hydrogeologic units monitored are: WT (weathered Lavery till); $T$ (unweathered Lavery till); $S$ (sand and gravel); K (Kent recessional sequence); TS (till-sand). Well position in SSWMU: U (upgradient); D (downgradient); B (background); $C$ (crossgradient). Example: $401 *(S: B)$ monitors background conditions in the sand and gravel unit.

${ }^{2}$ See p. E-3 for a description of codes and analytes. The parameters listed in this table, Table E-1C, are in addition to the contamination indicator parameters (I) and radiological indicator parameters (RI) routinely scheduled at all monitoring locations for 2003. Wells measured for potentiometric (water-level) data only are designated by "p."

* Monitoring for certain parameters is required by the RCRA $\$ 3008(h)$ Order on Consent. (See p. ECS-4.)

$$
E-6
$$




\section{Table E-1 (continued)}

\section{Groundwater Monitoring Network: Super Solid Waste Management Units}

\begin{tabular}{|c|c|c|c|c|c|c|}
\hline $\begin{array}{c}\text { SSWMUS } \\
\text { and } \\
\text { Constituent SWMUs }\end{array}$ & \multicolumn{2}{|c|}{$\begin{array}{c}\text { Well } \\
\text { ID } \\
\text { Number }^{1}\end{array}$} & $\begin{array}{l}\text { Additional } \\
\text { Analytes } \\
\text { Measured in } \\
\mathbf{2 0 0 3}^{2}\end{array}$ & \multicolumn{2}{|c|}{$\begin{array}{c}\text { Well } \\
\text { ID } \\
\text { Number }^{1}\end{array}$} & $\begin{array}{c}\text { Additional } \\
\text { Analytes } \\
\text { Measured in } \\
\mathbf{2 0 0 3}^{2}\end{array}$ \\
\hline \multicolumn{7}{|l|}{ Remote-Handled Waste Facility: } \\
\hline $\begin{array}{l}\text { (Monitor groundwater upgradient } \\
\text { and downgradient of the newly- } \\
\text { constructed facility. Not in an } \\
\text { SSWMU.) }\end{array}$ & $\begin{array}{l}1301 \\
1302\end{array}$ & $\begin{array}{l}\text { (T:D) } \\
\text { (S:D) }\end{array}$ & $\begin{array}{l}\text { M33, R, SV, V } \\
\text { M33, R, SV, V }\end{array}$ & $\begin{array}{l}1303 \\
1304\end{array}$ & $\begin{array}{l}(\mathrm{T}: \mathrm{U}) \\
(\mathrm{S}: \mathrm{U})\end{array}$ & $\begin{array}{l}\text { M33, R, SV, V } \\
\text { M33, R, SV, V }\end{array}$ \\
\hline \multicolumn{7}{|l|}{ Main Plant Area Well Points: } \\
\hline $\begin{array}{l}\text { (Monitor groundwater at various } \\
\text { locations north and east of the main } \\
\text { plant. Not in an SSWMU.) }\end{array}$ & $\begin{array}{l}\text { WP-A } \\
\text { WP-C } \\
\text { WP-H }\end{array}$ & $\begin{array}{l}(\mathrm{S}) \\
(\mathrm{S}) \\
(\mathrm{S})\end{array}$ & & & & \\
\hline \multicolumn{7}{|l|}{ Former Sand and Gravel Background: } \\
\hline $\begin{array}{l}\text { (Well originally used for background; } \\
\text { replaced by a combination of wells } 301 \text {, } \\
401 \text {, and } 706 . \text { Not in an SSWMU.) }\end{array}$ & NB1S & $(\mathrm{S}: \mathrm{B})$ & & & & \\
\hline \multicolumn{7}{|l|}{ North Plateau Groundwater Seeps: } \\
\hline $\begin{array}{l}\text { (Monitor groundwater emanating } \\
\text { from seeps along the north pleateau } \\
\text { edge. Not in an SSWMU.) }\end{array}$ & $\begin{array}{l}\text { SP04 } \\
\text { SP06 } \\
\text { SP11 }\end{array}$ & $\begin{array}{l}(\mathrm{S}) \\
(\mathrm{S}) \\
(\mathrm{S})\end{array}$ & $\begin{array}{l}\text { RI } \\
\text { RI } \\
\text { RI }\end{array}$ & $\begin{array}{l}\text { SP12* } \\
\text { GSEEP* }\end{array}$ & & $\begin{array}{l}\text { I, RI, V } \\
\text { I, RI, V }\end{array}$ \\
\hline
\end{tabular}

${ }^{1}$ Hydrogeologic unit monitored and well position in SSWMU follow the well ID in parentheses. Hydrogeologic units monitored are: WT (weathered Lavery till); $T$ (unweathered Lavery till); $S$ (sand and gravel); $K$ (Kent recessional sequence); TS (till-sand). Well position in SSWMU: U (upgradient); D (downgradient); B (background); $C$ (crossgradient). Example: 401*(S:B) monitors background conditions in the sand and gravel unit.

${ }^{2}$ See p. E-3 for a description of codes and analytes. The parameters listed in this table, Table E-1C, are in addition to the contamination indicator parameters (I) and radiological indicator parameters (RI) routinely scheduled at all monitoring locations for 2003. Wells measured for potentiometric (water-level) data only are designated by " $p$. "

* Monitoring for certain parameters is required by the RCRA $\$ 3008(h)$ Order on Consent. (See p. ECS-4.)

$$
E-7
$$


Table E-1 (concluded)

Groundwater Monitoring Network: Super Solid Waste Management Units

SSWMUS
and
Constituent SWMUs

Well
ID
Number $^{1}$

\author{
Additional \\ Analytes \\ Measured in \\ 2003 $^{2}$
}

\author{
Well \\ ID \\ Number $^{1}$
}

Additional

Analytes

Measured in

$\mathbf{2 0 0 3}^{2}$

Note: The SDA wells are sampled by NYSERDA under an independent monitoring program.

SSWMU \#11 -

State-Licensed Disposal Area (SDA)

- State-Licensed Disposal Area (NYSERDA)

$\begin{array}{lr}1101 \mathrm{~A} & \text { (WT:U) } \\ 1101 \mathrm{~B} & (\mathrm{~T}: \mathrm{U}) \\ 1101 \mathrm{C} & (\mathrm{K}: \mathrm{U}) \\ 1102 \mathrm{~A} & (\mathrm{WT}: \mathrm{D}) \\ 1102 \mathrm{~B} & (\mathrm{~T}: \mathrm{D}) \\ 1103 \mathrm{~A} & (\mathrm{WT:D}) \\ 1103 \mathrm{~B} & (\mathrm{~T}: \mathrm{D}) \\ 1103 \mathrm{C} & (\mathrm{K}: \mathrm{D}) \\ 1104 \mathrm{~A} & (\mathrm{WT}: \mathrm{D}) \\ 1104 \mathrm{~B} & (\mathrm{~T}: \mathrm{D}) \\ 1104 \mathrm{C} & (\mathrm{K}: \mathrm{D})\end{array}$

1105A (WT:D)

1105B (T:D)

1106A (WT:U)

1106B (T:U)

1107A (WT:D)

1108A (WT:U)

1109A (WT:U)

1109B (T:U)

1110A (WT:D)

1111A (WT:D)

${ }^{1}$ Hydrogeologic unit monitored and well position in SSWMU follow the well ID in parentheses. Hydrogeologic units monitored are: WT (weathered Lavery till); $T$ (unweathered Lavery till); $S$ (sand and gravel); $K$ (Kent recessional sequence); TS (till-sand). Well position in SSWMU: U (upgradient); D (downgradient); $B$ (background); $C$ (crossgradient). Example: $401 *(S: B)$ monitors background conditions in the sand and gravel unit.

${ }^{2}$ See p. E-3 for a description of codes and analytes. The parameters listed in this table, Table E-1C, are in addition to the contamination indicator parameters (I) and radiological indicator parameters (RI) routinely scheduled at all monitoring locations for 2003. Wells measured for potentiometric (water-level) data only are designated by " $p$."

* Monitoring for certain parameters is required by the RCRA $\$ 3008(h)$ Order on Consent. (See p. ECS-4.)

$E-8$ 


\section{Table E-2 \\ 2003 Indicator Results From the Sand and Gravel Unit}

\begin{tabular}{|c|c|c|c|c|c|c|}
\hline $\begin{array}{l}\text { Location } \\
\text { Code }\end{array}$ & $\begin{array}{l}\text { Hydraulic } \\
\text { Position }\end{array}$ & $\begin{array}{c}\mathbf{p H} \\
\text { (standard units) }\end{array}$ & $\begin{array}{c}\text { Conductivity } \\
\left(\mu \mathrm{mhos} / \mathrm{cm} @ 25^{\circ} \mathrm{C}\right)\end{array}$ & $\begin{array}{l}\text { Gross Alpha } \\
\qquad(\mu \mathrm{Ci} / \mathrm{mL})\end{array}$ & $\begin{array}{c}\text { Gross Beta } \\
\qquad(\mu \mathrm{Ci} / \mathrm{mL})\end{array}$ & $\begin{array}{l}\text { Tritium } \\
(\mu \mathrm{Ci} / \mathrm{mL})\end{array}$ \\
\hline 301 & UP(1) & 6.68 & 1,018 & $0.37 \pm 2.54 \mathrm{E}-09$ & $6.63 \pm 3.73 E-09$ & $2.82 \pm 8.53 \mathrm{E}-08$ \\
\hline 301 & $\mathrm{UP}(2)$ & 6.80 & 1,522 & $2.09 \pm 3.42 \mathrm{E}-09$ & $1.38 \pm 0.44 E-08$ & $1.00 \pm 0.86 \mathrm{E}-07$ \\
\hline 301 & $\mathrm{UP}(3)$ & 6.42 & 1,138 & $0.79 \pm 3.42 \mathrm{E}-09$ & $8.14 \pm 4.17 \mathrm{E}-09$ & $-7.66 \pm 8.50 \mathrm{E}-08$ \\
\hline 301 & $\mathrm{UP}(4)$ & 6.12 & 1,526 & $0.55 \pm 4.22 \mathrm{E}-09$ & $9.45 \pm 4.27 \mathrm{E}-09$ & $-1.81 \pm 8.24 \mathrm{E}-08$ \\
\hline 401 & UP(1) & 6.45 & 3,600 & $2.97 \pm 6.88 \mathrm{E}-09$ & $9.12 \pm 7.36 \mathrm{E}-09$ & $-3.01 \pm 8.48 \mathrm{E}-08$ \\
\hline 401 & $\mathrm{UP}(2)$ & 6.69 & 4,025 & $0.30 \pm 7.21 \mathrm{E}-09$ & $1.25 \pm 0.62 E-08$ & $2.49 \pm 8.58 \mathrm{E}-08$ \\
\hline 401 & UP(3) & 6.28 & 3,083 & $-1.77 \pm 7.23 \mathrm{E}-09$ & $3.12 \pm 6.87 \mathrm{E}-09$ & $-8.45 \pm 8.76 \mathrm{E}-08$ \\
\hline 401 & $\mathrm{UP}(4)$ & 6.24 & 2,513 & $3.51 \pm 6.13 \mathrm{E}-09$ & $5.08 \pm 7.44 \mathrm{E}-09$ & $1.22 \pm 8.35 \mathrm{E}-08$ \\
\hline 403 & UP(1) & 6.96 & 838 & $0.76 \pm 1.61 \mathrm{E}-09$ & $2.95 \pm 2.35 \mathrm{E}-09$ & $-5.97 \pm 8.38 \mathrm{E}-08$ \\
\hline 403 & $\mathrm{UP}(2)$ & 6.86 & 1,098 & $-0.31 \pm 1.55 \mathrm{E}-09$ & $5.08 \pm 2.37 \mathrm{E}-09$ & $1.02 \pm 0.89 \mathrm{E}-07$ \\
\hline 403 & $\mathrm{UP}(3)$ & 7.30 & 972 & $1.14 \pm 2.24 \mathrm{E}-09$ & $3.80 \pm 2.73 \mathrm{E}-09$ & $-3.61 \pm 8.55 \mathrm{E}-08$ \\
\hline 403 & $\mathrm{UP}(4)$ & 6.93 & 584 & $-0.47 \pm 1.22 \mathrm{E}-09$ & $2.30 \pm 2.42 \mathrm{E}-09$ & $0.52 \pm 8.29 \mathrm{E}-08$ \\
\hline 706 & $\mathrm{UP}(1)$ & 7.03 & 875 & $-0.38 \pm 1.12 \mathrm{E}-09$ & $1.27 \pm 0.16 E-08$ & $-7.40 \pm 7.96 \mathrm{E}-08$ \\
\hline 706 & $\mathrm{UP}(2)$ & 6.90 & 731 & $-0.10 \pm 1.04 \mathrm{E}-09$ & $9.82 \pm 2.20 \mathrm{E}-09$ & $6.19 \pm 8.88 \mathrm{E}-08$ \\
\hline 706 & UP(3) & 6.86 & 749 & $-0.12 \pm 1.55 \mathrm{E}-09$ & $7.88 \pm 2.28 E-09$ & $-4.40 \pm 8.53 \mathrm{E}-08$ \\
\hline 706 & UP(4) & 6.55 & 778 & $0.46 \pm 1.82 \mathrm{E}-09$ & $1.20 \pm 0.24 \mathrm{E}-08$ & $0.96 \pm 5.87 \mathrm{E}-08$ \\
\hline 1304 & $\mathrm{UP}(4)$ & 6.80 & 2,220 & $2.49 \pm 4.05 \mathrm{E}-09$ & $4.62 \pm 3.62 \mathrm{E}-09$ & $1.60 \pm 0.81 \mathrm{E}-07$ \\
\hline NB1S & $\mathrm{UP}(1)$ & 6.83 & 638 & $-0.63 \pm 1.09 \mathrm{E}-09$ & $0.94 \pm 1.73 \mathrm{E}-09$ & $-2.06 \pm 8.21 \mathrm{E}-08$ \\
\hline NB1S & $\mathrm{UP}(2)$ & 6.94 & 840 & $-0.68 \pm 1.03 \mathrm{E}-09$ & $4.20 \pm 1.89 \mathrm{E}-09$ & $-2.00 \pm 8.74 \mathrm{E}-08$ \\
\hline NB1S & $\mathrm{UP}(3)$ & 7.15 & 778 & $0.59 \pm 1.36 \mathrm{E}-09$ & $0.91 \pm 1.86 \mathrm{E}-09$ & $6.61 \pm 8.76 \mathrm{E}-08$ \\
\hline NB1S & $\mathrm{UP}(4)$ & 6.87 & 662 & $-0.13 \pm 1.52 \mathrm{E}-09$ & $2.02 \pm 1.74 \mathrm{E}-09$ & $-8.71 \pm 8.71 \mathrm{E}-08$ \\
\hline 201 & $\operatorname{DOWN}(1)$ & 6.66 & 1,834 & $3.42 \pm 4.99 \mathrm{E}-09$ & $2.84 \pm 0.61 E-08$ & $-1.26 \pm 0.84 \mathrm{E}-07$ \\
\hline 201 & $\operatorname{DOWN}(2)$ & 6.36 & 3,455 & $-0.79 \pm 5.92 \mathrm{E}-09$ & $7.04 \pm 0.84 E-08$ & $4.58 \pm 8.66 \mathrm{E}-08$ \\
\hline 201 & $\operatorname{DOWN}(3)$ & 6.29 & 3,224 & $-2.21 \pm 5.94 \mathrm{E}-09$ & $5.24 \pm 0.75 \mathrm{E}-08$ & $-1.11 \pm 0.86 \mathrm{E}-07$ \\
\hline 201 & DOWN(4) & 6.26 & 2,286 & $1.92 \pm 4.58 \mathrm{E}-09$ & $3.80 \pm 0.68 \mathrm{E}-08$ & $2.94 \pm 8.40 \mathrm{E}-08$ \\
\hline 1302 & DOWN(4) & 7.32 & 1,468 & $1.47 \pm 3.69 \mathrm{E}-09$ & $6.47 \pm 3.71 \mathrm{E}-09$ & $-4.40 \pm 8.62 \mathrm{E}-08$ \\
\hline 103 & DOWN(1) & 8.08 & 3,250 & $-1.09 \pm 6.23 \mathrm{E}-09$ & $6.76 \pm 1.03 E-08$ & $7.09 \pm 8.38 \mathrm{E}-08$ \\
\hline 103 & $\operatorname{DOWN}(2)$ & 7.32 & 10,260 & $-0.53 \pm 1.13 \mathrm{E}-08$ & $5.53 \pm 0.28 E-07$ & $-3.80 \pm 8.73 \mathrm{E}-08$ \\
\hline 103 & $\operatorname{DOWN}(3)$ & 7.59 & 7,939 & $4.76 \pm 9.04 \mathrm{E}-09$ & $3.03 \pm 0.14 \mathrm{E}-07$ & $4.75 \pm 8.94 \mathrm{E}-08$ \\
\hline 103 & DOWN(4) & 7.71 & 4,917 & $0.32 \pm 1.01 \mathrm{E}-08$ & $1.49 \pm 0.18 \mathrm{E}-07$ & $-1.34 \pm 0.86 \mathrm{E}-07$ \\
\hline 104 & $\operatorname{DOWN}(1)$ & 6.93 & 1,776 & $0.60 \pm 2.30 \mathrm{E}-09$ & $6.33 \pm 0.01 \mathrm{E}-05$ & $3.76 \pm 0.90 \mathrm{E}-07$ \\
\hline 104 & $\operatorname{DOWN}(2)$ & 6.40 & 1,684 & $0.26 \pm 3.15 \mathrm{E}-09$ & $5.92 \pm 0.02 E-05$ & $3.73 \pm 0.90 \mathrm{E}-07$ \\
\hline 104 & DOWN(3) & 6.75 & 1,904 & $1.98 \pm 3.30 \mathrm{E}-09$ & $7.49 \pm 0.02 \mathrm{E}-05$ & $3.26 \pm 0.86 \mathrm{E}-07$ \\
\hline 104 & DOWN(4) & 6.77 & 1,970 & $-2.18 \pm 4.44 \mathrm{E}-09$ & $7.60 \pm 0.02 E-05$ & $2.30 \pm 0.86 \mathrm{E}-07$ \\
\hline
\end{tabular}

Note: Bolding convention applied to these data. (See p. E-2C.)

Sample collection quarter is noted in parentheses next to hydraulic position. Hydraulic position is relative to other wells within the same hydrogeologic unit.

$$
E-9
$$




\section{Table E-2 (continued) 2003 Indicator Results From the Sand and Gravel Unit}

\begin{tabular}{|c|c|c|c|c|c|c|}
\hline $\begin{array}{l}\text { Location } \\
\text { Code }\end{array}$ & $\begin{array}{l}\text { Hydraulic } \\
\text { Position }\end{array}$ & $\begin{array}{c}\mathbf{p H} \\
\text { (standard units) }\end{array}$ & $\begin{array}{c}\text { Conductivity } \\
\left(\mu \mathrm{mhos} / \mathrm{cm} @ 25^{\circ} \mathrm{C}\right)\end{array}$ & $\begin{array}{l}\text { Gross Alpha } \\
\quad(\mu \mathrm{Ci} / \mathrm{mL})\end{array}$ & $\begin{array}{c}\text { Gross Beta } \\
(\mu \mathrm{Ci} / \mathrm{mL})\end{array}$ & $\begin{array}{c}\text { Tritium } \\
(\mu \mathrm{Ci} / \mathrm{mL})\end{array}$ \\
\hline 111 & DOWN(1) & 6.40 & 848 & $3.28 \pm 2.33 \mathrm{E}-09$ & $5.44 \pm 0.05 \mathrm{E}-06$ & $7.12 \pm 8.54 \mathrm{E}-08$ \\
\hline 111 & DOWN(2) & 6.45 & 657 & $1.70 \pm 1.92 \mathrm{E}-09$ & $4.20 \pm 0.04 \mathrm{E}-06$ & $3.22 \pm 0.91 \mathrm{E}-07$ \\
\hline 111 & DOWN(3) & 6.20 & 596 & $4.46 \pm 2.06 \mathrm{E}-09$ & $3.93 \pm 0.04 E-06$ & $2.60 \pm 0.89 \mathrm{E}-07$ \\
\hline 111 & DOWN(4) & 6.54 & 1,147 & $5.84 \pm 3.41 E-09$ & $9.67 \pm 0.07 E-06$ & $4.18 \pm 0.87 E-07$ \\
\hline 205 & $\operatorname{DOWN}(1)$ & 7.04 & 2,950 & $-4.58 \pm 5.38 \mathrm{E}-09$ & $1.34 \pm 0.56 \mathrm{E}-08$ & $-5.29 \pm 8.48 \mathrm{E}-08$ \\
\hline 205 & $\operatorname{DOWN}(2)$ & 6.91 & 2,235 & $0.05 \pm 3.74 \mathrm{E}-09$ & $1.51 \pm 0.42 \mathrm{E}-08$ & $4.78 \pm 6.23 \mathrm{E}-08$ \\
\hline 205 & DOWN(3) & 6.89 & 2,646 & $-2.99 \pm 6.03 E-09$ & $1.36 \pm 0.56 \mathrm{E}-08$ & $-8.24 \pm 8.76 \mathrm{E}-08$ \\
\hline 205 & DOWN(4) & 6.90 & 3,568 & $-3.60 \pm 5.03 \mathrm{E}-09$ & $1.24 \pm 0.79 E-08$ & $7.84 \pm 8.45 \mathrm{E}-08$ \\
\hline 406 & DOWN(1) & 7.02 & 955 & $0.00 \pm 1.80 \mathrm{E}-09$ & $5.85 \pm 3.57 \mathrm{E}-09$ & $1.11 \pm 0.85 \mathrm{E}-07$ \\
\hline 406 & DOWN(2) & 6.85 & 1,800 & $0.93 \pm 3.64 \mathrm{E}-09$ & $6.56 \pm 4.15 \mathrm{E}-09$ & $1.17 \pm 0.88 E-07$ \\
\hline 406 & DOWN(3) & 6.36 & 1,816 & $-0.23 \pm 3.89 \mathrm{E}-09$ & $7.32 \pm 3.80 \mathrm{E}-09$ & $-5.47 \pm 8.68 \mathrm{E}-08$ \\
\hline 406 & DOWN(4) & 6.54 & 1,378 & $-1.02 \pm 2.96 \mathrm{E}-09$ & $6.07 \pm 3.73 \mathrm{E}-09$ & $-1.54 \pm 8.64 \mathrm{E}-08$ \\
\hline 408 & $\operatorname{DOWN}(1)$ & 6.50 & 2,230 & $1.29 \pm 1.41 \mathrm{E}-08$ & $3.96 \pm 0.01 \mathrm{E}-04$ & $7.69 \pm 9.32 \mathrm{E}-08$ \\
\hline 408 & DOWN(2) & 6.77 & 2,095 & $1.33 \pm 4.51 \mathrm{E}-09$ & $3.22 \pm 0.01 \mathrm{E}-04$ & $1.94 \pm 1.04 E-07$ \\
\hline 408 & DOWN(3) & 6.71 & 2,445 & $0.00 \pm 2.79 \mathrm{E}-09$ & $5.11 \pm 0.01 E-04$ & $-1.12 \pm 0.90 \mathrm{E}-07$ \\
\hline 408 & DOWN(4) & 6.71 & 1,936 & $1.41 \pm 3.37 \mathrm{E}-09$ & $3.16 \pm 0.01 E-04$ & $1.74 \pm 0.99 \mathrm{E}-07$ \\
\hline 501 & $\operatorname{DOWN}(1)$ & 6.84 & 1,919 & $0.91 \pm 3.32 \mathrm{E}-09$ & $2.16 \pm 0.01 \mathrm{E}-04$ & $9.31 \pm 8.58 \mathrm{E}-08$ \\
\hline 501 & DOWN(2) & 6.79 & 1,749 & $6.10 \pm 4.29 \mathrm{E}-09$ & $1.94 \pm 0.01 \mathrm{E}-04$ & $2.38 \pm 8.81 \mathrm{E}-08$ \\
\hline 501 & DOWN(3) & 6.85 & 2,135 & $4.55 \pm 3.71 \mathrm{E}-09$ & $2.26 \pm 0.01 E-04$ & $1.46 \pm 0.89 \mathrm{E}-07$ \\
\hline 501 & DOWN(4) & 6.76 & 1,760 & $-3.46 \pm 4.21 \mathrm{E}-09$ & $1.66 \pm 0.01 E-04$ & $1.23 \pm 0.85 \mathrm{E}-07$ \\
\hline 502 & $\operatorname{DOWN}(1)$ & 6.70 & 2,010 & $0.23 \pm 3.33 \mathrm{E}-09$ & $1.86 \pm 0.01 \mathrm{E}-04$ & $6.37 \pm 8.56 \mathrm{E}-08$ \\
\hline 502 & $\operatorname{DOWN}(2)$ & 6.68 & 1,812 & $-1.16 \pm 3.20 \mathrm{E}-09$ & $1.74 \pm 0.01 \mathrm{E}-04$ & $1.51 \pm 0.87 \mathrm{E}-07$ \\
\hline 502 & $\operatorname{DOWN}(3)$ & 6.82 & 2,050 & $1.32 \pm 3.17 \mathrm{E}-09$ & $1.89 \pm 0.01 E-04$ & $3.62 \pm 8.52 \mathrm{E}-08$ \\
\hline 502 & DOWN(4) & 6.85 & 1,928 & $-1.59 \pm 4.76 \mathrm{E}-09$ & 1.71 $\pm 0.01 E-04$ & $1.76 \pm 0.84 E-07$ \\
\hline $602 \mathrm{~A}$ & $\operatorname{DOWN}(1)$ & 7.02 & 564 & $0.23 \pm 1.25 \mathrm{E}-09$ & $1.35 \pm 0.29 \mathrm{E}-08$ & $1.40 \pm 0.94 \mathrm{E}-07$ \\
\hline $602 \mathrm{~A}$ & DOWN(2) & 6.99 & 726 & $-0.25 \pm 1.24 \mathrm{E}-09$ & $1.44 \pm 0.38 \mathrm{E}-08$ & 1.14 $\pm 0.89 E-07$ \\
\hline $602 \mathrm{~A}$ & $\operatorname{DOWN}(3)$ & 6.96 & 728 & $0.95 \pm 1.34 \mathrm{E}-09$ & $1.08 \pm 0.28 E-08$ & $3.25 \pm 0.89 \mathrm{E}-07$ \\
\hline $602 \mathrm{~A}$ & DOWN(4) & 6.90 & 580 & $0.22 \pm 1.73 \mathrm{E}-09$ & $1.20 \pm 0.29 \mathrm{E}-08$ & $3.48 \pm 0.88 E-07$ \\
\hline 604 & $\operatorname{DOWN}(1)$ & 6.43 & 1,125 & $-1.03 \pm 1.68 \mathrm{E}-09$ & $5.43 \pm 2.00 \mathrm{E}-09$ & $-9.86 \pm 8.25 \mathrm{E}-08$ \\
\hline 604 & DOWN(2) & 6.97 & 1,074 & $1.65 \pm 1.99 \mathrm{E}-09$ & $6.50 \pm 2.64 \mathrm{E}-09$ & $5.21 \pm 5.90 \mathrm{E}-08$ \\
\hline 604 & $\operatorname{DOWN}(3)$ & 6.24 & 1,018 & $2.68 \pm 2.46 \mathrm{E}-09$ & $6.06 \pm 2.65 \mathrm{E}-09$ & $-9.28 \pm 8.66 \mathrm{E}-08$ \\
\hline 604 & DOWN(4) & 5.99 & 974 & $0.30 \pm 2.31 \mathrm{E}-09$ & $7.48 \pm 2.68 \mathrm{E}-09$ & $1.35 \pm 0.81 E-07$ \\
\hline 8605 & DOWN(1) & 6.70 & 1,356 & $6.42 \pm 3.38 E-09$ & $1.19 \pm 0.01 E-05$ & $6.18 \pm 0.92 E-07$ \\
\hline 8605 & DOWN(2) & 6.74 & 1,220 & $7.33 \pm 3.46 \mathrm{E}-09$ & $1.09 \pm 0.01 \mathrm{E}-05$ & $5.18 \pm 0.92 \mathrm{E}-07$ \\
\hline 8605 & $\operatorname{DOWN}(3)$ & 6.59 & 1,717 & $1.61 \pm 0.49 E-08$ & $9.75 \pm 0.07 \mathrm{E}-06$ & $4.90 \pm 0.88 \mathrm{E}-07$ \\
\hline 8605 & DOWN(4) & 6.51 & 2,280 & $1.47 \pm 0.35 \mathrm{E}-08$ & $8.87 \pm 0.04 E-06$ & $2.10 \pm 0.89 E-07$ \\
\hline
\end{tabular}

Note: Bolding convention applied to these data. (See p. E-2C.)

Sample collection quarter is noted in parentheses next to hydraulic position. Hydraulic position is relative to other wells within the same hydrogeologic unit. 


\section{Table E-2 (continued)}

\section{Indicator Results From the Sand and Gravel Unit}

\begin{tabular}{|c|c|c|c|c|c|c|}
\hline $\begin{array}{l}\text { Location } \\
\text { Code }\end{array}$ & $\begin{array}{c}\text { Hydraulic } \\
\text { Position }\end{array}$ & $\begin{array}{c}\mathbf{p H} \\
\text { (standard units) }\end{array}$ & $\begin{array}{c}\text { Conductivity } \\
\left(\mu \mathrm{mhos} / \mathrm{cm} @ 25^{\circ} \mathrm{C}\right)\end{array}$ & $\begin{array}{l}\text { Gross Alpha } \\
\qquad(\mu \mathrm{Ci} / \mathrm{mL})\end{array}$ & $\begin{array}{c}\text { Gross Beta } \\
(\mu \mathrm{Ci} / \mathrm{mL})\end{array}$ & $\begin{array}{c}\text { Tritium } \\
(\mu \mathrm{Ci} / \mathrm{mL})\end{array}$ \\
\hline 8607 & $\operatorname{DOWN}(1)$ & 6.25 & 1,091 & $-0.82 \pm 1.78 \mathrm{E}-09$ & $4.20 \pm 0.41 \mathrm{E}-08$ & $4.95 \pm 8.30 \mathrm{E}-08$ \\
\hline 8607 & $\operatorname{DOWN}(2)$ & 6.39 & 1,371 & $0.78 \pm 2.15 \mathrm{E}-09$ & $3.56 \pm 0.40 \mathrm{E}-08$ & $-9.92 \pm 9.28 \mathrm{E}-08$ \\
\hline 8607 & DOWN(3) & 6.23 & 1,214 & $-1.29 \pm 2.57 \mathrm{E}-09$ & $3.14 \pm 0.39 \mathrm{E}-08$ & $-0.49 \pm 8.94 \mathrm{E}-08$ \\
\hline 8607 & DOWN(4) & 6.24 & 908 & $1.21 \pm 1.87 \mathrm{E}-09$ & $3.06 \pm 0.38 E-08$ & $1.36 \pm 0.85 E-07$ \\
\hline 8609 & $\operatorname{DOWN}(1)$ & 6.99 & 1,897 & $1.30 \pm 2.49 \mathrm{E}-09$ & $1.62 \pm 0.02 E-06$ & $4.54 \pm 0.62 \mathrm{E}-07$ \\
\hline 8609 & DOWN(2) & 6.79 & 1,762 & $-0.16 \pm 2.56 \mathrm{E}-09$ & $1.26 \pm 0.02 \mathrm{E}-06$ & $5.23 \pm 0.92 \mathrm{E}-07$ \\
\hline 8609 & $\operatorname{DOWN}(3)$ & 6.95 & 1,896 & $1.27 \pm 3.06 \mathrm{E}-09$ & $1.60 \pm 0.03 \mathrm{E}-06$ & $3.64 \pm 0.91 E-07$ \\
\hline 8609 & DOWN(4) & 6.95 & 2,065 & $-3.39 \pm 3.13 \mathrm{E}-09$ & $1.50 \pm 0.02 \mathrm{E}-06$ & $4.48 \pm 0.88 \mathrm{E}-07$ \\
\hline 105 & $\operatorname{DOWN}(1)$ & 7.03 & 1,953 & $0.60 \pm 4.34 \mathrm{E}-09$ & $3.88 \pm 0.01 E-05$ & $1.90 \pm 0.88 \mathrm{E}-07$ \\
\hline 105 & $\operatorname{DOWN}(2)$ & 7.11 & $\mathbf{1 , 8 3 7}$ & $-0.32 \pm 3.73 E-09$ & $3.95 \pm 0.01 \mathrm{E}-05$ & $3.52 \pm 0.78 \mathrm{E}-07$ \\
\hline 105 & $\operatorname{DOWN}(3)$ & 6.92 & 1,950 & $3.26 \pm 3.23 E-09$ & $4.39 \pm 0.01 \mathrm{E}-05$ & $4.73 \pm 0.88 E-07$ \\
\hline 105 & DOWN(4) & 6.93 & 2,015 & $-2.28 \pm 3.05 \mathrm{E}-09$ & $4.68 \pm 0.01 E-05$ & $9.67 \pm 8.74 E-08$ \\
\hline 106 & $\operatorname{DOWN}(1)$ & 6.91 & 1,704 & $5.13 \pm 3.92 \mathrm{E}-09$ & $2.64 \pm 0.48 \mathrm{E}-08$ & $7.70 \pm 0.67 \mathrm{E}-07$ \\
\hline 106 & DOWN(2) & 6.94 & 1,809 & $-1.08 \pm 2.18 \mathrm{E}-09$ & $1.62 \pm 0.30 \mathrm{E}-08$ & $8.04 \pm 0.96 \mathrm{E}-07$ \\
\hline 106 & $\operatorname{DOWN}(3)$ & 6.68 & 1,564 & $2.89 \pm 3.58 \mathrm{E}-09$ & $2.18 \pm 0.49 \mathrm{E}-08$ & $5.40 \pm 0.66 \mathrm{E}-07$ \\
\hline 106 & DOWN(4) & 6.52 & 1,422 & $0.59 \pm 2.34 \mathrm{E}-09$ & $1.97 \pm 0.33 \mathrm{E}-08$ & $8.90 \pm 0.94 E-07$ \\
\hline 116 & DOWN(1) & 7.19 & 1,400 & $1.13 \pm 2.06 \mathrm{E}-09$ & $8.19 \pm 0.16 \mathrm{E}-07$ & $2.92 \pm 0.86 \mathrm{E}-07$ \\
\hline 116 & $\operatorname{DOWN}(2)$ & 7.84 & 879 & $-0.24 \pm 2.44 \mathrm{E}-09$ & $9.18 \pm 0.23 \mathrm{E}-07$ & $2.33 \pm 0.90 \mathrm{E}-07$ \\
\hline 116 & $\operatorname{DOWN}(3)$ & 7.15 & 1,052 & $2.64 \pm 2.60 \mathrm{E}-09$ & $5.88 \pm 0.19 E-07$ & $1.20 \pm 0.88 \mathrm{E}-07$ \\
\hline 116 & DOWN(4) & 7.11 & 1,428 & $7.03 \pm 4.62 \mathrm{E}-09$ & $1.02 \pm 0.02 \mathrm{E}-06$ & $1.12 \pm 0.88 E-07$ \\
\hline 605 & $\operatorname{DOWN}(1)$ & 7.38 & 796 & $0.00 \pm 1.57 \mathrm{E}-09$ & $4.15 \pm 0.35 \mathrm{E}-08$ & $-1.11 \pm 5.98 \mathrm{E}-08$ \\
\hline 605 & DOWN(2) & 6.97 & 1,109 & $-0.70 \pm 1.32 \mathrm{E}-09$ & $6.09 \pm 0.42 \mathrm{E}-08$ & $-0.46 \pm 8.78 \mathrm{E}-08$ \\
\hline 605 & DOWN(3) & 6.66 & 726 & $-0.45 \pm 1.34 \mathrm{E}-09$ & $3.05 \pm 0.30 \mathrm{E}-08$ & $-0.50 \pm 8.65 \mathrm{E}-08$ \\
\hline 605 & DOWN(4) & 6.71 & 616 & $0.65 \pm 1.32 \mathrm{E}-09$ & $4.50 \pm 0.36 \mathrm{E}-08$ & $6.41 \pm 8.46 \mathrm{E}-08$ \\
\hline 801 & $\operatorname{DowN}(1)$ & 6.51 & 1,146 & $0.64 \pm 2.34 \mathrm{E}-09$ & $5.94 \pm 0.05 \mathrm{E}-06$ & $-2.26 \pm 8.19 \mathrm{E}-08$ \\
\hline 801 & $\operatorname{DOWN}(2)$ & 6.94 & 1,498 & $-0.36 \pm 1.98 \mathrm{E}-09$ & $6.52 \pm 0.04 \mathrm{E}-06$ & $1.66 \pm 0.88 \mathrm{E}-07$ \\
\hline 801 & DOWN(3) & 6.53 & 1,345 & $1.20 \pm 2.00 \mathrm{E}-09$ & $4.55 \pm 0.04 \mathrm{E}-06$ & $2.42 \pm 0.89 \mathrm{E}-07$ \\
\hline 801 & DOWN(4) & 6.58 & 1,315 & $-2.22 \pm 3.51 \mathrm{E}-09$ & $4.31 \pm 0.04 \mathrm{E}-06$ & $1.41 \pm 0.81 \mathrm{E}-07$ \\
\hline 802 & $\operatorname{DOWN}(1)$ & 6.53 & 587 & $0.41 \pm 1.41 \mathrm{E}-09$ & $1.52 \pm 0.22 \mathrm{E}-08$ & $4.16 \pm 8.24 \mathrm{E}-08$ \\
\hline 802 & DOWN(2) & 7.01 & 296 & $0.00 \pm 6.28 \mathrm{E}-10$ & $6.68 \pm 1.63 \mathrm{E}-09$ & $1.68 \pm 8.63 \mathrm{E}-08$ \\
\hline 802 & DOWN(3) & 6.96 & 328 & $0.21 \pm 1.22 \mathrm{E}-09$ & $1.18 \pm 0.20 \mathrm{E}-08$ & $-8.45 \pm 8.49 \mathrm{E}-08$ \\
\hline 802 & DOWN(4) & 6.64 & 1,200 & $0.48 \pm 2.20 \mathrm{E}-09$ & $5.43 \pm 0.41 E-08$ & $2.45 \pm 0.61 E-07$ \\
\hline 803 & $\operatorname{DOWN}(1)$ & 6.97 & 1,389 & $-0.97 \pm 2.84 \mathrm{E}-09$ & $1.51 \pm 0.42 \mathrm{E}-08$ & $2.10 \pm 0.85 \mathrm{E}-07$ \\
\hline 803 & $\operatorname{DOWN}(2)$ & 7.03 & 1,370 & $-0.93 \pm 3.40 \mathrm{E}-09$ & $1.25 \pm 0.45 E-08$ & $1.83 \pm 0.87 \mathrm{E}-07$ \\
\hline 803 & DOWN(3) & 6.88 & 1,280 & $2.09 \pm 3.15 \mathrm{E}-09$ & $1.33 \pm 0.45 \mathrm{E}-08$ & $3.59 \pm 6.39 \mathrm{E}-08$ \\
\hline 803 & DOWN(4) & 7.00 & 1,254 & $0.90 \pm 3.52 \mathrm{E}-09$ & $1.81 \pm 0.45 E-08$ & $2.53 \pm 0.86 E-07$ \\
\hline
\end{tabular}

Note: Bolding convention applied to these data. (See p. E-2C.)

Sample collection quarter is noted in parentheses next to hydraulic position. Hydraulic position is relative to other wells within the same hydrogeologic unit. 
Table E-2 (concluded)

2003 Indicator Results From the Sand and Gravel Unit

\begin{tabular}{|c|c|c|c|c|c|c|}
\hline $\begin{array}{l}\text { Location } \\
\text { Code }\end{array}$ & $\begin{array}{l}\text { Hydraulic } \\
\text { Position }\end{array}$ & $\begin{array}{c}\mathbf{p H} \\
\text { (standard units) }\end{array}$ & $\begin{array}{c}\text { Conductivity } \\
\left(\mu \mathrm{mhos} / \mathrm{cm} @ 25^{\circ} \mathrm{C}\right)\end{array}$ & $\begin{array}{l}\text { Gross Alpha } \\
\qquad(\mu \mathrm{Ci} / \mathrm{mL})\end{array}$ & $\begin{array}{l}\text { Gross Beta } \\
(\mu \mathrm{Ci} / \mathrm{mL})\end{array}$ & $\begin{array}{l}\text { Tritium } \\
(\mu \mathrm{Ci} / \mathrm{mL})\end{array}$ \\
\hline 804 & DOWN(1) & 6.59 & 1,016 & $-1.56 \pm 1.95 \mathrm{E}-09$ & $2.90 \pm 0.11 \mathrm{E}-07$ & $1.46 \pm 0.60 \mathrm{E}-07$ \\
\hline 804 & DOWN(2) & 7.03 & $\mathbf{1 , 5 9 7}$ & $2.32 \pm 3.48 \mathrm{E}-09$ & $3.47 \pm 0.13 E-07$ & $6.55 \pm 6.23 \mathrm{E}-08$ \\
\hline 804 & DOWN(3) & 6.67 & 1,376 & $1.38 \pm 3.48 \mathrm{E}-09$ & $2.22 \pm 0.10 \mathrm{E}-07$ & $-0.91 \pm 8.64 \mathrm{E}-08$ \\
\hline 804 & DOWN(4) & 6.76 & 921 & $1.26 \pm 2.55 \mathrm{E}-09$ & $1.93 \pm 0.10 \mathrm{E}-07$ & $1.89 \pm 0.86 \mathrm{E}-07$ \\
\hline 8603 & DOWN(1) & 6.75 & 1,984 & $0.30 \pm 4.27 \mathrm{E}-09$ & $6.64 \pm 0.02 \mathrm{E}-05$ & 3.54 $\pm 0.87 E-07$ \\
\hline 8603 & DOWN(2) & 7.09 & 1,878 & $-0.85 \pm 3.19 \mathrm{E}-09$ & $6.10 \pm 0.02 E-05$ & $3.13 \pm 0.89 \mathrm{E}-07$ \\
\hline 8603 & DOWN(3) & 7.02 & 1,950 & $2.47 \pm 3.20 \mathrm{E}-09$ & $6.94 \pm 0.02 E-05$ & $3.50 \pm 0.86 \mathrm{E}-07$ \\
\hline 8603 & DOWN(4) & 7.12 & 1,995 & $-0.72 \pm 4.36 \mathrm{E}-09$ & $6.82 \pm 0.02 \mathrm{E}-05$ & $1.36 \pm 0.62 E-07$ \\
\hline 8604 & DOWN(1) & 7.23 & 1,959 & $0.00 \pm 3.35 \mathrm{E}-09$ & $3.72 \pm 0.01 E-05$ & $2.77 \pm 0.65 E-07$ \\
\hline 8604 & DOWN(2) & 6.80 & 1,654 & $-2.01 \pm 3.03 E-09$ & $4.21 \pm 0.01 \mathrm{E}-05$ & 4.07 $\pm 0.91 E-07$ \\
\hline 8604 & DOWN(3) & 7.20 & 1,950 & $2.88 \pm 2.09 \mathrm{E}-09$ & $5.06 \pm 0.01 \mathrm{E}-05$ & $3.78 \pm 0.92 \mathrm{E}-07$ \\
\hline 8604 & DOWN(4) & 7.14 & 1,961 & $-1.39 \pm 4.16 \mathrm{E}-09$ & $4.16 \pm 0.01 \mathrm{E}-05$ & $2.99 \pm 0.86 \mathrm{E}-07$ \\
\hline 8612 & DOWN(1) & 7.06 & 1,382 & $0.00 \pm 3.60 \mathrm{E}-09$ & $2.23 \pm 3.58 \mathrm{E}-09$ & $4.24 \pm 0.62 \mathrm{E}-07$ \\
\hline 8612 & DOWN(2) & 7.18 & 1,408 & $-0.11 \pm 3.25 E-09$ & $-1.69 \pm 3.58 \mathrm{E}-09$ & $5.08 \pm 0.93 E-07$ \\
\hline 8612 & DOWN(3) & 7.15 & 1,361 & 4.57 $\pm 4.00 \mathrm{E}-09$ & $-1.17 \pm 3.63 \mathrm{E}-09$ & $4.18 \pm 0.87 \mathrm{E}-07$ \\
\hline 8612 & DOWN(4) & 7.03 & 1,286 & $1.08 \pm 3.40 \mathrm{E}-09$ & $4.85 \pm 3.86 \mathrm{E}-09$ & $3.71 \pm 0.88 E-07$ \\
\hline
\end{tabular}

Note: Bolding convention applied to these data. (See p. E-2C.)

Sample collection quarter is noted in parentheses next to hydraulic position. Hydraulic position is relative to other wells within the same hydrogeologic unit.

$E-12$ 
Table E-3

\section{Indicator Results From the Lavery Till-Sand Unit}

\begin{tabular}{|c|c|c|c|c|c|c|}
\hline $\begin{array}{l}\text { Location } \\
\text { Code }\end{array}$ & $\begin{array}{c}\text { Hydraulic } \\
\text { Position }\end{array}$ & $\begin{array}{c}\mathbf{p H} \\
\text { (standard units) }\end{array}$ & $\begin{array}{c}\text { Conductivity } \\
\left(\mu \mathrm{mhos} / \mathrm{cm} @ 25^{\circ} \mathrm{C}\right)\end{array}$ & $\begin{array}{l}\text { Gross Alpha } \\
\qquad(\mu \mathrm{Ci} / \mathrm{mL})\end{array}$ & $\begin{array}{c}\text { Gross Beta } \\
(\mu \mathrm{Ci} / \mathrm{mL})\end{array}$ & $\begin{array}{r}\text { Tritium } \\
(\mu \mathrm{Ci} / \mathrm{mL})\end{array}$ \\
\hline 302 & $\mathrm{UP}(1)$ & 6.94 & 2,665 & $-4.69 \pm 4.13 E-09$ & $-0.37 \pm 4.82 \mathrm{E}-09$ & $-2.38 \pm 8.46 \mathrm{E}-08$ \\
\hline 302 & $\mathrm{UP}(2)$ & 6.88 & 2,880 & $-0.52 \pm 7.77 \mathrm{E}-09$ & $0.48 \pm 7.62 \mathrm{E}-09$ & $2.98 \pm 8.52 \mathrm{E}-08$ \\
\hline 302 & $\mathrm{UP}(3)$ & 6.93 & 3,247 & $2.26 \pm 9.76 \mathrm{E}-09$ & $1.27 \pm 0.80 \mathrm{E}-08$ & $-3.06 \pm 8.50 \mathrm{E}-08$ \\
\hline 302 & $\mathrm{UP}(4)$ & 6.39 & 3,188 & $3.50 \pm 7.04 \mathrm{E}-09$ & $3.07 \pm 7.46 \mathrm{E}-09$ & $4.33 \pm 8.42 \mathrm{E}-08$ \\
\hline 402 & $\mathrm{UP}(1)$ & 7.11 & 2,070 & $-0.41 \pm 5.13 \mathrm{E}-09$ & $5.64 \pm 4.73 \mathrm{E}-09$ & $1.26 \pm 8.59 \mathrm{E}-08$ \\
\hline 402 & $\mathrm{UP}(2)$ & 6.93 & 2,445 & $7.45 \pm 7.16 \mathrm{E}-09$ & $2.15 \pm 5.36 \mathrm{E}-09$ & $8.42 \pm 8.75 \mathrm{E}-08$ \\
\hline 402 & $\mathrm{UP}(3)$ & 7.12 & 2,274 & $0.71 \pm 3.88 \mathrm{E}-09$ & $-2.08 \pm 5.11 \mathrm{E}-09$ & $-8.66 \pm 8.78 \mathrm{E}-08$ \\
\hline 402 & $\mathrm{UP}(4)$ & 6.70 & 2,352 & $4.30 \pm 3.97 \mathrm{E}-09$ & $-0.58 \pm 4.90 \mathrm{E}-09$ & $2.00 \pm 7.92 \mathrm{E}-08$ \\
\hline 204 & $\operatorname{DOWN}(1)$ & 7.46 & 1,242 & $-1.92 \pm 1.80 \mathrm{E}-09$ & $-0.11 \pm 2.40 \mathrm{E}-09$ & $-9.89 \pm 8.44 \mathrm{E}-08$ \\
\hline 204 & $\operatorname{DOWN}(2)$ & 7.50 & 1,200 & $4.29 \pm 3.60 \mathrm{E}-09$ & $6.36 \pm 4.02 E-09$ & $8.44 \pm 8.69 \mathrm{E}-08$ \\
\hline 204 & $\operatorname{DOWN}(3)$ & 7.45 & 1,123 & $2.01 \pm 2.73 \mathrm{E}-09$ & $2.75 \pm 3.79 \mathrm{E}-09$ & $1.43 \pm 6.26 \mathrm{E}-08$ \\
\hline 204 & DOWN(4) & 7.31 & 1,094 & $-0.23 \pm 2.47 \mathrm{E}-09$ & $-0.23 \pm 3.51 E-09$ & $1.08 \pm 8.37 \mathrm{E}-08$ \\
\hline 206 & $\operatorname{DOWN}(1)$ & 7.58 & 1,190 & $-2.50 \pm 2.24 \mathrm{E}-09$ & $4.96 \pm 3.46 \mathrm{E}-09$ & $8.29 \pm 8.61 \mathrm{E}-08$ \\
\hline 206 & $\operatorname{DOWN}(2)$ & 7.43 & 1,208 & $-0.20 \pm 2.04 \mathrm{E}-09$ & $2.75 \pm 3.16 \mathrm{E}-09$ & $-1.39 \pm 8.67 \mathrm{E}-08$ \\
\hline 206 & $\operatorname{DOWN}(3)$ & 7.46 & 1,167 & $0.55 \pm 4.27 \mathrm{E}-09$ & $1.57 \pm 3.67 \mathrm{E}-09$ & $-4.71 \pm 8.79 \mathrm{E}-08$ \\
\hline 206 & DOWN(4) & 7.33 & 1,128 & $-1.51 \pm 3.07 \mathrm{E}-09$ & $3.86 \pm 3.89 \mathrm{E}-09$ & $0.23 \pm 8.31 \mathrm{E}-08$ \\
\hline 208 & $\operatorname{DOWN}(1)$ & 8.02 & 291 & $0.58 \pm 7.84 \mathrm{E}-10$ & $0.88 \pm 1.16 \mathrm{E}-09$ & $-0.59 \pm 8.43 \mathrm{E}-08$ \\
\hline 208 & $\operatorname{DOWN}(2)$ & 8.23 & 286 & $7.10 \pm 6.85 \mathrm{E}-10$ & $1.16 \pm 1.10 \mathrm{E}-09$ & $-6.82 \pm 8.58 \mathrm{E}-08$ \\
\hline 208 & $\operatorname{DOWN}(3)$ & 7.75 & 269 & $1.14 \pm 0.86 \mathrm{E}-09$ & $0.30 \pm 1.20 \mathrm{E}-09$ & $-1.04 \pm 0.86 \mathrm{E}-07$ \\
\hline 208 & DOWN(4) & 7.76 & 259 & $8.60 \pm 8.50 \mathrm{E}-10$ & $1.92 \pm 1.16 \mathrm{E}-09$ & $-1.07 \pm 0.82 \mathrm{E}-07$ \\
\hline
\end{tabular}

Note: Bolding convention applied to these data. (See p. E-2C.)

Sample collection quarter is noted in parentheses next to hydraulic position. Hydraulic position is relative to other wells within the same hydrogeologic unit. 


\section{Table E-4}

\section{Indicator Results From the Weathered Lavery Till Unit}

\begin{tabular}{|c|c|c|c|c|c|c|}
\hline $\begin{array}{l}\text { Location } \\
\text { Code }\end{array}$ & $\begin{array}{c}\text { Hydraulic } \\
\text { Position }\end{array}$ & $\begin{array}{c}\mathbf{p H} \\
\text { (standard units) }\end{array}$ & $\begin{array}{c}\text { Conductivity } \\
\left(\mu \mathrm{mhos} / \mathrm{cm} @ 25^{\circ} \mathrm{C}\right)\end{array}$ & $\begin{array}{l}\text { Gross Alpha } \\
\quad(\mu \mathrm{Ci} / \mathrm{mL})\end{array}$ & $\begin{array}{l}\text { Gross Beta } \\
(\mu \mathrm{Ci} / \mathrm{mL})\end{array}$ & $\begin{array}{l}\text { Tritium } \\
(\mu \mathrm{Ci} / \mathrm{mL})\end{array}$ \\
\hline 908 & $\mathrm{UP}(1)$ & 6.90 & 2,660 & $8.79 \pm 6.44 \mathrm{E}-09$ & $2.02 \pm 0.78 \mathrm{E}-08$ & $-0.29 \pm 8.16 \mathrm{E}-08$ \\
\hline 908 & $\mathrm{UP}(3)$ & 6.82 & 2,938 & $8.11 \pm 6.52 \mathrm{E}-09$ & $1.31 \pm 0.72 \mathrm{E}-08$ & $-1.60 \pm 0.85 \mathrm{E}-07$ \\
\hline 1005 & $\mathrm{UP}(1)$ & 7.18 & 940 & $1.35 \pm 2.48 \mathrm{E}-09$ & $4.90 \pm 2.58 \mathrm{E}-09$ & $-0.34 \pm 5.80 \mathrm{E}-08$ \\
\hline 1005 & $\mathrm{UP}(3)$ & 6.97 & 819 & $1.08 \pm 2.45 \mathrm{E}-09$ & $1.49 \pm 2.33 \mathrm{E}-09$ & $6.55 \pm 8.64 \mathrm{E}-08$ \\
\hline $1008 \mathrm{C}$ & $\mathrm{UP}(1)$ & 7.49 & 632 & $-1.45 \pm 1.36 \mathrm{E}-09$ & $0.47 \pm 1.88 \mathrm{E}-09$ & $6.78 \pm 8.29 \mathrm{E}-08$ \\
\hline $1008 \mathrm{C}$ & $\mathrm{UP}(3)$ & 7.30 & 600 & $0.57 \pm 1.52 \mathrm{E}-09$ & $-0.16 \pm 1.64 \mathrm{E}-09$ & $6.38 \pm 5.84 \mathrm{E}-08$ \\
\hline 906 & $\operatorname{DOWN}(1)$ & 7.55 & 536 & $1.12 \pm 1.50 \mathrm{E}-09$ & $4.46 \pm 1.95 \mathrm{E}-09$ & $-6.48 \pm 8.29 \mathrm{E}-08$ \\
\hline 906 & DOWN(3) & 7.22 & 564 & $0.99 \pm 1.54 \mathrm{E}-09$ & $3.51 \pm 1.88 \mathrm{E}-09$ & $-1.15 \pm 0.86 \mathrm{E}-07$ \\
\hline 1006 & $\operatorname{DOWN}(1)$ & 6.95 & 1,995 & $2.95 \pm 4.78 \mathrm{E}-09$ & 7.91 $\pm 6.94 \mathrm{E}-09$ & $-2.30 \pm 8.22 \mathrm{E}-08$ \\
\hline 1006 & $\operatorname{DOWN}(3)$ & 6.73 & 1,812 & $0.00 \pm 4.25 \mathrm{E}-09$ & $-1.38 \pm 6.80 \mathrm{E}-09$ & $-2.70 \pm 8.19 \mathrm{E}-08$ \\
\hline 1007 & $\operatorname{DOWN}(1)$ & 6.96 & 1,407 & $2.23 \pm 3.86 \mathrm{E}-09$ & $8.65 \pm 3.76 \mathrm{E}-09$ & $4.09 \pm 8.32 \mathrm{E}-08$ \\
\hline 1007 & DOWN(3) & 6.79 & 1,340 & $3.85 \pm 2.90 \mathrm{E}-09$ & $2.82 \pm 3.75 \mathrm{E}-09$ & $-2.78 \pm 8.72 \mathrm{E}-08$ \\
\hline NDATR & $\operatorname{DOWN}(1)$ & 7.69 & 791 & $0.42 \pm 1.94 \mathrm{E}-09$ & $1.29 \pm 0.06 \mathrm{E}-07$ & $2.05 \pm 0.12 E-06$ \\
\hline NDATR & DOWN(2) & 7.98 & 1,213 & $2.30 \pm 2.76 \mathrm{E}-09$ & $1.30 \pm 0.07 \mathrm{E}-07$ & $6.36 \pm 0.24 \mathrm{E}-06$ \\
\hline NDATR & DOWN(3) & 7.34 & 995 & $5.78 \pm 2.47 \mathrm{E}-09$ & $1.19 \pm 0.06 E-07$ & $6.30 \pm 0.24 \mathrm{E}-06$ \\
\hline NDATR & DOWN(4) & 7.21 & 913 & $1.40 \pm 1.54 \mathrm{E}-09$ & $1.49 \pm 0.05 E-07$ & $3.44 \pm 0.16 \mathrm{E}-06$ \\
\hline 909 & DOWN(1) & 6.74 & 1,513 & $-0.87 \pm 3.74 \mathrm{E}-09$ & $3.92 \pm 0.16 \mathrm{E}-07$ & $6.76 \pm 0.92 \mathrm{E}-07$ \\
\hline 909 & DOWN(3) & 6.21 & 1,341 & $3.34 \pm 5.48 \mathrm{E}-09$ & $3.54 \pm 0.15 \mathrm{E}-07$ & $7.92 \pm 0.95 \mathrm{E}-07$ \\
\hline
\end{tabular}

Note: Bolding convention applied to these data. (See p. E-2C.)

Sample collection quarter is noted in parentheses next to hydraulic position. Hydraulic position is relative to other wells within the same hydrogeologic unit.

$E-14$ 


\section{Table E-5 \\ 2003 Indicator Results From the Unweathered Lavery Till Unit}

\begin{tabular}{|c|c|c|c|c|c|c|}
\hline $\begin{array}{l}\text { Location } \\
\text { Code }\end{array}$ & $\begin{array}{c}\text { Hydraulic } \\
\text { Position }\end{array}$ & $\begin{array}{c}\mathbf{p H} \\
\text { (standard units) }\end{array}$ & $\begin{array}{c}\text { Conductivity } \\
\left(\mu \mathrm{mhos} / \mathrm{cm} @ 25^{\circ} \mathrm{C}\right)\end{array}$ & $\begin{array}{l}\text { Gross Alpha } \\
\qquad(\mu \mathrm{Ci} / \mathrm{mL})\end{array}$ & $\begin{array}{c}\text { Gross Beta } \\
(\mu \mathrm{Ci} / \mathrm{mL})\end{array}$ & $\begin{array}{l}\text { Tritium } \\
(\mu \mathrm{Ci} / \mathrm{mL})\end{array}$ \\
\hline 405 & $\mathrm{UP}(1)$ & 7.64 & 1,346 & $-1.04 \pm 2.48 \mathrm{E}-09$ & $2.00 \pm 0.43 E-08$ & $-4.00 \pm 8.43 \mathrm{E}-08$ \\
\hline 405 & $\mathrm{UP}(2)$ & 7.31 & 1,184 & $2.20 \pm 2.27 \mathrm{E}-09$ & $4.18 \pm 3.56 \mathrm{E}-09$ & $5.97 \pm 8.82 \mathrm{E}-08$ \\
\hline 405 & $\mathrm{UP}(3)$ & 7.58 & 1,187 & $4.23 \pm 6.38 \mathrm{E}-09$ & $4.13 \pm 7.52 \mathrm{E}-09$ & $-2.08 \pm 8.57 \mathrm{E}-08$ \\
\hline 405 & $\mathrm{UP}(4)$ & 7.03 & 1,865 & $2.62 \pm 2.83 \mathrm{E}-09$ & $7.63 \pm 2.83 \mathrm{E}-09$ & $3.34 \pm 8.32 \mathrm{E}-08$ \\
\hline 1303 & $\mathrm{UP}(4)$ & 7.21 & 470 & $3.56 \pm 1.49 \mathrm{E}-09$ & $5.30 \pm 1.39 \mathrm{E}-09$ & $3.34 \pm 8.08 \mathrm{E}-08$ \\
\hline 110 & DOWN(1) & 7.44 & 584 & $2.25 \pm 1.65 \mathrm{E}-09$ & $3.17 \pm 1.86 \mathrm{E}-09$ & $1.42 \pm 0.10 \mathrm{E}-06$ \\
\hline 110 & $\operatorname{DOWN}(2)$ & 7.45 & 600 & $1.47 \pm 1.33 \mathrm{E}-09$ & $3.15 \pm 1.82 \mathrm{E}-09$ & $1.35 \pm 0.11 \mathrm{E}-06$ \\
\hline 110 & $\operatorname{DOWN}(3)$ & 7.39 & 496 & $3.20 \pm 1.75 \mathrm{E}-09$ & $1.68 \pm 1.93 \mathrm{E}-09$ & $1.28 \pm 0.11 E-06$ \\
\hline 110 & DOWN(4) & 6.12 & 523 & $0.10 \pm 1.56 \mathrm{E}-09$ & $3.40 \pm 1.99 \mathrm{E}-09$ & $1.39 \pm 0.07 \mathrm{E}-06$ \\
\hline 704 & $\operatorname{DOWN}(1)$ & 6.70 & 948 & $-0.17 \pm 1.99 \mathrm{E}-09$ & $5.77 \pm 2.61 \mathrm{E}-09$ & $-6.84 \pm 8.17 \mathrm{E}-08$ \\
\hline 704 & $\operatorname{DOWN}(2)$ & 6.61 & 458 & $0.61 \pm 1.70 \mathrm{E}-09$ & $7.94 \pm 2.60 \mathrm{E}-09$ & $2.16 \pm 8.81 \mathrm{E}-08$ \\
\hline 704 & DOWN(3) & 6.54 & 832 & $0.43 \pm 1.38 \mathrm{E}-09$ & $6.32 \pm 1.99 \mathrm{E}-09$ & $8.07 \pm 8.68 \mathrm{E}-08$ \\
\hline 704 & DOWN(4) & 5.98 & 773 & $0.27 \pm 1.46 \mathrm{E}-09$ & $7.52 \pm 1.85 \mathrm{E}-09$ & $-2.37 \pm 8.37 \mathrm{E}-08$ \\
\hline 707 & $\operatorname{DOWN}(1)$ & 6.59 & 485 & $-1.00 \pm 0.87 \mathrm{E}-09$ & $5.26 \pm 1.65 \mathrm{E}-09$ & $-7.71 \pm 8.29 \mathrm{E}-08$ \\
\hline 707 & $\operatorname{DOWN}(2)$ & 6.64 & 386 & $2.00 \pm 7.27 \mathrm{E}-10$ & $4.29 \pm 1.50 \mathrm{E}-09$ & $-8.43 \pm 8.79 \mathrm{E}-08$ \\
\hline 707 & DOWN(3) & 6.38 & 406 & $1.03 \pm 1.02 E-09$ & $3.16 \pm 1.61 \mathrm{E}-09$ & $1.05 \pm 0.87 E-07$ \\
\hline 707 & DOWN(4) & 6.03 & 437 & $0.15 \pm 1.17 \mathrm{E}-09$ & $7.16 \pm 1.78 E-09$ & $3.20 \pm 8.36 \mathrm{E}-08$ \\
\hline 107 & $\operatorname{DOWN}(1)$ & 7.31 & 768 & $0.67 \pm 1.19 \mathrm{E}-09$ & $7.45 \pm 1.50 \mathrm{E}-09$ & $2.28 \pm 0.89 \mathrm{E}-07$ \\
\hline 107 & $\operatorname{DOWN}(2)$ & 7.37 & 761 & $0.00 \pm 1.37 \mathrm{E}-09$ & $6.22 \pm 2.15 E-09$ & $3.05 \pm 0.91 \mathrm{E}-07$ \\
\hline 107 & DOWN(3) & 7.26 & 800 & $0.20 \pm 1.69 \mathrm{E}-09$ & $7.03 \pm 2.21 \mathrm{E}-09$ & $2.11 \pm 0.91 E-07$ \\
\hline 107 & DOWN(4) & 6.97 & 772 & $-0.17 \pm 1.82 \mathrm{E}-09$ & $6.96 \pm 2.23 \mathrm{E}-09$ & $3.74 \pm 0.88 E-07$ \\
\hline 108 & $\operatorname{DOWN}(1)$ & 7.80 & 588 & $-0.62 \pm 1.27 \mathrm{E}-09$ & $2.23 \pm 1.82 \mathrm{E}-09$ & $-2.81 \pm 8.43 E-08$ \\
\hline 108 & $\operatorname{DOWN}(2)$ & 7.57 & 584 & $0.83 \pm 1.21 \mathrm{E}-09$ & $2.30 \pm 1.77 \mathrm{E}-09$ & $1.13 \pm 0.88 \mathrm{E}-07$ \\
\hline 108 & DOWN(3) & 7.48 & 554 & $2.36 \pm 1.51 \mathrm{E}-09$ & $0.74 \pm 1.84 \mathrm{E}-09$ & $1.23 \pm 0.90 \mathrm{E}-07$ \\
\hline 108 & DOWN(4) & 7.55 & 541 & $2.36 \pm 1.50 \mathrm{E}-09$ & $3.83 \pm 2.02 E-09$ & $1.54 \pm 0.85 E-07$ \\
\hline 409 & $\operatorname{DOWN}(1)$ & 8.00 & 440 & $8.74 \pm 9.47 \mathrm{E}-10$ & $1.78 \pm 1.23 \mathrm{E}-09$ & $6.10 \pm 8.36 \mathrm{E}-08$ \\
\hline 409 & $\operatorname{DOWN}(2)$ & 7.57 & 372 & $1.17 \pm 1.02 \mathrm{E}-09$ & $1.61 \pm 1.30 \mathrm{E}-09$ & $-0.81 \pm 8.46 \mathrm{E}-08$ \\
\hline 409 & DOWN(3) & 7.64 & 343 & $1.43 \pm 0.95 \mathrm{E}-09$ & $1.21 \pm 1.27 \mathrm{E}-09$ & $-1.82 \pm 8.74 \mathrm{E}-08$ \\
\hline 409 & DOWN(4) & 7.83 & 326 & $1.76 \pm 1.12 \mathrm{E}-09$ & $3.62 \pm 1.31 \mathrm{E}-09$ & $-3.24 \pm 8.26 \mathrm{E}-08$ \\
\hline 910 & DOWN(1) & 7.00 & 1,357 & $2.38 \pm 2.90 \mathrm{E}-09$ & $1.87 \pm 0.43 \mathrm{E}-08$ & $1.97 \pm 8.23 \mathrm{E}-08$ \\
\hline 910 & DOWN(3) & 7.20 & 1,013 & $2.78 \pm 2.94 \mathrm{E}-09$ & $1.35 \pm 0.43 \mathrm{E}-08$ & $5.33 \pm 5.84 \mathrm{E}-08$ \\
\hline
\end{tabular}

Note: Bolding convention applied to these data. (See p. E-2C.)

Sample collection quarter is noted in parentheses next to hydraulic position. Hydraulic position is relative to other wells within the same hydrogeologic unit. 


\section{Table E-6}

\section{Indicator Results From the Kent Recessional Sequence}

\begin{tabular}{|c|c|c|c|c|c|c|}
\hline $\begin{array}{l}\text { Location } \\
\text { Code }\end{array}$ & $\begin{array}{l}\text { Hydraulic } \\
\text { Position }\end{array}$ & $\underset{\text { (standard units) }}{\mathbf{p H}}$ & $\begin{array}{c}\text { Conductivity } \\
\left(\mu \mathrm{mhos} / \mathrm{cm} @ 25^{\circ} \mathrm{C}\right)\end{array}$ & $\begin{array}{c}\text { Gross Alpha } \\
(\mu \mathrm{Ci} / \mathrm{mL})\end{array}$ & $\begin{array}{c}\text { Gross Beta } \\
(\mu \mathrm{Ci} / \mathrm{mL})\end{array}$ & $\begin{array}{c}\text { Tritium } \\
(\mu \mathrm{Ci} / \mathrm{mL})\end{array}$ \\
\hline 901 & UP(1) & 7.75 & 376 & $0.44 \pm 1.04 \mathrm{E}-09$ & $3.32 \pm 1.53 \mathrm{E}-09$ & $-7.21 \pm 8.11 \mathrm{E}-08$ \\
\hline 901 & UP(3) & 7.62 & 318 & $0.73 \pm 1.03 \mathrm{E}-09$ & $2.43 \pm 1.47 \mathrm{E}-09$ & $-8.98 \pm 8.46 \mathrm{E}-08$ \\
\hline 902 & $\mathrm{UP}(1)$ & 7.74 & 457 & $1.62 \pm 0.94 \mathrm{E}-09$ & $3.91 \pm 1.32 \mathrm{E}-09$ & $-2.72 \pm 8.23 \mathrm{E}-08$ \\
\hline 902 & $\mathrm{UP}(3)$ & 7.80 & 435 & $1.15 \pm 1.37 \mathrm{E}-09$ & $1.56 \pm 1.83 \mathrm{E}-09$ & $-1.27 \pm 0.85 \mathrm{E}-07$ \\
\hline 1008B & $\mathrm{UP}(1)$ & 7.81 & 512 & $0.84 \pm 1.23 \mathrm{E}-09$ & $2.64 \pm 1.31 \mathrm{E}-09$ & $-5.15 \pm 8.17 \mathrm{E}-08$ \\
\hline 1008B & UP(3) & 7.76 & 361 & $0.77 \pm 1.09 \mathrm{E}-09$ & $2.48 \pm 1.24 \mathrm{E}-09$ & $2.46 \pm 8.24 \mathrm{E}-08$ \\
\hline 903 & DOWN(1) & 7.48 & 962 & $-2.69 \pm 1.68 \mathrm{E}-09$ & $5.13 \pm 2.46 \mathrm{E}-09$ & $-3.02 \pm 8.24 \mathrm{E}-08$ \\
\hline 903 & DOWN(3) & 7.42 & 921 & $0.23 \pm 1.40 \mathrm{E}-09$ & $1.41 \pm 1.65 \mathrm{E}-09$ & $-1.73 \pm 0.85 \mathrm{E}-07$ \\
\hline 8610 & DOWN(1) & 7.95 & 1,140 & $-1.39 \pm 2.28 \mathrm{E}-09$ & $5.65 \pm 2.78 \mathrm{E}-09$ & $-5.08 \pm 8.22 \mathrm{E}-08$ \\
\hline 8610 & DOWN(3) & 7.67 & 1,114 & $2.87 \pm 2.07 \mathrm{E}-09$ & $4.59 \pm 2.69 \mathrm{E}-09$ & $-5.44 \pm 8.67 \mathrm{E}-08$ \\
\hline 8611 & DOWN(1) & 7.66 & 935 & $1.51 \pm 2.13 \mathrm{E}-09$ & $1.67 \pm 0.30 \mathrm{E}-08$ & $5.01 \pm 8.58 \mathrm{E}-08$ \\
\hline 8611 & DOWN(2) & 7.60 & 1,006 & $1.00 \pm 2.30 \mathrm{E}-09$ & $0.94 \pm 2.53 \mathrm{E}-09$ & NS \\
\hline 8611 & DOWN(3) & 7.46 & 783 & $0.16 \pm 1.79 \mathrm{E}-09$ & $2.08 \pm 2.56 \mathrm{E}-09$ & $-9.59 \pm 8.62 \mathrm{E}-08$ \\
\hline
\end{tabular}

Note: Bolding convention applied to these data. (See p. E-2C.)

NS - Not sampled.

Sample collection quarter is noted in parentheses next to hydraulic position. Hydraulic position is relative to other wells within the same hydrogeologic unit.

$E-16$ 
Table E-7

\begin{tabular}{|c|c|c|c|c|c|c|}
\hline $\begin{array}{l}\text { Location } \\
\text { Code }\end{array}$ & $\begin{array}{l}\text { Hydraulic } \\
\text { Position }\end{array}$ & $\begin{array}{c}\mathbf{p H} \\
\text { (standard units) }\end{array}$ & $\begin{array}{c}\text { Conductivity } \\
\left(\mu \mathrm{mhos} / \mathrm{cm} @ 25^{\circ} \mathrm{C}\right)\end{array}$ & $\begin{array}{c}\text { Gross Alpha } \\
(\mu \mathrm{Ci} / \mathrm{mL})\end{array}$ & $\begin{array}{c}\text { Gross Beta } \\
(\mu \mathrm{Ci} / \mathrm{mL})\end{array}$ & $\begin{array}{l}\text { Tritium } \\
(\mu \mathrm{Ci} / \mathrm{mL})\end{array}$ \\
\hline GSEEP & DOWN(1) & 6.71 & 1,180 & $-1.31 \pm 2.12 \mathrm{E}-09$ & $7.21 \pm 2.92 \mathrm{E}-09$ & $5.38 \pm 0.91 \mathrm{E}-07$ \\
\hline GSEEP & $\operatorname{DOWN}(2)$ & 6.64 & 1,109 & $-1.08 \pm 2.20 \mathrm{E}-09$ & $2.81 \pm 2.63 \mathrm{E}-09$ & $5.03 \pm 0.91 \mathrm{E}-07$ \\
\hline GSEEP & $\operatorname{DOWN}(3)$ & 6.55 & 1,095 & $0.77 \pm 3.33 \mathrm{E}-09$ & $5.95 \pm 2.73 \mathrm{E}-09$ & $3.60 \pm 0.87 \mathrm{E}-07$ \\
\hline GSEEP & DOWN(4) & 6.57 & 974 & $0.34 \pm 1.93 \mathrm{E}-09$ & $3.61 \pm 2.59 \mathrm{E}-09$ & $4.09 \pm 0.89 \mathrm{E}-07$ \\
\hline SP04 & $\operatorname{DOWN}(1)$ & NS & NS & $-0.54 \pm 2.20 \mathrm{E}-09$ & $6.61 \pm 2.58 \mathrm{E}-09$ & $2.44 \pm 0.85 \mathrm{E}-07$ \\
\hline SP04 & DOWN(3) & NS & NS & $-1.09 \pm 2.52 \mathrm{E}-09$ & $5.73 \pm 2.02 \mathrm{E}-09$ & $2.49 \pm 0.65 \mathrm{E}-07$ \\
\hline SP06 & DOWN(1) & NS & NS & $-0.20 \pm 1.55 \mathrm{E}-09$ & $4.62 \pm 2.14 \mathrm{E}-09$ & $7.48 \pm 8.36 \mathrm{E}-08$ \\
\hline SP06 & DOWN(3) & NS & NS & $-1.14 \pm 1.27 \mathrm{E}-09$ & $2.39 \pm 1.85 \mathrm{E}-09$ & $0.97 \pm 9.10 \mathrm{E}-08$ \\
\hline SP11 & $\operatorname{DOWN}(1)$ & NS & NS & $-1.72 \pm 2.15 \mathrm{E}-09$ & $4.74 \pm 0.44 \mathrm{E}-08$ & $0.06 \pm 8.29 \mathrm{E}-08$ \\
\hline SP11 & DOWN(2) & NS & NS & $0.94 \pm 2.97 \mathrm{E}-09$ & $5.37 \pm 0.48 \mathrm{E}-08$ & NS \\
\hline SP11 & DOWN(3) & NS & NS & $-3.01 \pm 3.54 \mathrm{E}-09$ & $5.62 \pm 0.51 \mathrm{E}-08$ & $5.95 \pm 8.87 \mathrm{E}-08$ \\
\hline SP11 & DOWN(4) & NS & NS & NS & $5.72 \pm 0.46 \mathrm{E}-08$ & NS \\
\hline SP12 & DOW & 6.85 & 1,235 & -09 & $\mathrm{E}-09$ & $4.21 \pm 0.88 \mathrm{E}-07$ \\
\hline SP12 & DOWN(3) & 7.43 & 1,026 & $-1.11 \pm 1.58 \mathrm{E}-09$ & $-0.16 \pm 2.33 \mathrm{E}-09$ & $2.64 \pm 0.85 \mathrm{E}$ \\
\hline
\end{tabular}

Note: Bolding convention applied to these data. (See p. E-2C.)

NS - Not sampled.

Sample collection quarter is noted in parentheses next to hydraulic position. Hydraulic position is relative to other wells within the same hydrogeologic unit.

\section{Table E-8}

\section{Indicator Results From the North Plateau Well Points}

$\begin{array}{ccccccc}\begin{array}{c}\text { Location } \\ \text { Code }\end{array} & \begin{array}{c}\text { Hydraulic } \\ \text { Position }\end{array} & \begin{array}{c}\mathbf{p H} \\ (\text { standard units })\end{array} & \begin{array}{c}\text { Conductivity } \\ \left(\mu \mathrm{mhos} / \mathrm{cm} @ 25^{\circ} \mathrm{C}\right)\end{array} & \begin{array}{c}\text { Gross Alpha } \\ (\mu \mathrm{Ci} / \mathrm{mL})\end{array} & \begin{array}{c}\text { Gross Beta } \\ (\mu \mathrm{Ci} / \mathrm{mL})\end{array} & \begin{array}{c}\text { Tritium } \\ (\mu \mathrm{Ci} / \mathrm{mL})\end{array} \\ \text { WP-A } & \text { DOWN(4) } & 7.45 & 127 & -0.57 \pm 1.03 \mathrm{E}-09 & 2.41 \pm 0.43 \mathrm{E}-08 & 8.73 \pm 0.21 \mathrm{E}-06 \\ \text { WP-C } & \text { DOWN(4) } & 6.69 & 226 & 0.52 \pm 1.31 \mathrm{E}-09 & 7.67 \pm 0.63 \mathrm{E}-08 & 5.28 \pm 0.16 \mathrm{E}-05 \\ \text { WP-H } & \text { DOWN(4) } & 6.70 & 1,149 & 2.92 \pm 0.29 \mathrm{E}-08 & 1.11 \pm 0.01 \mathrm{E}-05 & 1.68 \pm 0.11 \mathrm{E}-06\end{array}$

Note: Bolding convention is not applicable to these data.

Sample collection quarter is noted in parentheses next to hydraulic position. Hydraulic position is relative to other wells within the same hydrogeologic unit. 


\begin{tabular}{|c|c|c|c|c|c|c|c|c|}
\hline \multicolumn{9}{|c|}{ Table E-9 } \\
\hline $\begin{array}{l}\text { Location } \\
\text { Code }\end{array}$ & $\begin{array}{l}\text { Sampling } \\
\text { Quarter }\end{array}$ & $\begin{array}{c}\text { 1,1-DCA } \\
(\mu \mathrm{g} / \mathrm{L})\end{array}$ & $\begin{array}{l}\text { DCDFMeth } \\
(\mu \mathrm{g} / \mathrm{L})\end{array}$ & $\begin{array}{c}\underset{(\mu \mathrm{g} / \mathrm{L})}{\text { 1,1-DCE }} \\
\text {. }\end{array}$ & $\underset{(\mu \mathrm{g} / \mathrm{L})}{\text { 1,2-DCE(total) }}$ & $\underset{(\mu \mathrm{g} / \mathrm{L})}{\text { 1,2-DCE(trans) }}$ & $\underset{(\mu \mathrm{g} / \mathrm{L})}{\mathbf{1 , 1 , 1 - T C A}}$ & $\underset{(\mu \mathrm{g} / \mathrm{L})}{\mathbf{T C E}}$ \\
\hline SP12 & $\begin{array}{l}1 \\
3\end{array}$ & $\begin{array}{l}<5.0^{*} \\
<5.0\end{array}$ & $\begin{array}{l}<5.0^{*} \\
<1.0\end{array}$ & $\begin{array}{l}<5.0 \\
<5.0\end{array}$ & $\begin{array}{l}\text { NS } \\
\text { NS }\end{array}$ & $\begin{array}{l}<1.0 \\
<1.0\end{array}$ & $\begin{array}{l}<5.0 \\
<5.0\end{array}$ & $\begin{array}{l}<5.0 \\
<5.0\end{array}$ \\
\hline 803 & $\begin{array}{l}1 \\
2 \\
3 \\
4\end{array}$ & $\begin{array}{l}<5.0^{*} \\
<5.0 \\
<5.0 \\
<5.0\end{array}$ & $\begin{array}{l}<5.0^{*} \\
<1.0 \\
<1.0 \\
<1.0\end{array}$ & $\begin{array}{l}<5.0 \\
<5.0 \\
<5.0 \\
<5.0\end{array}$ & $\begin{array}{l}\text { NS } \\
\text { NS } \\
\text { NS } \\
\text { NS }\end{array}$ & $\begin{array}{l}<1.0 \\
<1.0 \\
<1.0 \\
<1.0\end{array}$ & $\begin{array}{l}<5.0 \\
<5.0 \\
<5.0 \\
<5.0\end{array}$ & $\begin{array}{l}<5.0 \\
<5.0 \\
<5.0 \\
<5.0\end{array}$ \\
\hline 8609 & 1 & $<5.0$ & $<5.0$ & $<5.0$ & NS & $<5.0$ & $<5.0$ & $<5.0$ \\
\hline 8612 & $\begin{array}{l}1 \\
2 \\
3 \\
4\end{array}$ & $\begin{array}{l}\mathbf{1 5 . 0} \\
\mathbf{1 1 . 0} \\
12.0 \\
12.5\end{array}$ & $\begin{array}{l}3.7 \\
\mathbf{3 . 0} \\
\mathbf{4 . 0} \\
3.3\end{array}$ & $\begin{array}{l}<5.0^{*} \\
<5.0 \\
<5.0 \\
<5.0^{*}\end{array}$ & $\begin{array}{l}\mathbf{3 6 . 5} \\
\mathbf{2 7 . 3} \\
27.5 \\
31.0\end{array}$ & $\begin{array}{r}\mathbf{1 . 3} \\
<5.0 \\
<5.0 \\
<5.0\end{array}$ & $\begin{array}{l}1.4 \\
\mathbf{1 . 9} \\
1.8 \\
\mathbf{1 . 3}\end{array}$ & $\begin{array}{l}<5.0 \\
<5.0 \\
<5.0 \\
<5.0\end{array}$ \\
\hline
\end{tabular}

See Table E-14C for compound definition.

Note: Bolding convention applied to these data. (See p. E-2C.)

NS - Not sampled.

* Compound was reported at an estimated concentration less than the practical quantitation limit.

\section{Table E-10 \\ 2003 Tributyl Phosphate Results at Selected Groundwater Monitoring Locations}

$\begin{array}{ccc}\begin{array}{c}\text { Location } \\ \text { Code }\end{array} & \begin{array}{c}\text { Sampling } \\ \text { Quarter }\end{array} & \begin{array}{c}\text { Tributyl Phosphate (TBP) } \\ (\mu \mathrm{g} / \mathrm{L})\end{array} \\ 111 & 1 & <10.0 \\ & 3 & <10.0 \\ 8605 & 1 & 230 \\ & 3 & 180 \\ & 3 & 330\end{array}$

Practical quantitation limit is $10 \mu \mathrm{g} / \mathrm{L}$.

Note: Well 8605 was initially sampled in June 2003 and then resampled in July 2003. Both samples are part of the third-quarter sampling round.

$E-18$

WVDP Annual Site Environmental Report

Calendar Year 2003 
Table E-11

2003 Sampling Results for Metals ( $\mu \mathrm{g} / \mathrm{L})$

Title 6 NYCRR Appendix 33 List

\section{Location Hydraulic Antimony Arsenic Barium Beryllium Cadmium Chromium Cobalt Copper Code Position}

Sand and Gravel

$\begin{array}{rccccccccc}706 & \mathrm{UP}(4) & <10 & <10 & 175 & <1 & <5.0 & 58 & <50 & <25 \\ 1304 & \mathrm{UP}(4) & <10 & 89 & 882 & 5 & <5.0 & 160 & 71 & 190 \\ 1302 & \text { DOWN(4) } & <10 & 34 & 497 & 2 & <5.0 & 58 & <50 & 90 \\ 111 & \text { DOWN(1) } & <2 & <4 & 118 & <1 & <0.4 & <1 & 2 & 2 \\ 502 & \text { DOWN(1) } & \mathrm{NS} & 7 & 536 & \mathrm{NS} & <0.4 & 2,390 & 5 & 25 \\ 502 & \text { DOWN(3) } & \mathrm{NS} & <3 & 447 & \mathrm{NS} & <0.4 & 771 & 2 & 8 \\ 8605 & \text { DOWN(1) } & <2 & <4 & 140 & 1 & <0.4 & <1 & <2 & <1\end{array}$

\section{Weathered Till}

$\begin{array}{clllllllll}\text { NDATR } & \text { DOWN(1) } & <10 & <10 & \mathbf{5 4} & <1 & <5.0 & <5 & <50 & <25 \\ \text { NDATR } & \text { DOWN(2) } & <10 & <10 & 60 & <1 & <5.0 & <5 & <50 & <25 \\ \text { NDATR } & \text { DOWN(3) } & <10 & <10 & 55 & <1 & <5.0 & <5 & <50 & <25 \\ \text { NDATR } & \text { DOWN(4) } & <10 & <10 & \mathbf{6 1} & <1 & <5.0 & <5 & <50 & <25 \\ 909 & \text { DOWN(1) } & <10 & 15 & 204 & <1 & <5.0 & 13 & <50 & <25\end{array}$

Unweathered Till

$\begin{array}{rrrrrrrrrr}405 & \mathrm{UP}(4) & <10 & <10 & 207 & <1 & <5.0 & 346 & <50 & <25 \\ 1303 & \mathrm{UP}(4) & <10 & 19 & 441 & 2 & <5.0 & 46 & <50 & 48\end{array}$

Note: Bolding convention applied to these data. (See p. E-2C.)

NS - Not sampled.

Sample collection quarter is noted in parentheses next to hydraulic position. Hydraulic position is relative to other wells within the same hydrogeologic unit.

$E-19$ 


\section{Table E-11 (concluded) \\ 2003 Sampling Results for Metals $(\mu \mathrm{g} / \mathrm{L})$}

Title 6 NYCRR Appendix 33 List

\section{Location Hydraulic Lead Mercury Nickel Selenium Silver Thallium Tin Vanadium Zinc Code Position}

Sand and Gravel

$\begin{array}{rcccccccccr}706 & \mathrm{UP}(4) & 3 & <0.2 & <40 & <5 & <10 & <10 & <3,000 & <50 & <20 \\ 1304 & \mathrm{UP}(4) & 97 & <0.2 & 165 & <5 & <10 & 25 & <3,000 & 154 & 564 \\ 1302 & \text { DOWN(4) } & 46 & <0.2 & 78 & <5 & <10 & 13 & <3,000 & 73 & 256 \\ 111 & \text { DOWN(1) } & <2 & <0.1 & 5 & <4 & <1 & <6 & <3 & <1 & 4 \\ 502 & \text { DOWN(1) } & <2 & <0.1 & 76 & <4 & <1 & \mathrm{NS} & \mathrm{NS} & 8 & 17 \\ 502 & \text { DOWN(3) } & 3 & <0.1 & 41 & <4 & <1 & \mathrm{NS} & \mathrm{NS} & 3 & 14 \\ 8605 & \text { DOWN(1) } & <2 & <0.1 & <1 & 4 & <1 & <6 & <3 & <1 & 1\end{array}$

\section{Weathered Till}

\begin{tabular}{|c|c|c|c|c|c|c|c|c|c|c|}
\hline NDATR & DOWN(1) & $<4$ & $<0.2$ & $<40$ & $<5$ & $<10$ & $<10$ & $<3,000$ & $<50$ & $<20$ \\
\hline NDATR & DOWN (2) & $<3$ & $<0.2$ & $<40$ & $<6$ & $<10$ & $<10$ & $<3,000$ & $<50$ & $<20$ \\
\hline NDATR & DOWN(3) & $<3$ & $<0.2$ & $<40$ & $<5$ & $<10$ & $<10$ & $<3,000$ & $<50$ & $<20$ \\
\hline NDATR & DOWN(4) & $<3$ & $<0.2$ & $<40$ & $<5$ & $<10$ & $<10$ & $<3,000$ & $<50$ & $<20$ \\
\hline 909 & DOWN(1) & 10 & $<0.2$ & $<40$ & $<5$ & $<10$ & $<10$ & $<3,000$ & $<50$ & 43 \\
\hline
\end{tabular}

Unweathered Till

\begin{tabular}{|c|c|c|c|c|c|c|c|c|c|c|}
\hline NDATR & DOWN(1) & $<4$ & $<0.2$ & $<40$ & $<5$ & $<10$ & $<10$ & $<3,000$ & $<50$ & $<20$ \\
\hline 405 & $\mathrm{UP}(4)$ & 5 & $<0.2$ & 1,428 & $<5$ & $<10$ & $<10$ & $<3,000$ & $<50$ & 21 \\
\hline 1303 & $\mathrm{UP}(4)$ & 25 & $<0.2$ & 73 & $<5$ & $<10$ & $<10$ & $<3,000$ & 58 & 146 \\
\hline
\end{tabular}

Note: Bolding convention is not applicable to these data.

NS - Not sampled.

Sample collection quarter is noted in parentheses next to hydraulic position. Hydraulic position is relative to other wells within the same hydrogeologic unit.

$E-20$ 
Table E-12

2003 Sampling Results for Early Warning Monitoring Wells $(\mu g / L)$

$\begin{array}{ccccc}\begin{array}{c}\text { Location } \\ \text { Code }\end{array} & \begin{array}{c}\text { Sample } \\ \text { Quarter }\end{array} & \begin{array}{c}\text { Aluminum } \\ \text { Total }\end{array} & \begin{array}{c}\text { Iron } \\ \text { Total }\end{array} & \begin{array}{c}\text { Manganese } \\ \text { Total }\end{array} \\ 502 & (1) & 1,140 & 21,200 & 60.2 \\ & (3) & 563 & 4,840 & 25.2\end{array}$

Note: Bolding convention is not applicable to these data.

Sample collection quarter is noted in parentheses next to hydraulic position. Hydraulic position is relative to other wells within the same hydrogeologic unit.

$E-21$ 


\section{Table E-13 \\ 2003 Radioisotopic Results ( $\mu$ Ci/mL) From Selected \\ Groundwater Monitoring Locations}

\begin{tabular}{|c|c|c|c|c|}
\hline $\begin{array}{l}\text { Location } \\
\text { Code }\end{array}$ & $\begin{array}{l}\text { Hydraulic } \\
\text { Position }\end{array}$ & C-14 & Sr-90 & Tc-99 \\
\hline \multicolumn{5}{|c|}{ Sand and Gravel } \\
\hline 401 & $\mathrm{UP}(1)$ & $-0.31 \pm 1.40 \mathrm{E}-08$ & $1.38 \pm 2.17 \mathrm{E}-09$ & $-0.04 \pm 1.46 \mathrm{E}-09$ \\
\hline 706 & $\mathrm{UP}(4)$ & $-1.94 \pm 2.73 \mathrm{E}-08$ & $4.51 \pm 1.75 \mathrm{E}-09$ & $-0.69 \pm 1.67 \mathrm{E}-09$ \\
\hline 1304 & UP(4) & $1.02 \pm 2.72 \mathrm{E}-08$ & $6.33 \pm 2.77 \mathrm{E}-09$ & $1.15 \pm 1.87 \mathrm{E}-09$ \\
\hline 1302 & DOWN(4) & $0.97 \pm 2.71 \mathrm{E}-08$ & $4.22 \pm 2.39 \mathrm{E}-09$ & $-0.94 \pm 1.35 \mathrm{E}-09$ \\
\hline 111 & DOWN(1) & NS & $2.60 \pm 0.05 \mathrm{E}-06$ & NS \\
\hline 406 & DOWN(1) & $-0.13 \pm 1.39 \mathrm{E}-08$ & $2.66 \pm 1.51 \mathrm{E}-09$ & $3.05 \pm 1.96 \mathrm{E}-09$ \\
\hline 408 & DOWN(1) & $-1.39 \pm 1.37 \mathrm{E}-08$ & $1.57 \pm 0.01 \mathrm{E}-04$ & $2.51 \pm 0.28 \mathrm{E}-08$ \\
\hline 501 & DOWN(1) & NS & $1.11 \pm 0.01 \mathrm{E}-04$ & NS \\
\hline 502 & DOWN(1) & NS & $9.81 \pm 0.02 \mathrm{E}-05$ & NS \\
\hline $602 \mathrm{~A}$ & DOWN(1) & NS & $5.57 \pm 1.79 \mathrm{E}-09$ & NS \\
\hline $602 \mathrm{~A}$ & DOWN(3) & NS & $7.78 \pm 2.66 \mathrm{E}-09$ & NS \\
\hline 8605 & DOWN(1) & NS & $6.02 \pm 0.07 \mathrm{E}-06$ & NS \\
\hline 8609 & DOWN(1) & NS & $8.44 \pm 0.28 \mathrm{E}-07$ & NS \\
\hline 8609 & DOWN(3) & NS & $8.16 \pm 0.20 \mathrm{E}-07$ & NS \\
\hline 116 & DOWN(1) & NS & $4.20 \pm 0.12 \mathrm{E}-07$ & NS \\
\hline 116 & DOWN(3) & NS & $2.95 \pm 0.08 \mathrm{E}-07$ & NS \\
\hline 605 & DOWN(1) & NS & $2.22 \pm 0.29 \mathrm{E}-08$ & NS \\
\hline 605 & DOWN(3) & NS & $1.50 \pm 0.33 \mathrm{E}-08$ & NS \\
\hline 801 & DOWN(1) & NS & $3.05 \pm 0.05 \mathrm{E}-06$ & NS \\
\hline 801 & DOWN(2) & NS & $3.48 \pm 0.06 \mathrm{E}-06$ & NS \\
\hline 801 & DOWN(3) & NS & $2.27 \pm 0.05 \mathrm{E}-06$ & NS \\
\hline 801 & DOWN(4) & NS & $2.46 \pm 0.04 \mathrm{E}-06$ & NS \\
\hline 8603 & DOWN(1) & NS & $3.22 \pm 0.02 \mathrm{E}-05$ & NS \\
\hline 8603 & DOWN(3) & NS & $3.46 \pm 0.02 \mathrm{E}-05$ & NS \\
\hline
\end{tabular}

Note: Bolding convention applied to these data. (See p. E-2C.)

NS - Not sampled.

Sample collection quarter is noted in parentheses next to hydraulic position. Hydraulic position is relative to other wells within the same hydrogeologic unit.

$E-22$

WVDP Annual Site Environmental Report

Calendar Year 2003 


\section{Table E-13 (continued) \\ 2003 Radioisotopic Results ( $\mu \mathrm{Ci} / \mathrm{mL}$ ) From Selected \\ Groundwater Monitoring Locations}

$\begin{array}{ccccc}\begin{array}{c}\text { Location } \\ \text { Code }\end{array} & \begin{array}{c}\text { Hydraulic } \\ \text { Position }\end{array} & \mathbf{C - 1 4} & \text { Sr-90 } & \text { Tc-99 } \\ \text { Weathered Till } & & & & \\ & & & & \\ \text { NDATR } & \text { DOWN(1) } & 0.65 \pm 1.39 \mathrm{E}-08 & \mathbf{6 . 9 7} \pm \mathbf{0 . 4 0 E - 0 8} & -1.88 \pm 1.74 \mathrm{E}-09 \\ \text { NDATR } & \text { DOWN(1) } & 0.76 \pm 1.42 \mathrm{E}-08 & \mathbf{5 . 8 9} \pm \mathbf{0 . 4 5 E}-\mathbf{0 8} & -0.55 \pm 1.87 \mathrm{E}-09 \\ \text { NDATR } & \text { DOWN(3) } & 0.69 \pm 2.08 \mathrm{E}-08 & 6.39 \pm 0.58 \mathrm{E}-08 & \mathbf{1 . 2 7} \pm \mathbf{0 . 8 1 E}-\mathbf{0 9} \\ & & & \\ 909 & \text { DOWN(1) } & 0.84 \pm 1.43 \mathrm{E}-08 & 1.90 \pm 0.08 \mathrm{E}-07 & 5.01 \pm 1.97 \mathrm{E}-09\end{array}$

\section{Unweathered Till}

$\begin{array}{llllr}405 & \mathrm{UP}(4) & -2.60 \pm 2.96 \mathrm{E}-08 & 2.83 \pm 1.58 \mathrm{E}-09 & -0.26 \pm 1.46 \mathrm{E}-09 \\ 1303 & -0.28 \pm 2.67 \mathrm{E}-08 & 3.02 \pm 2.49 \mathrm{E}-09 & 8.15 \pm 3.63 \mathrm{E}-09\end{array}$

\section{North Plateau}
SP11
$\operatorname{DOWN}(2)$
NS
$2.68 \pm 0.37 \mathrm{E}-08$
NS

Note: Bolding convention applied to these data. (See p. E-2C.)

NS - Not sampled.

Sample collection quarter is noted in parentheses next to hydraulic position. Hydraulic position is relative to other wells within the same hydrogeologic unit.

E - 23 


\section{Table E-13 (continued) \\ 2003 Radioisotopic Results $(\mu \mathrm{Ci} / \mathrm{mL})$ From Selected \\ Groundwater Monitoring Locations}

\section{Location Hydraulic \\ Code}

Sand and Gravel

$\begin{array}{lcccccc}401 & \text { UP(1) } & -0.44 \pm 5.17 \mathrm{E}-10 & 0.13 \pm 6.13 \mathrm{E}-09 & 5.08 \pm 2.36 \mathrm{E}-10 & 2.36 \pm 0.58 \mathrm{E}-09 & 1.09 \pm 3.90 \mathrm{E}-11 \\ 706 & \text { UP(4) } & 0.92 \pm 4.66 \mathrm{E}-10 & -0.54 \pm 1.22 \mathrm{E}-08 & 1.90 \pm 2.88 \mathrm{E}-10 & 1.10 \pm 0.43 \mathrm{E}-09 & 0.58 \pm 6.98 \mathrm{E}-11 \\ 1304 & \mathrm{UP}(4) & 0.31 \pm 3.98 \mathrm{E}-10 & -1.15 \pm 8.30 \mathrm{E}-09 & 3.28 \pm 2.95 \mathrm{E}-10 & 2.71 \pm 3.23 \mathrm{E}-10 & 0.00 \pm 2.17 \mathrm{E}-10 \\ 1302 & \text { DOWN(4) } & 2.99 \pm 9.06 \mathrm{E}-10 & 2.27 \pm 5.56 \mathrm{E}-09 & 5.67 \pm 3.49 \mathrm{E}-10 & -0.85 \pm 3.53 \mathrm{E}-10 & 2.12 \pm 6.82 \mathrm{E}-11 \\ 406 & \text { DOWN(1) } & -1.40 \pm 1.17 \mathrm{E}-09 & -3.16 \pm 6.95 \mathrm{E}-09 & 0.89 \pm 1.06 \mathrm{E}-10 & 1.26 \pm 0.45 \mathrm{E}-09 & -0.28 \pm 4.53 \mathrm{E}-11 \\ 408 & \text { DOWN(1) } & 0.00 \pm 7.05 \mathrm{E}-09 & -0.27 \pm 2.40 \mathrm{E}-09 & 1.94 \pm 1.53 \mathrm{E}-10 & 4.62 \pm 0.70 \mathrm{E}-09 & 5.31 \pm 5.27 \mathrm{E}-11\end{array}$

\section{Weathered Till}

$\begin{array}{ccccccc}\text { NDATR } & \text { DOWN(1) } & 0.00 \pm 8.22 \mathrm{E}-10 & 4.50 \pm 6.79 \mathrm{E}-09 & 0.20 \pm 1.30 \mathrm{E}-10 & 1.16 \pm 0.48 \mathrm{E}-09 & 1.57 \pm 1.98 \mathrm{E}-11 \\ \text { NDATR } & \text { DOWN(3) } & 7.31 \pm 9.43 \mathrm{E}-10 & 1.33 \pm 6.34 \mathrm{E}-09 & 7.80 \pm 3.16 \mathrm{E}-10 & 7.89 \pm 3.90 \mathrm{E}-10 & 3.68 \pm 5.47 \mathrm{E}-11 \\ & & & & & & \\ 909 & \text { DOWN(1) } & 4.57 \pm 1.11 \mathrm{E}-09 & 2.08 \pm 4.53 \mathrm{E}-09 & 2.04 \pm 1.88 \mathrm{E}-10 & 5.40 \pm 7.18 \mathrm{E}-10 & 2.69 \pm 3.41 \mathrm{E}-11\end{array}$

\section{Unweathered Till}

$\begin{array}{lllllll}405 & \text { UP(4) } & 4.25 \pm 8.20 \mathrm{E}-10 & -0.31 \pm 1.05 \mathrm{E}-08 & 6.02 \pm 3.70 \mathrm{E}-10 & 1.32 \pm 0.50 \mathrm{E}-09 & -1.21 \pm 5.82 \mathrm{E}-11 \\ 1303 & \text { UP(4) } & 5.73 \pm 8.06 \mathrm{E}-10 & 0.97 \pm 4.10 \mathrm{E}-09 & 1.07 \pm 2.70 \mathrm{E}-10 & 1.98 \pm 3.05 \mathrm{E}-10 & -1.33 \pm 5.29 \mathrm{E}-11\end{array}$

Note: Bolding convention not applicable to these data.

Sample collection quarter is noted in parentheses next to hydraulic position. Hydraulic position is relative to other wells within the same hydrogeologic unit.

$E-24$

WVDP Annual Site Environmental Report

Calendar Year 2003 


\section{Table E-13 (concluded) \\ 2003 Radioisotopic Results $(\mu \mathrm{Ci} / \mathrm{mL})$ From Selected Groundwater Monitoring Locations}

$\begin{array}{cccccc}\begin{array}{c}\text { Location } \\ \text { Code }\end{array} & \begin{array}{c}\text { Hydraulic } \\ \text { Position }\end{array} & \mathbf{U}-233 / 234 & \mathbf{U}-235 / 236 & \mathbf{U}-238 & \begin{array}{c}\text { Total U } \\ (\mu \mathrm{g} / \mathrm{mL})\end{array}\end{array}$

Sand and Gravel

$\begin{array}{lccccc}401 & \text { UP(1) } & 9.65 \pm 3.93 \mathrm{E}-11 & 1.83 \pm 2.11 \mathrm{E}-11 & 5.22 \pm 2.89 \mathrm{E}-11 & 1.91 \pm 0.07 \mathrm{E}-04 \\ 706 & \text { UP(4) } & 1.58 \pm 1.05 \mathrm{E}-10 & 3.95 \pm 6.37 \mathrm{E}-11 & 4.59 \pm 6.98 \mathrm{E}-11 & 1.44 \pm 0.04 \mathrm{E}-04 \\ 1304 & \text { UP(4) } & 5.65 \pm 1.71 \mathrm{E}-10 & 3.24 \pm 4.45 \mathrm{E}-11 & 5.77 \pm 1.68 \mathrm{E}-10 & 1.30 \pm 0.04 \mathrm{E}-03 \\ 1302 & \text { DOWN(4) } & 1.53 \pm 0.28 \mathrm{E}-09 & 1.29 \pm 0.91 \mathrm{E}-10 & 1.26 \pm 0.25 \mathrm{E}-09 & 3.46 \pm 0.10 \mathrm{E}-03 \\ 406 & \text { DOWN(1) } & 1.30 \pm 0.46 \mathrm{E}-10 & 1.41 \pm 1.38 \mathrm{E}-11 & 8.76 \pm 3.70 \mathrm{E}-11 & 2.07 \pm 0.20 \mathrm{E}-04 \\ 408 & \text { DOWN(1) } & 4.83 \pm 0.85 \mathrm{E}-10 & 2.75 \pm 2.13 \mathrm{E}-11 & 2.60 \pm 0.62 \mathrm{E}-10 & 8.33 \pm 0.18 \mathrm{E}-04\end{array}$

Weathered Till

$\begin{array}{cccccc}\text { NDATR } & \text { DOWN(1) } & 1.13 \pm 0.12 \mathrm{E}-09 & 1.06 \pm 0.40 \mathrm{E}-10 & 8.76 \pm 1.06 \mathrm{E}-10 & 2.70 \pm 0.06 \mathrm{E}-03 \\ \text { NDATR } & \text { DOWN(3) } & 2.04 \pm 0.22 \mathrm{E}-09 & 1.52 \pm 0.64 \mathrm{E}-10 & 1.51 \pm 0.18 \mathrm{E}-09 & 4.39 \pm 0.07 \mathrm{E}-03 \\ & & & & & \\ 909 & \text { DOWN(1) } & 5.61 \pm 0.89 \mathrm{E}-10 & 3.66 \pm 2.17 \mathrm{E}-11 & 3.99 \pm 0.72 \mathrm{E}-10 & 8.82 \pm 0.33 \mathrm{E}-04\end{array}$

Unweathered Till

$\begin{array}{llllll}405 & \mathrm{UP}(4) & 4.66 \pm 1.50 \mathrm{E}-10 & 4.62 \pm 4.53 \mathrm{E}-11 & 3.80 \pm 1.33 \mathrm{E}-10 & 8.92 \pm 0.16 \mathrm{E}-04 \\ 1303 & \mathrm{UP}(4) & 1.76 \pm 0.30 \mathrm{E}-09 & 7.21 \pm 6.33 \mathrm{E}-11 & 1.49 \pm 0.27 \mathrm{E}-09 & 4.20 \pm 0.12 \mathrm{E}-03\end{array}$

Note: Bolding convention not applicable to these data.

Sample collection quarter is noted in parentheses next to hydraulic position. Hydraulic position is relative to other wells within the same hydrogeologic unit.

$E-25$ 


\section{Table E-14 \\ Practical Quantitation Limits (PQLs)}

COMPOUND

NYCRR Appendix 33 Volatiles

$\begin{array}{lr}\text { Acetone } & 10 \\ \text { Acetonitrile } & 100 \\ \text { Acrolein } & 11 \\ \text { Acrylonitrile } & 5 \\ \text { Allyl chloride } & 5 \\ \text { Benzene } & 5 \\ \text { Bromodichloromethane } & 5 \\ \text { Bromoform } & 5 \\ \text { Bromomethane } & 10 \\ \text { Carbon disulfide } & 10 \\ \text { Carbon tetrachloride } & 5 \\ \text { Chlorobenzene } & 5 \\ \text { Chloroethane } & 10 \\ \text { Chloroform } & 5 \\ \text { Chloromethane } & 10 \\ \text { Chloroprene } & 5 \\ \text { 1,2-Dibromo-3-chloropropane } & 5 \\ \text { Dibromochloromethane } & 5 \\ \text { 1,2-Dibromoethane } & 5 \\ \text { Dichlorodifluoromethane(DCDFMeth) } & 5 \\ \text { 1,1-Dichloroethane(1,1-DCA) } & 5 \\ \text { 1,2-Dichloroethane(1,2-DCA) } & 5 \\ \text { 1,1-Dichloroethylene(1,1-DCE) } & 5 \\ \text { 1,2-Dichloropropane } & 5 \\ \text { Ethyl benzene } & 5 \\ \text { Ethyl methacrylate } & 5 \\ \text { 2-Hexanone } & 10 \\ & \end{array}$

NYCRR Appendix 33 Metals

$\begin{array}{lc}\text { *Aluminum } & 200 \\ \text { Antimony } & 10 \\ \text { Arsenic } & 10 \\ \text { Barium } & 200 \\ \text { Beryllium } & 1 \\ \text { Cadmium } & 5 \\ \text { Chromium } & 10 \\ \text { Cobalt } & 50 \\ \text { Copper } & 25 \\ \text { *Iron } & 100\end{array}$

COMPOUND PQL

PQL

$(\mu g / L)$

$(\mu g / L)$

NYCRR Appendix 33 Volatiles

Isobutyl alcohol $\quad 100$

Methacrylonitrile 5

Methyl ethyl ketone 10

Methyl iodide 5

Methyl methacrylate 5

4-Methyl-2-pentanone 10

Methylene bromide $\quad 10$

Methylene chloride 5

Pentachloroethane 5

Propionitrile 50

Styrene 5

1,1,1,2-Tetrachloroethane 5

1,1,2,2-Tetrachloroethane 5

Tetrachloroethylene 5

Toluene 5

1,1,1-Trichloroethane (1,1,1-TCA) 5

1,1,2-Trichloroethane 5

1,2,3-Trichloropropane 5

Vinyl acetate $\quad 10$

Vinyl chloride $\quad 10$

Xylene (total) 5

cis-1,3-Dichloropropene 5

trans-1,2-Dichloroethylene (1,2-DCE[trans]) 5

trans-1,3-Dichloropropene 5

trans-1,4-Dichloro-2-butene 5

Trichloroethylene (TCE) 5

Trichlorofluoromethane 5

NYCRR Appendix 33 Metals

$\begin{array}{lc}\text { Lead } & 3 \\ \text { *Manganese } & 15 \\ \text { Mercury } & 0.2 \\ \text { Nickel } & 40 \\ \text { Selenium } & 5 \\ \text { Silver } & 10 \\ \text { Thallium } & 10 \\ \text { Tin } & 3,000 \\ \text { Vanadium } & 50 \\ \text { Zinc } & 20\end{array}$

Note: Specific quantitation limits are highly matrix-dependent and may not always be achievable.

* Not an NYCRR Appendix 33 parameter; sampled for the north plateau early warning program.

E - 26

WVDP Annual Site Environmental Report

Calendar Year 2003 


\section{Table E-14 (continued) \\ Practical Quantitation Limits (PQLs) \\ PQL \\ $(\mu g / L)$ \\ COMPOUND PQL \\ $(\mu g / L)$}

COMPOUND

NYCRR Appendix 33 Semivolatiles

Acenaphthene 10

Acenaphthylene 10

Acetophenone 10

2-Acetylaminofluorene 10

4-Aminobiphenyl 10

Aniline 10

Anthracene 10

Aramite 10

Benzo[a]anthracene 10

Benzo[a]pyrene 10

Benzo[b]fluoranthene 10

Benzo[ghi]perylene 10

Benzo[k]fluoranthene 10

Benzyl alcohol 10

Bis(2-chlorethyl)ether $\quad 10$

Bis(2-chloroethoxy)methane $\quad 10$

Bis(2-chloroisopropyl)ether $\quad 10$

Bis(2-ethylhexyl)phthalate $\quad 10$

4-Bromophenyl phenyl ether $\quad 10$

Butyl benzyl phthalate $\quad 10$

Chlorobenzilate 10

2-Chloronaphthalene 10

2-Chlorophenol 10

4-Chlorophenyl phenyl ether $\quad 10$

Chrysene 10

Di-n-butyl phthalate $\quad 10$

Di-n-octyl phthalate $\quad 10$

Diallate 10

Dibenz[a,h]anthracene $\quad 10$

Dibenzofuran 10

3,3-Dichlorobenzidine 10

2,4-Dichlorophenol 10

2,6-Dichlorophenol 10

Diethyl phthalate $\quad 10$

Dimethoate 10

7, 12-Dimethylbenz[a]anthracene $\quad 10$

3,3-Dimethylbenzidine 20

2,4-Dimethylphenol $\quad 10$

Dimethyl phthalate $\quad 10$

4,6-Dinitro-o-cresol 25

2,4-Dinitrophenol 25
NYCRR Appendix 33 Semivolatiles

2,4-Dinitrotoluene 10

2,6-Dinitrotoluene 10

Diphenylamine $\quad 10$

Ethyl methanesulfonate $\quad 10$

Famphur 10

Fluoranthene 10

Fluorene 10

Hexachlorobenzene $\quad 10$

Hexachlorobutadiene 10

Hexachlorocyclopentadiene $\quad 10$

Hexachloroethane 10

Hexachlorophene 100

Hexachloropropene 10

Indeno(1,2,3,-cd)pyrene $\quad 10$

Isodrin 10

Isophorone 10

Isosafrole 10

Kepone 10

Methapyrilene 10

Methyl methanesulfonate $\quad 10$

3-Methylcholanthrene $\quad 10$

2-Methylnaphthalene $\quad 10$

1,4-Naphthoquinone 10

1-Naphthylamine $\quad 10$

2-Naphthylamine 10

Nitrobenzene 10

5-Nitro-o-toluidine 10

4-Nitroquinoline 1-oxide $\quad 40$

N-Nitrosodi-n-butylamine $\quad 10$

N-Nitrosodiethylamine $\quad 10$

N-Nitrosodimethylamine 10

N-Nitrosodipropylamine 10

N-Nitrosodiphenylamine $\quad 10$

N-Nitrosomethylethylamine $\quad 10$

N-Nitrosomorpholine 10

N-Nitrosopiperidine 10

N-Nitrosopyrrolidine 10

Naphthalene $\quad 10$

0,0,0-Triethyl phosphorothioate $\quad 10$

0,0-Diethyl 0-2-pyrazinyl- phosphorothioate 10

Note: Specific quantitation limits are highly matrix-dependent and may not always be achievable.

$$
E-27
$$




\section{Table E-14 (concluded) \\ Practical Quantitation Limits (PQLs) \\ PQL \\ $(\mu g / L)$ \\ COMPOUND PQL \\ $(\mu g / L)$}

COMPOUND

NYCRR Appendix 33 Semivolatiles

p-(Dimethylamino)azobenzene $\quad 10$

p-Chloroaniline 10

p-Chloro-m-cresol 10

p-Cresol 10

p-Dichlorobenzene $\quad 10$

p-Nitroaniline 25

p-Nitrophenol 25

p-Phenylenediamine 10

Parathion 10

Pentachlorobenzene 10

Pentachloronitrobenzene $\quad 10$

Pentachlorophenol 25

Phenacetin 10

Phenanthrene 10

Phenol 10

Pronamide 10

Pyrene 10

Safrole 10

1,2,4,5-Tetrachlorobenzene $\quad 10$

Other Organic Compounds

1,2-Dichloroethelyne(Total) (1,2-DCE[total]) 10

Tributyl phosphate

5
NYCRR Appendix 33 Semivolatiles

2,3,4,6-Tetrachlorophenol 10

Tetraethyl dithiopyrophosphate $\quad 10$

1,2,4-Trichlorobenzene 10

2,4,5-Trichlorophenol 25

2,4,6-Trichlorophenol $\quad 10$

alpha,alpha-Dimethylphenethylamine $\quad 50$

m-Cresol 10

m-Dichlorobenzene 10

m-Dinitrobenzene 10

m-Nitroaniline 25

o-Cresol 10

o-Dichlorobenzene 10

o-Nitroaniline 25

o-Nitrophenol 10

o-Toluidine 10

sym-Trinitrobenzene $\quad 10$

2-Picoline 10

Pyridine 10

1,4-Dioxane 10

Note: Specific quantitation limits are highly matrix-dependent and may not always be achievable.

$E-28$ 


\section{Appendix $\mathrm{F}$ \\ Summary of Biological Data}

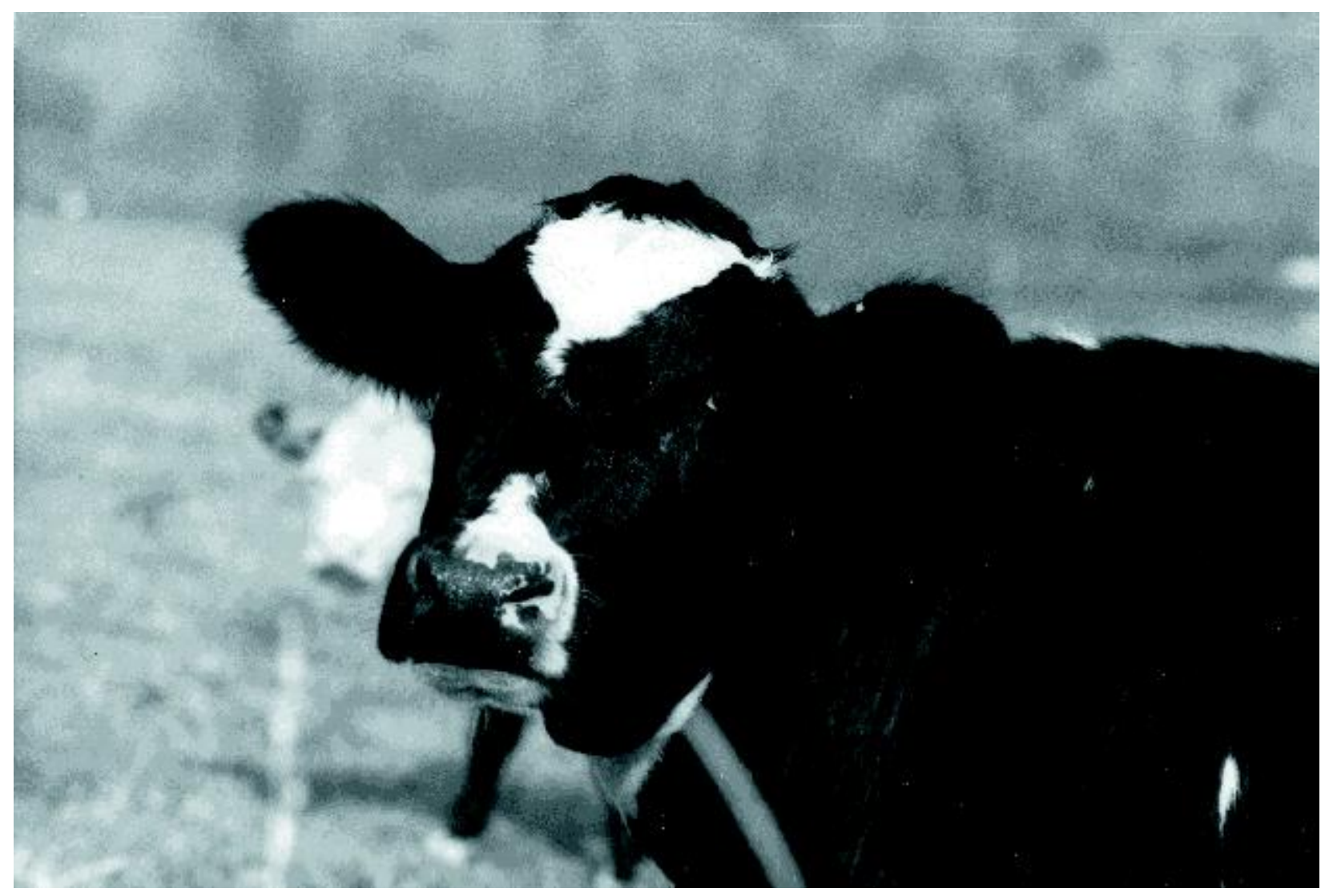

Milk and Meat Samples are Collected from Local Bovine Herds

$$
F-1
$$


The following tables contain a bolding convention devised to help the reader, when viewing the data, to quickly see the range of detectable measurements within a data series. A data series is a set of chemical or radionuclide measurements (e.g., gross alpha, gross beta, tritium) from a single location or from similar locations. Note that some tables contain data that should not be technically evaluated under this convention.

\section{Key to bolding convention:}

Results for each constituent constitute a single data series. If a radiological result is larger than the uncertainty term, the measurement is considered positive. Otherwise, a result is considered non-detectable.

If all results in a data series are positive, the lowest and highest values are bolded.

If a data series contains some positive results, the highest value is bolded.

If all values in a data series are nondetectable, no values are bolded.

$$
F-2
$$




\section{Table F-1 \\ 2003 Radioactivity Concentrations $(\mu \mathrm{Ci} / \mathrm{mL})$ in Milk}

\begin{tabular}{|c|c|c|c|c|c|}
\hline Location & H-3 & K-40 & Sr-90 & I-129 & Cs-137 \\
\hline \multicolumn{6}{|l|}{$\begin{array}{l}\text { BFMCTLN } \\
\text { (Control) }\end{array}$} \\
\hline 1st Quarter & $1.70 \pm 1.10 \mathrm{E}-07$ & $1.51 \pm 0.19 \mathrm{E}-06$ & $3.75 \pm 5.11 \mathrm{E}-10$ & $0.70 \pm 1.64 \mathrm{E}-10$ & $2.06 \pm 2.36 \mathrm{E}-09$ \\
\hline \multicolumn{6}{|l|}{$\begin{array}{l}\text { BFMCTLS } \\
\text { (Control) }\end{array}$} \\
\hline 1st Quarter & $1.34 \pm 1.04 \mathrm{E}-07$ & $1.47 \pm 0.18 \mathrm{E}-06$ & $5.60 \pm 5.50 \mathrm{E}-10$ & $-0.36 \pm 1.81 \mathrm{E}-10$ & $-1.28 \pm 2.77 \mathrm{E}-09$ \\
\hline 2nd Quarter & $0.32 \pm 1.04 \mathrm{E}-07$ & $1.32 \pm 0.16 \mathrm{E}-06$ & $2.54 \pm 2.43 \mathrm{E}-10$ & $-0.22 \pm 3.16 \mathrm{E}-10$ & $0.18 \pm 1.95 \mathrm{E}-09$ \\
\hline 3rd Quarter & $-0.45 \pm 1.07 \mathrm{E}-07$ & $1.49 \pm 0.18 \mathrm{E}-06$ & $2.30 \pm 4.63 \mathrm{E}-10$ & $-0.05 \pm 1.45 \mathrm{E}-10$ & $1.55 \pm 3.44 \mathrm{E}-09$ \\
\hline 4th Quarter & $1.39 \pm 1.16 \mathrm{E}-07$ & $1.41 \pm 0.11 \mathrm{E}-06$ & $9.33 \pm 5.85 \mathrm{E}-10$ & $0.26 \pm 3.00 \mathrm{E}-10$ & $-0.05 \pm 1.49 \mathrm{E}-09$ \\
\hline \multicolumn{6}{|l|}{$\begin{array}{l}\text { BFMREED } \\
\text { (NNW Farm) }\end{array}$} \\
\hline 1st Quarter & $0.49 \pm 1.02 \mathrm{E}-07$ & $1.35 \pm 0.17 E-06$ & $9.46 \pm 5.34 \mathrm{E}-10$ & $0.72 \pm 2.76 \mathrm{E}-10$ & $1.94 \pm 4.18 \mathrm{E}-09$ \\
\hline 2nd Quarter & $2.11 \pm 8.76 \mathrm{E}-08$ & $1.45 \pm 0.18 \mathrm{E}-06$ & $1.25 \pm 0.27 \mathrm{E}-09$ & $1.35 \pm 2.46 \mathrm{E}-10$ & $0.64 \pm 2.04 \mathrm{E}-09$ \\
\hline 3rd Quarter & $4.15 \pm 9.64 \mathrm{E}-08$ & $1.44 \pm 0.17 \mathrm{E}-06$ & $-0.17 \pm 4.33 \mathrm{E}-10$ & $3.19 \pm 2.85 \mathrm{E}-10$ & $1.79 \pm 2.20 \mathrm{E}-09$ \\
\hline 4th Quarter & $0.39 \pm 1.08 \mathrm{E}-07$ & $1.46 \pm 0.12 E-06$ & $1.36 \pm 0.63 \mathrm{E}-09$ & $0.16 \pm 2.55 \mathrm{E}-10$ & $2.42 \pm 2.31 \mathrm{E}-09$ \\
\hline \multicolumn{6}{|l|}{$\begin{array}{l}\text { BFMSCHT } \\
\text { (S Farm) }\end{array}$} \\
\hline Annual & $-1.28 \pm 1.08 \mathrm{E}-07$ & $1.11 \pm 0.10 \mathrm{E}-06$ & $1.41 \pm 0.34 \mathrm{E}-09$ & $4.70 \pm 4.35 \mathrm{E}-10$ & $1.28 \pm 1.63 \mathrm{E}-09$ \\
\hline \multicolumn{6}{|l|}{$\begin{array}{l}\text { BFMWIDR } \\
\text { (SE Farm) }\end{array}$} \\
\hline Annual & $1.28 \pm 1.20 \mathrm{E}-07$ & $1.06 \pm 0.07 \mathrm{E}-06$ & $7.71 \pm 2.93 \mathrm{E}-10$ & $-0.85 \pm 4.31 \mathrm{E}-10$ & $-0.01 \pm 1.44 \mathrm{E}-09$ \\
\hline
\end{tabular}

Note: Bolding convention applied to these data. See page F-2C.

$F-3$ 


\section{Table $\mathrm{F}-2$ \\ 2003 Radioactivity Concentrations $(\mu \mathrm{Ci} / \mathrm{g}-\mathrm{dry})$ in Meat}

2003 Radioactivity Concentrations in Beef

\begin{tabular}{|c|c|c|c|c|c|}
\hline Location & $\%$ Moisture & $\begin{array}{c}\mathbf{H}-\mathbf{3} \\
(\mu \mathrm{Ci} / \mathrm{mL})\end{array}$ & K-40 & Sr-90 & Cs-137 \\
\hline $\begin{array}{l}\text { Beef Flesh Backgr } \\
\text { (BFBCTRL 03/03) }\end{array}$ & 70.4 & $0.50 \pm 1.05 \mathrm{E}-07$ & $9.95 \pm 1.21 \mathrm{E}-06$ & $1.23 \pm 1.53 \mathrm{E}-09$ & $2.91 \pm 2.75 \mathrm{E}-08$ \\
\hline $\begin{array}{l}\text { Beef Flesh Backgr } \\
\text { (BFBCTRL 10/03) }\end{array}$ & 75.8 & $0.05 \pm 1.09 \mathrm{E}-07$ & $9.53 \pm 1.47 \mathrm{E}-06$ & $1.14 \pm 0.65 \mathrm{E}-09$ & $1.44 \pm 3.94 \mathrm{E}-08$ \\
\hline $\begin{array}{l}\text { Beef Flesh Near-S } \\
\text { (BFBNEAR 02/03) }\end{array}$ & 75.3 & $3.84 \pm 8.58 \mathrm{E}-08$ & $1.11 \pm 0.12 \mathrm{E}-05$ & $0.86 \pm 1.63 \mathrm{E}-09$ & $1.01 \pm 1.21 \mathrm{E}-08$ \\
\hline $\begin{array}{l}\text { Beef Flesh Near-S } \\
\text { (BFBNEAR 10/03) }\end{array}$ & 71.0 & $1.07 \pm 1.12 \mathrm{E}-07$ & $9.96 \pm 1.14 \mathrm{E}-06$ & $5.48 \pm 1.47 \mathrm{E}-09$ & $0.80 \pm 2.12 \mathrm{E}-08$ \\
\hline
\end{tabular}

$\underline{2003}$ Radioactivity Concentrations in Venison

Location

\% Moisture

H-3

K-40

Sr-90

Cs-137

Deer Flesh Background

$(\mu \mathrm{Ci} / \mathrm{mL})$

76.4

3.11 $\pm 1.22 \mathrm{E}-07$

1.01 $\pm 0.09 E-05$

1.74 $\pm 1.29 \mathrm{E}-09$

$1.06 \pm 0.25 E-07$

Deer Flesh Background

(BFDCTRL 12/03)

71.4

$2.81 \pm 1.20 \mathrm{E}-07$

$9.58 \pm 0.80 \mathrm{E}-06$

$-1.14 \pm 1.22 \mathrm{E}-09$

$2.55 \pm 2.05 \mathrm{E}-08$

Deer Flesh Background

(BFDCTRL 12/03)

73.4

$0.99 \pm 1.13 \mathrm{E}-07$

8.84 $\pm 0.97 E-06$

$-1.01 \pm 1.36 \mathrm{E}-09$

$3.13 \pm 3.39 \mathrm{E}-08$

Deer Flesh Near-Site

(BFDNEAR 10/03)

70.6

$0.98 \pm 1.14 \mathrm{E}-07$

$9.24 \pm 0.84 \mathrm{E}-06$

1.53 $\pm 1.23 E-09$

1.31 $\pm 0.31 E-07$

Deer Flesh Near-Site

(BFDNEAR 10/03)

69.4

$-0.24 \pm 1.08 \mathrm{E}-07$

8.81 $\pm 0.86 E-06$

$1.28 \pm 0.58 \mathrm{E}-09$

$3.04 \pm 1.88 \mathrm{E}-08$

Deer Flesh Near-Site

(BFDNEAR 10/03)

Note: Bolding convention applied to venison data. See page F-2C.

WVDP Annual Site Environmental Report

$$
F-4
$$




\section{Table F-3}

\section{Radioactivity Concentrations $(\mu \mathrm{Ci} / \mathrm{g}-$ dry) in Food Crops}

Location

$\%$ Moisture

H-3

K-40

Co-60

Sr-90

Cs-137

$(\mu \mathrm{Ci} / \mathrm{mL})$

CORN

Background

(BFVCTRC)

79.5

$2.96 \pm 1.50 \mathrm{E}-07$

$1.16 \pm 0.09 \mathrm{E}-05$

$0.54 \pm 1.30 \mathrm{E}-08$

$5.52 \pm 1.81 \mathrm{E}-09$

$0.26 \pm 1.22 \mathrm{E}-08$

Near-Site

(BFVNEAC)

75.4

$6.67 \pm 1.43 \mathrm{E}-07$

$1.12 \pm 0.10 \mathrm{E}-05$

$2.69 \pm 2.59 \mathrm{E}-08$

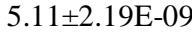

$0.19 \pm 2.84 \mathrm{E}-08$

\section{BEANS}

\section{Background}

(BFVCTRB)

90.9

$1.33 \pm 1.11 \mathrm{E}-07$

$3.24 \pm 0.36 \mathrm{E}-05$

$-0.96 \pm 8.03 \mathrm{E}-08$

$4.25 \pm 0.31 \mathrm{E}-08$

$4.30 \pm 6.54 \mathrm{E}-08$

Near-Site

(BFVNEAB)

92.6

$2.12 \pm 1.15 \mathrm{E}-07$

$1.77 \pm 0.33 \mathrm{E}-05$

$-2.65 \pm 8.09 \mathrm{E}-08$

$1.06 \pm 0.05 \mathrm{E}-07$

$1.54 \pm 6.32 \mathrm{E}-08$

\section{APPLES}

Background

(BFVCTRA)

87.8

$2.59 \pm 1.05 \mathrm{E}-07 \quad 5.23 \pm 0.73 \mathrm{E}-06$

$1.51 \pm 2.59 \mathrm{E}-08$

$2.95 \pm 1.26 \mathrm{E}-09$

$0.02 \pm 2.00 \mathrm{E}-08$

Near-Site

(BFVNEAAF)

81.0

$3.29 \pm 1.15 \mathrm{E}-07 \quad 8.44 \pm 0.97 \mathrm{E}-06$

$1.44 \pm 2.05 \mathrm{E}-08$

$6.83 \pm 1.05 \mathrm{E}-09$

$6.86 \pm 3.13 \mathrm{E}-08$

Note: Bolding convention not applicable to these data.

$$
\text { F - } 5
$$




\title{
Table F-4 \\ 2003 Radioactivity Concentrations ( $\mu$ Ci/g - dry) in Fish Flesh From Cattaraugus Creek
}

\author{
Cattaraugus Creek above the Springville Dam (BFFCATC)
}

\begin{tabular}{lccc} 
& & \multicolumn{2}{c}{ Annual 2003 } \\
Species & \% Moisture & Sr-90 & Cs-137 \\
Hog-nosed Sucker & 74.9 & $6.82 \pm 0.37 \mathrm{E}-08$ & $0.98 \pm 9.50 \mathrm{E}-08$ \\
Hog-nosed Sucker & 78.8 & $5.47 \pm 0.26 \mathrm{E}-08$ & $1.44 \pm 9.08 \mathrm{E}-08$ \\
Hog-nosed Sucker & 80.1 & $2.23 \pm 0.14 \mathrm{E}-07$ & $0.50 \pm 2.77 \mathrm{E}-07$ \\
Hog-nosed Sucker & 76.5 & $6.22 \pm 0.32 \mathrm{E}-08$ & $1.23 \pm 4.16 \mathrm{E}-07$ \\
Creek Chub & 80.6 & $\mathbf{3 . 4 0} \pm \mathbf{0 . 1 8 E}-\mathbf{0 7}$ & $1.04 \pm 1.36 \mathrm{E}-07$ \\
Hog-nosed Sucker & 80.8 & $\mathbf{1 . 0 4} \pm \mathbf{0 . 5 6 E}-\mathbf{0 8}$ & $7.04 \pm 8.17 \mathrm{E}-08$ \\
Hog-nosed Sucker & 76.9 & $1.26 \pm 0.67 \mathrm{E}-08$ & $4.43 \pm 8.88 \mathrm{E}-08$ \\
Hog-nosed Sucker & 75.5 & $1.18 \pm 0.07 \mathrm{E}-07$ & $0.39 \pm 1.06 \mathrm{E}-07$ \\
Hog-nosed Sucker & 78.0 & $1.65 \pm 0.67 \mathrm{E}-08$ & $2.25 \pm 6.88 \mathrm{E}-08$ \\
Hog-nosed Sucker & 76.2 & $2.31 \pm 0.66 \mathrm{E}-08$ & $5.19 \pm 5.81 \mathrm{E}-08$ \\
& & & \\
Average \% Moisture & 77.8 & & $<9.29 \mathrm{E}-08$ \\
& & & $<5.16 \mathrm{E}-07$ \\
Median & & $5.84 \mathrm{E}-08$ & \\
Maximum & & $3.40 \mathrm{E}-07$ & \\
Minimum & & $1.04 \mathrm{E}-08$ & $<$
\end{tabular}

\section{Cattaraugus Creek below the Springville Dam (BFFCATD)}

$\begin{array}{lcrr}\text { Species } & \text { \% Moisture } & \text { Sr-90 } & \text { Cs-137 } \\ \text { Steelhead Trout } & 77.9 & \mathbf{6 . 6 7} \pm \mathbf{1 . 8 3 E}-\mathbf{0 9} & \mathbf{3 . 0 8} \pm \mathbf{1 . 4 7 E}-08 \\ \text { Steelhead Trout } & 70.6 & 4.30 \pm 1.16 \mathrm{E}-09 & 0.30 \pm 2.33 \mathrm{E}-08 \\ \text { Steelhead Trout } & 70.7 & 3.46 \pm 9.00 \mathrm{E}-10 & 1.01 \pm 2.78 \mathrm{E}-08 \\ \text { Steelhead Trout } & 70.9 & 8.51 \pm 9.40 \mathrm{E}-10 & 1.08 \pm 2.41 \mathrm{E}-08 \\ \text { Steelhead Trout } & 76.6 & 1.85 \pm 0.93 \mathrm{E}-09 & 1.54 \pm 1.19 \mathrm{E}-08 \\ \text { Steelhead Trout } & 70.3 & 3.98 \pm 0.83 \mathrm{E}-09 & 2.21 \pm 2.08 \mathrm{E}-08 \\ \text { Steelhead Trout } & 75.8 & 3.77 \pm 0.93 \mathrm{E}-09 & 2.19 \pm 2.04 \mathrm{E}-08 \\ \text { Steelhead Trout } & 71.1 & 2.71 \pm 0.75 \mathrm{E}-09 & 2.89 \pm 2.63 \mathrm{E}-08 \\ \text { Steelhead Trout } & 70.7 & 1.81 \pm 0.72 \mathrm{E}-09 & 2.74 \pm 3.70 \mathrm{E}-08 \\ \text { Steelhead Trout } & 71.3 & 3.03 \pm 0.94 \mathrm{E}-09 & 0.00 \pm 3.00 \mathrm{E}-08 \\ & & & \\ \text { Average \% Moisture } & 72.6 & & \\ & & & \\ \text { Median } & & & \\ \text { Maximum } & & <.67 \mathrm{E}-09 & \\ \text { Minimum } & & <.00 \mathrm{E}-10 & 1.54 \mathrm{E}-08\end{array}$

Note: Bolding convention applied to these data. See page F-2C.

$$
F-6
$$




\section{Table F-4 (concluded) \\ 2003 Radioactivity Concentrations ( $\mu$ Ci/g - dry) in Fish Flesh \\ From Cattaraugus Creek}

\section{Cattaraugus Creek Background (BFFCTRL)}

\begin{tabular}{lccr} 
& & \multicolumn{2}{c}{ Annual 2003 } \\
Species & \% Moisture & Sr-90 & Cs-137 \\
White Sucker & 80.4 & $\mathbf{3 . 9 0} \pm \mathbf{0 . 3 0 E - 0 8}$ & $4.43 \pm 7.53 \mathrm{E}-08$ \\
White Sucker & 76.4 & $1.34 \pm 0.21 \mathrm{E}-08$ & $-0.26 \pm 8.44 \mathrm{E}-08$ \\
Brown Trout & 74.1 & $4.13 \pm 1.96 \mathrm{E}-09$ & $-0.27 \pm 1.13 \mathrm{E}-07$ \\
White Sucker & 77.3 & $1.34 \pm 0.17 \mathrm{E}-08$ & $6.31 \pm 8.29 \mathrm{E}-08$ \\
White Sucker & 77.6 & $1.37 \pm 0.27 \mathrm{E}-08$ & $0.33 \pm 1.74 \mathrm{E}-07$ \\
White Sucker & 78.6 & $1.02 \pm 0.31 \mathrm{E}-08$ & $4.12 \pm 6.26 \mathrm{E}-08$ \\
White Sucker & 80.4 & $1.89 \pm 0.63 \mathrm{E}-08$ & $2.48 \pm 7.33 \mathrm{E}-08$ \\
Hog-nosed Sucker & 75.4 & $2.31 \pm 0.56 \mathrm{E}-08$ & $6.09 \pm 8.24 \mathrm{E}-08$ \\
Hog-nosed Sucker & 76.4 & $1.94 \pm 0.41 \mathrm{E}-08$ & $-0.75 \pm 6.39 \mathrm{E}-08$ \\
Hog-nosed Sucker & 75.4 & $2.00 \pm 0.56 \mathrm{E}-08$ & $0.03 \pm 1.11 \mathrm{E}-07$ \\
& & & \\
Average \% Moisture & 77.2 & & $<1.74 \mathrm{E}-07$ \\
& & & $<6.26 \mathrm{E}-08$
\end{tabular}

Note: Bolding convention applied to these data. See page F-2C.

$$
F-7
$$


This page intentionally left blank

$$
F-8
$$




\section{Appendix G-1}

\section{Summary of Soil and Aquatic Sediment \\ Guidelines and Standards}

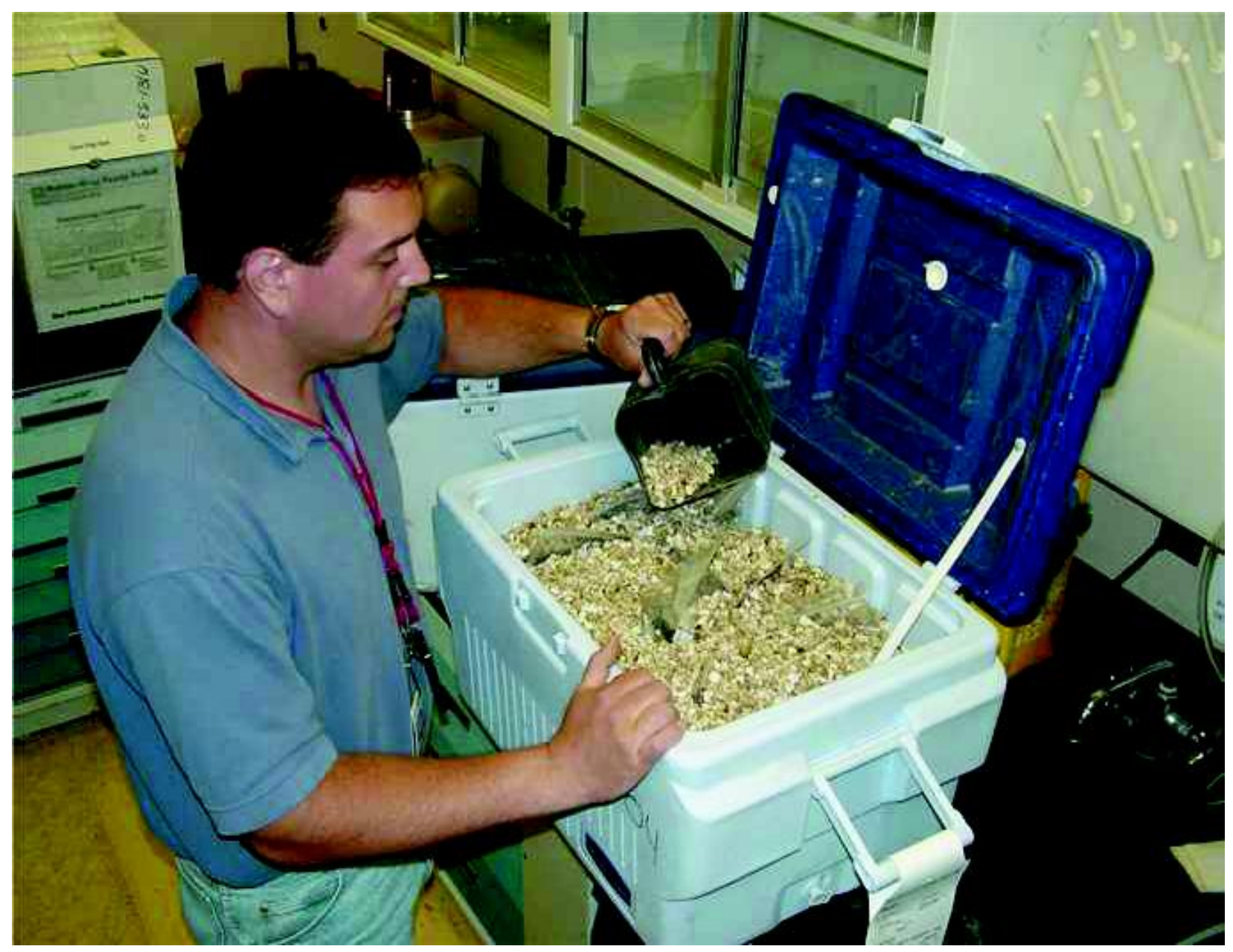

Packaging Samples for Shipment to Off-Site Laboratories

$G-1$ 
This page intentionally left blank

$G-2$ 


\section{Table G-1A}

\section{Eastern U.S.A. Background Concentrations for Soils ${ }^{a}$}

\begin{tabular}{|l|c|c|}
\hline \multicolumn{1}{|c|}{ Analyte } & Units & $\begin{array}{c}\text { Eastern U.S.A Background } \\
\text { Concentrations for Soil }\end{array}$ \\
\hline Aluminum & $\mathrm{mg} / \mathrm{kg}(\mathrm{ppm})$ & 33,000 \\
\hline Antimony & $\mathrm{mg} / \mathrm{kg}(\mathrm{ppm})$ & -- \\
\hline Arsenic & $\mathrm{mg} / \mathrm{kg}(\mathrm{ppm})$ & $3-12^{\mathrm{b}}$ \\
\hline Barium & $\mathrm{mg} / \mathrm{kg}(\mathrm{ppm})$ & $15-600$ \\
\hline Beryllium & $\mathrm{mg} / \mathrm{kg}(\mathrm{ppm})$ & $0-1.75$ \\
\hline Cadmium & $\mathrm{mg} / \mathrm{kg}(\mathrm{ppm})$ & $0.1-1$ \\
\hline Calcium & $\mathrm{mg} / \mathrm{kg}(\mathrm{ppm})$ & $130-35,000$ \\
\hline Chromium & $\mathrm{mg} / \mathrm{kg}(\mathrm{ppm})$ & $1.5-40^{\mathrm{b}}$ \\
\hline Cobalt & $\mathrm{mg} / \mathrm{kg}(\mathrm{ppm})$ & $2.5-60^{\mathrm{b}}$ \\
\hline Copper & $\mathrm{mg} / \mathrm{kg}(\mathrm{ppm})$ & $1-50$ \\
\hline Iron & $\mathrm{mg} / \mathrm{kg}(\mathrm{ppm})$ & $2,000-550,000$ \\
\hline Lead & $\mathrm{mg} / \mathrm{kg}(\mathrm{ppm})$ & $4-61^{\mathrm{c}}$ \\
\hline Magnesium & $\mathrm{mg} / \mathrm{kg}(\mathrm{ppm})$ & $100-5,000$ \\
\hline Manganese & $\mathrm{mg} / \mathrm{kg}(\mathrm{ppm})$ & $50-5,000$ \\
\hline Mercury & $\mathrm{mg} / \mathrm{kg}(\mathrm{ppm})$ & $0.001-0.2$ \\
\hline Nickel & $\mathrm{mg} / \mathrm{kg}(\mathrm{ppm})$ & $0.5-25$ \\
\hline Potassium & $\mathrm{mg} / \mathrm{kg}(\mathrm{ppm})$ & $8,500-43,000^{\mathrm{b}}$ \\
\hline Selenium & $\mathrm{mg} / \mathrm{kg}(\mathrm{ppm})$ & $0.1-3.9$ \\
\hline Silver & $\mathrm{mg} / \mathrm{kg}(\mathrm{ppm})$ & -- \\
\hline Sodium & $\mathrm{mg} / \mathrm{kg}(\mathrm{ppm})$ & $6,000-8,000$ \\
\hline Thallium & $\mathrm{mg} / \mathrm{kg}(\mathrm{ppm})$ & -- \\
\hline Vanadium & $\mathrm{mg} / \mathrm{kg}(\mathrm{ppm})$ & $1-300$ \\
\hline Zinc & $\mathrm{mg} / \mathrm{kg}(\mathrm{ppm})$ & $9-50$ \\
\hline
\end{tabular}

-- No reference level available for these analytes

${ }^{a}$ Source: New York State Department of Environmental Conservation "Technical and Administrative Guidance Memorandum (TAGM) \#4046"

${ }^{b}$ New York State background

${ }^{c}$ Background levels for lead vary widely. Average levels in undeveloped, rural areas may range from 4-61 ppm. Average background levels in metropolitan or suburban areas or near highways are much higher and typically range from 200-500 ppm.

$G-3$ 


\section{Table G-1B}

\section{Screening Concentrations for Contaminated Sediments ${ }^{a}$}

\begin{tabular}{|c|c|c|c|}
\hline Analyte & Units & Lowest Effect Level $^{\text {b }}$ & Severe Effect Level ${ }^{c}$ \\
\hline Aluminum & $\mathrm{mg} / \mathrm{kg}(\mathrm{ppm})$ & -- & -- \\
\hline Antimony & $\mathrm{mg} / \mathrm{kg}(\mathrm{ppm})$ & $2.0(\mathrm{~L})$ & $25.0(\mathrm{~L})$ \\
\hline Arsenic & $\mathrm{mg} / \mathrm{kg}(\mathrm{ppm})$ & $6.0(\mathrm{P})$ & $33.0(\mathrm{P})$ \\
\hline Barium & $\mathrm{mg} / \mathrm{kg}(\mathrm{ppm})$ & -- & -- \\
\hline Beryllium & $\mathrm{mg} / \mathrm{kg}(\mathrm{ppm})$ & -- & -- \\
\hline Cadmium & $\mathrm{mg} / \mathrm{kg}(\mathrm{ppm})$ & $0.6(\mathrm{P})$ & $9.0(\mathrm{~L})$ \\
\hline Calcium & $\mathrm{mg} / \mathrm{kg}(\mathrm{ppm})$ & -- & -- \\
\hline Chromium & $\mathrm{mg} / \mathrm{kg}(\mathrm{ppm})$ & $26.0(\mathrm{P})$ & $110.0(\mathrm{P})$ \\
\hline Cobalt & $\mathrm{mg} / \mathrm{kg}(\mathrm{ppm})$ & -- & -- \\
\hline Copper & $\mathrm{mg} / \mathrm{kg}(\mathrm{ppm})$ & $16.0(\mathrm{P})$ & $110.0(\mathrm{P})$ \\
\hline Iron & $\%$ & $2.0(\mathrm{P})$ & $4.0(\mathrm{P})$ \\
\hline Lead & $\mathrm{mg} / \mathrm{kg}(\mathrm{ppm})$ & $31.0(\mathrm{P})$ & $110.0(\mathrm{~L})$ \\
\hline Magnesium & $\mathrm{mg} / \mathrm{kg}(\mathrm{ppm})$ & -- & -- \\
\hline Manganese & $\mathrm{mg} / \mathrm{kg}(\mathrm{ppm})$ & $460.0(\mathrm{P})$ & $1,100.0(\mathrm{~L})$ \\
\hline Mercury & $\mathrm{mg} / \mathrm{kg}(\mathrm{ppm})$ & $0.15(\mathrm{~L})$ & $1.3(\mathrm{~L})$ \\
\hline Nickel & $\mathrm{mg} / \mathrm{kg}(\mathrm{ppm})$ & $16.0(\mathrm{P})$ & $50.0(\mathrm{~L})$ \\
\hline Potassium & $\mathrm{mg} / \mathrm{kg}(\mathrm{ppm})$ & -- & -- \\
\hline Selenium & $\mathrm{mg} / \mathrm{kg}(\mathrm{ppm})$ & -- & -- \\
\hline Silver & $\mathrm{mg} / \mathrm{kg}(\mathrm{ppm})$ & $1.0(\mathrm{~L})$ & $2.2(\mathrm{~L})$ \\
\hline Sodium & $\mathrm{mg} / \mathrm{kg}(\mathrm{ppm})$ & -- & -- \\
\hline Thallium & $\mathrm{mg} / \mathrm{kg}(\mathrm{ppm})$ & -- & -- \\
\hline Vanadium & $\mathrm{mg} / \mathrm{kg}(\mathrm{ppm})$ & -- & -- \\
\hline Zinc & $\mathrm{mg} / \mathrm{kg}(\mathrm{ppm})$ & $120.0(\mathrm{P} / \mathrm{L})$ & $270.0(\mathrm{~L})$ \\
\hline
\end{tabular}

-- No reference value available for these analytes

${ }^{a}$ Source: New York State Department of Environmental Conservation "Technical Guidance for Screening Contaminated Sediments," January 1999

${ }^{b}$ The Lowest Effect Level for each metal is the lowest of the either the Persaud et al. (1992) Lowest Effect Level or the Long and Morgan (1990) Effect Range-Low

${ }^{c}$ The Severe Effect Level for each metal is the lowest of either the Persaud et al. (1992) Severe Effect Level or the Long and Morgan (1990) Effect Range-Moderate

$L$ - An " $L$ " following a criterion indicates that it was taken from Long and Morgan (1990).

$P$ - A "P" following a criterion indicates that it was taken from Persaud et al. (1992).

\section{Table G-1C}

\section{Screening Thresholds for In-Water and Riparian Management of Sediment and Dredge Material ${ }^{a}$}

\begin{tabular}{|l|c|c|}
\hline \multicolumn{1}{|c|}{ Analyte } & Units & No Appreciable Contamination Level \\
\hline Arsenic & $\mathrm{mg} / \mathrm{kg}(\mathrm{ppm})$ & 14 \\
\hline Cadmium & $\mathrm{mg} / \mathrm{kg}(\mathrm{ppm})$ & $<1.2$ \\
\hline Copper & $\mathrm{mg} / \mathrm{kg}(\mathrm{ppm})$ & $<33$ \\
\hline Lead & $\mathrm{mg} / \mathrm{kg}(\mathrm{ppm})$ & $<33$ \\
\hline Mercury & $\mathrm{mg} / \mathrm{kg}(\mathrm{ppm})$ & 0.17 \\
\hline
\end{tabular}

${ }^{a}$ Source: Draft New York State Department of Environmental Conservation Technical and Operational Guidance Series (TOGs) \#5.1.9, "In-Water and Riparian Management of Sediment and Dredge Material" 


\section{Appendix G-2}

Soil and Sediment Data 
This page intentionally left blank

$G-6$ 


\section{Table G-2A}

\section{Results in On-Site Soils Downstream of the WVDP at Frank's Creek (SNSP006)}

\begin{tabular}{|c|c|c|c|c|c|c|}
\hline \multirow[b]{2}{*}{ Analyte } & \multirow[b]{2}{*}{ Units } & \multirow[b]{2}{*}{$\mathbf{N}$} & \multirow[b]{2}{*}{ SNSP006 } & \multicolumn{3}{|c|}{ Guidance Values } \\
\hline & & & & $\begin{array}{c}\text { Lowest Effect } \\
\text { Level }^{\mathrm{a}}\end{array}$ & $\begin{array}{c}\text { Severe Effect } \\
\text { Level }^{\mathrm{a}}\end{array}$ & $\begin{array}{c}\text { No Appreciable } \\
\text { Contamination } \\
\text { Level }^{\text {b }}\end{array}$ \\
\hline Gross Alpha & $\mu \mathrm{Ci} / \mathrm{g}$ & 1 & $7.95 \pm 2.83 \mathrm{E}-06$ & -- & -- & -- \\
\hline Gross Beta & $\mu \mathrm{Ci} / \mathrm{g}$ & 1 & $4.08 \pm 0.43 \mathrm{E}-05$ & -- & -- & -- \\
\hline K-40 & $\mu \mathrm{Ci} / \mathrm{g}$ & 1 & $1.48 \pm 0.16 \mathrm{E}-05$ & -- & -- & -- \\
\hline Co-60 & $\mu \mathrm{Ci} / \mathrm{g}$ & 1 & $0.97 \pm 2.63 \mathrm{E}-08$ & -- & -- & -- \\
\hline Sr-90 & $\mu \mathrm{Ci} / \mathrm{g}$ & 1 & $1.13 \pm 0.07 \mathrm{E}-06$ & -- & -- & -- \\
\hline Cs-137 & $\mu \mathrm{Ci} / \mathrm{g}$ & 1 & $1.08 \pm 0.12 \mathrm{E}-05$ & -- & -- & -- \\
\hline U-232 & $\mu \mathrm{Ci} / \mathrm{g}$ & 1 & $2.21 \pm 5.31 \mathrm{E}-08$ & -- & -- & -- \\
\hline U-233/234 & $\mu \mathrm{Ci} / \mathrm{g}$ & 1 & $6.20 \pm 1.80 \mathrm{E}-07$ & -- & -- & -- \\
\hline$U-235 / 236$ & $\mu \mathrm{Ci} / \mathrm{g}$ & 1 & $4.50 \pm 5.64 \mathrm{E}-08$ & -- & -- & -- \\
\hline U-238 & $\mu \mathrm{Ci} / \mathrm{g}$ & 1 & $6.42 \pm 1.81 \mathrm{E}-07$ & -- & -- & -- \\
\hline Total U & $\mu \mathrm{g} / \mathrm{g}$ & 1 & $2.99 \pm 0.04 \mathrm{E}-01$ & -- & -- & -- \\
\hline Pu-238 & $\mu \mathrm{Ci} / \mathrm{g}$ & 1 & $3.62 \pm 3.03 \mathrm{E}-08$ & -- & -- & -- \\
\hline $\mathrm{Pu}-239 / 240$ & $\mu \mathrm{Ci} / \mathrm{g}$ & 1 & $3.45 \pm 2.88 \mathrm{E}-08$ & -- & -- & -- \\
\hline Am-241 & $\mu \mathrm{Ci} / \mathrm{g}$ & 1 & $5.72 \pm 4.26 \mathrm{E}-08$ & -- & -- & -- \\
\hline Aluminum & $\mathrm{mg} / \mathrm{kg}$ & 1 & 5,975 & -- & -- & -- \\
\hline Antimony & $\mathrm{mg} / \mathrm{kg}$ & 1 & $<0.28$ & 2.0 & 25.0 & -- \\
\hline Arsenic & $\mathrm{mg} / \mathrm{kg}$ & 1 & 7.2 & 6.0 & 33.0 & 14 \\
\hline Barium & $\mathrm{mg} / \mathrm{kg}$ & 1 & 66.2 & -- & -- & -- \\
\hline Beryllium & $\mathrm{mg} / \mathrm{kg}$ & 1 & 0.36 & -- & -- & -- \\
\hline Cadmium & $\mathrm{mg} / \mathrm{kg}$ & 1 & 0.11 & 0.6 & 9.0 & $<1.2$ \\
\hline Calcium & $\mathrm{mg} / \mathrm{kg}$ & 1 & 17,450 & -- & -- & -- \\
\hline Chromium & $\mathrm{mg} / \mathrm{kg}$ & 1 & 9.5 & 26.0 & 110.0 & -- \\
\hline Cobalt & $\mathrm{mg} / \mathrm{kg}$ & 1 & 9.5 & -- & -- & -- \\
\hline Copper & $\mathrm{mg} / \mathrm{kg}$ & 1 & 17.0 & 16.0 & 110.0 & $<33$ \\
\hline Iron & $\%$ & 1 & 0.02 & 2.0 & 4.0 & -- \\
\hline Lead & $\mathrm{mg} / \mathrm{kg}$ & 1 & 11.9 & 31.0 & 110.0 & $<33$ \\
\hline Magnesium & $\mathrm{mg} / \mathrm{kg}$ & 1 & 6,760 & -- & -- & -- \\
\hline Manganese & $\mathrm{mg} / \mathrm{kg}$ & 1 & 592 & 460.0 & $1,100.0$ & -- \\
\hline Mercury & $\mathrm{mg} / \mathrm{kg}$ & 1 & $<0.02$ & 0.15 & 1.3 & 0.17 \\
\hline Nickel & $\mathrm{mg} / \mathrm{kg}$ & 1 & 19.1 & 16.0 & 50.0 & -- \\
\hline Potassium & $\mathrm{mg} / \mathrm{kg}$ & 1 & 706 & -- & -- & -- \\
\hline Selenium & $\mathrm{mg} / \mathrm{kg}$ & 1 & $<0.52$ & -- & -- & -- \\
\hline Silver & $\mathrm{mg} / \mathrm{kg}$ & 1 & $<0.15$ & 1.0 & 2.2 & -- \\
\hline Sodium & $\mathrm{mg} / \mathrm{kg}$ & 1 & 137.0 & -- & -- & -- \\
\hline Thallium & $\mathrm{mg} / \mathrm{kg}$ & 1 & $<0.56$ & -- & -- & -- \\
\hline Vanadium & $\mathrm{mg} / \mathrm{kg}$ & 1 & 12.8 & -- & -- & -- \\
\hline Zinc & $\mathrm{mg} / \mathrm{kg}$ & 1 & 67.6 & 120.0 & 270.0 & -- \\
\hline
\end{tabular}

Note: Effects of radiological substances are addressed with the evaluation of radiological dose to biota (see Chapter 2 [p. 2-32]).

$N$ - Number of samples

-- No reference standard available

a Screening guidelines for chemical constituents obtained from NYSDEC "Technical Guidance for Screening Contaminated Sediments"

${ }^{b}$ NYSDEC: Draft Technical and Operational Guidance Series 5.1.9, "In-Water and Riparian Management of Sediment and Dredge Material," January 2003.

$$
\text { G - } 7
$$


Table G-2B

2003 Results in On-Site Soils From North Swamp (SNSW74A)

\begin{tabular}{|c|c|c|c|c|}
\hline Analyte & Units & $\mathbf{N}$ & SNSW74A & Reference Value $^{a}$ \\
\hline Gross Alpha & $\mu \mathrm{Ci} / \mathrm{g}$ & 1 & $7.69 \pm 2.15 \mathrm{E}-06$ & -- \\
\hline Gross Beta & $\mu \mathrm{Ci} / \mathrm{g}$ & 1 & $2.34 \pm 0.28 \mathrm{E}-05$ & -- \\
\hline K-40 & $\mu \mathrm{Ci} / \mathrm{g}$ & 1 & $1.42 \pm 0.14 \mathrm{E}-05$ & -- \\
\hline Co-60 & $\mu \mathrm{Ci} / \mathrm{g}$ & 1 & $-1.21 \pm 2.84 \mathrm{E}-08$ & -- \\
\hline Sr-90 & $\mu \mathrm{Ci} / \mathrm{g}$ & 1 & $2.20 \pm 0.44 \mathrm{E}-07$ & -- \\
\hline Cs-137 & $\mu \mathrm{Ci} / \mathrm{g}$ & 1 & $2.55 \pm 0.20 \mathrm{E}-06$ & -- \\
\hline U-232 & $\mu \mathrm{Ci} / \mathrm{g}$ & 1 & $-0.34 \pm 2.54 \mathrm{E}-08$ & -- \\
\hline U-233/234 & $\mu \mathrm{Ci} / \mathrm{g}$ & 1 & $1.00 \pm 0.21 \mathrm{E}-06$ & -- \\
\hline U-235/236 & $\mu \mathrm{Ci} / \mathrm{g}$ & 1 & $1.13 \pm 0.76 \mathrm{E}-07$ & -- \\
\hline U-238 & $\mu \mathrm{Ci} / \mathrm{g}$ & 1 & $9.10 \pm 2.02 \mathrm{E}-07$ & -- \\
\hline Total U & $\mu \mathrm{g} / \mathrm{g}$ & 1 & $7.57 \pm 0.12 \mathrm{E}-01$ & -- \\
\hline Pu-238 & $\mu \mathrm{Ci} / \mathrm{g}$ & 1 & $2.67 \pm 2.61 \mathrm{E}-08$ & -- \\
\hline Pu-239/240 & $\mu \mathrm{Ci} / \mathrm{g}$ & 1 & $1.07 \pm 0.52 \mathrm{E}-07$ & -- \\
\hline Am-241 & $\mu \mathrm{Ci} / \mathrm{g}$ & 1 & $1.56 \pm 0.69 \mathrm{E}-07$ & -- \\
\hline Aluminum & $\mathrm{mg} / \mathrm{kg}$ & 1 & 7,850 & 33,000 \\
\hline Antimony & $\mathrm{mg} / \mathrm{kg}$ & 1 & 0.45 & -- \\
\hline Arsenic & $\mathrm{mg} / \mathrm{kg}$ & 1 & 11.3 & $3-12^{b}$ \\
\hline Barium & $\mathrm{mg} / \mathrm{kg}$ & 1 & 86.0 & $15-600$ \\
\hline Beryllium & $\mathrm{mg} / \mathrm{kg}$ & 1 & 0.45 & $0-1.75$ \\
\hline Cadmium & $\mathrm{mg} / \mathrm{kg}$ & 1 & 0.45 & $0.1-1$ \\
\hline Calcium & $\mathrm{mg} / \mathrm{kg}$ & 1 & 47,400 & $130-35,000$ \\
\hline Chromium & $\mathrm{mg} / \mathrm{kg}$ & 1 & 16.5 & $1.5-40^{\mathrm{b}}$ \\
\hline Cobalt & $\mathrm{mg} / \mathrm{kg}$ & 1 & 8.1 & $2.5-60^{\mathrm{b}}$ \\
\hline Copper & $\mathrm{mg} / \mathrm{kg}$ & 1 & 31.1 & $1-50$ \\
\hline Iron & $\mathrm{mg} / \mathrm{kg}$ & 1 & 20,500 & $2,000-550,000$ \\
\hline Lead & $\mathrm{mg} / \mathrm{kg}$ & 1 & 22.8 & $4-61^{c}$ \\
\hline Magnesium & $\mathrm{mg} / \mathrm{kg}$ & 1 & 12,200 & $100-5,000$ \\
\hline Manganese & $\mathrm{mg} / \mathrm{kg}$ & 1 & 1,230 & $50-5,000$ \\
\hline Mercury & $\mathrm{mg} / \mathrm{kg}$ & 1 & $<0.03$ & $0.001-0.2$ \\
\hline Nickel & $\mathrm{mg} / \mathrm{kg}$ & 1 & 24.3 & $0.5-25$ \\
\hline Potassium & $\mathrm{mg} / \mathrm{kg}$ & 1 & 1,010 & $8,500-43,000^{\mathrm{b}}$ \\
\hline Selenium & $\mathrm{mg} / \mathrm{kg}$ & 1 & $<0.68$ & $0.1-3.9$ \\
\hline Silver & $\mathrm{mg} / \mathrm{kg}$ & 1 & $<0.19$ & -- \\
\hline Sodium & $\mathrm{mg} / \mathrm{kg}$ & 1 & 229.0 & $6,000-8,000$ \\
\hline Thallium & $\mathrm{mg} / \mathrm{kg}$ & 1 & $<0.72$ & -- \\
\hline Vanadium & $\mathrm{mg} / \mathrm{kg}$ & 1 & 15.9 & $1-300$ \\
\hline Zinc & $\mathrm{mg} / \mathrm{kg}$ & 1 & 267.0 & $9-50$ \\
\hline
\end{tabular}

$N$ - Number of samples

-- No reference standard available for these analytes

${ }^{a}$ NYSDEC: Technical and Administrative Guidance Memorandum (TAGM) \#4046.

${ }^{b}$ New York State background

${ }^{c}$ Background levels vary widely. Average levels in undeveloped rural areas may range from 4-61 ppm (reported here). Average background levels in metropolitain or suburban areas, or near highways are much higher and typically range from 200-500 ppm.

$G-8$ 


\section{Table G-2C}

\section{Results in On-Site Soils From Northeast Swamp (SNSWAMP)}

\begin{tabular}{|c|c|c|c|c|}
\hline Analyte & Units & $\mathbf{N}$ & SNSWAMP & Reference Value $^{\mathrm{a}}$ \\
\hline Gross Alpha & $\mu \mathrm{Ci} / \mathrm{g}$ & 1 & $1.32 \pm 0.27 \mathrm{E}-05$ & -- \\
\hline Gross Beta & $\mu \mathrm{Ci} / \mathrm{g}$ & 1 & $4.41 \pm 0.36 \mathrm{E}-05$ & -- \\
\hline K-40 & $\mu \mathrm{Ci} / \mathrm{g}$ & 1 & $1.60 \pm 0.14 \mathrm{E}-05$ & -- \\
\hline Co-60 & $\mu \mathrm{Ci} / \mathrm{g}$ & 1 & $1.07 \pm 2.24 \mathrm{E}-08$ & -- \\
\hline Sr-90 & $\mu \mathrm{Ci} / \mathrm{g}$ & 1 & $2.11 \pm 0.08 \mathrm{E}-06$ & -- \\
\hline Cs-137 & $\mu \mathrm{Ci} / \mathrm{g}$ & 1 & $9.94 \pm 0.76 \mathrm{E}-06$ & -- \\
\hline U-232 & $\mu \mathrm{Ci} / \mathrm{g}$ & 1 & $2.40 \pm 5.76 \mathrm{E}-08$ & -- \\
\hline U-233/234 & $\mu \mathrm{Ci} / \mathrm{g}$ & 1 & $1.13 \pm 0.23 \mathrm{E}-06$ & -- \\
\hline U-235/236 & $\mu \mathrm{Ci} / \mathrm{g}$ & 1 & $9.99 \pm 6.92 \mathrm{E}-08$ & -- \\
\hline U-238 & $\mu \mathrm{Ci} / \mathrm{g}$ & 1 & $1.14 \pm 0.23 \mathrm{E}-06$ & -- \\
\hline Total U & $\mu \mathrm{g} / \mathrm{g}$ & 1 & $9.32 \pm 0.22 \mathrm{E}-01$ & -- \\
\hline Pu-238 & $\mu \mathrm{Ci} / \mathrm{g}$ & 1 & $2.63 \pm 0.87 \mathrm{E}-07$ & -- \\
\hline Pu-239/240 & $\mu \mathrm{Ci} / \mathrm{g}$ & 1 & $3.61 \pm 1.02 \mathrm{E}-07$ & -- \\
\hline Am-241 & $\mu \mathrm{Ci} / \mathrm{g}$ & 1 & $7.39 \pm 1.59 \mathrm{E}-07$ & -- \\
\hline Aluminum & $\mathrm{mg} / \mathrm{kg}$ & 1 & 10,400 & 33,000 \\
\hline Antimony & $\mathrm{mg} / \mathrm{kg}$ & 1 & 0.49 & -- \\
\hline Arsenic & $\mathrm{mg} / \mathrm{kg}$ & 1 & 12.0 & $3-12^{b}$ \\
\hline Barium & $\mathrm{mg} / \mathrm{kg}$ & 1 & 74.5 & $15-600$ \\
\hline Beryllium & $\mathrm{mg} / \mathrm{kg}$ & 1 & 0.53 & $0-1.75$ \\
\hline Cadmium & $\mathrm{mg} / \mathrm{kg}$ & 1 & 0.10 & $0.1-1$ \\
\hline Calcium & $\mathrm{mg} / \mathrm{kg}$ & 1 & 3,040 & $130-35,000$ \\
\hline Chromium & $\mathrm{mg} / \mathrm{kg}$ & 1 & 13.6 & $1.5-40^{\mathrm{b}}$ \\
\hline Cobalt & $\mathrm{mg} / \mathrm{kg}$ & 1 & 9.4 & $2.5-60^{\mathrm{b}}$ \\
\hline Copper & $\mathrm{mg} / \mathrm{kg}$ & 1 & 27.3 & $1-50$ \\
\hline Iron & $\mathrm{mg} / \mathrm{kg}$ & 1 & 24,500 & $2,000-550,000$ \\
\hline Lead & $\mathrm{mg} / \mathrm{kg}$ & 1 & 23.3 & $4-61^{\mathrm{c}}$ \\
\hline Magnesium & $\mathrm{mg} / \mathrm{kg}$ & 1 & 3,940 & $100-5,000$ \\
\hline Manganese & $\mathrm{mg} / \mathrm{kg}$ & 1 & 572 & $50-5,000$ \\
\hline Mercury & $\mathrm{mg} / \mathrm{kg}$ & 1 & 0.03 & $0.001-0.2$ \\
\hline Nickel & $\mathrm{mg} / \mathrm{kg}$ & 1 & 22.3 & $0.5-25$ \\
\hline Potassium & $\mathrm{mg} / \mathrm{kg}$ & 1 & 1,050 & $8,500-43,000^{b}$ \\
\hline Selenium & $\mathrm{mg} / \mathrm{kg}$ & 1 & $<0.45$ & $0.1-3.9$ \\
\hline Silver & $\mathrm{mg} / \mathrm{kg}$ & 1 & $<0.13$ & -- \\
\hline Sodium & $\mathrm{mg} / \mathrm{kg}$ & 1 & 37.0 & $6,000-8,000$ \\
\hline Thallium & $\mathrm{mg} / \mathrm{kg}$ & 1 & $<0.48$ & -- \\
\hline Vanadium & $\mathrm{mg} / \mathrm{kg}$ & 1 & 16.8 & $1-300$ \\
\hline Zinc & $\mathrm{mg} / \mathrm{kg}$ & 1 & 91.2 & $9-50$ \\
\hline
\end{tabular}

Note: Effects of radiological substances are addressed with the evaluation of radiological dose to biota (see

Chapter 2 [p. 2-32]).

$N$ - Number of samples

-- No reference standard available for these analytes

${ }^{a}$ NYSDEC: Technical and Administrative Guidance Memorandum (TAGM) \#4046.

${ }^{b}$ New York State background

${ }^{c}$ Background levels vary widely. Average levels in undeveloped rural areas may range from 4-61 ppm (reported here). Average background levels in metropolitain or suburban areas, or near highways are much higher and typically range from 200-500 ppm.

$G-9$ 
Table G-2D

2003 Results in Surface Soils Collected at Air Stations Around the WVDP

\begin{tabular}{|l|c|c|c|c|c|}
\hline \multicolumn{1}{|c|}{ Analyte } & Units & N & SFBOEHN & SFRSPRD & $\begin{array}{c}\text { Background Location } \\
\text { SFGRVAL }\end{array}$ \\
\hline Gross Alpha & $\mu \mathrm{Ci} / \mathrm{g}$ & 1 & $1.13 \pm 0.23 \mathrm{E}-05$ & $1.35 \pm 0.25 \mathrm{E}-05$ & $1.09 \pm 0.21 \mathrm{E}-05$ \\
\hline Gross Beta & $\mu \mathrm{Ci} / \mathrm{g}$ & 1 & $2.08 \pm 0.27 \mathrm{E}-05$ & $1.83 \pm 0.24 \mathrm{E}-05$ & $1.86 \pm 0.25 \mathrm{E}-05$ \\
\hline K-40 & $\mu \mathrm{Ci} / \mathrm{g}$ & 1 & $1.33 \pm 0.13 \mathrm{E}-05$ & $1.25 \pm 0.12 \mathrm{E}-05$ & $1.06 \pm 0.10 \mathrm{E}-05$ \\
\hline Co-60 & $\mu \mathrm{Ci} / \mathrm{g}$ & 1 & $1.00 \pm 4.04 \mathrm{E}-08$ & $-1.45 \pm 2.64 \mathrm{E}-08$ & $-0.23 \pm 2.42 \mathrm{E}-08$ \\
\hline Sr-90 & $\mu \mathrm{Ci} / \mathrm{g}$ & 1 & $1.08 \pm 0.30 \mathrm{E}-07$ & $7.83 \pm 3.04 \mathrm{E}-08$ & $1.85 \pm 0.39 \mathrm{E}-07$ \\
\hline Cs-137 & $\mu \mathrm{Ci} / \mathrm{g}$ & 1 & $4.68 \pm 0.78 \mathrm{E}-07$ & $1.17 \pm 0.12 \mathrm{E}-06$ & $6.47 \pm 0.73 \mathrm{E}-07$ \\
\hline $\mathbf{U}-\mathbf{2 3 2}$ & $\mu \mathrm{Ci} / \mathrm{g}$ & 1 & $2.14 \pm 2.97 \mathrm{E}-08$ & $1.19 \pm 3.40 \mathrm{E}-08$ & $2.31 \pm 3.12 \mathrm{E}-08$ \\
\hline $\mathbf{U}-233 / 234$ & $\mu \mathrm{Ci} / \mathrm{g}$ & 1 & $8.63 \pm 1.42 \mathrm{E}-07$ & $9.39 \pm 1.44 \mathrm{E}-07$ & $8.28 \pm 1.36 \mathrm{E}-07$ \\
\hline $\mathbf{U}-235 / 236$ & $\mu \mathrm{Ci} / \mathrm{g}$ & 1 & $5.95 \pm 3.96 \mathrm{E}-08$ & $4.25 \pm 3.20 \mathrm{E}-08$ & $2.18 \pm 0.73 \mathrm{E}-07$ \\
\hline $\mathbf{U}-238$ & $\mu \mathrm{Ci} / \mathrm{g}$ & 1 & $7.92 \pm 1.33 \mathrm{E}-07$ & $9.19 \pm 1.42 \mathrm{E}-07$ & $7.06 \pm 1.26 \mathrm{E}-07$ \\
\hline Total U & $\mu \mathrm{g} / \mathrm{g}$ & 1 & $1.93 \pm 0.05 \mathrm{E}+00$ & $1.86 \pm 0.04 \mathrm{E}+00$ & $1.98 \pm 0.06 \mathrm{E}+00$ \\
\hline Pu-238 & $\mu \mathrm{Ci} / \mathrm{g}$ & 1 & $0.16 \pm 1.54 \mathrm{E}-08$ & $-1.55 \pm 3.04 \mathrm{E}-09$ & $-3.96 \pm 4.48 \mathrm{E}-09$ \\
\hline Pu-239/240 & $\mu \mathrm{Ci} / \mathrm{g}$ & 1 & $4.08 \pm 3.27 \mathrm{E}-08$ & $3.72 \pm 3.11 \mathrm{E}-08$ & $1.38 \pm 1.90 \mathrm{E}-08$ \\
\hline Am-241 & $\mu \mathrm{Ci} / \mathrm{g}$ & 1 & $1.24 \pm 1.92 \mathrm{E}-08$ & $2.65 \pm 2.99 \mathrm{E}-08$ & $0.68 \pm 1.92 \mathrm{E}-08$ \\
\hline
\end{tabular}

\begin{tabular}{|l|c|c|c|c|c|}
\hline \multicolumn{1}{|c|}{ Analyte } & Units & N & SFFXVRD & SFRT240 & $\begin{array}{c}\text { Background Location } \\
\text { SFGRVAL }\end{array}$ \\
\hline Gross Alpha & $\mu \mathrm{Ci} / \mathrm{g}$ & 1 & $1.51 \pm 0.27 \mathrm{E}-05$ & $1.00 \pm 0.21 \mathrm{E}-05$ & $1.09 \pm 0.21 \mathrm{E}-05$ \\
\hline Gross Beta & $\mu \mathrm{Ci} / \mathrm{g}$ & 1 & $2.15 \pm 0.28 \mathrm{E}-05$ & $1.48 \pm 0.25 \mathrm{E}-05$ & $1.86 \pm 0.25 \mathrm{E}-05$ \\
\hline K-40 & $\mu \mathrm{Ci} / \mathrm{g}$ & 1 & $1.15 \pm 0.10 \mathrm{E}-05$ & $1.03 \pm 0.11 \mathrm{E}-05$ & $1.06 \pm 0.10 \mathrm{E}-05$ \\
\hline $\mathbf{C o - 6 0}$ & $\mu \mathrm{Ci} / \mathrm{g}$ & 1 & $-0.09 \pm 1.33 \mathrm{E}-08$ & $1.05 \pm 1.39 \mathrm{E}-08$ & $-0.23 \pm 2.42 \mathrm{E}-08$ \\
\hline Sr-90 & $\mu \mathrm{Ci} / \mathrm{g}$ & 1 & $1.33 \pm 0.30 \mathrm{E}-07$ & $1.59 \pm 0.34 \mathrm{E}-07$ & $1.85 \pm 0.39 \mathrm{E}-07$ \\
\hline $\mathbf{C s}-\mathbf{1 3 7}$ & $\mu \mathrm{Ci} / \mathrm{g}$ & 1 & $3.30 \pm 0.36 \mathrm{E}-07$ & $4.91 \pm 0.64 \mathrm{E}-07$ & $6.47 \pm 0.73 \mathrm{E}-07$ \\
\hline Pu-238 & $\mu \mathrm{Ci} / \mathrm{g}$ & 1 & $0.94 \pm 1.61 \mathrm{E}-08$ & $2.07 \pm 2.53 \mathrm{E}-08$ & $-3.96 \pm 4.48 \mathrm{E}-09$ \\
\hline $\mathbf{P u - 2 3 9 / 2 4 0}$ & $\mu \mathrm{Ci} / \mathrm{g}$ & 1 & $1.92 \pm 1.68 \mathrm{E}-08$ & $1.44 \pm 2.20 \mathrm{E}-08$ & $1.38 \pm 1.90 \mathrm{E}-08$ \\
\hline $\mathbf{A m - 2 4 1}$ & $\mu \mathrm{Ci} / \mathrm{g}$ & 1 & $0.18 \pm 1.32 \mathrm{E}-08$ & $0.63 \pm 1.76 \mathrm{E}-08$ & $0.68 \pm 1.92 \mathrm{E}-08$ \\
\hline
\end{tabular}

$N$ - Number of samples 
Table G-2D (concluded)

2003 Results in Surface Soils Collected at Air Stations Around the WVDP

\begin{tabular}{|c|c|c|c|c|c|}
\hline Analyte & Units & $\mathbf{N}$ & SFSPRVL & SFTCORD & $\begin{array}{c}\text { Background Location } \\
\text { SFGRVAL }\end{array}$ \\
\hline Gross Alpha & $\mu \mathrm{Ci} / \mathrm{g}$ & 1 & $1.23 \pm 0.24 \mathrm{E}-05$ & $1.19 \pm 0.32 \mathrm{E}-05$ & $1.09 \pm 0.21 \mathrm{E}-05$ \\
\hline Gross Beta & $\mu \mathrm{Ci} / \mathrm{g}$ & 1 & $1.85 \pm 0.25 \mathrm{E}-05$ & $2.98 \pm 0.34 \mathrm{E}-05$ & $1.86 \pm 0.25 \mathrm{E}-05$ \\
\hline K-40 & $\mu \mathrm{Ci} / \mathrm{g}$ & 1 & $1.26 \pm 0.09 \mathrm{E}-05$ & $1.99 \pm 0.21 \mathrm{E}-05$ & $1.06 \pm 0.10 \mathrm{E}-05$ \\
\hline Co-60 & $\mu \mathrm{Ci} / \mathrm{g}$ & 1 & $-0.51 \pm 1.41 \mathrm{E}-08$ & $-0.64 \pm 1.83 \mathrm{E}-08$ & $-0.23 \pm 2.42 \mathrm{E}-08$ \\
\hline Sr-90 & $\mu \mathrm{Ci} / \mathrm{g}$ & 1 & $1.90 \pm 0.38 \mathrm{E}-07$ & $1.05 \pm 0.31 \mathrm{E}-07$ & $1.85 \pm 0.39 \mathrm{E}-07$ \\
\hline Cs-137 & $\mu \mathrm{Ci} / \mathrm{g}$ & 1 & $3.90 \pm 0.47 \mathrm{E}-07$ & $3.99 \pm 0.53 \mathrm{E}-07$ & $6.47 \pm 0.73 \mathrm{E}-07$ \\
\hline Pu-238 & $\mu \mathrm{Ci} / \mathrm{g}$ & 1 & $-4.02 \pm 4.54 \mathrm{E}-09$ & $1.78 \pm 2.36 \mathrm{E}-08$ & $-3.96 \pm 4.48 \mathrm{E}-09$ \\
\hline $\mathrm{Pu}-239 / 240$ & $\mu \mathrm{Ci} / \mathrm{g}$ & 1 & $3.08 \pm 2.70 \mathrm{E}-08$ & $-2.81 \pm 3.90 \mathrm{E}-09$ & $1.38 \pm 1.90 \mathrm{E}-08$ \\
\hline Am-241 & $\mu \mathrm{Ci} / \mathrm{g}$ & 1 & $2.21 \pm 2.50 \mathrm{E}-08$ & $1.17 \pm 1.43 \mathrm{E}-08$ & $0.68 \pm 1.92 \mathrm{E}-08$ \\
\hline Analyte & Units & $\mathbf{N}$ & SFBLKST & SFWEVAL & $\begin{array}{c}\text { Background Location } \\
\text { SFGRVAL }\end{array}$ \\
\hline Gross Alpha & $\mu \mathrm{Ci} / \mathrm{g}$ & 1 & $9.33 \pm 2.14 \mathrm{E}-06$ & $1.42 \pm 0.26 \mathrm{E}-05$ & $1.09 \pm 0.21 \mathrm{E}-05$ \\
\hline Gross Beta & $\mu \mathrm{Ci} / \mathrm{g}$ & 1 & $2.18 \pm 0.27 \mathrm{E}-05$ & $2.14 \pm 0.29 \mathrm{E}-05$ & $1.86 \pm 0.25 \mathrm{E}-05$ \\
\hline K-40 & $\mu \mathrm{Ci} / \mathrm{g}$ & 1 & $1.62 \pm 0.07 \mathrm{E}-05$ & $1.27 \pm 0.13 \mathrm{E}-05$ & $1.06 \pm 0.10 \mathrm{E}-05$ \\
\hline Co-60 & $\mu \mathrm{Ci} / \mathrm{g}$ & 1 & $1.36 \pm 1.43 \mathrm{E}-08$ & $-0.77 \pm 1.74 \mathrm{E}-08$ & $-0.23 \pm 2.42 \mathrm{E}-08$ \\
\hline Sr-90 & $\mu \mathrm{Ci} / \mathrm{g}$ & 1 & $6.59 \pm 3.08 \mathrm{E}-08$ & $8.49 \pm 2.73 \mathrm{E}-08$ & $1.85 \pm 0.39 \mathrm{E}-07$ \\
\hline Cs-137 & $\mu \mathrm{Ci} / \mathrm{g}$ & 1 & $2.79 \pm 0.34 \mathrm{E}-07$ & $2.93 \pm 0.45 \mathrm{E}-07$ & $6.47 \pm 0.73 \mathrm{E}-07$ \\
\hline Pu-238 & $\mu \mathrm{Ci} / \mathrm{g}$ & 1 & $0.38 \pm 1.37 \mathrm{E}-08$ & $1.49 \pm 2.28 \mathrm{E}-08$ & $-3.96 \pm 4.48 \mathrm{E}-09$ \\
\hline $\mathrm{Pu}-239 / 240$ & $\mu \mathrm{Ci} / \mathrm{g}$ & 1 & $0.44 \pm 1.07 \mathrm{E}-08$ & $-1.56 \pm 3.06 \mathrm{E}-09$ & $1.38 \pm 1.90 \mathrm{E}-08$ \\
\hline Am-241 & $\mu \mathrm{Ci} / \mathrm{g}$ & 1 & $1.88 \pm 2.33 \mathrm{E}-08$ & $0.37 \pm 1.48 \mathrm{E}-08$ & $0.68 \pm 1.92 \mathrm{E}-08$ \\
\hline
\end{tabular}

$N$ - Number of samples

WVDP Annual Site Environmental Report

$G-11$

Calendar Year 2003 


\section{Table G-2E}

\section{Results in Stream Sediments Around the WVDP}

\begin{tabular}{|c|c|c|c|c|c|}
\hline Analyte & Units & $\mathbf{N}$ & SFCCSED & SFSDSED & $\begin{array}{c}\text { Background Location } \\
\text { SFBISED }\end{array}$ \\
\hline Gross Alpha & $\mu \mathrm{Ci} / \mathrm{g}$ & 1 & $5.34 \pm 1.97 \mathrm{E}-06$ & $6.38 \pm 2.01 \mathrm{E}-06$ & $5.65 \pm 2.01 \mathrm{E}-06$ \\
\hline Gross Beta & $\mu \mathrm{Ci} / \mathrm{g}$ & 1 & $1.59 \pm 0.28 \mathrm{E}-05$ & $1.51 \pm 0.26 \mathrm{E}-05$ & $1.07 \pm 0.25 \mathrm{E}-05$ \\
\hline K-40 & $\mu \mathrm{Ci} / \mathrm{g}$ & 1 & $1.31 \pm 0.12 \mathrm{E}-05$ & $1.33 \pm 0.15 \mathrm{E}-05$ & $1.27 \pm 0.14 \mathrm{E}-05$ \\
\hline Co-60 & $\mu \mathrm{Ci} / \mathrm{g}$ & 1 & $0.07 \pm 2.25 \mathrm{E}-08$ & $0.31 \pm 1.68 \mathrm{E}-08$ & $-1.19 \pm 1.46 \mathrm{E}-08$ \\
\hline Sr-90 & $\mu \mathrm{Ci} / \mathrm{g}$ & 1 & $4.72 \pm 3.12 \mathrm{E}-08$ & $0.36 \pm 2.59 \mathrm{E}-08$ & $1.74 \pm 2.71 \mathrm{E}-08$ \\
\hline Cs-137 & $\mu \mathrm{Ci} / \mathrm{g}$ & 1 & $1.47 \pm 0.31 \mathrm{E}-07$ & $2.25 \pm 0.39 \mathrm{E}-07$ & $5.86 \pm 2.27 \mathrm{E}-08$ \\
\hline U-232 & $\mu \mathrm{Ci} / \mathrm{g}$ & 1 & $-0.22 \pm 5.09 \mathrm{E}-08$ & $-0.01 \pm 3.29 \mathrm{E}-08$ & $-1.60 \pm 3.36 \mathrm{E}-08$ \\
\hline U-233/234 & $\mu \mathrm{Ci} / \mathrm{g}$ & 1 & $7.49 \pm 1.82 \mathrm{E}-07$ & $6.94 \pm 1.70 \mathrm{E}-07$ & $6.73 \pm 1.75 \mathrm{E}-07$ \\
\hline U-235/236 & $\mu \mathrm{Ci} / \mathrm{g}$ & 1 & $6.65 \pm 6.07 \mathrm{E}-08$ & $4.64 \pm 5.26 \mathrm{E}-08$ & $4.57 \pm 4.48 \mathrm{E}-08$ \\
\hline U-238 & $\mu \mathrm{Ci} / \mathrm{g}$ & 1 & $5.98 \pm 1.63 \mathrm{E}-07$ & $6.96 \pm 1.68 \mathrm{E}-07$ & $6.52 \pm 1.70 \mathrm{E}-07$ \\
\hline Total U & $\mu \mathrm{g} / \mathrm{g}$ & 1 & $9.35 \pm 0.15 \mathrm{E}-01$ & $1.47 \pm 0.02 \mathrm{E}+00$ & $1.55 \pm 0.02 \mathrm{E}+00$ \\
\hline Pu-238 & $\mu \mathrm{Ci} / \mathrm{g}$ & 1 & $0.00 \pm 1.36 \mathrm{E}-08$ & $0.49 \pm 1.29 \mathrm{E}-08$ & $0.00 \pm 1.24 \mathrm{E}-08$ \\
\hline Pu-239/240 & $\mu \mathrm{Ci} / \mathrm{g}$ & 1 & $-3.33 \pm 4.61 \mathrm{E}-09$ & $0.91 \pm 1.58 \mathrm{E}-08$ & $0.63 \pm 1.24 \mathrm{E}-08$ \\
\hline Am-241 & $\mu \mathrm{Ci} / \mathrm{g}$ & 1 & $1.03 \pm 1.65 \mathrm{E}-08$ & $0.40 \pm 1.31 \mathrm{E}-08$ & $5.15 \pm 5.05 \mathrm{E}-08$ \\
\hline Analyte & Units & $\mathbf{N}$ & SFTCSED & -- & $\begin{array}{c}\text { Background Location } \\
\text { SFBCSED }\end{array}$ \\
\hline Gross Alpha & $\mu \mathrm{Ci} / \mathrm{g}$ & 1 & $8.31 \pm 2.23 \mathrm{E}-06$ & -- & $6.66 \pm 1.98 \mathrm{E}-06$ \\
\hline Gross Beta & $\mu \mathrm{Ci} / \mathrm{g}$ & 1 & $1.88 \pm 0.27 \mathrm{E}-05$ & -- & $1.64 \pm 0.25 \mathrm{E}-05$ \\
\hline K-40 & $\mu \mathrm{Ci} / \mathrm{g}$ & 1 & $1.22 \pm 0.14 \mathrm{E}-05$ & -- & $1.29 \pm 0.14 \mathrm{E}-05$ \\
\hline Co-60 & $\mu \mathrm{Ci} / \mathrm{g}$ & 1 & $-0.60 \pm 1.56 \mathrm{E}-08$ & -- & $-0.44 \pm 2.55 \mathrm{E}-08$ \\
\hline Sr-90 & $\mu \mathrm{Ci} / \mathrm{g}$ & 1 & $1.68 \pm 2.63 \mathrm{E}-08$ & -- & $1.85 \pm 2.76 \mathrm{E}-08$ \\
\hline Cs-137 & $\mu \mathrm{Ci} / \mathrm{g}$ & 1 & $9.31 \pm 1.10 \mathrm{E}-07$ & -- & $3.85 \pm 4.05 \mathrm{E}-08$ \\
\hline U-232 & $\mu \mathrm{Ci} / \mathrm{g}$ & 1 & $0.03 \pm 2.07 \mathrm{E}-08$ & -- & $-0.10 \pm 4.34 \mathrm{E}-08$ \\
\hline U-233/234 & $\mu \mathrm{Ci} / \mathrm{g}$ & 1 & $5.84 \pm 1.49 \mathrm{E}-07$ & -- & $5.96 \pm 1.63 \mathrm{E}-07$ \\
\hline U-235/236 & $\mu \mathrm{Ci} / \mathrm{g}$ & 1 & $1.60 \pm 0.80 \mathrm{E}-07$ & -- & $3.16 \pm 3.92 \mathrm{E}-08$ \\
\hline U-238 & $\mu \mathrm{Ci} / \mathrm{g}$ & 1 & $5.10 \pm 1.39 \mathrm{E}-07$ & -- & $9.01 \pm 1.99 \mathrm{E}-07$ \\
\hline Total U & $\mu \mathrm{g} / \mathrm{g}$ & 1 & $8.18 \pm 0.14 \mathrm{E}-01$ & -- & $8.94 \pm 0.15 \mathrm{E}-01$ \\
\hline Pu-238 & $\mu \mathrm{Ci} / \mathrm{g}$ & 1 & $0.60 \pm 1.17 \mathrm{E}-08$ & -- & $1.25 \pm 1.73 \mathrm{E}-08$ \\
\hline Pu-239/240 & $\mu \mathrm{Ci} / \mathrm{g}$ & 1 & $1.05 \pm 1.67 \mathrm{E}-08$ & -- & $0.00 \pm 1.22 \mathrm{E}-08$ \\
\hline Am-241 & $\mu \mathrm{Ci} / \mathrm{g}$ & 1 & $0.18 \pm 1.36 \mathrm{E}-08$ & -- & $0.19 \pm 1.41 \mathrm{E}-08$ \\
\hline
\end{tabular}

$N$ - Number of samples

-- Not applicable; no additional sampling location 


\section{Appendix $\mathrm{H}$}

Summary of Direct Radiation Monitoring Data

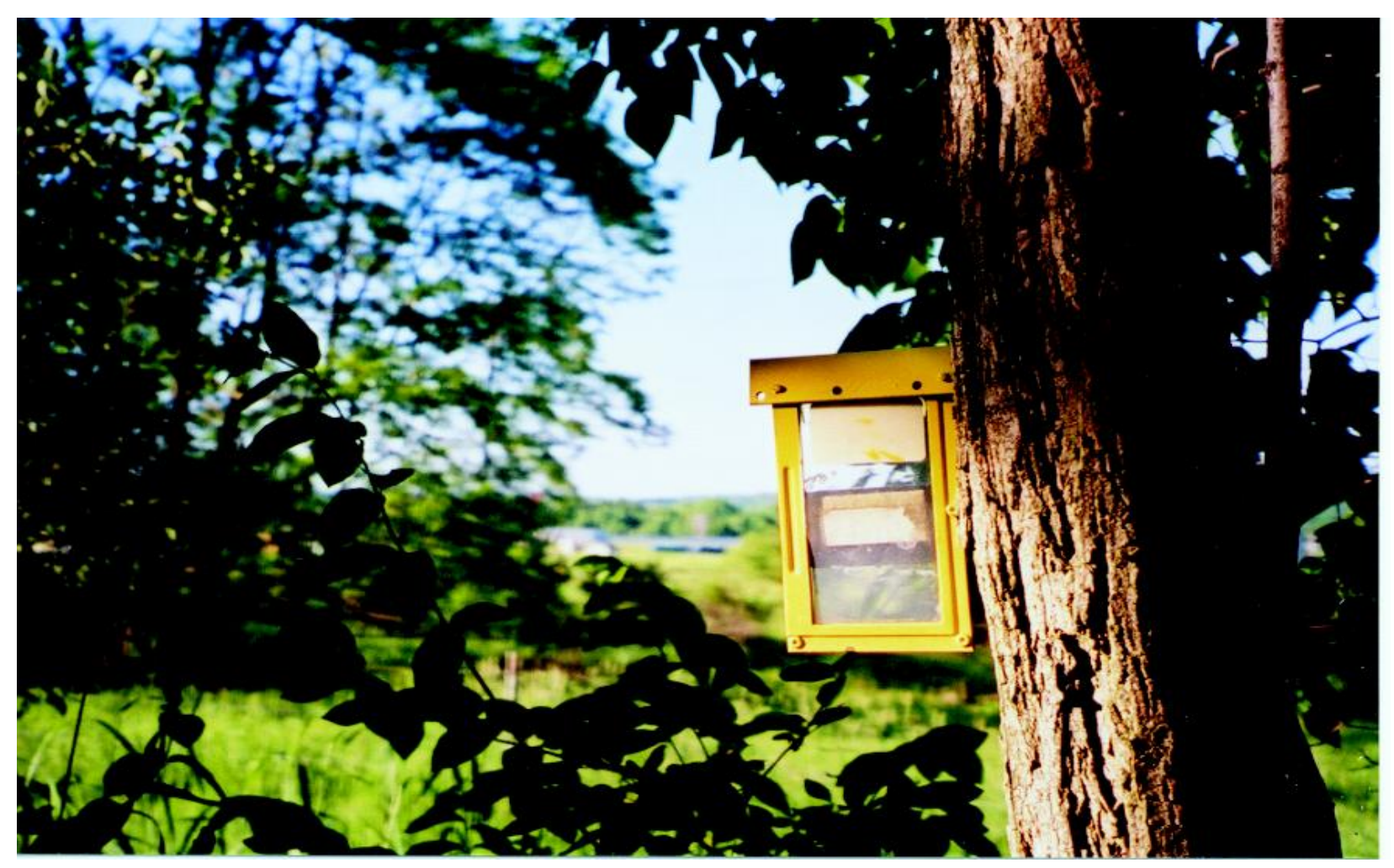

An Environmental TLD Package

H -1 
This page intentionally left blank

$H-2$ 
Table $\mathrm{H}-1$

\section{Summary of 2003 Quarterly Averages of Off-Site TLD Measurements (mR \pm 2 SD/quarter)}

\begin{tabular}{|c|c|c|c|c|c|}
\hline $\begin{array}{l}\text { Location } \\
\text { Number* }\end{array}$ & 1st Quarter & 2nd Quarter & 3rd Quarter & 4th Quarter & $\begin{array}{l}\text { Location } \\
\text { Average }\end{array}$ \\
\hline DFTLD01 & $15 \pm 4.3$ & $24 \pm 4.9$ & $20 \pm 4.4$ & $15 \pm 3.4$ & $18 \pm 4.3$ \\
\hline DFTLD02 & $14 \pm 4.2$ & $22 \pm 4.7$ & $20 \pm 4.4$ & $16 \pm 3.6$ & $18 \pm 4.2$ \\
\hline DFTLD03 & $13 \pm 4.1$ & $20 \pm 4.2$ & $16 \pm 3.8$ & $13 \pm 3.1$ & $16 \pm 3.8$ \\
\hline DFTLD04 & $14 \pm 4.2$ & $22 \pm 4.6$ & $20 \pm 4.4$ & $15 \pm 3.4$ & $18 \pm 4.2$ \\
\hline DFTLD05 & $15 \pm 4.3$ & $23 \pm 4.7$ & $19 \pm 4.3$ & $15 \pm 3.5$ & $18 \pm 4.2$ \\
\hline DFTLD06 & $14 \pm 4.2$ & $22 \pm 4.6$ & $19 \pm 4.3$ & $15 \pm 3.4$ & $17 \pm 4.1$ \\
\hline DFTLD07 & $13 \pm 4.1$ & $18 \pm 4.0$ & $16 \pm 3.7$ & $12 \pm 2.9$ & $15 \pm 3.7$ \\
\hline DFTLD08 & $15 \pm 4.3$ & $20 \pm 4.3$ & $19 \pm 4.2$ & $15 \pm 3.4$ & $17 \pm 4.1$ \\
\hline DFTLD09 & $15 \pm 4.3$ & $22 \pm 4.7$ & $18 \pm 4.1$ & $14 \pm 3.3$ & $17 \pm 4.1$ \\
\hline DFTLD10 & $13 \pm 4.0$ & $22 \pm 4.6$ & $19 \pm 4.2$ & $16 \pm 3.5$ & $17 \pm 4.1$ \\
\hline DFTLD11 & $13 \pm 4.1$ & $20 \pm 4.2$ & $17 \pm 3.8$ & $13 \pm 3.1$ & $15 \pm 3.8$ \\
\hline DFTLD12 & $15 \pm 4.3$ & $21 \pm 4.5$ & $20 \pm 4.4$ & $14 \pm 3.2$ & $17 \pm 4.1$ \\
\hline DFTLD13 & $14 \pm 4.2$ & $25 \pm 5.1$ & $22 \pm 4.7$ & $17 \pm 3.7$ & $19 \pm 4.5$ \\
\hline DFTLD14 & $14 \pm 4.2$ & $23 \pm 4.9$ & $20 \pm 4.4$ & $16 \pm 3.5$ & $18 \pm 4.3$ \\
\hline DFTLD15 & $14 \pm 4.1$ & $22 \pm 4.7$ & $19 \pm 4.2$ & $16 \pm 3.7$ & $18 \pm 4.2$ \\
\hline DFTLD16 & $13 \pm 4.1$ & $22 \pm 4.7$ & $20 \pm 4.3$ & $14 \pm 3.3$ & $17 \pm 4.1$ \\
\hline DFTLD17** & $15 \pm 4.3$ & NA & $\mathrm{NA}$ & NA & $15 \pm 4.3$ \\
\hline DFTLD20 & $12 \pm 4.0$ & $19 \pm 4.1$ & $16 \pm 3.7$ & $12 \pm 2.9$ & $15 \pm 3.7$ \\
\hline DFTLD21 & $15 \pm 4.3$ & $23 \pm 4.8$ & $20 \pm 4.4$ & $15 \pm 3.4$ & $18 \pm 4.3$ \\
\hline DFTLD22 & $15 \pm 4.3$ & $26 \pm 5.3$ & $21 \pm 4.5$ & $17 \pm 3.8$ & $19 \pm 4.5$ \\
\hline DFTLD23** & $15 \pm 4.3$ & $22 \pm 4.7$ & $20 \pm 4.5$ & $14 \pm 3.3$ & $18 \pm 4.2$ \\
\hline DFTLD37** & $17 \pm 4.5$ & NA & NA & NA & $17 \pm 4.5$ \\
\hline DFTLD41** & $13 \pm 4.1$ & $\mathrm{NA}$ & NA & NA & $13 \pm 4.1$ \\
\hline
\end{tabular}

* Off-site locations are shown on Figures A-11 through A-13 (pp. A-11 through A-13).

** Background measurements are provided by off-site TLDs 17, 23, 37, and 41. Locations 17, 37, and 41 were removed from the program after the first quarter of CY 2003.

NA - Not available.

Conversion factor: Milliroentgen $(\mathrm{mR})$ units are used to report exposure rates in air. To convert $\mathrm{mR}$ to mrem (dose to humans), a conversion factor of 1.03 must be applied. For example, a reported exposure rate of $18.1 \mathrm{mR} /$ quarter would be equivalent to $18.6 \mathrm{mrem} / q u a r t e r$ (based upon dose-equivalent phantom calibration using cesium-137).

$H-3$ 
Table $\mathrm{H}-2$

Summary of 2003 Quarterly Averages of On-Site TLD Measurements (mR $\pm 2 S D / q u a r t e r)$

$\begin{array}{lccccr}\begin{array}{l}\text { Location } \\ \text { Number* }\end{array} & \text { 1st Quarter } & \text { 2nd Quarter } & \text { 3rd Quarter } & \text { 4th Quarter } & \begin{array}{r}\text { Location } \\ \text { Average }\end{array} \\ & & & & & \\ \text { DNTLD18 } & 26 \pm 6.0 & 34 \pm 6.8 & 29 \pm 6.1 & 24 \pm 5.1 & 28 \pm 6.0 \\ \text { DNTLD19 } & 16 \pm 4.5 & 26 \pm 5.4 & 23 \pm 5.0 & 18 \pm 3.9 & 21 \pm 4.7 \\ \text { DNTLD24 } & 492 \pm 96.5 & 584 \pm 114.5 & 486 \pm 95.3 & 471 \pm 92.4 & 508 \pm 100.1 \\ \text { DNTLD25 } & 24 \pm 5.6 & 28 \pm 5.8 & 24 \pm 5.1 & 19 \pm 4.1 & 24 \pm 5.2 \\ \text { DNTLD26 } & 17 \pm 4.7 & 27 \pm 5.6 & 25 \pm 5.3 & 20 \pm 4.3 & 22 \pm 5.0 \\ \text { DNTLD27 } & 15 \pm 4.3 & 25 \pm 5.2 & 20 \pm 4.4 & 18 \pm 3.9 & 20 \pm 4.5 \\ \text { DNTLD28 } & 16 \pm 4.5 & 26 \pm 5.4 & 23 \pm 4.9 & 16 \pm 3.6 & 20 \pm 4.6 \\ \text { DNTLD29 } & 16 \pm 4.5 & 28 \pm 5.8 & 23 \pm 4.9 & 17 \pm 3.8 & 21 \pm 4.8 \\ \text { DNTLD30 } & 17 \pm 4.6 & 27 \pm 5.5 & 23 \pm 5.0 & 19 \pm 4.1 & 21 \pm 4.8 \\ \text { DNTLD31 } & 16 \pm 4.4 & 23 \pm 4.8 & 21 \pm 4.6 & 15 \pm 3.5 & 19 \pm 4.4 \\ \text { DNTLD32 } & 24 \pm 5.6 & 34 \pm 6.8 & 27 \pm 5.6 & 24 \pm 5.0 & 27 \pm 5.8 \\ \text { DNTLD33 } & 25 \pm 5.9 & 37 \pm 7.4 & 32 \pm 6.7 & 29 \pm 5.9 & 31 \pm 6.5 \\ \text { DNTLD34 } & 44 \pm 9.1 & 56 \pm 11.2 & 48 \pm 9.7 & 45 \pm 9.0 & 48 \pm 9.8 \\ \text { DNTLD35 } & 70 \pm 14.0 & 80 \pm 15.7 & 65 \pm 13.0 & 60 \pm 11.9 & 69 \pm 13.7 \\ \text { DNTLD36 } & 91 \pm 18.1 & 41 \pm 8.3 & 34 \pm 7.0 & 33 \pm 6.6 & 50 \pm 11.1 \\ \text { DNTLD38 } & 27 \pm 6.2 & 38 \pm 7.6 & 34 \pm 7.0 & 23 \pm 4.8 & 30 \pm 6.5 \\ \text { DNTLD39 } & 38 \pm 8.1 & 56 \pm 11.2 & 50 \pm 9.9 & 44 \pm 8.8 & 47 \pm 9.6 \\ \text { DNTLD40 } & 99 \pm 19.7 & 132 \pm 26.0 & 113 \pm 22.2 & 103 \pm 20.2 & 112 \pm 22.2 \\ \text { DNTLD42 } & 75 \pm 15.0 & 88 \pm 17.3 & 78 \pm 15.3 & 67 \pm 13.3 & 77 \pm 15.3 \\ \text { DNTLD43 } & 26 \pm 6.0 & 33 \pm 6.6 & 28 \pm 5.9 & 23 \pm 4.9 & 28 \pm 5.9\end{array}$

* On-site locations are shown on Figure A-10 (p. A-10).

Conversion factor: Milliroentgen $(m R)$ units are used to report exposure rates in air. To convert $m R$ to mrem (dose to humans), a conversion factor of 1.03 must be applied. For example, a reported exposure rate of $18.1 \mathrm{mR} /$ quarter would be equivalent to $18.6 \mathrm{mrem} / q u a r t e r$ (based upon dose-equivalent phantom calibration using cesium-137).

$H-4$ 
Table $\mathrm{H}-3$

Third-Quarter 2003 TLD Results and Instantaneous Exposure Rate Readings $(\mu R / h r)$ With a High-Pressure Ion Chamber (HPIC) at Each Monitoring Location

\begin{tabular}{|c|c|c|c|c|c|}
\hline $\begin{array}{l}\text { Off-Site } \\
\text { Location } \\
\text { Number }\end{array}$ & $\begin{array}{c}\text { 3rd-Quarter } \\
\text { TLD Result }\end{array}$ & $\begin{array}{l}\text { August } 2003 \\
\text { HPIC Result }\end{array}$ & $\begin{array}{l}\text { On-Site } \\
\text { Location } \\
\text { Number }\end{array}$ & $\begin{array}{l}\text { 3rd-Quarter } \\
\text { TLD Result }\end{array}$ & $\begin{array}{l}\text { August } 2003 \\
\text { HPIC Result }\end{array}$ \\
\hline DFTLD01 & 8.91 & 9.23 & DNTLD18 & 13.03 & 15.07 \\
\hline DFTLD02 & 8.77 & 8.93 & DNTLD19 & 10.24 & 10.27 \\
\hline DFTLD03 & 7.27 & 8.33 & DNTLD24 & 215.48 & 255.50 \\
\hline DFTLD04 & 8.86 & 8.33 & DNTLD25 & 10.46 & 11.47 \\
\hline DFTLD05 & 8.55 & 8.90 & DNTLD26 & 10.95 & 10.63 \\
\hline DFTLD06 & 8.51 & 8.80 & DNTLD27 & 8.90 & 8.73 \\
\hline DFTLD07 & 7.09 & 9.03 & DNTLD28 & 10.10 & 9.30 \\
\hline DFTLD08 & 8.24 & 8.80 & DNTLD29 & 9.98 & 9.90 \\
\hline DFTLD09 & 8.02 & 8.53 & DNTLD30 & 10.28 & 11.23 \\
\hline DFTLD10 & 8.38 & 8.70 & DNTLD31 & 9.40 & 9.90 \\
\hline DFTLD11 & 7.31 & 9.07 & DNTLD32 & 11.88 & 12.13 \\
\hline DFTLD12 & 8.77 & 9.17 & DNTLD33 & 14.36 & 14.57 \\
\hline DFTLD13 & 9.53 & 9.00 & DNTLD34 & 21.45 & 20.67 \\
\hline DFTLD14 & 8.82 & 9.13 & DNTLD35 & 28.98 & 35.60 \\
\hline DFTLD15 & 8.24 & 8.70 & DNTLD36 & 15.11 & 18.10 \\
\hline DFTLD16 & 8.69 & 8.70 & DNTLD38 & 15.21 & 16.17 \\
\hline DFTLD20 & 7.00 & 8.90 & DNTLD39 & 21.95 & 22.80 \\
\hline DFTLD21 & 8.86 & 8.60 & DNTLD40 & 49.88 & 51.20 \\
\hline DFTLD22 & 9.17 & 10.73 & DNTLD42 & 34.36 & 23.13 \\
\hline DFTLD23 & 9.03 & 8.50 & DNTLD43 & 12.50 & 13.87 \\
\hline
\end{tabular}

$H-5$ 


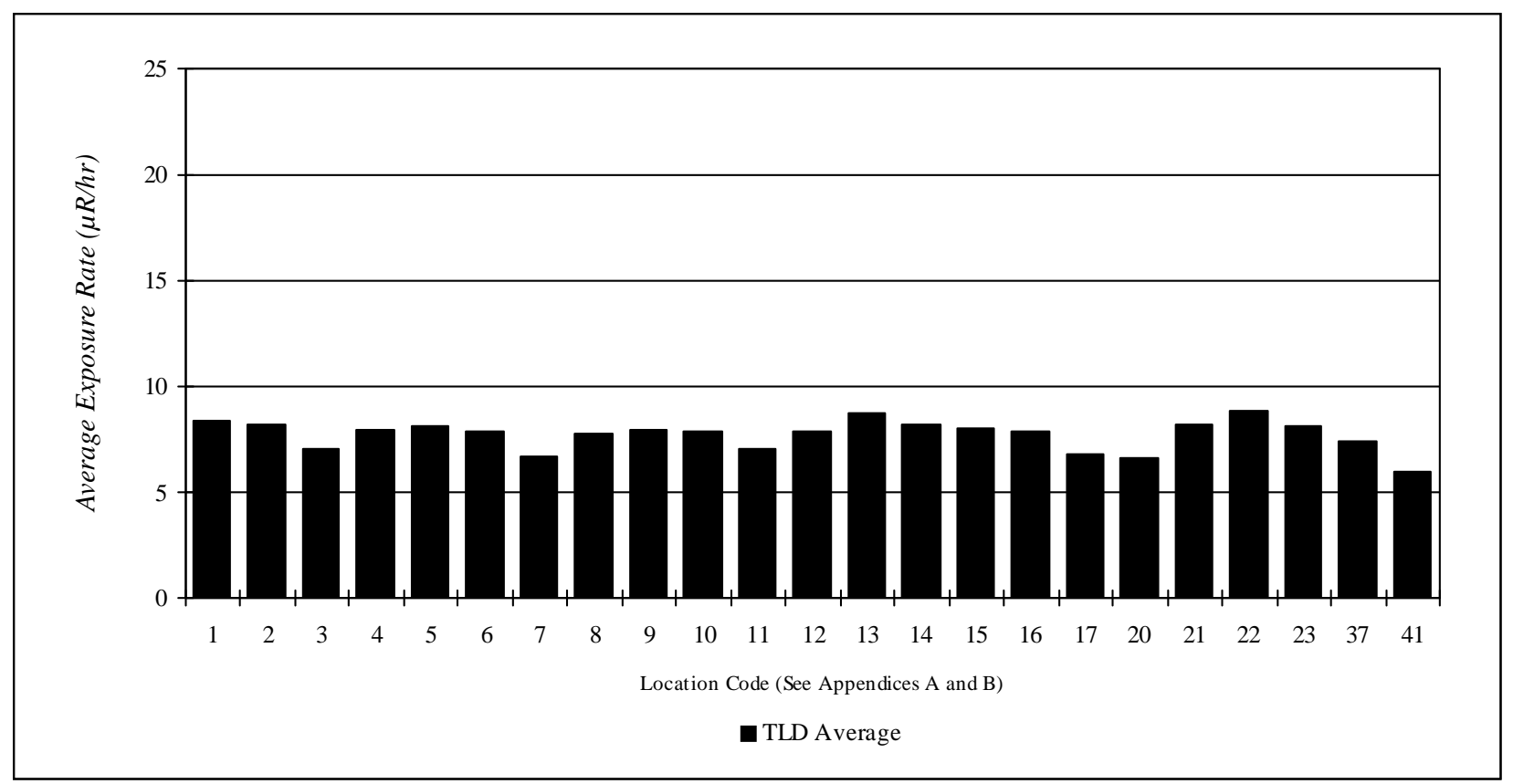

Figure H-1. 2003 Average Yearly Gamma Exposure Rates Around the WVDP

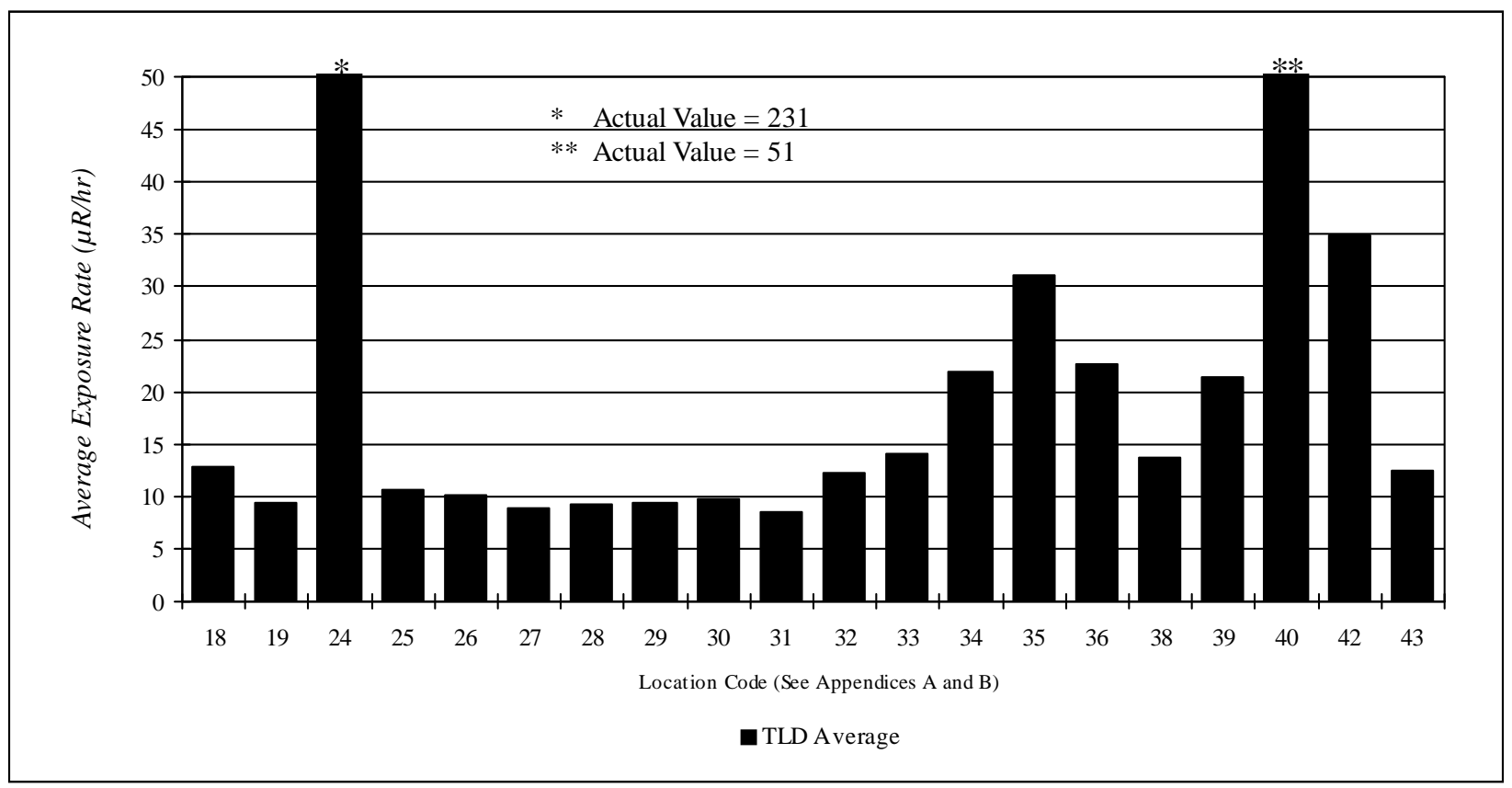

Figure H-2. 2003 Average Yearly Gamma Exposure Rates on the WVDP

$$
H-6
$$




\section{Appendix I \\ Summary of Meteorological Data}

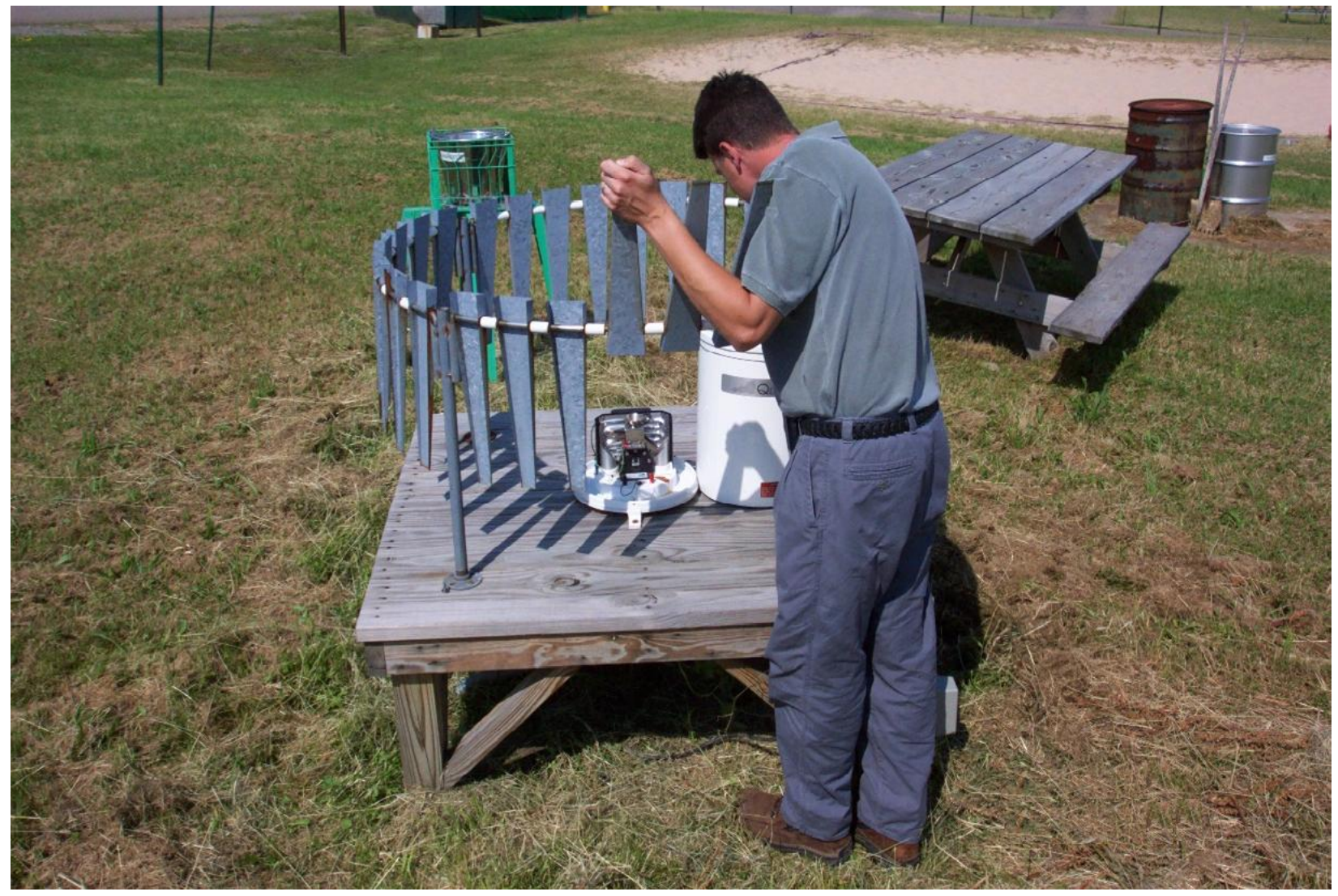

Checking the On-Site Rain Gauge

$I-1$ 
This page intentionally left blank

$$
I-2
$$




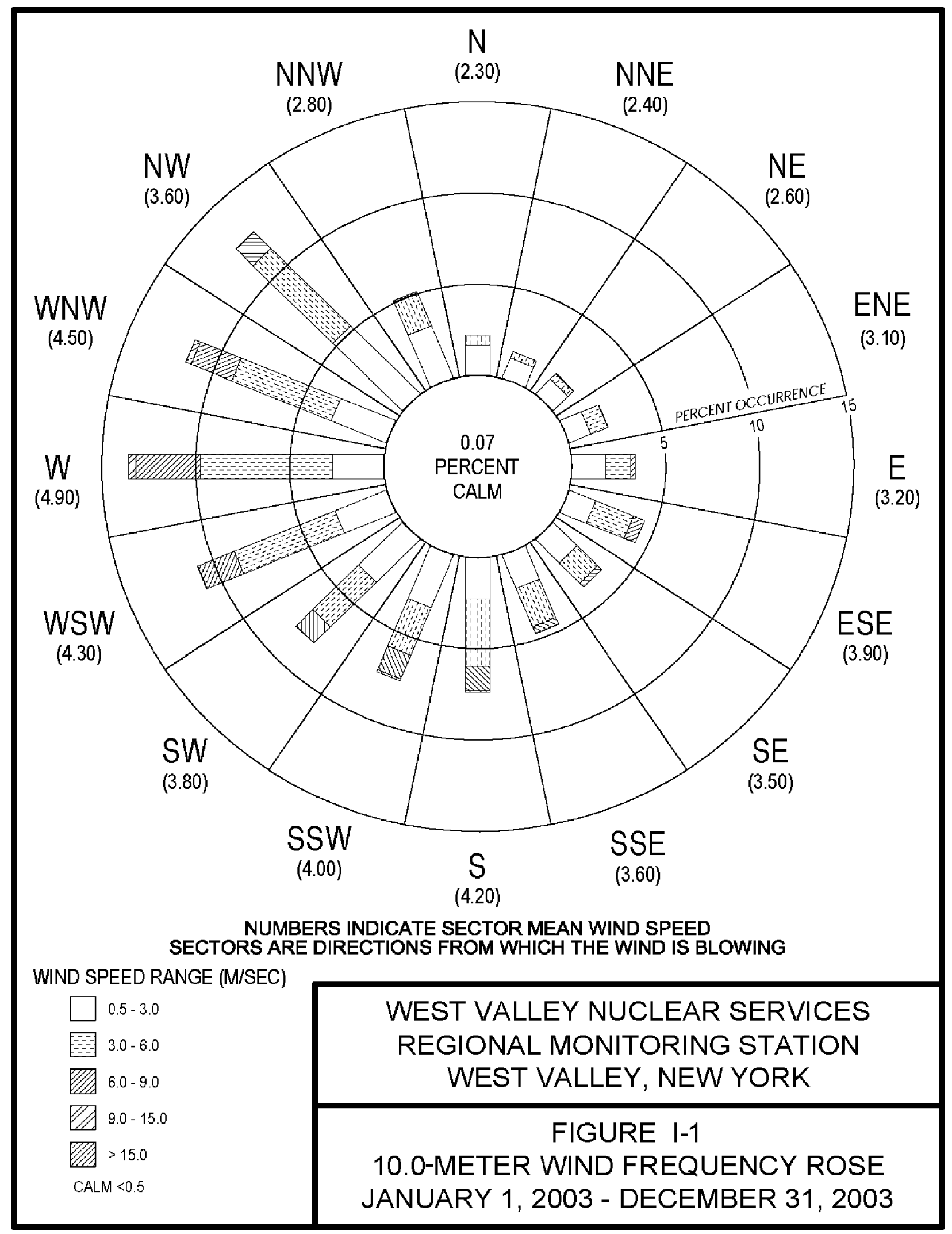

$I-3$ 


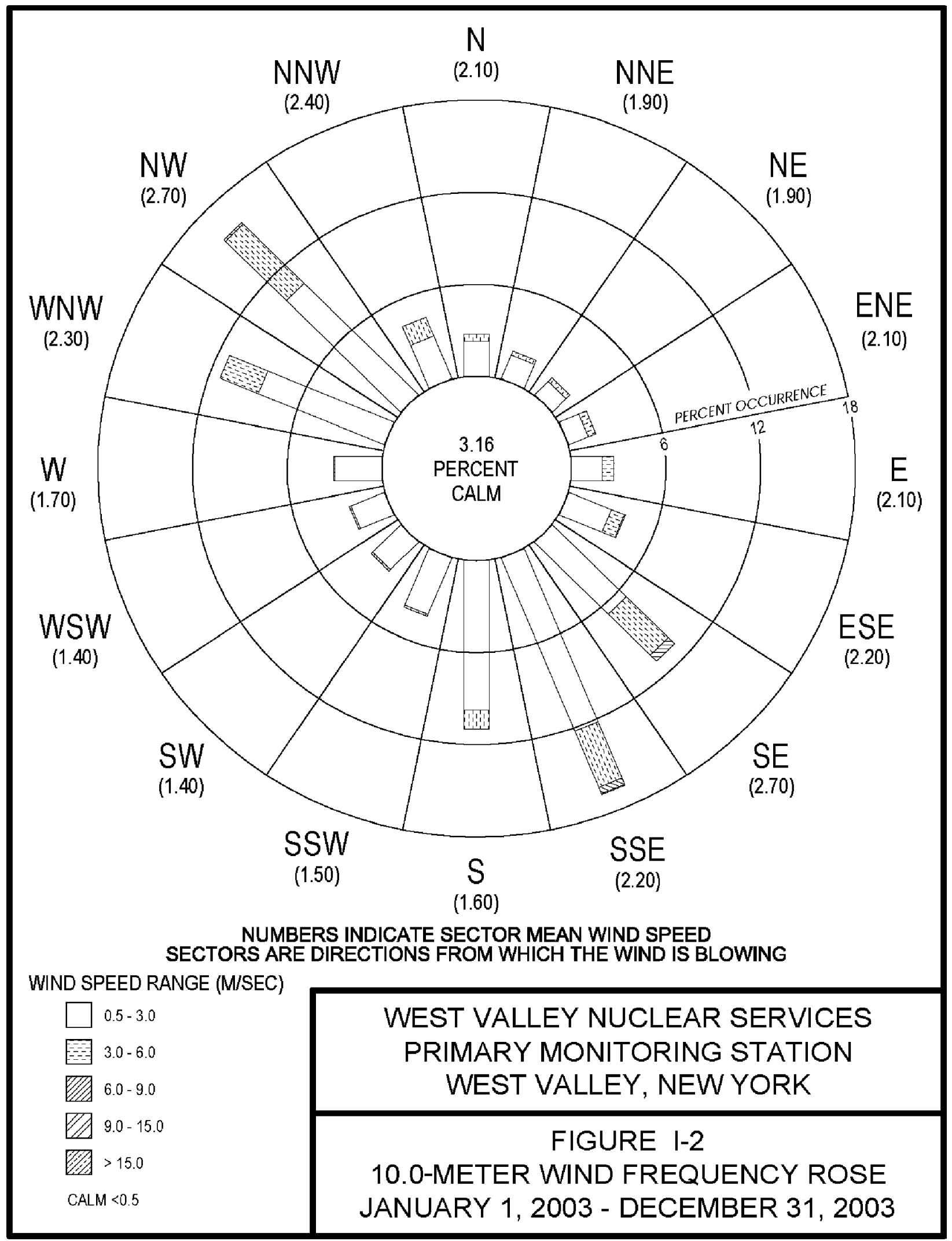

WVDP Annual Site Environmental Report

Calendar Year 2003 


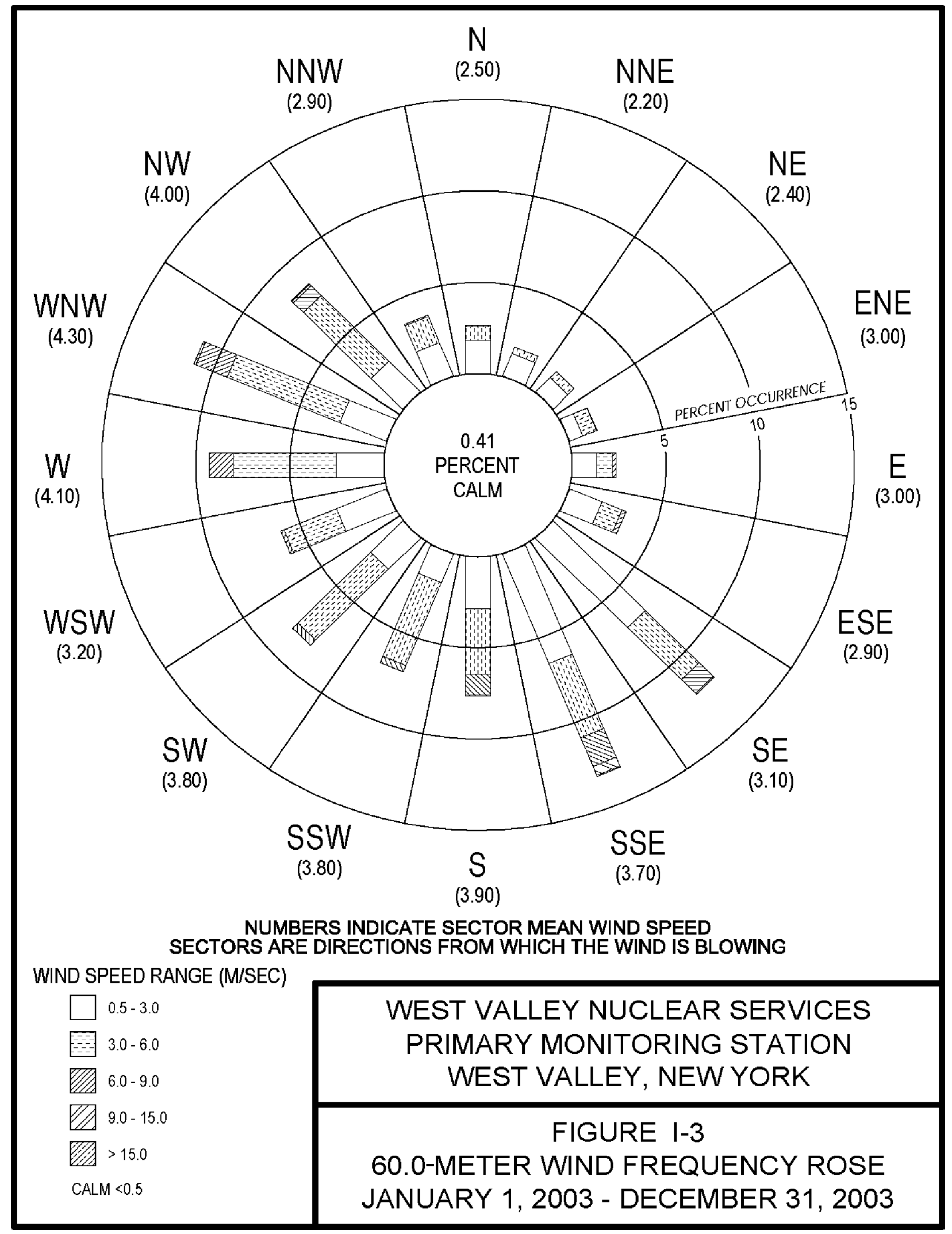

I - 5 


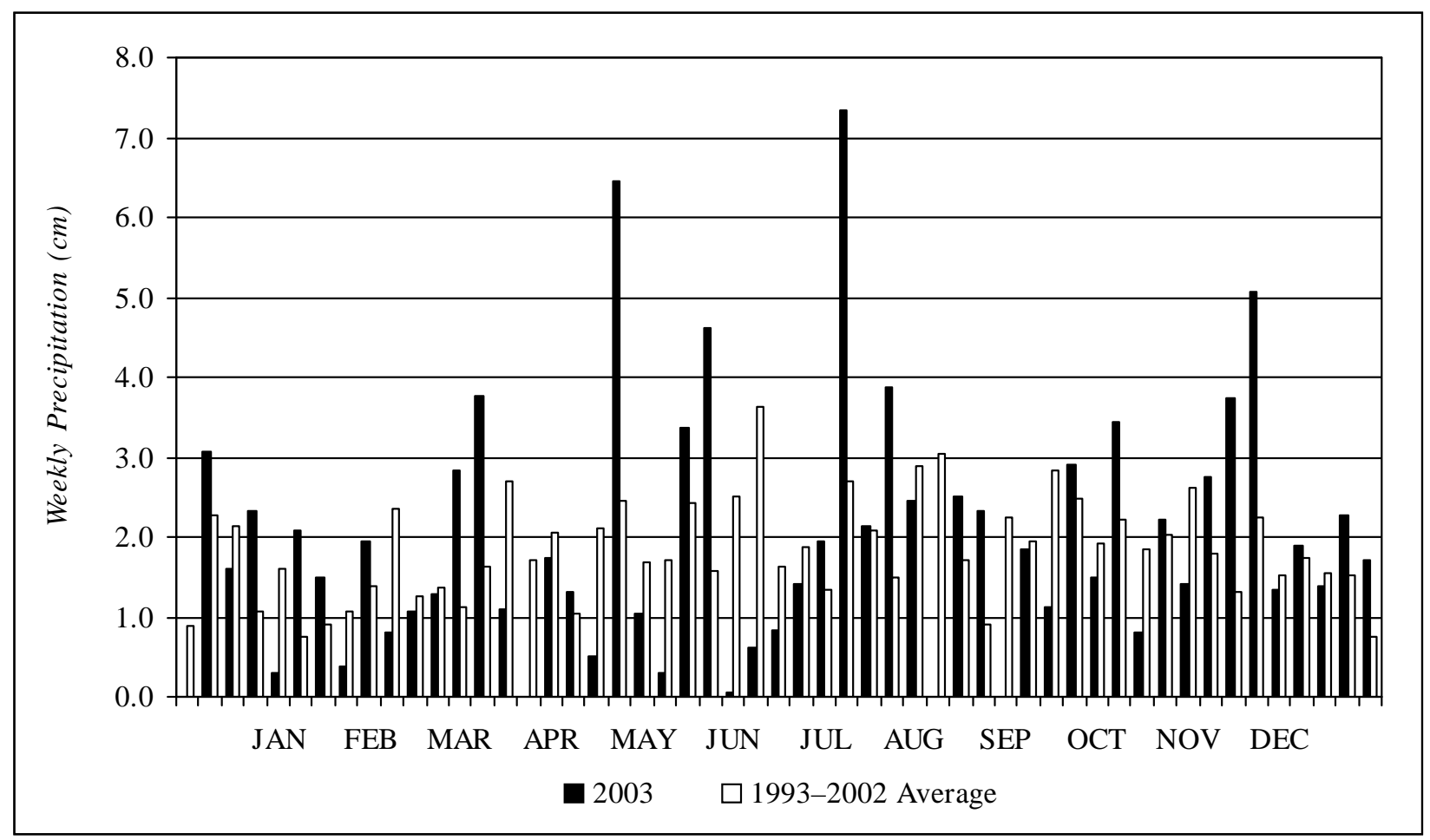

Figure I-4. Calendar Year 2003 Weekly Precipitation

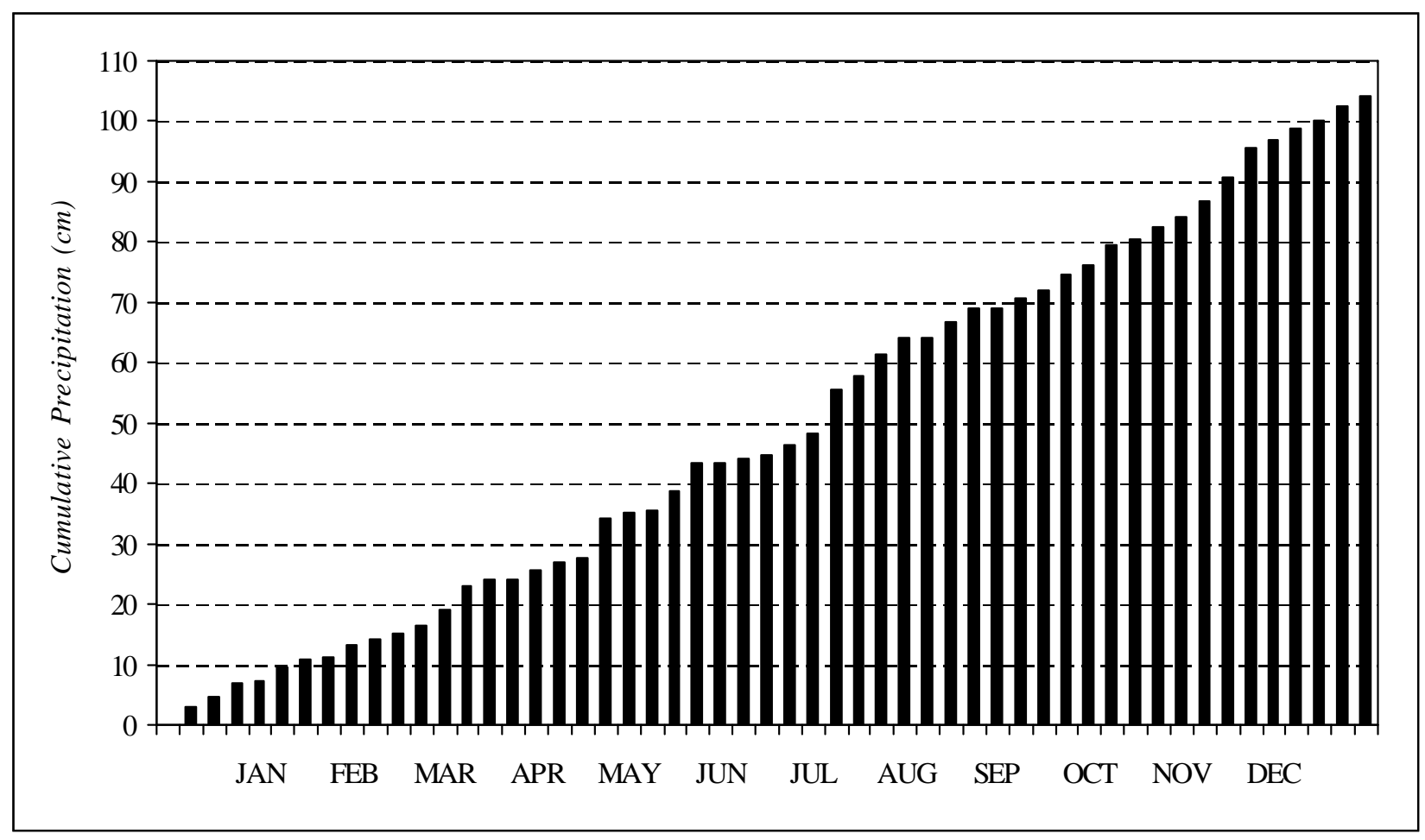

Figure I-5. Calendar Year 2003 Cumulative Precipitation

$$
I-6
$$




\section{Table I-1}

\section{Site Precipitation Collection Data}

\begin{tabular}{|c|c|c|c|c|c|c|c|c|c|}
\hline \multirow{2}{*}{$\begin{array}{l}\text { Week } \\
\text { Ending: }\end{array}$} & \multicolumn{2}{|c|}{ Weekly } & \multicolumn{2}{|c|}{ Cumulative } & \multirow{2}{*}{$\begin{array}{l}\text { Week } \\
\text { Ending: }\end{array}$} & \multicolumn{2}{|c|}{ Weekly } & \multicolumn{2}{|c|}{ Cumulative } \\
\hline & $(\mathrm{cm})$ & (inches) & $(\mathrm{cm})$ & (inches) & & $(\mathrm{cm})$ & (inches) & $(\mathrm{cm})$ & (inches) \\
\hline Jan 03 & 0.00 & 0.00 & 0.00 & 0.00 & Jul 04 & 0.84 & 0.33 & 44.81 & 17.64 \\
\hline Jan 10 & 3.07 & 1.21 & 3.07 & 1.21 & Jul 11 & 1.42 & 0.56 & 46.23 & 18.20 \\
\hline Jan 17 & 1.60 & 0.63 & 4.67 & 1.84 & Jul 18 & 1.96 & 0.77 & 48.18 & 18.97 \\
\hline $\operatorname{Jan} 24$ & 2.31 & 0.91 & 6.99 & 2.75 & Jul 25 & 7.34 & 2.89 & 55.52 & 21.86 \\
\hline Jan 31 & 0.30 & 0.12 & 7.29 & 2.87 & Aug 01 & 2.13 & 0.84 & 57.66 & 22.70 \\
\hline Feb 07 & 2.08 & 0.82 & 9.37 & 3.69 & Aug 08 & 3.86 & 1.52 & 61.52 & 24.22 \\
\hline Feb 14 & 1.50 & 0.59 & 10.87 & 4.28 & Aug 15 & 2.46 & 0.97 & 63.98 & 25.19 \\
\hline Feb 21 & 0.38 & 0.15 & 11.25 & 4.43 & Aug 22 & 0.00 & 0.00 & 63.98 & 25.19 \\
\hline Feb 28 & 1.96 & 0.77 & 13.21 & 5.20 & Aug 29 & 2.51 & 0.99 & 66.50 & 26.18 \\
\hline Mar 07 & 0.79 & 0.31 & 14.00 & 5.51 & Sep 05 & 2.31 & 0.91 & 68.81 & 27.09 \\
\hline Mar 14 & 1.07 & 0.42 & 15.06 & 5.93 & Sep 12 & 0.00 & 0.00 & 68.81 & 27.09 \\
\hline Mar 21 & 1.27 & 0.50 & 16.33 & 6.43 & Sep 19 & 1.83 & 0.72 & 70.64 & 27.81 \\
\hline Mar 28 & 2.82 & 1.11 & 19.15 & 7.54 & Sep 26 & 1.12 & 0.44 & 71.76 & 28.25 \\
\hline Apr 04 & 3.76 & 1.48 & 22.91 & 9.02 & Oct 03 & 2.90 & 1.14 & 74.65 & 29.39 \\
\hline Apr 11 & 1.09 & 0.43 & 24.00 & 9.45 & Oct 10 & 1.50 & 0.59 & 76.15 & 29.98 \\
\hline Apr 18 & 0.00 & 0.00 & 24.00 & 9.45 & Oct 17 & 3.43 & 1.35 & 79.58 & 31.33 \\
\hline Apr 25 & 1.73 & 0.68 & 25.73 & 10.13 & Oct 24 & 0.79 & 0.31 & 80.37 & 31.64 \\
\hline May 02 & 1.30 & 0.51 & 27.03 & 10.64 & Oct 31 & 2.21 & 0.87 & 82.58 & 32.51 \\
\hline May 09 & 0.51 & 0.20 & 27.53 & 10.84 & Nov 07 & 1.42 & 0.56 & 84.00 & 33.07 \\
\hline May 16 & 6.45 & 2.54 & 33.99 & 13.38 & Nov 14 & 2.74 & 1.08 & 86.74 & 34.15 \\
\hline May 23 & 1.04 & 0.41 & 35.03 & 13.79 & Nov 21 & 3.73 & 1.47 & 90.47 & 35.62 \\
\hline May 30 & 0.30 & 0.12 & 35.33 & 13.91 & Nov 28 & 5.05 & 1.99 & 95.53 & 37.61 \\
\hline Jun 06 & 3.35 & 1.32 & 38.68 & 15.23 & Dec 05 & 1.32 & 0.52 & 96.85 & 38.13 \\
\hline Jun 13 & 4.62 & 1.82 & 43.31 & 17.05 & Dec 12 & 1.91 & 0.75 & 98.76 & 38.88 \\
\hline Jun 20 & 0.05 & 0.02 & 43.36 & 17.07 & Dec 19 & 1.40 & 0.55 & 100.15 & 39.43 \\
\hline Jun 27 & 0.61 & 0.24 & 43.97 & 17.31 & Dec 26 & 2.26 & 0.89 & 102.41 & 40.32 \\
\hline & & & & & Dec 31 & 1.70 & 0.67 & 104.11 & 40.99 \\
\hline
\end{tabular}

$$
I-7
$$


Table I-2

2003 Annual Temperature Summary at the 10-Meter Primary Meteorological Tower

\begin{tabular}{lcccccc} 
Month & \multicolumn{2}{c}{$\begin{array}{c}\text { Average Temperature } \\
\mathbf{N}_{\mathbf{C}}\end{array}$} & $\mathbf{N}_{\mathbf{F}}$ & \multicolumn{2}{c}{ Maximum Temperature } & \multicolumn{2}{c}{ Minimum Temperature } \\
& & & $\mathbf{N}_{\mathbf{C}}$ & $\mathbf{N}_{\mathbf{F}}$ & & $\mathbf{N}_{\mathbf{F}}$ \\
January & -8.1 & 17.4 & 4.4 & 39.9 & -23.4 & -10.1 \\
February & -6.6 & 20.1 & 7.1 & 44.8 & -21.3 & -6.3 \\
March & 0.9 & 33.6 & 20.3 & 68.5 & -21.1 & -6.0 \\
April & 6.7 & 44.1 & 26.6 & 79.9 & -8.6 & 16.5 \\
May & 11.7 & 53.1 & 24.8 & 76.6 & 0.2 & 32.4 \\
June & 16.3 & 61.3 & 29.9 & 85.8 & 1.2 & 34.2 \\
July & 19.1 & 66.4 & 28.5 & 83.3 & 9.0 & 48.2 \\
August & 19.4 & 66.9 & 28.7 & 83.7 & 6.1 & 43.0 \\
September & 14.9 & 58.8 & 24.8 & 76.6 & 3.8 & 38.8 \\
October & 8.0 & 46.4 & 24.5 & 76.1 & -1.5 & 29.3 \\
November & 5.8 & 42.4 & 23.9 & 75.0 & -9.1 & 15.6 \\
December & -1.0 & 30.2 & 12.9 & 55.2 & -11.8 & 10.8 \\
& & & & & & \\
Annual Average & 7.3 & 45.1 & 21.4 & 70.5 & -6.4 & 20.5
\end{tabular}

\section{Table I-3}

2003 Annual Barometric Pressure Summary

(station pressure - inches of mercury)

$\begin{array}{lrcr}\text { Month } & \text { Average Pressure } & \text { Maximum Pressure } & \text { Minimum Press } \\ \text { January } & 28.44 & 28.90 & 27.55 \\ \text { February } & 28.46 & 29.03 & 27.58 \\ \text { March } & 28.45 & 28.82 & 28.07 \\ \text { April } & 28.51 & 28.94 & 28.03 \\ \text { May } & 28.45 & 28.81 & 27.92 \\ \text { June } & 28.47 & 28.72 & 28.18 \\ \text { July } & 28.50 & 28.77 & 28.16 \\ \text { August } & 28.57 & 28.93 & 28.35 \\ \text { September } & 28.59 & 28.84 & 28.12 \\ \text { October } & 28.47 & 28.74 & 27.71 \\ \text { November } & 28.51 & 29.15 & 27.84 \\ \text { December } & 28.49 & 29.00 & 27.94 \\ & & & \\ \text { Annual Average } & 28.49 & 28.89 & 27.95\end{array}$

$I-8$

WVDP Annual Site Environmental Report

Calendar Year 2003 


\section{Appendix J \\ Summary of Quality Assurance Crosscheck Analyses}

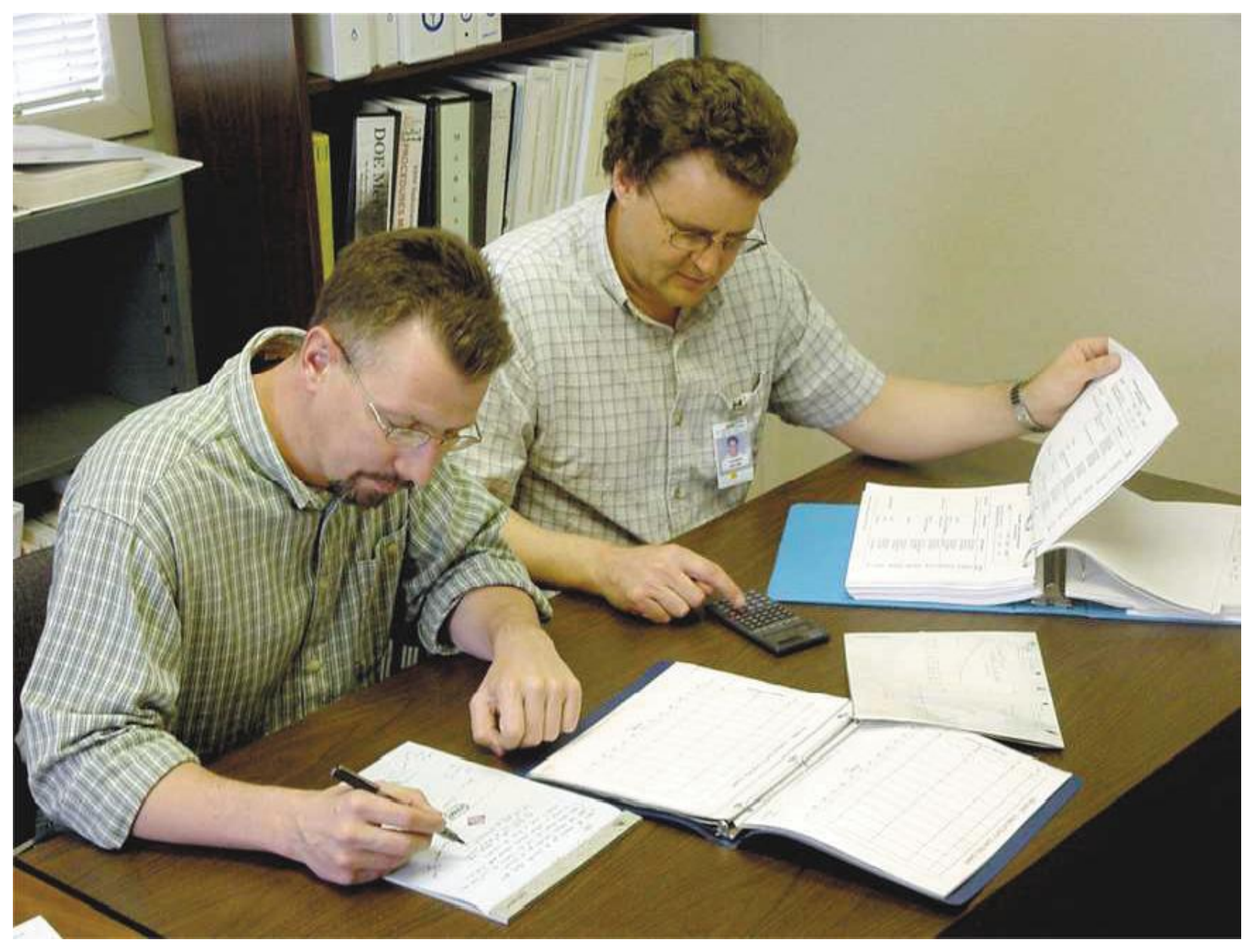

\section{Validating Data}

$J-1$ 
This page intentionally left blank

$$
J-2
$$




\section{Table J-1}

\section{Comparison of Radiological Results With Known Results of Crosscheck Samples From the DOE Environmental Measurements Laboratory (EML) Quality Assessment Program (QAP) 58; EML-621 QAP 0303; June 2003}

\begin{tabular}{|c|c|c|c|c|c|c|c|}
\hline Analyte & Matrix & Units & Actual & Reported & Ratio & Accept? & Analyzed b \\
\hline Co-60 & Air filter & $\mathrm{Bq} /$ filter & $3.35 \mathrm{E}+01$ & $3.55 \mathrm{E}+01$ & 1.060 & Yes & ELAB \\
\hline Co-60 & Air filter & $\mathrm{Bq} /$ filter & $3.35 \mathrm{E}+01$ & $3.53 \mathrm{E}+01$ & 1.054 & Yes & ELAB \\
\hline Cs-137 & Air filter & $\mathrm{Bq} /$ filter & $9.97 \mathrm{E}+01$ & $1.08 \mathrm{E}+02$ & 1.079 & Yes & ELAB \\
\hline Cs-137 & Air filter & $\mathrm{Bq} /$ filter & $9.97 \mathrm{E}+01$ & $1.06 \mathrm{E}+02$ & 1.067 & Yes & ELAB \\
\hline Gross Alpha & Air filter & $\mathrm{Bq} /$ filter & $1.17 \mathrm{E}+00$ & $1.24 \mathrm{E}+00$ & 1.060 & Yes & ELAB \\
\hline Gross Alpha & Air filter & $\mathrm{Bq} /$ filter & $1.17 \mathrm{E}+00$ & $1.28 \mathrm{E}+00$ & 1.094 & Yes & ELAB \\
\hline Gross Beta & Air filter & $\mathrm{Bq} /$ filter & $1.50 \mathrm{E}+00$ & $1.69 \mathrm{E}+00$ & 1.127 & Yes & ELAB \\
\hline Gross Beta & Air filter & $\mathrm{Bq} /$ filter & $1.50 \mathrm{E}+00$ & $1.63 \mathrm{E}+00$ & 1.087 & Yes & ELAB \\
\hline Mn-54 & Air filter & $\mathrm{Bq} /$ filter & $4.38 \mathrm{E}+01$ & $4.56 \mathrm{E}+01$ & 1.040 & Yes & ELAB \\
\hline Mn-54 & Air filter & $\mathrm{Bq} /$ filter & $4.38 \mathrm{E}+01$ & $4.57 \mathrm{E}+01$ & 1.042 & Yes & ELAB \\
\hline Am-241 & Air filter & $\mathrm{Bq} /$ filter & $3.40 \mathrm{E}-01$ & $3.25 \mathrm{E}-01$ & 0.956 & Yes & GEL \\
\hline Co-60 & Air filter & $\mathrm{Bq} /$ filter & $3.35 \mathrm{E}+01$ & $3.44 \mathrm{E}+01$ & 1.028 & Yes & GEL \\
\hline Cs-137 & Air filter & $\mathrm{Bq} /$ filter & $9.97 \mathrm{E}+01$ & $1.06 \mathrm{E}+02$ & 1.059 & Yes & GEL \\
\hline Gross Alpha & Air filter & $\mathrm{Bq} /$ filter & $1.17 \mathrm{E}+00$ & $1.27 \mathrm{E}+00$ & 1.082 & Yes & GEL \\
\hline Gross Beta & Air filter & $\mathrm{Bq} /$ filter & $1.50 \mathrm{E}+00$ & $1.42 \mathrm{E}+00$ & 0.944 & Yes & GEL \\
\hline Mn-54 & Air filter & $\mathrm{Bq} /$ filter & $4.38 \mathrm{E}+01$ & $4.61 \mathrm{E}+01$ & 1.053 & Yes & GEL \\
\hline $\mathrm{Pu}-238$ & Air filter & $\mathrm{Bq} /$ filter & $5.20 \mathrm{E}-01$ & $4.96 \mathrm{E}-01$ & 0.954 & Yes & GEL \\
\hline $\mathrm{Pu}-239$ & Air filter & $\mathrm{Bq} /$ filter & $3.30 \mathrm{E}-01$ & $3.24 \mathrm{E}-01$ & 0.982 & Yes & GEL \\
\hline Sr-90 & Air filter & $\mathrm{Bq} /$ filter & $2.80 \mathrm{E}+00$ & $2.62 \mathrm{E}+00$ & 0.937 & Yes & GEL \\
\hline U-234 & Air filter & $\mathrm{Bq} /$ filter & $2.40 \mathrm{E}-01$ & $2.40 \mathrm{E}-01$ & 1.000 & Yes & GEL \\
\hline $\mathrm{U}-238$ & Air filter & $\mathrm{Bq} /$ filter & $2.40 \mathrm{E}-01$ & $2.35 \mathrm{E}-01$ & 0.979 & Yes & GEL \\
\hline $\mathrm{U}$ (total) & Air filter & $\mu \mathrm{g} /$ filter & $1.97 \mathrm{E}+01$ & $1.47 \mathrm{E}+01$ & 0.745 & Pass & GEL \\
\hline Ac-228 & Soil & $\mathrm{Bq} / \mathrm{kg}$ & $5.76 \mathrm{E}+01$ & $5.48 \mathrm{E}+01$ & 0.951 & Yes & GEL \\
\hline Am-241 & Soil & $\mathrm{Bq} / \mathrm{kg}$ & $1.56 \mathrm{E}+01$ & $1.11 \mathrm{E}+01$ & 0.708 & Pass & GEL \\
\hline Bi-212 & Soil & $\mathrm{Bq} / \mathrm{kg}$ & $6.06 \mathrm{E}+01$ & $3.80 \mathrm{E}+01$ & 0.627 & Yes & GEL \\
\hline $\mathrm{Bi}-214$ & Soil & $\mathrm{Bq} / \mathrm{kg}$ & $6.70 \mathrm{E}+01$ & $5.08 \mathrm{E}+01$ & 0.758 & No & GEL \\
\hline Cs-137 & Soil & $\mathrm{Bq} / \mathrm{kg}$ & $1.45 \mathrm{E}+03$ & $1.46 \mathrm{E}+03$ & 1.008 & Yes & GEL \\
\hline $\mathrm{K}-40$ & Soil & $\mathrm{Bq} / \mathrm{kg}$ & $6.36 \mathrm{E}+02$ & $6.97 \mathrm{E}+02$ & 1.097 & Yes & GEL \\
\hline $\mathrm{Pb}-212$ & Soil & $\mathrm{Bq} / \mathrm{kg}$ & $5.79 \mathrm{E}+01$ & $5.98 \mathrm{E}+01$ & 1.032 & Yes & GEL \\
\hline $\mathrm{Pb}-214$ & Soil & $\mathrm{Bq} / \mathrm{kg}$ & $7.11 \mathrm{E}+01$ & $6.03 E+01$ & 0.848 & Pass & GEL \\
\hline $\mathrm{Pu}-239$ & Soil & $\mathrm{Bq} / \mathrm{kg}$ & $2.34 \mathrm{E}+01$ & $2.50 \mathrm{E}+01$ & 1.067 & Yes & GEL \\
\hline Sr-90 & Soil & $\mathrm{Bq} / \mathrm{kg}$ & $6.44 \mathrm{E}+01$ & $5.08 \mathrm{E}+01$ & 0.789 & Pass & GEL \\
\hline Th-234 & Soil & $\mathrm{Bq} / \mathrm{kg}$ & $1.27 \mathrm{E}+02$ & $1.19 \mathrm{E}+02$ & 0.939 & Yes & GEL \\
\hline U-234 & Soil & $\mathrm{Bq} / \mathrm{kg}$ & $1.20 \mathrm{E}+02$ & $1.09 \mathrm{E}+02$ & 0.911 & Yes & GEL \\
\hline U-238 & Soil & $\mathrm{Bq} / \mathrm{kg}$ & $1.25 \mathrm{E}+02$ & $1.13 \mathrm{E}+02$ & 0.901 & Yes & GEL \\
\hline $\mathrm{U}$ (total) & Soil & $\mu \mathrm{g} / \mathrm{g}$ & $1.01 \mathrm{E}+01$ & $8.35 E+00$ & 0.827 & Yes & GEL \\
\hline
\end{tabular}

Acceptance is based on the reported-to-actual ratio, assigned statistically on a case-by-case basis. Yes indicates a ratio within warning limits. Pass indicates a ratio within control limits but outside warning limits. No indicates a ratio outside control limits. Samples were analyzed by either the WVDP Environmental Laboratory (ELAB) or General Engineering Laboratory (GEL).

$$
\text { J - } 3
$$


Table J-1 (concluded)

\section{Comparison of Radiological Results With Known Results of Crosscheck Samples From the DOE Environmental Measurements Laboratory (EML) Quality Assessment Program (QAP) 58; EML-621 QAP 0303; June 2003}

\begin{tabular}{|c|c|c|c|c|c|c|c|}
\hline Analyte & Matrix & Units & Actual & Reported & Ratio & Accept? & Analyzed b \\
\hline Am-241 & Veg & $\mathrm{Bq} / \mathrm{kg}$ & $3.51 \mathrm{E}+00$ & $3.67 \mathrm{E}+00$ & 1.044 & Yes & GEL \\
\hline $\mathrm{Cm}-244$ & Veg & $\mathrm{Bq} / \mathrm{kg}$ & $2.01 \mathrm{E}+00$ & $2.06 \mathrm{E}+00$ & 1.026 & Yes & GEL \\
\hline Co-60 & Veg & $\mathrm{Bq} / \mathrm{kg}$ & $1.21 \mathrm{E}+01$ & $1.40 \mathrm{E}+01$ & 1.155 & Yes & GEL \\
\hline Cs-137 & Veg & $\mathrm{Bq} / \mathrm{kg}$ & $4.44 \mathrm{E}+02$ & $4.75 \mathrm{E}+02$ & 1.069 & Yes & GEL \\
\hline $\mathrm{K}-40$ & Veg & $\mathrm{Bq} / \mathrm{kg}$ & $1.12 \mathrm{E}+03$ & $1.33 \mathrm{E}+03$ & 1.189 & Yes & GEL \\
\hline $\mathrm{Pu}-239$ & Veg & $\mathrm{Bq} / \mathrm{kg}$ & $5.17 \mathrm{E}+00$ & $5.17 \mathrm{E}+00$ & 1.000 & Yes & GEL \\
\hline Sr-90 & Veg & $\mathrm{Bq} / \mathrm{kg}$ & $6.50 \mathrm{E}+02$ & $6.11 \mathrm{E}+02$ & 0.940 & Yes & GEL \\
\hline Co-60 & Water & $\mathrm{Bq} / \mathrm{L}$ & $2.34 \mathrm{E}+02$ & $2.35 \mathrm{E}+02$ & 1.006 & Yes & ELAB \\
\hline Cs-134 & Water & $\mathrm{Bq} / \mathrm{L}$ & $3.05 \mathrm{E}+01$ & $2.80 \mathrm{E}+01$ & 0.918 & Yes & ELAB \\
\hline Cs-137 & Water & $\mathrm{Bq} / \mathrm{L}$ & $6.38 \mathrm{E}+01$ & $6.37 \mathrm{E}+01$ & 0.998 & Yes & ELAB \\
\hline Gross Alpha & Water & $\mathrm{Bq} / \mathrm{L}$ & $3.78 \mathrm{E}+02$ & $2.72 \mathrm{E}+02$ & 0.721 & Pass & ELAB \\
\hline Gross Beta & Water & $\mathrm{Bq} / \mathrm{L}$ & $6.28 \mathrm{E}+02$ & $6.47 \mathrm{E}+02$ & 1.031 & Yes & ELAB \\
\hline $\mathrm{H}-3$ & Water & $\mathrm{Bq} / \mathrm{L}$ & $3.90 \mathrm{E}+02$ & $4.11 \mathrm{E}+02$ & 1.054 & Yes & ELAB \\
\hline Sr-90 & Water & $\mathrm{Bq} / \mathrm{L}$ & $4.34 \mathrm{E}+00$ & $4.32 \mathrm{E}+00$ & 0.995 & Yes & ELAB \\
\hline Am-241 & Water & $\mathrm{Bq} / \mathrm{L}$ & $2.13 \mathrm{E}+00$ & $2.20 \mathrm{E}+00$ & 1.033 & Yes & GEL \\
\hline Co-60 & Water & $\mathrm{Bq} / \mathrm{L}$ & $2.34 \mathrm{E}+02$ & $2.38 \mathrm{E}+02$ & 1.016 & Yes & GEL \\
\hline Cs-134 & Water & $\mathrm{Bq} / \mathrm{L}$ & $3.05 \mathrm{E}+01$ & $2.67 \mathrm{E}+01$ & 0.875 & Pass & GEL \\
\hline Cs-137 & Water & $\mathrm{Bq} / \mathrm{L}$ & $6.38 \mathrm{E}+01$ & $6.28 \mathrm{E}+01$ & 0.984 & Yes & GEL \\
\hline Gross Alpha & Water & $\mathrm{Bq} / \mathrm{L}$ & $3.78 \mathrm{E}+02$ & $3.97 \mathrm{E}+02$ & 1.051 & Yes & GEL \\
\hline Gross Beta & Water & $\mathrm{Bq} / \mathrm{L}$ & $6.28 \mathrm{E}+02$ & $6.83 \mathrm{E}+02$ & 1.088 & Yes & GEL \\
\hline $\mathrm{H}-3$ & Water & $\mathrm{Bq} / \mathrm{L}$ & $3.90 \mathrm{E}+02$ & $4.53 \mathrm{E}+02$ & 1.161 & Yes & GEL \\
\hline $\mathrm{Pu}-238$ & Water & $\mathrm{Bq} / \mathrm{L}$ & $3.33 \mathrm{E}+00$ & $3.43 \mathrm{E}+00$ & 1.031 & Yes & GEL \\
\hline $\mathrm{Pu}-239$ & Water & $\mathrm{Bq} / \mathrm{L}$ & $3.92 \mathrm{E}+00$ & $4.18 \mathrm{E}+00$ & 1.067 & Yes & GEL \\
\hline Sr-90 & Water & $\mathrm{Bq} / \mathrm{L}$ & $4.34 \mathrm{E}+00$ & $7.55 \mathrm{E}+00$ & 1.739 & No & GEL \\
\hline U-234 & Water & $\mathrm{Bq} / \mathrm{L}$ & $2.05 \mathrm{E}+00$ & $2.25 \mathrm{E}+00$ & 1.098 & Yes & GEL \\
\hline U-238 & Water & $\mathrm{Bq} / \mathrm{L}$ & $2.16 \mathrm{E}+00$ & $2.28 \mathrm{E}+00$ & 1.056 & Yes & GEL \\
\hline $\mathrm{U}$ (total) & Water & $\mu \mathrm{g} / \mathrm{mL}$ & $1.70 \mathrm{E}-01$ & $1.67 \mathrm{E}-01$ & 0.982 & Yes & GEL \\
\hline
\end{tabular}

Acceptance is based on the reported-to-actual ratio, assigned statistically on a case-by-case basis. Yes indicates a ratio within warning limits. Pass indicates a ratio within control limits but outside warning limits. No indicates a ratio outside control limits. Samples were analyzed by either the WVDP Environmental Laboratory (ELAB) or General Engineering Laboratory (GEL).

$J-4$ 
Table J-2

\section{Comparison of Radiological Results With Known Results of Crosscheck Samples From the DOE Environmental Measurements Laboratory (EML) Quality Assessment Program (QAP) 59; QAP 0309; December 2003}

\begin{tabular}{|c|c|c|c|c|c|c|c|}
\hline Analyte & Matrix & Units & Actual & Reported & Ratio & Accept? & Analyzed b \\
\hline Co-60 & Air filter & $\mathrm{Bq} /$ filter & $5.51 \mathrm{E}+01$ & $5.86 \mathrm{E}+01$ & 1.064 & Yes & ELAB \\
\hline Co-60 & Air filter & $\mathrm{Bq} /$ filter & $5.51 \mathrm{E}+01$ & $5.82 \mathrm{E}+01$ & 1.057 & Yes & ELAB \\
\hline Cs- 137 & Air filter & $\mathrm{Bq} /$ filter & $5.48 \mathrm{E}+01$ & $6.01 \mathrm{E}+01$ & 1.096 & Yes & ELAB \\
\hline Cs-137 & Air filter & $\mathrm{Bq} /$ filter & $5.48 \mathrm{E}+01$ & $5.79 \mathrm{E}+01$ & 1.057 & Yes & ELAB \\
\hline Gross Alpha & Air filter & $\mathrm{Bq} /$ filter & $3.11 \mathrm{E}+00$ & $3.18 \mathrm{E}+00$ & 1.023 & Yes & ELAB \\
\hline Gross Alpha & Air filter & $\mathrm{Bq} /$ filter & $3.11 \mathrm{E}+00$ & $3.19 \mathrm{E}+00$ & 1.026 & Yes & ELAB \\
\hline Gross Beta & Air filter & $\mathrm{Bq} /$ filter & $3.89 \mathrm{E}+00$ & $4.26 \mathrm{E}+00$ & 1.095 & Yes & ELAB \\
\hline Gross Beta & Air filter & $\mathrm{Bq} /$ filter & $3.89 \mathrm{E}+00$ & $4.12 \mathrm{E}+00$ & 1.059 & Yes & ELAB \\
\hline Mn-54 & Air filter & $\mathrm{Bq} /$ filter & $5.80 \mathrm{E}+01$ & $6.01 \mathrm{E}+01$ & 1.037 & Yes & ELAB \\
\hline Mn-54 & Air filter & $\mathrm{Bq} /$ filter & $5.80 \mathrm{E}+01$ & $6.08 \mathrm{E}+01$ & 1.049 & Yes & ELAB \\
\hline Am-241 & Air filter & $\mathrm{Bq} /$ filter & $4.35 \mathrm{E}-01$ & $4.16 \mathrm{E}-01$ & 0.956 & Yes & GEL \\
\hline Co-60 & Air filter & $\mathrm{Bq} /$ filter & $5.51 \mathrm{E}+01$ & $5.17 \mathrm{E}+01$ & 0.938 & Yes & GEL \\
\hline Cs- 137 & Air filter & $\mathrm{Bq} /$ filter & $5.48 \mathrm{E}+01$ & $5.16 \mathrm{E}+01$ & 0.941 & Yes & GEL \\
\hline Gross Alpha & Air filter & $\mathrm{Bq} /$ filter & $3.11 \mathrm{E}+00$ & $2.83 \mathrm{E}+00$ & 0.911 & Yes & GEL \\
\hline Gross Beta & Air filter & $\mathrm{Bq} /$ filter & $3.89 \mathrm{E}+00$ & $3.14 \mathrm{E}+00$ & 0.808 & Pass & GEL \\
\hline Mn-54 & Air filter & $\mathrm{Bq} /$ filter & $5.80 \mathrm{E}+01$ & $5.44 \mathrm{E}+01$ & 0.938 & Yes & GEL \\
\hline $\mathrm{Pu}-238$ & Air filter & $\mathrm{Bq} /$ filter & $2.29 \mathrm{E}-01$ & $2.25 \mathrm{E}-01$ & 0.983 & Yes & GEL \\
\hline $\mathrm{Pu}-239$ & Air filter & $\mathrm{Bq} /$ filter & 4.01E-01 & $3.90 \mathrm{E}-01$ & 0.973 & Yes & GEL \\
\hline Sr-90 & Air filter & $\mathrm{Bq} /$ filter & $2.06 \mathrm{E}+00$ & $1.69 \mathrm{E}+00$ & 0.820 & Yes & GEL \\
\hline $\mathrm{U}$ (total) & Air filter & $\mu \mathrm{g} /$ filter & $3.21 \mathrm{E}+01$ & $2.85 \mathrm{E}+01$ & 0.887 & Pass & GEL \\
\hline Ac- 228 & Soil & $\mathrm{Bq} / \mathrm{kg}$ & $5.08 \mathrm{E}+01$ & $4.72 \mathrm{E}+01$ & 0.930 & Yes & GEL \\
\hline Am-241 & Soil & $\mathrm{Bq} / \mathrm{kg}$ & $1.84 \mathrm{E}+01$ & $1.91 \mathrm{E}+01$ & 1.040 & Yes & GEL \\
\hline $\mathrm{Bi}-212$ & Soil & $\mathrm{Bq} / \mathrm{kg}$ & $5.39 \mathrm{E}+01$ & $2.97 \mathrm{E}+01$ & 0.551 & Pass & GEL \\
\hline Bi-214 & Soil & $\mathrm{Bq} / \mathrm{kg}$ & $3.44 \mathrm{E}+01$ & $2.55 \mathrm{E}+01$ & 0.741 & No & GEL \\
\hline Cs- 137 & Soil & $\mathrm{Bq} / \mathrm{kg}$ & $1.97 \mathrm{E}+03$ & $1.88 \mathrm{E}+03$ & 0.951 & Yes & GEL \\
\hline $\mathrm{K}-40$ & Soil & $\mathrm{Bq} / \mathrm{kg}$ & $4.88 \mathrm{E}+02$ & $5.14 \mathrm{E}+02$ & 1.054 & Yes & GEL \\
\hline $\mathrm{Pb}-212$ & Soil & $\mathrm{Bq} / \mathrm{kg}$ & $5.07 \mathrm{E}+01$ & $5.16 \mathrm{E}+01$ & 1.017 & Yes & GEL \\
\hline $\mathrm{Pb}-214$ & Soil & $\mathrm{Bq} / \mathrm{kg}$ & $3.52 \mathrm{E}+01$ & $2.79 \mathrm{E}+01$ & 0.793 & Pass & GEL \\
\hline $\mathrm{Pu}-238$ & Soil & $\mathrm{Bq} / \mathrm{kg}$ & $1.46 \mathrm{E}+01$ & $1.52 \mathrm{E}+01$ & 1.044 & Yes & GEL \\
\hline $\mathrm{Pu}-239$ & Soil & $\mathrm{Bq} / \mathrm{kg}$ & $3.04 \mathrm{E}+01$ & $3.37 \mathrm{E}+01$ & 1.109 & Yes & GEL \\
\hline Sr-90 & Soil & $\mathrm{Bq} / \mathrm{kg}$ & $8.03 E+01$ & $7.45 \mathrm{E}+01$ & 0.928 & Yes & GEL \\
\hline Th-234 & Soil & $\mathrm{Bq} / \mathrm{kg}$ & $1.16 \mathrm{E}+02$ & $8.90 \mathrm{E}+01$ & 0.768 & Pass & GEL \\
\hline $\mathrm{U}$ (total) & Soil & $\mu \mathrm{g} / \mathrm{g}$ & $1.03 \mathrm{E}+01$ & $8.89 \mathrm{E}+00$ & 0.865 & Yes & GEL \\
\hline
\end{tabular}

Acceptance is based on the reported-to-actual ratio, assigned statistically on a case-by-case basis. Yes indicates a ratio within warning limits. Pass indicates a ratio within control limits but outside warning limits. No indicates a ratio outside control limits. Samples were analyzed by either the WVDP Environmental Laboratory (ELAB) or General Engineering Laboratory (GEL).

$J-5$ 
Table J-2 (concluded)

Comparison of Radiological Results With Known Results of Crosscheck Samples From the DOE Environmental Measurements Laboratory (EML) Quality Assessment Program (QAP) 59; QAP 0309; December 2003

$\begin{array}{llcccccc}\text { Analyte } & \text { Matrix } & \text { Units } & \text { Actual } & \text { Reported } & \text { Ratio } & \text { Accept? } & \text { Analyzed by: } \\ & & & & & & & \\ \text { Co-60 } & \text { Water } & \text { Bq/L } & 5.13 \mathrm{E}+02 & 4.92 \mathrm{E}+02 & 0.958 & \text { Yes } & \text { ELAB } \\ \text { Cs-134 } & \text { Water } & \mathrm{Bq} / \mathrm{L} & 6.30 \mathrm{E}+01 & 5.87 \mathrm{E}+01 & 0.932 & \text { Yes } & \text { ELAB } \\ \text { Cs-137 } & \text { Water } & \mathrm{Bq} / \mathrm{L} & 8.03 \mathrm{E}+01 & 7.86 \mathrm{E}+01 & 0.979 & \text { Yes } & \text { ELAB } \\ \text { Gross Alpha } & \text { Water } & \mathrm{Bq} / \mathrm{L} & 6.22 \mathrm{E}+02 & 4.80 \mathrm{E}+02 & 0.772 & \text { Pass } & \text { ELAB } \\ \text { Gross Beta } & \text { Water } & \mathrm{Bq} / \mathrm{L} & 1.95 \mathrm{E}+03 & 1.83 \mathrm{E}+03 & 0.937 & \text { Yes } & \text { ELAB } \\ \text { H-3 } & \text { Water } & \mathrm{Bq} / \mathrm{L} & 4.46 \mathrm{E}+02 & 5.04 \mathrm{E}+02 & 1.130 & \text { Yes } & \text { ELAB } \\ \text { Sr-90 } & \text { Water } & \mathrm{Bq} / \mathrm{L} & 7.04 \mathrm{E}+00 & 6.65 \mathrm{E}+00 & 0.945 & \text { Yes } & \text { ELAB } \\ \text { Am-241 } & \text { Water } & \mathrm{Bq} / \mathrm{L} & 8.76 \mathrm{E}+00 & 7.64 \mathrm{E}+00 & 0.872 & \text { Pass } & \text { GEL } \\ \text { Co-60 } & \text { Water } & \mathrm{Bq} / \mathrm{L} & 5.13 \mathrm{E}+02 & 5.13 \mathrm{E}+02 & 1.000 & \text { Yes } & \text { GEL } \\ \text { Cs-134 } & \text { Water } & \mathrm{Bq} / \mathrm{L} & 6.30 \mathrm{E}+01 & 5.78 \mathrm{E}+01 & 0.918 & \text { Yes } & \text { GEL } \\ \text { Cs-137 } & \text { Water } & \mathrm{Bq} / \mathrm{L} & 8.03 \mathrm{E}+01 & 7.94 \mathrm{E}+01 & 0.989 & \text { Yes } & \text { GEL } \\ \text { Gross Alpha } & \text { Water } & \mathrm{Bq} / \mathrm{L} & 6.22 \mathrm{E}+02 & 5.18 \mathrm{E}+02 & 0.832 & \text { Yes } & \text { GEL } \\ \text { Gross Beta } & \text { Water } & \mathrm{Bq} / \mathrm{L} & 1.95 \mathrm{E}+03 & 1.65 \mathrm{E}+03 & 0.850 & \text { Yes } & \text { GEL } \\ \text { H-3 } & \text { Water } & \mathrm{Bq} / \mathrm{L} & 4.46 \mathrm{E}+02 & 5.10 \mathrm{E}+02 & 1.144 & \text { Yes } & \text { GEL } \\ \text { Pu-238 } & \text { Water } & \mathrm{Bq} / \mathrm{L} & 2.07 \mathrm{E}+00 & 1.95 \mathrm{E}+00 & 0.941 & \text { Yes } & \text { GEL } \\ \text { Pu-239 } & \text { Water } & \mathrm{Bq} / \mathrm{L} & 4.99 \mathrm{E}+00 & 4.90 \mathrm{E}+00 & 0.983 & \text { Yes } & \text { GEL } \\ \text { Sr-90 } & \text { Water } & \mathrm{Bq} / \mathrm{L} & 7.04 \mathrm{E}+00 & 5.85 \mathrm{E}+00 & 0.830 & \text { Pass } & \text { GEL }\end{array}$

Acceptance is based on the reported-to-actual ratio, assigned statistically on a case-by-case basis. Yes indicates a ratio within warning limits. Pass indicates a ratio within control limits but outside warning limits. No indicates a ratio outside control limits. Samples were analyzed by either the WVDP Environmental Laboratory (ELAB) or General Engineering Laboratory (GEL).

$J-6$ 


\section{Table J-3}

Comparison of Results From Crosscheck Samples Analyzed for Water Quality Parameters as Part of the EPA's 2003 Discharge Monitoring Report - Quality Assurance (DMR-QA) Study 23 for the National Pollutant Discharge Elimination System (NPDES)

$\begin{array}{llrrrc}\text { Analyte } & \text { Units } & \text { Actual } & \text { Reported } & \text { Accept? } & \text { Analyzed by: } \\ & & & & & \\ \text { Aluminum } & \mu \mathrm{g} / \mathrm{L} & 662 & 671 & \text { Yes } & \mathrm{STL} \\ \text { Ammonia (as nitrogen) } & \mathrm{mg} / \mathrm{L} & 7.54 & 7.75 & \text { Yes } & \mathrm{STL} \\ \text { Arsenic } & \mu \mathrm{g} / \mathrm{L} & 279 & 278 & \text { Yes } & \mathrm{STL} \\ \text { Biochemical oxygen demand } & \mathrm{mg} / \mathrm{L} & 29.9 & 26.0 & \text { Yes } & \mathrm{STL} \\ \text { Cadmium } & \mu \mathrm{g} / \mathrm{L} & 242 & 236 & \text { Yes } & \mathrm{STL} \\ \text { Chlorine, total residual } & \mathrm{mg} / \mathrm{L} & 1.42 & 1.58 & \text { Yes } & \mathrm{WVNSCO} \\ \text { Chromium } & \mu \mathrm{g} / \mathrm{L} & 369 & 360 & \text { Yes } & \mathrm{STL} \\ \text { Cobalt } & \mu \mathrm{g} / \mathrm{L} & 477 & 486 & \text { Yes } & \mathrm{STL} \\ \text { Copper } & \mu \mathrm{g} / \mathrm{L} & 280 & 284 & \text { Yes } & \mathrm{STL} \\ \text { Cyanide, total } & \mathrm{mg} / \mathrm{L} & 0.638 & 0.618 & \text { Yes } & \mathrm{STL} \\ \text { Oil and grease (gravimetric) } & \mathrm{mg} / \mathrm{L} & 24.0 & 23.9 & \text { Yes } & \mathrm{STL} \\ \text { Iron } & \mu \mathrm{g} / \mathrm{L} & 389 & 454 & \mathrm{No} & \mathrm{STL} \\ \text { Lead } & \mu \mathrm{g} / \mathrm{L} & 237 & 238 & \text { Yes } & \mathrm{STL} \\ \text { Manganese } & \mu \mathrm{g} / \mathrm{L} & 175 & 175 & \text { Yes } & \mathrm{STL} \\ \text { Mercury } & \mu \mathrm{g} / \mathrm{L} & 11.7 & 10.5 & \text { Yes } & \mathrm{STL} \\ \text { Nickel } & \mu \mathrm{g} / \mathrm{L} & 895 & 903 & \text { Yes } & \mathrm{STL} \\ \text { Nitrate (as nitrogen) } & \mathrm{mg} / \mathrm{L} & 3.89 & 3.81 & \text { Yes } & \mathrm{STL} \\ \text { pH } & \mathrm{SU} & 8.80 & 8.77 & \text { Yes } & \mathrm{WVNSCO} \\ \text { Phenolics, total } & \mathrm{mg} / \mathrm{L} & 0.641 & 0.571 & \text { Yes } & \mathrm{STL} \\ \text { Selenium } & \mu \mathrm{g} / \mathrm{L} & 621 & 619 & \text { Yes } & \mathrm{STL} \\ \text { Suspended solids, total } & \mathrm{mg} / \mathrm{L} & 58.0 & 55.0 & \text { Yes } & \mathrm{STL} \\ \text { Vanadium } & \mu \mathrm{g} / \mathrm{L} & 469 & 469 & \text { Yes } & \mathrm{STL} \\ \text { Zinc } & \mu \mathrm{g} / \mathrm{L} & 917 & 916 & \text { Yes } & \mathrm{STL}\end{array}$

Samples provided by Environmental Research Associates (ERA).

Analyses were conducted by Severn Trent Laboratories (STL) or WVNSCO, as indicated.

Acceptance limits are determined by ERA or NYSDOH, as applicable. Yes indicates a ratio within warning limits. Pass indicates a ratio within control limits but outside warning limits. No indicates a ratio outside control limits.

$$
J-7
$$


This page intentionally left blank

$$
J-8
$$




\section{Appendix $\mathrm{K}$ \\ Environmental Laws, Regulations, Standards, and Orders}

$K-1$ 
This page intentionally left blank

$$
K-2
$$




\title{
Table $\mathrm{K}-1$
}

\section{U.S. Department of Energy Radiation Protection Standards and Derived Concentration Guides ${ }^{1}$}

\author{
Effective Dose Equivalent Radiation Standard for Protection of the Public \\ Continuous exposure of any member of the public from routine activities: \\ All exposure pathways $=100 \mathrm{mrem} / \mathrm{year}(1 \mathrm{mSv} / \mathrm{yr})$ effective dose equivalent
}

\section{U.S. Department of Energy Derived Concentration Guides (DCGs) for Inhaled Air or Ingested Water $(\mu \mathrm{Ci} / \mathrm{mL})$}

\begin{tabular}{|c|c|c|c|c|c|c|c|}
\hline Radionuclide & $\begin{array}{c}\text { Half-life }^{2,3} \\
\text { (years) }\end{array}$ & In Air & In Water & Radionuclide & $\begin{array}{c}\text { Half-life } e^{2,3} \\
\text { (years) }\end{array}$ & In Air & In Water \\
\hline H-3* & $1.23 \mathrm{E}+01$ & $1 \mathrm{E}-07$ & $2 \mathrm{E}-03$ & Eu-152 & $1.36 \mathrm{E}+01$ & $5 \mathrm{E}-11$ & $2 \mathrm{E}-05$ \\
\hline C-14* & $5.73 E+03$ & $6 \mathrm{E}-09$ & 7E-05 & Eu-154* & $8.80 \mathrm{E}+00$ & $5 \mathrm{E}-11$ & $2 \mathrm{E}-05$ \\
\hline K-40 & $1.28 \mathrm{E}+09$ & 9E-10 & 7E-06 & Eu-155 & $4.96 \mathrm{E}+00$ & $3 \mathrm{E}-10$ & $1 \mathrm{E}-04$ \\
\hline Fe-55 & $2.70 \mathrm{E}+00$ & $5 \mathrm{E}-09$ & 2E-04 & Th-232 & $1.40 \mathrm{E}+10$ & $7 E-15$ & $5 \mathrm{E}-08$ \\
\hline Co-60* & $5.27 \mathrm{E}+00$ & $8 \mathrm{E}-11$ & $5 \mathrm{E}-06$ & U-232* & $7.20 \mathrm{E}+01$ & $2 \mathrm{E}-14$ & $1 \mathrm{E}-07$ \\
\hline Ni-59 & $7.50 \mathrm{E}+04$ & 4E-09 & 7E-04 & U-233* & $1.59 \mathrm{E}+05$ & 9E-14 & $5 \mathrm{E}-07$ \\
\hline Ni-63 & $1.00 \mathrm{E}+02$ & 2E-09 & $3 E-04$ & U-234* & $2.44 \mathrm{E}+05$ & 9E-14 & $5 \mathrm{E}-07$ \\
\hline Sr-90* & $2.86 \mathrm{E}+01$ & $9 \mathrm{E}-12$ & $1 \mathrm{E}-06$ & U-235* & $7.04 \mathrm{E}+08$ & $1 \mathrm{E}-13$ & $6 \mathrm{E}-07$ \\
\hline Y-90 & $7.31 \mathrm{E}-03$ & $1 \mathrm{E}-09$ & $1 \mathrm{E}-05$ & U-236* & $2.34 \mathrm{E}+07$ & $1 \mathrm{E}-13$ & $5 \mathrm{E}-07$ \\
\hline Zr-93 & $1.53 \mathrm{E}+06$ & $4 \mathrm{E}-11$ & 9E-05 & U-238* & $4.47 \mathrm{E}+09$ & $1 \mathrm{E}-13$ & $6 \mathrm{E}-07$ \\
\hline Nb-93m & $1.46 \mathrm{E}+01$ & $4 \mathrm{E}-10$ & $3 E-04$ & Np-239 & $6.45 \mathrm{E}-03$ & $5 E-09$ & $5 \mathrm{E}-05$ \\
\hline Tc-99* & $2.13 \mathrm{E}+05$ & 2E-09 & $1 \mathrm{E}-04$ & Pu-238* & $8.78 \mathrm{E}+01$ & $3 E-14$ & $4 \mathrm{E}-08$ \\
\hline Ru-106 & $1.01 \mathrm{E}+00$ & $3 E-11$ & $6 \mathrm{E}-06$ & Pu-239* & $2.41 \mathrm{E}+04$ & $2 \mathrm{E}-14$ & $3 \mathrm{E}-08$ \\
\hline Cd-113m & $1.37 \mathrm{E}+01$ & $8 \mathrm{E}-12$ & 9E-07 & Pu-240* & $6.57 \mathrm{E}+03$ & $2 \mathrm{E}-14$ & $3 \mathrm{E}-08$ \\
\hline Sn-126 & $1.00 \mathrm{E}+05$ & $1 \mathrm{E}-10$ & $8 \mathrm{E}-06$ & Pu-241 & $1.44 \mathrm{E}+01$ & $1 \mathrm{E}-12$ & 2E-06 \\
\hline Sb-125 & $2.77 \mathrm{E}+00$ & $1 \mathrm{E}-09$ & $5 \mathrm{E}-05$ & Am-241* & $4.32 \mathrm{E}+02$ & $2 \mathrm{E}-14$ & $3 \mathrm{E}-08$ \\
\hline Te-125m & $1.59 \mathrm{E}-01$ & 2E-09 & 4E-05 & Am-242m & $1.52 \mathrm{E}+02$ & $2 \mathrm{E}-14$ & $3 \mathrm{E}-08$ \\
\hline I-129* & $1.57 \mathrm{E}+07$ & 7E-11 & $5 \mathrm{E}-07$ & Am-243 & $7.38 \mathrm{E}+03$ & $2 \mathrm{E}-14$ & $3 \mathrm{E}-08$ \\
\hline Cs-134 & $2.06 \mathrm{E}+00$ & $2 \mathrm{E}-10$ & 2E-06 & Cm-243 & $2.85 \mathrm{E}+01$ & $3 \mathrm{E}-14$ & $5 \mathrm{E}-08$ \\
\hline Cs-135 & $2.30 \mathrm{E}+06$ & $3 \mathrm{E}-09$ & $2 \mathrm{E}-05$ & Cm-244 & $1.81 \mathrm{E}+01$ & $4 \mathrm{E}-14$ & $6 \mathrm{E}-08$ \\
\hline Cs-137* & $3.02 \mathrm{E}+01$ & $4 \mathrm{E}-10$ & $3 \mathrm{E}-06$ & Gross Alpha & NA & $2 \mathrm{E}-14$ & $3 \mathrm{E}-08$ \\
\hline Pm-147 & $2.62 \mathrm{E}+00$ & $3 \mathrm{E}-10$ & $1 \mathrm{E}-04$ & (as Am-241) & & & \\
\hline Sm-151 & $9.00 \mathrm{E}+01$ & $4 \mathrm{E}-10$ & $4 \mathrm{E}-04$ & $\begin{array}{l}\text { Gross Beta } \\
\text { (as Sr-90) }\end{array}$ & NA & $9 \mathrm{E}-12$ & $1 \mathrm{E}-06$ \\
\hline
\end{tabular}

${ }^{1}$ DOE Order 5400.5 (February 8, 1990). Effective May 8, 1990. (See Derived Concentration Guides [p. 1-5] in Chapter 1, Environmental Program Information.)

${ }^{2}$ U.S. Department of Energy. 1981. Radioactive Decay Tables. Washington, D.C.: Technical Information Center, U.S. Department of Energy.

${ }^{3}$ Shleien, et al. 1998. Handbook of Health Physics and Radiological Health Safety. 3rd ed. Baltimore, Maryland: Williams \& Wilkins.

* Radionuclides measured in WVDP effluent.

NA - Not applicable.

$K-3$ 


\section{Table K-2 \\ Environmental Laws, Regulations, Standards, and Orders}

The following environmental standards and laws are applicable, in whole or in part, to the West Valley Demonstration Project. Although the list covers the major activities at the West Valley Demonstration Project, it does not constitute a complete enumeration.

Atomic Energy Act of 1954, 42 United States Code (USC) §2011 et seq., as amended, and federal implementing regulations.

Clean Air Act (CAA). Pub. L. No. 84-159. 42 USC $\$ 7401$ et seq., as amended, and federal and state implementing regulations.

Comprehensive Environmental Response, Compensation, and Liability Act (CERCLA). Pub. L. No. 96-510. 42 USC $\$ 9601$ et seq. (including Superfund Amendments and Reauthorization Act [SARA] of 1986), and federal implementing regulations.

DOE Order 231.1A. August 19, 2003. Environment, Safety, and Health Reporting, replaces DOE Orders 231.1 and 232.1A.

DOE Order 414.1A. September 29, 1999. Quality Assurance, including Change 1 (July 12, 2001).

DOE Order 435.1. July 9, 1999. Radioactive Waste Management, including Change 1 (August 28, 2001).

DOE Order 440.1A. March 27, 1998. Worker Protection Management for DOE Federal and Contractor Employees.

DOE Order 450.1. January 15, 2003. Environmental Protection Program, cancels DOE Order 5400.1.

DOE Order 451.1B. October 26, 2000. National Environmental Policy Act Compliance Program, including Change 1 (September 28, 2001).

DOE Order 5400.5. February 8, 1990. Radiation Protection of the Public and the Environment, including Change 2 (January 7, 1993).

DOE Order 5480.4. May 15, 1984. Environmental Protection, Safety, and Health Protection Standards, including Change 4 (January 7, 1993).

DOE Policy 141.1. May 2, 2001. Department of Energy Management of Cultural Resources.

DOE Policy 141.2. May 2, 2003. Public Participation and Community Relations.

$K-4$ 


\section{Table K-2 (continued) Environmental Laws, Regulations, Standards, and Orders}

DOE Regulatory Guide DOE/EH-0173T. January 1991. Environmental Regulatory Guide for

Radiological Effluent Monitoring and Environmental Surveillance.

DOE Standard DOE-STD-1153-2002. July 2002. A Graded Approach for Evaluating Radiation Doses to Aquatic and Terrestrial Biota.

Emergency Planning and Community Right-to-Know Act (EPCRA) of 1986. Pub. L. No. 99-499. 42 USC $\$ 11001$ et seq., and federal implementing regulations.

Endangered Species Act of 1973. Pub. L. No. 93-205. 16 USC $\$ 1531$ et seq., and federal and state implementing regulations.

Environmental Conservation Law of the New York State Consolidated Laws and state implementing regulations (NYCRR).

Executive Order 11988. Floodplain Management.

Executive Order 11990. Protection of Wetlands.

Executive Order 13101. Greening the Government Through Waste Prevention, Recycling, and Federal Acquisition.

Executive Order 13148. Greening the Government Through Leadership in Environmental Management.

Federal Water Pollution Control Act (Clean Water Act [CWA]). Pub. L. No. 95-217. 33 USC \$1251 et seq., as amended, and federal and state implementing regulations.

Migratory Bird Treaty Act. 16 USC §703-712 as amended, and federal and state implementing regulations.

National Environmental Policy Act (NEPA) of 1969. Pub. L. No. 91-190. 42 USC §4321 et seq., as amended, and federal implementing regulations.

National Historic Preservation Act of 1966. Pub. L. No. 102-575. 16 USC $\$ 470$ et seq., and federal implementing regulations.

Resource Conservation and Recovery Act (RCRA). Pub. L. No. 94-580. 42 USC 6901 et seq., as amended, and federal and state implementing regulations.

$K-5$ 


\section{Table K-2 (concluded) Environmental Laws, Regulations, Standards, and Orders}

Safe Drinking Water Act (SDWA). Pub. L. No. 93-523. 42 USC $\$ 300 f$ et seq., as amended, and federal and state implementing regulations.

Toxic Substances Control Act (TSCA). Pub. L. No. 94-469. 15 USC §2601 et seq., as amended, and federal implementing regulations.

U.S. Environmental Protection Agency. 1992. Region II Administrative Order on Consent. Docket No. II RCRA 3008(h)-92-0202. In the Matter of: Western New York Nuclear Service Center.

U.S. Environmental Protection Agency. 1996. West Valley Demonstration Project Federal Facilities Compliance Act Order.

Water quality standards contained in the New York State Pollutant Discharge Elimination System (SPDES) permit issued for the facility are listed in Table C-1A. Airborne emissions are regulated by the Environmental Protection Agency under the National Emission Standards for Hazardous Air Pollutants (NESHAP), 40 CFR §61 Subpart H (December 15, 1989, including amendments effective September 9, 2002).

$K-6$ 


\section{Table $\mathrm{K}-3$ \\ West Valley Demonstration Project Act \\ (Public Law 96-368 [S. 2443]; October 1, 1980)}

(As presented in Exhibit G of the Cooperative Agreement between United States Department of Energy and New York State Energy Research and Development Authority on the Western New York Nuclear Service Center at West Valley, New York; Effective October 1, 1980 as amended September 18, 1981.)

EXHIBIT G

\section{WEST VALLEY PROJECT DEMONSTRATION ACT}

PUBLIC LAW 96-368 [S. 2443]; October 1, 1980

\section{WEST VALLEY DEMONSTRATION PROJECT ACT}

For Legislative History of this and other Laws, see Table 1, Public

Laws and Legislative History, at end of final volume

An Act to authorize the Department of Energy to carry out a high-level liquid

nuclear waste management demonstratlon project

Be it enacted by the Senate and House of Representatives of the United States of America in Congress assembled,

SECTION 1. This Act may be cited as the "West Valley Demonstration Project Act".

SEc. 2. (a) The Secretary shall carry out, in accordance with this Act, a high level radioactive waste management demonstration project at the Western New York Service Center in West Valley, New York, for the purpose of demonstrating solidification techniques which can be used for preparing high level radioactive waste for disposal. Under the project the Secretary shall carry out the following activities:

(1) The Secretary shall solidify, in a form suitable for transportation and disposal, the high level radioactive waste at the Center by vitrification or by such other technology which the Secretary determines to be the most effective for solidification.

(2) The Secretary shall develop containers suitable for the permanent disposal of the high level radioactive waste solidified at the Center.

(3) The Secretary shall, as soon as feasible, transport, in accordance with applicable provisions of law, the waste solidified at the Center to an appropriate Federal repository for permanent disposal.

(4) The Secretary shall, in accordance with applicable licensing requirements, dispose of low level radioactive waste and transuranic waste produced by the solidification of the high level radioactive waste under the project.

(5) The Secretary shall decontaminate and decommission(A) the tanks and other facilities of the Center in which the high level radioactive waste solidified under the project was stored,

(B) the facilities used in the solidification of the waste, and

(C) any material and hardware used in connection with the project,

in accordance with such requirements as the Commission may prescribe.

(b) Before undertaking the project and during the fiscal year ending September 30,1981 , the Secretary shall carry out the following: (1) The Secretary shall hold in the vicinity of the Center public
hearings to inform the residents of the area in which the Center is located of the activities proposed to be undertaken under the project and to receive their comments on the project.

(2) The Secretary shall consider the various technologies available for the solidification and handling of high level radioactive waste taking into account the unique characteristics of such waste at the Center.

94 STAT. 1347

\section{G-1}

$K-7$
West Valley Demonstration Project Act. 42 USC 2021a

note.

2 USC 2021a

note.

Activities. 


\begin{abstract}
(3) The Secretary shall-
(A) undertake detailed engineering and cost estimates for the project.

(B) prepare a plan for the safe removal of the high level radioactive waste at the Center for the purposes of solidification and include in the plan provisions respecting the safe breaching of the tanks in which the waste is stored, operating equipment to accomplish the removal, and sluicing techniques,

(C) conduct appropriate safety analyses of the project, and

(D) prepare required environmental impact analyses of the project.

(4) The Secretary shall enter into a cooperative agreement

42 USC 501 note.

State costs, percentage.

Licensing amendment application.

42 USC 2011 note. 42 USC 5801 note.

Publications in Federal Register. with the State in accordance with the Federal Grant and Cooperative Agreement Act of 1977 under which the State will carry out the following:

(A) The State will make available to the Secretary the facilities of the Center and the high level radioactive waste at the Center which are necessary for the completion of the project. The facilities and the waste shall be made available without the transfer of title and for such period as may be required for completion of the project.

(B) The Secretary shall provide technical assistance in securing required license amendments.

(C) The State shall pay 10 per centum of the costs of the project, as determined by the Secretary. In determining the costs of the project, the Secretary shall consider the value of the use of the Center for the project. The State may not use Federal funds to pay its share of the cost of the project, but may use the perpetual care fund to pay such share.

(D) Submission jointly by the Department of Energy and the State of New York of an application for a licensing amendment as soon as possible with the Nuclear Regulatory Commission providing for the demonstration.

(c) Within one year from the date of the enactment of this Act, the Secretary shall enter into an agreement with the Commission to establish arrangements for review and consultation by the Commission with respect to the project: Provided, That review and consultation by the Commission pursuant to this subsection shall be conducted informally by the Commission and shall not include nor require formal procedures or actions by the Commission pursuant to the Atomic Energy Act of 1954, as amended, the Energy Reorganization Act of 1974 , as amended, or any other law. The agreement shall provide for the following:

(1) The Secretary shall submit to the Commission, for its review and comment, a plan for the solidification of the high level radioactive waste at the Center, the removal of the waste for purposes of its solidification, the preparation of the waste for disposal, and the decontamination of the facilities to be used in solidifying the waste. In preparing its comments on the plan, the Commission shall specify with precision its objections to any provision of the plan. Upon submission of a plan to the Commission, the Secretary shall publish a notice in the Federal Register of the submission of the plan and of its availability for public inspection, and, upon receipt of the comments of the Commission respecting a plan, the Secretary shall publish a notice in the Federal Register of the receipt of the comments and of the availability of the comments for public inspection. If the Secre-
\end{abstract}

94 STAT. 1348

$K-8$ 
tary does not revise the plan to meet objections specified in the comments of the Commission, the Secretary shall publish in the Federal Register a detailed statement for not so revising the plan.

(2) The Secretary shall consult with the Commission with respect to the form in which the high level radioactive waste at the Center shall be solidified and the containers to be used in the permanent disposal of such waste.

(3) The Secretary shall submit to the Commission safety analysis reports and such other information as the Commission may require to identify any danger to the public health and safety which may be presented by the project.

(4) The Secretary shall afford the Commission access to the Center to enable the Commission to monitor the activities under the project for the purpose of assuring the public health and safety.

(d) In carrying out the project, the Secretary shall consult with the Administrator of the Environmental Protection Agency, the Secretary of Transportation, the Director of the Geological Survey, and the commercial operator of the Center.

SEC. 3. (a) There are authorized to be appropriated to the Secretary for the project not more than $\$ 5,000,000$ for the fiscal year ending September 30, 1981.

(b) The total amount obligated for the project by the Secretary shall be 90 per centum of the costs of the project.

(c) The authority of the Secretary to enter into contracts under this Act shall be effective for any fiscal year only to such extent or in such amounts as are provided in advance by appropriation Acts.

SEC. 4. Not later than February 1, 1981, and on February 1 of each calendar year thereafter during the term of the project, the Secretary shall transmit to the Speaker of the House of Representatives and the President pro tempore of the Senate an up-to-date report containing a detailed description of the activities of the Secretary in carrying out the project, including agreements entered into and the costs incurred during the period reported on and the activities to be undertaken in the next fiscal year and the estimated costs thereof.

SEC. 5. (a) Other than the costs and responsibilities established by this Act for the project, nothing in this Act shall be construed as affecting any rights, obligations, or liabilities of the commercial operator of the Center, the State, or any person, as is appropriate, arising under the Atomic Energy Act of 1954 or under any other law, contract, or agreement for the operation, maintenance, or decontamination of any facility or property at the Center or for any wastes at the Center. Nothing in this Act shall be construed as affecting any applicable licensing requirement of the Atomic Energy Act of 1954 or the Energy Reorganization Act of 1974. This Act shall not apply or be extended to any facility or property at the Center which is not used in conducting the project. This Act may not be construed to expand or diminish the rights of the Federal Government.

(b) This Act does not authorize the Federal Government to acquire title to any high level radioactive waste at the Center or to the Center or any portion thereof.

SEC. 6. For the purposes of this Act:

(1) The term "Secretary" means the Secretary of Energy.

(2) The term "Commission" means the Nuclear Regulatory

Reports and other information to Commission.

Consultation with

EPA and others.

Appropriation authorization. 42 USC 2021a note.

Commission.

(3) The term "State" means the State of New York.

94 STAT. 1349

$K-9$ 
(4) The term "high level radioactive waste" means the high level radioactive waste which was produced by the reprocessing at the Center of spent nuclear fuel. Such term includes both liquid wastes which are produced directly in reprocessing, dry solid material derived from such liquid waste, and such other material as the Commission designates as high level radioactive waste for purposes of protecting the public health and safety.

(5) The term "transuranic waste" means material contaminated with elements which have an atomic number greater than 92, including neptunium, plutonium, americium, and curium, and which are in concentrations greater than 10 nanocuries per gram, or in such other concentrations as the Commission may prescribe to protect the public health and safety.

(6) The term "low level radioactive waste" means radioactive waste not classified as high level radioactive waste, transuranic waste, or byproduct material as defined in section $11 \mathrm{e}$. (2) of the Atomic Energy Act of 1954.

(7) The term "project" means the project prescribed by section 42 USC 2014.

(8) The term "Center" means the Western New York Service Center in West Valley, New York.

Approved October 1, 1980. 


\section{Appendix L}

Summary of New York State Energy Research and Development Authority (NYSERDA)

Groundwater Monitoring Data for the New York State-Licensed Disposal Area (SDA)

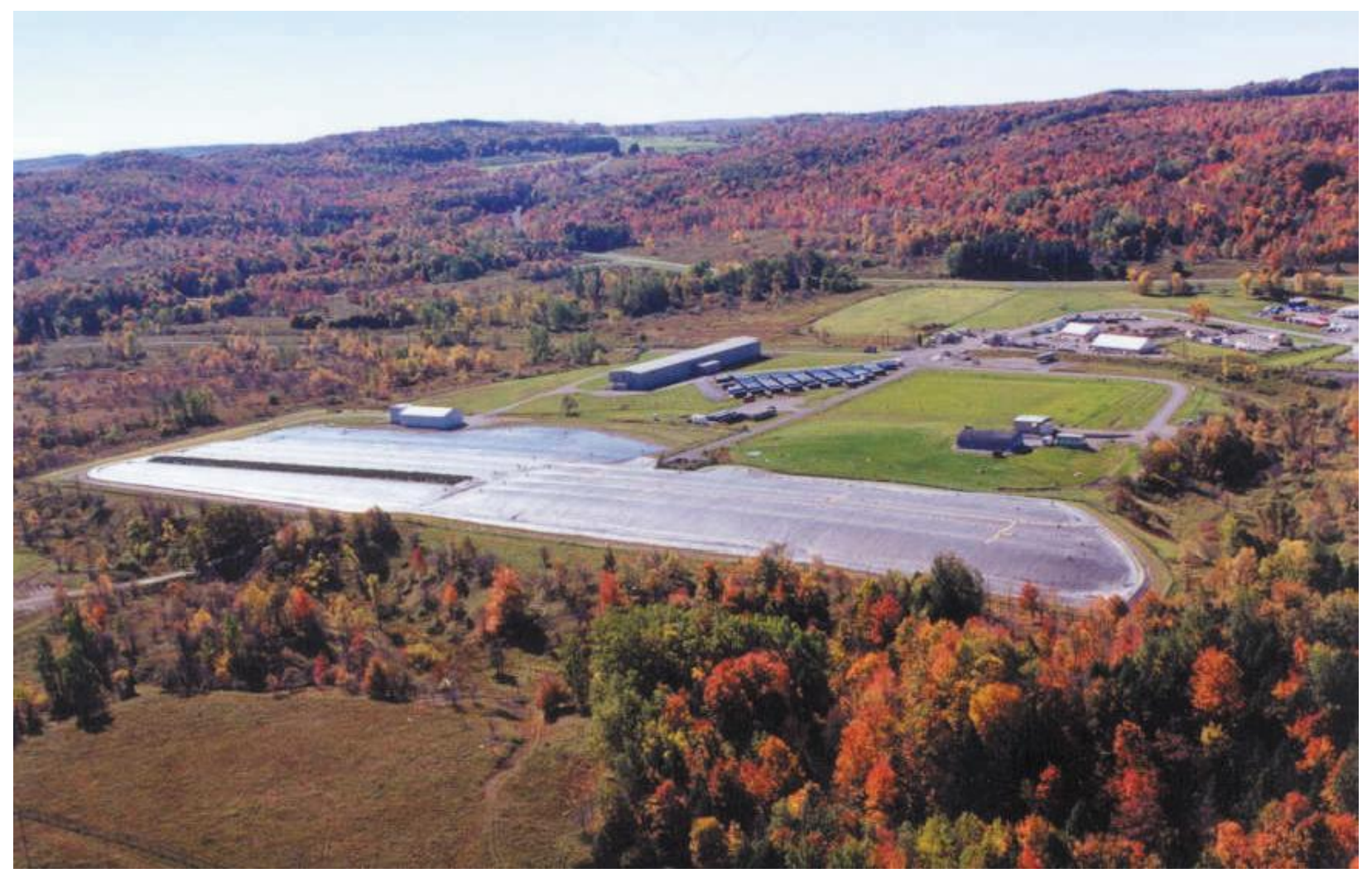

An Aerial View of the New York State-Licensed Disposal Area (SDA)

$$
L-1
$$


This page intentionally left blank

$$
L-2
$$


Table L-1

2003 Contamination Indicator Results From SDA Monitoring Wells

\begin{tabular}{|c|c|c|c|c|c|}
\hline $\begin{array}{l}\text { Sample } \\
\text { Location }\end{array}$ & Date & $\begin{array}{c}\text { Conductivity } \\
\left(\mu \mathrm{mhos} / \mathrm{cm} @ 25^{\circ} \mathrm{C}\right)\end{array}$ & $\begin{array}{c}\mathbf{p H} \\
\text { (standard units) }\end{array}$ & $\begin{array}{c}\text { Temperature } \\
\left({ }^{\circ} \mathrm{C}\right)\end{array}$ & $\begin{array}{c}\text { Turbidity } \\
\text { (NTU) }\end{array}$ \\
\hline WNW1101A & June & 678 & 7.27 & 9.2 & 2.51 \\
\hline WNW1101A & December & 591 & 7.41 & 9.0 & 2.28 \\
\hline WNW1101B & June & 625 & 7.55 & 10.5 & 7.32 \\
\hline WNW1101B & December & 575 & 7.58 & 8.0 & 113.20 \\
\hline WNW1101C & June & 384 & 7.75 & 9.7 & $>1,000.00$ \\
\hline WNW1101C & December & 331 & 7.45 & 7.9 & 225.00 \\
\hline WNW1102A & June & 710 & 7.50 & 10.9 & 24.10 \\
\hline WNW1102A & December & 701 & 7.19 & 8.3 & 17.00 \\
\hline WNW1102B & June & 517 & 7.09 & 9.9 & 6.88 \\
\hline WNW1102B & December & 546 & 7.54 & 8.4 & 13.50 \\
\hline WNW1103A & June & 994 & 7.05 & 9.2 & 36.00 \\
\hline WNW1103A & December & 910 & 7.14 & 9.0 & 23.50 \\
\hline WNW1103B & June & 576 & 7.41 & 10.5 & 11.80 \\
\hline WNW1103B & December & 576 & 7.41 & 10.5 & 11.80 \\
\hline WNW1103B & December & 649 & 7.27 & 8.3 & 23.50 \\
\hline WNW1104A & June & 625 & 7.10 & 10.1 & 1.33 \\
\hline WNW1104A & December & 733 & 7.37 & 9.5 & 2.71 \\
\hline WNW1104B & June & 637 & 7.38 & 10.5 & 1.04 \\
\hline WNW1104B & December & 589 & 7.38 & 9.0 & 1.79 \\
\hline WNW1104B & December & 589 & 7.38 & 9.0 & 1.79 \\
\hline WNW1105A & June & 640 & 7.37 & 8.6 & $>1,000.00$ \\
\hline WNW1105A & December & 648 & 7.26 & 8.6 & 101.00 \\
\hline WNW1105B & June & 667 & 7.53 & 10.1 & $>1,000.00$ \\
\hline WNW1105B & December & 643 & 7.87 & 7.7 & 106.00 \\
\hline WNW1106A & June & 708 & 7.36 & 9.9 & 3.57 \\
\hline WNW1106A & December & 672 & 7.13 & 9.4 & 5.91 \\
\hline WNW1106B & June & 718 & 7.28 & 10.4 & 99.50 \\
\hline WNW1106B & December & 658 & 7.51 & 9.2 & 518.00 \\
\hline WNW1107A & June & 1,796 & 6.71 & 10.0 & 1.31 \\
\hline WNW1107A & December & 1,725 & 6.75 & 10.5 & 1.01 \\
\hline
\end{tabular}

All data in Tables L-1 through L-3 have been provided by NYSERDA.

$L-3$

WVDP Annual Site Environmental Report

Calendar Year 2003 


\section{Table L-1 (concluded) 2003 Contamination Indicator Results From SDA Monitoring Wells}

$\begin{array}{cccccr}\begin{array}{c}\text { Sample } \\ \text { Location }\end{array} & \text { Date } & \begin{array}{c}\text { Conductivity } \\ \left(\mu \mathrm{mhos} / \mathrm{cm} @ 25^{\circ} \mathrm{C}\right)\end{array} & \begin{array}{c}\mathbf{p H} \\ (\text { standard units })\end{array} & \begin{array}{c}\text { Temperature } \\ \left({ }^{\circ} \mathrm{C}\right)\end{array} & \begin{array}{c}\text { Turbidity } \\ (\mathrm{NTU})\end{array} \\ \text { WNW1108A } & \begin{array}{c}\text { June } \\ \text { December }\end{array} & 742 & 7.31 & 9.7 & 89.50 \\ \text { WNW1108A } & 764 & 7.26 & 8.9 & >1,000.00 \\ \text { WNW1109A } & \text { June } & 517 & 7.42 & 8.8 & 11.10 \\ \text { WNW1109A } & \text { December } & 536 & 7.28 & 9.2 & 6.09 \\ \text { WNW1109B } & \text { June } & 436 & 7.46 & 9.0 & 30.70 \\ \text { WNW1109B } & \text { December } & 425 & 7.28 & 8.7 & 34.70 \\ \text { WNW1111A } & & & & & \\ \text { WNW1111A } & \text { June } & 942 & 7.15 & 10.1 & 20.20 \\ & \text { December } & 915 & 7.14 & 8.0 & 2.07\end{array}$

All data in Tables L-1 through L-3 have been provided by NYSERDA.

$L-4$ 
Table L-2

2003 Radiological Indicator Results From SDA Monitoring Wells $(\mu \mathrm{Ci} / \mathrm{mL})$

\section{Sample \\ Location}

WNW1101A

WNW1101A

WNW1101B

WNW1101B

WNW1101C

WNW1101C

WNW1102A

WNW1102A

WNW1102B

WNW1102B

WNW1103A

WNW1103A

WNW1103B

WNW1103B

WNW1103B

WNW1103C

WNW1103C

WNW1104A

WNW1104A

WNW1104B

WNW1104B

WNW1104B

WNW1104C

WNW1104C

WNW1105A

WNW1105A

WNW1105B

WNW1105B

WNW1106A

WNW1106A
Date

June

December

June

December

June
December

June

December

June

December

June

December

June

June

December

June

December

June

December

June
December
December

June

December

June

December

June

December

June

December
Gross Alpha

$2.03 \pm 1.00 \mathrm{E}-09$

$3.10 \pm 1.30 \mathrm{E}-09$

$3.35 \pm 1.30 \mathrm{E}-09$

$3.04 \pm 1.40 \mathrm{E}-09$

$3.59 \pm 6.00 \mathrm{E}-10$

$1.53 \pm 1.00 \mathrm{E}-09$

$2.29 \pm 1.00 \mathrm{E}-09$

$3.50 \pm 1.60 \mathrm{E}-09$

$6.26 \pm 7.40 \mathrm{E}-10$

$1.02 \pm 0.78 \mathrm{E}-09$

$2.99 \pm 1.40 \mathrm{E}-09$

$5.66 \pm 2.40 \mathrm{E}-09$

$1.73 \pm 0.87 \mathrm{E}-09$

$2.23 \pm 1.10 \mathrm{E}-09$

$1.05 \pm 1.10 \mathrm{E}-09$

$1.15 \pm 0.85 \mathrm{E}-09$

$1.53 \pm 0.94 \mathrm{E}-09$

$1.97 \pm 1.20 \mathrm{E}-09$

$2.19 \pm 1.20 \mathrm{E}-09$

$1.40 \pm 0.90 \mathrm{E}-09$

$1.12 \pm 0.88 \mathrm{E}-09$

$6.46 \pm 7.60 \mathrm{E}-10$

$4.17 \pm 3.70 \mathrm{E}-09$

$4.48 \pm 4.40 \mathrm{E}-09$

$3.08 \pm 1.30 \mathrm{E}-09$

$3.33 \pm 1.80 \mathrm{E}-09$

$2.37 \pm 1.20 \mathrm{E}-09$

$8.50 \pm 3.00 \mathrm{E}-09$

$2.50 \pm 1.20 \mathrm{E}-09$

$4.36 \pm 2.00 \mathrm{E}-09$
Gross Beta

$4.68 \pm 1.90 \mathrm{E}-09$

$5.58 \pm 2.00 \mathrm{E}-09$

$3.11 \pm 1.30 \mathrm{E}-09$

$2.08 \pm 1.60 \mathrm{E}-09$

$1.87 \pm 1.00 \mathrm{E}-09$

$1.99 \pm 0.85 \mathrm{E}-09$

$1.33 \pm 1.70 \mathrm{E}-09$

$2.08 \pm 1.50 \mathrm{E}-09$

$1.75 \pm 1.30 \mathrm{E}-09$

$1.77 \pm 1.20 \mathrm{E}-09$

$2.88 \pm 2.30 \mathrm{E}-09$

$6.27 \pm 2.40 \mathrm{E}-09$

$2.54 \pm 1.70 \mathrm{E}-09$

$1.56 \pm 1.60 \mathrm{E}-09$

$2.65 \pm 1.50 \mathrm{E}-09$

$8.51 \pm 2.70 \mathrm{E}-09$

$5.55 \pm 1.70 \mathrm{E}-09$

$8.49 \pm 2.40 \mathrm{E}-09$

$4.08 \pm 1.80 \mathrm{E}-09$

$3.15 \pm 1.30 \mathrm{E}-09$

$2.84 \pm 1.50 \mathrm{E}-09$

$2.34 \pm 1.40 \mathrm{E}-09$

$9.19 \pm 6.10 \mathrm{E}-09$

$1.21 \pm 0.61 \mathrm{E}-08$

$1.95 \pm 1.50 \mathrm{E}-09$

$4.77 \pm 1.50 \mathrm{E}-09$

$5.02 \pm 1.70 \mathrm{E}-09$

$2.69 \pm 1.30 \mathrm{E}-09$

$3.17 \pm 2.10 \mathrm{E}-09$

$5.08 \pm 1.70 \mathrm{E}-09$
H-3

$1.15 \pm 0.49 \mathrm{E}-07$

$7.89 \pm 5.40 \mathrm{E}-08$

$0.55 \pm 4.00 \mathrm{E}-08$

$-2.58 \pm 4.80 \mathrm{E}-08$

$1.76 \pm 4.10 \mathrm{E}-08$

$-7.36 \pm 4.20 \mathrm{E}-08$

$3.34 \pm 0.66 \mathrm{E}-07$

$2.36 \pm 0.66 \mathrm{E}-07$

$0.82 \pm 4.00 \mathrm{E}-08$

$-1.36 \pm 4.70 \mathrm{E}-08$

$4.82 \pm 0.77 \mathrm{E}-07$

$3.67 \pm 0.74 \mathrm{E}-07$

$4.08 \pm 4.30 \mathrm{E}-08$

$0.06 \pm 3.90 \mathrm{E}-08$

$-2.66 \pm 4.70 \mathrm{E}-08$

$1.35 \pm 4.00 \mathrm{E}-08$

$-0.99 \pm 4.60 \mathrm{E}-08$

$1.71 \pm 0.53 \mathrm{E}-07$

$2.15 \pm 0.64 \mathrm{E}-07$

$-0.66 \pm 3.80 \mathrm{E}-08$

$-2.85 \pm 4.60 \mathrm{E}-08$

$-4.80 \pm 4.50 \mathrm{E}-08$

$-0.59 \pm 3.90 \mathrm{E}-08$

$-2.30 \pm 4.70 \mathrm{E}-08$

$1.86 \pm 0.55 \mathrm{E}-07$

$1.01 \pm 0.55 \mathrm{E}-07$

$-1.34 \pm 3.80 \mathrm{E}-08$

$1.79 \pm 4.80 \mathrm{E}-08$

$6.32 \pm 0.90 \mathrm{E}-07$

$5.05 \pm 0.82 \mathrm{E}-07$

All data in Tables L-1 through L-3 have been provided by NYSERDA.

$$
L-5
$$




\section{Table L-2 (concluded) \\ 2003 Radiological Indicator Results From SDA Monitoring Wells $(\mu \mathrm{Ci} / \mathrm{mL})$}

$\begin{array}{cc}\begin{array}{c}\text { Sample } \\ \text { Location }\end{array} & \text { Date } \\ \text { WNW1106B } & \\ \text { WNW1106B } & \begin{array}{c}\text { June } \\ \text { December }\end{array} \\ \text { WNW1107A } & \begin{array}{c}\text { June } \\ \text { December }\end{array} \\ \text { WNW1107A } & \text { June } \\ \text { WNW1108A } & \text { December } \\ \text { WNW1108A } & \text { June } \\ \text { WNW1109A } & \text { December } \\ \text { WNW1109A } & \text { June } \\ \text { WNW1109B } & \text { December } \\ \text { WNW1109B } & \text { December } \\ \text { WNW1110A } & \text { June } \\ \text { WNW1111A } & \text { December }\end{array}$

Gross Alpha

$1.92 \pm 1.00 \mathrm{E}-09$

$1.41 \pm 1.20 \mathrm{E}-09$

$5.32 \pm 3.10 \mathrm{E}-09$

8.17+5.20E-09

$4.84 \pm 1.70 \mathrm{E}-09$

$3.71 \pm 1.90 \mathrm{E}-09$

$2.64 \pm 1.30 \mathrm{E}-09$

$2.77 \pm 1.30 \mathrm{E}-09$

$4.54 \pm 4.50 \mathrm{E}-10$

$7.91 \pm 6.70 \mathrm{E}-10$

$1.17 \pm 0.46 \mathrm{E}-08$

$6.08 \pm 2.10 \mathrm{E}-09$

$4.34 \pm 2.50 \mathrm{E}-09$

\section{Gross Beta}

$3.83 \pm 2.00 \mathrm{E}-09$

$4.46 \pm 1.60 \mathrm{E}-09$

$3.08 \pm 0.69 \mathrm{E}-08$

$2.38 \pm 0.55 \mathrm{E}-08$

$2.90 \pm 1.90 \mathrm{E}-09$

$3.39 \pm 1.60 \mathrm{E}-09$

$2.60 \pm 1.40 \mathrm{E}-09$

$3.11 \pm 1.20 \mathrm{E}-09$

$1.12 \pm 0.98 \mathrm{E}-09$

$1.93 \pm 0.90 \mathrm{E}-09$

$7.92 \pm 3.10 \mathrm{E}-09$

$3.80 \pm 2.50 \mathrm{E}-09$

$4.80 \pm 2.20 \mathrm{E}-09$
H-3

$-1.20 \pm 3.80 \mathrm{E}-08$

$-2.72 \pm 4.60 \mathrm{E}-08$

$1.13 \pm 0.08 \mathrm{E}-05$

$1.17 \pm 0.09 \mathrm{E}-05$

$1.39 \pm 0.51 \mathrm{E}-07$

$5.83 \pm 5.20 \mathrm{E}-08$

$2.96 \pm 0.63 \mathrm{E}-07$

$2.50 \pm 0.64 \mathrm{E}-07$

$4.46 \pm 0.75 \mathrm{E}-07$

$4.25 \pm 0.77 \mathrm{E}-07$

$1.90 \pm 0.60 \mathrm{E}-07$

$2.37 \pm 0.58 \mathrm{E}-07$

$2.29 \pm 0.64 \mathrm{E}-07$

All data in Tables L-1 through L-3 have been provided by NYSERDA.

$$
L-6
$$


Table L-3

2003 Radioisotopic Results From SDA Monitoring Wells ( $\mu$ Ci/mL)

$\begin{array}{cccccc}\begin{array}{c}\text { Sample } \\ \text { Location }\end{array} & \text { Date } & \text { Actinium-228 } & \text { Bismuth-214 } & \text { Carbon-14 } & \text { Cesium-134 } \\ \text { WNW1101A } & & & & \\ \text { WNW1101B } & \text { June } & 1.45 \pm 1.10 \mathrm{E}-08 & 2.18 \pm 6.50 \mathrm{E}-09 & -0.27 \pm 3.70 \mathrm{E}-09 & 0.74 \pm 3.40 \mathrm{E}-09 \\ \text { WNW1101C } & \text { June } & 0.17 \pm 2.30 \mathrm{E}-08 & 0.30 \pm 1.30 \mathrm{E}-08 & 0.77 \pm 3.70 \mathrm{E}-09 & 5.90 \pm 5.00 \mathrm{E}-09 \\ \text { WNW1102A } & \text { June } & -0.03 \pm 1.10 \mathrm{E}-08 & -0.66 \pm 7.90 \mathrm{E}-09 & 2.10 \pm 3.70 \mathrm{E}-09 & -2.39 \pm 3.90 \mathrm{E}-09 \\ \text { WNW1102B } & \text { June } & 0.65 \pm 2.00 \mathrm{E}-08 & 0.62 \pm 1.10 \mathrm{E}-08 & 0.46 \pm 3.70 \mathrm{E}-09 & 0.22 \pm 5.50 \mathrm{E}-09 \\ \text { WNW1103A } & \text { June } & 0.39 \pm 1.50 \mathrm{E}-08 & -4.68 \pm 7.90 \mathrm{E}-09 & 7.98 \pm 3.80 \mathrm{E}-09 & -1.70 \pm 4.00 \mathrm{E}-09 \\ \text { WNW1103B } & \text { June } & 0.99 \pm 1.30 \mathrm{E}-08 & 2.97 \pm 6.40 \mathrm{E}-09 & 5.37 \pm 3.70 \mathrm{E}-09 & -2.48 \pm 2.90 \mathrm{E}-09 \\ \text { WNW1103B } & \text { June } & 0.31 \pm 1.70 \mathrm{E}-08 & -9.40 \pm 9.20 \mathrm{E}-09 & -1.48 \pm 4.50 \mathrm{E}-09 & 3.95 \pm 4.30 \mathrm{E}-09 \\ \text { WNW1104A } & \text { June } & 1.02 \pm 1.00 \mathrm{E}-08 & 5.57 \pm 6.90 \mathrm{E}-09 & -0.91 \pm 3.70 \mathrm{E}-09 & 1.18 \pm 3.00 \mathrm{E}-09 \\ \text { WNW1104B } & \text { June } & -0.41 \pm 1.30 \mathrm{E}-08 & -0.56 \pm 7.50 \mathrm{E}-09 & 5.61 \pm 3.70 \mathrm{E}-09 & 0.99 \pm 2.90 \mathrm{E}-09 \\ \text { WNW1104C } & \text { June } & 6.07 \pm 8.00 \mathrm{E}-09 & -0.87 \pm 6.30 \mathrm{E}-09 & 8.66 \pm 4.70 \mathrm{E}-09 & -0.28 \pm 2.80 \mathrm{E}-09 \\ \text { WNW1105A } & \text { December } & \text { NA } & \text { NA } & 1.99 \pm 3.90 \mathrm{E}-09 & \text { NA } \\ \text { WNW1105B } & \text { June } & 1.04 \pm 1.40 \mathrm{E}-08 & -1.02 \pm 0.93 \mathrm{E}-08 & 1.67 \pm 3.60 \mathrm{E}-09 & -0.29 \pm 4.00 \mathrm{E}-09 \\ \text { WNW1106A } & \text { June } & 1.25 \pm 2.30 \mathrm{E}-08 & 1.30 \pm 1.10 \mathrm{E}-08 & 2.86 \pm 3.70 \mathrm{E}-09 & 2.30 \pm 5.60 \mathrm{E}-09 \\ \text { WNW1106B } & \text { June } & -1.70 \pm 2.00 \mathrm{E}-08 & 1.06 \pm 1.60 \mathrm{E}-08 & -0.62 \pm 3.70 \mathrm{E}-09 & 3.90 \pm 4.80 \mathrm{E}-09 \\ \text { WNW1107A } & \text { June } & -0.28 \pm 2.00 \mathrm{E}-08 & -0.56 \pm 1.20 \mathrm{E}-08 & -2.70 \pm 3.60 \mathrm{E}-09 & 3.34 \pm 5.30 \mathrm{E}-09 \\ \text { WNW1108A } & \text { June } & -0.19 \pm 1.50 \mathrm{E}-08 & -4.08 \pm 7.70 \mathrm{E}-09 & 3.02 \pm 3.70 \mathrm{E}-09 & -0.49 \pm 3.50 \mathrm{E}-09 \\ \text { WNW1109A } & \text { June } & 0.14 \pm 1.80 \mathrm{E}-08 & 1.59 \pm 9.80 \mathrm{E}-09 & 1.26 \pm 3.60 \mathrm{E}-09 & 0.88 \pm 4.60 \mathrm{E}-09 \\ \text { WNW1109B } & \text { June } & -1.49 \pm 1.60 \mathrm{E}-08 & -8.53 \pm 9.30 \mathrm{E}-09 & 3.04 \pm 3.70 \mathrm{E}-09 & 1.18 \pm 3.90 \mathrm{E}-09 \\ \text { WNW1111A } & \text { June } & -0.57 \pm 2.00 \mathrm{E}-08 & -0.40 \pm 1.10 \mathrm{E}-08 & 0.52 \pm 3.70 \mathrm{E}-09 & 1.77 \pm 5.70 \mathrm{E}-09 \\ & \text { June } & 0.95 \pm 1.30 \mathrm{E}-08 & -5.73 \pm 9.30 \mathrm{E}-09 & 0.73 \pm 3.60 \mathrm{E}-09 & 1.39 \pm 4.10 \mathrm{E}-09\end{array}$

All data in Tables L-1 through L-3 have been provided by NYSERDA.

NA - Not available. Some scheduled analyses could not be performed due to insufficient sample.

$L-7$

WVDP Annual Site Environmental Report

Calendar Year 2003 
Table L-3 (continued) 2003 Radioisotopic Results From SDA Monitoring Wells $(\mu \mathrm{Ci} / \mathrm{mL})$

\begin{tabular}{|c|c|c|c|c|c|}
\hline $\begin{array}{c}\text { Sample } \\
\text { Location }\end{array}$ & Date & Cesium-137 & Cobalt-57 & Cobalt-60 & Iodine-129 \\
\hline WNW1101A & June & $-0.28 \pm 2.70 \mathrm{E}-09$ & $0.83 \pm 1.20 \mathrm{E}-08$ & $-0.02 \pm 2.70 \mathrm{E}-09$ & $0.00 \pm 1.30 \mathrm{E}-10$ \\
\hline WNW1101B & June & $0.22 \pm 5.50 \mathrm{E}-09$ & $-0.54 \pm 2.30 \mathrm{E}-08$ & $0.56 \pm 5.00 \mathrm{E}-09$ & $-1.00 \pm 2.00 \mathrm{E}-10$ \\
\hline WNW1101C & June & $2.24 \pm 3.70 \mathrm{E}-09$ & $-1.47 \pm 1.60 \mathrm{E}-08$ & $-1.96 \pm 3.40 \mathrm{E}-09$ & $-1.02 \pm 1.90 \mathrm{E}-10$ \\
\hline WNW1102A & June & $3.69 \pm 4.40 \mathrm{E}-09$ & $0.51 \pm 1.80 \mathrm{E}-08$ & $-2.33 \pm 4.40 \mathrm{E}-09$ & $-0.59 \pm 1.80 \mathrm{E}-10$ \\
\hline WNW1102B & June & $0.31 \pm 3.50 \mathrm{E}-09$ & $1.00 \pm 1.30 \mathrm{E}-08$ & $2.17 \pm 3.80 \mathrm{E}-09$ & $1.20 \pm 1.70 \mathrm{E}-10$ \\
\hline WNW1103A & June & $-1.13 \pm 3.00 \mathrm{E}-09$ & $-0.06 \pm 1.20 \mathrm{E}-08$ & $2.92 \pm 3.00 \mathrm{E}-09$ & $-0.60 \pm 1.40 \mathrm{E}-10$ \\
\hline $\begin{array}{l}\text { WNW1103B } \\
\text { WNW1103B }\end{array}$ & $\begin{array}{l}\text { June } \\
\text { June }\end{array}$ & $\begin{array}{r}-1.01 \pm 3.90 \mathrm{E}-09 \\
1.04 \pm 2.80 \mathrm{E}-09\end{array}$ & $\begin{array}{r}1.62 \pm 1.80 \mathrm{E}-08 \\
-1.23 \pm 1.20 \mathrm{E}-08\end{array}$ & $\begin{array}{r}3.49 \pm 3.20 \mathrm{E}-09 \\
-2.06 \pm 3.00 \mathrm{E}-09\end{array}$ & $\begin{array}{l}1.47 \pm 2.00 \mathrm{E}-10 \\
0.76 \pm 1.30 \mathrm{E}-10\end{array}$ \\
\hline WNW1104A & June & $-0.98 \pm 3.00 \mathrm{E}-09$ & $-1.18 \pm 1.30 \mathrm{E}-08$ & $0.88 \pm 3.50 \mathrm{E}-09$ & $-0.70 \pm 1.30 \mathrm{E}-10$ \\
\hline WNW1104B & June & $-0.18 \pm 2.50 \mathrm{E}-09$ & $-0.47 \pm 1.10 \mathrm{E}-08$ & $0.81 \pm 2.00 \mathrm{E}-09$ & $0.10 \pm 2.00 \mathrm{E}-10$ \\
\hline WNW1105A & June & $2.70 \pm 3.50 \mathrm{E}-09$ & $-0.43 \pm 1.50 \mathrm{E}-08$ & $-2.27 \pm 3.90 \mathrm{E}-09$ & $0.30 \pm 1.30 \mathrm{E}-10$ \\
\hline WNW1105B & June & $2.20 \pm 5.30 \mathrm{E}-09$ & $1.85 \pm 2.30 \mathrm{E}-08$ & $-1.17 \pm 4.40 \mathrm{E}-09$ & $0.03 \pm 1.30 \mathrm{E}-10$ \\
\hline WNW1106A & June & $2.24 \pm 4.70 \mathrm{E}-09$ & $0.03 \pm 2.10 \mathrm{E}-08$ & $2.40 \pm 4.80 \mathrm{E}-09$ & $-0.04 \pm 1.40 \mathrm{E}-10$ \\
\hline WNW1106B & June & $1.70 \pm 4.80 \mathrm{E}-09$ & $0.08 \pm 1.70 \mathrm{E}-08$ & $2.09 \pm 5.50 \mathrm{E}-09$ & $-0.25 \pm 1.70 \mathrm{E}-10$ \\
\hline WNW1107A & June & $2.27 \pm 3.70 \mathrm{E}-09$ & $-0.22 \pm 1.20 \mathrm{E}-08$ & $-1.70 \pm 3.40 \mathrm{E}-09$ & $0.41 \pm 1.50 \mathrm{E}-10$ \\
\hline WNW1108A & June & $-2.06 \pm 3.70 \mathrm{E}-09$ & $-0.45 \pm 1.60 \mathrm{E}-08$ & $0.47 \pm 4.10 \mathrm{E}-09$ & $0.45 \pm 2.00 \mathrm{E}-10$ \\
\hline WNW1109A & June & $-3.76 \pm 4.00 \mathrm{E}-09$ & $-0.09 \pm 1.70 \mathrm{E}-08$ & $6.12 \pm 4.20 \mathrm{E}-09$ & $1.78 \pm 2.10 \mathrm{E}-10$ \\
\hline WNW1109B & June & $1.89 \pm 4.30 \mathrm{E}-09$ & $0.64 \pm 2.10 \mathrm{E}-08$ & $1.30 \pm 4.20 \mathrm{E}-09$ & $-0.23 \pm 1.30 \mathrm{E}-10$ \\
\hline WNW1111A & June & $-2.76 \pm 3.60 \mathrm{E}-09$ & $-0.79 \pm 1.50 \mathrm{E}-08$ & $1.39 \pm 3.80 \mathrm{E}-09$ & $-0.49 \pm 1.30 \mathrm{E}-10$ \\
\hline
\end{tabular}

All data in Tables L-1 through L-3 have been provided by NYSERDA. 


\section{Table L-3 (continued)}

\section{Radioisotopic Results From SDA Monitoring Wells $(\mu \mathrm{Ci} / \mathrm{mL})$}

\begin{tabular}{|c|c|c|c|c|c|}
\hline $\begin{array}{c}\text { Sample } \\
\text { Location }\end{array}$ & Date & Lead-212 & Lead-214 & Potassium-40 & Radium-224 \\
\hline WNW1101A & June & $-2.33 \pm 4.20 \mathrm{E}-09$ & $1.04 \pm 0.80 \mathrm{E}-08$ & $-2.50 \pm 4.00 \mathrm{E}-08$ & $-2.42 \pm 4.30 \mathrm{E}-09$ \\
\hline WNW1101B & June & $0.08 \pm 1.10 \mathrm{E}-08$ & $-0.22 \pm 1.10 \mathrm{E}-08$ & $-1.51 \pm 1.20 \mathrm{E}-07$ & $0.08 \pm 1.20 \mathrm{E}-08$ \\
\hline WNW1101C & June & $1.10 \pm 5.10 \mathrm{E}-09$ & $-1.07 \pm 0.77 \mathrm{E}-08$ & $-0.98 \pm 4.70 \mathrm{E}-08$ & $1.14 \pm 5.30 \mathrm{E}-09$ \\
\hline WNW1102A & June & $6.21 \pm 5.60 \mathrm{E}-09$ & $7.63 \pm 7.80 \mathrm{E}-09$ & $-0.01 \pm 1.10 \mathrm{E}-07$ & $6.44 \pm 5.80 \mathrm{E}-09$ \\
\hline WNW1102B & June & $4.99 \pm 4.20 \mathrm{E}-09$ & $5.05 \pm 6.00 \mathrm{E}-09$ & $-2.87 \pm 8.50 \mathrm{E}-08$ & $5.16 \pm 4.30 \mathrm{E}-09$ \\
\hline WNW1103A & June & $0.32 \pm 1.10 \mathrm{E}-08$ & $4.52 \pm 5.80 \mathrm{E}-09$ & $-4.77 \pm 5.80 \mathrm{E}-08$ & $0.34 \pm 1.20 \mathrm{E}-08$ \\
\hline WNW1103B & June & $0.30 \pm 1.00 \mathrm{E}-08$ & $-4.44 \pm 8.40 \mathrm{E}-09$ & $-1.18 \pm 0.99 \mathrm{E}-07$ & $0.31 \pm 1.10 \mathrm{E}-08$ \\
\hline WNW1103B & June & $6.34 \pm 6.00 \mathrm{E}-09$ & $1.51 \pm 6.20 \mathrm{E}-09$ & $0.86 \pm 4.30 \mathrm{E}-08$ & $6.56 \pm 6.20 \mathrm{E}-09$ \\
\hline WNW1104A & June & $3.46 \pm 6.50 \mathrm{E}-09$ & $-4.72 \pm 6.40 \mathrm{E}-09$ & $-4.65 \pm 5.50 \mathrm{E}-08$ & $3.58 \pm 6.70 \mathrm{E}-09$ \\
\hline WNW1104B & June & $-0.38 \pm 4.30 \mathrm{E}-09$ & $1.89 \pm 6.40 \mathrm{E}-09$ & $0.33 \pm 4.30 \mathrm{E}-08$ & $-0.40 \pm 4.40 \mathrm{E}-09$ \\
\hline WNW1105A & June & $-2.31 \pm 5.30 \mathrm{E}-09$ & $-1.34 \pm 0.90 \mathrm{E}-08$ & $-0.51 \pm 5.60 \mathrm{E}-08$ & $-2.38 \pm 5.40 \mathrm{E}-09$ \\
\hline WNW1105B & June & $1.06 \pm 0.99 \mathrm{E}-08$ & $-0.62 \pm 1.10 \mathrm{E}-08$ & $-1.26 \pm 1.20 \mathrm{E}-07$ & $1.09 \pm 1.00 \mathrm{E}-08$ \\
\hline WNW1106A & June & $-3.73 \pm 7.70 \mathrm{E}-09$ & $-0.62 \pm 1.10 \mathrm{E}-08$ & $-1.62 \pm 1.10 \mathrm{E}-07$ & $-3.85 \pm 7.90 \mathrm{E}-09$ \\
\hline WNW1106B & June & $7.28 \pm 6.10 \mathrm{E}-09$ & $4.30 \pm 8.50 \mathrm{E}-09$ & $-1.50 \pm 1.20 \mathrm{E}-07$ & $7.51 \pm 6.30 \mathrm{E}-09$ \\
\hline WNW1107A & June & $-3.06 \pm 4.60 \mathrm{E}-09$ & $2.01 \pm 6.90 \mathrm{E}-09$ & $-5.09 \pm 8.00 \mathrm{E}-08$ & $-3.16 \pm 4.80 \mathrm{E}-09$ \\
\hline WNW1108A & June & $-2.04 \pm 5.90 \mathrm{E}-09$ & $6.30 \pm 9.00 \mathrm{E}-09$ & $4.73 \pm 8.00 \mathrm{E}-08$ & $-2.12 \pm 6.10 \mathrm{E}-09$ \\
\hline WNW1109A & June & $4.60 \pm 6.80 \mathrm{E}-09$ & $-6.25 \pm 8.30 \mathrm{E}-09$ & $0.17 \pm 1.10 \mathrm{E}-07$ & $4.74 \pm 7.10 \mathrm{E}-09$ \\
\hline WNW1109B & June & $-4.63 \pm 7.50 \mathrm{E}-09$ & $-0.25 \pm 1.00 \mathrm{E}-08$ & $0.33 \pm 1.20 \mathrm{E}-07$ & $-4.78 \pm 7.70 \mathrm{E}-09$ \\
\hline WNW1111A & June & $-3.25 \pm 5.40 \mathrm{E}-09$ & $-9.12 \pm 8.30 \mathrm{E}-09$ & $2.50 \pm 5.50 \mathrm{E}-08$ & $-3.35 \pm 5.60 \mathrm{E}-09$ \\
\hline
\end{tabular}

All data in Tables L-1 through L-3 have been provided by NYSERDA.

$$
\text { L - } 9
$$




\section{Table L-3 (continued)}

\section{Radioisotopic Results From SDA Monitoring Wells $(\mu \mathrm{Ci} / \mathrm{mL})$}

$\begin{array}{cccccc}\begin{array}{c}\text { Sample } \\ \text { Location }\end{array} & \text { Date } & \text { Radium-226 } & \text { Strontium-90 } & \text { Technetium-99 } & \text { Thallium-208 } \\ \text { WNW1101A } & & & & \\ \text { WNW1101B } & \text { June } & 2.18 \pm 6.50 \mathrm{E}-09 & 2.37 \pm 5.20 \mathrm{E}-10 & 1.08 \pm 1.30 \mathrm{E}-09 & 1.58 \pm 2.80 \mathrm{E}-09 \\ \text { WNW1101C } & \text { June } & 0.30 \pm 1.30 \mathrm{E}-08 & 3.38 \pm 4.70 \mathrm{E}-10 & 1.77 \pm 1.50 \mathrm{E}-09 & -0.13 \pm 5.60 \mathrm{E}-09 \\ \text { WNW1102A } & \text { June } & -0.64 \pm 7.90 \mathrm{E}-09 & 3.44 \pm 3.20 \mathrm{E}-10 & -0.52 \pm 8.30 \mathrm{E}-10 & 1.50 \pm 3.20 \mathrm{E}-09 \\ \text { WNW1102B } & \text { June } & 0.62 \pm 1.10 \mathrm{E}-08 & 1.16 \pm 0.60 \mathrm{E}-09 & 0.92 \pm 1.00 \mathrm{E}-09 & 6.73 \pm 4.60 \mathrm{E}-09 \\ \text { WNW1103A } & \text { June } & -4.67 \pm 7.90 \mathrm{E}-09 & 4.48 \pm 3.80 \mathrm{E}-10 & 1.93 \pm 9.30 \mathrm{E}-10 & 3.32 \pm 3.30 \mathrm{E}-09 \\ \text { WNW1103B } & \text { June } & 2.97 \pm 6.40 \mathrm{E}-09 & 3.65 \pm 4.20 \mathrm{E}-10 & 0.81 \pm 8.10 \mathrm{E}-10 & -0.96 \pm 3.80 \mathrm{E}-09 \\ \text { WNW1103B } & \text { June } & -9.37 \pm 9.20 \mathrm{E}-09 & 5.64 \pm 5.90 \mathrm{E}-10 & 2.68 \pm 8.30 \mathrm{E}-10 & 0.44 \pm 5.20 \mathrm{E}-09 \\ \text { WNW1104A } & \text { June } & 5.52 \pm 6.90 \mathrm{E}-09 & 2.51 \pm 5.80 \mathrm{E}-10 & 6.60 \pm 8.90 \mathrm{E}-10 & 2.10 \pm 2.60 \mathrm{E}-09 \\ \text { WNW1104B } & \text { June } & -0.58 \pm 7.50 \mathrm{E}-09 & 4.62 \pm 4.50 \mathrm{E}-10 & -1.98 \pm 8.00 \mathrm{E}-10 & -0.64 \pm 3.70 \mathrm{E}-09 \\ \text { WNW1105A } & \text { June } & -0.88 \pm 6.30 \mathrm{E}-09 & 5.54 \pm 5.30 \mathrm{E}-10 & 0.55 \pm 1.20 \mathrm{E}-09 & -0.71 \pm 2.70 \mathrm{E}-09 \\ \text { WNW1105B } & \text { June } & -1.02 \pm 0.93 \mathrm{E}-08 & 3.65 \pm 3.30 \mathrm{E}-10 & -0.88 \pm 9.50 \mathrm{E}-10 & 4.77 \pm 3.60 \mathrm{E}-09 \\ \text { WNW1106A } & \text { June } & 1.30 \pm 1.10 \mathrm{E}-08 & 2.64 \pm 3.40 \mathrm{E}-10 & 3.99 \pm 9.40 \mathrm{E}-10 & -0.90 \pm 6.20 \mathrm{E}-09 \\ \text { WNW1106B } & \text { June } & 1.06 \pm 1.60 \mathrm{E}-08 & 1.12 \pm 0.58 \mathrm{E}-09 & 1.13 \pm 1.30 \mathrm{E}-09 & 0.95 \pm 5.70 \mathrm{E}-09 \\ \text { WNW1107A } & \text { June } & -0.56 \pm 1.20 \mathrm{E}-08 & 7.40 \pm 4.20 \mathrm{E}-10 & 2.25 \pm 1.50 \mathrm{E}-09 & 5.34 \pm 4.80 \mathrm{E}-09 \\ \text { WNW1108A } & \text { June } & -4.38 \pm 7.80 \mathrm{E}-09 & 7.65 \pm 1.90 \mathrm{E}-09 & 0.95 \pm 1.80 \mathrm{E}-09 & 2.65 \pm 3.30 \mathrm{E}-09 \\ \text { WNW1109A } & \text { June } & 1.59 \pm 9.80 \mathrm{E}-09 & 9.23 \pm 5.00 \mathrm{E}-10 & -1.35 \pm 7.70 \mathrm{E}-10 & -0.85 \pm 4.40 \mathrm{E}-09 \\ \text { WNW1109B } & \text { June } & -8.56 \pm 9.30 \mathrm{E}-09 & 3.64 \pm 3.70 \mathrm{E}-10 & -1.32 \pm 8.40 \mathrm{E}-10 & -0.55 \pm 4.80 \mathrm{E}-09 \\ \text { WNW1111A } & \text { June } & -0.40 \pm 1.10 \mathrm{E}-08 & 2.68 \pm 5.40 \mathrm{E}-10 & 1.39 \pm 1.70 \mathrm{E}-09 & 0.86 \pm 6.60 \mathrm{E}-09 \\ & -6.50 \pm 9.40 \mathrm{E}-09 & 6.00 \pm 5.30 \mathrm{E}-10 & 2.64 \pm 7.90 \mathrm{E}-10 & 3.04 \pm 3.50 \mathrm{E}-09\end{array}$

All data in Tables L-1 through L-3 have been provided by NYSERDA. 


\section{Table L-3 (concluded) 2003 Radioisotopic Results From SDA Monitoring Wells $(\mu \mathrm{Ci} / \mathrm{mL})$}

\begin{tabular}{|c|c|c|c|}
\hline $\begin{array}{c}\text { Sample } \\
\text { Location }\end{array}$ & Date & Thorium-234 & Uranium-235 \\
\hline WNW1101A & June & $1.05 \pm 4.00 \mathrm{E}-07$ & $0.19 \pm 1.10 \mathrm{E}-08$ \\
\hline WNW1101B & June & $7.72 \pm 8.50 \mathrm{E}-07$ & $2.74 \pm 2.30 \mathrm{E}-08$ \\
\hline WNW1101C & June & $1.26 \pm 4.80 \mathrm{E}-07$ & $-0.48 \pm 1.50 \mathrm{E}-08$ \\
\hline WNW1102A & June & $7.47 \pm 7.40 \mathrm{E}-07$ & $0.96 \pm 1.70 \mathrm{E}-08$ \\
\hline WNW1102B & June & $3.39 \pm 4.40 \mathrm{E}-07$ & $0.60 \pm 1.30 \mathrm{E}-08$ \\
\hline WNW1103A & June & $-2.74 \pm 5.00 \mathrm{E}-07$ & $0.78 \pm 1.20 \mathrm{E}-08$ \\
\hline WNW1103B & June & $-1.95 \pm 5.20 \mathrm{E}-07$ & $0.89 \pm 1.70 \mathrm{E}-08$ \\
\hline WNW1103B & June & $-0.92 \pm 3.40 \mathrm{E}-07$ & $0.31 \pm 1.10 \mathrm{E}-08$ \\
\hline WNW1104A & June & $0.69 \pm 4.30 \mathrm{E}-07$ & $-0.01 \pm 1.20 \mathrm{E}-08$ \\
\hline WNW1104B & June & $0.66 \pm 4.70 \mathrm{E}-07$ & $0.20 \pm 1.10 \mathrm{E}-08$ \\
\hline WNW1105A & June & $0.51 \pm 5.60 \mathrm{E}-07$ & $0.89 \pm 1.60 \mathrm{E}-08$ \\
\hline WNW1105B & June & $3.55 \pm 7.60 \mathrm{E}-07$ & $0.24 \pm 2.00 \mathrm{E}-08$ \\
\hline WNW1106A & June & $5.61 \pm 7.20 \mathrm{E}-07$ & $0.91 \pm 2.00 \mathrm{E}-08$ \\
\hline WNW1106B & June & $3.65 \pm 7.70 \mathrm{E}-07$ & $0.74 \pm 1.80 \mathrm{E}-08$ \\
\hline WNW1107A & June & $4.58 \pm 5.60 \mathrm{E}-07$ & $0.89 \pm 1.20 \mathrm{E}-08$ \\
\hline WNW1108A & June & $3.19 \pm 4.50 \mathrm{E}-07$ & $0.47 \pm 1.60 \mathrm{E}-08$ \\
\hline WNW1109A & June & $1.31 \pm 5.60 \mathrm{E}-07$ & $-0.12 \pm 1.60 \mathrm{E}-08$ \\
\hline WNW1109B & June & $-0.68 \pm 7.70 \mathrm{E}-07$ & $0.30 \pm 2.10 \mathrm{E}-08$ \\
\hline WNW1111A & June & $-2.81 \pm 5.70 \mathrm{E}-07$ & $0.12 \pm 1.60 \mathrm{E}-08$ \\
\hline
\end{tabular}

All data in Tables L-1 through L-3 have been provided by NYSERDA.

$L-11$ 
This page intentionally left blank

$$
L-12
$$

